1.

(T) $r \mathrm{~B}^{\mathrm{s}}$

$x=2 x^{2}=\frac{1}{2}$

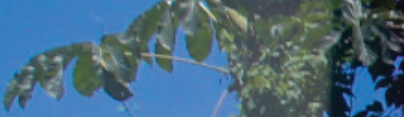
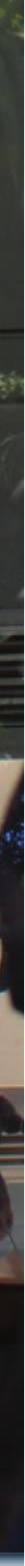

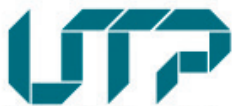

Universidad Tecnológica de Pereira

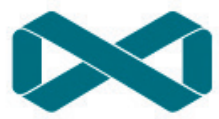

Editorial UTP 


\section{Nancy Constanza Córdoba Córdoba}

(Nueva York, NY, Estados Unidos, 1958).

Magister en Literatura de la Universidad Tecnológica de Pereira, Especialista en Dermatología del Centro Dermatológico "Federico Lleras Acosta", Pontificia Universidad Javeriana, Médica cirujana de la Universidad Colegio Mayor de Nuestra Señora del Rosario, Facultad de Medicina.

Profesora titular en la Facultad de Ciencias de la Salud de la Universidad Tecnológica de Pereira.

Ha publicado artículos en revistas especializadas nacionales e internacionales.

Pertenece al Grupo de Investigación en Medicina Interna de la Universidad Tecnológica de Pereira; línea de investigación en Dermatología.

Primer puesto, Primer Concurso de Fotografía, Facultad de Ciencias de la Salud, 2006. Fotografia de la portada, Revista Médica de Risaralda. 2006;12(2)

nanco@utp.edu.co 


\section{La piel en la enfermedad sistémica Abordaje clínico y diagnóstico}

Nancy Constanza Córdoba

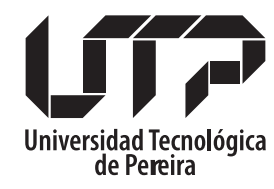

Facultad de Ciencias de la Salud

Colección Trabajos de Investigación

2019 


\section{Córdoba, Nancy Constanza}

La piel en la enfermedad sistémica: abordaje clínico y diagnóstico / Nancy Constanza

Córdoba. - Pereira: Universidad Tecnológica de Pereira, 2019.

287 páginas: ilustrado. - (Colección Trabajos de Investigación).

eISBN: 978-958-722-371-2

1. Enfermedades de la piel 2. Dermatosis 3. Enfermedades sistémicas 4. Enfermedades del sistema neurológico 5. Enfermedades gastrointestinales 6. Enfermedades del sistema endocrino 7. Enfermedades cardiovasculares 8. Enfermedades renales 9. Enfermedades reumatológicas 10. Dermatosis paraneoplásicas

CDD. 616.5

La piel en la enfermedad sistémica. Abordaje clínico y diagnóstico

(C) Nancy Constanza Córdoba

(C) Universidad Tecnológica de Pereira

Primera edición, 2019

eISBN: 978-958-722-371-2

Proyecto de investigación "La piel en la enfermedad sistémica" código 513-12

Universidad Tecnológica de Pereira

Vicerrectoría de Investigaciones, Innovación y Extensión

Editorial Universidad Tecnológica de Pereira

Coordinador editorial UTP

Luis Miguel Vargas Valencia

luismvargas@utp.edu.co

Tel:3137381

Edificio 9, Biblioteca Central "Jorge Roa Martínez"

Cra. 27 No. 10-02 - Los Álamos

Pereira, Colombia

www.utp.edu.co

Foto Cubierta:

De la serie: "A través de los cristales"

"A través de la piel"

Nancy Constanza Córdoba, 2019

Montaje y producción:

Universidad Tecnológica de Pereira

Centro Recursos Informáticos y Educativos, CRIE

Reservados todos los derechos 
A Sandra Muvdi y a Olga Lucía Pinto por el entusiasmo para que este proyecto pudiera realizarse.

Y a Carlos Arturo Hernández

por su esmerada y reorientadora revisión.

A Amalia y a Santiago

A mi familia 


\section{Contenido}

Índice de cuadros y figuras

Agradecimientos

Prólogo

Introducción

Capítulo 1.

$\begin{array}{ll}\text { Sistema cutáneo neuroinmunocrino } & 17\end{array}$

Capítulo 2.

Enfermedades de origen endocrinológico $\quad 32$

$\begin{array}{ll}\text { Diabetes mellitus } & 34\end{array}$

Enfermedades de la glándula tiroides $\quad 66$

Hipotiroidismo $\quad 69$

$\begin{array}{ll}\text { Hipertiroidismo } & 73\end{array}$

$\begin{array}{ll}\text { Enfermedades de las glándulas suprarrenales } & 78\end{array}$

Síndrome de Cushing $\quad 80$

Enfermedad de Addison $\quad 82$

$\begin{array}{ll}\text { Hiperandrogenismo } & 83\end{array}$

Capítulo 3. $\quad 91$

Enfermedades del sistema neurológico $\quad 91$

Síndromes neurocutáneos $\quad 93$

Enfermedades neuroectodérmicas $\quad 95$

Síndrome de Sturge-Weber 95

Enfermedad de von Hippel-Lindau $\quad 95$

Neurofibromatosis o enfermedad de von Reckinghausen $\quad 95$

Epiloia o enfermedad de Pringle-Burneville $\quad 99$

Capítulo 4. 106

$\begin{array}{ll}\text { Enfermedades gastrointestinales } & 106\end{array}$

$\begin{array}{ll}\text { Alteraciones nutricionales } & 109\end{array}$

$\begin{array}{ll}\text { Enfermedad inflamatoria intestinal } & 118\end{array}$

Ileítis regional o enfermedad de Crohn 118

$\begin{array}{ll}\text { Colitis ulcerativa } & 119\end{array}$

Otras enfermedades gastrointestinales $\quad 125$

Enfermedades hepatobiliares y pancreáticas $\quad 129$

Alteraciones gastrointestinales, tumores de piel y neoplasias $\quad 139$ 
Capítulo 5.

$\begin{array}{lr}\text { Enfermedad renal crónica } & 145\end{array}$

Capítulo 6. $\quad 154$

Enfermedades cardiovasculares y broncopulmonares $\quad 154$

$\begin{array}{ll}\text { Síndromes cardiocutáneos } & 157\end{array}$

$\begin{array}{ll}\text { Alteraciones broncopulmonares } & 169\end{array}$

$\begin{array}{lr}\text { Capítulo } 7 . & 180\end{array}$

$\begin{array}{lr}\text { Alteraciones hematológicas y vasculares } & 180\end{array}$

$\begin{array}{ll}\text { Fenómenos vasculares reactivos } & 184\end{array}$

Púrpuras y vasculitis 192

$\begin{array}{lr}\text { Capítulo 8. } & 208\end{array}$

Enfermedades del tejido conjuntivo 208

Lupus eritematoso $\quad 210$

$\begin{array}{ll}\text { Esclerosis sistémica o esclerodermia } & 221\end{array}$

Esclerosis localizada $\quad 224$

Esclerosis sistémica $\quad 225$

$\begin{array}{ll}\text { Dermatomiositis } & 227\end{array}$

Enfermedad mixta del tejido conjuntivo, síndrome de superposición o enfermedad indeterminada 230

$\begin{array}{ll}\text { Síndrome de Sjögren } & 230\end{array}$

Artritis reumatoidea $\quad 232$

Síndrome de anticuerpos antifosfolípido $\quad 234$

$\begin{array}{lr}\text { Capítulo 9. } & 240\end{array}$

$\begin{array}{ll}\text { Dermatosis paraneoplásicas } & 240\end{array}$

$\begin{array}{ll}\text { Conclusiones } & 269\end{array}$ 


\section{Índice de cuadros y figuras}

Cuadro 3.1 Síndromes neurocutáneos, enfermedades neuroectodérmicas

Cuadro 3.2 Rasopatías

Cuadro 4.1 Alteraciones nutricionales

Cuadro 8.1 Lupus eritematoso sistémico, Criterios del American College

of Rheumatology modificados en 2012

Cuadro 9.1 Pápulas faciales, marcadoras de malignidad

\section{Figuras}

Figura 2.1

Figura 2.2

Figura 2.3

Figura 2.4

Figura 2.5

Figura 2.6

Figura 2.7

Figura 2.8

Figura 2.9

Figura 2.10

Figura 2.11

Figura 2.12

Figura 2.13

Figura 2.14

Figura 2.15

Figura 2.16

Figura 2.17

Figura 2.18

Figura 2.19

Figura 2.20

Figura 2.21

Figura 2.22

Figura 2.23

Figura 2.24

Figura 2.25

Figura 2.26

Figura 2.27

Figura 2.28

Figura 2.29
Dermopatía diabética

Ampollas diabéticas

Necrobiosis lipoídica

Granuloma anular

Acantosis nigricans en pliegues y superficies extensoras

Acrocordones

Prurigo: pápulas decapitadas por el rascado

Notalgia parestésica

Candidiasis: oral, en pliegues y en uñas

Micosis superficiales: pitiriasis versicolor

Micosis superficiales: dermatomicosis y onicomicosis

Celulitis por Staphylococcus aureus

Infecciones por Pseudomonas aeruginosa

Diabetes mellitus: rubor diabético, eritema semejante a la erisipela

Macroangiopatía, necrosis de los dedos de los pies

Microangiopatía: uñas en pinza, uñas triangulares

Artropatía de Charcot

Úlceras de tipo mal perforante plantar

Piel amarilla en las palmas

Engrosamiento de la piel de las manos

Escleredema en nuca

Xantelasmas

Liquen plano oral

Psoriasis

Vitiligo

Bocio

Madarosis: alopecia difusa de la cola de las cejas

Alopecia areata

Mixedema generalizado 
Figura 2.30

Figura 2.31

Figura 2.32

Figura 2.33

Figura 2.34

Figura 2.35

Figura 2.36

Figura 2.37

Figura 2.38

Figura 3.1

Figura 3.2

Figura 3.3

Figura 3.4

Figura 3.5

Figura 3.6

Figura 3.7

Figura 4.1

Figura 4.2

Figura 4.3

Figura 4.4

Figura 4.5

Figura 4.6

Figura 4.7

Figura 4.8

Figura 4.9

Figura 4.10

Figura 4.11

Figura 4.12

Figura 4.13

Figura 4.14

Figura 4.15

Figura 4.16

Figura 4.17

Figura 4.18

Figura 5.1

Figura 5.2

Figura 5.3

Figura 5.4

Figura 5.5

Figura 5.6

Figura 6.1
Mixedema periorbitario

Hiperpigmentación en hipertiroidismo

Alteraciones ungulares en enfermedad tiroidea

a. Onicolisis, b. coiloniquia y c. acropaquia

Exoftalmía por oftalmopatía infiltrativa

Urticaria crónica

Queratodermia y acropustulosis palmoplantar

Síndrome de Cushing: joroba de búfalo, facies de luna llena y

estrías purpúricas

Hiperpigmentación en la enfermedad de Addison

Hirsutismo, acné en hiperandrogenismo

Manchas café con leche

Efélides axilares

Neurofibromas

Angiofibromas faciales

Tumores de Koenen y fibromas en la mucosa oral

Máculas hipopigmentadas con forma de hojas de fresno

Placa de chagrin o de shagreen: hamartoma de tejido conjuntivo

Estomatitis aftosa

Pénfigo vulgar

Desnutrición de tipo kwashiorkor

Lineas de Muehrcke

Lengua lisa y despulida, lengua geográfica

Pioderma gangrenoso

Síndrome de Rendu-Osler

Dermatitis herpetiforme

Púrpura palpable de Henoch-Schönlein

Ictericia, telangiectasias, telangiectasias

Eritema palmar

Ictericia, placas eccematosas en obstrucción biliar

Cirrosis e hipertensión portal

Liquen rojo plano

Hepatitis $\mathrm{C}$ y vasculitis

Hemocromatosis

Signo de Grey Turner

Síndrome de Peutz-Jeghers

Hiperpigmentación lineal, prurito

Líneas blanquecinas: xerosis y prurito, xerosis

Lesiones de tipo prúrigo

¿Prurigo o dermatosis perforante?

Uñas mitad y mitad

Ausencia de lúnula

Dedos en palillo de tambor en la infancia 
Figura 6.2

Figura 6.3

Figura 6.4

Figura 6.5

Figura 6.6

Figura 6.7

Figura 6.8

Figura 6.9

Figura 6.10

Figura 6.11

Figura 6.12

Figura 6.13

Figura 6.14

Figura 6.15

Figura 6.16

Figura 6.17

Figura 7.1

Figura 7.2

Figura 7.3

Figura 7.4

Figura 7.5

Figura 7.6

Figura 7.7

Figura 7.8

Figura 7.9

Figura 7.10

Figura 7.11

Figura 7.12

Figura 7.13

Figura 7.14

Figura 7.15

Figura 7.16

Figura 7.17

Figura 7.18

Figura 7.19

Figura 8.1

Figura 8.2

Figura 8.3

Figura 8.4

Figura 8.5

Figura 8.6
Pliegue diagonal en el lóbulo auricular

Psoriasis

Xantomas

Policondritis del pabellón auricular

Pseudoxantoma elástico

Aracnodactilia, síndrome de Marfán

Enrojecimiento por insuficiencia mitral

Enrojecimiento por insuficiencia tricuspídea

Endocarditis bacteriana

Pigmentación por amlodipino

Uñas amarillas por compromiso broncopulmonar

Uñas en vidrio de reloj

Dedos en palillo de tambor

Histoplasmosis, criptococosis, sida

Tuberculosis: escrofuloderma

Sarcoidosis en cicatrices, nariz, peribucales y peripalpebrales

Lesión púrpura, lesión violácea

Lupus eritematoso sistémico, alteraciones de la coagulación

Síndrome varicoso, pigmentación ocre y purpúrica

Urticaria vasculítica

Eritema multiforme

Síndrome de Stevens-Johnson y necrolisis epidérmica tóxica

Eritema anular

Enfermedad de Lyme: eritema crónico migrans y exantema

Síndrome de Sweet

Eritema nudoso

Púrpura actínica

Púrpura secundaria al uso de esteroides

Oclusión vascular, lesiones necróticas distales

Úlceras arteriales por hipercoagulabilidad

Vasculitis leucocitoclásica: macular, papular, livedoide

y necrótica

Púrpura palpable de Henoch-Schönlein

Poliarteritis nodosa

Granulomatosis con poliangeítis

Granulomatosis eosinofílica con poliangeítis

Lupus eritematoso sistémico: eritema en alas de mariposa y exantema generalizado

Lupus subagudo variedad psoriasiforme

Lupus eritematoso discoide crónico

Lupus tumidus

Lupus eritematoso sistémico, vasculitis distal

Lupus eritematoso sistémico, alopecia difusa 
Figura 8.7

Figura 8.8

Figura 8.9

Figura 8.10

Figura 8.11

Figura 8.12

Figura 8.13

Figura 8.14

Figura 8.15

Figura 9.1

Figura 9.2

Figura 9.3

Figura 9.4

Figura 9.5

Figura 9.6

Figura 9.7

Figura 9.8

Figura 9.9

Figura 9.10

Figura 9.11

Figura 9.12

Figura 9.13

Figura 9.14

Figura 9.15

Figura 9.16

Figura 9.17

Figura 9.18

Figura 9.19

Figura 9.20
Síndrome de Evans, lupus eritematoso sistémico

Fenómeno de Raynaud

Esclerosis sistémica

Esclerodermia localizada: morfea en placas

Esclerodermia difusa

Dermatomiositis, pápulas de Gottron, eritema en heliotropo

Pioderma gangrenoso en la artritis reumatoidea

Artritis reumatoidea: nódulos en manos y en codos

Livedo reticularis

Nódulos solitarios

Metástasis en conglomerados

Nódulo de la hermana María José

Carcinoma de mama, metástasis zosteriforme

Hiperpigmentación, melanosis palmo-plantar

Amiloidosis: lesiones pardo-purpúricas palpebrales

Acantosis nigricans en superficies extensoras, acantosis

y papilomatosis en mucosas

Manos con aspecto de tripa

Queratodermia plantar, manos de mecánico

Queratodermia punctata

Síndrome de Bazex

Ictiosis adquirida

Signo de Leser-Trélat

Dedos en palillo de tambor: osteoartropatía hipertrófica

Dermatomiositis: a. eritema en heliotropo en párpados, b. signo del chal

Pénfigo paraneoplásico

Síndrome de Sweet

Pioderma gangrenoso

Tromboflebitis migratoria

Hipercoagulabilidad, vasculitis: pápulas decapitadas por el rascado, isquemia digital, fenómeno de Raynaud 


\section{Agradecimientos}

Por la edición final, las revisiones del texto y las sugerencias a Carlos Arturo Hernández; por las revisiones iniciales a Olga Lucía Pinto, Sandra Muvdi, Ángela González, Sergio Córdoba, Francisco Javier Leal, Amalia Leal y César Valencia.

Por otra parte, a Santiago Leal, por la ayuda en la selección y optimización de las fotografías.

A todos mis alumnos y a los pacientes que me enseñaron tantas cosas para que hoy pueda entregar este acercamiento a la piel y sus relaciones con la enfermedad sistémica. 


\section{Prólogo}

Ha sido una costumbre frecuente el separar los diferentes campos de la Medicina, como si un área en particular no guardara relación con la otra. Se ha convertido, entonces, la ciencia médica en una 'colcha de retazos' en donde el médico se dedica a una en particular, abandonando las otras, o disminuyendo su interés por las mismas.

Si hemos aprendido a lo largo del tiempo en el estudio de esta ciencia, es regresar al pensamiento y a la práctica de nuestros antecesores que, sabiamente, trataban a la Medicina como un todo, con la integralidad que esto trae. Y es innegable la gran ayuda e implicaciones que tiene el conocer de los diferentes temas que muchas veces nos llevan a diagnósticos y tratamientos acertados, simplemente por tener en cuenta áreas que erróneamente se consideran sin importancia o de poca ayuda, relacionada con la cual el médico está dedicado.

Este libro de la doctora Córdoba es una hermosa, valiosa y muy útil 'herramienta' para todos los profesionales de la Medicina -independiente de su campo de acción- en donde este órgano, la piel, el segundo en extensión del cuerpo humano, y el conocimiento de las enfermedades más importantes del mismo, nos aportan una ayuda invaluable en la práctica diaria de esta hermosa ciencia y arte a la vez.

Desde el punto de vista cardiovascular, por mencionar la especialidad a la cual le he dedicado ya casi 40 años, el conocimiento de las demás especialidades me ha enseñado cada vez más, que la medicina es una y solo una. Que el saber de lo demás es gigantesco en su aporte al diagnóstico y al tratamiento de las diferentes enfermedades que, con mucha frecuencia, no lo hubiésemos podido realizar, si no tuviésemos el conocimiento e interés por las demás.

Por mencionar algunos ejemplos de mi campo, puedo decir que el solo examinar la piel, me ha aportado muchas veces diagnósticos certeros y tratamientos adecuados, que no lo hubiese podido hacer si no hubiese mirado inicialmente su piel. La cianosis y su relación con el cortocircuito cardíaco de derecha a izquierda, o las metahemoglobinemias. La acrocianosis que nos hace pensar en en la vasoconstricción de pequeños vasos, o la reducción del flujo periférico en la insuficiencia cardíaca y el choque. Las telangiectasias hereditarias y su asociación con el síndrome de Osler-Weber-Rendu, o la esclerodermia. El cambio de coloración de la la piel a los tonos grises que nos obligan a la sospecha de la hemocromatosis. La ictericia. Las equimosis y su relación con la anticoagulación; las petequias, con la antiagregación plaquetaria. Las clásicas lesiones de las vasculitis con las cuales, en una cantidad importante de pacientes nos hacen pensar en la endocarditis infecciosa. Los xantomas y los xantelasmas y el pensar en dislipidemia. Las alteraciones de 
la elasticidad de la piel y enfermedades del tipo del síndrome de Marfan o pseuxantoma elástico, las lentiginosis y su relación con enfermedades como el síndrome LEOPARD. Los cambios dérmicos asociados con las enfermdades del colágeno; los hamartomas faciales y su asociación con tumores cardíacos, etc.

Solo por mencionar algunos pocos ejemplos, y de una de las especialidades de la medicina.

Así, pues, el aporte de este texto a todo el gremio médico -cualquiera que sea su área de trabajo o especialidad- es inmenso. Nos hace reflexionar sobre la integralidad por la cual abogamos con tanta frecuencia en el abordaje de nuestros pacientes. Y el ver el enfermo como un todo, iniciando por, tal vez, el órgano más sencillo de examinar, la piel, y con lo cual podemos obtener tal cantidad de información que muchas veces se desconoce, no se enseña o no se le da la verdadera importancia que merece en nuestras facultades de Medicina; esto es muchas veces responsable de malos diagnósticos y tratamientos erróneos o, simplemente, desconocimiento de enfermedades que amenazan la vida de nuestro paciente.

A medida que cada día aumentan los adelantos científicos en el orden de la teconología en general, es fundamental regresar a lo básico, a la parte semiológica y su inmensa contribución en el diagnóstico y en el tratamiento de nuestros pacientes.

Espero que este libro aporte buena información y síntesis para el lector, que sea un aliciente para la investigación y el interés por todo lo relacionado con la visión holística de nuestro paciente.

Eduardo Ramírez Vallejo, MD, FACP, FACC.

Profesor titular, Facultad de Ciencias de la Salud

Universidad Tecnológica de Pereira 


\section{Introducción}

"Hipócrates ya se refería a la piel como el espejo del cuerpo".

La piel es el órgano más grande del cuerpo humano, ocupa dos metros cuadrados; es, a la vez, el más externo y, por lo tanto, el más visible, de tal manera que su exploración física muestra no solo las lesiones que pueden estar afectándola directamente, sino que también permite apreciar el efecto de algunos cambios internos. Por tal razón, su análisis aporta datos para la comprensión de las alteraciones de los órganos internos.

Desde el inicio de una enfermedad sistémica se presentan signos y síntomas en la piel. Por ello, todo médico general debe estar familiarizado con estas manifestaciones cutáneas para que pueda, de manera rápida, llegar a un diagnóstico clínico temprano, que le permita luego confirmar esa posible alteración e iniciar el tratamiento más adecuado o remitir al especialista experto en la alteración por tratar. Asimismo, debe conocer las células que conforman la piel para entender sus funciones y, también, los diferentes tipos de lesiones cutáneas que le ayudarán a reconocer lo que está sucediendo a nivel sistémico.

Este documento tiene como objetivo fundamental demostrar que la piel no solo es una envoltura externa, sino que es un órgano autónomo en muchas funciones para enfrentarse a un medio externo adverso y que, además de su función protectora, posee una serie de capacidades intrínsecas como órgano inmunitario y endocrino, que le permiten una interacción activa con los órganos internos.

Es decir que la piel es parte del sistema neuroinmunocrino porque, además de responder como un gran receptor sensorial, hace parte del sistema inmunitario y endocrino. La modulación del sistema inmunitario está dada por neuropéptidos sensoriales, hormonas, citocinas y factores de crecimiento. Existe un eje de retroalimentación con factores que regulan la transcripción, regulados a su vez por otras sustancias, como la hormona del crecimiento (Growth Hormone, GH), el factor liberador de la corticotropina (Corticotropin Releasing Hormone, $\mathrm{CRH}$ ), la hormona adrenocorticotropica (Adrenocorticotropic hormone, ACTH), la melanocortina, las $\beta$-endorfinas y el cortisol, que regulan la función activa de barrera de la piel como órgano endocrino e inmunitario, además de las funciones conocidas de queratinización, pigmentación, seborregulación y otras para mantener la termorregulación y la homeostasis sistémica.

Considerando que el examen dermatológico puede ser la clave para detectar un proceso sistémico, el clínico debe reconocer el tipo de lesiones que se presentan con mayor frecuencia: máculas, pápulas, nódulos, quistes, tumores, vesículas, ampollas, úlceras, 
pústulas, etc., porque dependiendo de su localización, del tiempo de aparición de las mismas y de los síntomas acompañantes configura los diversos cuadros clínicos que le permitirán relacionarlos con alguna enfermedad localizada o sistémica.

Cada uno de los capítulos revisa las manifestaciones cutáneas de las enfermedades más representativas de los sistemas del cuerpo humano neurológico, endocrinológico y hematológico, y las interacciones con el aparato cardiovascular, el respiratorio, el gastrointestinal y el renal, al igual que las alteraciones que se producen en las enfermedades del tejido conjuntivo. Por último, se muestra cómo los tumores malignos de los órganos internos tienen una repercusión importante en la piel y, por tal razón, se presentan las lesiones paraneoplásicas con el propósito de llegar a un diagnóstico oportuno de las lesiones malignas que las desencadenan.

Esta recopilación está basada en la experiencia clínica de la autora y en una revisión amplia de la literatura médica especializada, con la cual se pretendió revisar las creencias vigentes del conocimiento actual de cada tema. Por consiguiente, no es innovadora en el sentido de presentar algo desconocido, sin embargo, al final de cada expresión clínica se consigna un comentario que expresa la experiencia personal en cuanto a la frecuencia de presentación o a la manera como aparecen las lesiones. Es, por otro lado, una investigación que le da prioridad al criterio clínico.

No es una revisión para el dermatólogo experto, ni pretende abarcar todas las enfermedades existentes, pero sí busca enfocar al médico que no es dermatólogo en el reconocimiento de situaciones que lo pueden alertar de una enfermedad sistémica. Su mirada afinada le permitirá reconocer las lesiones que se presentan en la piel como manifestación de los procesos patológicos internos con el propósito de llegar a un diagnóstico acertado de manera más temprana. 


\section{Capítulo 1}

\section{Sistema cutáneo neuroinmunocrino}

"La naturaleza no es cáscara y almendra, ella es un todo integral".

Teniendo en cuenta la estratégica posición de la piel, en medio de lo externo y lo corporal interno, la diversidad de funciones que posee para la adecuada preservación de la homeostasis y la comunicación permanente que tiene con los órganos internos, se hace necesario ahondar en el conocimiento de las intrincadas e innumerables interrelaciones para comprender cómo lo que sucede en los órganos internos tiene repercusión en la piel.

El hombre es un ser completo, su mente y su cuerpo están unidos estrechamente y ya desde la antigüedad se postulaba la importancia de la relación entre la mente y el cuerpo. Platón y, luego, Aristóteles postulaban la imposibilidad de que el alma tuviese relación con el cuerpo, debía existir algo en el ser humano que permitía esa conexión y este, parecía ser el cerebro. alma, mente y cerebro. Este conocimiento inició la comprensión para lo que luego Galeno establecería que las capacidades psicológicas estaban relacionadas con el cerebro y que este sería el que determinaría el comportamineto del cuerpo.

Desde entonces, los antiguos ya comprendían que el equilibrio entre diferentes sustancias internas -que llamaban 'humores'- permitía la salud y que el desequilibrio predisponía a las enfermedades. Además, en la Edad Media, se consideraba a la melancolía como un factor importante en el desencadenamiento de las enfermedades. Se percibía que todo lo que un ser siente y experimenta repercute en sus órganos vitales, tanto internos como externos.

Este conocimiento que podemos entender mejor ahora, se debe a que el ser humano posee unos sistemas de información semejantes en varios de sus tejidos que le permiten esta interacción permanente. Sistemas que se intercomunican por medio de receptores y sustancias que se fijan a ellos o que salen de las células implicadas, como vesículas extracelulares o 'exosomas' que llevan fragmentos de información de una célula a otra o a la circulación y desencadenan un determinado tipo de respuesta (2). 
Entre 1853 y 1859, Claude Bernard esbozó los principios generales de las funciones del sistema nervioso y sus acciones sobre la temperatura, las secreciones y la glucosa (3). Bernard partió de la idea de que los organismos vivos - 'el medio interno'- se encuentran en constante interacción fisicoquímica con el medio que les rodea. Esta interacción es bidireccional y está orientada a un fin: la autoconservación de dicho organismo, su interacción con otros para la conservación de la homeostasia o los dos. "Cuando un agente físico-químico interactúa con una célula, esta produce un efecto fisiológico que le es propio", como secretar una hormona, contraerse, emitir una descarga eléctrica, dilatarse, etc. Estas primeras aproximaciones permitieron comprender la influencia del sistema nervioso en los demás órganos.

Con relación a la piel, quizá el primero que consideró la influencia de los factores psicológicos en la aparición de una lesión dermatológica -el liquen rojo plano- fue Sir Erasmus Wilson en 1869.

Tan solo en 1930, Hans Selye expresó un concepto que permitió integrar con mayor precisión estas interacciones. Selye utilizó la palabra 'estrés' para referirse a que "sea cual sea la respuesta específica, se activa al mismo tiempo una respuesta inespecífica, que es siempre independiente de cuál sea la respuesta específica" (4). Es decir que existían otros fenómenos paralelos al hecho mismo que se estaba analizando y que podían explicar otras manifestaciones a distancia. Esta situación permitió empezar a visualizar la compleja serie de interrelaciones que existen entre los diferentes sistemas del organismo que más tarde se entenderían mejor, cuando él mismo, en 1946, habló de las interacciones entre el sistema nervioso, el endocrino y el inmunitario.

No debemos olvidar tampoco a otro padre de la inmunología moderna, Robert Good, quien documentó la importancia del timo y de las amígdalas en el desarrollo de la inmunidad: Sin ellos no sería posible entender la importancia del concepto de la piel como parte del sistema inmunológico, ya que estructuralmente los corpúsculos de Hassall del timo son semejantes a la epidermis, y el hecho de que ellos existan determinan que el timo haya sido funcional, es decir que la piel tiene una función similar a la de un inmenso timo extendido (5).

Todos estos conocimientos iniciaron una aproximación a una serie de interacciones que ocurren en el eje hipotálamo-hipófisis-glándulas suprarrenales y que también existen entre el sistema nervioso simpático y la médula suprarrenal. Selye denominó a este conjunto de respuestas y a sus correspondientes síntomas el 'síndrome general de adaptación' (6). 
Una vez iniciada la comprensión que lleva a suponer que las emociones posiblemente se traducen en secreciones que hacen que el sistema nervioso central influya sobre otros órganos mediante sustancias tales como los neurotransmisores: la epinefrina o adrenalina, la noradrenalina, la acetilcolina, la serotonina, la dopamina $\mathrm{y}$, en general, las neuroendorfinas, y comprendiendo a la vez, que el mismo sistema nervioso central está influenciado por los diferentes péptidos hormonales que provienen del sistema endocrino, y agregando que los elementos del sistema inmunitario también se suman con sus receptores y citocinas a esta intrincada malla de conexiones, es que podemos entender cómo muchas de las funciones inmunitarias, neurológicas y endocrinas están interrelacionadas.

La piel no sólo es un tejido que proviene del ectodermo, que puede contener los diferentes órganos y servir de sostén o permitir el adecuado equilibrio hidroelectrolítico, sino que también es indispensable para la termorregulación, la percepción de sí mismo y de lo que acontece externamente, en la síntesis de la vitamina $\mathrm{D}$ y en la melanogénesis. Por otro lado, es una barrera física, química y biológica del cuerpo frente al medio externo para protegernos activamente de las diferentes noxas a las que nos enfrentamos diariamente, sean microorganismos o eventos fisicoquímicos los que nos afecten, y lo hace a través de diversos péptidos antimicrobianos, la barrera establecida por la cohesión de sus células y la presencia de proteasas de serina. En conjunto con un sistema inmunitario activo con liberación de interleucinas y factores de necrosis tumoral. Por tales razones, la piel posee ciertas características para cumplir con sus funciones en esta adecuada interacción entre el medio externo y el interno.

La piel, como parte del sistema inmunitario, está estrechamente ligada al sistema neuroendocrino, y es en ella donde se visualiza lo que sucede con estas interrelaciones que comprometen el eje hipotálamo-hipófisis y los órganos endocrinos y, posiblemente, sea el lugar donde se modulan estas respuestas.

Es en la comprensión de estas relaciones psicológicas, neuroendocrinas e inmunoloógicas y la aparición de la enfermedad, donde varios científicos se dedicaron a entender lo que sucedía. Algunos de ellos, como Joseph Breuer o Sigmund Freud, profundizaron en la comprensión de la influencia psicológica en las enfermedades y este último inició el estudio del psicoanálisis. Otros se dedicaron a estudiar las interrelaciones hormonales o neurológicas y las interacciones entre ambos sistemas para entender que sucede en el estado de salud y cómo se manifiestan en la enfermedad.

En cuanto al concepto de que la piel hace parte de esta intrincada red psiconeuroinmunocrina, podemos decir que hace mucho tiempo que entendemos 
sus relaciones con el sistema nervioso. El hecho de que la piel se deriva -al igual que el sistema nervioso- del ectodermo, hizo suponer que debía tener funciones semejantes por su origen. Posee, además, las células de Merkel, células neuroepiteliales sensoriales y unos corpúsculos capaces de dar cuenta de sensaciones como el frío y el calor, o de transmitir impresiones como el prurito o el dolor, que son experiencias sensoriales desagradables, mediadas por las mismas vías y receptores sensitivos somáticos, que comparten el sistema antero-lateral de la médula; también, que es por medio de las raíces posteriores ascendentes de la vía de las fibras a y $\delta$ (si se presenta de manera aguda) o por las fibras C (si es crónico), que se transportan estos impulsos nerviosos que, a la vez, se transmiten a los núcleos ventrales del tálamo en el área sensitivo-somática ventral y luego van a la corteza cerebral.

En esta complicada red, el prurito y el dolor pueden expresar alteraciones sistémicas, ya sea por liberación de histamina y serotonina, o al estimular otros receptores y fibras nerviosas $\mathrm{u}$ opioides, o por la elevación de ciertos productos inflamatorios involucrados en la enfermedad sistémica alterar estas fibras.

La liberación de estas diversas sustancias por parte de los diferentes sistemas en las alteraciones renales, hepatocolestáticas, hematológicas, endocrinológicas (diabetes, hipotiroidismo e hipertiroidismo), en el síndrome de neoplasia endocrina múltiple, o en el síndrome carcinoide, se hacen visibles externamente y la piel es la que da cuenta de la alteración interna. Por otro lado, algunas alteraciones, como las alteraciones tiroideas, la anemia ferropénica o la anemia perniciosa, la hipoalbuminenia o la pérdida de proteínas, pueden inducir cambios en los anexos - pelos y uñas- que estarán alterados en su forma, o en la pigmentación o en la falta de crecimiento. Además, el crecimiento rápido de las células de cualquier órgano, es decir, la aparición de algunos tumores que son capaces de liberar sustancias proqueratinizantes o melanogénicas, se harán visibles en diversas manifestaciones de la piel que se describen más adelante en este texto.

Continuando con la comprensión de estas interacciones, debemos recordar que, quizá, quien da los primeros pasos para entender a la piel como 'un órgano inmunológico’ cercano al sistema neurológico fue Marion Sulzberguer (1895-1983) como lo refiere Stephe I. Katz en su artículo "The skin as an immunologic organ. A tribute to Marion B. Sulzberger", que se publicó en el Journal of the American Academy of Dermatology (7). Marion B. Sulzberger expresó que la piel podía ser tan compleja como el cerebro humano y, a la vez, ser el más humano de todos los órganos en su característica de unicidad: "Skin... next to the human brain, probably the most complex as well as the most uniquely human of all organs" (7), iniciando así la comprensión de que este tejido estaría participando en todas las interrelaciones posibles de lo que se considera un sistema neurológico e inmunitario activo, con 
células con capacidad para instruir a ciertos linfocitos $\mathrm{T}$, con células capaces de presentar antígenos, de producir citocinas y, además, de tener receptores para todas ellas.

El comprender que la piel hace parte del sistema inmunitario y del hormonal ha tomado muchos años. El estudio sistemático de la piel como órgano inmunológico se expuso en las décadas de 1980 y 1990, con numerosos artículos que hablaban de la piel como un sistema asociado al sistema inmunitario más que un órgano en sí (8). Stephen I. Katz, en el artículo publicado en septiembre de 1985 en el Journal of the American Academy of Dermatology, incluye por primera vez a la piel como un órgano inmunológico (7).

Demostraciones de ello se van dando poco a poco. Inicialmente, se encontraron semejanzas histopatológicas entre la estructura de la epidermis y la de los corpúsculos de Hassall del timo (9), que sólo aparecen si el timo es funcional y ha albergado a los linfocitos $\mathrm{T}$ para su total maduración, lo que se llama el homing, es decir, como el lugar donde maduran las células. De tal manera que estas semejanzas permitieron pensar que la piel podía ser otro lugar alterno de actividad funcional para la maduración o para la adquisición de alguna información por parte de los linfocitos T.

Esto se ha confirmado últimamente, al encontrar en la capa granular de la epidermis la presencia del gen codificador de la proteína transmembrana 45A (TMEM45A mRNA) y su proteína asociada; al igual que se encuentra en el timo. Esta expresión de TMEM45A está ligada a la queratinización, y la acumulación de la proteína es detectada en epidermis natal y reconstituida al igual que en los corpúsculos de Hassall del timo (10). Lo anterior permite comprender que la piel es como un inmenso timo extendido y que, por tal razón, posee estructuras semejantes a él, segrega citocinas y posee receptores para ellas y que, en un momento dado, puede ser un lugar donde se especialicen subpoblaciones de linfocitos T (11).

Ciertas células $\mathrm{T}$ de memoria parecen recordar el lugar donde se convirtieron en tales al contacto con un antígeno. Eso les sucede a las de la piel que poseen un marcador llamado CLA (Cutaneous Lymphocyte Antigen) por ser el antígeno asociado a los linfocitos cutáneos (12). El CLA es un receptor que permite la diferenciación de los linfocitos. Estas células se han encontrado en la mayoría de los procesos inflamatorios que tienen lugar en la piel, como la dermatitis de contacto, la dermatitis atópica, la psoriasis, los linfomas cutáneos, la alopecia areata, las erupciones por medicamentos, etc. 
Entre los elementos constitutivos del sistema inmunitario de la piel, se demostró que en ella también existían células dendríticas. Las más conocidas son las células de Langerhans, que se encuentran en la epidermis, intercaladas en la capa basal. El hecho de haberlas encontrado y de relacionarlas con el sistema fagocitario mononuclear (13), es decir, con capacidad de captar antígenos y presentarlos a los linfocitos $\mathrm{T}$, permitió comprender cómo se producen en la piel las diferentes reacciones de hipersensibilidad retardada tales como la respuesta a la proteína purificada derivada de Mycobacterium tuberculosis (Purified Protein Derivative, PPD) o las reacciones de las dermatitis alérgicas de contacto o de los eccemas en general.

Además, la posterior demostración de que estas células dendríticas poseían receptores no solo para Fc-IgG (fragment crystallizable region) y C3b, sino también para Fc de alta y de baja afinidad para la IgE, y que, por lo tanto, esta inmunoglobulina se podía fijar tanto a los mastocitos como a las células dendríticas, nos permitieron entender por qué en el eccema infantil o en la dermatitis atópica donde es muy importante la elevación de la IgE, aparecían vesículas propias de las reacciones tipo IV, o retardadas, y no ronchas propias de las reacciones de tipo I, o inmediatas, que sería lo que antiguamente se podría haber considerado $(14,15)$.

Este hallazgo, a su vez, permitió la comprensión de varias cosas; una de ellas fue entender las relaciones entre las reacciones de tipo I y la IV, además de explicar por qué en algunos casos encontramos alteraciones relacionadas con la intervención de la IgE, pero sin niveles sanguíneos altos de la misma. Esto debido a que existen dos tipos de receptores para la IgE, uno de alta afinidad y otro de baja afinidad. El de alta afinidad, FceR1, es el que está presente en las células dendríticas, los monocitos, los basófilos mastocitos y los neutrófilos; es el que se relaciona con los niveles elevados de IgE en sangre, lo que no sucede con el receptor de baja afinidad, receptor CD23, presente en las células dendríticas y en los monocitos. Se han descrito otras células dendríticas, con capacidad para presentar antígenos que, dependiendo del lugar en el que se encuentren y debido a cambios en sus receptores e incluso morfológicos, van tomando otros nombres, como son las células indeterminadas y las células veladas, que cumplen funciones similares, de fagocitosis o de presentación de antígenos, en cada sitio donde se encuentran hasta llevar la información al ganglio linfático.

Las mismas células endoteliales de la unidad endotelial dérmica con capacidad de adherirse a estas células linfoides, cumplen un papel muy importante junto con las quimiocinas, las selectinas y las integrinas, al ser capaces de transportarlas y conducirlas a la epidermis para que modulen las respuestas inflamatorias frente a los diferentes antígenos mediante reacciones de hipersensibilidad inmediatas y retardadas (16), sin olvidar que en la dermis encontramos, además, linfocitos, mastocitos y eosinófilos. 
El hecho de que todos estos componentes de la piel hagan parte del sistema inmunitario nos permite entender que, probablemente, por esta razón, es allí, en la piel, donde observamos las lesiones exantemáticas, pues quizá es en ella donde se resuelve la eliminación de virus como el herpes, el citomegalovirus, el de Epstein-Barr, el togavirus, el parvovirus, el virus ECHO (Enteric Cytopathic Human Orphan), el Coxsackie, etc., que producen estas lesiones conocidas como exantemas generalizados, o tal vez solo visualizamos los cambios propios que las alteraciones vasculares inducen, como está referido en la literatura.

En la comprensión de la importancia que tenía la piel como órgano inmune se estudiaron, además de las células de Langerhans, otros elementos constitutivos del sistema inmunitario, como las células presentadoras inductoras de supresión. Se encontró afinidad de los linfocitos T por la piel, por lo que se configuró, en ese momento, como los tejidos linfoides asociados a la piel (Skin-Associated Lymphoid Tissues, SALT) (17). Se habló de la importancia de la inmunomodulación en ella, pero solo hasta que se identificó que los queratinocitos segregan factores inmunorreguladores, como el factor activador de linfocitos T epidérmicos (Epidermal Thymocyte Activating Factor, ETAF) para proveer un microambiente especial a estas células linforreticulares intraepidérmicas, es que se le dio toda la importancia (18). Asimismo, se demostró la gran cantidad de interleucinas que se producen en la piel, IL-1, IL-6, TNF (Tumor Necrosis Factor), IL-17 y todos los receptores que hay para ellas, y se pudo visualizar un panorama más completo en el que se muestra cómo la piel hace parte activa del sistema inmunitario.

De la misma manera, se inició una visualización de la piel como órgano endocrino al encontrar receptores para glucocorticoides, insulina, hormona estimulante de tiroides (Thyroid Stimulating Hormone, TSH), estrógenos (19), andrógenos, hormona liberadora de corticotropina (Corticotropin-Releasing Hormone, CRH, o Corticotropin-Releasing Factor, CRF) (20), urocortina, prolactina y hormona de crecimiento, entre otras, y luego evidencias de que allí se producen o se activan parte de estas hormonas, según lo reportado por Slominsky y Zouboulis y otros autores como Tuckey y Stocco en múltiples artículos, y que han demostrado que la piel es parte activa del sistema endocrino (21).

Las hormonas, en general, y en particular la hormona activadora de corticotropina (Adrenocorticotropic Hormone, ACTH), la $\beta$ endorfina, el péptido intestinal vasoactivo (Vasoactive Intestinal Polypeptide, VIP), la somatostatina, la sustancia $\mathrm{P}$, los neuropéptidos, los neurotransmisores y las citocinas son moléculas de comunicación entre diferentes células. Estos pequeños polipéptidos que actúan en forma autocrina, paracrina o endocrina permiten la comunicación entre los 
sistemas nervioso, endocrino e inmunitario, razón por la cual nos referimos a las interacciones neuroinmunocrinas de la piel, debido a que ella participa de manera activa en todas estas interacciones.

Así como el sistema nervioso central tiene receptores para citocinas, también existen receptores para neurotransmisores (5-HT, Ach, NE, DA, GABA), neuropéptidos (VIP, somatostatina, sustancia P), ACTH, $\beta$ endorfinas y fibras noradrenérgicas distribuidos en los órganos linfoides y sus efectos son mediados por receptores de neurotransmisores sobre las células del sistema inmunitario. La presencia de receptores adrenérgicos $\beta 2$ en las subpoblaciones de células linfoides facilita la unión de la norepinefrina para alterar la liberación de citocinas, factores de crecimiento y moléculas inmunológicas que cruzan la barrera hematoencefálica y que alteran las funciones cerebrales (22).

Como se puede apreciar, el sistema inmunitario tiene receptores para neurotransmisores, hormonas y neuropéptidos y posee una gran cantidad de células que producen diferentes citocinas, entre ellas interleucinas, interferón (IFN), factor de necrosis tumoral (FNT), factores de crecimiento de macrófagos, de granulocitos y de ambos que interactúan con el sistema nervioso y endocrino y que tienen acción sobre múltiples órganos. El sistema endocrino tiene receptores para citocinas, hormonas y neurotransmisores, y produce ACTH, cortisol, hormona de crecimiento, prolactina, TSH, hormona folículo-estimulante (Follicle-Stimulating Hormone, FSH) y hormona luteinizante (Luteinizing Hormone, LH), de tal manera que son sistemas que reciben y emiten señales entre ellos, lo que demuestra que tienen una estrecha relación.

La piel también produce hormonas $(23,24)$ y citocinas y tiene receptores para neurotransmisores, hormonas, neuropéptidos y citocinas, todos ellos expresados en los queratinocitos y algunos específicamente en otro tipo de células, como las células de Langerhans, los melanocitos, los fibroblastos, los mastocitos y el endotelio vascular, o en los diferentes anexos, y algunas en los adipocitos, las células de Schwann o en las células musculares (25).

Además, la piel humana produce y metaboliza glucocorticoides y hormonas sexuales. Es un órgano en el cual las actividades emanadas de las hormonas esteroideas y su influencia repercuten en la regulación local y sistémica inmunológica y se vinculan así a los procesos inflamatorios y autoinmunes en general y están reguladas, a su vez, por factores locales, por elementos constitutivos de la inmunidad innata y por la radiación ultravioleta.

En la mayoría de los artículos publicados, cuando se consideran las relaciones entre la piel y el sistema neuroinmunocrino, se refieren a su influencia 
bidireccional, pero es importante afirmar que simplemente es un sistema único: la piel hace parte de esos sistemas: neurológico, inmunológico y endocrino. Es un órgano neuroinmunocrino, así que la piel expresa y produce los mismos tipos de sustancias que los otros sistemas y tiene receptores para poder interactuar con ellos.

En la revisión de Slominsky del 2012, describe como la 5-hidroxitriptamina -mejor conocida como la serotonina- es un mediador importante entre el sistema neurocrino y la piel (26). En la epidermis y en la dermis se expresan las enzimas requeridas para la transformación del triptófano a 5-hidroxitriptamina y se demuestra que ciertas células de la piel, como los melanocitos, al menos en ratones, producen serotonina. Esta serotonina regula los sistemas vascular e inmunitario. Además de producirse serotonina en las células de la piel, estas también responden a su influencia, que ocurre tanto en los melanocitos, como en los queratinocitos y en los fibroblastos dérmicos. Este conocimiento es importante para el planteamiento de posibles nuevos tratamientos de las lesiones de piel, utilizando supresores o inhibidores de estas sustancias.

En conclusión, la piel, como parte del sistema inmune y endocrino, es un órgano que responde como un gran receptor sensorial y la modulación del sistema inmunitario está dada por neuropéptidos sensoriales, hormonas, citocinas y factores de crecimiento. Existe un eje de retroalimentación, con factores que regulan la transcripción, regulados, a su vez, por otras sustancias como la hormona de crecimiento (Growth Hormone, GH), el factor liberador de corticotropina (CRF), la $\mathrm{ACTH}$, la melanocortina, las $\beta$ endorfinas y el cortisol que regulan la función activa de barrera de la piel como órgano endocrino e inmunitario, además de las funciones conocidas de queratinización, pigmentación, seborregulación y otras para mantener la termorregulación y la homeostasis sistémica.

Al hablar de la piel debemos hablar del sistema neuroinmunocrino cutáneo, ya que no solo es neuroinmunitario sino que también hace parte del sistema endocrinológico. Christos C. Zouboulis lo ha demostrado en diversos artículos, en los que incluye a la piel como uno de los órganos del sistema endocrino, al encontrar que hace parte de una comunidad de órganos que tienen diferentes células con capacidad de emitir, recibir y coordinar diferentes señales moleculares que se pueden considerar hormonales (21-24).

Como veíamos anteriormente, se sabía que la piel tenía receptores para varias hormonas, entre ellas para la hormona tiroidea, la hormona del crecimiento, los corticosteroides, el factor insulinoides de crecimiento (Insulin-Like Growth Factors, IGF) y los neuropéptidos (27), pero, ahora sabemos que también en ella se producen glucocorticoides y esteroides sexuales. Estas hormonas no solo tienen receptores, 
sino que, además, allí se sintetizan y, a la vez, pueden activarse o eliminarse. Al activarse en la piel cumplen su actividad biológica como sucede con el eje liberador de la hormona corticotropina-propiomelanocortina, la vitamina $\mathrm{D}$, los retinoides, los eicosanoides y los ligandos del receptor activador de peroxisomas (21).

Cada vez es más claro que la piel humana produce hormonas que se liberan a la circulación o que estimulan internamente sus propias células. Ejemplo de ellos es la síntesis de los esteroides sexuales: los andrógenos en el hombre y los estrógenos en la mujer se sintetizan localmente a partir de precursores suprarrenales inactivos de la dihidroepiandrosterona (DHEA) y de la androstenediona y se convierten a testosterona (28) o a 5-dehidrotestosterona (5-DHT), gracias a la 5-a-reductasa o a la 17- $\beta$-hidroxiesteroide dehidrogenasa (29). Se estima que la formación intracrina de estrógenos en la mujer sea del $75 \%$ en el tejido periférico, incluida la piel; el otro porcentaje proviene del ovario, de la testosterona suprarrenal o de la androstenediona (30) y se sabe que durante la menopausia esta producción puede llegar al $100 \%$, es decir que depende solo de la piel, lo que demuestra que es un órgano endocrino per se (24).

La hormona del crecimiento y el factor insulinoide 1 de crecimiento (InsulinLike Growth Factor-1, IGF-1) tienen una función directa de regulación del factor insulinoide de crecimiento, unido a la proteína 3 de unión (IGF-Binding Protein-3) en la piel, lo cual sugiere que, en ciertas circunstancias, los fibroblastos dérmicos pueden ser más importantes que el hígado en la regulación del depósito de este factor insulinoide de crecimiento unida a la proteína 3.

La piel produce hormonas que son muy importantes para todo el organismo, y que se liberan a la circulación, como sucede con la hormona tiroidea y la vitamina D. La hormona tiroidea está comprometida en la proliferación y diferenciación epidérmica, en el crecimiento del pelo y en la reparación de tejido por parte de los fibroblastos. La piel es el único sitio de síntesis de colecalciferol, el cual se deriva del colesterol $(31,32)$. Los queratinocitos epidérmicos contienen la maquinaria necesaria para producir tanto el calcitriol como el receptor de la vitamina D. Para ello requieren del estímulo de la radiación ultravioleta y su principal función es la de estimular la absorción intestinal de calcio y fosfatos.

De una manera más detallada, ahora se sabe que la piel tiene receptores para la hormona liberadora de corticotropina y urocortina en el queratinocito, el melanocito y el mastocito; receptores para la melanocortina en los queratinocitos, los melanocitos, las células de Langerhans, el endotelio vascular, los fibroblastos y las glándulas ecrinas, apocrinas y sebáceas. 
Los siguientes receptores se encuentran distribuidos en diferentes estructuras cutáneas: receptores opioides $\mu$ y $\varepsilon$ en los queratinocitos, la vaina radicular externa del pelo y las glándulas sudoríparas y sebáceas; receptores para la hormona del crecimiento en los queratinocito, los melanocitos, los folículos pilosos, los fibroblastos, las glándulas ecrinas, los adipocitos, las células de Schwann y las células musculares, y receptores para la prolactina, la hormona luteinizante y la gonadotrofina coriónica en los queratinocitos, los folículos pilosos y las glándulas sebáceas y ecrinas (33). Además, receptores de neurocinina en los queratinocitos, el endotelio, los mastocitos, las células de Langerhans y los fibroblastos, y otros receptores misceláneos, a saber, purinoreceptores activados por nucleótidos de adenosina $\mathrm{o}$ adenina en los queratinocitos, los folículos pilosos, las glándulas sebáceas y ecrinas y las células de melanoma; receptores para $\mathrm{T}_{3}$ en los queratinocitos, los fibroblastos, los folículos pilosos, las glándulas sebáceas y ecrinas, y los melanocitos.

Se ha demostrado, además, la síntesis de los siguientes péptidos y hormonas en las diferentes capas de la piel: en la epidermis: vitamina $\mathrm{D}$, péptido relacionado con la hormona paratiroidea (Parathyroid Hormone, PTH), andrógenos, $\mathrm{T}_{3}$, L-dopa, catecolaminas, acetilcolina, serotonina, glutamato, aspartato, hormona liberadora de corticotropina, urocortina $\alpha, \beta$ y $\gamma$, hormona melanoestimulante, ACTH, $\beta$ endorfina y encefalinas; en la dermis y en las estructuras anexas: vitamina $D$, péptido relacionado con la $\mathrm{PTH}$, estrógenos, andrógenos, L-dopa, catecolaminas, acetilcolina, serotonina, glutamato, aspartato, hormona liberadora de corticotropina, urocortina $\alpha, \beta$ y $\gamma$, hormona melanoestimulante, ACTH, $\beta$ endorfina, encefalinas, GH e histamina; en el tejido adiposo: leptina, adiposina, proteína estimulante de la acilación (Acylation Stimulating Protein, ASP), proteína del adipocito relacionada con el complemento, FNT- $\alpha$, factor inhibidor de la migración de macrófagos, angiotensinógeno e inhibidor del activador del plasminógeno de tipo I.

Los neuropéptidos generados en la piel por las células cutáneas residentes y circulantes son: el péptido liberador de gastrina, la somatostatina, el neuropéptido Y, el péptido auricular natriurético, las neurocininas, la sustancia $\mathrm{P}$, la neurotensina, el péptido del gen relacionado con la calcitonina, el péptido intestinal vasoactivo, la bradicinina, la colescistocinina, las endotelinas, la hormona liberadora de corticotropina, las urocortinas, $\alpha, \beta$ y $\gamma$, la hormona melanoestimulante, ACTH, $\beta$ endorfina y las encefalinas. En las terminaciones nerviosas: la sustancia P, las neurocininas, la neurotensina, el CGRP (Calcitonin Gene-Related Peptide), el péptido intestinal vasoactivo, la somatostatina, el neuropéptido y el péptido auricular natriurético, la bradicinina, la colecistocinina, las endotelinas $\alpha, \beta$ y $\gamma$, la hormona melanoestimulante, la ACTH, las endorfinas, las encefalinas, la hormona liberadora de corticotropina (CRH), la urocortina y la dinorfina. 
El descubrimiento del factor liberador de la corticotropina (CRF) o la hormona liberadora de corticotropina $(\mathrm{CRH})$ y sus correspondientes receptores CRFR-1 y -2 ha sido uno de los hallazgos fundamentales para entender la regulación de la función de la barrera epidérmica, de la inmunidad en la piel, de la pigmentación, del funcionamiento de los anexos y de otras funciones dérmicas necesarias para mantener una homeostasis local y sistémica (20).

El factor liberador de corticotropina puede ser liberado por las células inmunitarias o por el tejido nervioso en respuesta a las situaciones emocionales o ambientales generadoras de estrés, que activan el eje hipotálamo-hipófisisglandulas suprarrenales y que mediante ese estímulo sensorial o por la producción de diversas sustancias inmunológicas de carácter humoral, permiten que se vuelva a la normalidad. La secuencia de péptidos que se desencadenan en tales situaciones incluyen: las urocortina 1 y 3/CRF, la propiomelanocortina, la ACTH, la hormona melanoestimulante y las $\beta$ endorfinas.

La expresión de estos péptidos y de sus receptores, regulados ambientalmente por situaciones estresantes, radiación ultravioleta $\mathrm{B}$ y otras, $\mathrm{y}$ su posterior disfunción, afecta la piel y otros órganos, lo que puede evidenciarse en algunas enfermedades sistémicas. Este conocimiento nos permite entender algunas de las expresiones cutáneas de enfermedades sistémicas y nos lleva a pensar que también se pueden utilizar diferentes medicamentos agonistas o antagonistas, según sea el caso, que al regular el factor liberador de la corticotropina o su receptor también controlen los fenómenos inflamatorios cutáneos derivados de esta estimulación. Este conocimiento podría utilizarse principalmente para aquellas enfermedades que dependen del estrés, como son la dermatitis atópica, el liquen rojo plano, la alopecia areata y una variedad de la psoriasis.

Continuando con la comprensión de todas estas interacciones, debemos recordar que la proliferación de los linfocitos en los órganos linfoides primarios y secundarios -incluida la piel- depende no solo de la hormona del crecimiento sino también de la prolactina. De tal manera que si se presentan alteraciones en ella, se reflejarán en la piel y en sus anexos. Estos órganos linfoides están inervados y, por consiguiente, los estímulos nerviosos que reciben repercuten en su comportamiento, al igual que sucede con células, como los mastocitos, que responden al estímulo nervioso. Recordemos que entre las sustancias que se producen en el sistema nervioso, la acetilcolina y la sustancia $\mathrm{P}$ son inmunoestimuladoras y antiinflamatorias, mientras que interleucinas, como la IL-6, que es segregada por la hipófisis tras inducción con lipoolisacáridos, acetato miristato de forbol, IL-1 $\beta$, FNT, activación de la pituitaria adenilciclasa, gen del péptido relacionado con la calcitonina, el IFN- $\gamma$, y la prostaglandina E2, son sustancias proinflamatorias que, a su vez, son inhibidas por los glucocorticoides, la vasopresina y la oxitocina. 
El hipotálamo también tiene hormonas, como la vasopresina y la oxitocina, que se acumulan en la neurohipófisis, y hormonas excitadoras de la adenohipófisis (34) que, a su vez, segregan la ACTH o hormonas estimuladoras de la cápsula suprarrenal para inducir la producción de aldosterona, cortisol y adrenalina; hormona estimulante del tiroides (Thyroid Stimulating Hormone, TSH) para producir tiroxina y calcitonina; hormona del crecimiento $(\mathrm{GH})$ para producir crecimiento de los huesos y factor de crecimiento de insulina, y hormonas estimulantes del crecimiento de las gónadas, como la FSH que estimula a los testículos y a los ovarios para que produzcan hormonas sexuales (estrógenos, progesterona y testosterona) y, además, la prolactina que es la hormona estimulante de las glándulas mamarias. Todas estas hormonas van a influir en el desarrollo y en la estimulación de la piel y de sus anexos pues, como vimos anteriormente, existen receptores para todas ellas.

La disfunción neuroinmunocrina participa en la patogénesis de diferentes enfermedades en general con repercusión en la piel, debido a que, si se producen cambios en la producción de alguna sustancia de origen neurológico, tales como endorfinas, serotonina, noradrenalina o catecolaminas, repercutirá en la función inmunológica y, a su vez, en la producción de diferentes hormonas.

Se sabe que en la depresión se encuentra un aumento de la IL-6, la cual actúa como una sustancia proinflamatoria mediante receptores $\beta$ adrenérgicos; en los pacientes con virus herpes IV o virus de Epstein-Barr se encuentran niveles bajos de linfocitos T CD8; de forma similar, en el cáncer se encuentra una disminución de células asesinas naturales (Natural Killer, NK), una subpoblación de linfocitos T, lo que demuestra que las relaciones neuroinmunes están presentes.

También podemos ver que existen relaciones neuroendocrinas en las endocrinopatías en las que se pueden producir trastornos afectivos y alteraciones de la conducta. Tanto la enfermedad de Addison como el síndrome de Cushing y el hipotiroidismo se asocian a la depresión. Tras el estrés, se desencadena una hiperactividad hormonal, con aumento de la vasopresina, el cortisol y la prolactina, y con disminución de la testosterona. Las enfermedades tiroideas autoinmunitarias, como la artritis reumatoide y el lupus eritematoso sistémico, pueden iniciarse después de situaciones de estrés o de depresión.

Se puede concluir que cuando se comprenden estas relaciones psiconeuroinmunocrinas, se entiende que las emociones y cualquier alteración patológica en alguno de nuestros órganos -aun en las respuestas alérgicas, autoinmunitarias o tumorales- tienen representación en la piel y que también al ser la piel parte del sistema endocrino e inmunitario, su participación es crucial en la eliminación de algunas infecciones, en la modulación de diversas respuestas 
inflamatorias y que quizá sea más importante de lo que pensamos en la homeostasis de las respuestas endocrinas.

Por todo esto, es indispensable partir de este conocimiento complejo del sistema neuroinmunocrino cutáneo, que se considera a la piel como parte de sus órganos constituyentes; con el fin de conocer todas estas diferentes interacciones para comprender el por qué de la aparición de las manifestaciones en la piel de las diferentes enfermedades sistémicas.

\section{Referencias}

1. Bennett MR. Development of the concept of mind. Aust N Z J Psychiatry. 2007;41:943-56.

2. Campos JH, Soares RP, Ribeiro K, Cronemberger-Andrade A, Batista WL, Torrecilhas AC. Extracellular vesicles: Role in inflammatory responses and potential uses in vaccination in cancer and infectious diseases. J Immunol Res. 2015;2015:e832057.

3. Jörgens V, Grüsser M. Happy birthday, Claude Bernard. Diabetes. 2013;62:2181-2.

4. Selye H. A syndrome produced by diverse noxious agents. Nature. 1936;138:32-3.

5. Bahna SL. Father of modern immunology--Robert A. Good (1922-2003). Ann Allergy Asthma Immunol. 2015;114:265-8.

6. Selye H. The stress of life. New York, NY: McGraw-Hill Book Company; 1976.

7. Katz SI. The skin as an immunologic organ. A tribute to Marion B. Sulzberger. J Am Acad Dermatol. 1985;13:530-6.

8. Bos J. The skin as an organ of immunity. Clin Exp Immunol. 1997;107:3-5.

9. Thiers B. Epidermis and immunology. En: Dermatology, immunology and allergy. Basilea: CV Mosby Company; 1985. p. 211-6.

10. Hayez A, Malaisse J, Roegiers E, Reynier M, Renard C, Haftek M, et al. High TMEM45A expression is correlated to epidermal keratinization. Exp Dermatol. 2014;23:339-44.

11. Bodey B, Bodey B Jr, Kaiser HE. Dendritic type, accessory cells within the mammalian thymic microenvironment. Antigen presentation in the dendritic neuro-endocrine-immune cellular network. In vivo. 1997;11:351-70.

12. Picker LJ, Treer JR, Ferguson-Darnell B, Collins PA, Bergstresser PR, Tersrappen LW. Control of lymphocyte recirculation in man. II. Differential regulation of the cutaneous lymphocyte associated antigen, a tissue-selective homing receptor for skin-homing $\mathrm{T}$ cells. J Immunol. 1993;150:1122-36.

13. Bagot M, Heslan M, Dubertret L, Roujeau JC, Touraine R, Levy JP. Antigen-presenting properties of human epidermal cells compared with peripheral blood mononuclear cells. Br J Dermatol. 1985;113(Suppl.28):55-60.

14. Dehlink E, Baker AH, Yen E, Nurko S, Fiebiger E. Relationships between levels of serum IgE, cell-bound IgE, and IgE-receptors on peripheral blood cells in a pediatric population. PLoS One. 2010;5:e12204.

15. Bieber T. Fc epsilon RII/CD23 on epidermal Langerhans' cells. Res Immunol. 1992;143:445-7. 
16. Úsuga YA, Velásquez MM. Mecanismos que controlan la migración del linfocito $\mathrm{T}$ a la piel. Revista de la Asociación Colombiana de Dermatología. 2011;19:57-66.

17. Streilen J. Circuits and signals of the skin-associated lymphoid tissues (SALT). J Invest Dermatol. 1985;85:10-3.

18. Sauder D. Biologic properties of epidermal cell thymocite-activating factor (ETAF). J Invest Dermatol. 1985;85:176-9.

19. Pelletier G, Ren L. Localization of sex steroid receptors in human skin. Histol Histopathol. 2004;19:629-36.

20. Slominski AT, Zmijewski MA, Zbytek B, Tobin DJ, Theoharides TC, Rivier J. Key role of CRF in the skin stress response system. Endocrinol Rev. 2013;34:827-84.

21. Zouboulis CC. The human skin as a hormone target and an endocrine gland. Hormones. Athens. 2004;3:9-26.

22. Rajan ST, Priyanka HP. Bidirectional communication between the neuroendocrine system and the immune system: Relevance to health and diseases. Ann Neurosci. 2012;19:40-6.

23. Slominski A, Wortsman J, Paus R, Elias PM, Tobin DJ, Feingold KR. Skin as an endocrine organ: Implications for its function. Drug Discov Today Dis Mech. 2008;5:137-44.

24. Zouboulis C C. The skin as an endocrine organ. Dermatoendocrinol. 2009;1:250-2.

25. Cuéllar IC. Sistema neuro-inmuno-endocrino-cutáneo: tiroides y piel. Univérsitas Médica. 2003;44:199-204.

26. Slominski AT, Zmijewski MA, Skobowiat C, Zbytek B, Slominski RM, Steketee JD. Sensing the environment: Regulation of local and global homeostasis by the skin neuroendocrine system. Adv Anat Embryol Cell Biol. 2012; 212:1-98.

27. Hodak E, Gottlieb AB, Anzilotti M, Krueger JG. The insulin-like growth factor 1 receptor is expressed by epithelial cells with proliferative potential in human epidermis and skin appendages: Correlation of increased expression with epidermal hyperplasia. J Invest Dermatol. 1996;106:56470 .

28. Chen W, Tsai SJ, Tsai JC, Zouboulis CC. Testosterone synthesized in cultured human SZ95 sebocytes mainly derives from dehydroepiandrosterone. Exp Dermatol. 2010;19:470-2.

29. Samson M, Labrie F, Zouboulis CC, Luu-The V. Biosynthesis of dihydrotestosterone by a pathway that does not require testosterone as intermediate in the SZ95 sebaceous gland cell line. J Invest Dermatol. 2010;130:602-4.

30. Labrie F, Luu-The V, Labrie C, Pelletier G, El-Alfy M. Intracrinology and the skin. Horm Res. 2000;54:218-29.

31. Schuessler M, Astecker N, Herzig G, Vorisek G, Schuster I. Skin is an autonomous organ in synthesis, two-step activation and degradation of vitamin D(3): CYP27 in epidermis completes the set of essential vitamin D(3)-hydroxylases. Steroids. 2001;66:399-408.

32. Lehmann B, Knuschke P, Meurer M. A novel pathway for hormonally active calcitriol. Horm Res. 2000;54:312-5.

33. Zouboulis CC, Chen WC, Thornton MJ, Qin K, Rosenfield R. Sexual hormones in human skin. Horm Metab Res. 2007;39:85-95.

34. Strong JA. Endocrine and metabolic diseases. Pituitary diseases. Br Med J. 1976;6010:640-2. 


\section{Capítulo 2}

\section{Enfermedades de origen endocrinológico}

Las alteraciones de la función de las glándulas endocrinas del organismo -hipófisis, tiroides, paratiroides, timo, suprarrenales, páncreas, gónadas: ovarios y testículos- se conocen como alteraciones endocrinológicas. Esta disfunción puede presentarse en una sola de las glándulas o comprometer varias a consecuencia de un mecanismo autoinmunitario basado en la acción de los autoanticuerpos y de los linfocitos $\mathrm{T}$ activados frente a distintos antígenos de las glándulas endocrinas.

\section{Síndromes poliglandulares autoinmunitarios}

Se conocen como síndromes poliglandulares autoinmunitarios a la coexistencia de, al menos, dos alteraciones de las glándulas endocrinas, que pueden estar, a la vez, asociadas con otras enfermedades autoinmunológicas (1). Se han propuesto varias hipótesis para explicar estas alteraciones que llevan al bloqueo de la función hormonal. Estas podrían ser la pérdida de la capacidad de supresión de clonas autorreactivas, una respuesta a la presencia de antígenos extraños al organismo o a la liberación de antígenos habitualmente inaccesibles al sistema inmunitario. Esta pérdida de la inmunotolerancia frente a las propias proteínas que actúan como antígenos, llevaría a la alteración de la glándula.

Los síndromes poliglandulares autoinmunitarios son la causa más frecuente de la infiltración linfocitaria de las glándulas endocrinas con la destrucción progresiva y lenta de las mismas, que acaba causando una insuficiencia hormonal. Algunos de los autoanticuerpos que están comprometidos y cuya medición se puede ser solicitar para confirmar estas alteraciones se resumen en la tabla contigua (2).

Los síndromes poliglandulares se asocian a otras enfermedades autoinmunitarias, como la artritis reumatoidea, el lupus eritematoso sistémico, el síndrome de Sjögren, la esclerosis sistémica, la anemia perniciosa, el vitiligo, la alopecia areata, la miastenia gravis y la psoriasis. Se dice que las alteraciones simultáneas de otras glándulas se presentan más relacionadas con la diabetes mellitus de tipo I, aunque también se ven en la diabetes de tipo II. Por otro lado, no debemos olvidar que los síndromes poliglandulares también se asocian con la candidiasis mucocutánea. 


\begin{tabular}{|c|c|}
\hline Alteración glandular o autoinmunológica & Tipo de anticuerpos relacionados \\
\hline Insuficiencia suprarrenal primaria & Suprarrenales: anti- $21-\mathrm{OH}$, anti-17-OH \\
\hline Tiroiditis de Hashimoto & Antiperoxidasa, antitiroglobulina \\
\hline Enfermedad de Graves & $\begin{array}{l}\text { Para el receptor de TSH, y TPO } \\
\text { (antiperoxidasa) }\end{array}$ \\
\hline Hipoparatiroidismo & Para el receptor del calcio \\
\hline Hipogonadismo & De células esteroideas : P450 / 17-OH \\
\hline Diabetes mellitus de tipo 1 & $\begin{array}{l}\text { Anticélulas de los islotes pancreáticos, } \\
\text { anti-GAD(acido glutámico decarboxilasa), } \\
\text { IA2 (proteína } 2 \text { asociada a insulinoma), } \\
\text { insulina, Glut2 (anti- transportador de la } \\
\text { glucosa) }\end{array}$ \\
\hline Hepatitis autoimmunitaria & $\begin{array}{l}\text { Para enzimas citocromo P450D6, } \\
\text { P4501A2 } \\
\text { Antimitocondria, antimúsculo liso, } \\
\text { antinucleares (ANA) }\end{array}$ \\
\hline Gastritis autoimmunitaria & $\begin{array}{l}\text { ATP-asa de los canales de potasio e } \\
\text { hidrogeno de las células parietales } \\
\text { gástricas }\end{array}$ \\
\hline Enfermedad celiaca & Antitransglutaminidasa, antigliadina \\
\hline Anemia perniciosa & Relacionados con el factor intrínseco \\
\hline Vitiligo & $\begin{array}{l}\text { Antitirosinasa, antimelanocitos o } \\
\text { antitirosin-hidroxilasa }\end{array}$ \\
\hline
\end{tabular}

Las manifestaciones cutáneas son muy frecuentes en las endocrinopatías. Si, por ejemplo, existe una exagerada producción de la hormona del crecimiento por parte de la glándula hipófisis, comúnmente asociada a un adenoma de la pituitaria, se puede encontrar una acromegalia en la cual todos los órganos crecen de manera exagerada, incluida la piel. Las manos y los pies son de mayor tamaño y la piel aumenta hasta plegarse y dar un aspecto de sobreabundancia conocido como cutis vertecis gyrata. Por otro lado, si existe un aumento de la producción de prolactina puede inhibirse la gonadotrofina coriónica y desarrollarse un síndrome de ovario 
poliquístico con un incremento de los andrógenos suprarrenales y las subsecuentes alteraciones menstruales, galactorrea, hirsutismo, caída del pelo y acné.

Esta revisión busca describir aquellas enfermedades en las que se encuentran mayor cantidad de alteraciones de la piel, como son la diabetes mellitus (3), las alteraciones de la función tiroidea, tanto hipertiroidismo como hipotiroidismo, y algunas de las alteraciones de las glándulas suprarrenales como son las enfermedades de Addison y la de Cushing. Por otro lado, se hace énfasis en el tipo de estudios que se deben ordenar cuando se encuentran manifestaciones de hiperandrogenismo.

\section{Diabetes mellitus}

La diabetes mellitus es una enfermedad progresiva en la que está comprometido el metabolismo de los carbohidratos y de los lípidos, y se caracteriza por el aumento de la glucosa en el plasma. Existen dos tipos de diabetes: la de tipo I, o juvenil, y la de tipo II, o del adulto. Esta última es la que ocupa el primer lugar entre las enfermedades endocrinas.

La incidencia de la diabetes en la población mundial se ha incrementado. Según Pérez (4), en 1994, la frecuencia de la diabetes se estimaba en el $1 \%$ de la población general. La Organización Mundial de la Salud (OMS) estimó que, si en 1985 había 30 millones de personas afectadas por ella, y que si para el 2005 esta cifra se había incrementado a 217 millones, se espera que para el 2030 se incremente a 366 millones o más $(5,6)$. En todo el mundo se adelantan estudios para estimar su prevalencia dado el rápido incremento de su presentación y el tipo de complicaciones cardiovasculares que muchos individuos tienen, incluida la muerte.

En Colombia y en Latinoamérica, existen varios estudios que tienen en cuenta esta situación (7-9). En agosto de 2017, en Colombia, se reunió un comité de expertos en diabetes mellitus y en sus complicaciones (enfermedades cardiovasculares) para analizar un factor de riesgo importante para su desarrollo, la prediabetes (10). En este término se incluyen aquellos individuos que tienen alterada la glucemia en ayunas, cuando los valores están entre 100 y $125 \mathrm{mg} / \mathrm{dl}$, o presentan una intolerancia a la glucosa si después de una ingestión de una sobrecarga oral de 75 g de glucosa, los valores de la glucemia a las dos horas se encuentran entre 140 y 190 $\mathrm{mg} / \mathrm{dl}$ o si los valores de la hemoglobina 'glicosilada' están entre 5,7 y 6,4. Dada esta condición de 'prediabetes', no se debe olvidar que también es importante hacerles seguimiento a aquellos pacientes con historia familiar de diabetes, sobrepeso u obesidad, hipertensión y dislipidemia. 
En Colombia, se estima que la prevalencia ajustada por edad (20 a 79 años) es del 8 al $10 \%$ (11). Por esta razón, se considera necesario iniciar una pronta intervención en esta situación, y dado que en este tipo de individuos se presentan con frecuencia numerosas manifestaciones en la piel es importante tenerlas en cuenta en los dos tipos de diabetes mellitus, la de tipo I y la de tipo II.

Asimismo, la diabetes se ha considerado una alteración hormonal: al agotarse la producción de insulina en el páncreas, no hay control sobre los niveles de glucemia, los cuales se elevan y esto repercute en los diferentes sistemas, entre ellos en la piel. Además, si los pacientes presentan resistencia a la insulina, sus niveles se incrementan en la sangre y se hace visible con una alteración denominada 'acantosis nigricans'.

No se debe olvidar que esta resistencia anormal a la insulina puede enmarcarse en lo que se ha denominado el 'síndrome metabólico' (12), en el que se encuentra obesidad, hipertensión, dislipidemia y un riesgo aumentado de enfermedad cardiovascular (13), acompañado a veces de lesiones eritemato-escamosas en la piel, del tipo de la psoriasis. Los pacientes con síndrome metabólico pueden tener diabetes o no tenerla. La diabetes también se asocia a alteraciones de otras glándulas endocrinas y puede, además, acompañar otras enfermedades autoinmunológicas como ya se mencionó anteriormente.

De todos los pacientes diabéticos, al menos, el $30 \%$ presenta lesiones en la piel (4), incluso en algunos casos el compromiso cutáneo es el primer signo que aparece, puede preceder las manifestaciones primarias por muchos años, lo cual hace imperante la identificación de las alteraciones de la piel como marcadores de enfermedad (14). Entre estas lesiones, las que se reportan con mayor frecuencia son las infecciones de la piel, las alteraciones neurológicas y los efectos y las complicaciones que se originan con las alteraciones de la microcirculación cutánea, que se pueden presentar, además, en el riñón y en la retina.

Es importante anotar que un síntoma inicial muy frecuente en la diabetes es el prurito, quizá el primer síntoma. Algunos cambios visibles, como las lesiones de acantosis nigricans en los pliegues, se aprecia en aquellos individuos que presentan resistencia a la insulina -con insulinemia- que, por lo general, son obesos. En la mayoría de los individuos diabéticos, se encuentra una alteración en la cara anterior de las piernas, conocida como la 'dermopatía diabética'. Asimismo, se pueden presentar otras lesiones que varían en frecuencia de una población a otra, como la piel engrosada y de aspecto escleroso -más visible en las manos-, la rubeosis facial o las lesiones erisipeloides en las piernas por alteración del sistema nervioso autónomo, los xantomas eruptivos, el granuloma anular generalizado, las ampollas diabeticorum y lesiones del tipo de la psoriasis, el vitiligo o el liquen oral $(15,16)$. 
Se pueden encontrar diferentes tipos de lesiones cutáneas en un mismo pacientealolargo de suenfermedad (17); algunas se consideran específicasy otrasestán asociadas a los cambios neurológicos, vasculares o infecciosos, como ya se mencionó.

\section{Manifestaciones cutáneas de la diabetes mellitus}

A las lesiones o síntomas que se presentan con mayor frecuencia en nuestra población, se les llaman 'lesiones cutáneas asociadas'.

El prurito es quizá la primera de ellas. Suele ser el síntoma inicial y puede reaparecer si no existe un control adecuado de la enfermedad. Las otras lesiones asociadas a la diabetes mellitus, son secundarias a las alteraciones vasculares o neurológicas y a los procesos infecciosos.

Asimismo, se ve con mucha frecuencia un engrosamiento de la piel de los dedos de las manos, de aspecto esclerodermiforme, amarillenta en las palmas y en las plantas y una leve queratodermia en las plantas de pies.

Sin embargo, a continuación, se describen de manera clásica las lesiones específicas que aparecen relacionadas en la literatura con la diabetes mellitus.

\section{Alteraciones cutáneas específicas}

Como alteraciones puramente cutáneas, o específicas, se han descrito la dermopatía diabética, las lesiones ampollosas, la necrobiosis lipoídica, el granuloma anular y la acantosis nigricans.

Teniendo en cuenta la gran prevalencia de las lesiones que corresponden a la dermopatía diabética, este tipo de lesión debería ser el única que se considere.

Es muy poco frecuente encontrar ampollas únicas asociadas, necrobiosis lipoídica y granuloma anular. La necrobiosis lipoídica en una zona similar a la de la dermopatía, es decir, en la cara anterior de piernas, podría hacer parte de ella. Y el granuloma anular, cuando se presenta, suele ser múltiple y más frecuente en los individuos sin control de la glucemia o puede acompañar otras endocrinopatías.

En cuanto a la acantosis nigricans, se presenta en zonas como la nuca o las axilas, es decir, en los pliegues y acompaña con mayor frecuencia a la obesidad, como reflejo de la resistencia a la insulina que presentan estos pacientes.

En algunos pacientes diabéticos se pueden observar lesiones pigmentadas y con una mayor liquenificación de la piel o leve engrosamiento en las superficies extensoras de la piel de los codos, las rodillas o los tobillos. 


\section{Dermopatía diabética}

Se ha dicho que del 7 al $70 \%$ de los pacientes diabéticos presentan dermopatía diabética. Es más, se la considera la dermatosis más frecuente de la diabetes. Para algunos es un signo de la microangiopatía y puede asociarse a otras complicaciones de la diabetes mellitus, como la neuropatía, la nefropatía y la retinopatía. También se ha observado asociada la enfermedad arterial coronaria (18).

Se caracteriza por la aparición de máculas de 0,5 a $2 \mathrm{~cm}$ de diámetro que, inicialmente, pueden ser rojizas o de color parduzco; en algunos casos, se encuentran escoriaciones que derivan en costras y evolucionan dejando zonas atróficas e hiperpigmentadas de color marrón, localizadas en los miembros inferiores, principalmente en las piernas y parecen ser más frecuentes en los hombres (figura 2.1).

Esta pigmentación pretibial, se describe como una alteración vascular secundaria a los depósitos de hemosiderina. Puede confundirse con el inicio de una necrobiosis lipoídica o con otras pigmentaciones por hemosiderina, como sucede si el paciente presenta, además, un síndrome varicoso, debido a que el aumento de la presión venosa es el que produce la extravasación de eritrocitos que luego producen la pigmentación.
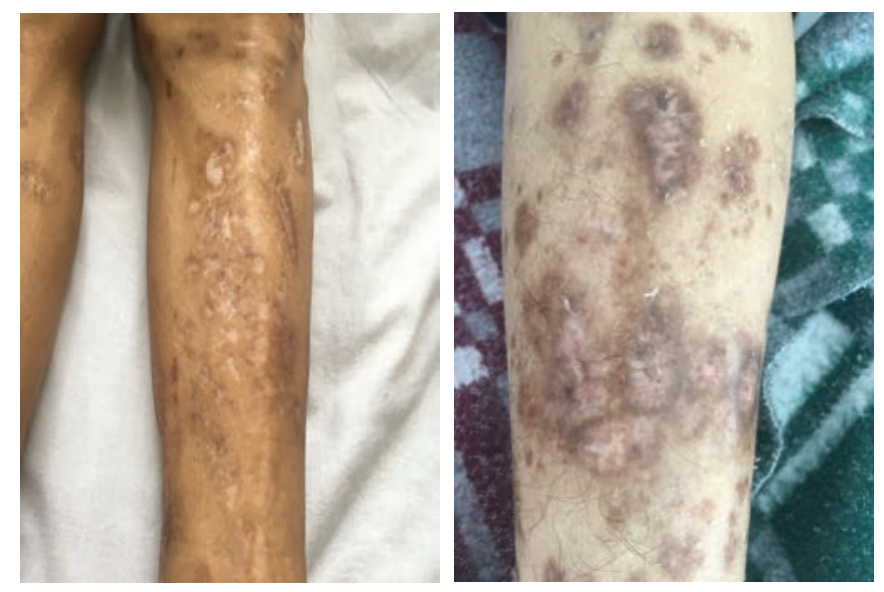

Figura 2.1. Dermopatía diabética. Se caracteriza por la aparición de máculas de 0,5 a $2 \mathrm{~cm}$ de diámetro de color parduzco. Evolucionan dejando zonas atróficas, hipopigmentadas o hiperpigmentadas, de color marrón, localizadas en los miembros inferiores, principalmente en las piernas, y cuales parecen ser más frecuentes en los hombres.

A nuestro modo de ver, lo que se ha denominado 'dermopatía diabética', puede traducir un conglomerado de eventos que dan como resultado final unas máculas hiperpigmentadas, pardas, con lesiones atróficas, posiblemente secundarias a eventos ampollosos, vasculares o infecciosos. 


\section{Lesiones ampollosas}

De los pacientes diabéticos, el $0,5 \%$ o menos hacen ampollas, la denominada bullosis diabeticorum. Estas ampollas de 0,5 a 1 o $2 \mathrm{~cm}$ de diámetro son asintomáticas y con contenido estéril, de aparición espontánea, sin antecedentes de trauma o infección: se presentan más frecuentemente en las piernas y en los pies y algunas veces en las manos o en los antebrazos (figura 2.2). Esta alteración es más frecuente en los hombres diabéticos con enfermedad de larga data, con neuropatía periférica, retinopatía y nefropatía; se relacionan también con la alteración de la microcirculación. Debe hacerse un diagnóstico diferencial, ya que se podrían presentar por la alteración neurológica o asociarse a un proceso infeccioso. En algunos casos, se pueden presentar ampollas asociadas a una porfiria cutánea tarda.

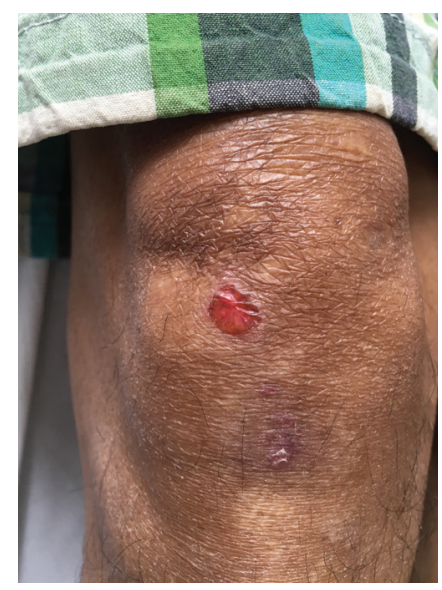

Figura 2.2. Ampollas diabéticas. Se trata de lesiones ampollosas sin alteraciones inflamatorias alrededor, son asintomáticas y aparecen de forma espontánea en un porcentaje muy bajo de pacientes, el 0,5\% o menos.

\section{Necrobiosis lipoídica}

En el 0,3 al 1,6\% de los pacientes diabéticos se encuentra la necrobiosis lipoidea o lipoídica. La etiología de esta necrobiosis es poco clara. Se ha asociado con alteraciones en la microcirculación, anomalías del colágeno y alteraciones inmunológicas.

El término 'necrobiosis' en sí se refiere a un tejido que ha sufrido una disminución de la perfusión y evoluciona hacia la necrosis -aunque no llega a ella porque alcanza a recuperarse- de tal modo que, sin perderse el tejido, este se ve afectado y adelgazado. 
Se describen como placas ovaladas, circunscritas, de bordes irregulares e indurados, eritematosos, que crecen centrífugamente y dejan una zona central amarillo-parduzca, de aspecto atrófico con telangiectasias superficiales o con visualización de los vasos debido al adelgazamiento de la piel, que pueden ulcerarse. Las lesiones pueden ser únicas o múltiples y bilaterales. La región pretibial es el área típicamente afectada (19).

Su inicio es hacia los treinta años de edad y es tres veces más frecuente en las mujeres que en los hombres (figura 2.3).

En el examen histopatológico se encuentra una reacción vascular neutrofílica con formación de granulomas y degeneración del colágeno y de los anexos que conlleva la atrofia cutánea y puede estar ulcerada.
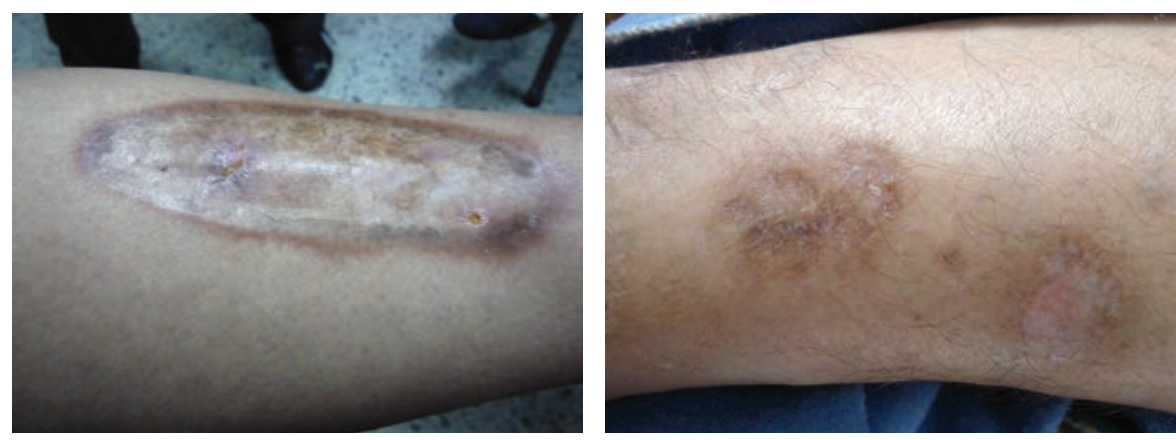

Figura 2.3. Necrobiosis lipoídica. Se trata de unas placas ovaladas, circunscritas, de bordes más notorios, eritematosos, que crecen centrífugamente y dejan una zona central amarilloparduzca, de aspecto atrófico con telangiectasias superficiales o con visualización de los vasos debido al adelgazamiento de la piel, que pueden ulcerarse, localizadas en región pretibial.

Se creía que del 60 al 90\% de los individuos con necrobiosis lipoídica tenían diabetes o alguna alteración de la tolerancia a la glucosa o que la tendrían en el futuro. Sin embargo, algunos estudios retrospectivos sugieren que no necesariamente está relacionada con la alteración de la glucemia; según el estudio hecho por Müller y Winkelmann en 1966 (20), de 19 pacientes no diabéticos en el momento del diagnóstico que tenían necrobiosis lipoídica, con 10 años en promedio, el $42 \%$ fue diagnosticado finalmente con diabetes y muchos con prueba normal de la tolerancia a la glucosa y tenían historia familiar de diabetes.

Sin embargo, un estudio retrospectivo posterior en tres hospitales de Dublin en 1999, sugirió que la asociación con la alteración de la glucosa estaba lejos de ser prominente. De los 65 pacientes con necrobiosis lipoídica, solo el $11 \%$ tenía diabetes, el $18 \%$ tenía historia familiar de diabetes y únicamente el $11 \%$ tenía alterada la 
tolerancia a la glucosa después de un seguimiento de 15 años (21); de todas maneras, se debe considerar la asociación, ya que estos individuos posiblemente tienen una mayor predisposición de presentar un metabolismo anormal de la glucosa, o pueden presentar una disfunción vascular o neurológica. Por otro lado, cuando los pacientes presentan necrobiosis lipoídica, parece que desarrollan con mayor frecuencia retinopatía y proteinuria (22) y, por lo tanto, es importante hacerle seguimiento a los pacientes que las presentan para iniciar un adecuado manejo temprano.

\section{Granuloma anular}

Este trastorno inflamatorio benigno de etiología desconocida y usualmente de resolución espontánea, se presenta con mayor frecuencia en las extremidades superiores e inferiores. Se encuentra localizado en el $10 \%$ de los casos o diseminado en el $21 \%(23,24)$. Existe una degeneración local del colágeno con áreas de inflamación y formación de granulomas y fibrosis. Asimismo, se observan pápulas pequeñas, firmes de color eritematoso, ligeramente amarillento, asintomáticas, que suelen localizarse de manera circular en las extremidades (figura 2.4).
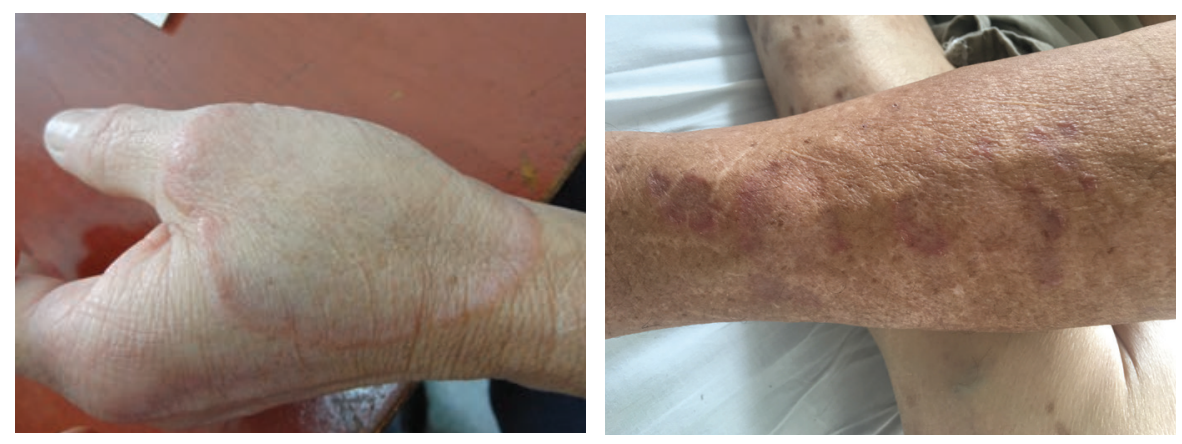

Figura 2.4. Granuloma anular. Se observan lesiones circulares, con pequeñas pápulas, firmes de color eritematoso, ligeramente amarillento; a veces confluyen y semejan un cordón que se distribuye de manera circular en la periferia de las placas, que son de diversos tamaños. Suelen ser múltiples en relación con las enfermedades sistémicas dentro del concepto de enfermedad poliglandular.

El granuloma anular puede aparecer en las áreas de trauma repetido, en cuyo caso el granuloma anular es único. Cuando se observan varios en un mismo individuo, suelen relacionarse más con enfermedades sistémicas poliglandulares.

En los pacientes diabéticos, se encuentra con mayor frecuencia la forma diseminada (25). La asociación con la diabetes es controvertida, aunque algunos estudios reportan que el 9,7\% de los pacientes con granulomas anulares son diabéticos, en otro estudio se encontró específicamente relacionado con dislipidemia. 
Por otro lado, estas dos manifestaciones -necrobiosis lipoídica y granuloma anular- podrían ser dos formas de un mismo proceso y las diferencias se deberían posiblemente a variabilidades individuales, quizá genéticas o estructurales, o al momento en que se encuentran las lesiones en el tiempo de evolución de la enfermedad $(26,27)$.

\section{Acantosis nigricans}

Las lesiones descritas como acantosis nigricans se refieren a la presencia de unas zonas de piel más oscura, engrosada y de aspecto aterciopelado, principalmente en la piel de la nuca, las axilas, la región antecubital, las fosas poplíteas (28) y la región inguinal.

La acantosis nigricans fue descrita por Pollitzer en 1890 (29), inicialmente asociada a neoplasias. Por esta razón, cuando se encontró asociada a la resistencia a la insulina, se le llamo también 'pseudoacantosis nigricans' o 'acantosis nigricans benigna'. Cuando se presenta, lo hace generalmente en personas con sobrepeso $u$ obesidad y presupone una resistencia a la insulina. Este engrosamiento epidérmico con hiperqueratosis -focal o difusa- y simétrica con hiperpigmentación de la piel, no se presenta con lesiones palmo-plantares ni en la mucosa oral, como sí lo hace la acantosis nigricans que se asocia con procesos malignos.

Las lesiones de aspecto aterciopelado que se presentan con preferencia topográfica en los pliegues: la nuca (figura 2.5. a), los pliegues y las caras de flexión de las extremidades son una expresión de resistencia a la insulina, no de una diabetes.

La insulina es un factor de crecimiento para la epidermis. La acantosis nigricans benigna, como manifestación inicial de resistencia a la insulina, debe tenerse en cuenta desde la adolescencia y puede acompañar al síndrome metabólico con un mayor riesgo de enfermedad cardiovascular. En estos pacientes, se encuentra con cierta frecuencia la presencia de síndromes poliglandulares, diabetes, hipotiroidismo, enfermedad de Adisson y también se puede ver en los acromegálicos. Algunos pacientes presentan lesiones engrosadas e hiperpigmentadas en el dorso de las coyunturas de los dedos de las manos, en los codos o en las rodillas, y pueden aparecer tanto en la acantosis nigricans benigna como en la maligna y se pueden observar en algunos pacientes diabéticos. (figura 2.5. b). 

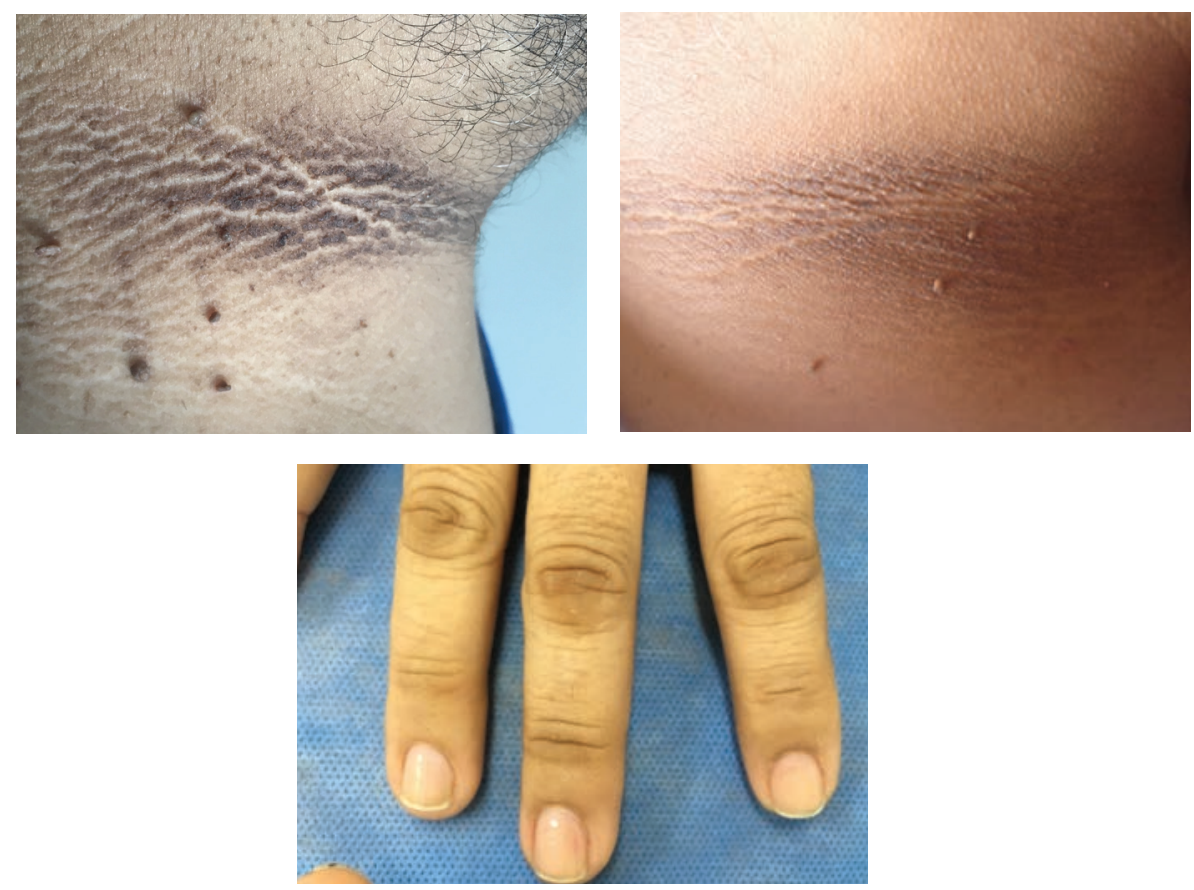

Figura 2.5. Acantosis nigricans en pliegues y superficies extensoras: se caracteriza por la presencia de unas zonas de piel más oscura, engrosada y de aspecto aterciopelado, principalmente en la piel de los pliegues, es decir, en la nuca, las axilas, la región antecubital, las fosas poplíteas y la región inguinal. Algunos pacientes presentan lesiones engrosadas e hiperpigmentadas en el dorso de las coyunturas de los dedos de las manos, en los codos o en las rodillas, que podría ser otra variedad de acantosis nigricans.

\section{Acrocordones}

Algunos pacientes también pueden presentar en estos pliegues, unas excrecencias filiformes, pendulares, suaves, únicas o múltiples, algunas del color de la piel, otras hiperpigmentadas debidas a un aumento de tejido fibroelástico -llamadas fibroepiteliomas- que también se conocen como moluscos péndulos o acrocordones (figura 2.6), asociadas a una hiperactividad epidérmica y fibroblástica.

Estas proliferaciones dérmicas, formadas de fibras de colágeno y vasos sanguíneos, están rodeadas por una delgada capa de piel y aparecen en los párpados, en el cuello y en las axilas; también se han asociado con resistencia a la insulina. 
En resumen, en la acantosis nigricans existe una hiperactividad epidérmica y fibroblástica, con resistencia periférica a la insulina y elevación de las concentraciones de insulina que estimulan el crecimiento epidérmico, posiblemente activando los receptores del factor insulínico de crecimiento (IGF-1) (30).
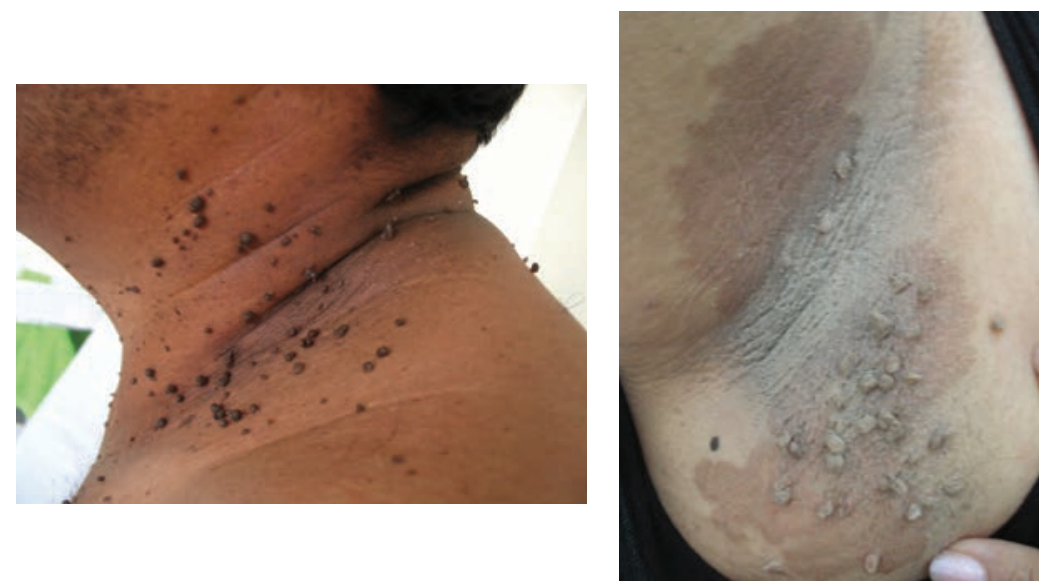

Figura 2.6. Acrocordones. También se conocen como fibroepiteliomas. Se trata de unas excrecencias filiformes, pendulares, suaves, únicas o múltiples, algunas del color de la piel, otras hiperpigmentadas, que aparecen en las zonas de los pliegues debidas a un aumento de tejido fibroelástico. En la figura a, se aprecian junto con lesiones de acantosis nigricans; en la figura $b$, los acrocordones se encuentran sobre una piel con acantosis nigricans y con una coloración pardo-rojiza de base debido a una infección por Corynebacterium spp., conocida como eritrasma.

\section{Lesiones cutáneas asociadas}

Si bien se han descrito las lesiones cutáneas, conocidas como específicas, no son las que se presentan con mayor frecuencia en la piel de los pacientes con diabetes, con excepción de la dermopatía diabética.

Las que se presentan en la mayoría de los pacientes son el prurito, la xerosis, las infecciones, las alteraciones vasculares, las alteraciones neurológicas y otras alteraciones secundarias al exceso de metabolitos circulantes. Se pueden presentar otro tipo de asociaciones asi como reacciones cutáneas secundarias al tratamiento.

\section{Prurito y xerosis}

Las alteraciones metabólicas son quizá las primeras responsables del prurito. La hiperglucemia per se al alterar los filetes nerviosos pequeños induce prurito. Es 
importante anotar que el prurito, aun sin lesiones, es una de las manifestaciones iniciales de la diabetes, principalmente cuando se presenta en el cuero cabelludo, en el tercio medio de la espalda, hacia la región interna de los omoplatos, en la región de los trocánteres hacia la región lateral superior de los muslos o en los genitales y que, en ocasiones, se acompaña de lesiones de tipo prurigo, con pápulas decapitadas por el rascado (figura 2.7).
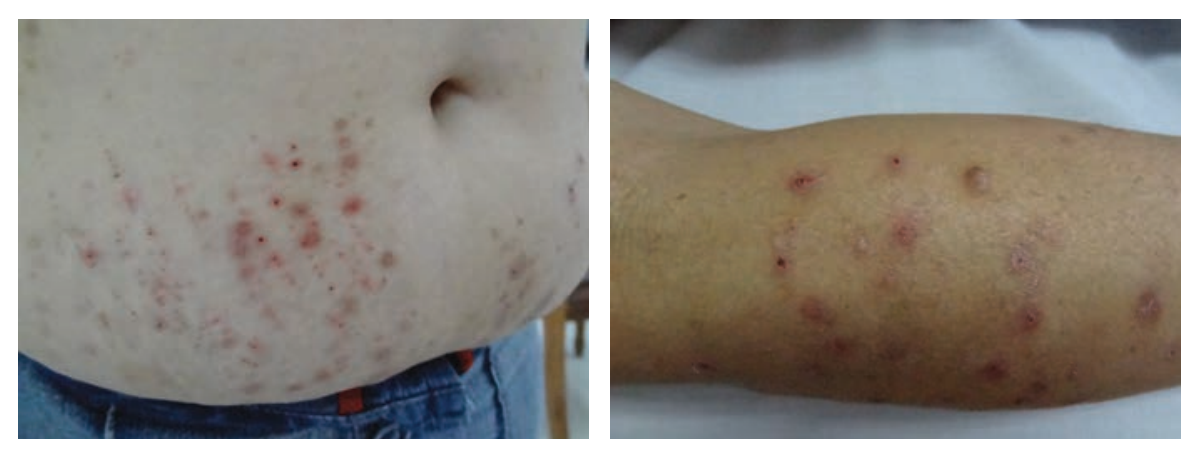

Figura 2.7. Prurigo: pápulas decapitadas por el rascado. Con esta denominación se conocen unas lesiones elevadas de tipo pápulas, con hiperpigmentación y engrosamiento de la piel y escoriaciones debidas al rascado; por esto, se dice 'decapitadas por el rascado'. Cuando este tipo de lesiones se presenta, se debe sospechar diabetes, insuficiencia renal crónica, obstrucción biliar, neoplasias o sida.

El prurito y la xerosis pueden llevar a la aparición de otras manifestaciones como son una pigmentación en la espalda debido a una permanente sensación incómoda que provoca la rasquiña, que se ha denominado 'notalgia parestésica'. Es frecuente en la región inferior del omoplato izquierdo, pudiendo observarse también en otras zonas del tercio supero-posterior de la espalda; cuando la molestia se presenta en la cara externa y superior de los muslos, se habla de 'meralgia parestésica. En ambos casos se observan zonas hiperpigmentadas (figura 2.8) con liquenificación o engrosamiento de la piel y escoriaciones.

Asimismo, es frecuente el prurito en el cuero cabelludo, la región púbica, vulvar y anogenital, donde, además, a veces se presenta acompañada de una candidiasis. La xerosis, o piel seca, también puede aparecer acompañando la alteración neurológica y suele ser un factor que por sí solo desencadena prurito, y esta descrito con mayor frecuencia en los pacientes con diabetes mellitus de tipo I. 

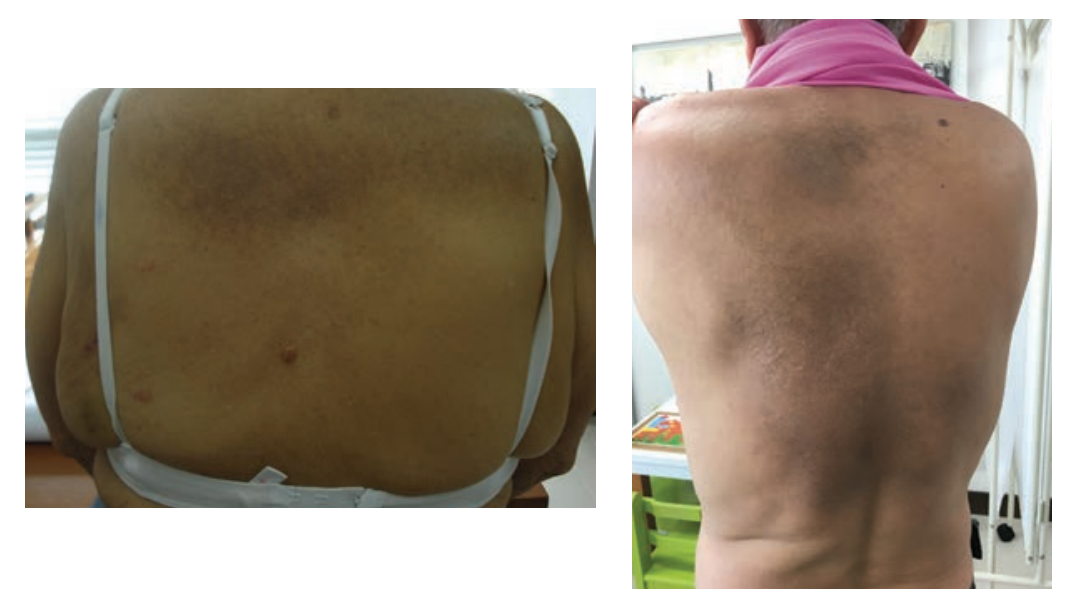

Figura 2.8. Notalgia parestésica. Debido a la alteración neurológica que se presenta en los pacientes con diabetes mellitus, en la parte postero-superior de la espalda se percibe una sensación de molestia (ardor, picazón, comezón) que desencadena el roce permanente de esa zona del cuerpo y genera una zona hiperpigmentada y engrosada, 'liquenificada'.

\section{Infecciones}

Las infecciones cutáneas asociadas a la diabetes mellitus se presentan con una frecuencia del 20 al $50 \%$, principalmente en la diabetes mellitus de tipo II. Están relacionadas con un pobre control de la glucemia y, en general, son infecciones difíciles de erradicar.

La hiperglucemia posee efectos deletéreos sobre la respuesta inmunológicas y como consecuencia de estas alteraciones se presentan infecciones por levaduras, dermatofitos o mohos. Las más frecuentes son las desencadenadas por Candida spp. y Pityrosporum spp. (Malazzezia), y por los dermatofitos, entre ellos Trichophyton sp., Microsporum sp. y Epidermophyton sp.

También se pueden presentar infecciones causadas por bacterias, como Staphylococcus aureus y Streptococcus pyogenes u otras como Corynebacterium spp. y Pseudomonas spp.; ocasionalmente, pueden ser polimicrobianas. El hecho de que una infección de esta índole sea de difícil manejo o se extienda más de lo esperado, debe alertar al médico para que descarte una posible diabetes.

\section{Infecciones micóticas}

Las infecciones micóticas que con mayor frecuencia afectan a los pacientes diabéticos son las que se mencionan a continuación. 
Candidiasis. Quizá se trate de la infección más frecuente que se halla en los pacientes diabéticos. Las lesiones se presentan con mayor frecuencia en las zonas húmedas, o sea, en las mucosas o en los pliegues cutáneos, también es frecuente la afectación de las uñas.

Las condiciones de humedad y maceración de los pliegues favorecen esta infección cutánea que ha recibido el nombre de 'intertrigo candidiásico'. Se manifiesta con eritema, brillantez y humedad en los ángulos de la boca, en los espacios interdigitales de las manos y de los pies, en la región inframamaria o en la región inguino-crural; además, en la periferia de estas zonas eritematosas se pueden observar 'collares' con descamación, como resultado de la aparición de lesiones vésico-ampollosas secundarias a la respuesta de hipersensibilidad retardada frente a la cándida.

Se habla de candidiasis oral o genital si están comprometidas las mucosas. Si se presenta en el ángulo de la boca se ha denominado 'perleche.' Es clásico encontrar, quizá más en niños con diabetes, una estomatitis oral generalizada, en la que se observa un material blancuzco como algodonoso que se adhiere a las áreas fisuradas de la cavidad oral.

Así como existe compromiso de la mucosa oral, también se puede encontrar un compromiso vulvo-vaginal en la mujeres adolescentes o en las embarazadas debido a alteraciones hormonales o con diabetes mellitus y que puede ser la primera manifestación de la enfermedad. De manera similar, en el hombre se puede encontrar una balanitis o balanopostitis, caracterizada por la aparición de un eritema brillante rodeado de una zona descamativa blanquecina que afecta el glande y el surco balano-prepucial, algunas veces rodeado de lesiones pápulo-pustulosas o de pequeños collares con descamación. El germen más frecuentemente asociado es Candida albicans, aunque a veces se encuentran otras especies en las lesiones, como Candida glabrata o Candida tropicalis (31).

Por las mismas condiciones de calor y humedad permanente es frecuente encontrar alteraciones en las uñas u onixis, una separación de la lámina ungular del lecho, que se conoce como onicólisis, o una inflamación periungular que se ha llamado perionixis o paroniquia y que corresponde a una zona enrojecida y engrosada, fría e indolora -en comparación con una infección bacteriana que es muy dolorosa- alrededor de la uña con pérdida de la cutícula. En la onixis candidiásica, estas se encuentran friables y fracturadas generalmente lateralmente (figura 2.9. a, b y c). Si luego aparece un color verdoso en estas uñas separadas del lecho ungular, se puede suponer y confirmar por laboratorio una posible infección secundaria, por Pseudomonas spp, que se puede encontrar asociada. 

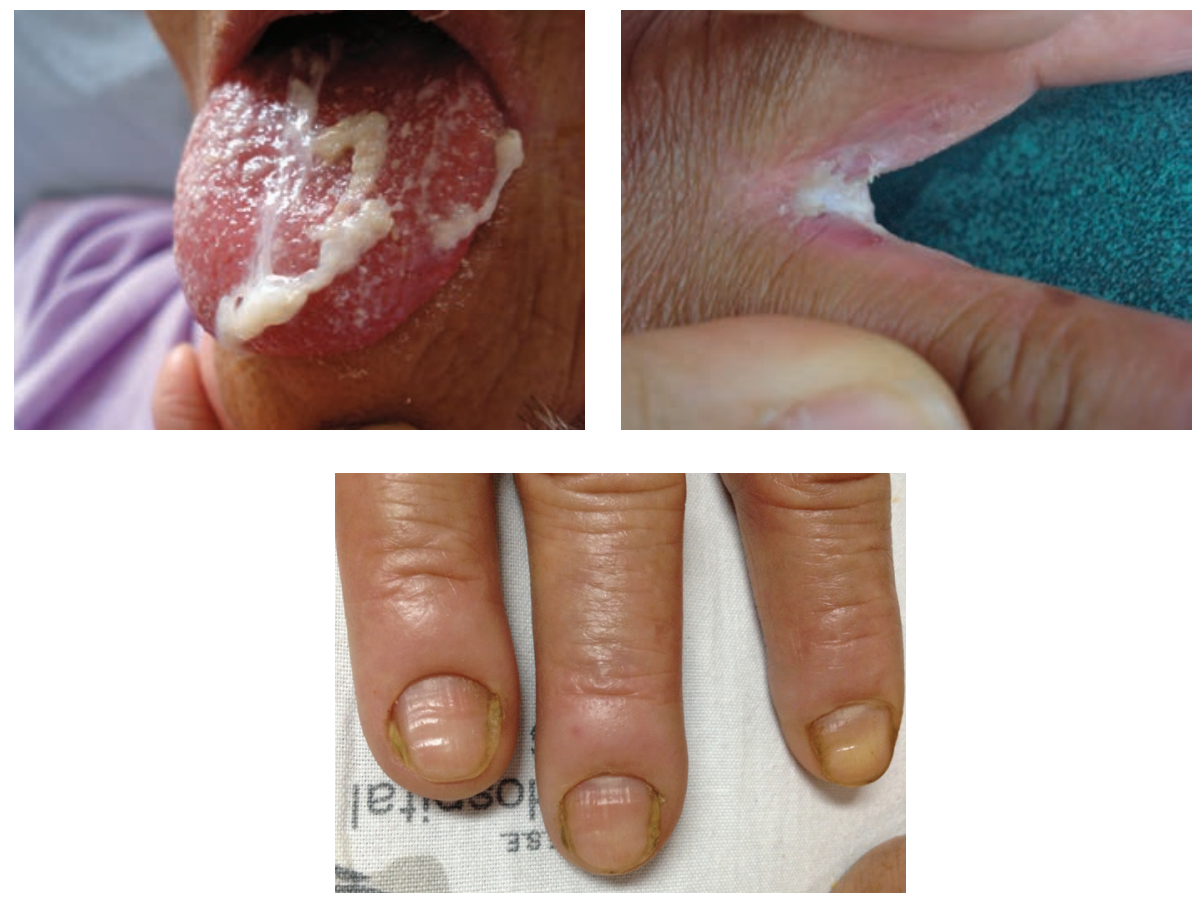

Figura 2.9 Candidiasis. Oral: en esta infección se visualiza una mucosa enrojecida con formación de grumos blanquecinos que se pueden retirar fácilmente con un aplicador. En pliegues: debido al calor o a la humedad, estas zonas se observan enrojecidas brillantes y húmedas, y en la periferia se encuentran unas lesiones vesiculosas como una respuesta de hipersensibilidad retardada frente al microorganismo, lo que genera lesiones de tipo eccema, llamadas lesiones satélites. En uñas: la candidiasis ungular puede afectar la región periungular (perionixis), la uñas en sí mismas (onixis) o separar la lámina del lecho ungular (onicólisis).

Pitiriasis versicolor. El crecimiento exagerado de Pityrosporum spp. o Malazzezia furfur, genera una entidad conocida como pitiriasis versicolor, caracterizada por la aparición de lesiones de diversos colores con discreta inflamación y descamación en áreas principalmente seborreicas, es decir, en el rostro y en el tronco. Las lesiones que suelen ser numulares, o sea, en forma de moneda, según el color de la piel del paciente, se pueden ver rosadas o eritematosas, blanquecinas o grisáceas con una descamación muy discreta y fina que no siempre es evidente (figura 2.10), por lo que se utiliza pasar un objeto romo sobre la piel afectada que la hace evidente (signo de la uñada). Suelen aparecer en gran cantidad y persistir por tiempos prolongados. Si aparecen en ausencia de exposición al calor y a la humedad, se debe sospechar una alteración hormonal. 


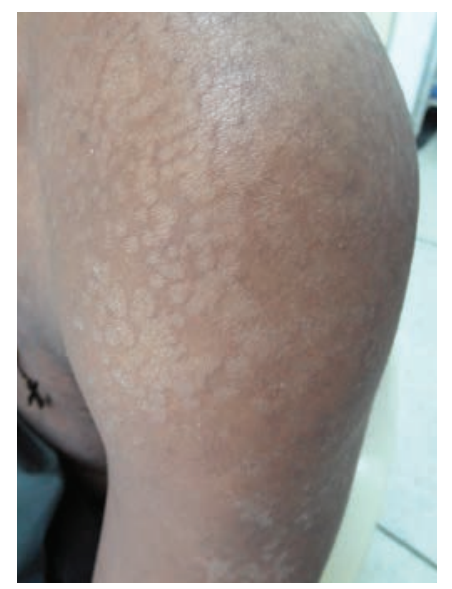

Figura 2.10. Micosis superficiales: pitiriasis versicolor. En las lesiones por Malazzesia furfur se observan una placas con un cambio de coloración que puede variar según el color de la piel del paciente, rosadas o eritematosas, blanquecinas o grisáceas que presentan una descamación muy discreta y fina que no siempre es evidente en la superficie, razón por la cual se habla de pitiriasis.

Dermatofitos. Las infecciones crónicas por dermatofitos se presentan, generalmente, por una respuesta inmunitaria inadecuada o por la presencia de factores que favorecen su crecimiento. Los agentes etiológicos que se encuentran con mayor frecuencia son: Trichophyton rubrum, Trichophyton mentagrophytes y Epidermophyton floccosum. Si afectan la piel en general, se llaman dermatomicosis, antiguamente conocidas como tiñas, del cuerpo o corporis, de la región inguinal o cruris y de la región interdigital o pedis. Cuando el compromiso no es cutáneo, sino de uñas, hablamos de onicomicosis (figura $2.11 \mathrm{a} \mathrm{y} \mathrm{b).}$

En los pacientes diabéticos, las afectaciones de los pies y de las uñas necesitan tratamiento adecuado y observación constante, porque se puede agregar una infección bacteriana, que desencadena fácilmente un proceso ulcerativo o necrótico en el pie debido a las alteraciones vasculares y neurológicas de base del paciente; la resolución de estas lesiones es difícil y puede llevar a la amputación de los dedos comprometidos. 

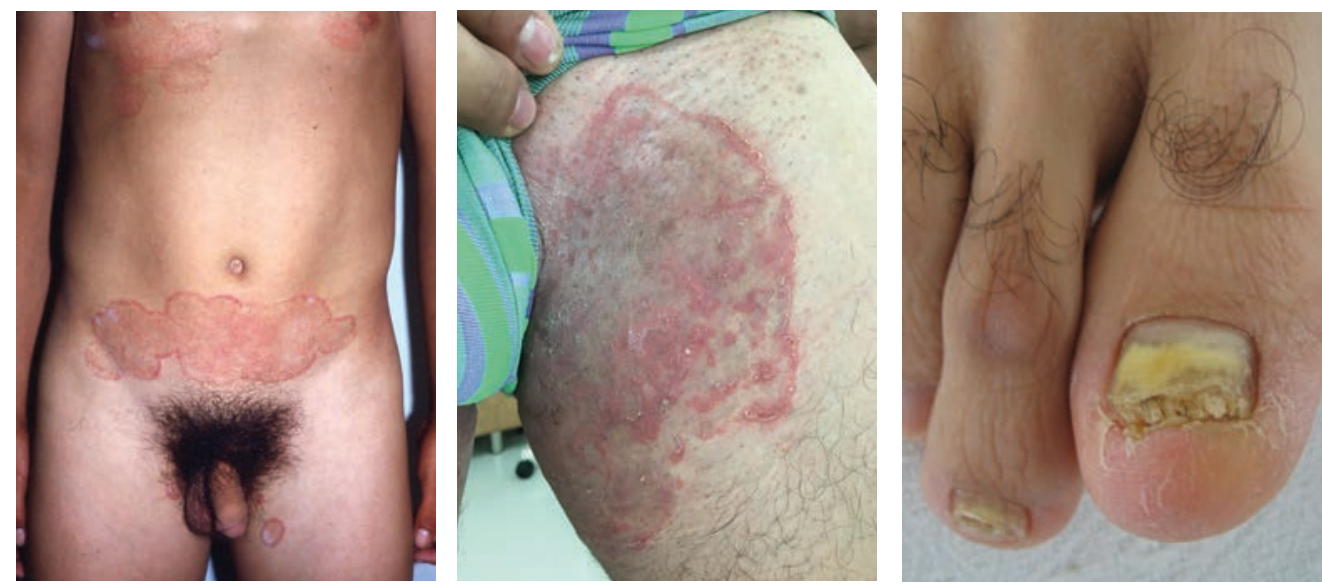

Figura 2.11. Micosis superficiales: dermatomicosis: en la invasión de la piel por dermatofitos se aprecia una lesión numular que aumenta de tamaño, de manera progresiva, en cuyos bordes se observan unas lesiones llamadas 'activas' de tipo vesículas. Onicomicosis: se refiere al crecimiento e invasión de las uñas por diferentes "hongos", las que pueden verse engrosadas, desmoronadas o tomando pigmentaciones blanquecinas $\mathrm{u}$ oscuras dependiendo del microorganismo que lo invada, sea dermatofito o moho.

También se pueden presentar otras infecciones micóticas por ficomicetos, conocidos comúnmente como mohos, que infectan las úlceras de las piernas de los pacientes diabéticos o en las heridas quirúrgicas de los mismos. Algunas series describen infecciones micóticas profundas en pacientes diabéticos descompensados, como la mucormicosis producida por el género Mucor, cuyas lesiones purulentas y necróticas se suelen presentar en las mucosas del tabique nasal y en el paladar (5).

La frecuencia de candidiasis, principalmente oral, en los pacientes con diabetes mellitus, se estima en $75 \%$, comparado con el $35 \%$ en los individuos sanos (32). Es importante agregar que el grado de extensión, la gravedad de la lesión y la dificultad de su manejo es lo que nos permite pensar que podemos estar frente a un individuo con alteraciones de su respuesta inmunitaria y, específicamente en este caso, que tenga una elevación de la concentración de la glucosa. El 70 \% de los individuos normales puede tener en su cavidad oral Candida spp., aunque no desarrollan lesiones serias como sucede en el 43,3\% de los pacientes diabéticos (33). En algunas series de pacientes diabéticos, se describe onicomicosis en el 87,5\% de los que tenían diabetes mellitus de tipo 2 y en el 12,5\% de los que tenían diabetes mellitus de tipo1, planteándose así una asociación mayor con la diabetes mellitus de tipo 2 y la presencia de esta complicación (34). 


\section{Infecciones bacterianas}

Los principales agentes etiológicos de estas infecciones son Staphylococcus aureus y Streptococcus pyogenes o Streptococcus $\beta$ hemolítico del grupo A. También se pueden observar infecciones por Corynebacterium minutissimum o por Pseudomonas spp., e incluso por otros gérmenes.

Los factores implicados en la susceptibilidad a las infecciones son la alteración de la microcirculación, es decir, la enfermedad arterial periférica, la falta de sensibilidad como resultado de la neuropatía periférica, que origina alteraciones del tejido por presiones inadecuadas que facilitan las úlceras y, a su vez, las alteraciones de la inmunidad celular. Se encuentran, además, alteraciones en el proceso de cicatrización, posiblemente por estar alterada la organización trabecular del ácido hialurónico (14).

Las infecciones desencadenadas por Streptococcus $\beta$ hemolítico del grupo A y por $S$. aureus se presentan con lesiones de tipo impétigo, ectima, abscesos, forúnculos o celulitis (figura 2.12).
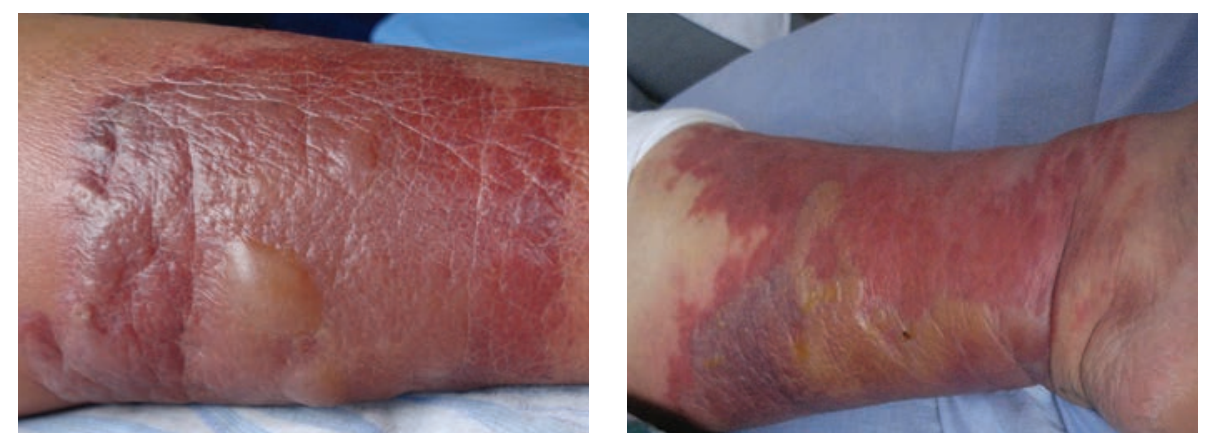

Figura 2.12. Celulitis por Staphylococcus aureus. La celulitis por Staphylococcus aureus es una infección del tejido subcutáneo profundo con placas eritematosas, edematosas, calientes y dolorosas con aparición de ampollas, acompañadas de síntomas generales.

Las corinebacterias causan lesiones en aquellos sitios de humedad prevalente. El eritrasma, causado por Corynebacterium minutissimum, se presenta en las axilas y en las ingles, con un cambio de tonalidad de la piel a color pardo-rojizo; la llamada queratolisis punctata, también causada por Corynebacterium spp., se ve como unos agujeros en la planta del pie blanquecina por la humedad.

La infección cutánea por Pseudomonas aeruginosa se presenta concomitantemente con una otitis externa y causa unas úlceras de aspecto necrótico, acompañadas de celulitis o puede comprometer las uñas, las cuales se ven verdosas (figura 2.13). 

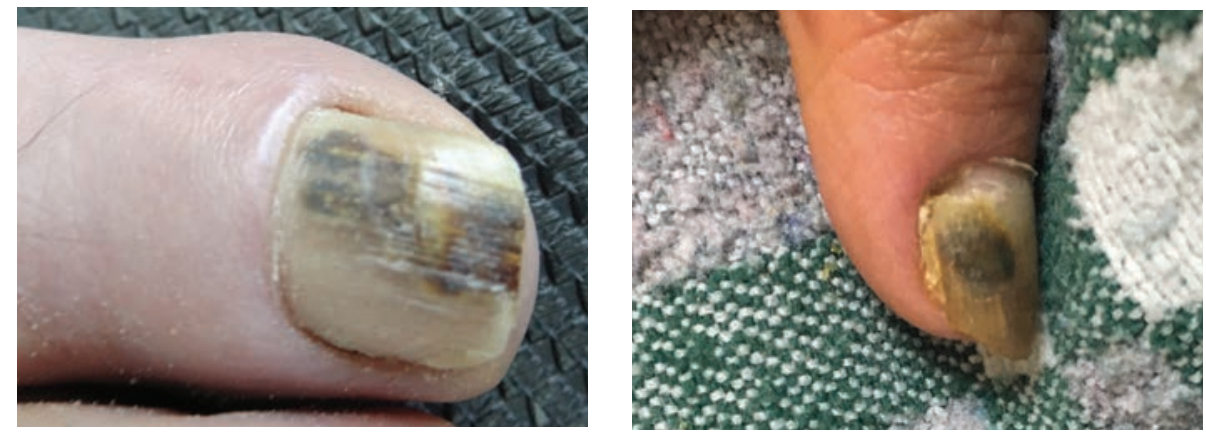

Figura 2.13. Infecciones por Pseudomonas aeruginosa. Cuando Pseudomonas aeruginosa afecta la piel, causa unas úlceras de aspecto necrótico, acompañadas de celulitis, o compromete las uñas, las cuales se ven verdosas.

La infección subcutánea y disecante llamada fascitis necrosante, puede asociarse a una infección por Streptococccus $\beta$ hemolítico o puede ser polimicrobiana (35) y, como su nombre lo indica, la velocidad de crecimiento de las bacterias y sus lesiones profundas progresivas, disecantes y necróticas, pueden ser mortales si no se inicia un tratamiento precoz con antibióticos y desbridamiento del tejido afectado. En los pacientes con diabetes mellitus son frecuentes las infecciones ungulares por bacterias por P. aeruginosa, S. aureus, E. coli o Proteus mirabilis (4).

\section{Alteraciones vasculares}

Algunas alteraciones vasculares disminuyen la luz de los vasos y suelen ser secundarias a la ateromatosis y la arterioesclerosis. La enfermedad arterial se presenta tanto en los grandes vasos (macroangiopatía) como en la microcirculación (microangiopatía), dando lugar a lesiones visibles en la piel. Se acompañan habitualmente de alteraciones neurológicas y, aunque intentamos separarlas, casi siempre se observan simultáneamente los dos procesos.

De tal manera que las lesiones que se describen a continuación pueden ser aparentemente vasculares, pero quizá su aparición se desencadene por las alteraciones neurológicas dependientes del sistema nervioso autónomo.

\section{Rubor diabético}

Esta alteración con característico enrojecimiento o rubor crónico de la cara y el cuello (figura 2.14. a) y, a veces, en las extremidades, se produce por la disminución del tono vasoconstrictor (efecto simpático) de los vasos afectados y por el aumento del flujo en los plexos venosos dérmicos; además, debido al adelgazamiento de la membrana basal capilar, quizá se debería considerar en lo que 
concierne a las alteraciones neurológicas, pero dado que nos remite a una alteración de vasos la hemos incluido en esta sección. Esta alteración empeora con los productos vasodilatadores, incluidos el alcohol y la cafeína.

\section{Telangiectasias periungulares}

Se producen en el $49 \%$ de los pacientes diabéticos, son dilataciones o tortuosidades de los capilares visibles en los pliegues ungulares donde puede verse, además, un eritema o un oscurecimiento y adelgazamiento de la piel que en ocasiones acompaña la aparente esclerosis y un edema que se constituyen en un indicador de microangiopatía funcional.

Es de anotar que este adelgazamiento distal de la piel periungular con la observación de pequeños vasos también puede ser un indicador de alteraciones neurológicas, ya que se ha encontrado luego de accidentes cerebrovasculares. Se debe hacer el diagnóstico diferencial con lesiones similares encontradas en esta región periungular de pacientes con enfermedad del tejido conjuntivo, como la dermatomiositis, la esclerodermia o en el síndrome CREST (calcinosis, fenómeno de Raynaud, esclerosis y telangiectasias); en ellos, los vasos dilatados suelen ser de mayor tamaño, megacapilares o asas agrandadas irregularmente (19).
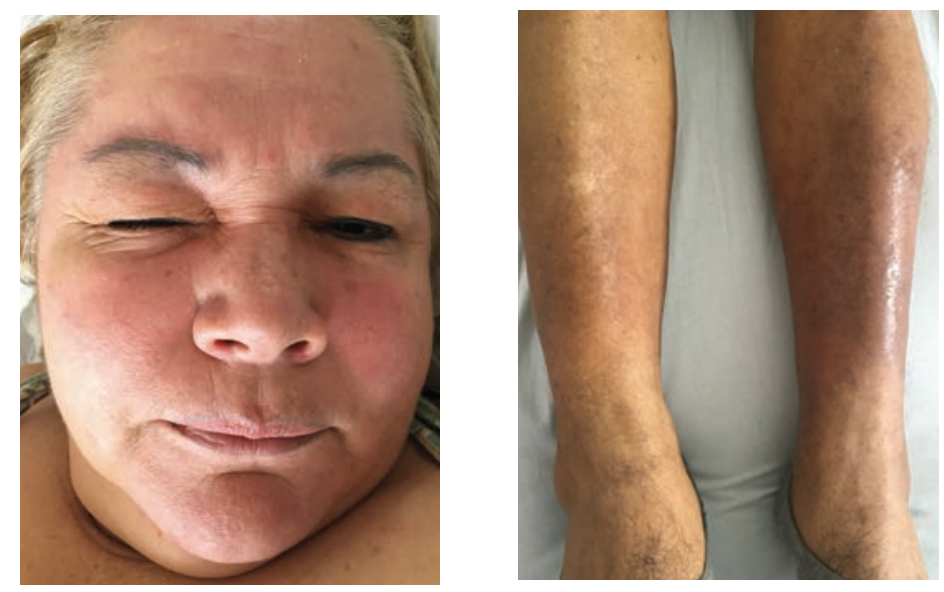

Figura 2.14. Diabetes mellitus: rubor diabético, esta alteración se caracteriza por un enrojecimiento o rubor crónico en la cara y el cuello. Eritema semejante a la erisipela. Este eritema se produce por la disminución del tono vasoconstrictor (efecto simpático) en los vasos afectados y por el aumento del flujo en los plexos venosos dérmicos de las extremidades inferiores. 


\section{Eritema semejante a erisipela}

Puede aparecer un eritema en la piel de las extremidades que semeja el comienzo de una celulitis y que, a veces, es el comienzo de una disminución de la perfusión u otro fenómeno secundario a la alteración del sistema nervioso autónomo (figura 2.14. b).

\section{Disminución de la perfusión}

La aterosclerosis y la enfermedad vascular ocurren a edades más tempranas y con un patrón más difuso y periférico en las extremidades inferiores de los diabéticos. Esta disminución de la perfusión permite encontrar un pie frío, con la piel adelgazada, sin vello y con una evidente disminución de los pulsos distales. El paciente ocasionalmente refiere claudicación intermitente y consulta o ha consultado por otras alteraciones que implican la disminución de la perfusión, como un infarto de miocardio, un accidente cerebrovascular isquémico, alteraciones renales secundarias a la nefroesclerosis o por otras lesiones isquémicas en piernas y pies, principalmente. Cuando el evento de la disminución de la perfusión es de aparición abrupta, se aprecia una necrosis de los dedos de los pies (figura 2.15).

Es posible, además, observar cambios en las uñas de los pies. En los casos, en los que la alteración vascular arterial oclusiva no es total y si se prolonga por mucho tiempo, las uñas se ven afectadas; inicialmente, se arquean y parece como si se entorcharan, por lo que se han descrito como 'uñas en pinza', y si el efecto continúa en el tiempo se engruesan y dan un aspecto triangular que se puede confundir con una onicomicosis, fenómeno que no ha sido descrito en la literatura (figura 2.16 a $\mathrm{yb})$.
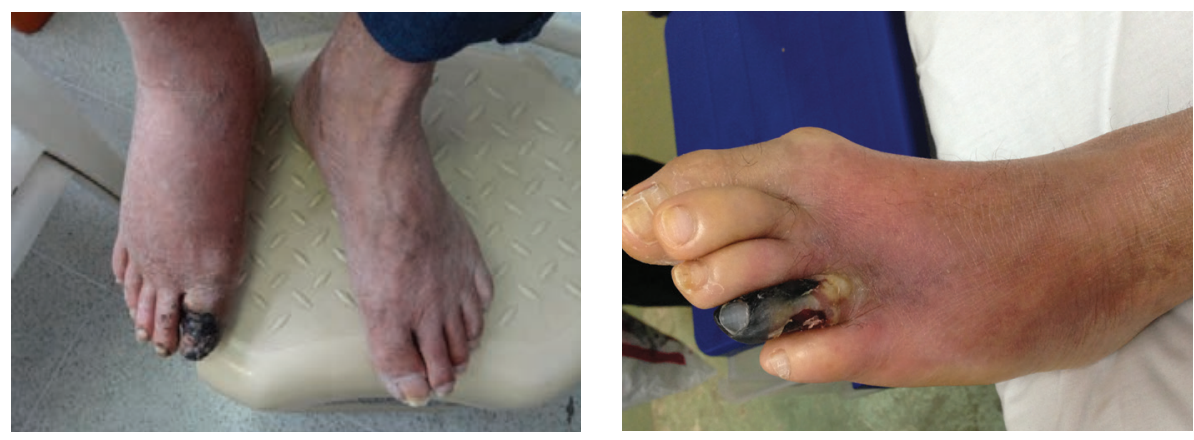

Figura 2.15. Macroangiopatía: necrosis de los dedos de los pies. Se produce por la disminución de la perfusión, bien sea por una obstrucción ateromatosa o por la disminución de la luz del vaso, asociada generalmente a una inflamación mayor o a una infección. 
Se detecta enfermedad arterial periférica en el $22 \%$ de los pacientes diabéticos, cuyo diagnóstico data de menos de un año, y en más del $50 \%$ de los pacientes diabéticos diagnosticados hace más de 10 años. Hasta el $60 \%$ de los pacientes diabéticos presenta oclusión de las arterias metatarsianas, en cambio, la incidencia de oclusión aorto-ilíaca es similar a la de los pacientes que no son diabéticos.
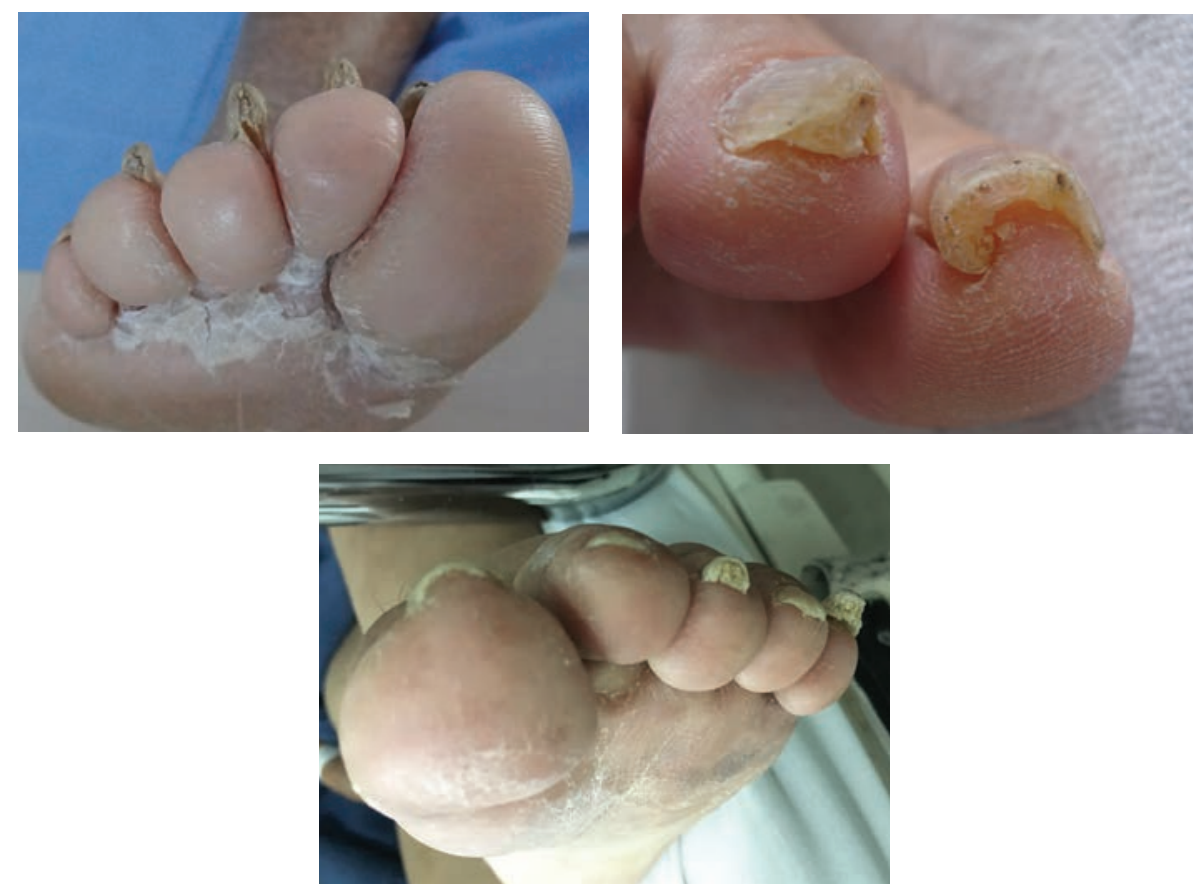

Figura 2.16 Microangiopatía: a. uñas en pinza y b. uñas triangulares. Las uñas se ven afectadas por las alteraciones vasculares oclusivas, más cuando estas no son totales; si se prolongan por mucho tiempo, se van arqueando y parece como si se entorcharan, por lo que se han descrito como 'uñas en pinza'; si esta situación se prolonga en el tiempo o es de mayor magnitud la oclusión o alteración vascular, pueden llegar a engrosarse y dar un aspecto triangular.

\section{Alteraciones neurológicas}

Las alteraciones neurológicas comprometen los nervios periféricos y el sistema nervioso autónomo. Existe una polineuropatía distal y simétrica que afecta los nervios tanto a nivel motor como sensitivo.

La neuropatía sensitiva es el factor que se asocia de manera más constante con la aparición de úlceras en los pies. Entre el 60 y el $80 \%$ de los pacientes con úlceras tiene neuropatía que se manifiesta por alteraciones distales como sensación de cambios de temperatura en la planta del pie, parestesias, disestesias o anestesia 
completa. Esto último favorece el trauma repetido o la presión constante en una zona específica con la posterior aparición de úlceras.

La neuropatía autonómica puede afectar el cuello del pie y se puede observar edema y signos inflamatorios en un pie no ulcerado que aumenta el volumen del mismo y lleva a una subluxación -desalineación de los huesos que conforman una articulación- con deformidad del pie. A esta alteración se le ha llamado 'pie de Charcot' o 'artropatía de Charcot' (figura 2.17), la cual juega un rol significativo en la aparición de infecciones, al disminuirse las respuestas vasomotoras y glandulares con la consiguiente alteración de la hidratación y pérdida de la regulación térmica de la piel; esto genera cambios de sus características, tales como sequedad, resquebrajamiento, edema y fisuras que constituyen la puerta de entrada para las infecciones.

La neuropatía motora axonal no es menos importante y contribuye a la aparición de las úlceras plantares al producir una atrofia muscular y un desequiibrio de los tendones lo cual hace que aumente la presión en ciertas superficies del apoyo plantar. Este cambio de presiones, junto con la alteración sensitiva, facilita la isquemia del tejido y la formación posterior de la úlcera.

Para confirmar el compromiso neuronal motor y sensitivo existen métodos de evaluación simples como la búsqueda de la ausencia de los reflejos aquilianos o la insensibilidad a la estimulación con un monofilamento de nylon en la planta del pie. Es indispensable su exploración ya que son factores predictores de riesgo de úlceras plantares.

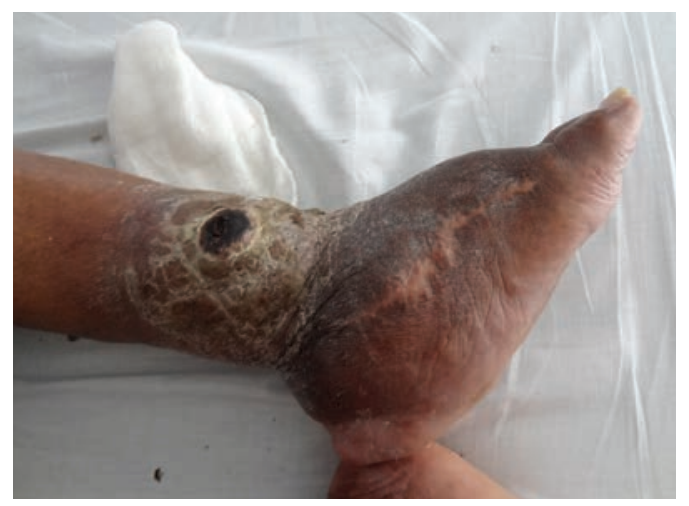

Figura 2.17. Artropatía de Charcot. La neuropatía autonómica puede afectar el cuello del pie. Se puede observar edema y signos inflamatorios en un pie que no necesariamente esté ulcerado con aumento del volumen del mismo y a una posterior subluxación y desalineación de los huesos que conforman una articulación y deformidad del pie. 
Las úlceras se producen por isquemia del tejido de la planta del pie en las zonas de presión, habitualmente en la zona de los metatarsianos, el talón o los bordes laterales de presión de los dedos. Son úlceras perforantes secundarias a la alteración de la sensibilidad (figura 2.18).
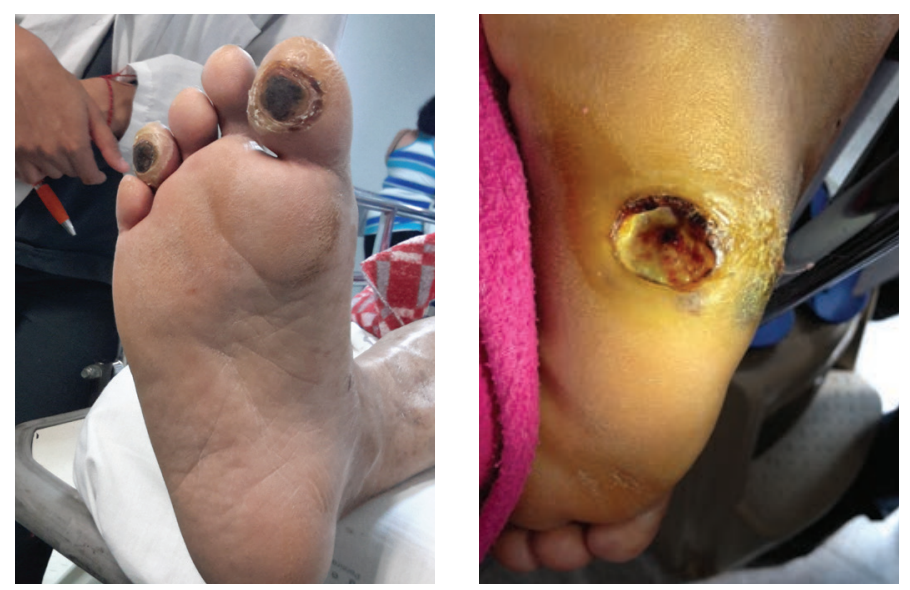

Figura 2.18. Úlceras de tipo mal perforante plantar. Estas úlceras se producen por la isquemia del tejido de la planta del pie en las zonas de presión, habitualmente en la zona de los metatarsianos, el talón o los bordes laterales de los dedos, los cuales permanecen demasiado tiempo bajo la condición de presión debido a la alteración de la sensibilidad en la planta del pie.

Los pies de los pacientes que se ven afectados con frecuencia por esta neuropatía, se encuentran tibios y bien perfundidos, con pulsos palpables, pero podemos encontrar una disminución de la sudoración, o la piel seca y con tendencia a hacer fisuras. La anhidrosis localizada y la xerosis dependen del grado de la neuropatía autonómica.

Se producen con mucha frecuencia lesiones en los pies de los pacientes diabéticos, lo que ha llevado a hablar del 'pie diabético', en el cual es frecuente encontrar úlceras. Es importante considerar que en el origen de estas lesiones juega papel importante tanto lo neurológico como lo vascular. En el caso de lo vascular, ya sea por aterosclerosis, por oclusión de los grandes vasos o por microangiopatía, se encuentran cambios en la temperatura y lesiones necróticas por isquemia; si es por las alteraciones neurológicas, tanto por compromiso del sistema nervioso autónomo que permiten la manifestación del pie de Charcot, o por alteraciones motoras y sensitivas que llevan a la falta de sensibilidad, cambios en la sudoración, sequedad o úlceras en las zonas de presión, del tipo mal perforante plantar, corresponden a necrosis de tejido que se evidencia en la aparición de escaras. A su vez, esta puerta de entrada facilita la aparición de infecciones que pueden llegar a afectar incluso el 
hueso con presencia de osteomielitis. Estas alteraciones en los pies son un motivo frecuente de consulta.

Se pueden apreciar otros cambios que denotan una neuropatía periférica, como son la llamada 'notalgia parestésica' en la que se encuentra una alteración de la sensibilidad en el tercio medio-posterior de la espalda, y la 'meralgia parestésica' en la piel sobre los trocánteres en el tercio supero-externo de los muslos, en la que la alteración de la sensibilidad produce sensaciones de ardor, calor o prurito en estas zonas. En ambos casos, la sensación de molestia se debe a la alteración de los nervios periféricos; es una especie de parestesia y su hallazgo obliga investigar la alteración de la glucemia. Este prurito suele causar una hiperpigmentación en dicha zona y un engrosamientro de la piel debido a la reiterada inflamación por el roce o rascado continuo.

En resumen, las alteraciones del funcionamiento simpático-parasimpático causan rubor en mejillas, notalgia y meralgia parestésica, pie de Charcot con engrosamiento de la región maleolar, y secundarios a la falta de sensibilidad, se encuentra con frecuencia hiperqueratosis y úlceras en las zonas de presión de las prominencias óseas, las llamadas 'ulceras por presión'.

\section{Alteraciones secundarias a metabolitos circulantes en exceso o trastornos metabólicos generales}

No se puede olvidar que las alteraciones fisiológicas, bioquímicas y clínicas en ciertos individuos con susceptibilidad genética, conocidas como síndrome metabólico, pueden llevar a un incremento del riesgo de enfermedades cardiovasculares en pacientes con diabetes mellitus. Este síndrome está definido por varios factores: resistencia a la insulina, obesidad y dislipidemia (36) que, a su vez, lleva a aterogénesis, hipertensión arterial, disfunción endotelial y a un estado de hipercoagulabilidad asociado a un estado de estrés crónico (37).

También se presentan alteraciones secundarias a metabolitos circulantes en exceso o trastornos metabólicos generales que se evidencian con la presencia de piel amarilla y engrosada. Aparecen xantomas, si existe dislipidemia. Por otro lado, pueden aparecer trastornos por eliminación transepidérmica de fibras elásticas o colágenas alteradas asociadas generalmente a la alteración renal concomitante.

Piel amarilla. La piel de los diabéticos tiene, en ocasiones, un tinte amarillento que se aprecia mejor en las palmas (figura 2.19), en las plantas o en las uñas, secundaria posiblemente al engrosamiento de la piel, aunque también puede relacionarse con una mayor sensibilidad a la ingestión excesiva de carotenos (38). Los niveles aumentados de carotenos - es decir, la carotinemia- se deben a 
la falta de conversión hepática de la vitamina A. Sin embargo, su elevación se ha relacionado más con alteraciones tiroideas y puede también verse si existe una anormal funcionamiento hepático o renal.

La piel y las uñas amarillas también pueden estar presentes por los productos finales de la glucosilación avanzada. Se debe hacer el diagnóstico diferencial con otras alteraciones que causan anomalías en las uñas, ya que normalmente suelen encontrarse uñas más gruesas en los ancianos o en las onicomicosis, y con pigmentación amarillenta en los pacientes con alteraciones respiratorias.

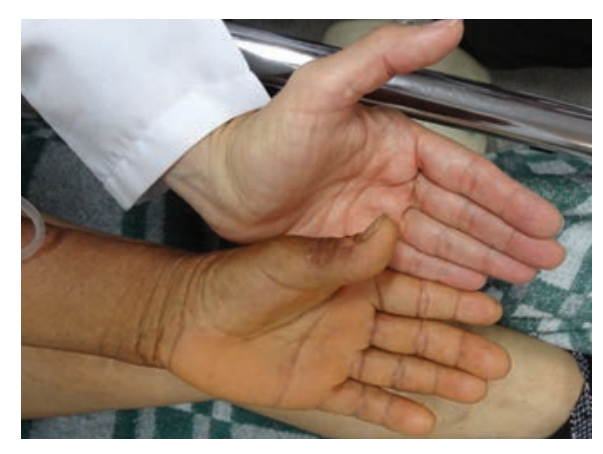

Figura 2.19. Piel amarilla en las palmas. La piel de los diabéticos tiene, en ocasiones, un tinte amarillento que se aprecia mejor en palmas, plantas o en las uñas, secundaria posiblemente al engrosamiento de la piel, aunque también puede relacionarse con una mayor sensibilidad a la ingestión de carotenos.

Engrosamiento de la piel y aspecto esclerodermiforme. La piel de los pacientes diabéticos se siente gruesa y, en ocasiones, se observa una coloración amarillenta, debido a este aumento de grosor. No se pliega fácilmente y se palpa un poco más esclerosa en el dorso de los dedos de las manos y de los pies. Este engrosamiento puede presentarse en las palmas y en las plantas. Del 8 al $50 \%$ de los pacientes la presentan (39). Se asocia con una diabetes de larga evolución y un pobre control de la glucemia (figura 2.20).

El engrosamiento suele ser asintomático, clínicamente aparente y localizado o mínimamente visible pero medible por ecografía. Se describe, además, un engrosamiento o un mixedema en la región posterior del cuello y en las regiones superiores de los brazos y del tórax, llamado 'escleredema diabeticorum'. 

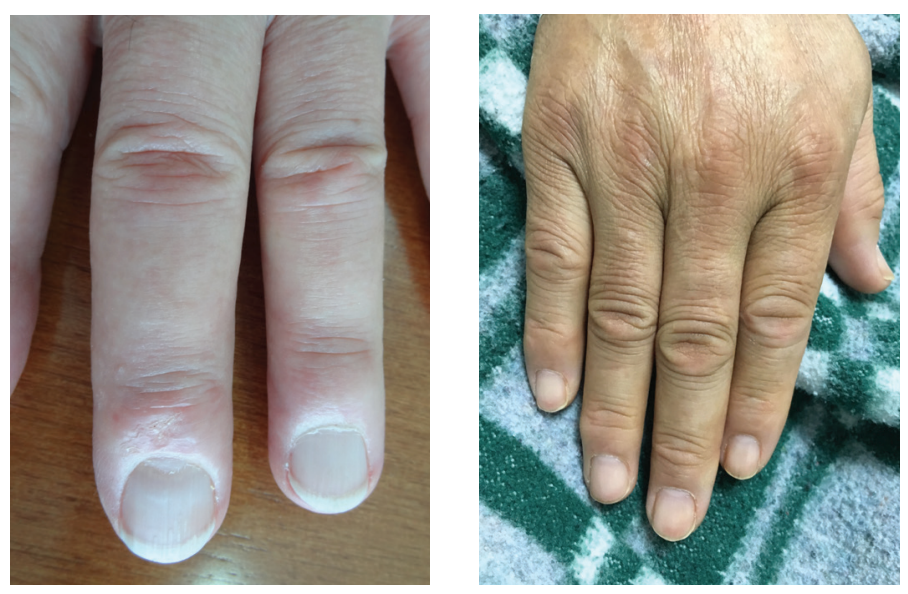

Figura 2.20. Engrosamiento de la piel de las manos y de los pies. La piel del dorso de los dedos de las manos y de los pies se siente gruesa y, en ocasiones, se observa una coloración amarillenta, debido a este aumento de grosor. No se pliega fácilmente y se palpa un poco más esclerosa.

Este afecta a los pacientes diabéticos de larga evolución, obesos y con complicaciones cardiovasculares coexistentes; el escleredema adultorum de Buschke (40) -que no es muy frecuente- se percibe como una induración simétrica en la parte alta de la espalda y del cuello (figura 2.21), que se extiende lentamente a los hombros y a los brazos. El engrosamiento que posiblemente esté relacionado con un aumento del colágeno por depósitos dérmicos de mucopolisacáridos, glucosaminoglucanos o por daño microvascular, puede llevar a la limitación de la movilidad articular. Por otro lado, se puede encontrar asociado a infecciones por Streptococcus spp., a paraproteinemias como el mieloma múltiple o a otras neoplasias y, también, a enfermedades autoinmunitarias (41).

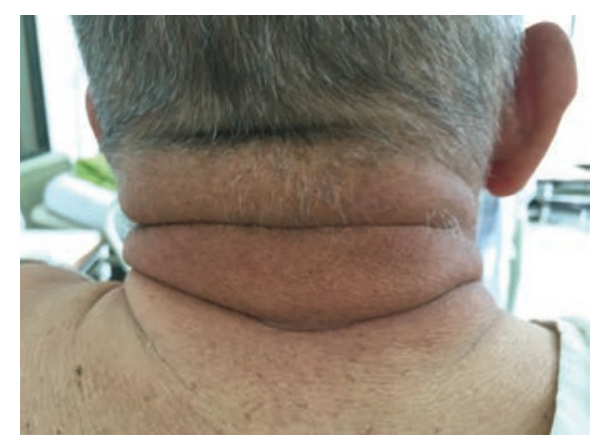

Figura 2.21. Escleredema de la nuca. El escleredema de la nuca se percibe como una induración simétrica en la parte alta de la espalda y del cuello. 
Xantomas o xantomatosis eruptiva. Son una expresión de la dislipidemia que hace parte del síndrome metabólico (36). Se caracterizan por presentar depósitos de grasas visibles en la piel. Estos depósitos pueden ser únicos en párpados, conocidos como xantelasmas (figura 2.22), en cuyo caso no siempre existe la alteración hiperlipémica, o pueden ser múltiples y aparecen de manera eruptiva, los xantomas, presentándose como pápulas en racimos, que se palpan firmes, son de color amarillento o ligeramente eritematoso, diseminados en las superficies extensoras de las extremidades y son indoloros.

Se originan por la acumulación de lipoproteínas en los macrófagos dérmicos, como se puede confirmar con la histopatología al visualizarse la infiltración de macrófagos cargados de lípidos, las células espumosas. En el caso de los xantomas eruptivos están asociados principalmente al aumento de los triglicéridos en sangre de más de $1.000 \mathrm{mg} / \mathrm{dl}$. Se han asociado a hiperlipidemia, glucosuria e hiperglucemia (42).

En su aparición parece ser muy importante el papel de una hormona que se produce en los adipocitos llamada leptina. Esta hace parte de la red de elementos que regulan la homeostasis de los sistemas neuroinmunocrinos, indispensable en la regulación de las acciones de la insulina y sus efectos sobre el metabolismo de la grasa. Algunos pacientes diabéticos pueden tener una disminución de la cantidad de esta hormona y presentan resistencia a la insulina y, en otros pacientes, se puede observar lipotoxicidad y depósitos grasos en las células $\beta$ del páncreas, en el miocardio, el hígado, el riñón o músculo-esqueléticos.

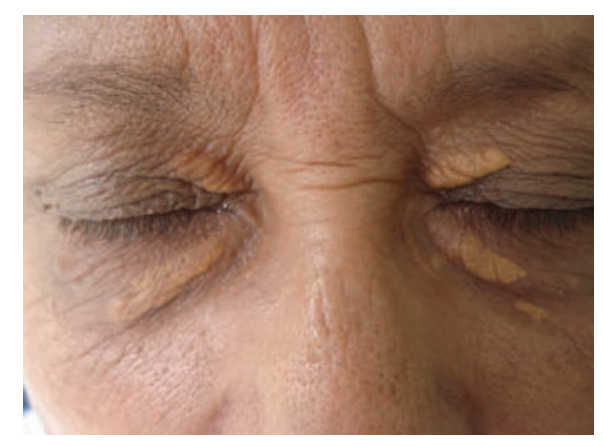

Figura 2.22. Xantelasmas. Se denominan así a unas pápulas circunscritas de 0,2 a 0,9 cm de diámetro, alargadas, de color amarillento, en las que se observan unos depósitos de grasas visibles a través de la piel de los párpados. Pueden acompañar o no a una dislipidemia.

De igual manera, esta hormona juega un papel importante en las lipodistrofias secundarias al tratamiento con ciertos medicamentos, por ejemplo, en pacientes con virus de la inmunodeficiencia adquirida (HIV) que reciben tratamiento HAART 
(Highly Active Antiretroviral Therapy) y que presentan pérdida de grasa corporal en alguna parte del cuerpo. La administración de leptina disminuye la lipotoxicidad.

Dermatosis perforantes adquiridas. En aquellos pacientes diabéticos con insuficiencia renal crónica, se encuentran algunas lesiones por perforación transepidérmica con eliminación cutánea de elementos del tejido conjuntivo (colágeno o fibras elásticas) (43) en quienes aparecen de manera característica unas pápulas o nódulos eritematosos o pigmentados con centros umbilicados hiperqueratósicos que suelen ser muy pruriginosos.

Se clasifican histopatológicamente en cuatro tipos: enfermedad de Kyrle, foliculitis perforante, elastosis serpiginosa perforante y colagenosis reactiva perforante, aunque a nivel clínico no se hace necesaria esta distinción.

Se dice que son de patogénesis desconocida, aunque probablemente los altos niveles de productos azoados, las alteraciones en la glucolisación, los niveles altos de fibronectina o por depósitos de calcio, se producen las alteraciones de las fibras elásticas y del colágeno que se tornan como cuerpos extraños y, por tal razón, el cuerpo trabaja en su eliminación. Por otra parte, el hiperparatiroidismo secundario, asociado a la diabetes mellitus parece relacionarse con estas dermatosis perforantes al igual que con la calcifilaxis vistas en los pacientes en insuficiencia renal crónica (44).

Estas fibras alteradas son eliminadas a través de la piel como si fueran cuerpos extraños. Los trastornos perforantes cutáneos, o dermatosis perforantes adquiridas, son más frecuentes si la diabetes mellitus está asociada a la alteración renal. Se presentan en el $5 \%$ de los pacientes diabéticos con insuficiencia renal crónica que se encuentran en diálisis. Es posible que algunos de los pacientes que se diagnostican con lesiones papulosas decapitadas por el rascado, que denominamos prurigo, puedan presentar este tipo de alteración. Si se observa en el centro de la lesión una mayor queratosis, se puede haber iniciado un proceso de eliminación de estas fibras alteradas y presentar estas dermatosis perforantes, lo que se podría aclarar con la toma de una biopsia de piel. Suelen verse más en pacientes diabéticos de larga data, generalmente con diabetes mellitus de tipo 1.

\section{Reacciones cutáneas secundarias al tratamiento}

Insulina. Al instaurar un tratamiento con insulina, se pueden generar efectos cutáneos secundarios de manera localizada en el lugar de la inyección de insulina. Estas lipodistrofias pueden ser una lipoatrofia local con pérdida de la grasa o, de manera menos frecuente, una lipohipertrofia por acumulación de fragmentos de la insulina aplicada, que también se describían como 'insulinomas'. Estas alteraciones 
casi no se presentan en la actualidad, debido a que las nuevas insulinas purificadas y las insulinas humanas recombinantes, no causan estas lipodistrofias.

Hipoglucemiantes orales. Se puede apreciar una mayor cantidad de efectos secundarios a la ingestión de hipoglicemiantes orales, tales como las sulfonilureas de primera generación, con aparición de eritema macular o flushing si se ingiere alcohol, reacciones de hipersensibilidad o de fotosensibilidad, prurito o urticaria e incluso aparición de enfermedades ampollosas semejantes al eritema multiforme (45). Estos se ven cada vez con menor frecuencia debido a que eran efectos de las sulfonilureas de primera generación, como la clorpropamida y la tolbutamida, y no están descritos con los nuevos medicamentos que no tienen efectos secundarios en la piel, sino más bien a nivel gastrointestinal (46).

\section{Otras asociaciones}

Se reporta en la literatura que del 1,6 al 3,3\% de los pacientes diabéticos presentan liquen plano oral (47). La asociación entre liquen plano y diabetes ha sido motivo de controversia. Las lesiones son blancas y reticuladas y se localizan preferentemente sobre la lengua y en la porción posterior e inferior de la mucosa malar (jugal) (figura 2.23). Su aspecto blanquecino ramificado, recuerda una hoja de helecho o los líquenes del agua de donde, posiblemente, derive su nombre (48-50). Se pueden encontrar otras lesiones de liquen plano no necesariamente en la cavidad oral. Además de la asociación con el liquen plano, se ha encontrado diabetes mellitus asociada a enfermedades autoinmunitariass como el vitiligo, la psoriasis (figura 2.24), la esclerosis sistémica, la artritis reumatoidea, el lupus eritematoso sistémico o la colitis ulcerativa (51).

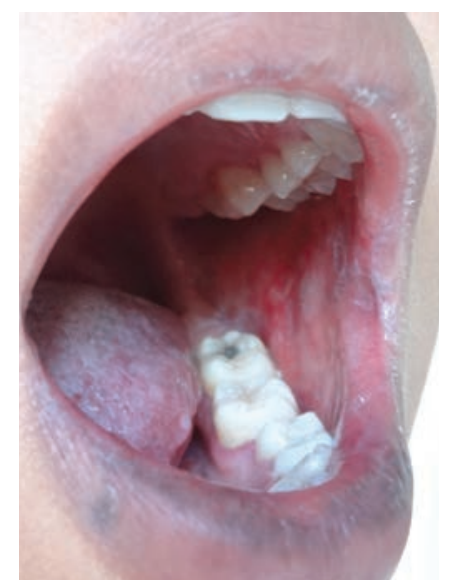

Figura 2.23. Liquen plano oral. Se refiere a unas lesiones blancas y reticuladas que se localizan preferentemente sobre la lengua y en la porción posterior e inferior de la mucosa malar (jugal). También pueden acompañarse de lesiones papulosas, poligonales, de un color rosavioláceo característico con estrías blanquecinas (wikham) en el centro, muy pruriginosas en la piel. 

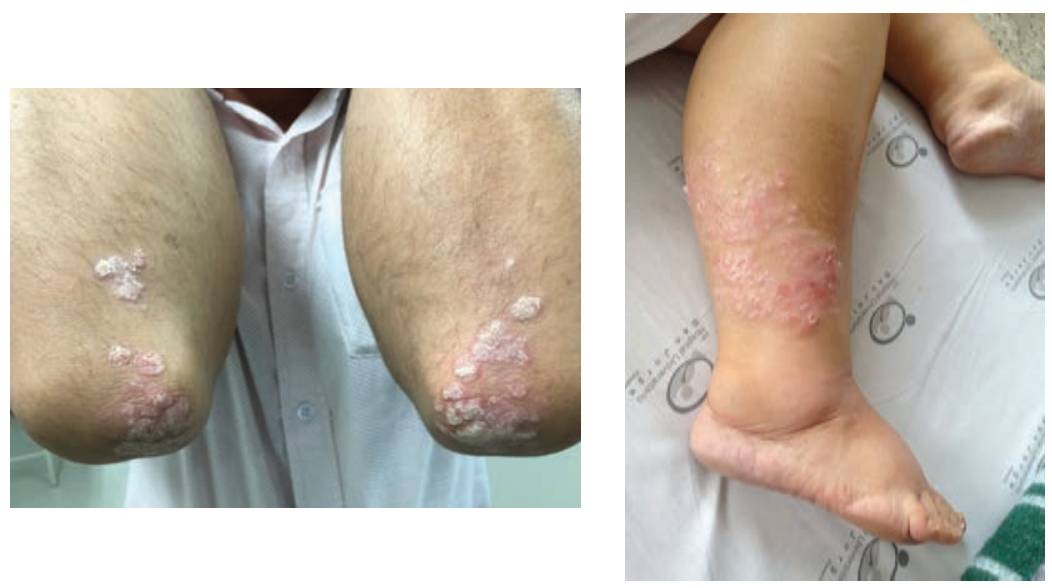

Figura 2.24. Psoriasis. Estas placas eritematoescamosas, a veces infiltradas y gruesas, que aparecen con mayor frecuencia en el cuero cabelludo, los codos, las rodillas, la región sacra y que pueden extenderse al tronco y a las extremidades se pueden presentar en los pacientes con alteraciones metabólicas. Las uñas afectadas por la psoriasis suelen estar separadas del lecho ungular, lo que se conoce como onicólisis, y presentan una coloración amarilloparduzca en la zona más proximal, llamada 'mancha de aceite'. Su importancia radica en que se asocian con una dislipidemia y pueden correlacionarse con el compromiso articular.

El $15 \%$ de los pacientes diabéticos presentan úlceras en las extremidades inferiores, las piernas y los pies, con una incidencia anual del 1 al $4 \%$ y del $25 \%$ en la vida en general. Suele ser la primera causa de hospitalización temprana. El $85 \%$ de las amputaciones están precedidas de úlceras. El $56 \%$ de las úlceras se infectan lo cual genera altos costos para el paciente; por esta razón, es importante revisar siempre los pies de estos pacientes. Es por todo esto que se hace énfasis en el concepto del pie diabético.

El término de 'pie diabético' se aplica al hallazgo de una lesión ulcerativa en uno de los pies del paciente con diabetes. Pero, dado que una variedad de condiciones patológicas está presente y que se desencadena la úlcera o ruptura de la barrera cutánea, el nombre debe considerar la presencia de las alteraciones neurológicas, vasculares e infecciosas. Siendo, quizá, la más importante, la alteración neuropática, es decir, la alteración sensorial de la extremidad inferior inducida por la hiperglucemia sostenida que, generalmente, es la responsable de la úlcera, la cual se presenta posterior a un traumatismo agudo que genera una úlcera en diferentes zonas del pie o que, inducida por la alteración de la sensibilidad, se presenta en los sitios de prominencias óseas como una úlcera por presión.

La excesiva presión sobre una zona de la piel o el trauma repetido debido a la alteración propioceptiva, desencadena inicialmente eritema que luego, si continúa, permite la aparición de ampollas. De ceder el estímulo de la presión sobre el tejido, aparece la hiperqueratosis y posterior callosidad o, de persistir la presión, 
se presenta la necrosis del tejido con formación de la úlcera, por lo que se habla de 'úlcera isquémica o por presión', también llamada 'mal perforante plantar'. Por estas razones, las localizaciones más frecuentes son los sitios de prominencias óseas en el pie: la zona media plantar, a nivel de las cabezas de los metatarsianos, la epífisis distal del primero y quinto metatarsianos, la cara lateral externa del primero y quinto dedo por presión con el calzado, y en la región calcánea.

La úlcera se presenta frecuentemente en la zona plantar; es de forma oval, profunda, de bordes callosos y base granulada. En los dedos es de forma redondeada, inicialmente indolora, excepto cuando hay presencia de infección y el dolor puede ser moderado o intenso, si el compromiso vascular periférico es importante. Como se puede observar, además de la alteración neurológica y vascular periférica, el trauma debido a las alteraciones de la biomecánica del pie y la infección subsiguiente agravan la situación previamente establecida. El calzado inapropiado es la causa más común del trauma. La presencia de callos, es decir, de zonas de presión que sufren de falta de oxigenación predispone a su presentación.

A las alteraciones neurológicas se suman las alteraciones vasculares e infecciosas, con ausencia de pulsos tibiales, frialdad y palidez, y con la aparición de lesiones isquémicas y necróticas, con halo eritematoso, que son muy dolorosas y llevan a la pérdida del tejido.

La isquemia puede contribuir en 30 a $40 \%$ a la aparición de úlceras, y en mayor medida, a la existencia de la necrosis distal. La neuropatía predispone a la infección al permitir que estas úlceras plantares se formen y sean la puerta de entrada de diversos microorganismos. En ausencia de úlceras, el $60 \%$ de las infecciones comienza en los espacios interdigitales, seguido de la región periungular en $30 \%$ y el restante $10 \%$ en otras zonas. La infección se puede extender a planos más profundos con celulitis que lleva a fascitis, abscesos o aun a compromiso óseo con osteomielitis.

La infección se desencadena frecuentemente por una lesión superficial, favorecida por la sequedad y la atrofia cutánea, generalmente después de un trauma, así parezca mínimo, o desencadenado por el prurito, sin relación con el grado de isquemia. El hecho de tener fisuras y lesiones secundarias a las infecciones fúngicas en las regiones interdigitales que permiten la entrada de un microorganismo bacteriano es una causa frecuente. Estas condiciones se asocian a un mínimo dolor y en la mayoría de los casos no producen fiebre, escalofríos ni manifestaciones sépticas sistémicas y es, tal vez, la razón por la que los pacientes consultan tardíamente. 
El curso del proceso depende del tipo de germen involucrado y de la rapidez en establecer el tratamiento adecuado. Se precisa con urgencia el desbridamiento del tejido necrótico y el tratamiento antibiótico adecuado. Por otra parte, la alteración de los mecanismos de reparación en el paciente diabético puede llevar a un acentuado retraso en el proceso de cicatrización con tendencia a la cronicidad de las heridas.

La seriedad del compromiso del pie se evalúa en diferentes grados ya que se constituye en el principal factor de riesgo para la amputación de la extremidad. Existe una clasificación de la gravedad del 'pie diabético' conocida como la escala de Wagner (52), a saber:

- 0: pie en riesgo: enfermedad vascular y neuropatía periférica, deformidades, pérdida de la visión, nefropatía, edad avanzada

- 1: úlcera superficial

- 2: úlcera profunda (tendón, hueso, ligamento, articulación)

- 3: infección localizada (celulitis, absceso, osteomielitis)

- 4: gangrena local

- 5: gangrena extensa

El adecuado cuidado de los pies por parte del paciente, de su familia y del equipo médico, permite evitar el desarrollo de complicaciones y, por tanto, mejora la calidad e integridad de vida del paciente diabético.

Cualquier herida cuyo proceso de cicatrización no se ajuste a los parámetros normales debe ser considerada crónica, lo que se asocia a un peor pronóstico, sobre todo si se mantiene abierta por cuatro semanas o más.

Para concluir se quiere dar una idea de cuáles son las lesiones que se presentan con mayor frecuencia en los pacientes diabéticos. En un estudio chileno reciente, Fajre, et al. (53), encontraron que después de 10 años de evolución de la enfermedad, eran más frecuentes las lesiones de piel, mucosas y faneras, y que las lesiones más frecuentes en los 118 pacientes examinados fueron: "Onicomicosis $(27,1 \%)$, dermatopatia diabética (16,9\%), macroangiopatía (15,3\%), tiña corporis $(14,4 \%)$, xerosis $(13,6 \%)$, prurito $(6,8 \%)$, acantosis nigricans $(5,9 \%)$, queratosis seborreicas (5,1\%), pie diabético (4,2\%)".

Refieren que, en su grupo de pacientes, los que tenían diabetes mellitus de tipo I presentaban onicomicosis, xerosis e infecciones por dermatofitos de tipo tiña corporis, y los que tenían diabetes mellitus de tipo II tenían en un mayor porcentaje lesiones de tipo onicomicosis, macroangiopatía e infecciones por estafilococos. 
"De los pacientes con dermatopatia diabética, cuatro pacientes (20\%) tenían diabetes mellitus de tipo 1 y 16 pacientes diabetes mellitus de tipo 2 . La macroangiopatía que se caracterizaba clínicamente como atrofia de piel de las piernas, palidez al elevarlas, frialdad de la piel, distrofia ungueal (sic), y retraso en el retorno de la coloración postpresión; se presentó en un grupo de 18 pacientes de los cuales el 94,4\% (17) tenían una diabetes mellitus de tipo 2 y 5,6\% (1) una diabetes mellitus de tipo 1".

\section{Enfermedades de la glándula tiroides}

La glándula tiroides como un reloj biológico, mediante la hormona tiroidea organiza el metabolismo energético de nuestro cuerpo, controlando el consumo de oxígeno y la síntesis proteica (54). Regula el crecimiento de la epidermis, debido a que está involucrada en la diferenciación epidérmica, en la formación y en el crecimiento del cabello y en la secreción de las glándulas apocrinas, ecrinas y sebáceas. Influye, también, en la producción de proteoglucanos por parte de los fibroblastos dérmicos y es imprescindible en la melanogénesis (55).

La hormona tiroidea controla las diferentes fases fisiológicas, actuando a nivel de los procesos celulares de biosíntesis y degradación que mantienen la homeostasis corporal. La hormona liberadora de tirotrofina (TRH) a nivel hipotalámico estimula la adenohipófisis a producir tiroestimulina (TSH) que a la vez estimula a la glándula tiroides para producir T4. La T4, o tiroxina, es una prohormona que es fisiológicamente activa después de que los iones yoduros ingeridos en la dieta se oxidan y se unen a la tiroxina, la monoyodotirosina, la diyodotirosina, y, finalmente, es convertida en triyodotironina o T3, gracias al proceso de pérdida de yodo que se lleva a cabo en múltiples tejidos, incluida la piel, por enzimas específicas llamadas 'deyodasas' (56). Es importante recordar que la piel tiene receptores para T3 (57), que se encuentran en el queratinocito, al igual que en el fibroblasto, el folículo piloso, la glándula sebácea y en las glándulas sudoríparas.

Así que las hormonas tiroideas se hacen activas en la piel por el proceso de pérdida de yodo y, también, la piel es blanco de estas señales hormonales ya que hay células residentes y circulantes que expresan receptores para ellas. De tal modo que, como receptora y a la vez fuente de hormonas tiroideas activas, la piel es capaz de generar respuestas endocrinas específicas y es uno de los principales lugares de regulación de la hormona tiroidea. La T3 actúa específicamente en el folículo piloso, interviniendo en el ciclo y en el crecimiento folicular, y sobre el melanocito, participando en los procesos de melanogénesis, por lo que es frecuente encontrar alteraciones del crecimiento del pelo y alteraciones de la pigmentación, como el 
melasma o el vitiligo (figura 2.25) asociados a enfermedad tiroidea, como sucede en la enfermedad de Graves o en otras alteraciones tiroideas.
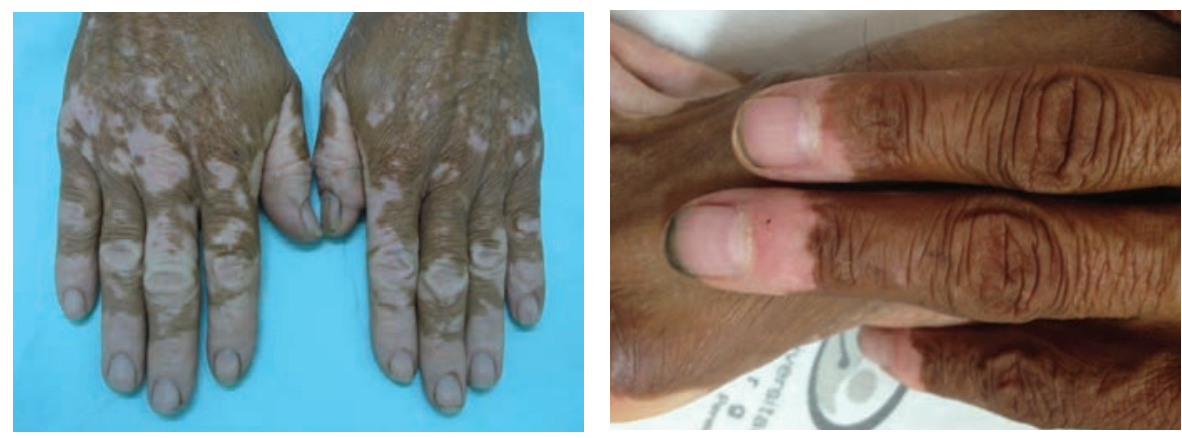

Figura 2.25. Vitiligo. Se refiere a la aparición de zonas blanquecinas por falta de pigmento melánico que, con frecuencia, se acompañan de alteraciones del crecimiento del pelo, y se asocian a la enfermedad tiroidea, como sucede en la enfermedad de Graves. Se sabe que la hormona tiroidea actúa interviniendo en el ciclo y en el crecimiento folicular, y sobre el melanocito, participando en los procesos de melanogénesis.

Las alteraciones de la ingestión de yodo son determinantes para una buena función de la hormona tiroidea. El hipotiroidismo congénito, definido como una disminución de la hormona tiroidea presente al nacimiento, es un trastorno de la síntesis de la hormona tiroidea. Puede ser un estado transitorio o permanente, primario, secundario o periférico. Primario, cuando existen alteraciones del desarrollo de la glándula tiroidea, defectos en la producción de TSH o algunas mutaciones que involucran genes que controlan las señales de transducción o niveles de TSH; secundario o central, debido a alteraciones pituitarias, con alteración de la hormona liberadora de tirotropina (TRH), y periférica, cuando existe una alteración del transporte o del metabolismo de la TSH o de los receptores periféricos.

Los niños que sufren de hipotiroidismo congénito pueden tener alteraciones en sus genes que expliquen la alteración de la adecuada formación de la hormona tiroidea o ser hijos de madres que estaban ingiriendo medicamentos antitiroideos, o que tienen anticuerpos que interfieren con una buena formación de la hormona tiroidea o con alterados niveles de ingestión de yodo $(58,59)$.

En esta alteración, la glándula tiroides no secreta cantidades suficientes de hormona tiroidea in utero o en estados perinatales tempranos. Se encuentra con frecuencia un bebé letárgico, somnoliento, con hipotonía, llanto ronco, mala deglución, con macroglosia y retardo mental, asociado a hernia umbilical, acumulación de grasa clavicular, con piel fría, seca y pálida, proceso que también se ha llamado 'cretinismo'. 
La glándula tiroides es fácil de palpar (60), dada su localización y, ocasionalmente, se encuentra un aumento de su tamaño que se denomina 'bocio' (figura 2.26). Si a la palpación se detecta una lesión tumoral, se puede observar una deformidad o apreciar una sensación más leñosa que la habitual, o, en caso de estar avanzado el proceso neoplásico y tener metástasis, estas se presentan en los ganglios linfáticos regionales sobre todo en el carcinoma papilar de tiroides que metastatiza localmente, ya que rara vez lo hace a distancia a diferencia del carcinoma folicular de tiroides que sí lo hace. El carcinoma medular de tiroides originado en las células $\mathrm{C}$ o parafoliculares originadas en la cresta neural, se puede relacionar con neuromas mucosos, feocromocitomas, neurofibromas, lentiginosis difusa, manchas café con leche, o con el síndrome de Cowden (61), que se caracteriza por la aparición de múltiples hamartomas, entre ellos unas lesiones tumorales pequeñas de aspecto papuloso, brillantes, que aparecen en la piel de rostro llamadas 'triquilemomas'.

En el cuello también podemos encontrar unas lesiones de aspecto tumoral, que realmente son formaciones quísticas y que no implican alteración de la glándula tiroidea y corresponden a una alteración del cierre del ducto tirogloso. Durante la embriogénesis, la glándula tiroides desciende al cuello y mantiene una conexión con la lengua mediante un estrecho tubo, llamado el ducto tirogloso. Estas lesiones, llamadas quistes tiroglosos, son los que se presentan como un abultamiento a los lados de la línea media del cuello, por alteraciones en el descenso embrionario; representan el $70 \%$ de los quistes congénitos de cuello sin que impliquen una alteración sistémica y raramente se torman malignos.

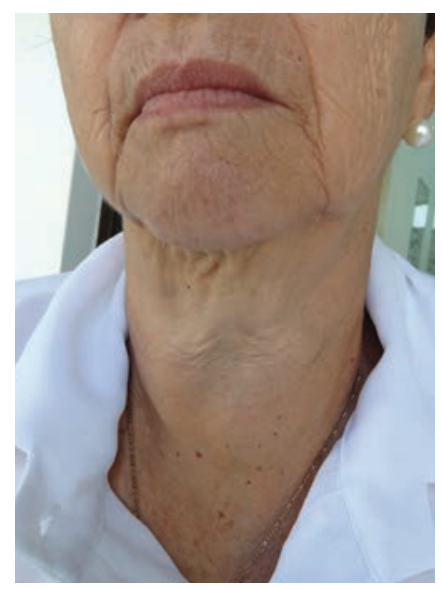

Figura 2.26. Bocio. Se refiere a un aumento del tamaño de la glándula tiroides. Puede tratarse de un aumento de características benignas intentando aumentar la función de la misma, en los casos de alteración de la producción de hormona tiroidea, como sucedía cuando la sal no tenía yodo, o puede estar asociado a una neoplasia, en cuyo caso la palpación es leñosa y el crecimiento es asimétrico e irregular. 
A continuación se detallan las alteraciones que se presentan en la piel, secundarias a la hipofunción de la glándula o hipotiroidismo, y las que aparecen en la hiperfunción o hipertiroidismo. Se hace énfasis en la necesidad de solicitar la medición de anticuerpos antitiroideos ante una patología tiroidea para aclarar si el origen de la alteración está asociado a una enfermedad tiroidea autoimmunitaria o no, bien sea la enfermedad de Graves o la tiroiditis de Hashimoto. En la enfermedad de Graves, existe una tirotoxicosis, mientras que en la tiroiditis de Hashimoto se encuentra un hipotiroidismo.

\section{Hipotiroidismo}

La alteración del funcionamiento de la glándula tiroidea por hipofunción, con presencia de niveles insuficientes de hormona tiroidea circulante T4 (tiroxina) se denomina 'hipotiroidismo' y también se presenta como una resistencia de las células sobre las que ejerce su función. Puede ser congénito, primario, debido a un defecto en la estructura ganglionar tiroidea, secundario a una insuficiencia hipofisiaria, o terciario a partir de una secreción insuficiente de hormona liberadora de tirotrofina (TRH) a nivel del hipotálamo.

Es más frecuente la alteración primaria, en la cual se encuentra la hormona tiroidea T4 por debajo de $0,8 \mathrm{ng} / \mathrm{dl}$ y la hormona tiroestimulante (TSH) alta, por encima de $4.0 \mathrm{ng} / \mathrm{dl}$ (62). Gencer, et al., consideran eutiroideo a quien presente una concentración de TSH de 0,45 a $4.49 \mathrm{mIU} / \mathrm{L}$ y hablan de una frecuencia de $8 \%$ de hipotiroidismo subclínico (63).

El hipotiroidismo es más frecuente en la mujer que en el hombre, y en las poblaciones que tienen en su dieta un alto contenido de yodo (64). Si bien el yodo es esencial para la producción de la hormona tiroidea (T4) y de la T3 y, con anterioridad, se veía asociado a la falta de ingestión de yodo y, por esta razón, se agregó a la sal. Existe un fenómeno conocido como 'efecto Wolff-Chaikoff' (65), en el que la inhibición de la unión del yodo en la glándula tiroidea por exceso de yodo en la ingestión resulta en una cesación de la síntesis de hormona tiroidea. De tal manera que esto también se debe tener en cuenta. Puede aparecer debido a enfermedades tiroideas autoinmunitarias, como una tiroiditis autoinmune crónica de Hashimoto o una tiroiditis subaguda; puede ser secundaria a la terapia con yodo radioactivo para la enfermedad de Graves, o posterior a la extirpación quirúrgica de la glándula. Se ve si es inadecuado el reemplazo terapéutico del hipotiroidismo clínico, o posterior a la terapia con carbonato de litio.

La disminución de la hormona tiroidea puede producir inicialmente una sensación de cansancio, un incremento del sueño, algún nivel de depresión y cambios en la piel y en los anexos. En la piel de los pacientes con hipotiroidismo, 
se encuentra con frecuencia ( 80 a $90 \%$ ) piel seca y adelgazada. Esta sequedad, o xerodermia, podría explicarse en parte por la disminución en la producción sebácea, por alteraciones del sudor y, quizá, por la disminución de la biosíntesis de lípidos epidérmicos. La sequedad recuerda la ictiosis; las palmas y las plantas están hipohidróticas e hiperqueratósicas, y debido a ello es frecuente el prurito. Existe fragilidad capilar que lleva a la aparición de equimosis y púrpuras y, a veces, se encuentran xantomas eruptivos, aunque no son tan frecuentes.

La piel se encuentra pálida y puede ser debido a vasoconstricción, anemia o ambas. Se acompaña de intolerancia al frío con cambios mínimos de la temperatura. La hipotermia se presenta por disminución en la tasa metabólica que causa como reflejo vasoconstricción periférica y que como se anotó anteriormente puede aumentar la palidez que, por otro lado, se hace más notoria debido al incremento del contenido de agua y mucopolisacáridos en la dermis (54) lo cual altera la refracción de la luz. En ocasiones, se acompaña de un tinte amarillento, más notorio en las palmas y en las plantas, por acumulación de carotenos en el estrato córneo, por disminución de la conversión hepática de $\beta$ carotenos a vitamina A cuando la ingestión es importante.

Las alteraciones en el pelo se caracterizan por la pérdida difusa del pelo, con aspecto opaco, cómo 'apagado', con pérdida del brillo; el pelo se encuentra quebradizo y presenta un crecimiento lento, que puede ser una manifestación temprana. Los pacientes presentan un aumento de la entrada en télogeno y, por esta razón, hay caída fácil del mismo; asimismo, se puede apreciar en las cejas, con pérdida de la cola de las mismas, llamada 'madarosis' (figura 2.27).

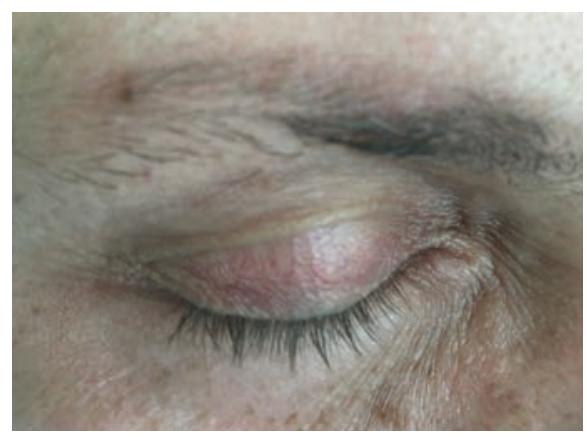

Figura 2.27 Madarosis: alopecia difusa de la cola de las cejas. Los pacientes hipotiroideos presentan un aumento de la entrada en telógeno y, por esta razón, hay caída fácil del pelo, lo que se puede apreciar en las cejas, con pérdida de la cola de las mismas.

Se encuentra también caída del pelo en áreas circunscritas sin alteraciones de la piel, llamada 'alopecia areata' (figura 2.28), la cual se puede asociar a otras 
enfermedades autoinmunitarias. Es frecuente encontrarla en diferentes trastornos tiroideos, al igual que la presencia de alteraciones en las uñas, las cuales son frágiles, quebradizas, con pérdida del brillo y crecimiento lento, y, ocasionalmente, se encuentran separadas las láminas ungulares del lecho, lo que se conoce como 'onicólisis'.

Si la alteración de la tiroides es más importante y lleva ya cierto tiempo, se encuentra el signo cutáneo más característico que es el mixedema generalizado (figura 2.29), causado por el depósito de mucopolisacáridos (ácido hialurónico y condroitín sulfato) en la dermis. La piel se ve engrosada, seca, firme y áspera al tacto.

Este estado mixedematoso se puede confundir con edema ya que el acúmulo de mucopolisacáridos al absorber agua da un aspecto de engrosamiento, que parece un edema que no deja fóvea y, si bien suele ser generalizado, a veces se hace más notorio en la región periorbiaria (figura 2.30) en los labios y en la lengua o en regiones distales (acral), como las piernas, las manos y los pies.

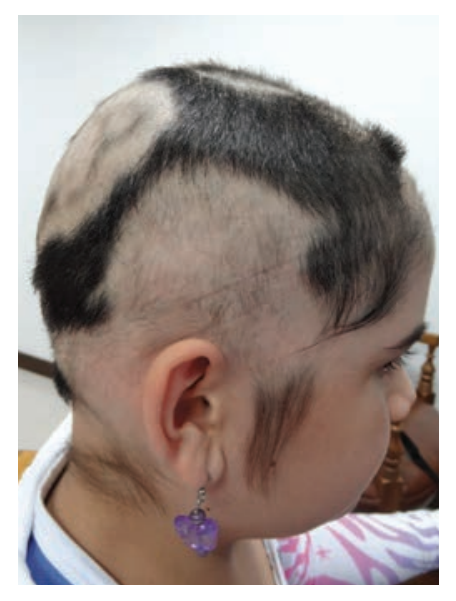

Figura 2.28. Alopecia areata. Son áreas numulares desprovistas de pelo o con pelos adelgazados proximalmente y que se caen con facilidad. Cuando repuebla, los pelos nuevos pueden ser hipopigmentados, llamados polióticos. En algunos casos, se puede asociar a una alteración tiroidea y puede acompañarse de vitiligo.

El mixedema puede comprometer las cuerdas vocales y la orofaringe cambiando el tono de la voz. En algunos pacientes hipotiroideos se presenta una hiperpigmentación marrón en las mejillas, llamada 'melasma' (66), y algunos pacientes presenta lesiones de acné, que se ve incrementado al iniciar el tratamiento, debido a que aumenta aún más su expresión. 

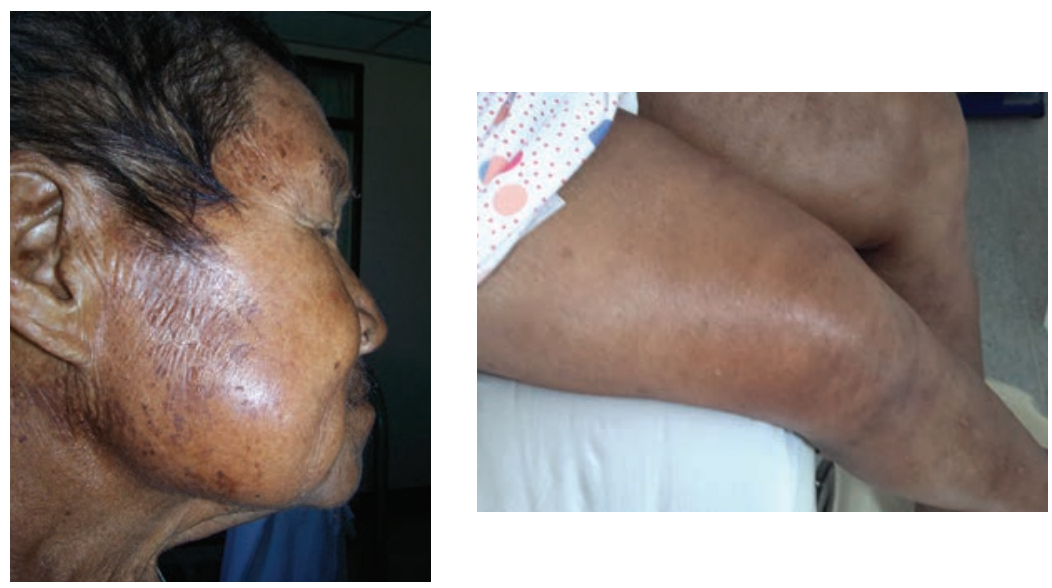

Figura 2.29. Mixedema generalizado. Se trata de una dermopatía infiltrativa presente en los hipotiroideos, causado por depósitos de mucopolisacáridos (ácido hialurónico y condroitin sulfato) en la dermis. La piel se ve engrosada, seca y firme. Este estado mixedematoso puede ser confundido con edema ya que el acúmulo de mucopolisacáridos al absorber agua da un aspecto de engrosamiento, que parece un edema que no deja fóvea.

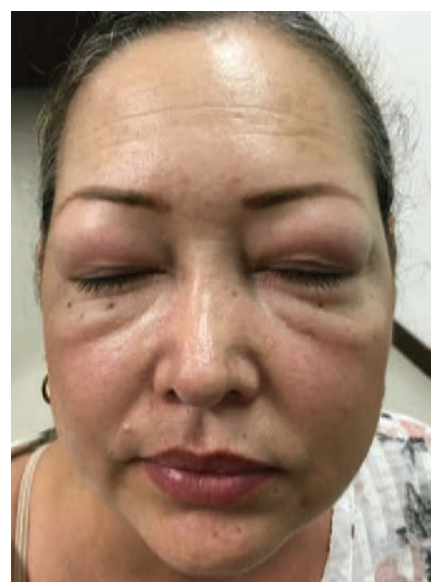

Figura 2.30. Mixedema periorbitario. Este depósito de mucopolisacáridos, si bien suele ser generalizado, a veces se hace más notorio con un aumento de los tejidos blandos en ciertas regiones como la región periorbiaria, en los labios y en la lengua, o en regiones distales (acral), como las piernas, las manos y los pies. El mixedema puede comprometer las cuerdas vocales y la orofaringe cambiando el tono de la voz.

Existen múltiples estudios con respecto a estas manifestaciones; se ha seleccionado una serie latinoamericana que habla de las manifestaciones cutáneas del hipotiroidismo: es el reporte de Gómez Zanni (62), quien encontró las siguientes manifestaciones dermatológicas cómo las más frecuentes: melasma, xerodermia, acné, efluvio telógeno, vitiligo, fragilidad 
ungular y queratodermia. En la serie de Ai, et al. (67), encontraron piel seca, caída del pelo y mixedema como las más frecuentes, seguidas de prurito y urticaria, y menos frecuentemente, la disminución de la sudoración, carotinemia, púrpuras y equimosis, alopecia difusa y xantelasmas.

\section{Hipertiroidismo}

El hipertiroidismo se presenta cuando los tejidos se exponen a concentraciones elevadas de hormonas tiroideas. Se habla de hipertiroidismo o de tirotoxicosis. No es fácil encontrar su verdadera frecuencia, se encuentra baja la hormona tiroestimulante (TSH), por debajo de $0,1 \mathrm{mIU} / \mathrm{L}$. Se estima que la prevalencia es de cerca de 2,5\% en mujeres y menos del 0,2\% en hombres (68). Puede estar relacionado con una dieta con bajo contenido de yodo (64).

En la mayoría de los casos se presenta asociado a la enfermedad de Graves (69), considerada una enfermedad autoinmunitaria de carácter familiar asociada al HLA-B8 y HLA-DR3, en la que se encuentra bocio acompañado de oftalmopatía infiltrativa; también puede estar relacionado con el bocio tóxico multinodular o con nódulos solitarios hiperfuncionantes, con un adenoma folicular tóxico, a la fase transitoria de una tiroiditis subaguda, posterior a una tiroiditis posparto o secundario a una sobredosificación con hormona tiroidea. También se puede relacionar con la aparición de tumores, cuya producción hormonal estimule la producción de hormona tiroidea, como sucede con los tumores de la glándula pituitaria, el coriocarcinoma o los carcinomas embrionarios testiculares.

Las manifestaciones generales que con mayor frecuencia acompañan al hipertiroidismo son: nerviosismo, pérdida de peso, debilidad, labilidad emocional, palpitaciones y temblor; las cutáneas más relevantes son: piel caliente y con hiperhidrosis, hiperpigmentación (figura 2.31), pelo delgado y pérdida difusa del pelo, alopecia areata, onicólisis distal y coiloniquia, acropaquia, mixedema pretibial - llamado 'dermopatía de la enfermedad de Graves'-, vitiligo, prurito y urticaria. La piel de los pacientes hipertiroideos es delgada y lisa, suele estar eritematosa, caliente y húmeda; húmeda por la hiperhidrosis, y eritematosa y caliente por el aumento de la vasodilatación periférica.

El cabello es fino y delgado, y puede haber una disminución de la población pilosa con caída acelerada del mismo y presentación de una alopecia difusa, o asociarse a la aparición de una alopecia areata. 


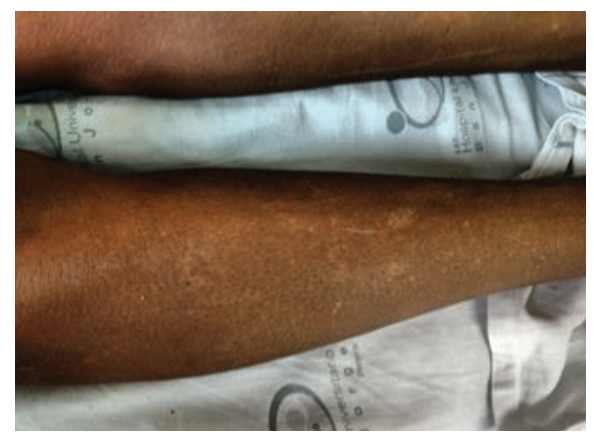

Figura 2.31. Hiperpigmentación en el hipertiroidismo. Como se ha podido apreciar, la melanogénesis está regulada por diferentes estímulos, hipofisiarios con el aumento de MSH y ACTH, o por el aumento de la hormona tiroidea, en cuyo caso producen una hiperpigmentación generalizada.

Las alteraciones ungulares presentes en el $5 \%$ de los pacientes hipertiroideos corresponden a uñas delgadas y blandas, que se quiebran fácilmente. En algunas ocasiones, se encuentra una onicólisis distal, que se ha denominado 'uñas de Plummer', ) (figura 2.32 a) y una superficie cóncava de la lámina ungular o coiloniquia (figura 2.32 b). Existe, además, con frecuencia, un ensanchamiento digital, con engrosamiento de los dedos de las manos y de los pies, y proliferación subperióstica, y menos frecuentemente en los huesos largos con neoformación ósea perióstica, que afecta principalmente las falanges proximales de los dedos de los pies y de las manos, que se denomina acropaquia (70) (figura $2.32 \mathrm{c}$ ).

Se presenta, además, una dermopatía infiltrativa o mixedema, pero este no es generalizado, siendo más frecuente en la región pretibial, por los depósitos de mucopolisacáridos hidrofílicos en la sustancia fundamental de la dermis, y que se puede observar en otras zonas con placas en los hombros o en los brazos.

En estos pacientes se encuentra un factor sérico circulante que estimula la producción de glucosaminoglucanos por parte de los fibroblastos de la dermis de los miembros inferiores, ya que estos son más sensibles a este factor. Otros coadyuvantes en la aparición del mixedema pretibial son los traumatismos locales y la obstrucción linfática. El compromiso suele ser bilateral, asimétrico, con formación de pápulas, nódulos o placas de color rosado o pardo-violáceo con apariencia superficial de piel de naranja. Otras células también han sido implicadas en la producción del depósito de material mucopolisacárido, como son los queratinocitos, los adipocitos y las células endoteliales, al igual que factores humorales como el factor de crecimiento similar a la insulina. También se ha encontrado que estos pacientes pueden presentar un aumento de los tejidos blandos del ojo con exoftalmia (figura 2.33), una oftalmopatía infiltrativa por estimulación prolongada de la hormona tiroidea (71). 

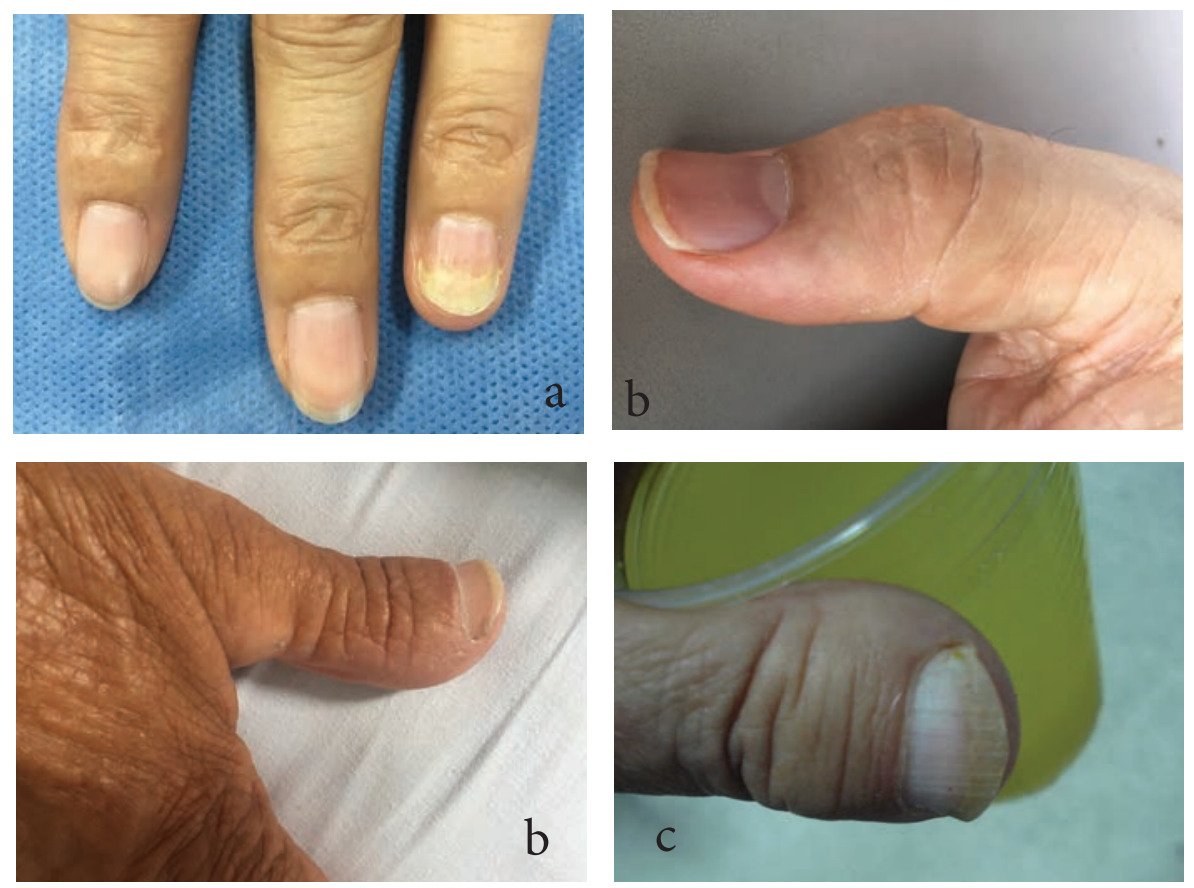

Figura 2.32. Alteraciones ungulares en enfermedad tiroidea, a. Onicólisis. Algunos pacientes hipotiroideos pueden tener diferentes alteraciones en las uñas: onicólisis, es decir, una separación de la lámina del lecho ungular; b. Coiloniquia que va desde uñas aplanadas hasta las que toman el aspecto de una cuchara con una superficie cóncava de la lámina ungular, también llamadas 'uñas de Plummer'. c. Acropaquia. Se refiere a un ensanchamiento digital, con engrosamiento de los dedos de las manos y de los pies, y proliferación subperióstica que afecta, principalmente, las falanges distales de los dedos de los pies y de las manos, y que puede hacer ver una uña más corta; se describe en el hipertiroidismo.

Los pacientes tienen, en ocasiones, una hiperpigmentación difusa que obedece a la mayor liberación de la hormona adrenocorticotrófica para compensar la mayor degradación de cortisol. Se ha reportado que existe una fuerte asociación entre el melasma y la disfunción tiroidea (62). También es frecuente encontrar el vitiligo asociado a una enfermedad tiroidea autoinmunitaria y puede ser la primera manifestación del hipertiroidimo y del hipotiroidismo. 

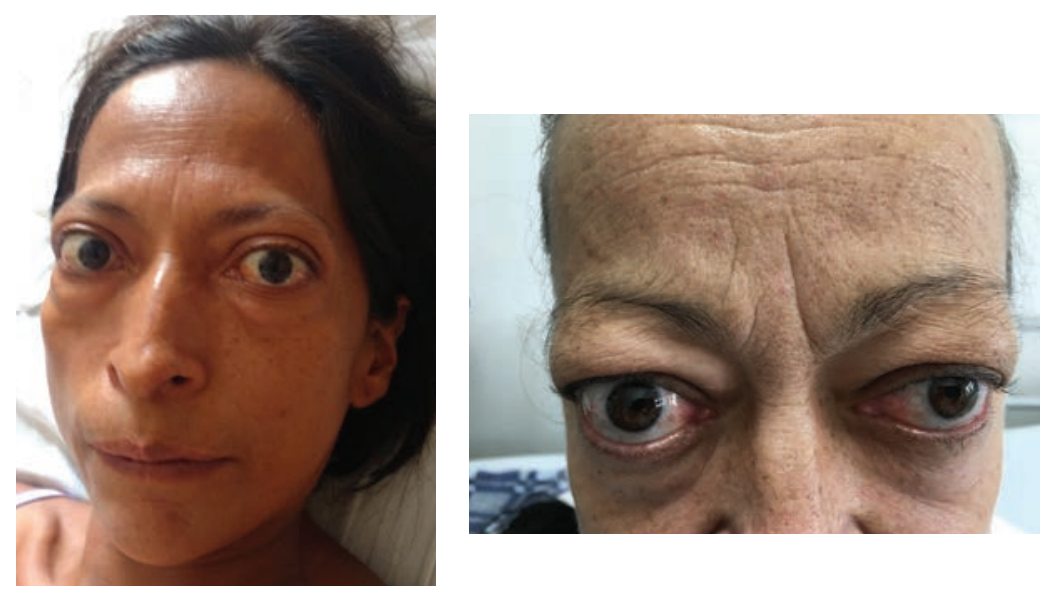

Figura 2.33. Exoftalmia por oftalmopatía infiltrativa. Se ha encontrado que los pacientes hipertiroideos pueden presentar un aumento de los tejidos blandos del ojo con exoftalmia, una oftalmopatía infiltrativa por estimulación prolongada de la hormona tiroidea.

Los pacientes hipertiroideos pueden presentar prurito generalizado, dermografismo o aun tener una urticaria. Está descrito que en la enfermedad autoinmunitaria de la tiroides se presenta una urticaria crónica (figura 2.34) (72, 73). También se ha descrito enfermedad tiroidea autoinmunitaria asociada a la queratodermia palmoplantar (74) y a la acropustulosis palmo-plantar (figura 2.35).

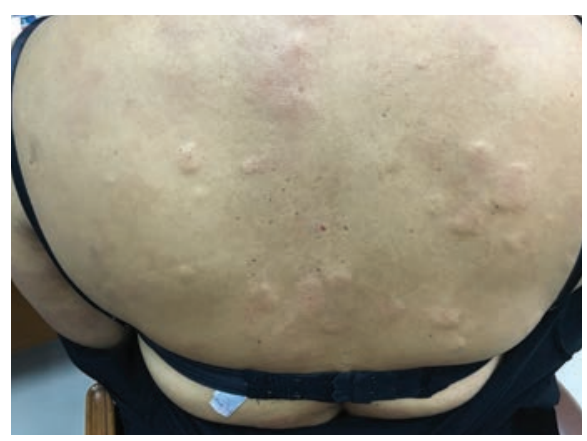

Figura 2.34. Urticaria crónica. La urticaria se caracteriza por la aparición de lesiones de tipo pápulas edematosas y pruriginosas en cualquier parte del tegumento cutáneo. Cuando las lesiones, que suelen durar minutos a horas, aparecen diariamente por un tiempo mayor a seis u ocho semanas, se habla de urticaria crónica. Se presenta con frecuencia en la enfermedad autoinmunitaria de la tiroides. 

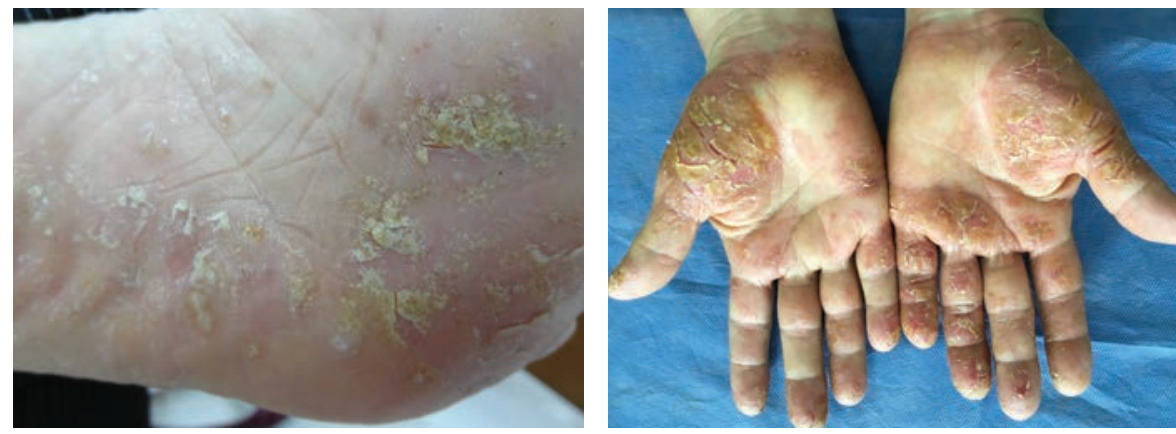

Figura 2.35. Queratodermia y acropustulosis palmo-plantar. Los pacientes hipotiroideos pueden presentar una queratodermia plantar superficial, semejante a la que se presenta en algunos pacientes diabéticos. Otras lesiones que también se pueden presentar son las queratodermias más gruesas o lesiones acropustulosas semejantes a las observadas en las palmas y en las plantas de los pacientes con psoriasis, o puede tratarse de una psoriasis que los acompaña, tanto a los pacientes diabéticos como a los hipotiroideos.

\section{Otros trastornos cutáneos asociados a alteraciones de la glándula tiroides}

Las enfermedades de la glándula tiroides se asocian a la alopecia areata en el $8 \%$ de los casos (68), a algunas enfermedades ampollosas, como el pénfigo vulgar, el penfigoide ampolloso o la dermatitis herpetiforme -llamada también enfermedad de Duhring- Brocq-, siendo esta última la más frecuente, ya que un tercio de los pacientes que la presentan tienen alteración de la función tiroidea (75). La dermatitis herpetiforme se puede asociar, a su vez, a otras endocrinopatías o a enfermedades autoinmunitariass, como la anemia autoinmunitaria, el lupus eritematoso sistémico o el síndrome de Sjögren. A todo paciente con alteraciones de la tiroides, se le debe buscar de manera temprana la enfermedad endocrina o autoinmunitaria asociada que, con frecuencia, se presenta en los pacientes que tienen anticuerpos positivos antitiroideos, antitiroglobulinas o antiperoxidasas.

Las alteraciones de los lípidos también se pueden observar en los pacientes con hipotiroidismo. Su aumento se manifiesta con lesiones de tipo xantoma, que son la principal manifestación cutánea de las dislipidemias, principalmente de la hipercolesterolemia. Son acumulaciones de lípidos contenidos en histiocitos espumosos que se localizan en la dermis o en los tendones y, en general, se presentan como pápulas firmes, lisas y amarillentas.

Se ha descrito enfermedad de Graves asociada a la dermatitis atópica, acantosis nigricans y síndrome de Sweet, hipertiroidismo asociado a la psoriasis, granuloma anular generalizado en pacientes con tiroiditis autoinmunitaria, y mixedema y tirotoxicosis asociados al pseudoxantoma elástico (68). 
Es importante recordar que el vitiligo es un trastorno de la pigmentación, con aparición de máculas blancas o acrómicas, que conlleva una pérdida de la función de los melanocitos y se asocia a la enfermedad tiroidea en la forma simétrica o no segmentaria, que corresponde del 85 al $90 \%$ del total del vitiligo. Puede empezar en la infancia, aunque es más frecuente de manera más tardía, suele ser progresivo y puede comprometer el pelo; en este caso, se habla de poliosis.

El vitiligo está asociado a una historia personal o familiar de autoinmunidad y suele aparecer en los sitios de presión, fricción o trauma. Se debe recordar que es el más común de los trastornos hipopigmentarios, con una prevalencia de 0,5 a $2 \%$ de la población mundial. Se inicia a cualquier edad, con picos entre los 10 y los 30 años. La mitad de los pacientes tiene lesiones antes de los 20 años y son usualmente progresivas.

En la histopatología se encuentra una pérdida de los melanocitos epidérmicos. En el 80\% de los pacientes se encuentran anticuerpos antimelanocitos, anticuerpos antitiroideos (antiperoxidasa, antimicrosómicos) o ambos. El vitiligo generalizado y simétrico se asocia con enfermedades autoinmuntarias; aproximadamente, el $30 \%$ de los pacientes las desarrollan, entre ellas las más frecuentes son la diabetes mellitus, la gastritis atrófica, la linfopenia de linfocitos T CD4, la espondiloartritis anquilosante, las tiroiditis, la colitis ulcerativa y la artritis reumatoidea.

Se encuentra como antecedentes una historia familiar o personal de enfermedades tiroideas en la tiroiditis de Hashimoto y en la enfermedad de Graves, en la diabetes mellitus de tipo 1, el síndrome poliendocrino autoinmunitario, la alopecia areata, la enfermedad de Addison, la artritis reumatoidea, el lupus eritematoso sistémico, la psoriasis, la miastenia gravis, la anemia perniciosa y la morfea o esclerosis en placas. Se sabe que los familiares de primer grado de los pacientes con vitiligo, presentan un riesgo aumentado de enfermedad autoinmunitaria, incluido el vitiligo.

La medición de la TSH y de los anticuerpos antitiroideos (antitiroglobulina o antimicrosómicos) son de gran ayuda para detectar una enfermedad tiroidea autoimmunitaria. Los títulos de los anticuerpos antiperoxidasa pueden estar muy elevados en la tiroiditis de Hashimoto.

\section{Enfermedades de las glándulas suprarrenales}

Para entender el funcionamiento de cualquier glándula, es muy importante recordar que las glándulas están regidas por el eje hipotálamo-hipófisis o glándula pituitaria, y los efectos que sus productos de secreción tienen sobre ellas. 
La glándulas tiroides, las suprarrenales, los ovarios, los testículos y la glándula mamaria están íntimamente relacionadas y su función depende de un mecanismo de retroalimentación. Se debe partir del hecho de que los péptidos hipotalámicos estimulan la pituitaria anterior o adenohipófisis para que exista una adecuada producción de hormona del crecimiento $(\mathrm{GH})$, hormona estimuladora de la tiroides (TSH), hormona adrenocorticotrópica (ACTH) y prolactina, que actúan sobre los diferentes tejidos: hígado, piel, fibroblastos, tiroides, glándulas suprarrenales y mamas, estimulándolos. También se produce dopamina en la glándula hipófisis, que tiene un efecto inhibitorio sobre la secreción de la prolactina.

Si bien es la hipófisis la encargada de estas secreciones por un mecanismo de retroalimentación, la alteración de la liberación de un exceso de sus secreciones produce efectos en los órganos blanco mencionados y este aumento exagerado de alguna de dichas sustancias produce un efecto en la piel. Por ejemplo, si existe una exagerada producción de la hormona del crecimiento por parte de la hipófisis, comúnmente asociada a un adenoma de la pituitaria, se puede encontrar una acromegalia, en la cual todos los órganos crecen de manera exagerada, incluida la piel.

Si el aumento en la producción es de la hormona adrenocorticotrópica (ACTH), esta influye sobre las glándulas suprarrenales, con un aumento de la producción de los corticosteroides andrógenos y mineralocorticoides, que se producen en la corteza de las glándulas suprarrenales y con la aparición de lesiones como estrías, acné o vello en zonas consideradas masculinas o hirsutismo, debido a los efectos de esta hiperproducción.

Las glándulas suprarrenales están localizadas en el polo superior de los riñones y se componen de una corteza de origen mesodérmico y de una parte central llamada médula suprarrenal, de origen ectodérmico, que secretan diferentes productos: en la corteza, se sintetizan mineralocorticoides, glucocorticoides y andrógenos suprarrenales; en la médula, se producen las catecolaminas como la adrenalina y la noradrenalina. A continuación se revisan las alteraciones que aparecen en la piel cuando existe un funcionamiento exagerado de la corteza de la glándula suprarrenal, el llamado síndrome de Cushing, y cuando existe una insuficiencia funcional de la misma o enfermedad de Addison.

Al final, se describe cómo la exagerada producción de andrógenos produce alteraciones en la piel semejantes a la hiperfunción suprarrenal, aunque este aumento de andrógenos puede provenir de la alteración en órganos diferentes, bien sea los ovarios o la hipófisis y es importante tenerlos en cuenta para el diagnóstico diferencial. 


\section{Síndrome de Cushing}

Se conocen dos tipos de alteraciones que dan como resultado efectos parecidos, la enfermedad de Cushing y el síndrome de Cushing. Se habla de enfermedad deCushing cuando existe un incremento dela síntesis deglucocorticoides, generalmente por hiperplasia suprarrenal secundaria a la producción exagerada de ACTH por parte de un tumor hipofisiario.

Cuando el aumento de la producción de ACTH está dado por un tumor suprarrenal o de otro tipo de tejido, generalmente neoplásico, como sucede en el carcinoma de células pequeñas del pulmón, el carcinoma bronquial o el carcinoma medular de tiroides o, de igual manera, por una carga exógena de glucocorticoides muy alta o por tiempo prolongado, hablamos del síndrome de Cushing (76).

La administración exógena de corticoides es la causa más frecuente de este síndrome, pero cuando se presente sin que exista esta, debe investigarse su origen que puede ser debido a un tumor de la corteza suprarrenal (77), más frecuente en las mujeres, o por una lesión tumoral en la glándula pituitaria, o dependiente de la hiperproducción por parte de otros tumores, como son los de pulmón, bronquio o tiroides, en cuyo caso se presentan con mayor frecuencia en los hombres. El síndrome de Cushing no es frecuente en los niños, aunque se han reportado asociados a neuroblastomas o tumores neuroendocrinos (78).

El efecto del aumento de los glucocorticoides, relacionado con la secreción aumentada de corticotropina hipofisiaria, puede acompañarse de los efectos del aumento de las hormonas estimulantes de la melanogénesis a (MSH- $\alpha$ ) y $\beta$ $(\mathrm{MSH}-\beta)$ que son las directamente responsables del estímulo que da lugar a una pigmentación aumentada de la piel. Estas hormonas se derivan de una prohormona, la propiomelanocortina, responsable de la producción de $\mathrm{ACTH}, \mathrm{MSH}$ y $\beta$ endorfina (79).

Tanto en la enfermedad como en el síndrome de Cushing se encuentra una serie de alteraciones secundarias al aumento exagerado y crónico de los glucocorticoides. Se observa una alteración en la redistribución de la grasa subcutánea, con cambios en el tejido conjuntivo dérmico que da como resultado una obesidad central, es decir, más notoria en el tronco que en las extremidades, las que, por el contrario, se encuentran delgadas; asimismo, existe la aparición de una especie de joroba en el tercio superior de la espalda, que se ha comparado a la joroba de un búfalo (figura 2.36. a). 

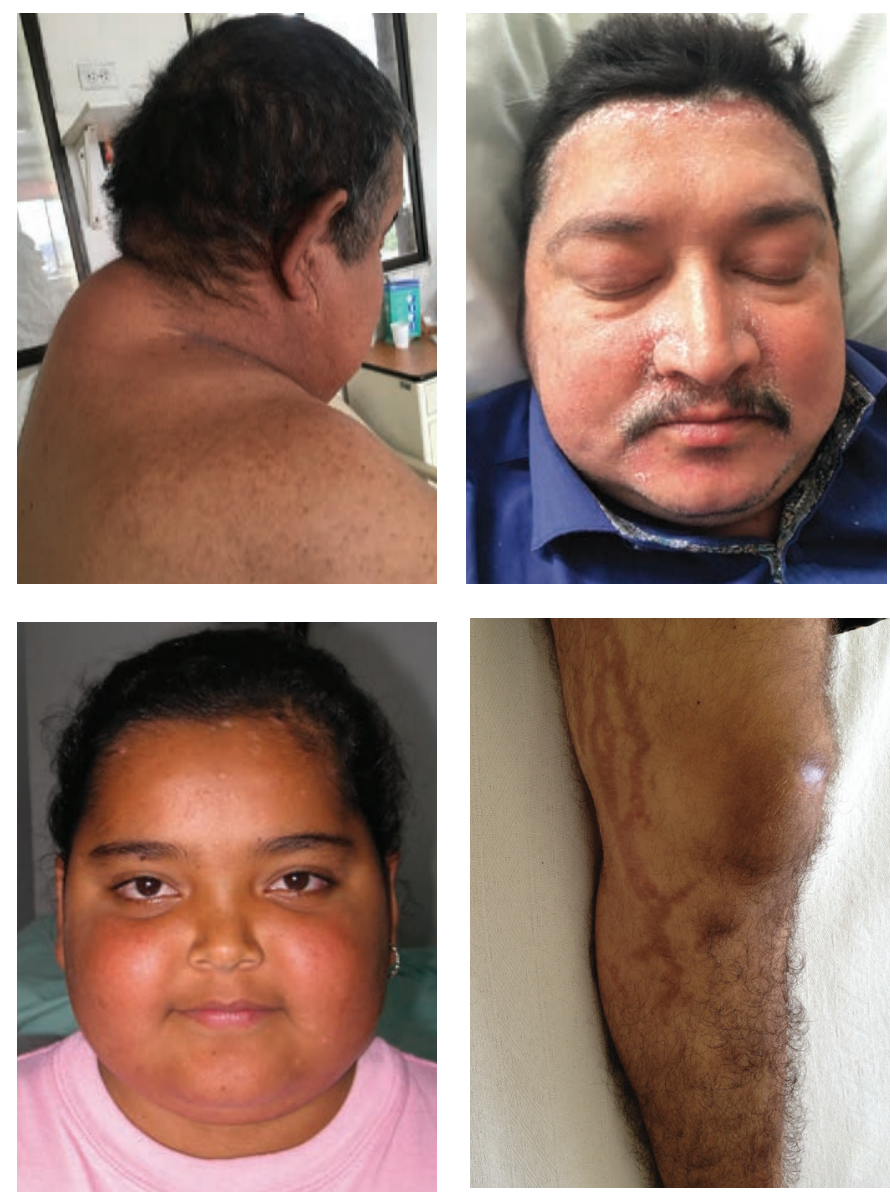

Figura 2.36. Síndrome de Cushing. Estas alteraciones son secundarias al aumento exagerado y crónico de los glucocorticoides. Joroba de búfalo: se observa una alteración en la redistribución de la grasa subcutánea, con cambios en el tejido conjuntivo dérmico que da como resultado una obesidad central, es decir, más notoria en el tronco que en las extremidades, las que, por el contrario, se encuentran delgadas; existe la aparición de una especie de joroba en el tercio superior de la espalda, que se ha comparado a la de un búfalo. Facies de luna llena: en el rostro, los depósitos grasos en las mejillas le dan un aspecto de facies de luna llena. Estrías purpúricas: aparecen, además, estrías purpúricas y zonas atróficas secundarias a las alteraciones en la división celular de la epidermis y en la síntesis de mucopolisacáridos y colágeno.

El rostro tiene depósitos grasos en las mejillas y da un aspecto de facies de luna llena (figura 2.36. b). Aparecen estrías purpúricas (figura 2.36. c) y zonas atróficas secundarias a las alteraciones en la división celular de la epidermis y en la síntesis de mucopolisacáridos y colágeno. La piel delgada y con aumento de la fragilidad vascular puede dar lugar a equimosis. Se puede ver la piel ligeramente 
hiperpigmentada con hipertricosis y, ocasionalmente, con un aumento del vello en zonas característicamente masculinas que se llama hirsutismo; puede haber también un ligero aumento de las lesiones de acné.

Del total de los pacientes que presentan un síndrome de Cushing, del 5 al 10 $\%$ están asociados a una neoplasia, y del 50 al $60 \%$ de ellos a tumores pulmonares neuroendocrinos (80). En estos pacientes no se presenta la alteración en la redistribución de la grasa, lo que ayuda para el diagnóstico diferencial.

\section{Enfermedad de Addison}

La deficiencia de la producción de ACTH y, a su vez, de la producción de hormonas adrenocorticales es indistinguible de la insuficiencia adrenocortical primaria, o enfermedad de Addison, y puede ser causada por una alteración autoinmunitaria que lesiona la glándula suprarrenal o ser secundaria a una infiltración inflamatoria e infecciosa ya sea por Mycobacterium tuberculosis o por otros microorganismos como Paraccocidiodes braziliensis o Histoplasma capsulatum. También podría ser desencadenada por una hemorragia o por una neoplasia que altere el tejido glandular.

$\mathrm{Al}$ presentarse este proceso, la hipófisis aumenta la producción de ACTH y de $\mathrm{MSH}$, tratando de compensar esta alteración en la producción de corticoides, dando lugar a una hiperpigmentación de la piel. Los síntomas generales, que aparecen inicialmente, están dados por la disminución de la producción de corticosteroides, e incluyen debilidad, náuseas y eventual colapso circulatorio. El cambio más notorio es la pigmentación oscura de la piel que es más evidente en las zonas expuestas al sol, en los pliegues, en los dedos y en las uñas (melanoniquia) y en la mucosa oral (81), ya sea malar (jugal), en las encías o en la lengua (figura 2.37). 

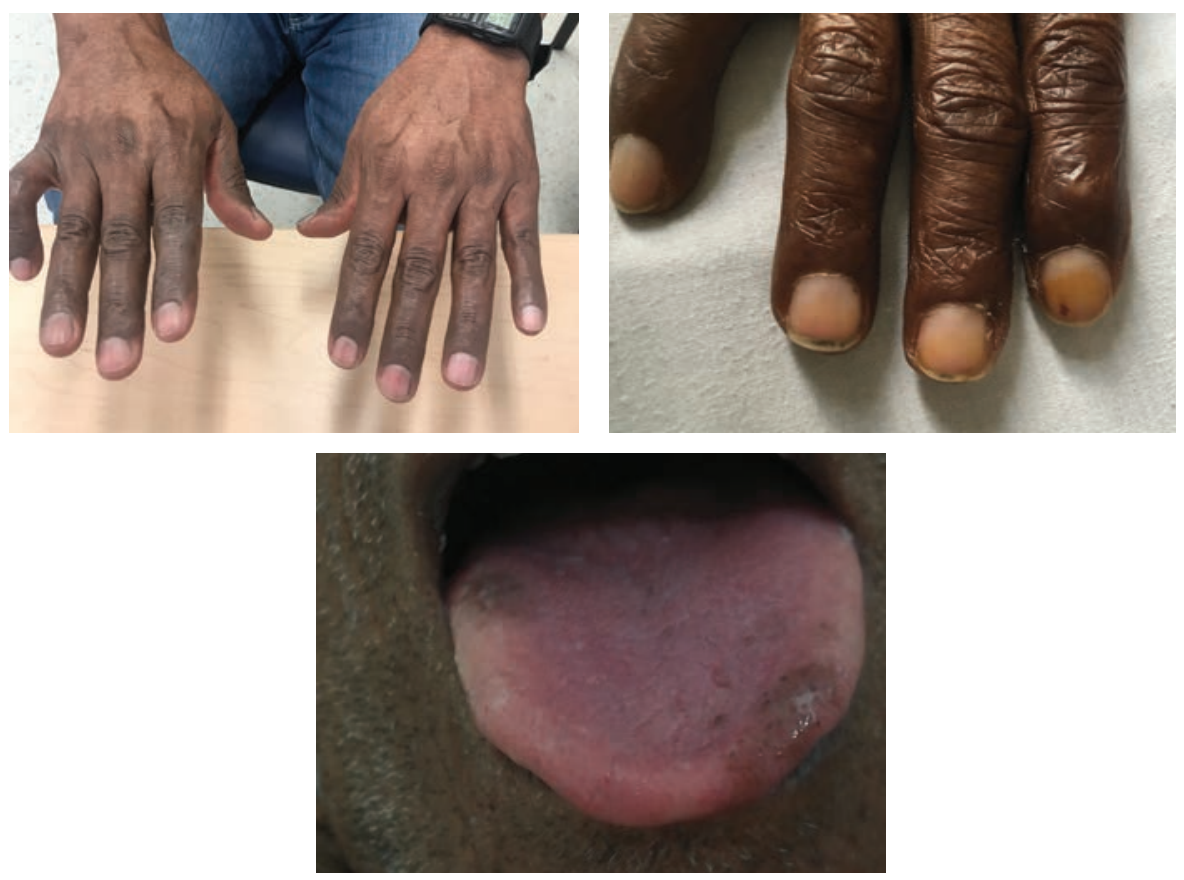

Figura 2.37. Hiperpigmentación en la enfermedad de Addison. Se produce una hiperpigmentación difusa que obedece a la mayor liberación de hormona adrenocorticotrófica para compensar la mayor degradación de cortisol. La pigmentación oscura de la piel de estos pacientes es más evidente en las zonas expuestas al sol, en los pliegues, en los dedos, (Cortesia Dr. Santiago Vallejo) en las uñas (melanoniquia) y en la mucosa oral, ya sea malar (jugal), en las encías o en la lengua.

\section{Hiperandrogenismo}

Es importante tener en cuenta que cuando se valora un paciente de sexo femenino con seborrea, acné, hirsutismo y alopecia androgénica, se puede estar ante una entidad patológica en la que se encuentra una elevación de los andrógenos, es decir, un hiperandrogenismo. Estas pacientes pueden tener, además, amenorrea, síndrome metabólico y obesidad.

Puede tratarse de un síndrome de ovario poliquístico u otra alteración con hiperandrogenismo que acompañe, a su vez, otra endocrinopatía, ya que como se vio anteriormente las alteraciones endocrinológicas no siempre se presentan por separado (2). En 1994, los expertos en enfermedades endocrinas, como nos refiere Zouboulis, et al. (82), clasificaron estos hallazgos cutáneos en cuatro grupos, según la etiología: 1) idiopático, 2) ovárico, 3) suprarrrenal y 4) seborrea, acné, hirsutismo y alopecia, por hiperprolactinemia y luego agregaron un quinto, el síndrome de HAIRAN (síndrome hiperandrogénico con resistencia a la insulina y aparición de acantosis nigricans). 
En el capítulo inicial, se discutió que en la piel existen receptores para los andrógenos a nivel del folículo pilosebáceo y que la actividad de la aromatosa 5 alfa-reductasa no es igual en todas las personas; de tal manera que la expresión del aumento del vello corporal puede variar y, en ocasiones, es difícil en un momento dado distinguir entre una hipertricosis fisiológica y la debida a una alteración hormonal, pero si se presenta, además, un hirsutismo, este nos ayudar a hacer la diferencia.

El $80 \%$ de los pacientes tienen microadenomas cromófobos en la pituitaria -también los hay basófilos- con producción aumentada de ACTH que lo lleva a una hiperplasia cortical suprarrenal. Esta alteración es más común en las mujeres que en los hombres, en una proporción de 5 a 1 (79).

En todos los casos, se deben solicitar exámenes para confirmar cuál es la causa desencadenante del hiperandrogenismo. Se puede tratar de un síndrome de ovario poliquístico, trastorno endocrino que se presenta en la mujer con amenorrea, hirsutismo, obesidad, resistencia a la insulina y acné. Estas pacientes tienen, además un riesgo siete veces mayor de desarrollar diabetes mellitus de tipo II. También puede ser que el hiperandrogenismo sea secundario a una alteración funcional de una o más enzimas involucradas en la esteroidogénesis suprarrenal, por un aumento de la prolactina o por la presencia de un tumor suprrarenal o hipofisiario como se mencionó anteriormente.

Existen variaciones genéticas que determinan estas alteraciones, por ejemplo, el polimorfismo del gen PPAR (Peroxisoma Proliferator-Activated Receptor) asociado a la regulación del metabolismo lipídico $\gamma$ a la hipertensión. Se encontró asociado con el incremento de la sensibilidad a la insulina en las mujeres con poco hirsutismo en el síndrome de ovario poliquístico, pero no es fácil investigarlas. Así que en caso de hirsutismo se deben ordenar algunos exámenes que permitan aclarar el origen de la alteración. Si el aumento es de ACTH, se pueden encontrar niveles elevados de cortisol plasmático (8 a.m./4 p.m.); si la alteración depende de la glándula suprarrenal, se encuentra elevado el sulfato de dehidroepiandrosterona; si es a causa de una alteración ovárica, se puede encontrar elevada la producción de testosterona total y libre. También, se puede encontrar un aumento de los 17 cetosteroides en la orina de 24 horas, sin poder precisar su origen. Puede ser necesaria una radiografía de silla turca, una prueba de FSH y LH, o una ecografía transvaginal para descartar la presencia de tumores o de un síndrome de ovario poliquístico.

El exceso de andrógenos es un trastorno que se presenta en el $7 \%$ de las mujeres en edad fértil; en la mujer se manifiesta con alopecia androgénica, hirsutismo (figura 2.38) e irregularidades menstruales o con alteraciones de la función ovárica y puede acompañar a un síndrome metabólico, por lo que también 
se debe estudiar una posible resistencia a la insulina. Si bien el síndrome de ovario poliquístico es la causa más común de este hiperandrogenismo, debe estudiarse una posible hiperplasia suprarrenal congénita debida a la deficiencia de 21 hidroxilasa o de $11 \beta$ hidroxilasa.

Se debe recordar que la resistencia a la insulina aparece de base para la diabetes mellitus de tipo II para la gota, la hiperplasia suprarrenal no clásica, el hígado graso y el síndrome de ovario poliquístico. Por otra parte, se pueden encontrar niveles elevados de TSH y de cortisol y pueden estar relacionados con una hiperplasia suprarrenal.

En resumen, en el estudio de un paciente con sospecha de hiperandrogenismo, se debe solicitar: TSH, anticuerpos antiperoxidasa y antitiroglobulina, sulfato de dehidroepiandrosterona, androstenediona, $17 \mathrm{OH}$ progesterona, $17 \mathrm{OH}$ pregnenolona, FSH, LH, 11 deoxicortisol, deoxicorticosterona, hemoglobina 'glicosilada', testosterona libre y total. Y, por último, los 17 cetosteroides en orina de 24 horas nos brindan una idea general de la posible existencia de un aumento de los andrógenos.
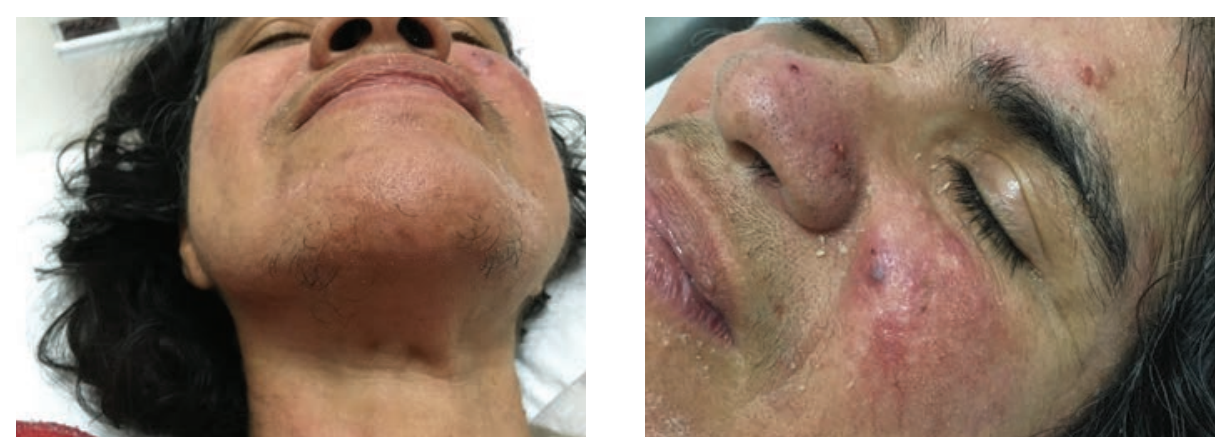

Figura 2.38. Hirsutismo, acné en hiperandrogenismo. El exceso de andrógenos es un trastorno que se presenta en el $7 \%$ de las mujeres en edad fértil. En la mujer, se manifiesta con alopecia androgénica, hirsutismo, acné e irregularidades menstruales.

\section{Referencias}

1. Betterle C, Dal Pra C, Mantero F, Zanchetta R. Autoimmune adrenal insufficiency and autoimmune polyendocrine syndromes: autoantibodies, autoantigens, and their applicability in diagnosis and disease prediction. Endocr Rev. 2002;23:327-64.

2. Molina-Garrido MJ, Guillén-Ponce C, Guirado-Risueño M, Mora A, Carrato A. Pluriglandular autoinmune syndrome. Revisión. Anales de Medicina Interna. 2007;24:445-52. 
3. Pavlovic MD, Milenkovic T, Dinic M, Mišović M, Daković D, Todorović S, et al. The prevalence of cutaneous manifestations in young patients with type 1 diabetes. Diabetes Care. 2007;30:19647.

4. Pérez M, Steven K. Cutaneous manifestations of diabetes mellitus. J Am Acad Dermatol. 1994;30:519-34. Pérez MI, Kohn SR. Cutaneous manifestations of diabetes mellitus. J Am Acad Dermatol. 1994;30: 519-31.

5. King H, Aubert RE, Herman WH. Global burden of diabetes: 1995-2025: prevalence, numerical estimates and projections. Diabetes Care. 1998;21:1414-31.

6. Rathmann W, Giani G. Global prevalence of diabetes: Estimates for the year 2000 and projections for 2030. Diabetes Care. 2004;27:2568-9.

7. Gómez-Arbeláez D, Alvarado-Jurado L, Ayala-Castillo M, Forero-Naranjo L, Camacho PA, López-Jaramillo P. Evaluation of the Finnish Diabetes Risk Score to predict type 2 diabetes mellitus in a Colombian population. A longitudinal observational study. World J Diabetes. 2015;6:1337-44.

8. Aschner P, Muñoz O, Giron D, García O, Fernández-Ávila D, L Casas, et al. Clinical practice guideline for the prevention, early detection, diagnosis, management and follow-up of type 2 diabetes mellitus in adults. Colomb Med (Cali). 2016;47:109-30.

9. Rosas-Saucedo J, Enrique CA, Brito-Córdova G, García-Bruce H, Costa-Gil J, Lyra R, RosasGuzmán J. Consenso de Prediabetes. Documento de Posición de la Asociación Latinoamericana de Diabetes (ALAD). Rev ALAD. 2017;7:184-202.

10. López-Jaramillo P, Calderón C, Castillo J, Escobar ID, Melgarejo E, Parra GA. Prediabetes in Colombia: Expert Consensus.Colomb Med (Cali). 2017;48:191-203.

11. International Diabetes Federation. Diabetes Atlas. 7th edition. Brussels (Belgium): International Diabetes Federation; 2017.

12. Padhi T, Garima Metabolic syndrome and skin: Psoriasis and beyond. Indian J Dermatol. 2013;58:299-305.

13. Simmons RK, Coleman RL, Price HC, Holman RR, Khaw KT, Wareham NJ, Griffin SJ. Performance of the UK Prospective Diabetes Study Risk Engine and the Framingham Risk Equations in estimating cardiovascular disease in the EPIC- Norfolk Cohort. Diabetes Care. 2009;32:708-13.

14. Duff M, Demidova O, Blackburn S, Shubrook J. Cutaneous manifestations of diabetes mellitus. Clin Diabetes. 2015;33:40-8.

15. Mahajan S, Koranne RV, Sharma SK. Cutaneous manifestation of diabetes mellitus. Indian J Dermatol Venereol Leprol. 2003;69:105-8.

16. Ragunatha S, Anitha B, Inamadar AC, Palit A, Devarmani SS. Cutaneous disorders in 500 diabetic patients attending diabetic clinic. Indian J Dermatol. 2011;56:160-4.

17. Abraham Z, Lahat N, Kinarty A, Feuerman EJ. Psoriasis, necrobiosis lipoidica, granuloma annulare, vitiligo and skin infections in the same diabetic patient. J Dermatol. 1990;17:440-7.

18. Morgan AJ, Schwartz RA. Diabetic dermopathy: A subtle sign with grave implications. J Am Acad Dermatol. 2008;58:447-51.

19. Van Hattem S, Bootsma AH. Skin manifestations of diabetes. Cleve Clin J Med. 2008;75:772-87.

20. Müller SA, Winkelmann RK. Necrobiosis lipoidica diabeticorum: A clinical and pathological investigation of 171 cases. Arch Dermatol. 1966;93:272-81. 
21. O’Toole EA, Kennedy U, Nolan J, Young M, Rogers S, Barnes L. Necrobiosis lipoidica: Only a minority of patients have diabetes mellitus. Br J Dermatol. 1999;140:283-6.

22. Verrotti A, Chiarelli F, Amerio P, Morgese G.Necrobiosis lipoidica diabeticorum in children and adolescents: A clue for underlying renal and retinal disease. Pediatr Dermatol. 1995;12:220-3.

23. Dicken $\mathrm{CH}$, Carrington SG, Winkelmann RK. Generalized granuloma annulare. Arch Dermatol. 1969;99:556-63.

24. Hawryluk EB, Izikson L, English JC.Non-infectious granulomatous diseases of the skin and their associated systemic diseases: An evidence-based update to important clinical questions. Am J Clin Dermatol. 2010;11:171-81.

25. Dabski K, Winkelmann RK. Generalized granuloma annulare: Clinical and laboratory findings in 100 patients. J Am Acad Dermatol. 1989;20:39-47.

26. Davison JE, Davies A, Moss C, Kirk JM, Taibjee SM, Agwu JC. Links between granuloma annulare, necrobiosis lipoidica diabeticorum and childhood diabetes: A matter of time? Pediatr Dermatol. 2010;27:178-81.

27. Dandona P, Freedman D, Barter S, Majewski BB, Rhodes EL, Watson B. Glycosylated haemoglobin in patients with necrobiosis lipoidica and granuloma annulare. Clin Exp Dermatol. 1981;6:299-302.

28. Phiske MM. An approach to acanthosis nigricans. Indian Dermatol Online J. 2014;5:239-49.

29. Pollitzer S. Acanthosis nigricans. In: Unna PG, Morris M, Besnier E, editors. International atlas of rare skin disease. London: HK Lewis \& Company; 1890. p. 1-3.

30. Herrera-Ceballos E, Bosh R, Pérez-Villa L. Acantosis nigricans. En: Herrera- Ceballos E, Moreno-Carazao A, Caballero-Requena L, Rodríguez-Peralto J, editores. Dermatología: correlación clínico-patológica. Guadalajara: Universidad de Guadalajara; 2007. p. 23-5.

31. Goswami R, Dadhwal V, Tejaswi S, Datta K, Paul A, Haricharan RN, Banerjee U, Kochupillai NP. Species-specific prevalence of vaginal candidiasis among patients with diabetes mellitus and its relation to their glycaemic status. J Infect. 2000;41:162-6.

32. Bartholomew GA, Rodu B, Bell DS. Oral candidiasis in patients with diabetes mellitus: A thorough analysis. Diabetes Care. 1987;10:607-12.

33. Pallavan B, Ramesh V, Dhanasekaran BP, Nirima Oza N, Sudip Indu, Govindarajan V. Comparison and correlation of candidal colonization in diabetic patients and normal individuals. J Diabetes Metab Disord. 2014;13:66.

34. Huntley AC. The cutaneous manifestations of diabetes mellitus. J Am Acad Dermatol. 1982;7:427-55.

35. Parra-Caballero P, Pérez-Esteban S, Patiño-Ruiz M, Santos-Castañeda S, García- Vadillo J. Actualización en fasciítis necrotizante. Semin Fund Esp Reumatol. 2012;13:41-8.

36. Barkas F, Elisaf M, Liberopoulos E, Liontos A, Rizos EC. High triglyceride levels alter the correlation of apolipoprotein B with low- and non-high-density lipoprotein cholesterol mostly in individuals with diabetes or metabolic syndrome. Atherosclerosis. 2016;247:58-63.

37. Kaur J. A comprehensive review on metabolic syndrome. Cardiol Res Pract. 2014;2014:e943162.

38. Maharshak N, Shapiro J, Trau H. Carotenoderma--A review of the current literature. Int J Dermatol. 2003;42:178-81.

39. Cole GW, Headley J, Skowsky R. Scleredema diabeticorum: A common and distinct cutaneous manifestation of diabetes mellitus. Diabetes Care. 1983;6:189-92. 
40. Meguerditchian C, Jacquet P, Béliard S, Benderitter T, Valéro R, Carsuzza F, et al. Scleredema adultorum of Buschke: An under recognized skin complication of diabetes. Diabetes Metab. 2006;32:481-4.

41. Alves J, Judas T, Ferreira T, Matos D, Bártolo E. Scleredema associated with Sjögren’s syndrome. An Bras Dermatol. 2015;90(Suppl.1):81-3.

42. Batra P, Singhal R, Shah D. Diabetic lipemia presenting as eruptive xanthomas in a child with autoimmune polyglandular syndrome type IIIa. J Pediatr Endocrinol Metab. 2014;27:569-71.

43. Rapini RP, Herbert AA, Drucker CR. Acquired perforating dermatosis. Evidence for combined transepidermal elimination of both collagen and elastic fibers. Arch Dermatol. 1989;125:10748.

44. Robles-Méndez JC, Vázquez-Martínez O, Ocampo-Candiani J. Skin manifestations of chronic kidney disease. Actas Dermosifiliogr. 2015;106:609-22.

45. Harris EL. Adverse reactions to oral antidiabetic agents. Br Med J. 1971;3:29-30.

46. Cheng YY, Fantus IG. Oral antihyperglycemic therapy for type 2 diabetes mellitus. CMAJ. 2005;172:213-26.

47. Lundström IM. Incidence of diabetes mellitus in patients with oral lichen planus. Int J Oral Surg. 1983;12:147-52.

48. Negrato CA, Tarzia O. Buccal alterations in diabetes mellitus. Diabetol Metab Syndr. 2010;2:2-3.

49. Albrecht M, Bánóczy J, Dinya E, Tamás G., Jr. Occurrence of oral leukoplakia and lichen planus in diabetes mellitus. J Oral Pathol Med. 1992;21:364-6.

50. Ahmed I, Nasreen S, Jehangir U, Wahid Z. Frequency of oral lichen planus in patients with noninsulin dependent diabetes mellitus. J Pak Assoc Derm. 2012;22:30-4.

51. Ghosh K, Das K, Ghosh S, Chakraborty S, Jatua SK, Bhattacharya A, Ghosh M. Prevalence of skin changes in diabetes mellitus and its correlation with internal diseases: A single center observational study. Indian J Dermatol. 2015;60:465-9.

52. Oyibo SO, Jude EB, Tarawneh I, Nguyen HC, Harkless LB, Boulton AJ. A comparison of two diabetic foot ulcer classification systems: The Wagner and the University of Texas wound classification systems. Diabetes Care. 2001;24:84-8.

53. Fajre X, Pérez L, Pardo J, Dreyse J, Herane MI. Manifestaciones cutáneas de diabetes mellitus. Rev Méd Chile. 2009;137:894-9.

54. Hernández IM, Marrero Y. Cutaneous manifestations of common endocrine disease. In: Sánchez NP, editor. Atlas of Dermatology in Internal Medicine. Springer; 2012. p. 53-8.

55. Slominsky A, Wortsman J. Neuroendocrinology of the skin. Endocr Rev. 2000;21:457-87.

56. Grando S. Physiology of endocrine skin interrelations. JAAD. 1993;28:981-2.

57. Cuéllar IC. Sistema neuro-inmuno-endocrino-cutáneo: tiroides y piel. Universitas Medica 2003;44:199-204.

58. Rastogi MV, LaFranchi SH. Congenital hypothyroidism. Orphanet J Rare Dis. 2010;10;5:17.

59. Sinha R, Yen PM. Cellular action of thyroid hormone. En: De Groot LJ, Chrousos G, Dungan K, et al., editors. Endotext [Internet]. South Dartmouth: MDText.com, Inc.; 2018. Disponible en: https://www.ncbi.nlm.nih.gov/books/NBK285568/

60. Führer D, Brix K, Biebermann H. Understanding the healthy thyroid state in 2015. Eur Thyroid J. 2015;4(Suppl.1):1-8.

61. Rosen T, Kleman GA. Thyroid and skin. En Callen J, editor. Dermatological signs of internal 
disease. Second edition. Filadelfia: WB Saunders; 1995 p. 189-96.

62. Gómez-Zanni MS, Campana R, Papa M, Ragazzini L, Monetti E, Trakál JJ. Manifestaciones cutáneas en pacientes con hipotiroidismo. Dermatol Argent. 2008;14:196-9.

63. Gencer B, Collet TH, Virgini V, Bauer DC, Gussekloo J, Cappola AR, et al. Subclinical thyroid dysfunction and the risk of heart failure events: An individual participant data analysis from 6 prospective cohorts. Circulation. 2012;126:1040-9.

64. Laurberg P, Nøhr SB, Pedersen KM, Hreidarsson AB, Andersen S, Bülow Pedersen I, et al. Thyroid disorders in mild iodine deficiency. Thyroid. 2000;10:951-63.

65. Heymann WR. Potassium iodide and the Wolff-Chaikoff effect: Relevance for the dermatologist. JAAD. 2000;42:490-2.

66. Lutfi RJ, Fridmanis M, Misiunas AL, Pafume O, Gonzalez EA, Villemur JA, et al. Association of melasma with thyroid autoimmunity and other thyroidal abnormalities and their relationship to the origin of the melasma. J Clin Endocrinol Metab. 1985;61:28-31.

67. Ai JD, Leonhardt JM, Heymann WR. Autoimmune thyroid diseases: Etiology, pathogenesis, and dermatologic manifestations. J Am Acad Dermatol. 2003;48:641-62.

68. Heymann WR. Cutaneous manifestations of thyroid disease. J Am Acad Dermatol. 1992;26:885902.

69. Reddy SV, Gupta SK, Jain M. Dermopathy of Graves' disease: Clinico-pathological correlation. Indian J Endocrinol Metab. 2012;16:460-2.

70. Gutch M, Sanjay S, Razi SMo, Gupta KK. Thyroid acropachy: Frequently overlooked finding. Indian J Endocrinol Metab. 2014;18:590-1.

71. Cooper DS. Hyperthyroidism. Lancet. 2003;362:459-68. Cooper DS, Laurberg P. Hyperthyroidism in pregnancy. Lancet Diabetes Endocrinol. 2013;1:238-49.

72. Turktas I, Gokcora N, Demirsoy S, Cakir N, Onal E. The association of chronic urticaria and angioedema with autoimmune thyroiditis. Int J Dermatol. 1997;36:187-90.

73. Saini S, Callen J. Chronic urticaria: Clinical manifestations, diagnosis, pathogenesis, and natural history. UpToDate; 2014. Disponible en: https://www.uptodate.com/contents/chronicurticaria-clinical-manifestations-diagnosis-pathogenesis-and-natural-history.

74. Lestre S, Lozano E, Meireles C, Barata-Feio A. Autoimmune thyroiditis presenting as palmoplantar keratoderma. Case Rep Med. 2010;2010:604890.

75. Kavala M, Kural E, Kocaturk E, Zindanci I, Turkoglu Z, . Can B. tçThe evaluation of thyroid diseases in patients with pemphigus vulgaris. Scientific World Journal. 2012;2012:146897.

76. Stratakis CA. Cushing syndrome caused by adrenocortical tumors and hyperplasias (corticotrophin-independent Cushing syndrome). Endocr Dev. 2008;13:117-32.

77. Lang PG. Adrenal disorders. In: Callen JP, editor. Cutaneous aspects of internal disease. London: Year Book Medical Publishers; 1981. p. 451-62.

78. Normann T, Hanven J, Mjolnerod O. Cushing syndrome in an infant associated with neuroblastoma in two ectopic adrenal glands. J Pediatr Surg. 1971;6:169-75.

79. Davidovici BB, Orion E, Wolf R. Cutaneous manifestations of pituitary gland diseases. Clin Dermatol. 2008;26:288-95.

80. Pelosof LC, Gerber DE. Paraneoplastic syndromes: An approach to diagnosis and treatment. Mayo Clin Proc. 2010;85:838-54.

81. Graves L ${ }^{\text {rd }}$, Klein RM, Walling AD. Addisonian crisis precipitated by thyroxine therapy: A 
complication of type 2 autoimmune polyglandular syndrome. South Med J. 2003;96:824-7.

82. Orfanos CE, Adler YD, Zouboulis CC. The SAHA syndrome. Horm Res. 2000;54:251-8. 


\section{Capítulo 3}

\section{Enfermedades del sistema neurológico}

Se sabe que el sistema cutáneo neuroinmunocrino es uno solo, por tanto, se infiere que el sistema neurológico y la piel están estrechamente vinculados. Iniciando porque tienen un origen común ectodérmico, de tal manera que la embriogénesis es común en cuanto se derivan de la cresta neural, de donde se generan las células pigmentarias, las envolturas de los nervios, las meninges y los ganglios simpáticos.

Es por tal razón que las alteraciones neurológicas suelen asociarse a alteraciones en la piel, especialmente con manifestaciones que comprometen las células pigmentarias. Por tal motivo, y aunque aún no están estudiadas todas las relaciones que pueden encontrarse entre estos dos sistemas, debe tenerse en cuenta una posible alteración neurológica ante algún cambio pigmentario. Sin embargo, para considerarlo se habla de una cantidad mínima de lesiones pigmentarias, según cada alteración.

Los síndromes neurocutáneos y las enfermedades neuroectodérmicas son conocidas porque presentan anormalidades pigmentarias o vasculares, con presencia de tumores cutáneos que acompañan las alteraciones congénitas o la presencia de tumores del sistema nervioso central o periférico. Son más del dominio del especialista que del médico general. Se resumen en el cuadro 3.1, con el fin de conocerlas y poder saber en un determinado caso si se trata de alguna entidad específica en la que se expresan lesiones en los dos sistemas: piel y sistema nervioso.

En estos pacientes se suelen encontrar ciertos defectos en la morfología craneofacial o calcificaciones intracerebrales, presencia de convulsiones, algún grado de déficit cognitivo (retardo mental) o dificultades de aprendizaje, trastornos cardíacos, macrocefalia, neurofibromas o predisposición a tumores del sistema nervioso -meduloblastomas, meningiomas u otros tumores- que acompañan la aparición de diversas lesiones cutáneas: máculas hipopigmentadas, manchas de color café con leche o lesiones de tipo lentigo o efélide. En algunas de ellas las alteraciones de la coloración de la piel pueden asumir un patrón en mosaico, con patrones que seleccionan ciertas áreas del cuerpo, como sucede en la incontinentia pigmenti o en el mosaico pigmentario de tipo hipomelanosis de Ito. 
En los últimos años se han comprendido mejor estas alteraciones neurocutáneas con los estudios de genética celular y molecular de las mismas y el hallazgo de las posibles alteraciones en las vías de señalización intraneuronales y extraneuronales, como RAS, MAPK (Mitogen-Activated Protein Kinases), mTOR (Mechanistic Target of Rapamycin), P13K/AKT y GNAQ (1). En el caso de estas alteraciones neurológicas, debido a que las mutaciones se dan en la línea germinal, estas provocan anomalías en el desarrollo del individuo que son visibles desde el nacimiento.

Dado que las mutaciones se presentan en los genes que codifican proteínas de la vía RAS/MAPK, se conocen como rasopatías (cuadro 3.2). Esta mutación que se presenta en la línea germinal y se produce en los genes RAS que codifican componentes de la vía de señalización dependiente de la cinasa de las proteínas de activación mitógena (MAPK), está presente en enfermedades como la neurofibromatosis de tipo 1 (NF-1), el síndrome de Legius, el síndrome de Noonan y el síndrome de Noonan con lentiginosis múltiple, antiguamente llamado LEOPARD (Lentigenes, Electrocardiographic conduction abnormalities, Ocular hypertelorism, Pulmonary stenosis, Abnormal genitalia, Retarded growth, Deafness) (2). También se podrían explicar aquí, la esclerosis tuberosa, el síndrome de Sturge-Weber, el síndrome de Klippel-Trénaunay, el síndrome de Bean o Blue Rubber Bleb Nevus Syndrome (BRBNS), el síndrome PHACE (Posterior fossa brain malformations, Hemangioma, Arterial lesions (blood vessel abnormalities in the head or neck), Cardiac (heart) abnormalities/aortic coarctation, and Eye abnormalities), la incontinentia pigmenti, la melanosis neurocutánea de tipo Ito, el síndrome de Proteus y otras facomatosis pigmento-vasculares o pigmento-queratóticas, como el síndrome de Costello, el síndrome cardio-facio-cutáneo y el síndrome de malformación capilar-arteriovenosa.

En otras entidades, como el síndrome de Cowden, el síndrome de BannayanRiley- Ruvalcaba, el síndrome del carcinoma basocelular nevoide o síndrome de Gorlin-Gotz, el síndrome del cromosoma Ring 14, el síndrome de deficiencia constitucional de la reparación de errores de apareamiento de MMR y el síndrome de McCune-Albright, se presentan diferentes alteraciones tumorales de tipo hamartoma, que pueden presentarse tanto en la piel como en el sistema neurológico y que, además, se pueden acompañar de tumoraciones en el tubo digestivo (poliposis 'hamartomatosa') con tendencia a convertirse en tumores malignos.

Algunos de estos síndromes presentan expresiones más acentuadas en la piel, con cambios pigmentarios y otros más a nivel neurológico. No todos comparten todas las características y, por esta razón, se agrupan en el cuadro 9.2, en el que se especifican los principales hallazgos; este cuadro se encuentra en el capítulo de los 
síndromes paraneoplásicos ya que el reconocimiento de las lesiones en piel debe inducir una vigilancia para hacer un diagnóstico temprano de las lesiones tumorales.

Por último, no debemos olvidar otra alteración determinada genéticamente que incluye manifestaciones en la piel, los vasos y el sistema nervioso, como es la ataxia-telangiectasia, enfermedad autosómica recesiva con daño neurológico progresivo e inmunodeficiencia caracterizada por un déficit de inmunoglobulinas, alteraciones de los linfocitos $\mathrm{B}, \mathrm{T}, \mathrm{CD} 4 \mathrm{y} \mathrm{CD} 8$, cuyos pacientes presentan una ataxia cerebelosa, disfunción cognitiva y aparición de telangiectasias en la conjuntiva bulbar ocular y, a veces, en la piel. Debido a su alteración inmunitaria presentan una mayor predisposición a las infecciones y pueden presentar linfomas y tumores de las glándulas salivales.

Es de anotar que hemos observado algunos pacientes con alteraciones de la médula espinal debido a discopatías, hernias o secciones traumáticas por accidentes, que pueden presentar lesiones distales de la alteración con aparición de queratodermias y pigmentaciones de melanina, como si un estímulo permanente de los factores de crecimiento epidérmico y pigmentario estuviese intentando reparar el daño y se hiciera visible en la piel de las palmas o de las plantas, dependiendo del lugar de afectación de la médula espinal.

Por esta razón es que en el estudio de las queratodermias -lo mismo que en el de las pigmentaciones mélanicas palmo-plantares que se ven frecuentemente asociadas a las neoplasias- se debe considerar la posibilidad de una compresión o de una sección medular -que puede ser evidente-como una causa posible de ellas.

A continuación, mencionaremos algunas de estas enfermedades congénitas o síndromes genéticamente determinados, en los cuales el hecho de encontrar un compromiso simultáneo del sistema nervioso central y de la piel nos permite identificar rápidamente el síndrome, ya que se buscará la alteración neurológica al visualizar las lesiones de la piel.

\section{Síndromes neurocutáneos}

Se pueden encontrar varios procesos que presentan vasculitis y que afectan tanto al sistema nervioso como a la piel, pero que se presentan con menor frecuencia; solo mencionaremos dos de ellos como característicos y más frecuentes, el síndrome de Behçet y el síndrome de Vogt-Koyanagi-Harada. 
El síndrome de Behçet es una enfermedad crónica sistémica con vasculitis, con una prevalencia entre 20 a 421 individuos por cada 100.000 habitantes, más frecuente en los países del Mediterráneo, asociada al complejo mayor de histocompatibilidad HLA-B51 (3) y al HLA-B51/B5 y que se presenta con períodos de remisión seguidos por exacerbaciones.

Se caracteriza por la aparición de ulceraciones orales y genitales e inflamación ocular (uveítis, células en el humor vítreo y vasculitis en la retina). Puede tener compromiso del tronco cerebral, con cuadros de confusión (delirium), con psicosis y síndromes meningoencefálicos o de hipertensión endocraneana y, a veces, se acompaña de otras lesiones en piel tales como eritema nudoso y lesiones pápulo-pustulares.

Es de etiología desconocida que puede ser desencadenado como una respuesta de hipersensibilidad o de reacción cruzada a alguna infección. Se encuentra presente el fenómeno de patergia que consiste en que las lesiones se pueden reproducir en las zonas donde hay un traumatismo y que para fines diagnósticos se inyecta solución salina en la dermis de la piel sana del paciente y se espera a que las lesiones se reproduzcan.

El síndrome de Vogt-Koyanagi-Harada es una enfermedad inflamatoria autoinmunitaria poco frecuente, que afecta varios órganos en los que hay melanocitos y se caracteriza por presentar una inflamación granulomatosa difusa (4). Como muchas otras enfermedades, puede aparecer como respuesta ante un microorganismo, posiblemente un virus, y dependiendo de la genética se monta o no una respuesta inmunológica. Se ha encontrado una mayor susceptibilidad a esta enfermedad asociada al alelo HLA-DRB $1^{\star} 0405$.

Afecta las meninges, los ojos, la piel y el sistema auditivo interno. Se reporta una fase inicial con compromiso meningo-encefálico y síntomas neurológicos; una segunda fase con compromiso de los ojos en el que aparece una uveítis posterior y los pacientes pueden presentar un glaucoma o un desprendimiento de la retina, y una tercera fase con manifestaciones cutáneas, generalmente con alteraciones en la pigmentación. Aún no se conoce su fisiopatología, pero, al parecer, juega un papel importante la subpoblación de linfocitos T 17/23.

En resumen, podemos tener una uveítis granulomatosa, alteraciones de la audición, hiperpigmentación cutánea o, por el contrario, poliosis, vitiligo, leucodermia, alopecia y un cuadro meningo-encefálico (5). 


\section{Enfermedades neuroectodérmicas}

Las facomatosis, o enfermedades neuroectodérmicas, son un grupo heterogéneo de lesiones que afectan el sistema nervioso, los ojos, la piel y, a veces, comprometen otras vísceras (6). Se agrupan con este nombre porque presentaban tumores retinianos o facomas. Estos síndromes neuro-óculo-cutáneos tumorales hereditarios incluyen la neurofibromatosis -o enfermedad de von Recklinghausen-, la esclerosis tuberosa o epiloia (epilepsia, bajo coeficiente intelectual, angiofibromas), el síndrome de Sturge-Weber y el síndrome de von Hippel-Lindau.

Se presentan por alteraciones en genes específicos que ya han sido identificados, con alteraciones primarias de la cresta neural y con compromiso secundario de los elementos mesenquimales de sostén. Estos genes comprometidos actúan como supresores de tumores, regulando el crecimiento celular y su diferenciación; al encontrarse anulada su función, por una mutación somática que anula el segundo alelo, se permite el crecimiento de ciertos tejidos y, por consiguiente, lo que caracteriza a estas enfermedades es la presencia de lesiones tumorales (7).

En el caso de la neurofibromatosis, la esclerosis tuberosa y el síndrome de von Hippel-Lindau, su herencia es de carácter autosómico dominante, aunque también pueden aparecen de novo como una mutación. El síndrome de Sturge-Weber es de carácter autosómico recesivo.

El síndrome de Sturge-Weber es un trastorno neurocutáneo congénito que aparece de manera esporádica con carácter hereditario autosómico recesivo. Se caracteriza por una angiomatosis encéfalo-trigemino que se manifiesta por la aparición de una mancha de color vino oporto, que toma las ramas del nervio trigémino y suele afectar las leptomeninges. Puede acompañarse de afectación vascular del globo ocular, de glaucoma y de convulsiones, lo mismo que de dificultades en el aprendizaje. Es causado por una mutación somática en el gen GNAQ (8).

La enfermedad de von Hippel-Lindau es de carácter autosómico dominante. Se caracteriza por la aparición de neoplasias en el sistema nervioso central, asociada a tumores malignos y benignos de varios órganos. Se pueden encontrar hemangiomas retinianos, faciales y espinales, asociados a tumores del cerebelo. Puede asociarse también a la aparición de quistes renales o de carcinoma renal.

La neurofibromatosis, o enfermedad de von Recklinghausen, es el más común de los síndromes neurocutáneos. La neurofibromatosis de tipo 1 aparece en 1 de cada 2.000 a 4.500 personas (9). Fue descrita por von Recklinghausen en 1882. Tiene una distribución mundial y afecta a todas las razas. 
Es una enfermedad multisistémica, hereditaria con un patrón autosómico dominante, con una mutación heredada o que se presenta por una mutación espontánea del locus NF-1 del brazo largo del cromosoma 17 que codifica para una proteína supresora de tumores, la neurofibromina, que estaría alterada en estos casos. Se han identificado alteraciones del cromosoma 17q11.2, 19 y 22q con alteraciones en la cresta neural de donde se derivan las células pigmentarias, las envolturas de los nervios, las meninges y los ganglios simpáticos (10).

Se presentan anomalías del desarrollo en los tejidos y en los órganos de origen ectodérmico con hiperplasia y neoplasia de los mismos. Los pacientes pueden presentar asimetría craneofacial y otras alteraciones músculo-esqueléticas, en la piel (manchas de color de café con leche, pecas axilares o inguinales), convulsiones y aparición de neurofibromas y gliomas ópticos, el $50 \%$ de ellos, además, presentan un neurofibroma plexiforme. Algunos pacientes han presentado defectos congénitos del corazón o tienen alteraciones gastrointestinales, oculares y una predisposición a presentar neoplasias benignas, como el feocromocitoma, o pueden asociarse a otras neoplasias malignas. El grado de hiperplasia de los tejidos de origen mesodérmico y endodérmico es variable, desde muy discreto hasta muy grave.

Ahora se conoce que la neurofibromatosis de tipo 1 pertenecel al grupo de enfermedades conocidas como rasopatías en las que la mutación germinal se produce en los genes que codifican componentes de la vía MAPK y, por ello, aparecen los tumores (11).

La neurofibromatosis de tipo 2 que tiene una prevalencia de 1 en 3.500 individuos (12), se presenta con alteraciones tumorales del tipo de los schwanomas en los nervios vestibulares (VIII par). El gen alterado está en el brazo largo del cromosoma 22. Algunos presentan, además, meningiomas o ependimomas, especialmente de la columna cervical.

Riccardi (12), clasificó la neurofibromatosis en diferentes tipos, ya que no todos los pacientes presentaban las mismas alteraciones. Hablo de la neurofibromatosis clásica -o de von Recklinghausen o de tipo 1-, de la de tipo 2 y de otras variedades de tipos de lesiones que presentaban patrones mixtos o de aparición de manchas de color de café con leche y efélides en los pliegues sin neurofibromatosis, ni nódulos de Lysch -conocido ahora como el síndrome de Legius. Algunos pacientes tienen comprometido solo un segmento de su cuerpo, como siguiendo un patrón pigmentario de cruce de razas, pigmentary miscegeny como si fuese una herencia en mosaico. Otros tienen neurofibromatosis de aparición tardía, con aparición de neurofibromas después de los 30 años. 
Los hallazgos de piel más importantes son las manchas de color de café con leche que miden de 1 a $3 \mathrm{~cm}$ y son la primera manifestación de la enfermedad, generalmente, seis o más máculas (figura 3.1), las pecas o efélides axilares e inguinales de 2 a $3 \mathrm{~mm}$ (figura 3.2). Los neurofibromas son tumores benignos derivados de las vainas de los nervios periféricos, que pueden ser cutáneos, subcutáneos o plexiformes, y que solo se hacen visibles en la adolescencia (figura 3.3).
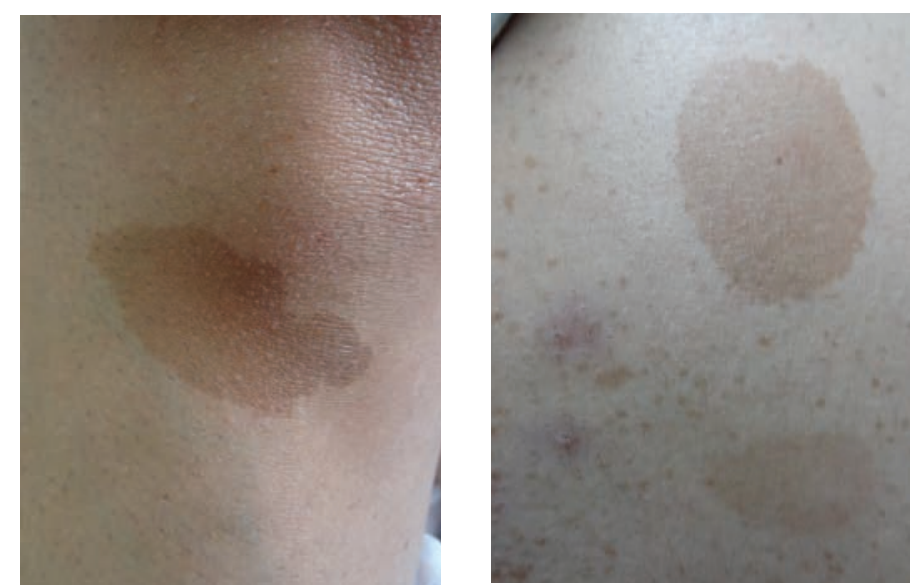

Figura 3.1. Manchas café con leche. Los pacientes con neurofibromatosis presentan desde el nacimiento unas manchas de color de café con leche como primera manifestación de la alteración, denominadas así por su color pardo claro; suelen medir de $1 \mathrm{a} 3 \mathrm{~cm}$ y, característicamente, deben ser más de seis.

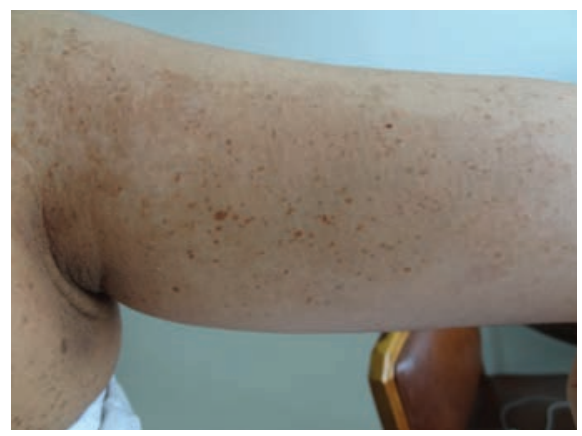

Figura 3.2. Efélides axilares. Las pecas, o efélides, axilares e inguinales son pequeñas máculas de 2 a $3 \mathrm{~mm}$ de diámetro, localizadas en estas zonas y, a veces, se extienden a otras zonas del cuerpo. 

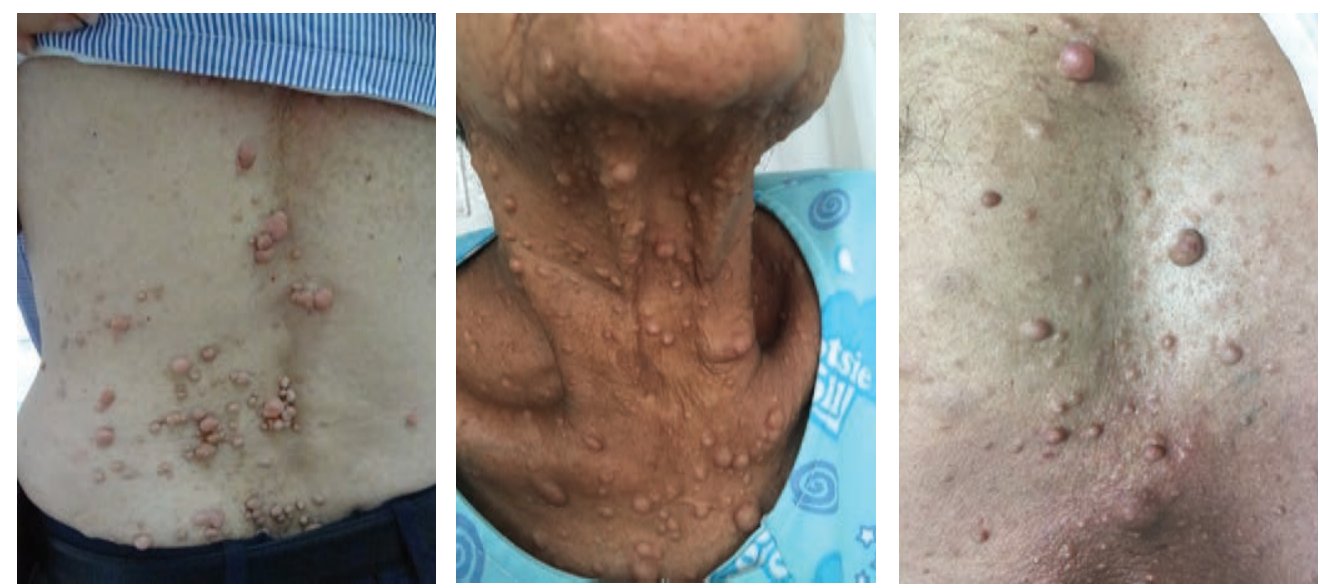

Figura 3.3. Neurofibromas. Los neurofibromas son tumores benignos derivados de las vainas de los nervios periféricos, que pueden ser cutáneos, subcutáneos o plexiformes, y que solo se hacen visibles en la adolescencia. Son lesiones de variados tamaños que, característicamente, se deprimen fácilmente en el centro.

Se encuentran, además, hamartomas pigmentarios en el iris -llamados nódulos de Lisch-, gliomas de la vía óptica y diversa variedad de tumores de la vaina de los nervios periféricos, acompañados de alteraciones óseas que pueden ser escasas y discretas o numerosas y llamativas, como asimetrías por hipertrofias localizadas, cifoescoliosis, displasia de los huesos largos, del esfenoides, pseudoartrosis, macrocefalia, pectum excavatum u otros.

Ocasionalmente, se acompaña de otros tumores, como del feocromocitoma, cuya manifestación inicial es generalmente una crisis hipertensiva, o de astrocitomas o schwanomas. Asimismo, se pueden presentar convulsiones, déficit de atención o dificultades de aprendizaje y, en algunos casos, retardo mental leve, pero nunca tan frecuentes como en la esclerosis tuberosa.

Las efélides, los nólulos de Lisch y los neurofibromas pueden aparecer desde los cinco a los siete años de edad, y son más notorios en la adolescencia. Son de localización variable y se presentan más agrupados, difusos o plexiformes. Estas lesiones tumorales blandas, característicamente, se deprimen en el centro con la palpación y presión de las mismas. Su localización puede ser cutánea o subcutánea y comprometer nervios más profundos, intraneurales y plexiformes, que se pueden evidenciar con una ecografía cutánea de alta resolución. Se recomienda no extraer estos tumores si no es necesario, ya que algunos se pueden transformar en neurofibrosarcomas. 
En algunos pacientes con neurofibromatosis se han presentado lesiones como xantogranulomas juveniles o nevos anémicos y se han encontrado asociados a leucemias mielomonocíticas.

La esclerosis tuberosa, enfermedad de Pringle-Bourneville o epiloia es un trastorno autosómico dominante, descrito por Bourneville en 1880, en el que se ha identificado la mutación de dos genes: TSC1 y TSC2 (13). Sin embargo, se pueden encontrar padres no afectados en el $60 \%$ de los casos, es decir que aparece como una mutación de novo. Rara vez se encuentra asociada a la neurofibromatosis de tipo 1. La incidencia es de 1 en cada 6.000 nacidos vivos.

El gen afectado TSC1 se encuentra en 9q34 del cromosoma 9, y el TSC2 en 16p13.3 del cromosoma 16; codifican para las proteínas hamartina y tuberina, y su función es la de inhibir la proliferación celular. De tal manera que, si se inactivan, crecen tumores de tipo hamartoma, tal como sucede en el complejo de la esclerosis tuberosa (14). Generalmente, los pacientes consultan inicialmente por un cuadro convulsivo, y las manifestaciones neurológicas están presentes en el $80 \%$ de los casos.

El nombre de EPILOIA surgió como un acrónimo de las alteraciones que se reportaban, así: EPI: epilepsia; LOI: low intelligence, déficit cognitivo, y A: adenomas sebáceos. En realidad, esas lesiones tumorales en piel que se denominaron inicialmente como adenomas sebáceos, no lo son, son angiofibromas y aparecen en el rostro, principalmente en las mejillas, en los surcos nasogenianos, las alas de la nariz y el mentón (figura 3.4).
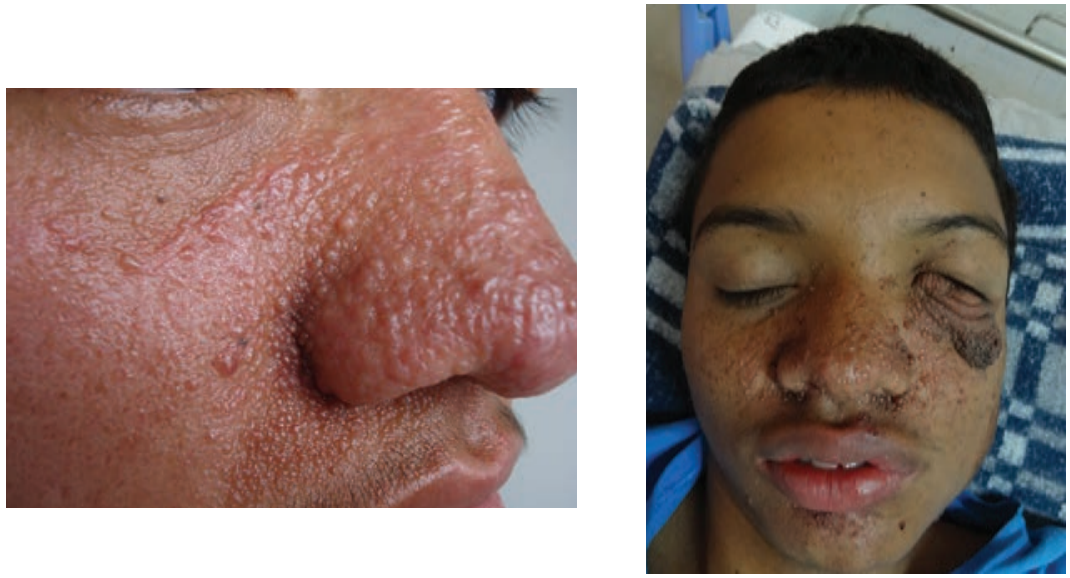

Figura 3.4. Angiofibromas faciales. Se trata de la aparición de pequeñas lesiones tumorales de 1 a $3 \mathrm{~mm}$ de diámetro, firmes, de color piel y ligeramente rojizas; son angiofibromas que, característicamente, aparecen en el dorso nasal y en las mejillas desde la infancia y aumentan de tamaño en la adolescencia. 
Además de las convulsiones, se describen coreas a causa de los tumores hallados en la corteza cerebral, del tipo tubérculos corticales, y a la presencia de nódulos subependimarios. Se presentan trastornos cognitivos y del comportamiento. Se pueden encontrar hamartomas en la región periventricular y retiniana. De tal manera que tendremos un paciente, generalmente, adolescente que presenta un déficit de atención e hiperactividad o con alteraciones del sueño.

En la piel, además de los angiofibromas faciales, se pueden encontrar otros fibromas en regiones periungulares o subungulares llamados los tumores de Koenen (figura 3.5a) y también en la mucosa oral (figura 3.5b).
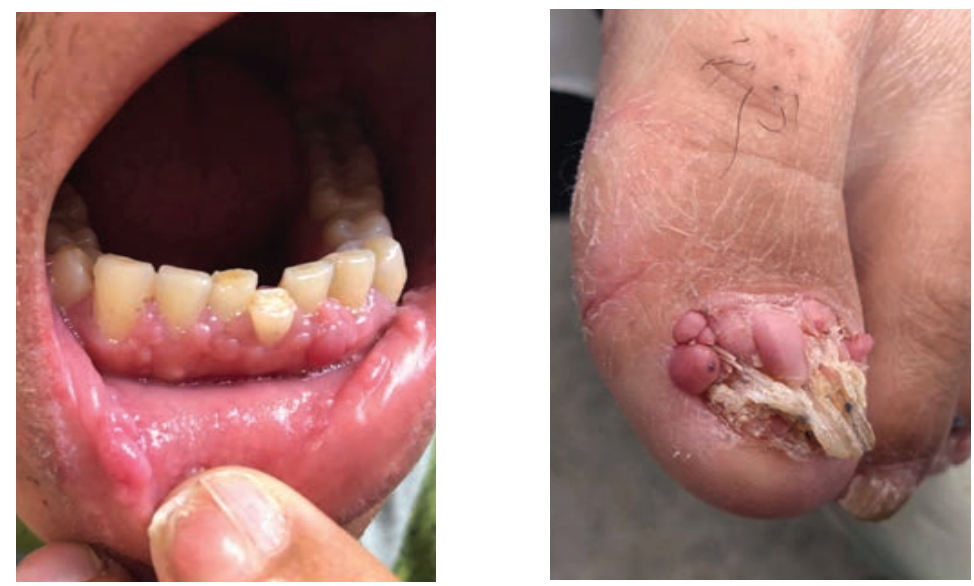

Figura 3.5 Tumores de Koenen y fibromas en la mucosa oral. En la piel de los pacientes con esclerosis tuberosa, se pueden encontrar otros fibromas. Tumores de Koenen. Los más frecuentes se encuentran en las regiones periungulares o subungulares. Fibromas en la mucosa oral, pueden presentarse en otros lugares, como en este caso, en la encía.

Son características también unas máculas hipopigmentadas lanceoladas que aparecen desde el nacimiento y que debido a la forma y semejanza se han comparado con las de las hojas de fresno y se consideran relacionadas si son más de tres. Pueden alternar con otras máculas hipopigmentadas e hiperpigmentadas (figura 3.6). 

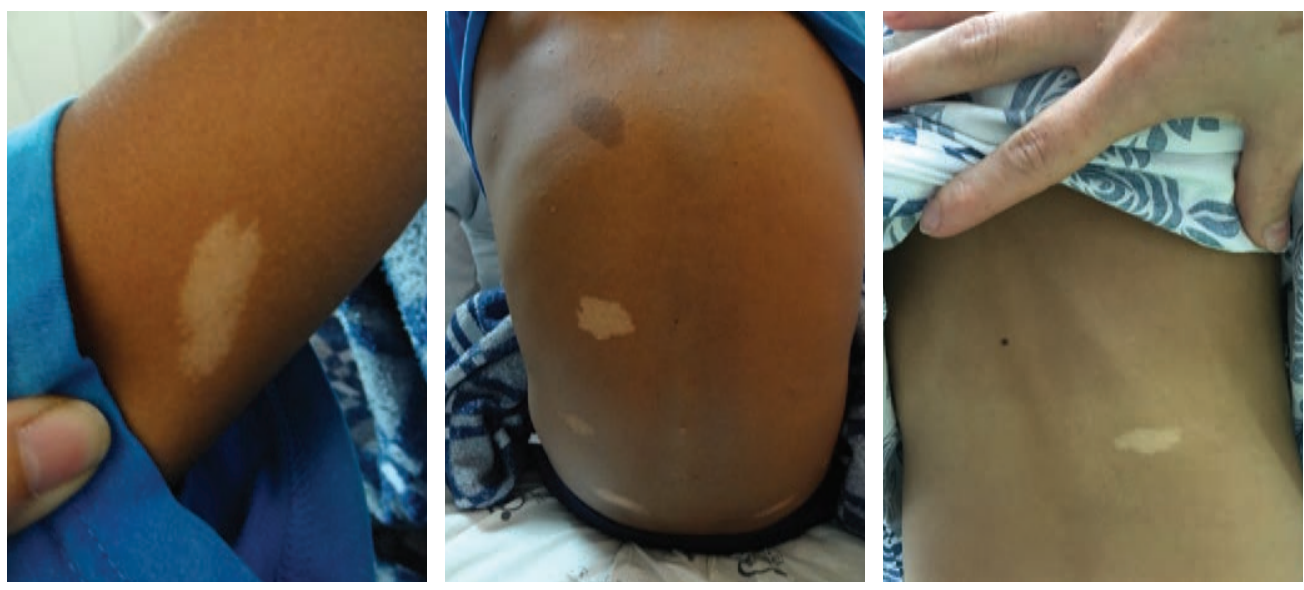

Figura 3.6. Máculas hipopigmentadas con forma de hojas de fresno. Las máculas hipopigmentadas son frecuentemente lanceoladas, por esta razón, recuerdan la forma de las hojas de esta planta. Suelen ser más de tres y aparecen desde el nacimiento en la esclerosis tuberosa. Como se puede observar en una de las figuras, pueden alternar con otras maáculas hipopigmentadas o hiperpigmentadas.

Puede aparecer, además, otro tipo de tumor de tejido conjuntivo, que se presenta con mayor frecuencia en la región lumbosacra y que tiene el aspecto de una piel gruesa y elevada con pliegues, de un color piel o ligeramente más pardo-amarillento, llamada placa de chagrin o de shagreen (figura 3.7)

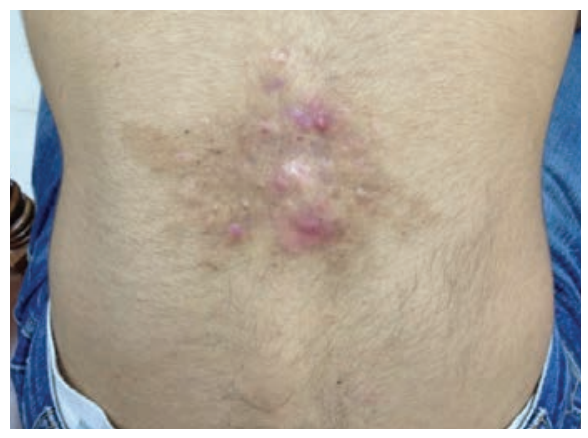

Figura 3.7. Placa de chagrín o de shagreen: hamartoma de tejido conjuntivo de tejido conjuntivo. Puede aparecer, además, otro tipo de tumor del tejido conjuntivo, que se presenta con mayor frecuencia en la región lumbosacra y que tiene el aspecto de una piel gruesa y elevada con pliegues, de un color piel o ligeramente más pardo-amarillento. 
Además del compromiso neurológico y de la piel, se encuentran alteraciones en la retina, en el riñón, en el corazón y, raramente, en el pulmón. En el riñón, se describen angiomiolipomas en el 55 al $75 \%$ de los pacientes; rabdomiomas en el corazón en el $60 \%$ de los pacientes (14), y menos frecuentemente aparece en el pulmón una linfangiomatosis en la que las células musculares atípicas crecen peribronquiales, perivasculares o perilinfáticas; son más frecuentes en las mujeres.

Como en muchas otras enfermedades, se describen criterios mayores y menores para establecer el diagnóstico de esclerosis tuberosa.

Los criterios mayores incluyen los hallazgos más importantes y frecuentes como son: los angiofibromas faciales, los fibromas ungulares, la presencia del parche o placa de chagrin (de shagreen o nevos del tejido conjuntivo), las máculas hipopigmentadas semejantes a las hojas de fresno (más de tres) que son las primeras en aparecer, la presencia de un tubérculo cortical o de nódulos subependimarios, un hamartoma retiniano (llamados facomas) o un tumor subependimario de células gigantes; también pueden presentarse un rabdomioma cardiaco único o múltiple, un angiomiolipoma renal y el hallazgo de una linfangiomiomatosis.

Como criterios menores se mencionan hipoplasia del esmalte dental, fibromas gingivales, pólipos de tipo hamartomas del recto, quistes óseos, migración radial de las líneas cerebrales y un parche acrómico en la retina, lesiones cutáneas en confetti, es decir, un grupo de máculas pequeñas e hipopigmentadas, y múltiples quistes renales.

El diagnóstico clínico se hace con los hallazgos cutáneos, que son las máculas hipopigmentadas, los angiofibromas, el parche de chagrin (shagreen) y el hecho de haber presentado algún trastorno cognitivo, de comportamiento o convulsivo, por lo que debe solicitarse un electroencefalograma, practicarse un examen de fondo de ojo, una tomografía computarizada o una resonancia magnética cerebral, una ecografía renal y un electrocardiograma con ecografía cardiaca, además de consultar al neurólogo y al dermatólogo. 


\section{Cuadro 3.1 Síndromes neurocutáneos y enfermedades neuroectodérmicas}

\begin{tabular}{|c|c|c|c|c|}
\hline \multicolumn{2}{|c|}{ Síndromes neurocutáneos } & Alteraciones pigmentarias en la piel & Alteracio & Alteraciones en el sistema nervioso \\
\hline HLA comprometido & Alteración & Entidad & Vasculitis S.Nervioso & Vasculitis piel \\
\hline $\begin{array}{l}\text { HLA B-51 } \\
\text { HLA B51/B5 }\end{array}$ & & Síndrome de Behçet & $\begin{array}{l}\text { Compromiso de tronco cerebral } \\
\text { Síndromes meningoencefálicos } \\
\text { Hipertensión endocraneana } \\
\text { Estados de confusión } \\
\text { Psicosis }\end{array}$ & $\begin{array}{l}\text { Úlceras orales y genitales } \\
\text { Lesiones papulo-pustulosas } \\
\text { Eritema nudoso } \\
\text { Vasculitis ocular }\end{array}$ \\
\hline HLA- DRB1*0405 & $\begin{array}{l}\text { Subpoblación de linfocitos } \\
\text { T 17/23 } \\
\text { Inflamación granulomatosa }\end{array}$ & $\begin{array}{l}\text { Síndrome de Vogt-Koyanagi- } \\
\text { Harada }\end{array}$ & $\begin{array}{l}\text { Lesiones en donde hay melanoci- } \\
\text { tos: meninges, } \\
\text { Ojos: uveitis granulomatosa; } \\
\text { Oído interno: alteraciones de la } \\
\text { audición }\end{array}$ & Alteraciones de la pigmentación \\
\hline
\end{tabular}

\begin{tabular}{|l|l|}
\hline $\begin{array}{l}\text { Enfermedades neuroectodérmicas } \\
\text { o facomatosis }\end{array}$ & $\begin{array}{l}\text { Tumores retinianos o facomas } \\
\text { Síndromes neuro-oculo-cutáneos }\end{array}$ \\
\hline
\end{tabular}

\begin{tabular}{|c|c|c|c|c|}
\hline Genética Herencia & Alteración & Entidad & S. Nervioso Ojos & Piel y otros órganos \\
\hline $\begin{array}{l}\text { Autosómico recesivo } \\
\text { Mutación somática del gen } \\
\text { GNAQ }\end{array}$ & & Síndrome de Sturge-Weber & $\begin{array}{l}\text { Suele afectar vasos de } \\
\text { leptomeninges y ojo } \\
\text { Convulsiones } \\
\text { Dificultades de aprendizaje } \\
\text { Glaucoma }\end{array}$ & $\begin{array}{l}\text { Mancha de color vino } \\
\text { oporto }\end{array}$ \\
\hline Autosómico dominante & & $\begin{array}{l}\text { Enfermedad de von Hippel } \\
\text { Lindau }\end{array}$ & \begin{tabular}{|lrl}
$\begin{array}{l}\text { Neoplasias en } \\
\text { nervioso }\end{array}$ & sistema \\
$\begin{array}{l}\text { Hemangiomas } \\
\text { o espinales }\end{array}$ & retinianos \\
\end{tabular} & $\begin{array}{l}\text { Hemangiomas faciales } \\
\text { Quistes o Cáncer Renal }\end{array}$ \\
\hline $\begin{array}{l}\text { Autosómico dominante } \\
\text { Mutación espontánea del } \\
\text { locus NF-1 del brazo largo } \\
\text { del cromosoma } 17 \\
\text { en el } 17 \text { q11.2 } \\
\text { Otras alteraciones del } \\
\text { cromosoma } 19 \text { y } 22 \text { q } \\
\text { Brazo largo del cromo- } \\
\text { soma } 22\end{array}$ & Neurofibromina & 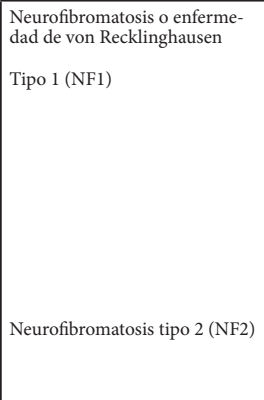 & $\begin{array}{l}\text { Alteraciones de la cresta neu- } \\
\text { ral de donde se derivan los } \\
\text { melanocitos, las envolturas de } \\
\text { los nervios, las meninges, los } \\
\text { ganglios simpáticos } \\
\text { Glioma óptico } \\
\text { Nódulos de Lysch } \\
\text { Neurofibroma plexiforme } \\
\text { Convulsiones } \\
\text { Schwanomas en nervios } \\
\text { vestibulares } \\
\text { Meningiomas o ependi- } \\
\text { momas }\end{array}$ & $\begin{array}{l}\text { Manchas café con leche } \\
\text { Efélides o pecas } \\
\text { Neurofibromas } \\
\text { Alteraciones muscu- } \\
\text { loesqueléticas } \\
\text { Neoplasias benignas o } \\
\text { malignas } \\
\text { Xantogranulomas } \\
\text { Nevus anémicos }\end{array}$ \\
\hline $\begin{array}{l}\text { Autosómico dominante } \\
\text { Mutación del gen } \\
\text { TSC } 1 \text { en el cromosoma 9, } \\
\text { en el 9q34 } \\
\text { del gen TSC2 en el cromo- } \\
\text { soma 16, en el 16p13.3 }\end{array}$ & $\begin{array}{l}\text { Hamartina } \\
\text { Tuberina }\end{array}$ & $\begin{array}{l}\text { Epiloia o enfermedad de Prin- } \\
\text { gle-Burneville }\end{array}$ & $\begin{array}{l}\text { Tumores del tipo } \\
\text { hamartomas } \\
\text { Coreas } \\
\text { Convulsiones } \\
\text { Déficit cognitivo o de atención } \\
\text { Alteraciones del aprendizaje } \\
\text { Lesiones en retina }\end{array}$ & $\begin{array}{l}\text { Máculas hipopigmentadas, } \\
\text { similares a hojas de fresno } \\
\text { Otras máculas hiperpig- } \\
\text { mentadas o hipopigmen- } \\
\text { tadas. } \\
\text { Tumores de tipo hamar- } \\
\text { tomas } \\
\text { Angiofibromas } \\
\text { Fibromas de encías } \\
\text { Fibromas } \\
\text { Periungulares: } \\
\text { Tumores de Koenen } \\
\text { Riñon, corazón o pulmón }\end{array}$ \\
\hline
\end{tabular}




\section{Cuadro 3.2. Rasopatías}

\begin{tabular}{|c|c|c|}
\hline $\begin{array}{l}\text { Mutación en la línea germinal en genes } \\
\text { que codifican las proteínas } \\
\text { RAS en la vía MAPK }\end{array}$ & & $\begin{array}{l}\text { Síndromes } \\
\text { neuro-cardio-facio-cutáneos }\end{array}$ \\
\hline NF1 neurofibromina & Manchas café con leche & Neurofibromatosis tipo 1 \\
\hline SPRED1 & Manchas café con leche, efélides, lipomas & Síndrome de Legius \\
\hline $\begin{array}{l}\text { Alteración de los genes en la parte superior } \\
\text { de la cascada } \\
\text { PTPN11, SOS1 } \\
\text { Neurofibromina } \\
\text { PTPN11 y neurofibromina } \\
\text { riesgo mayor de sufrir } \\
\text { leucemia mielomonocítica }\end{array}$ & $\begin{array}{l}\text { Manchas café con leche } \\
\text { Nevus melanocíticos } \\
\text { Linfedema } \\
\text { Retraso mental leve }\end{array}$ & Síndrome de Noonan \\
\hline $\begin{array}{l}\text { Alteración del gen KRAS y de los genes de } \\
\text { la parte inferior de la cascada } \\
\text { PTPN11 }\end{array}$ & $\begin{array}{l}\text { Manchas café con leche oscuras } \\
\text { Efélides } \\
\text { Funciones cognitivas alteradas } \\
\text { Pliegues redundantes } \\
\text { Alteraciones de queratinización } \\
\text { Anomalías del pelo }\end{array}$ & $\begin{array}{l}\text { Síndrome de Noonan con } \\
\text { lentiginosis múltiple, antiguamente } \\
\text { LEOPARD }\end{array}$ \\
\hline $\begin{array}{l}\text { Alteraciones en el gen HRAS } \\
\text { KRAS } \\
\text { BRAF } \\
\text { MEK1 }\end{array}$ & $\begin{array}{l}\text { Fibrilación auricular } \\
\text { Hiperpigmentación } \\
\text { Piel laxa } \\
\text { Papilomas periorificiales } \\
\text { Tumores de tejidos blandos }\end{array}$ & Síndrome de Costello \\
\hline $\begin{array}{l}\text { Mutaciones en la vía RAS/MAPK } \\
\text { BRAF } \\
\text { MEK1-2 }\end{array}$ & $\begin{array}{l}\text { Manchas café con leche } \\
\text { Pelo corto, escaso } \\
\text { Ictiosis } \\
\text { Hiperqueratosis folicular } \\
\text { Nevus múltiples adquiridos }\end{array}$ & Sindrome cardio-facio-cutáneo \\
\hline \multirow[t]{3}{*}{$\begin{array}{l}\text { Mutaciones en la vía RAS/MAPK } \\
\text { RASA1 }\end{array}$} & $\begin{array}{l}\text { Malformaciones capilares y } \\
\text { arteriovenosas } \\
\text { Fistulas arteriovenosas } \\
\end{array}$ & $\begin{array}{l}\text { Síndrome de malformación } \\
\text { capilar-arteriovenosa. }\end{array}$ \\
\hline & $\begin{array}{l}\text { Manchas hipopigmentadas e } \\
\text { hiperpigmentadas }\end{array}$ & Esclerosis tuberosa \\
\hline & Mancha vino oporto & Sturge Weber \\
\hline
\end{tabular}

\section{Referencias}

1. Ruggieri M, Praticò AD. Mosaic neurocutaneous disorders and their causes. Semin Pediatr Neurol. 2015;22:207-33.

2. Hernández-Martín A, Torrelo A. Rasopatías: trastornos del desarrollo con predisposición al cáncer y manifestaciones cutáneas. Actas Dermosifiliogr. 2011;102:402-416. 
3. Verity DH, Marr JE, Ohno S, Wallace GR, Stanford MR. Behçet's disease, the silk road and HLA-B51: Historical and geographical perspectives. Tissue Antigens. 1999;54:213-20.

4. $\quad$ Fang W, Yang P. Vogt-Koyanagi-Harada syndrome. Curr Eye Res. 2008;33:517-23.

5. Greco A, Fusconi M, Gallo A, Turchetta R, Marinelli C, Macri GF, et al. VogtKoyanagi-Harada syndrome. Autoimmun Rev. 2013;12:1033-8.

6. Nowak CB. The phakomatoses: Dermatologic clues to neurologic anomalies. Semin Pediat Neurol. 2007;14:140-9.

7. Hottinger AF, Khakoo Y. Update on the management of familial central nervous system tumor syndromes. Curr Neurol Neurosci Rep. 2007;7:200-7.

8. Shirley MD, Tang H, Gallione CJ, Baugher JD, Frelin LP, Cohen B, et al. SturgeWeber syndrome and port-wine stains caused by somatic mutation in GNAQ. N Engl J Med. 2013;368:1971-9.

9. Friedman JM, Birch PH. Type 1 neurofibromatosis: A descriptive analysis of the disorder in 1,728 patients. Am J Med Genet. 1997;70:138-43.

10. Koga T, Iwasaki H, Ishiguro M, Matsuzaki A, Kikuchi M. Losses in chromosomes 17,19 , and 22q in neurofibromatosis type 1 and sporadic neurofibromas: A comparative genomic hybridization analysis. Cancer Genet Cytogenet. 2002;136:113-20.

11. Rauen KA, Huson SM, Burkitt-Wright E, Evans DG, Farschtschi S, Ferner RE, et al. Recent developments in neurofibromatoses and RASopathies: Management, diagnosis and current and future therapeutic avenues. Am J Med Genet A. 2015;167A:1-10.

12. Radtke HB, Sebold CD, Allison C, Haidle JL, Schneider G. Neurofibromatosis type 1 in genetic counseling practice: Recommendations of the National Society of Genetic Counselors. J Genet Couns. 2007;16:387-407.

13. Orlova KA, Crino PB. The tuberous sclerosis complex. Ann N Y Acad Sci. 2010;1184:87-105.

14. Torres V, Contreras GA, Serrano N, Páez MC, Guzmán MC. Complejo de la esclerosis tuberosa, revisión de tema y presentación de caso. Rev Asoc Colomb Dermatol. 2011;19:76-81. 


\section{Capítulo 4}

\section{Enfermedades gastrointestinales}

La piel y el sistema gastrointestinal son dos órganos en estrecha relación. Las enfermedades del tracto gastrointestinal que pueden tener expresión en la piel son numerosas, de tal manera que es importante reconocer las lesiones que pueden aparecer para sospechar la alteración interna. En este acercamiento a lo que puede verse en la piel relacionado con las alteraciones del sistema gastrointestinal, lo primero que se considerará son las alteraciones nutricionales. Estas se manifiestan con lesiones en la piel y en las mucosas por la falta de consumo de ciertos nutrientes en algunos casos o por falta de ingestión de los mismos, ya sea por enfermedad general, inapetencia, de manera voluntaria o por alergia; en otros casos sucede por la falta de absorción de algunos nutrientes o de otros elementos indispensables para que los primeros se puedan absorber.

Además de estas lesiones relacionadas con las alteraciones nutricionales, se tendrán en cuenta otras manifestaciones cutáneas relacionadas con enfermedades gastrointestinales. Cada segmento del tubo digestivo alterado puede estar expresando simultáneamente lesiones en él y en la piel. Dado que las lesiones que se presentan en la mucosa oral son fácilmente visibles, podemos sospechar de manera rápida algunas alteraciones gastrointestinales.

Por orden segmentario, en la mucosa oral, además de las lesiones por las alteraciones nutricionales, en general, se pueden encontrar con mayor frecuencia pequeñas lesiones ulcerativas, dolorosas, denominadas como 'aftas' y, cuando se habla de la mucosa que las incluye, se dice que el paciente tiene una estomatitis aftosa (figura 4.1).

Estas lesiones llamadas 'aftas' corresponden a pequeñas zonas necróticas de la mucosa oral y se ven de color blanquecino, contrario a las lesiones necróticas de la piel que se ven de color negro; pueden aparecer en diversas enfermedades del tipo vasculitis como en el síndrome de Behçet o en la enfermedad de Crohn. 


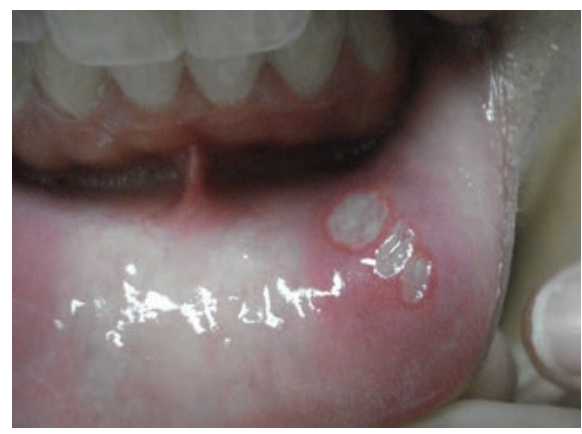

Figura 4.1. Estomatitis aftosa. Se trata de la aparición de pequeñas lesiones ulcerativas en la mucosa oral, conocidas como 'aftas'. En general, son pequeñas zonas de necrosis, que se ven blancas en la mucosa, no negras como en la piel. La etiología suele ser multifactorial. Algunas de tipo vasculitis se pueden ver en el síndrome de Behçet o en la enfermedad inflamatoria intestinal.

Se pueden observar otras lesiones similares, más eritematosas, de carácter infeccioso, como en el caso del herpes simple; también se pueden observar lesiones ulcerativas en las enfermedades autoinmunitarias como las que aparecen en la mucosa en el pénfigo vulgar. Por esta razón es que, si estamos frente a unas lesiones ulcerativas en la mucosa oral, de mayor tamaño o que no ceden rápidamente al tratamiento, o que se presentan de manera recidivante, se deben ordenar algunos exámenes de laboratorio para buscar aclarar el origen de las mismas y se debe obtener una biopsia que precise ante qué tipo de proceso nos encontramos.

El pénfigo vulgar es una enfermedad autoinmunitaria caracterizada por la presencia de ampollas intraepidérmicas que pueden afectar cualquier parte de la superficie de la piel o de las mucosas. Su incidencia es de 0,5 a 3,2 casos por 100.000 habitantes por año (1) y, en un alto porcentaje de casos, las lesiones iniciales se presentan solo en la mucosa oral, algunas veces afectan la mucosa malar y las encías como denudaciones, otras pueden ser ulcerativas (figura 4.2).

En esta enfermedad existen unos autoanticuerpos contra un antígeno crucial de la unión intercelular a nivel de los queratinocitos, las desmogleínas 1 y 3. Estas cadherinas están unidas por integrinas, proteínas que hacen parte de los desmosomas o sitios de unión. Estos autoanticuerpos antidesmogleínas inducen acantólisis, es decir, separación de las células y, por lo tanto, formación de ampollas y también se detectan en la sangre. 


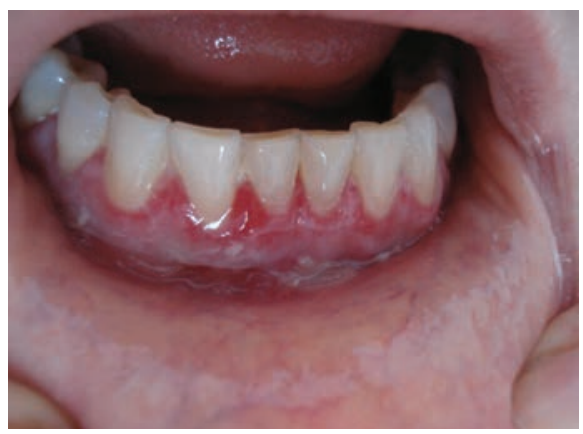

Figura 4.2. Pénfigo vulgar. También se pueden observar lesiones ulcerativas en las enfermedades autoinmunitarias, como es el caso de las ampollas intraepidérmicas que aparecen en la mucosa en el pénfigo vulgar.

Por otro lado, los procesos inflamatorios que comprometen al esófago y al estómago no se manifiestan de manera temprana con lesiones en la piel, a menos que se produzca una alteración en la absorción de los alimentos en la mucosa gástrica, o que esta haya sido aislada por cirugías restrictivas; se observan, entonces, las alteraciones nutricionales por exclusión en la absorción o falta de ingestión de algunos elementos. Es importante anotar que la presencia de ciertas infecciones o de la respuesta inmunitaria que se desencadena frente a ellas, puede hacerse notar en lo que se ha denominado 'lesiones vasculares reactivas en la piel'. Es el caso de la presencia de Helicobacter pylori a nivel gástrico, que se ha relacionado con la aparición de púrpura de Henoch-Schönlein (2), púrpura trombocitopénica inmunitaria (3), urticaria crónica $(4,5)$, eritema nudoso $(6)$ y rosácea $(7)$.

En los procesos neoplásicos, tales como en los adenocarcinomas de esófago o gástrico, se pueden observar algunas lesiones paraneoplásicas, como la acantosis nigricans o la acroqueratosis de Bazex, debido a que este tipo de neoplasias son capaces de producir mayor cantidad de factores de crecimiento, que generan alteraciones en la piel por el crecimiento exagerado de la misma, como sucede en las ya mencionadas y que se analizan en el último capítulo como parte de las dermatosis paraneoplásicas.

Se debe tener en cuenta que la mayor cantidad de lesiones cutáneas en relación con alguna alteración gastrointestinal se van a ver relacionadas con las alteraciones nutricionales o con las enfermedades inflamatorias intestinales. En estas, las lesiones que aparecen en la piel suelen ser secundarias a una vasculitis y también afectan la mucosa oral, y como pueden comprometer, además, el aparato ocular y las articulaciones al mismo tiempo, estas asociaciones alertan al clínico para su búsqueda. 
En muchas ocasiones, el individuo se preocupa más por las lesiones de la piel que por las que afectan otros órganos y consulta cuando aparecen, así su cuadro intestinal lleve más tiempo; por esta razón, el conocimiento de las lesiones de piel es importante para orientar el diagnóstico. Recordemos que, si hay recaídas del cuadro intestinal, las lesiones de la piel pueden volver a aparecer y, de ahí, la importancia de saberlas identificar. Por último, se consideran otros procesos que presentan simultáneamente lesiones en la piel y en el sistema gastrointestinal, como sucede en las alteraciones pancreáticas y hepatobiliares.

\section{Alteraciones nutricionales}

Las lesiones cutáneas debidas a las alteraciones nutricionales se presentan con gran frecuencia en nuestros países, principalmente en la primera infancia y en la vejez, debidas a la desnutrición en general. Pueden aparecer por falta de consumo de ciertos alimentos, como es el caso de algunos individuos vegetarianos, los alcohólicos y los alérgicos y, también, se pueden presentar cuando los individuos tienen alteraciones de la absorción intestinal o por falta de ingestión en enfermedades crónicas o en las cirugías reductoras del tamaño del estómago. Los pacientes a quienes se les practican derivaciones del tipo de derivación (bypass) intestinal, presentan lesiones pápulo-vesiculosas o pápulo-pustulosas estériles, diseminadas, cuya interpretación podría estar relacionada con el paso de bacterias del intestino hacia el estómago y, de ahí, al torrente sanguíneo, debido a que se habría alterado la mecánica de la barrera propia de los esfínteres naturales.

Asimismo, si el individuo presenta un proceso neoplásico que obstruye algún lugar del tubo digestivo y no le permite el ingreso de alimentos, se presentan alteraciones nutricionales. De igual manera, puede presentarse en las enfermedades crónicas o si presentan neoplasias de otra índole, en cuyo caso el paciente ha perdido el interés por la comida o son los medicamentos que recibe los que lo mantienen inapetente, le producen una mucositis ambas o se ha agregado una candidiasis. Algunos de estos aspectos parecen muy simples y no por ello, deben pasar inadvertidos.

Hasta ahora se ha hecho especial énfasis en las alteraciones que se producen por el déficit de nutrientes, pero tenemos que considerar, además, que la ingestión de algunos alimentos puede ocasionar o acentuar algunas enfermedades dermatológicas, tal y como sucede en la rosácea y en la dermatitis seborreica tras el consumo de alcohol. Por otro lado, algunos alimentos se deben suprimir en los individuos que no toleran el ácido acetilsalicílico, los suplementos preservativos o los colorantes para evitar manifestaciones por hipersensibilidad, en el caso de las lesiones de piel, para evitar la aparición de prurito o urticaria. 
Del mismo modo, en los individuos alérgicos a ciertos alimentos, estos pueden ocasionar manifestaciones generales como migraña, asma o diarrea, y también son capaces de exacerbar la dermatitis atópica, el prurito o la aparición de una urticaria.

En el caso de la psoriasis, o en algunas dermatitis de contacto, también es necesario eliminar ciertos alimentos. Los pacientes que sufren de psoriasis, deben aprender sobre los ácidos grasos esenciales que pueden ingerir, según el tipo de alimentación que tengan, ya que estos se incorporan a la membrana de las células y generan sustancias proinflamatorias que perpetúan las lesiones dependiendo de si son más o menos proinflamatorios. Los ácidos grasos esenciales provenientes de las carnes rojas son más inflamatorios que los derivados de los pescados o de las verduras, siendo los ácidos grasos omega 3 los menos inflamatorios.

Otro tipo de alteración que se debe tener en cuenta en cuanto a la alimentación, es el de los individuos que presentan dermatitis de contacto al níquel, debido a que, si ingieren alimentos que puedan contenerlo o que hayan sido cultivados en suelos ricos en él, además de las lesiones iniciales eccematosas en la zona de contacto, pueden presentar lesiones eccematosas en las palmas de las manos o ser generalizadas.

Otras alteraciones de la piel, como sucede en el caso del acné, se pueden presentar también por exceso de ingestión de azúcares y carbohidratos que desencadenan hiperinsulimemia y aumento de la síntesis de andrógenos (8).

Existen otros trastornos genéticos y metabólicos en los que se pueden presentar lesiones en la piel, para lo cual hay que tener en cuenta que ciertos nutrientes deben ser eliminados según el tipo de alteración para evitar que se presenten las lesiones, como sucede en el caso de la fenilcetonuria, la tirosinemia y la homocistinuria.

Con el fin de aclarar este concepto, R. Ruiz-Maldonado nos presenta en su artículo las principales aminoacidurias y sus manifestaciones en piel (9). Las alteraciones asociadas a la fenilcetonuria, en la que la carencia de la enzima hidroxilasa de la fenilalanina se traduce en la incapacidad de metabolizar la tirosina a partir de la fenilalanina, la cual se acumula y causa daño al sistema nervioso central y a la piel con la aparición de lesiones eccematosas o seborreicas. Los pacientes suelen tener el cabello claro y la piel blanca, con ojos azules y un olor característico.

En cuanto a la tirosinemia, el aumento de la tirosina se presenta con lesiones hepáticas, renales, del sistema nervioso y en la piel en la que aparece una queratodermia palmo-plantar. $\mathrm{O}$, en el caso de la homocistinuria, los individuos 
afectados presentan un cabello fino y escaso con eritema malar y livedo reticularis; otros trastornos menos frecuentes pueden presentarse en estas aminoacidurias.

Cuando se consumen ciertos alimentos, se pueden desencadenar ciertas alteraciones, como sucede en la enteropatía por gluten, en la cual aparecen, además del compromiso del íleo o enteropático, unas lesiones ampollosas tensas en el caso de la dermatitis herpetiforme, por lo cual el gluten debe ser eliminado de la dieta.

Se han revisado algunas de las causas de las alteraciones cutáneas que tienen relación con la ingestión de ciertos alimentos y cómo se deben evitar algunos alimentos para no desarrollar ni exacerbar ciertas enfermedades.

Ahora revisaremos el hecho que si no se consumen ciertos nutrientes, se pueden presentar ciertas alteraciones en la piel (10). En los casos extremos de desnutrición grave, se presenta la desnutrición de tipo marasmo, por deficiencia de todos los nutrientes, cuyos individuos tienen un aspecto famélico que hace evidente su estado, con una piel delgada, arrugada y seca.
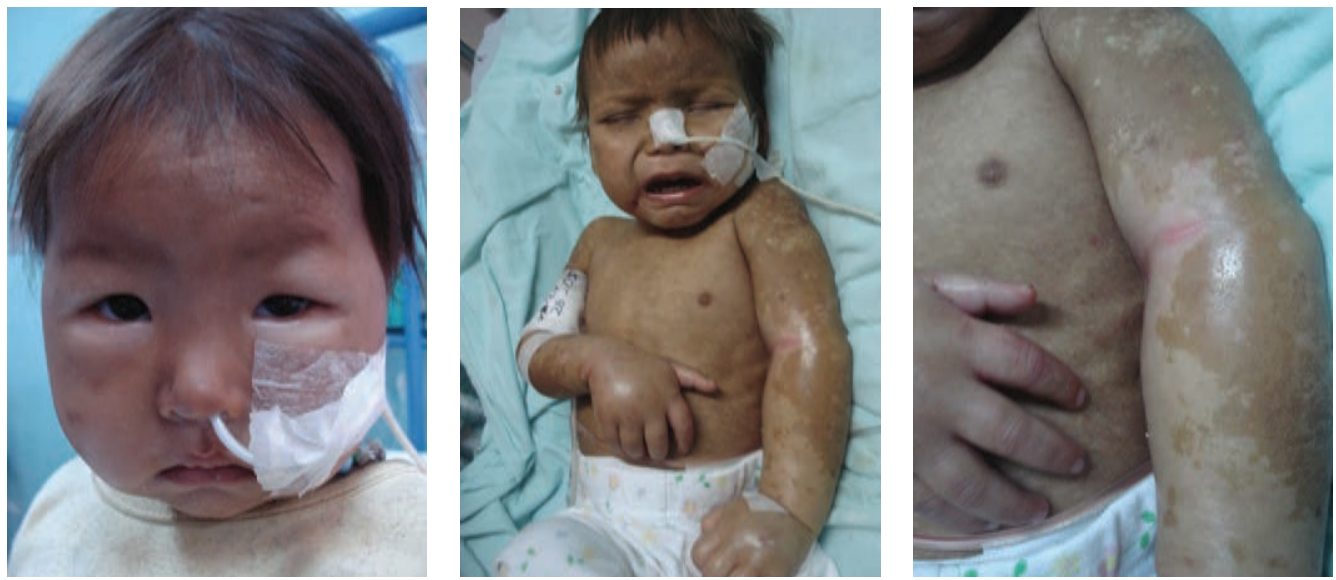

Figura 4.3. Desnutrición de tipo kwashiorkor. Los niños que solo se alimentan con carbohidratos presentan una variedad de desnutrición en la que se observa un edema importante debido a que tienen muy bajas las concentraciones de proteínas. La piel presenta lesiones eritemato-descamativas e hiperpigmentadas, similares a las de una piel quemada, que pueden parecerse a las de la pelagra, pero, a diferencia de esta que se encuentra circunscrita a las zonas expuestas a la luz, ellas serán generalizadas.

En la desnutrición de tipo kwashiorkor cuya ingestión está basada principalmente en carbohidratos y es baja en proteínas, los niños presentan un edema importante debido a que tienen una concentración muy baja de albúmina y se ven en 
la piel unas lesiones eritemato-descamativas e hiperpigmentadas, similares a las que aparecen en la pelagra, pero, a diferencia de esta que se encuentra circunscrita a las zonas expuestas a la luz, ellas serán generalizadas (figura 4.3).

Estos niños también presentan cambios en la coloración del pelo que, además de encontrarse opaco, presenta varias tonalidades; por esta razón, se dice que tienen el 'signo de la bandera'.

Es importante saber que tanto la hipoalbuminemia como la baja en las concentraciones de las proteínas, se hace visible en las uñas. En el primer caso, cuando la albúmina está por debajo de 2, aparecen unas sombras blanquecinas, lineales, en el lecho ungular que atraviesan transversalmente la uña, llamadas líneas de Muehrcke (11) (figura 4.4). Si la disminución es de proteínas en general, la lúnula no es visible.
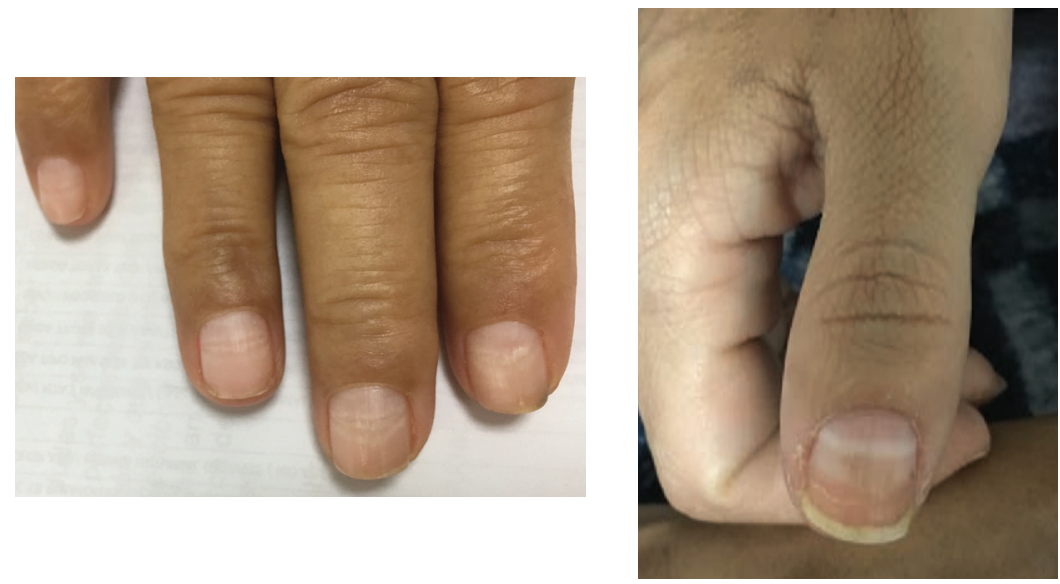

Figura 4.4. Líneas de Muehrcke. Cuando la albúmina está por debajo de 2, aparecen unas sombras blanquecinas, lineales, en el lecho ungular que atraviesan transversalmente la uña, llamadas líneas de Muehrcke, Y si aparece en el dedo pulgar han sido llamadas líneas de Mees.

Es muy importante reconocer las deficiencias en la ingestión de vitaminas o, en algunos casos, la falta de ciertas enzimas necesarias para su absorción. La piel se ve afectada por la falta de los componentes del complejo B, a saber, la tiamina o vitamina $B_{1}$, la rivoflavina o vitamina $B_{2}$, la niacina o vitamina $B_{3}$, la piridoxina o vitamina $\mathrm{B}_{6}$, la biotina, el ácido fólico o la cianocobalamina o vitamina $\mathrm{B}_{12}$, o de otras vitaminas como la $\mathrm{A}$, la $\mathrm{C}$ y la $\mathrm{D}_{3}$.

Se encuentran lesiones en la piel si faltan algunos elementos traza, como sucede con la falta de zinc, que es indispensable en la formación del pelo y de las 
uñas y es necesario para una adecuada respuesta inmunitaria; el selenio, para el buen funcionamiento enzimático de la peroxidasa del glutatión; el cobre, indispensable en la formación del cartílago y de las fibras elásticas; el manganeso, en la formación del cartílago, y el cromo que parece jugar un papel fundamental en la tolerancia a la glucosa; de igual manera, el cobalto, el molibdeno y el yodo tienen su papel en la formación de las hormonas tiroideas. Los pacientes con deficiencia de hierro, además de la anemia microcítica, presentan notoria caída del pelo y alteraciones en la formación de las uñas, las que se ven encorvadas en forma de cuchara, por lo que esta alteración se ha llamado 'coiloniquia' -recordemos que también se puede presentar en el hipotiroidismo.

Si existe una deficiencia de zinc por alteraciones en su absorción, se desarrollan lesiones en la piel como parte de una enfermedad conocida como la acrodermatitis enteropática (12), de transmisión autosómica recesiva (locus génico 8q24.3), en la que existe esta alteración por un déficit enzimático que no permite absorber este elemento. El pelo se cae fácilmente y aparecen lesiones vesiculosas, o se ven zonas ligeramente erosivas con eritema y descamación alrededor de los genitales y de la boca, que semejan una candidiasis y que comprometen, en ocasiones, la mucosa oral; las lesiones también aparecen en las axilas y en otras zonas de las extremidades y pueden tener un aspecto más escamoso (13).

Algunos pacientes con alteraciones de la glándula tiroides tienen bajas concentraciones de selenio y su restitución puede ayudar al manejo de las manifestaciones propias del hipotiroidismo. Se han descrito, también, bajos niveles de selenio en la psoriasis, en la dermatitis atópica y en la dermatitis herpetiforme (14).

Para un buen funcionamiento de la piel y de otros órganos, son necesarias las vitaminas, así que se deben conocer y pensar en ellas en casos de encontrar alteraciones de la piel. Se dividen en hidrosolubles y no se almacenan, como la vitamina $\mathrm{C}$ y el complejo $\mathrm{B}$, y las liposolubles que se almacenan en el cuerpo como la vitamina $\mathrm{A}$, la $\mathrm{D}$, la $\mathrm{E}$ y la $\mathrm{K}$, que son absorbidas con lipoproteínas en el intestino delgado.

Entre las vitaminas hidrosolubles, la vitamina $\mathrm{C}$, o ácido ascórbico, es necesaria para la síntesis de colágeno e indispensable en la cicatrización; puede prevenir la colonización de ciertos microorganismos que crecen a $\mathrm{pH}$ alcalino, como sucede con Proteus spp. en el aparato urinario. Si la dieta es pobre en frutas y verduras y existe un déficit de vitamina $C$, se presenta el 'escorbuto' que es causado por una deficiencia prolongada de esta vitamina, que determina alteraciones en la síntesis del colágeno y trastornos en la utilización del ácido fólico y del hierro (15). 
Se ven afectados los vasos sanguíneos, los huesos y los dientes en crecimiento, lo que se traduce en alteraciones mucocutáneas, musculoesqueléticas, oftalmológicas, cardiorrespiratorias y gastrointestinales.

Las alteraciones cutáneas se caracterizan por lesiones de tipo queratosis pilaris con un halo hemorrágico en la periferia o por alteraciones hemorrágicas de las mucosas pudiendo encontrarse petequias; se ha reportado también pérdida del pelo.

En la actualidad, es una enfermedad poco frecuente debido a la fácil consecución de frutas cítricas, como el limón, la mandarina y la naranja, y otros alimentos que la contienen como las bayas rojas en general -como la ciruela kakadu, el camu camu, el escaramujo y la acerola-, la guayaba, la grosella negra, los pimientos rojo y verde, el perejil, el brócoli, las coles de Bruselas, la espinaca, el pomelo, las fresas, el kiwi y muchos otros. Por otro lado, suele adquirirse en los suplementos vitamínicos más utilizados.

No obstante, sus deficiencias aparecen o se desarrollan en pacientes con alteraciones digestivas o psicológicas, en ciertos esquemas alimentarios, en alcohólicos o por carencia de la enzima que transforma el gluconato en ascorbato.

En las deficiencias del complejo B, el cual se encuentra, en general, en los cereales de grano entero, el arroz integral, las carnes, la yema de huevo, los vegetales de hoja verde, la leche, los quesos, los pescados y otros, se generan diferentes alteraciones, dependiendo de cuál de ellas sea la que más falte. Si la deficiencia es de vitamina $B_{1}$, o tiamina, que ocasiona el beri-beri, el paciente presenta anorexia, debilidad muscular, alteraciones cardiacas y polineuritis, y en la piel puede presentarse un edema generalizado con sensación de plantas quemantes y lesiones sintomáticas en la boca con una lengua enrojecida y una sensación ardiente (16).

Si la deficiencia es de vitamina $\mathrm{B}_{2}$, o rivoflavina, se pueden apreciar lesiones en la mucosa oral, con queilitis, o una lengua lisa y despulida (figura 4.5a), o a parches llamada 'lengua geográfica' (figura 4.5b). En la piel, a veces aparece una descamación semejante a la de la dermatitis seborreica.

Si la deficiencia es de vitamina $\mathrm{B}_{3}$, niacina o acido nicotínico, se presentan lesiones en la piel acompañadas de alteraciones gastrointestinales y del sistema nervioso. Esta deficiencia se conoce como pelagra con la clásica tríada de dermatitis, diarrea y demencia. La dermatitis se caracteriza por lesiones eritemato-descamativas en las áreas expuestas que dejan una acentuada hiperpigmentación. 

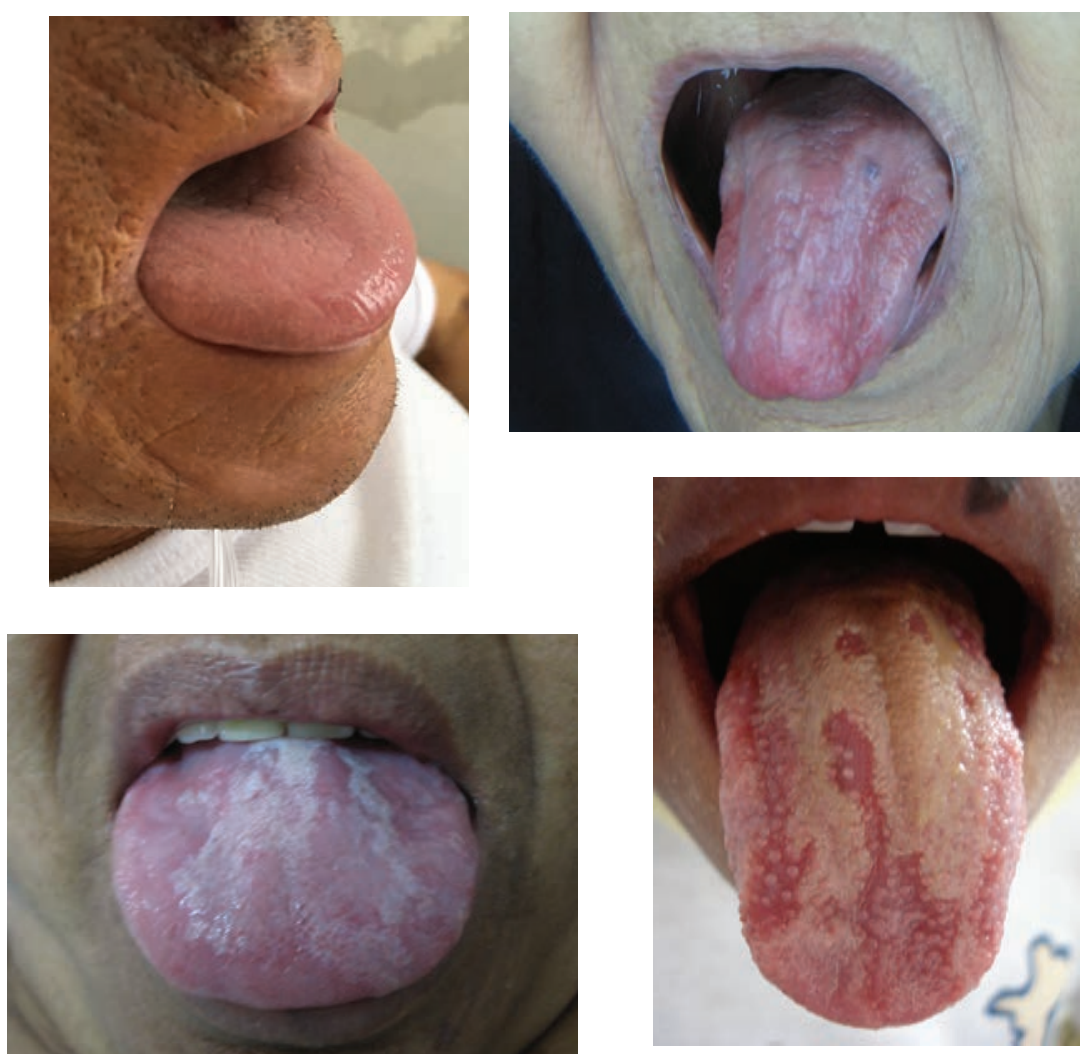

Figura 4.5. Lengua lisa y despulida, lengua geográfica. Las deficiencias del complejo B producen alteraciones en el pelo, las uñas y la cavidad oral. Si la deficiencia es de vitamina $\mathrm{B}_{2}$, o rivoflavina, se pueden apreciar lesiones en la mucosa oral, con queilitis, o una lengua lisa y despulida o a parches llamada 'lengua geográfica'

Si la deficiencia es de vitamina $B_{6}$, o fosfato de piridoxina, que participa en la formación de la piel y de las glándulas sebáceas, se puede encontrar una descamación semejante a la de la dermatitis seborreica, y alteraciones del sistema nervioso; se presenta con mayor frecuencia en individuos alcohólicos.

Si la deficiencia es de vitamina $\mathrm{B}_{8}$, o biotina, puede aparecer una alopecia difusa o un eritema y descamación semejante a la de la dermatitis seborreica, desencadenada por el déficit de vitamina $\mathrm{B}_{6}$, o lesiones eccematosas acompañadas de un pelo opaco y con caída del mismo. Esta última se presenta más en niños lactantes desnutridos o con alteraciones de la biotinidasa (17).

Si existe deficiencia de la vitamina $\mathrm{B}_{9}$, o ácido fólico, se presenta una anemia acompañada de alopecia difusa, exantema eritematoso, mioclonías y ataxia, esto debido a que este elemento es indispensable para la división y multiplicación celular. 
Si la deficiencia es de vitamina $B_{12}$, o cianocobalamina, contenida en las proteínas, principalmente del hígado, la carne, la yema de huevo, el pollo y la leche entre otros, necesaria para intervenir en la síntesis de ADN y ARN, se puede presentar una anemia perniciosa (18); además, puede acompañarse de una deficiencia de folatos que se presenta como una anemia megaloblástica, acompañada de gastritis atrófica, con lesiones en las mucosas semejantes a las aftas y que, también, se manifiestan con alguna alteración de la pigmentación de la piel, generalmente hipopigmentación y vitiligo.

La vitamina A se encuentra en los alimentos de origen animal, como el hígado, los huevos y los derivados lácteos. Otros alimentos que la contienen son las zanahorias, el brócoli, las espinacas y algunas frutas, como el melón y los albaricoques. $\mathrm{Su}$ deficiencia se manifiesta de diferentes maneras, ya que participa en la formación de la piel, las mucosas, los dientes y los huesos y favorece la visión en penumbra. En la piel, podemos encontrar xerosis, hiperqueratosis folicular y alopecia difusa.

La vitamina $\mathrm{D}$ es un esteroide derivado del colesterol; se sintetiza en el hígado y puede ser de origen vegetal o animal, y está contenida en los pescados o en la yema de huevo; al entrar en relación con los rayos ultravioleta forma colecalciferol o vitamina $\mathrm{D}_{3}$. Su principal función es la de estimular la absorción intestinal del calcio y de los fosfatos, necesarios para la formación de los huesos. Si la deficiencia de vitamina $\mathrm{D}$ sucede en la infancia se presenta raquitismo y, si es en la edad adulta, es menos notorio el compromiso óseo, aunque puede participar en el aumento de la caída del pelo (19).

También se han relacionado las bajas concentraciones de vitamina D con la aparición del síndrome metabólico.

La vitamina E, cuyas principales fuentes son las semillas de girasol, las almendras, el aguacate, la espinaca y la granola, parece tener múltiples funciones entre las cuales se destaca su función antioxidante capaz de prevenir la arteriosclerosis, la enfermedad cardiovascular y el cáncer. Su deficiencia no se hace evidente en alguna lesión particular en la piel.

La vitamina $K$, contenida en la alfalfa, los aceites vegetales y las verduras de hoja verde, es producida normalmente por las bacterias intestinales y es necesaria para el funcionamiento de varios factores involucrados en la coagulación. Su deficiencia por alteraciones en la absorción intestinal, afecta la síntesis hepática de estos factores de coagulación dependientes de la vitamina $\mathrm{K}$ y da como resultado la presencia de hemorragias. Es poco frecuente a menos que exista un daño hepático importante. 
Además de las alteraciones de la piel y de las mucosas, secundarias a la falta de ingestión de ciertos alimentos, también se presentan fenómenos alérgicos frente al consumo de algunos alimentos: unos con manifestaciones de índole gastrointestinal, con vómitos, cólicos o episodios diarreicos, es decir, la alergia no se presenta con síntomas como asma, urticaria y angioedema, dermatitis atópica, o aparición de cefaleas de tipo jaqueca, sino que también pueden afectar el sistema gastrointestinal.

Cuadro 4.1. Alteraciones nutricionales

\section{Deficiencia}

Vitamina C

Complejo B

$\mathrm{B}_{1}$, tiamina

$\mathrm{B}_{2}$, riboflavina

$\mathrm{B}_{3}$, niacina

$\mathrm{B}_{5}$, ácido pantoténico

$\mathrm{B}_{6}$, piridoxina

$\mathrm{B}_{8}$,biotina

$\mathrm{B}_{9}$, ácido fólico

$\mathrm{B}_{12}$, cianocobalamina

Vitamina A

Vitamina D

Vitamina E

Vitamina K

Zinc
Raquitismo

\section{Patología}

Escorbuto

Beri-beri

Pelagra

Anemia megaloblástica

Anemia perniciosa

Acrodermatitis enteropática.

\section{Alteraciones principales}

Síntesis del colágeno

Cicatrización

Queratosis pilar

Lesiones hemorrágicas en las mucosas

Edema, plantas quemantes, lengua sensible, ardiente

Queilitis, lengua lisa, geográfica

Diarrea, dermatitis, demencia

Dermatitis: lesiones eritemato-

descamativas en zonas fotoexpuestas

Hormigueo de manos

Dermatitis seborreica

Dermatitis eritemato-descamativa, seborreica, caída del pelo y opaco

Anemia, ataxia, alopecia, exantema

Anemia, gastritis, aftas, vitíligo

Xerosis, hiperqueratosis folicular y alopecia difusa

Disminución de absorción de calcio, caída del pelo

Hemorragias

Lesiones eritemato-descamativas, vesiculosas o ligeramente erosivas periorificiales 


\section{Enfermedad inflamatoria intestinal}

La enfermedad inflamatoria intestinal incluye enfermedades de carácter crónico que comprometen la estructura y el funcionamiento de cualquier parte del tracto gastrointestinal, desde la boca hasta el ano; el más importante es el compromiso inflamatorio transmural de la mucosa intestinal.

Las dos expresiones más importantes de la enfermedad inflamatoria intestinal son la enfermedad de Crohn y la colitis ulcerativa, pudiendo encontrarse un estado intermedio denominado colitis no clasificable o indeterminada, pero para mayor brevedad nos referiremos a las dos primeras, ya que la diferenciación se hace en la histopatología y puede corresponder a un espectro de la misma enfermedad. Las dos enfermedades se caracterizan por la presencia de episodios de dolor abdominal y diarrea, y se acompañan de manifestaciones cutáneas.

El diagnóstico de estas dos enfermedades inflamatorias intestinales que comprometen la mucosa de manera crónica, se basa en la arquitectura de la alteración a nivel patológico. De tal modo que si no obtenemos una biopsia en el momento más agudo del proceso no tendremos una certeza diagnóstica.

La prevalencia de estas entidades está determinada por la susceptibilidad genética de los individuos que la padecen y parece estar circunscrita a ciertas regiones geográficas dependiendo de cada país. El estrés y ciertos alimentos pueden desencadenar los síntomas.

De otra manera, podríamos decir que la respuesta inflamatoria en los individuos genéticamente susceptibles se desencadena por la alteración de la función de barrera de la mucosa intestinal (20), posiblemente por alteraciones de la inmunidad innata para el reconocimiento de ciertas bacterias o de alteraciones de la microflora entérica a ese nivel (21).

\section{Ileítis regional o enfermedad de Crohn}

La enfermedad de Crohn es una enfermedad inflamatoria crónica que afecta cualquier porción del tracto gastrointestinal, en especial, el intestino delgado y el colon. En los pacientes con enfermedad de Crohn se han demostrado alteraciones en el cromosoma 16, "con mutaciones en el gen NOD2 que da lugar a la expresión de receptores citosólicos para señales bacterianas, que se expresa en monocitos y en el factor nuclear activado (NF-KB)". Se encuentran relacionados también otros cromosomas, como el 12, 6 y el 14 (22). Los mediadores inflamatorios son del tipo Th1, y la flora entérica es un promotor de la respuesta inflamatoria por medio de las 
células $\mathrm{M}$ que median el paso de antígenos a través del epitelio. El antígeno entra en contacto con los linfocitos y los macrófagos, generando una selección de linfocitos Th1 con producción de metaloproteinasas (estromolisina 1) y destrucción tisular que luego, mediante diferentes interleucinas, recluta más células inflamatorias y el daño será mayor (23).

Juliao Baños, et al., encontraron que la localización más frecuente de la enfermedad de Crohn fue ileocólica en el $50 \%$, en íleo terminal el 18,8 \%, en colon el 28,1 \% y solo el 3,1\% tenía compromiso del tracto digestivo superior.

La inflamación es transmural con infiltrados inflamatorios crónicos, fibrosis que afecta todas las capas y desarrollo de granulomas no caseificantes, que quizá se relacionan con la respuesta anormal frente a la microflora entérica. El daño tisular parece esta mediado por un fenómeno autoinmunitario.

Los síntomas inespecíficos son la aparición de náuseas, anorexia, fatiga, fiebre, sudoración nocturna y pérdida de peso, y los específicos, la aparición de dolor abdominal, diarrea nocturna crónica y sangrado rectal (24). Se ha mencionado que el tabaquismo contribuye al desarrollo de la enfermedad.

La sospecha diagnóstica es clínica y se confirma con la endoscopia intestinal y la histopatología. Se encuentran úlceras con regiones indemnes de la mucosa intestinal. En la histopatología, se observa que la mucosa presenta un infiltrado inflamatorio compuesto por linfocitos y células plasmáticas junto a neutrófilos que aparecen en las criptas formando abscesos. Las criptas tienen distorsión estructural con disminución de ramificaciones y de células caliciformes. De tal manera que el diagnóstico es clínico, endoscópico e histopatológico.

Las manifestaciones cutáneas son frecuentes y, en ocasiones, suceden como extensión del proceso intestinal con aparición de abscesos perianales y fístulas. Otras dermatosis son la estomatitis aftosa, el eritema multiforme, el eritema nudoso, la vasculitis cutánea y el pioderma gangrenoso que pueden acompañarla.

\section{Colitis ulcerativa}

La colitis ulcerativa es una enfermedad inflamatoria crónica con una patogénesis poco clara. Se trata de una enfermedad del colon sin granulomas. En los pacientes con colitis ulcerativa se encuentran alteraciones de los cromosomas 3, 7 y 12 y de otros de otras señales inhibitorias tales como ECMI, HERC2, STAT3, PTPN2 (25). 
En los estudios de Genome Wide Association Scan Studies (GWAS), se ha encontrado que las variaciones del gen $I L 23 R$ hacen parte de una base genética común asociada a enfermedades inflamatorias como la colitis ulcerativa, la espondilitis anquilosante y la psoriasis, y variantes del gen PTPN2 en la diabetes de tipo 1. Un metanálisis de GWAS demostró que la mitad de los loci conocidos para la enfermedad de Crohn también son compartidos con la colitis ulcerativa (21).

Es importante entender que la expresión inflamatoria exagerada es la que genera la patología, y que es la base genética la que determina la respuesta inmune específica; por esta razón, existen variaciones de una población a otra. Para la colitis ulcerativa, existe una mayor tendencia de padecer la enfermedad en la raza caucásica y en los judíos ashkenazi (26), con una fuerte asociación entre la presencia de HLADR2 y el desarrollo de la enfermedad.

En el mundo, se estima que, por cada 100.000 habitantes, 396 sufren de enfermedad inflamatoria intestinal. En Norteamérica, se reportan anualmente un millón de casos (25). Se presenta, principalmente, entre los 15 y los 30 años de edad con un segundo pico de aparición entre los 50 y los 70 años. La colitis ulcerativa tiende a ser más común en el hombre y la enfermedad de Crohn más frecuente en las mujeres.

La afectación del colon en la colitis ulcerativa suele iniciarse en el recto y se extiende de manera variable y en forma proximal hasta el ciego, de tal forma que el 60 $\%$ de los pacientes tienen pancolitis; el $15 \%$, proctitis, y el $25 \%$, colitis izquierda (27). La enfermedad se presenta por brotes, en los que aumenta el grado de inflamación y el cuadro se agudiza con posteriores períodos de remisión. El cuadro clínico se caracteriza por dolor abdominal, diarrea, rectorragia, pujo y tenesmo, siendo muy importantes la rectorragia y la diarrea. En el estudio de Juliao Baños, et al., 35,5 \% tenía colitis extensa; $45 \%$, colitis izquierda, y 19,5\% proctitis. Las manifestaciones cutáneas más frecuentes son el pioderma gangrenoso, la pioestomatitis y el eritema nudoso.

\section{Manifestaciones extraintestinales en la enfermedad inflamatoria intestinal}

Se ha demostrado que la enfermedad de Crohn y la colitis ulcerativa presentan numerosas manifestaciones extraintestinales $y$, al menos, una tercera parte de los pacientes las expresan, entre ellas $15 \%$ se manifiestan en la piel (28). En un estudio colombiano, observacional y descriptivo, hecho en Medellín entre los años 2001 y 2009 , se encontró que el 80,7 \% de los pacientes con enfermedad inflamatoria intestinal presentaba colitis ulcerativa y que el $15,8 \%$ presentaba enfermedad de Crohn (29). 
En el artículo de revisión de Vargas, Jaramillo y Pérez de la Fundación Santafé de Bogotá en el 2006 (30), reportaron que estas manifestaciones extraintestinales de la enfermedad intestinal inflamatoria se pueden clasificar en dos grupos, las directamente relacionadas con la enfermedad inflamatoria intestinal, que se presentan a nivel cutáneo, musculoesquelético, hepatobiliar, ocular y metabólico, y las que solo aparecen asociadas a enfermedades autoinmunitarias.

A nivel musculoesquelético podemos encontrar artritis, osteoporosis y osteartropatía hipertrófica; a nivel hepatobiliar, colangitis esclerosante primaria, hepatitis autoinmune, cirrosis, hígado graso y granulomas hepáticos en la enfermedad de Crohn; a nivel ocular, uveítis, epiescleritis y escleromalacia. Se ha encontrado que el compromiso articular en la enfermedad de Crohn está presente en el $25 \%$ de los casos con artralgias y artritis. A nivel cutáneo, en el $15 \%$ de los casos, se encuentran lesiones de tipo eritema nudoso, pioderma gangrenoso o lesiones ulcerativas tipo 'aftas' en la boca; y a nivel ocular, en el $5 \%$ de los casos, epiescleritis, uveítis e iritis recurrente (24). La colitis ulcerativa se ha asociado a la colangitis esclerosante primaria, la espondilitis anquilosante, la periartritis migratoria, la sacroileítis, la uveítis y a lesiones cutáneas como el pioderma gangrenoso.

Para una clasificación más precisa, se toman las lesiones cutáneas encontradas en la colitis ulcerativa y en la ileítis regional, que hacen parte de la enfermedad primaria, y se dividen en específicas, relacionadas con la enfermedad, e inespecíficas o reactivas, es decir que si aparecen no necesariamente el paciente presenta una enfermedad inflamatoria intestinal. También se reportan otras enfermedades de piel no tan frecuentes o complicaciones secundarias de la misma enfermedad inflamatoria intestinal que se han llamado de tipo 'miscelánea' (29).

Las lesiones cutáneas específicas son: úlceras anorrectales, fisuras, abscesos, estomatitis, pioestomatitis y fístulas. Estas aparecen simultáneamente con el proceso gastrointestinal, en el momento de mayor actividad de la enfermedad y se dice que las más frecuentes son la estomatitis aftosa, las fisuras y las fístulas.

Las lesiones cutáneas inespecíficas, o reactivas, que se describen con mayor frecuencia son: el eritema nudoso, el pioderma gangrenoso (figura 4.6), las erupciones vesículo-pustulares, la vasculitis necrosante y la poliarteritis nudosa cutánea. 

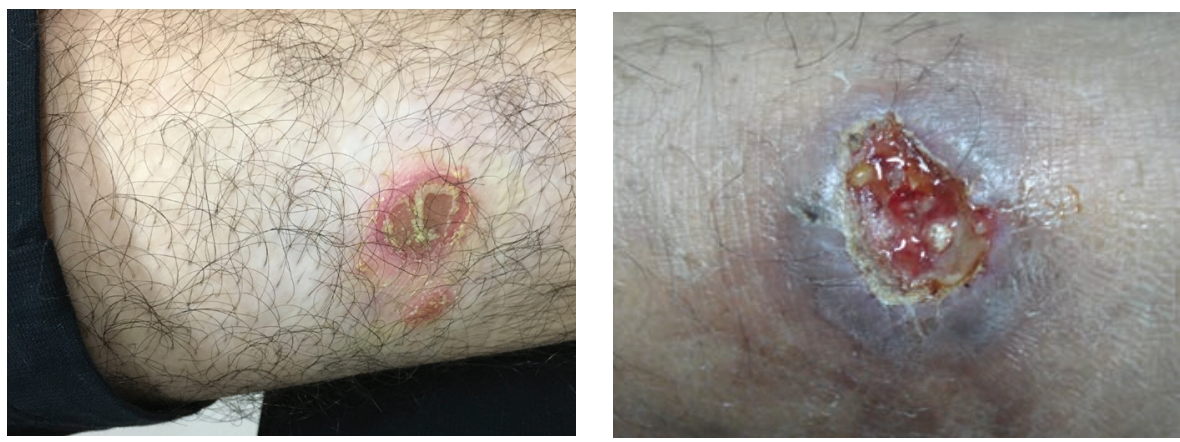

Figura 4.6. Pioderma gangrenoso. Se caracteriza por la aparición de una lesión de tipo pústula o un nódulo en la piel que rápidamente se ulcera y cuyos bordes son violáceos, enrollados con exudados mucopurulentos o hemorrágicos y que alcanza tamaños de 2 a 20 $\mathrm{cm}$. Puede presentarse en cualquier sitio y las lesiones pueden ser únicas o múltiples.

Entre las 'misceláneas' se encuentran la epidermólisis ampollosa adquirida, el vitiligo, la psoriasis y la amiloidosis secundaria, y debido a la alteración inflamatoria de la mucosa se puede encontrar, además, lesiones secundarias a la falta de absorción de ciertas vitaminas o elementos traza, con la aparición de lesiones como xerosis, acrodermatitis enteropática (deficiencia de zinc), púrpuras (deficiencia de vitamina $\mathrm{C}$ y $\mathrm{K}$ ), escorbuto, pelagra (deficiencia de niacina), glositis y queilitis (deficiencia de vitamina $\mathrm{B}_{1}, \mathrm{~B}_{3}, \mathrm{~B}_{6}$ y $\mathrm{B}_{12}$ ), o un eccema inespecifico (deficiencia de ácidos grasos esenciales) con alteraciones de las uñas y del pelo (deficiencia de proteínas) y, a veces, con retardo del crecimiento en los niños y los adolescentes que la padecen. Por otro lado, debe considerarse también la posibilidad de que aparezcan lesiones secundarias a la ingestión de fármacos para el control de la misma enfermedad inflamatoria intestinal.

Se ha descrito la enfermedad inflamatoria intestinal asociada a enfermedades autoinmunitariass, como la alopecia areata, el vitiligo, la urticaria, la anemia hemolítica, la púrpura de Henoch-Schönlein, la bronqueolitis obliterante, la espondilitis anquilosante, la pancreatitis, la cirrosis biliar primaria, la colangitis esclerosante primaria, la polimiositis, la diabetes mellitus, el fenómeno de Raynaud, la artritis reumatoidea, el síndrome de Sjögren, la enfermedad tiroidea, la granulomatosis de Wegener y la arteritis de Takayasu (30).

\section{Lesiones cutáneas en la enfermedad inflamatoria intestinal}

La estomatitis aftosa es el problema oral más comúnmente asociado a la enfermedad inflamatoria intestinal; afecta del 4 al $10 \%$ de los pacientes con colitis 
ulcerativa y del 4 al 20\% de pacientes con enfermedad de Crohn. Clínicamente son difíciles de distinguir de las lesiones de tipo herpes simple o de las que se ven en el síndrome de Beçhet. Se debe estudiar la aparición de una o más úlceras orales de fondo blanquecino, con bordes eritematosos bien definidos y con extensión y número variable. La etiología suele ser multifactorial; la enfermedad inflamatoria intestinal por sí misma puede causar estas lesiones en las mucosas tanto como la asociación con alteraciones nutricionales por déficit del complejo $\mathrm{B}$, de hierro, de folatos o de vitamina $\mathrm{B}_{12}(30)$.

Las fisuras y las fístulas aparecen principalmente en la enfermedad de Crohn $\mathrm{y}$, además de ser la manifestación cutánea más frecuente, suelen ser la primera manifestación de la enfermedad. La región más afectada es la del perineo (50 a 60 $\%)$, aunque a veces afectan la pared abdominal y la piel alrededor del ostoma, si hay una ostomía.

Las erupciones vésico-pustulares se encuentran asociadas a la colitis ulcerativa en 1 a $6 \%$ de los pacientes; aparecen como pústulas sobre placas eritematosas en la piel sana y, en contadas ocasiones, evolucionan a úlceras o a lesiones necróticas únicas o múltiples. Se pueden ver también en las mucosas y están relacionadas con los periodos de actividad de la enfermedad.

El eritema nudoso se presenta en 2 a $4 \%$ de los pacientes con enfermedad de Crohn y en el $11 \%$ de los pacientes con colitis ulcerativa, con aparición de nódulos inflamatorios en las extremidades inferiores. Estas lesiones son dolorosas y son más palpables que visibles dada su localización hipodérmica; se trata de una paniculitis del tabique, sin vasculitis, y con presencia de un infiltrado de neutrófilos en el período agudo y luego, con el tiempo, se encuentran infiltrados de linfocitos e histiocitos.

El síndrome de Sweet es una dermatosis neutrofílica febril que no es exclusiva de la enfermedad inflamatoria intestinal; es más, se asocia con mayor frecuencia a un trastorno linfoproliferativo o secundaria a diferentes infecciones. Suele acompañarse de fiebre, aparición de leucocitosis y afectación de otros sistemas -gastrointestinal, pulmonar, renal o del sistema nervioso central-, con aparición de placas papulosas eritematosas e infiltradas, más superficiales que las del eritema nudoso, una especie de estado intermedio entre una placa de eritema figurado o urticaria y una de eritema nudoso; suelen ser dolorosas y acompañarse de síntomas generales.

El pioderma gangrenoso es una enfermedad poco frecuente de la piel que fue descrita por Brunsting, Goeckerman y O'Leary en 1930 (31). Es una dermatosis neutrofílica no infecciosa. Se caracteriza por la aparición de una pústula o de un nódulo en la piel que rápidamente se ulcera y cuyos bordes son 
violáceos, enrollados con exudados mucopurulentos o hemorrágicos y alcanza tamaños de 2 a $20 \mathrm{~cm}$. Se presenta frecuentemente en la cara anterior de la tibia, aunque puede presentarse en cualquier sitio, y las lesiones ser únicas o múltiples.

Se estima una frecuencia anual de 1 caso por 100.000 habitantes o 2 casos por millón. La edad promedio de inicio está entre los 20 y los 50 años. Es una dermatosis neutrofílica que acompaña a las enfermedades inflamatorias intestinales, principalmente a la colitis ulcerativa, a una enfermedad reumatológica, como la artritis reumatoidea, o a una discrasia sanguínea. No hay mucha claridad sobre su patogénesis, si es una vasculitis, una dermatosis neutrofílica o un fenómeno reactivo.

Es una entidad poco frecuente, pero se estima que, al menos la mitad de los pacientes con colitis ulcerativa, pueden presentar la lesión (32). Tiene una mayor incidencia entre los 20 y los 50 años de edad, las mujeres son las más afectadas y solo el $4 \%$ de los casos se encuentra en la población pediátrica (30).

Comienza como una pústula estéril que progresa rápidamente a una úlcera dolorosa de tamaño y profundidad variables de bordes eritemato-violáceos, con fondo granulomatoso y exudado hemorrágico o necrótico, única o múltiple, acompañada ocasionalmente de síntomas generales: fiebre, mialgias y artralgias. Ocurre comúnmente en los miembros inferiores (región pretibial), aunque puede presentarse en otros sitios diferentes. Tiene una tendencia a ubicarse en las zonas de trauma. Se asocia en el $74 \%$ de los pacientes con una enfermedad inflamatoria intestinal, más frecuentemente a la colitis ulcerativa que a la enfermedad de Crohn.

El pioderma gangrenoso, como fenómeno reactivo, no es exclusivo de la enfermedad inflamatoria intestinal y puede encontrarse asociado a diferentes procesos en los que también debe pensarse en caso de encontrar este tipo de lesiones ulcerativas, como son las enfermedades mieloproliferativas como la anemia aplásica, la trombocitopenia esencial, el linfoma de Hodgkin, la leucemia mieloide aguda y crónica, las gammapatías monoclonales, la mielofibrosis, el mieloma o la policitemia vera, en cuyo caso se pueden encontrar lesiones en las extremidades superiores. Además, puede asociarse a enfermedades reumatológicas, como la osteoartritis, la artritis psoriásica, la artritis reumatoidea, las artritis seronegativas, la espondilitis y el lupus eritematoso sistémico. De manera menos frecuente, se ha reportado en pacientes con acné, hepatitis crónica activa, deficiencias del complemento, diabetes mellitus, anemia de Falconi, hepatitis C, infección por el virus de la inmunodeficiencia humana, hemoglobinuria paroxística, cirrosis biliar primaria, sarcoidosis y granulomatosis de Wegener. 
El diagnóstico es clínico e histopatológico. Por los resultados de los estudios de inmunohistoquímica se sabe que existen integrinas aberrantes sobre los neutrófilos e inhibidores de la elastasa relacionados con los queratinocitos; algunas interleucinas y el factor de necrosis tumoral están aumentados.

Las úlceras se presentan con mayor frecuencia en las extremidades inferiores; las ulceraciones superficiales localizadas en los brazos y en la cara, como se mencionó anteriormente, se relacionan más con enfermedades hematológicas del tipo leucemia mieloide aguda. La presentación en niños es rara y se puede localizar en la región perianal o en la genital, pudiendo aparecer en el escroto. En ocasiones, es de naturaleza ampollosa. Se ha descrito un pioderma gangrenoso periostomal, posterior a las cirugías abdominales por neoplasias.

La histopatología no es específica. En la fase inicial, existe un denso infiltrado neutrofílico, con foliculitis profunda supurativa, y si la muestra se toma del centro de la úlcera se describe como una dermatitis purulenta con paniculitis y numerosos macrófagos e histiocitos. Cuando hay regresión de la lesión, que se puede presentar hasta en el $40 \%$ de los casos, se encuentra una vasculitis leucocitoclásica. Se han descrito otras alteraciones en la enfermedad inflamatoria intestinal, vasculitis necrosantes en los pacientes con colitis ulcerativa y poliarteritis nudosa cutánea en los pacientes con enfermedad de Crohn (33).

La historia clínica debe ser completa; en caso de existir lesiones sospechosas de pioderma gangrenoso -que pueden parecer simples lesiones pustulosas que aún no son ulcerativas y que hace pensar en un posible origen infeccioso- se debe tomar una muestra para gérmenes comunes que servirá para descartar la etiología infecciosa y obtener una biopsia de piel, que puede demostrar si se trata de un pioderma gangrenoso. Se adelanta un estudio del tracto gastrointestinal y se aclara si existe o no asociación con enfermedades reumatológicas o hematológicas, en cuyo caso se debe hacer un aspirado de médula ósea.

\section{Otras enfermedades gastrointestinales}

Existen otras enfermedades en las que simultáneamente hay alteraciones en la piel y en las mucosas con lesiones en el sistema gastrointestinal. En primer lugar, esto sucede en las enfermedades del tejido conjuntivo como son el lupus eritematoso sistémico, la esclerodermia y la dermatomiositis, en las que se puede afectar la piel y el tubo digestivo; estas enfermedades se analizan en el capítulo dedicado a ellas. 
Existen algunas enfermedades que se deben conocer porque presentan anormalidades congénitas de los vasos, a veces visibles en la piel o en las mucosas y que se presentan también en la mucosa del tubo digestivo y ocasionan sangrado digestivo. Es el caso del síndrome de Rendu-Osler-Weber en el que se encuentra una mucosa oral con ectasias vasculares, más notorias en la lengua y en la cavidad oral (figura 4.7), que pueden extenderse a lo largo del tubo digestivo y presentarse en otras zonas de la piel (34). Este síndrome también se ha descrito asociado a la cirrosis biliar primaria (35).

En segundo lugar está la angiomatosis de tipo blue rubber bleb nevus (36) en la que se encuentran múltiples malformaciones venosas y hemangiomas en la piel (hemangioma neonatal difuso), que se ven como lesiones angiomatosas de color azuloso y que, a veces, también aparecen en las vísceras con una frecuencia mayor de sangrado digestivo y anemia ferropénica; pueden comprometer el sistema nervioso central, el hígado y el músculo (37).

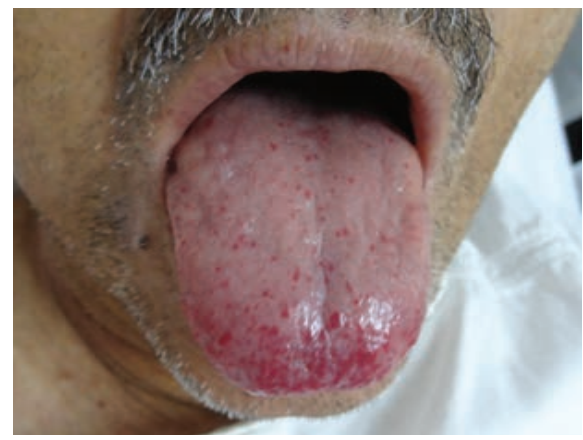

Figura 4.7. Síndrome de Rendu-Osler-Weber . En esta alteración genética, se encuentra una mucosa oral con ectasias vasculares, más notorias en la lengua y en la cavidad oral, que pueden extenderse a lo largo del tubo digestivo y presentarse en otras zonas de la piel.

Finalmente, en algunos trastornos del tejido elástico y conjuntivo también se alteran los vasos, con fácil extravasación de la sangre como sucede en los pacientes con pseudoxantoma elástico en los que se encuentran unas pápulas amarillentas en el cuello y en las axilas acompañadas de un trastorno de hiperelasticidad. Asimismo, en los pacientes con síndrome de Ehrles-Danlos, con alteración del colágeno, en los que el aumento de la elasticidad es notorio en las extremidades, unido a una tendencia al sangrado que se hace evidente en la piel, con aparición de equimosis, y en la mucosa gastrointestinal con aparición de sangrado gastrointestinal.

Existen otros cuadros en los que se encuentra simultáneamente la aparición de lesiones en la piel y en el sistema gastrointestinal; entre ellos los más relevantes son la dermatitis herpetiforme con lesiones de tipo ampolla, la púrpura de Henoch- 
Schönlein con púrpura palpable y el síndrome de Behçet, con estomatitis aftosa en la mucosa oral y en la genital asociada a otras alteraciones secundarias a la vasculitis.

La dermatitis herpetiforme es una enfermedad ampollosa muy pruriginosa, llamada así o enfermedad de Dühring-Brocq. Se asocia a una enteropatía por sensibilidad al gluten, de curso crónico con períodos de remisión y de exacerbaciones, que se conoce con el nombre general de enfermedad celiaca.

Las lesiones cutáneas se caracterizan por la aparición de ampollas desde muy temprana edad. Estas lesiones ampollosas son tensas y, a veces, muy pequeñas, de 0,3 a $0,8 \mathrm{~cm}$ y pueden semejar un eccema. Se presentan en el tronco y en las superficies extensoras de las extremidades -rodillas y codos-, y en los glúteos, aunque pueden extenderse a toda la extremidad (figura 4.8). En la histopatología se encuentran unos infiltrados neutrófílicos en la dermis papilar, con presencia de microabscesos y depósitos granulares de IgA en la unión dermoepidérmica. Existe otro proceso ampolloso similar, pero sin enteropatía, que es la dermatitis herpetiforme lineal por $\operatorname{Ig} \mathrm{A}$.

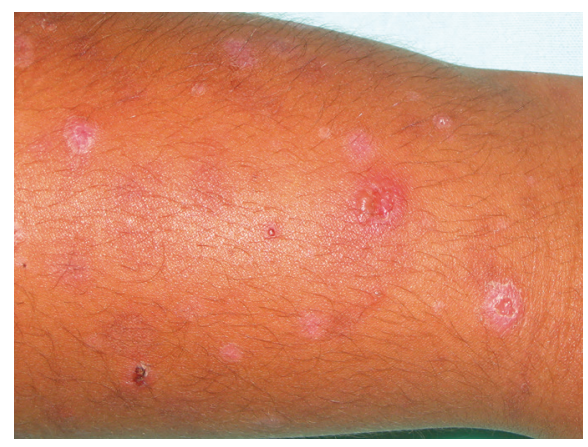

Figura 4.8. Dermatitis herpetiforme. Las lesiones cutáneas se caracterizan por la aparición de ampollas tensas y a veces son muy pequeñas, de $0.3 \mathrm{a} 0.8 \mathrm{~cm}$, pueden semejar un eccema. Se presentan en tronco y superficies extensoras de extremidades, tales como rodillas codos, glúteos, pero puede extenderse a toda la extremidad.

Cuando se encuentre un paciente con dermatitis herpetiforme, se debe investigar la enfermedad celiaca e introducir al paciente en una dieta libre de gluten. Se ha mencionado que algunos péptidos del gluten interactúan con la enzima tisular denominada transglutaminasa (TTG) que despierta la respuesta inmunitaria para el montaje de anticuerpos IgM e IgA frente a esta TTG, y frente a la gliadina, y por reacción cruzada se montaría una respuesta frente a algún elemento de la unión epidérmica. La alteración que se produce en las uniones celulares da lugar a las ampollas. 
Es importante recordar que, además del manejo inicial con una dieta libre de gluten, se debe establecer un tratamiento con diamino-difenil-sulfona o dapsona.

No se debe olvidar que la dermatitis herpetiforme se puede asociar a otras alteraciones autoinmunitarias y con mayor frecuencia a las enfermedades tiroideas. Una tercera parte de los pacientes con dermatitis herpetiforme tiene enfermedad tiroidea.

La dermatitis herpetiforme y la enfermedad celiaca tienen una fuerte asociación con los antígenos de histocompatibilidad de clase II, DR3 y DQw2 y con los alelos DQ A1* 0501 y B1 0201 del cromosoma 6 (38).

La púrpura de Henoch-Schönlein es otro fenómeno en el que aparecen lesiones en la piel y sintomatología gastrointestinal, secundarias al depósito de complejos inmunes en los vasos sanguíneos como consecuencia de una reacción cruzada posterior a una infección faríngea por estreptococo $\beta$ hemolítico (figura 4.9).
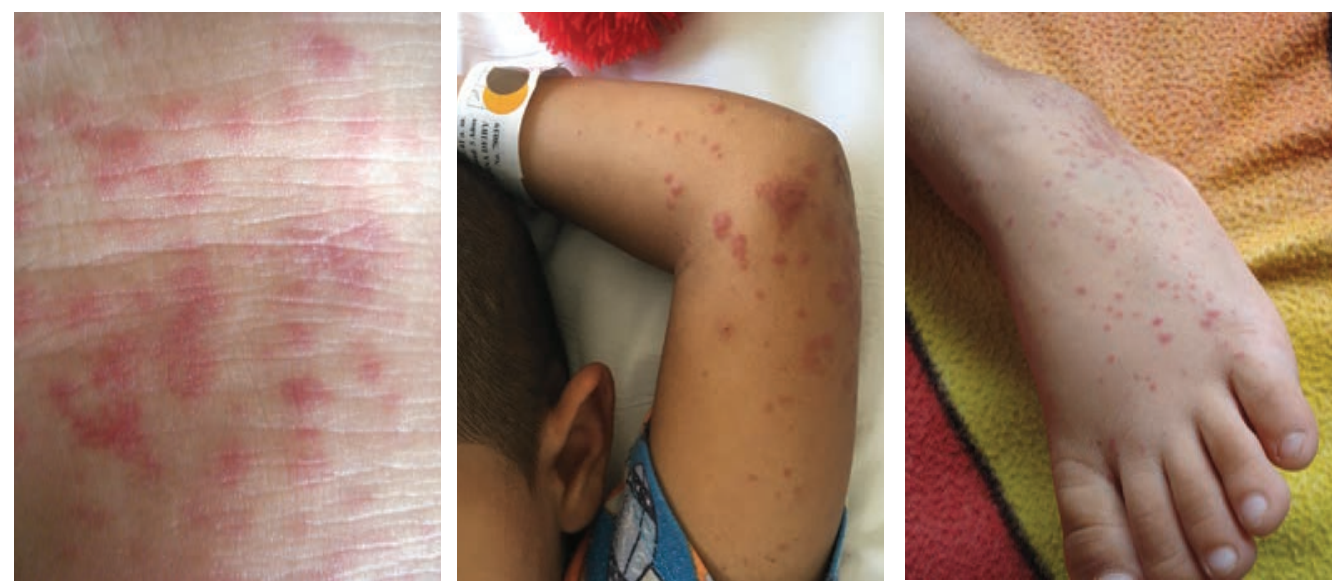

Figura 4.9. Púrpura palpable de Henoch-Schönlein. Como respuesta a un proceso infeccioso, se forman complejos inmunes del tipo IgA, cuyos depósitos alrededor de los vasos sanguíneos producen una vasculitis que se expresa con la aparición de unas lesiones papulosas elevadas de color púrpura, en las que, a veces, se ve una zona central más rojiza u oscura, casi como si se pudiera ver el vaso comprometido que se ha llamado también 'púrpura palpable' Aparece con mayor frecuencia en las extremidades inferiores y es muy pruriginosa; se acompaña de un fuerte dolor abdominal, debido al mismo fenómeno de vasculitis en la mucosa gastrointestinal.

Los depósitos de $\operatorname{IgA}$ alrededor de los vasos sanguíneos producen una vasculitis que se expresa con la aparición de unas lesiones papulosas elevadas de color púrpura, en las cuales a veces se aprecia una zona central más rojiza u oscura, 
casi como si se pudiera ver el vaso comprometido que se ha llamado también 'púrpura palpable'. Aparece con mayor frecuencia en las extremidades inferiores y es muy pruriginosa; se acompaña de un fuerte dolor abdominal, debido a que el mismo fenómeno de vasculitis se está presentando en la mucosa gastrointestinal. Puede llegar a comprometer otros órganos y si el compromiso renal es importante deja lesiones en él y de esto depende el pronóstico del evento.

El síndrome de Behçet es una enfermedad crónica, sistémica, de vasculitis. Tiene una prevalencia entre 20 y 421 individuos por cada 100.000 habitantes y es más frecuente en los países del Mediterráneo, asociada al complejo mayor de histocompatibilidad HLA-B51 y HLA-B51/B5 (39).

Se caracteriza por la aparición de ulceraciones orales y genitales e inflamación ocular (uveítis, células en el humor vítreo y vasculitis en la retina). Puede presentar compromiso del tronco cerebral, con cuadros de confusión con psicosis y con síndromes meningo-encefálicos o de hipertensión endocraneana, y acompañarse de otras lesiones en la piel como eritema nudoso y lesiones pápulo-pustulares.

\section{Enfermedades hepatobiliares y pancreáticas}

\section{Enfermedades hepatobiliares}

El hígado cumple una función muy importante en la filtración y en el almacenamiento de la sangre y del hierro, en el metabolismo de carbohidratos, proteínas y grasas, en la producción de muchas proteínas, incluidos los factores de la coagulación, y en la producción de la bilis. Se reconoce una asociación entre las enfermedades hepáticas y la piel, es decir, existe una interacción entre estos dos sistemas. En enfermedades como la hemocromatosis, la sarcoidosis, la dislipidemia, la histiocitosis o en la deficiencia de a 1 antitripsina, los dos órganos pueden estar afectados. Los individuos con enfermedad hepática crónica presentan con frecuencia lesiones en la piel; las que observamos con más frecuencia son: la ictericia (figura 4.10a), las telangiectasias (figura 4.10b) y el eritema palmar (figura 4.11) (40). Si las tres están presentes, el paciente podría tener una cirrosis; si encontramos, además, la presencia de prurito, hiperpigmentación, ictericia y xantomas podemos estar ante un paciente con una cirrosis biliar primaria.

La ictericia se refiere a una coloración amarillenta de la piel, las escleróticas y las membranas mucosas, que resulta del exceso de bilirrubinas en la sangre y su depósito en estos tejidos. Se hace notoria si las concentraciones de la bilirrubina son de 2,5 a $3 \mathrm{mg} / \mathrm{dl}$. 

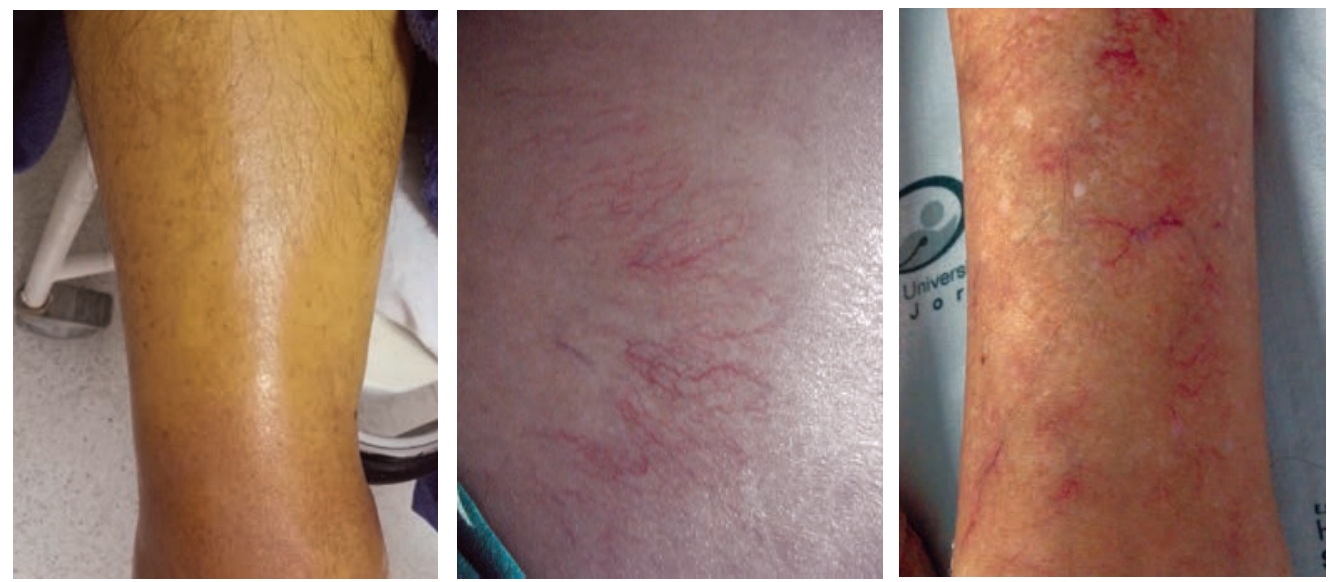

Figura 4.10 Ictericia, telangiectasias. En la hepatitis, el hallazgo más característico es el cambio de la coloración de la piel y de las mucosas, es decir, la ictericia; además, pueden aparecer alteraciones vasculares, prurito y lesiones de tipo exantema, urticaria o vasculitis.

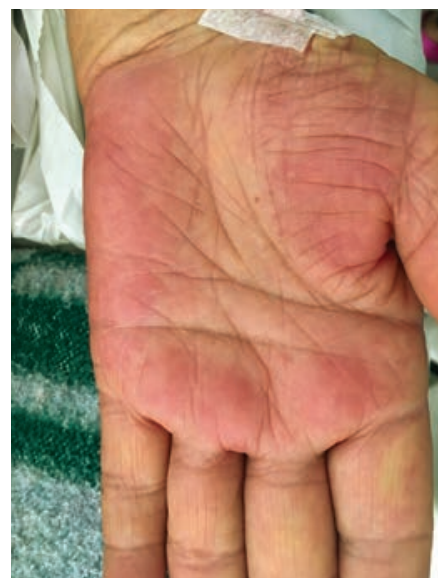

Figura 4.11. Eritema palmar. Estas manifestaciones suelen observarse con frecuencia en los pacientes con alteraciones hepáticas.

Debe distinguirse de otros procesos que producen una coloración amarilla o naranja, principalmente, en las palmas de las manos y en las plantas de los pies, como son la carotinemia por el exceso en el consumo de carotenos contenidos en las frutas y en las verduras de color amarillo, o una coloración naranja por el exceso de licopenos contenidos en el tomate. La diferenciación es fácil teniendo en cuenta que en la ictericia, la pigmentación amarilla compromete las escleróticas y las mucosas. 
Las dilataciones de los capilares, o telangiectasias, también llamadas 'arañas vasculares', por la forma que tienen ya que salen ramificaciones de un punto central que, en ocasiones, es ligeramente más papuloso, pueden aparecer en cualquier parte del cuerpo. Se ven con mayor frecuencia en el rostro, en la parte alta del tronco y en las extremidades superiores. No son exclusivas de la alteración hepática, pueden ser incluso hereditarias en cuyo caso son más frecuentes en la parte alta de la espalda o en las mejillas, o aparecen como lesiones névicas pequeñas, llamadas 'nevos rubí, que suelen aparecer después de los 40 años.

Sin embargo, si aparecen muchas de estas lesiones puntiformes o de crecimiento rápido o aumentan de tamaño en poco tiempo es importante indagar sobre la posibilidad de algún proceso anormal que explique la existencia de una alteración hepática, una enfermedad hepatorrenal, un aumento de los estrógenos internos o externos, o como parte de otro fenómeno que altere el funcionamiento hepático.

Los otros hallazgos constantes en las alteraciones hepáticas son el enrojecimiento palmar, más notorio quizá en la región hipotenar, llamado 'eritema palmar' que quizá sea causado por un aumento de las prostaciclinas y del óxido nitroso (41), y la sensación de prurito que también es un síntoma muy importante que aparece acompañando, generalmente, las obstrucciones de los conductos biliares y, en ocasiones, lleva a la presencia de lesiones similares al prurigo, con zonas papulosas más pigmentadas y con liquenificación.

Si el paciente viene, además, con algún estado consuntivo o si por la misma enfermedad hepática resulta en una mala absorción de las proteínas, los carbohidratos, las vitaminas y los elementos traza, esta falta de nutrientes se hace presente con las alteraciones cutáneas ya descritas por la falta de dichos nutrientes y presentará, además, una esteatorrea (42).

\section{Colestasis}

Se llama así al fenómeno por el cual se quedan en el hígado ciertas sustancias que no pueden ser excretadas por los conductos biliares y que aumentan los ácidos y las sales biliares en la sangre. Este aumento, al igual que el de las bilirrubinas, se relaciona con las manifestaciones cutáneas de la colestasis hepática en la piel, que son la ictericia y una sensación de picazón, llamada prurito (43).

Este prurito suele iniciarse en las palmas y en las plantas y luego puede generalizarse; aparece discreto en la colestasis por el embarazo, después del consumo de ciertos medicamentos, como los anovulatorios, los anabolizantes, la eritromicina y la fenotiazina, o más intenso en el $100 \%$ de los pacientes con cirrosis biliar primaria 
y, en ellos, el síntoma del prurito antecede por años a la aparición de la ictericia. Se presenta en pacientes con lesiones tumorales extrahepáticas. No suele asociarse a la hepatitis infecciosa. Se ha descubierto que puede relacionarse también con un incremento del ácido lisofosfatídico derivado de la lisofosfatidilcolina por acción de la enzima autotaxina y parece ser el principal factor en la inducción del prurito (44).

En las obstrucciones de las vías biliares depende de la magnitud de las mismas: si el prurito es leve y transitorio puede ser debido solo a una obstrucción por cálculos en los conductos biliares, pero si es intenso y prolongado, posiblemente, se trata de una obstrucción tumoral. El prurito generalizado se acompaña de escoriaciones, lesiones eccematosas (figura 4.12), o lesiones de tipo prurigo, es decir, lesiones de tipo pápulas decapitadas por el rascado.
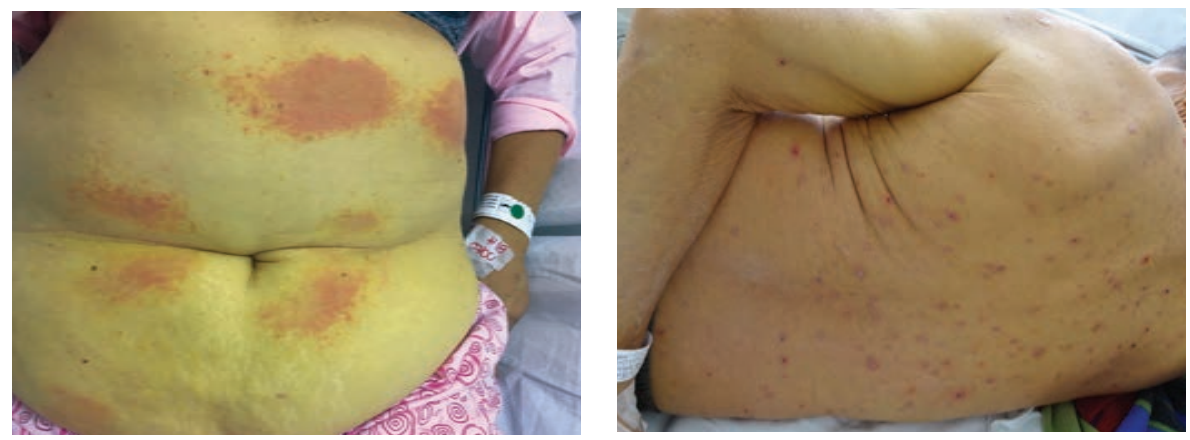

Figura 4.12. Ictericia, placas eccematosas en la obstrucción biliar. El prurito generalizado se acompaña de escoriaciones, lesiones eccematosas o lesiones de tipo prurigo.

Si la ictericia es leve y transitoria podemos estar ante una enfermedad de Gilbert, si es persistente puede tratarse de una hepatitis colestásica como sucede si la paciente está embarazada o si toma anticonceptivos, o puede estar asociada a una colangitis esclerosante o a una cirrosis biliar primaria.

El síndrome de Gilbert es una alteración hereditaria multifactorial asociada con un aumento de la bilirrubina (hiperbilirrubinemia no conjugada) en sangre y, por lo general, no presenta síntomas o son mínimos, o puede acompañarse de cansancio y una leve ictericia. Se presenta después de un largo ayuno o tras no haber dormido lo suficiente. Generalmente, pasa desapercibido, pero existen algunos reportes en pacientes que refirieron cambios discretos tales como picazón general, xerodermia o descamación leve, manifestaciones bucales de tipo aftas y alteraciones en las uñas. 
A continuación, se describen algunas de las lesiones cutáneas más frecuentes en alteraciones como la cirrosis, la hipertensión portal, las hepatitis o las relacionadas con su infección.

\section{Cirrosis e hipertensión portal}

En la mayoría de los pacientes con cirrosis se presentan numerosos signos cutáneos que son muy útiles para el diagnóstico. Son frecuentes las lesiones vasculares llamadas telangiectasias en forma de arañas (figura 4.13) que se presentan por la vasodilatación de los vasos pequeños y se localizan en las áreas expuestas al sol como la cara, los antebrazos, las manos y la parte superior del tórax. También es frecuente encontrar un eritema palmar y lesiones secundarias a las alteraciones de la coagulación que se manifiestan por lesiones de color púrpura o violáceas en la piel, o se acompañan de sangrados, como epistaxis, sangrados gingivales o, en etapas más avanzadas, otros más importantes, como sucede cuando se presenta una hemorragia digestiva alta a consecuencia de la presión venosa aumentada y la existencia de várices esofágicas por la hipertensión portal, en cuyo caso la ascitis y la encefalopatía porto-sistémica están acompañando el cuadro. La piel se puede ver ligeramente más pigmentada y los vasos venosos se hacen más visibles en el tronco, generalmente en la zona periumbilical y hacia arriba del ombligo, en lo que se ha llamado aumento de la circulación colateral por el incremento de la presión venosa.
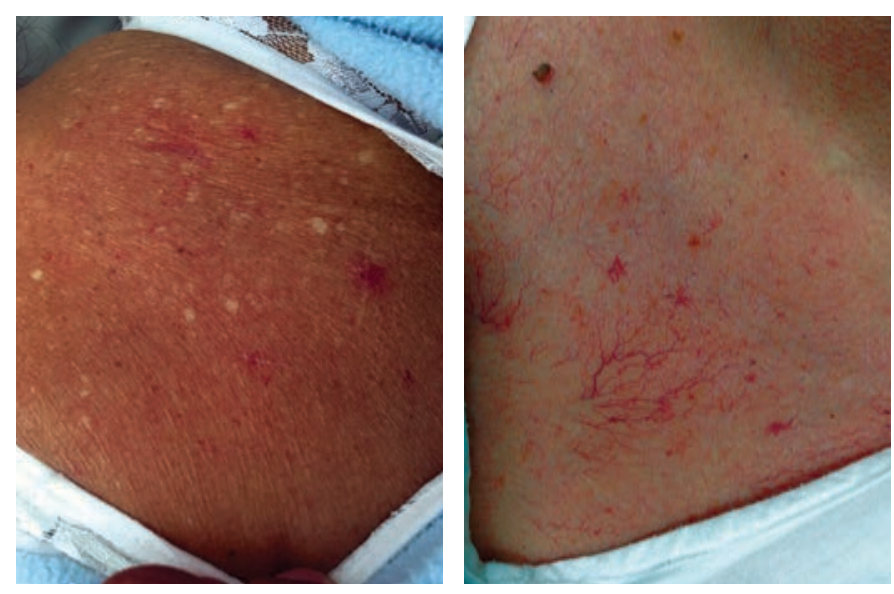

Figura 4.13. Cirrosis e hipertensión portal. En los pacientes cirróticos con hipertensión portal es frecuente encontrar las lesiones vasculares llamadas 'telangiectasias', en forma de arañas, que se presentan por la vasodilatación de los vasos pequeños.

También se puede encontrar una coloración rojiza o violácea de la lúnula y se han descrito uñas blanquecinas, opacas con una banda hiperpigmentada distal de 1 a $2 \mathrm{~mm}$ de grosor, conocidas como 'uñas de Terry' (45). Asimismo, se pueden ver 
alteraciones en el vello corporal, con pérdida en los antebrazos, en las axilas y en el pubis. En los varones hay menos vello en la cara y en el pecho, y una distribución de aspecto femenino a nivel púbico $y$, a veces, se acompaña de atrofia testicular y ginecomastia.

En la cirrosis biliar primaria, la manifestación más importante es el prurito, un tipo de alteración autoinmunitaria más frecuente en la mujer. Se inicia en las palmas y en las plantas y luego se extiende a toda la superficie corporal (46). Cuando es intenso se acompaña de las lesiones que dejan las huellas del rascado con hiperpigmentación cutánea.

También, se describe en estos pacientes, el aumento de la frecuencia de xantomas y xantelasmas -pápulas amarillentas por materiales de depósito frecuentes en los párpados-, secundarios a dislipoproteinemias con aumento de los trigliréridos y con bajos niveles de colesterol HDL (47).

Asimismo, en estos pacientes se pueden presentar lesiones de tipo liquen rojo plano (figura 4.14), caracterizadas por la aparición de pápulas aplanadas, poligonales, de color púrpura, con estrías centrales -llamadas estrías de Wickham-, muy pruriginosas, en la cara anterior de los tercios inferiores de los antebrazos, el cuello y las extremidades inferiores o de manera diseminada; suelen comprometer los folículos pilosos y la mucosa oral con lesiones blanquecinas con aspecto de liquen con ramificaciones que, a veces, también pueden verse de color púrpura. También, se ha descrito la presencia de liquen rojo plano asociado a la hepatitis $\mathrm{C}$ y menos frecuentemente a la hepatitis B o en la enfermedad inflamatoria intestinal (48). De cualquier manera, cuando un paciente presente un liquen rojo, debe investigarse la posibilidad de alguna alteración de naturaleza hepatobiliar.

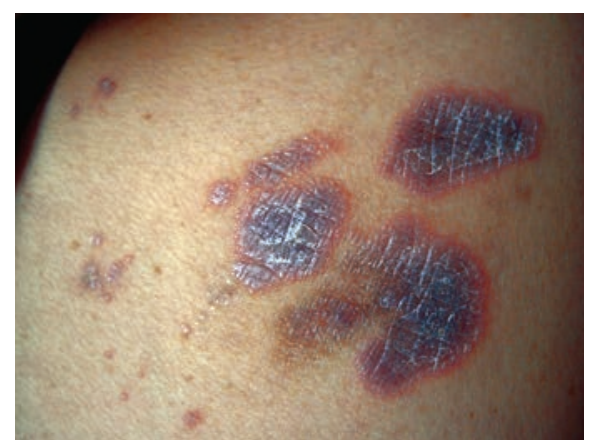

Figura 4.14. Liquen rojo plano. Se caracteriza por la aparición de lesiones papulares planas, poligonales, de color púrpura, con tramas centrales blanco grisaseas (estrías de Wickham) muy pruriginosas; se localizan en las muñecas y en las superficies de flexión de las extremidades para extenderse posteriormente a toda la superficie corporal y pueden afectar las mucosas y el cuero cabelludo, suele acompañar a enfermedades hepáticas o del conducto biliar, tales como la hepatitis $\mathrm{C}$ y la cirrosis biliar primaria. 
En la cirrosis biliar secundaria por la obstrucción prolongada parcial o completa del colédoco o de sus ramas principales, o como complicación de una colangitis primaria esclerosante -trastorno inmunitario progresivo del árbol biliar intrahepático y extrahepático-, se puede encontrar ictericia y prurito, además de fiebre y dolor en el hipocondrio derecho.

\section{Hepatitis}

En las hepatitis, sobre todo en las de origen viral, el hallazgo más característico es la aparición de una coloración amarillenta de la piel y las mucosas, es decir, la ictericia y pueden aparecer prurito y lesiones de tipo exantema, urticaria o vasculitis.

Se sabe que las hepatitis más frecuentes y conocidas son la A, la B y la C. Las lesiones en piel varían dependiendo de si el proceso es agudo, como en la hepatitis A, o si se prolonga en el tiempo como en las hepatitis B o C. En las hepatitis se han descrito lesiones en la piel asociadas a las alteraciones por el exceso de inmunoglobulinas o de complejos inmunes que se depositan en los vasos; son la urticaria por vasculitis, la crioglobulinemia (49), la poliarteritis nudosa o el síndrome de Gianotti-Crosti.

El síndrome de Gianotti-Crosti es una acrodermatitis pápulo-vesicular frecuente en niños, acompañada de alteraciones generales como febrícula y malestar general discreto (50). Esta erupción pápulo-vesicular, o liquenoide, que se presenta en forma bilateral, principalmente en las extremidades y más en las manos y en los pies, se puede ver en la cara y en los glúteos, tiene una duración de dos a tres semanas y se ha asociado a las hepatitis virales A o B y, posiblemente, a otras infecciones virales como citomegalovirus, Epstein-Barr y otros.

En la hepatitis A no son tan frecuentes las alteraciones de la piel, aunque existen reportes de alteraciones secundarias a la crioglobulinemia (51), al síndrome de Gianotti-Crosti y a la urticaria que incluso antecede la ictericia y que, por esta razón, se habla de una hepatitis anictérica.

En la hepatitis B se encuentran diversas manifestaciones cutáneas: pueden aparecer unas lesiones máculo-papulares urticariformes, semejantes a las que aparecen en la enfermedad del suero (prototipo dela reacción por complejos inmunes) en cerca del $10 \%$ de los pacientes (52). Estas lesiones dérmicas de tipo urticaria también pueden ser parte de una urticaria por vasculitis, con lesiones de mayor duración y que dejan lesiones de color púrpura. Se acompañan de poliartralgias, proteinuria y hematuria. También se puede presentar un eritema nudoso (53) o una poliarteritis nudosa, que es una vasculitis sistémica necrosante, con lesioness de tipo púrpura, nódulos ulcerados o livedo reticularis; el $50 \%$ de estos pacientes presentan anticuerpos de superficie positivos para el virus de la hepatitis B (HbsAg) (54). 
La hepatitis C crónica se acompaña en algunas ocasiones de lesiones cutáneas de livedo reticularis, caracterizado por la visualización de una especie de malla vascular azul-rojiza presente en las extremidades y aun en el tronco, que se acentúa con la exposición al frío. Puede asociarse con una urticaria con vasculitis leucocitoclásica (55) con lesiones de aspecto de púrpura (figura 4.15), o urticariformes (56) que producen prurito. Puede presentarse como una crioglobulinemia (57) (inmunoglobulinas séricas que precipitan a bajas temperaturas). Son frecuentes en el mieloma múltiple y la macroglobulinemia, aunque también se han descrito en hepatopatías y, especialmente, asociadas a las hepatitis B y C, y si existen crioglobulinas en el suero, se puede ver como una urticaria inducida por el frío como se ha visto en estos pacientes con infección por virus de la hepatitis C. Se han reportado otras lesiones de tipo eritema multiforme, eritema nudoso y otras. En el $20 \%$ de los casos se puede asociar a un liquen rojo plano (58). Se ha reportado también la posibilidad de alguna asociación entre la hepatitis C y el síndrome de Sjögren (59) ya que se han demostrado alteraciones de las glándulas salivales semejantes a las del síndrome de Sjögren en algunos pacientes con hepatitis C.

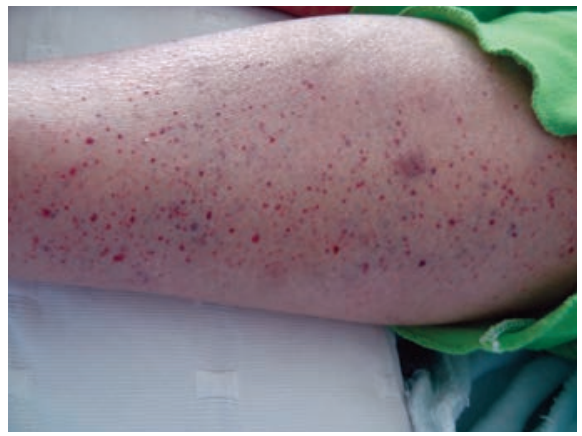

Figura 4.15. Hepatitis $\mathrm{C}$ y vasculitis. En la hepatitis, el hallazgo más característico es el cambio de la coloración de la piel y de las mucosas, es decir, la ictericia; además, pueden aparecer alteraciones vasculares, prurito y lesiones de tipo exantema, urticaria o vasculitis.

Finalmente, recordemos otros procesos que aparecen con relativa frecuencia en los que se ven lesiones de piel asociados a alteraciones hepáticas como son algunas porfirias, la hemocromatosis y el síndrome de Reynolds

\section{Porfirias}

Las porfirias se presentan cuando existe un déficit de alguna enzima que participa en la síntesis de la hemoglobina (60). Son un grupo numeroso de entidades en las que la acumulación de metabolitos intermedios (porfirinas) son las responsables de las manifestaciones clínicas y de laboratorio. En algunas de ellas no existen signos cutáneos, por lo que solo consideramos dos de ellas por ser las que presentan lesiones evidentes en la piel: la porfiria cutánea tarda y la porfiria eritropoyética. 
La porfiria cutánea tarda se produce por una disminución de la actividad de la enzima decarboxilasa del uroporfirinógeno, la cual participa en la síntesis del grupo hem en la formación de la hemoglobina en los glóbulos rojos. Puede ser hereditaria o adquirida. En ella se encuentran diversas lesiones en la piel de las zonas expuestas al sol debidas a la acentuada fragilidad cutánea; las más frecuentes son la aparición de escoriaciones y vésico-ampollas ante mínimos traumatismos en el dorso de las manos, que dejan un cambio de coloración de la piel y quistes de millo residuales y cicatrices. Además de estas lesiones ampollosas, se puede encontrar una hiperpigmentación y un aspecto esclerodermiforme de la piel acompañada de hipertricosis en la región malar, en la fronto-temporal y en las orejas. El diagnóstico se hace por el hallazgo del aumento de porfirinas en sangre, orina y heces. Existen algunos factores predisponentes (61) como son el consumo de alcohol, la ingestión de estrógenos en la mujer, la exposición a hidrocarburos halogenados utilizados en la producción de pesticidas, el aumento de hierro - es decir, la hemosiderosis hepática-, la hemocromatosis, la diabetes mellitus, las infecciones por el virus de la hepatitis C (62) o por el virus de la inmunodeficiencia humana. Se reporta un mayor riesgo de desarrollar carcinoma hepatocelular y linfoma.

La porfiria eritropoyética congénita es un trastorno menos común que se manifiesta con lesiones en piel de tipo urticaria y angioedema importante en las zonas de piel expuestas al sol.

\section{Hemocromatosis}

La hemocromatosis es una entidad en la cual existe una alteración genética con un patrón autosómico recesivo, que se evidencia por un trastorno en el metabolismo del hierro. El depósito local y generalizado de hierro en los tejidos es superior al normal y este exceso de hierro que se deposita en los tejidos los lesiona. El hígado es uno de los órganos más afectados y puede llegar a una cirrosis. Se presenta con una típica hiperpigmentación cutánea bronceada generalizada (figura 4.16), ligeramente más llamativa en las zonas expuestas al sol. Se han encontrado numerosas mutaciones, pero es importante tener en cuenta la C282Y y la H63D. Para aclarar la situación y llegar a su diagnóstico, se requiere confirmar los altos valores de hierro sérico y el aumento en la saturación de transferrina (63). 

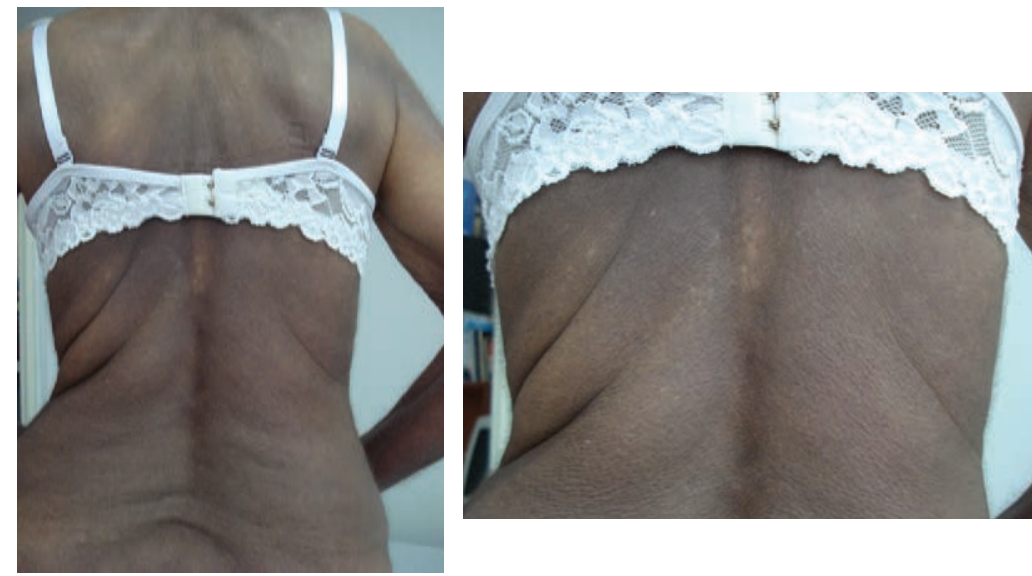

Figura 4. 16. Hemocromatosis. Se presenta con una hiperpigmentación cutánea bronceada generalizada, con una piel como aterciopelada, y ligeramente más llamativa en las zonas expuestas al sol; es secundaria al exceso de hierro por defectos en su metabolismo.

\section{Síndrome de Reynolds}

Se trata de la coexistencia de esclerosis sistémica o síndrome CREST (Calcinosis, Raynaud's phenomenon, Esophageal dysmotility, Sclerodactyly, and Telangiectasia) y cirrosis biliar primaria, con inflamación y destrucción de los conductos biliares asociado con otra enfermedad autoinmunitaria en el $50 \%$ de los casos. Los pacientes tienen alteraciones detectables en sangre como son SS positivos, con 9 a 29\% de ANA positivos de patrón anticentrómero y empieza la cirrosis biliar primaria de forma insidiosa con fatiga, prurito y sin ictericia (64).

\section{Enfermedades pancreáticas}

Existen algunas manifestaciones cutáneas asociadas a enfermedades pancreáticas que vale la pena mencionar. Se trata de la aparición de una equimosis periumbilical (signo de Grey-Turner) (figura 4.17) o de una equimosis en flancos (signo de Cullen) en casos de inflamación del páncreas, es decir, en una pancreatitis aguda. Se ha reportado, además, la aparición de una paniculitis pancreática o enzimática asociada a un adenocarcinoma de páncreas, en la que se presenta una necrosis grasa subcutánea; asimismo, un adenocarcinoma de páncreas asociado a una tromboflebitis migratoria. También está descrito un tipo de eritema figurado, llamado eritema migratorio necrolítico, que consiste en la aparición de lesiones eritematosas en cuyo borde existe una especie de denudación, es decir, una descamación como si 
el tejido del borde se fuera necrosando superficialmente, asociado a la presencia de un tumor de los islotes alfa del páncreas, un glucagonoma.

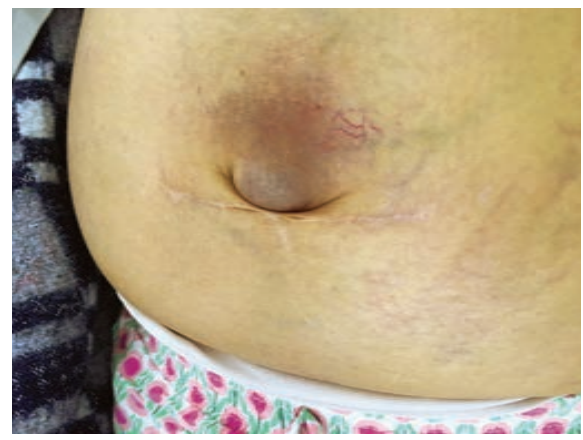

Figura 4.17. Signo de Grey-Turner. Cuando se presenta una inflamación del páncreas, se pueden observar unos fenómenos hemorrágicos secundarios al estiramiento que producen estos tejidos inflamados. Se trata de la aparición de una equimosis periumbilical.

\section{Alteraciones gastrointestinales, tumores benignos de piel y neoplasias}

Finalmente, se encuentra un grupo de síndromes -la mayoría de carácter hereditario, de transmisión autosómica dominante- con diferentes mutaciones que alteran los genes supresores de tumores. En ellos se presenta una poliposis intestinal asociada a la presencia de tumores benignos de tipo hamartoma en la piel y en otros órganos, en los que existe una predisposición a convertirse en neoplasias malignas (Véase cuadro 9.1)

Son poco frecuentes, desde 1 en 200.000 hasta 1 en 1'000.000 de individuos. Son los síndromes de Gardner, Cowden, Cronkhite-Canada, Peutz-Jeghers; también se pueden presentar pólipos intestinales asociados a neoplasias en el síndrome de Birt-Hogg-Dubé.

Las lesiones tumorales en la piel se caracterizan por pequeñas tumoraciones de $5 \mathrm{~mm}$ o menos, que varían desde color piel, ligeramente amarillentas, eritematoparduzcas, hasta más translúcidas en el rostro, principalmente, y, en algunos casos, en la mucosa oral. Lo que debe llamar la atención es que se encuentren numerosas, mínimo 5 lesiones.

El síndrome de Gardner un trastorno ligado a 5q21-q22, en el que se encuentra una poliposis adenomatosa familiar con hipertrofia congénita del epitelio 
pigmentario, asociado a múltiples lesiones tumorales de los tejidos blandos de tipo pilomatrixoma, tricoma múltiples, tumores desmoides u óseos (osteomas), quistes epidermoides, fibromas y lipomas (65). Estos pólipos pueden convertirse en malignos.

En el síndrome de Cowden, o síndrome de hamartomas múltiples, trastorno ligado a 10q23, en el que se encuentran los pólipos gastrointestinales asociados a hamartomas de diferente origen -ectodérmico, mesodérmico o endodérmico en múltiples órganos incluidas la piel y las mucosas- con presencia de papilomatosis oral, triquilemomas, neuromas mucosos que se acompañan de una queratosis distal (acral) o pits en las palmas y en las plantas (66). Existe un mayor riesgo de carcinoma de tiroides y de mama en estos pacientes, aunque pueden presentarse otros carcinomas, como el colorrectal o el de endometrio.

En el síndrome de Cronkhite-Canada, raro trastorno considerado no hereditario, se encuentran pólipos de tipo hamartoma en el tracto gastrointestinal asociados con alteraciones distróficas de las uñas, alopecia e hiperpigmentación cutánea; además, se puede presentar diarrea, hipoproteinemia, pérdida de peso y dolor abdominal (67). Los tumores malignos se pueden desarrollar en el tubo digestivo, como un carcinoma gástrico o de colon.

En el síndrome de Peutz-Jeghers (figura 4.18) se ha encontrado que la predisposición genética está asociada al compromiso de la cinasa de la serina treonina STK11, también llamada LKB1. Se acompaña de poliposis intestinal de tipo hamartoma; estos pacientes presentan unas lesiones pigmentarias mucocutáneas de tipo lentigo en la mucosa oral, en los labios y en las regiones perianal, periumbilical o en los genitales, excepcionalmente en otros lugares como las plantas y las palmas. Estos pólipos tienen un bajo potencial de convertirse en neoplasias malignas, pero, a veces lo hacen y pueden aparecer tumores en otros sitios como en la mama o o en el aparato genital femenino. Estas lesiones hiperpigmentadas pueden estar presentes al nacimiento o aparecer años después; se caracterizan por ser máculas de color marrón o negro de menos de $5 \mathrm{~mm}$ en los sitios anteriormente nombrados (68).

El síndrome de Birt-Hogg-Dubé es una genodermatosis rara, descrita en 1977, ocasionada por mutaciones del gen FLCN (foliculina), que actúa como supresor tumoral (69). Se presenta con aparición de tumores benignos derivados de la unidad pilosebácea de tipo fibrofoliculoma, tricodiscoma o ambos, asociados a neoplasias renales; también se ha encontrado la presencia de quistes pulmonares asociados con neumotórax y algunos casos de poliposis intestinal asociados con cáncer colorrectal (70). 


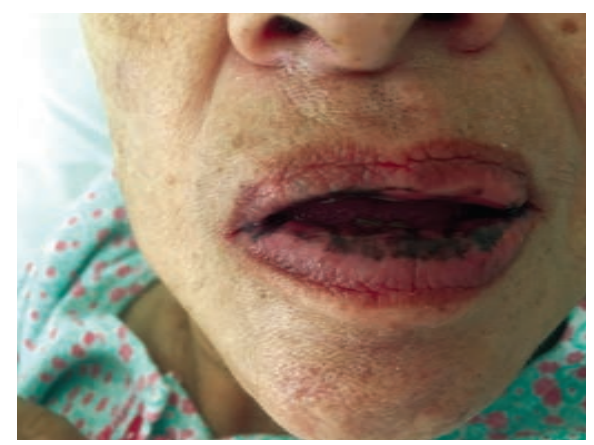

Figura 4.18. Síndrome de Peutz-Jeghers. Acompañando la poliposis intestinal de tipo hamartoma, estos pacientes presentan unas lesiones pigmentarias mucocutáneas de tipo lentigo en la mucosa oral, en los labios y en las regiones perianal, periumbilical o en los genitales, excepcionalmente en otros lugares como las plantas de los pies y las palmas de las manos.

Las lesiones tumorales benignas se ven como pequeñas lesiones tumorales lisas, de aspecto papuloso, de unos $0,5 \mathrm{~cm}$ de diámetro, de color piel, ligeramente rosado-amarillentas, localizadas generalmente en el rostro. Se requiere obtener una biopsia de las lesiones cutáneas para llegar al diagnóstico definitivo y se debe investigar la presencia de alguna alteración renal, pólipos intestinales o de otras alteraciones tumorales.

Algunos tumores también dan metástasis a la mucosa gastrointestinal como son los carcinomas hepatocelulares, el melanoma y, raramente, el carcinoma de pulmón; se manifiesta con un sangrado digestivo.

\section{Referencias}

1. Micoli G, Musumeci MD, Letizia M, Nasca MR. Epidemiologic analysis and clinical course of 84 consecutive cases of pemphigus in Eastern Sicily. Int J Dermatol. 1998;37:197-200.

2. Xiong LJ, Mao M. Current views of the relationship between Helicobacter pylori and HenochSchonlein purpura in children. World J Clin Pediatr. 2016;5:82-8.

3. Jaing TH, Yang CP, Hung IJ, Chiu CH, Chang KW. Efficacy of Helicobacter pylori eradication on platelet recovery in children with chronic idiopathic thrombocytopenic purpura. Acta Paediatr. 2003;92:1153-7.

4. Greaves MW. Chronic idiopathic urticaria and H. pylori: Not directly causative but could there be a link? Allergy CIin Immunol Int. 2001;13:23-6.

5. Hizal M, Tuzun B, Wolf R, Tuzun Y. The relationship between Helicobacter pylori IgG antibody and autologous serum test in chronic urticaria. Int J Dermatol. 2000;39:443-5.

6. Capella GL. Chronic erythema nodosum circumstantially linked with Helicobacter pylori 
infection: Where is the evidence? Dermatology. 2009;219:86.

7. Diaz C, O'Callaghan C, Khan A, Ilchyshyn A. Rosacea: A cutaneous marker of Helicobacter pylori infection? Results of a pilot study. Acta Derm Venereol. 2003;83:282-6.

8. Smith R, Mann N, Brave A. A low glicemic load diet improves symptoms in acné vulgaris patients: A randomized controlled trial. Am J Clin Nutr. 2007;86:107-15.

9. Becerril-Chihu G, Ruiz-Maldonado R. Manifestaciones cutáneas de las aminoacidurias. Actas Dermosifiliogr. 1998;89:75-85.

10. Kaimal S, Thappa D M. Diet in dermatology: Revisited. Indian J Dermatol Venereol Leprol. 2010;76:103-15.

11. Muehrcke RC. The fingernails in chronic hypoalbuminaemia; a new physical sign. Br Med J. 1956;1:1327-8.

12. Dinulos JGH, Zembowicz A. Case 32-2008: A 10-year-old girl with recurrent oral lesions and cutaneous bullae. N Engl J Med. 2008;359:1718-24.

13. Sehgal VN, Jain S. Acrodermatits enteropathica. Clin Dermatol. 2000;18:745-8.

14. Dharmasena A. Selenium supplementation in thyroid associated ophthalmopathy: An update. Int J Ophthalmol. 2014;7:365-75.

15. Kinsman R, Hood J. Some behavioral effects of ascorbic acid deficiency. Am J Clin Nutr $.1971 ; 24: 455-64$

16. Vila-Mas A, Puig-Sanz L. Manifestaciones cutáneas y enfermedades digestivas. Protocolos diagnósticos y terapéuticos en dermatología pediátrica. En: Protocolos diagnósticos y terapéuticos en dermatología pediátrica. ¿Ciudad?: ¿Casa editora?; 2007. p. 287-93.

17. Kiykim E, Kiykim A, Cansever MS, Zeybek CA. Biotinidase deficiency mimicking primary immune deficiencies. BMJ Case Rep. 2015;2015:bcr2014209275.

18. Abdulmanea AA, Alsaeed AH, Shaik AP, AlGahtani FH. Prevalence of pernicious anemia in patients with macrocytic anemia and low serum B12. Pak J Med Sci. 2014;30:1218-22.

19. Rosen CJ, Adams JS, Bikle DD, Black DM, Demay MB, Manson JE, et al. The non-skeletal effects of vitamin D: An Endocrine Society Scientific Statement. Endocrinol Rev. 2012;33:456-92.

20. Podolsky DK. Inflammatory bowel disease. N Eng J Med. 2002;347:417-29.

21. Nunes T, Fiorino G, Danese S, Sans M. Familial aggregation in inflammatory bowel disease: Is it genes or environment? World J Gastroenterol. 2011;17:2715-22.

22. Hendrickson BA, Gokhale R, Cho JH. Clinical aspects and pathophysiology of inflammatory bowel disease. Clin Microbiol Rev. 2002;15:79-94.

23. McGovern DP, Gardet A, Törkvist L, Goyette P, Essers J, Taylor KD, et al. Genome-wide association identifies multiple ulcerative colitis susceptibility loci. Nat Genet. 2010;42:332-7.

24. Hanauer SB, Sanborn W. The management of Crohn's disease in adults. Am J Gastroenterol. 2001;96:635-43

25. Loftus EV Jr, Sandborn WJ. Epidemiology of inflammatory bowel disease. Gastroenterol Clin North Am. 2002;31:1-20.

26. Roth MP, Petersen GM, McElree C, Vadheim CM, Panish JF, Rotter JI. Familial empiric risk estimates of inflammatory bowel disease in Ashkenazi jews. Gastroenterology. 1989;96:1016-20.

27. Fantobal A, Amaro P. Manifestaciones cutáneas de las enfermedades gastrointestinales. Gastr Latinoam. 2005;16:39-57.

28. Hanauer SB. Inflammatory bowel disease: Epidemiology, pathogenesis, and therapeutic 
opportunities. Inflamm Bowel Dis. 2006;12:S3-9.

29. Baños FJ, Ruiz-Vélez MH, Flórez-Arango JF, Donado-Gómez JH, Marin Zuluaga JI, Monsalve Arango C, et al. Fenotipo e historia natural de la enfermedad inflamatoria intestinal en un centro de referencia en Medellín, Colombia. Rev Colomb Gastroenterol. 2010;25:240-51.

30. Vargas C, Jaramillo C, Pérez I. Manifestaciones cutáneas de enfermedades inflamatorias gastrointestinales. Rev Colomb Gastroenterol. 2006;21:286-99.

31. Powell FC, Su WRD, Perry HO. Pyoderma grangrenosum: Classification and management. J Am Acad Dermatol. 1996;34:395-409.

32. Alavi A, Sajic D, Cerci FB, Ghazarian D, Rosenbach M, Jorizzo J. Neutrophilic dermatoses: An update. Am J Clin Dermatol. 2014;15:413-23.

33. Pineda-Ovalle LF. Enfermedad inflamatoria intestinal en Colombia: ¿Está cambiando nuestro perfil epidemiológico? Rev Colomb Gastroenterol. 2010;25:235-8.

34. Govani FS, Shovlin CL. Hereditary hemorrhagic telangiectasia: A clinical and scientific review. Eur J Hum Gen. 2009;17:860-71.

35. Macaluso FS, Maida M, Alessi N, Cabibbo G, Cabibi D. Primary biliary cirrhosis and hereditary hemorrhagic telangiectasia: When two rare diseases coexist. World J Hepatol. 2013;5:288-91.

36. Bean WB. Blue rubber bleb nevi of the skin and gastrointestinal tract. In: Bean WB, editor. Vascular spiders and related lesions of the skin. Springfield, IL: Charles C. Thomas; 1958. p. 178-85.

37. Mogler C, Beck C, Kulozik A, Penzel R, Schirmacher P, Breuhahn K. Elevated expression of c-kit in small venous malformations of blue rubber bleb nevus syndrome. Rare Tumors. 2010;2:99-100

38. Pérez S, de Peña J, Ramos-Garibay A, Pérez CA. Dermatitis herpetiforme. Rev Cent Dermatol Pascua. 2007;16:137-42

39. Verity DH, Marr JE, Ohno S, Wallace GR, Stanford MR. Behçet's disease, the Silk Road and HLA-B51: Historical and geographical perspectives. Tissue Antigens. 1999;54:213-20.

40. Martínez-Escribano J. Dermatosis y hepatitis. Revista Internacional de Dermatología y Dermocosmética Clínica. 2001;4:388-94.

41. Serrao R, Zirwas M, English JC. Palmar erythema. Am J Clin Dermatol. 2007;8:347-56.

42. Dogra S, Jindal R. Cutaneous manifestations of common liver diseases. J Clin Exp Hepatol. 2011;1:177-84.

43. Bergasa NV, Jones EA. The pruritus of cholestasis. Semin Liver Dis. 1993;13:319-27.

44. Kremer AE, Martens JJ, Kulik W, Ruëff F, Kuiper EMM, van Buuren HR, et al. Lysophosphatidic acid is a potential mediator of cholestatic pruritus. Gastroenterology. 2010;139:1008-18.

45. Lakshmi BS, Ram R, Kumar VS. Terry’s nails. Indian J Nephrol. 2015;25:184.

46. Wands JR, Dienstag JL, Bhan AK, Feller ER, Isselbacher KJ. Circulating immune complexes and complement activation in primary biliary cirrhosis. N Engl J Med. 1978;298:233-7.

47. Macías-Rodríguez RU, Torre-Delgadillo A. Xanthelasmas and xanthomatas striatum palmare in primary biliary cirrhosis. Ann Hepatol. 2006;5:49.

48. Gruppo Italiano Studi Epidemiologici in Dermatologia (GISED). Lichen planus and liver disease: A multicentre case control study. BMJ. 1990;300:227-30.

49. Davis M, Su D. Cryoglobulinemia: Recent findings in cutaneous and extracutaneous manifestations. Int J Dermatol. 1996;35:240-8.

50. Gianotti F. Papular acrodermatitis of childhood and other papulo-vesicular acrolocated syndromes. Br J Dermatol. 1979;100:49-59. 
51. Hillman M, Oren R, Zlotogorski A, Shouval D. Vasculitis and cryoglobulinemia associated with persisting cholestatic hepatitis A virus infection. Am J Gastroenterol. 1990;85:586-7.

52. Vaida GA, Goldman MA, Bloch KJ. Testing for hepatitis B virus in patients with chronic urticaria and angioedema. J Allergy Clin Immunol. 1983;72:193-8.

53. Maggiore G, Grifeo S, Marzani MD. Erythema nodosum and hepatitis B virus (HBV) infection. J Am Acad Dermatol. 1983;9:602-3.

54. Thomas RH, Black MM. The wide clinical spectrum of polyarteritis nodosa with cutaneous involvement. Clin Exp Dermatol. 1983;8:47-59.

55. Jorizzo JL. Classification of vasculitis. J Invest Dermatol. 1993;100:106S-10.

56. Siddique N, Pereira BN, Hasan Arshad S. Hepatitis C and urticaria: Cause and effect? Allergy. 2004;59:668.

57. Pakula AS, Garden JM, Roth SI. Cryoglobulinemia and cutaneous leukocytoclastic vasculitis associated with hepatitis C virus infection. J Am Acad Dermatol. 1993;28:850-3.

58. Schissel DJ, Elston DM. Lichen planus associated with hepatitis C. Cutis. 1998;61:90-2.

59. Aceti A, Taliani G, Sorice M, Amendolea MA. HCV and Sjögren's syndrome. Lancet. 1992;339:1425-6.

60. Puy H, Gouya L, Deybach JC. Porphyrias. Lancet. 2010;375:924-37.

61. Iribas JL, Weidmann J, Reyes MA, Korol V, Coronica M, Sixto M, Albertengo A. Porfiria cutánea tardía: reporte de cinco casos. Rev Argent Dermatol. 2008;89:45-52.

62. Fargion S, Piperno A, Cappellini MD, Sampietro M, Fracanzani AL, Romano R, et al. Hepatitis C virus and porphyria cutanea tarda: Evidence of a strong association. Hepatology. 1992;16:1322-6.

63. Powell LW, Seckington RC, Deugnier Y. Haemochromatosis. Lancet. 2016;388:706-16.

64. Launay D, Hebbar M, Janin A, Hachulla E, Hatron PY, Devulder B. Primary biliary cirrhosis and systemic scleroderma (Reynolds syndrome): Apropós of 8 new cases. The contribution of accessory salivary gland biopsy. Rev Med Interne. 1998;19:393-8.

65. Gardner EJ. A genetic and clinical study of intestinal polyposis, a predisposing factor for carcinoma of the colon and rectum. Am J Hum Genet. 1951;3:167-76.

66. Bubien V, Bonnet F, Brouste V, Hoppe S, Barouk-Simonet E, David A, et al. High cumulative risks of cancer in patients with PTEN hamartoma tumour syndrome. J Med Genet. 2013;50:255-63.

67. Cronkhite LW Jr, Canada WJ. Generalized gastrointestinal polyposis; an unusual syndrome of polyposis, pigmentation, alopecia and onychotrophia. N Engl J Med. 1955;252:1011-5.

68. Gutiérrez-Benjumea A, Rojo-García J, Aguilera-Llovet MA, García-Arqueza C, Casanovas-Lax J, Aguayo-Maldonado J. Síndrome de Peutz-Jeghers. An Esp Pediatr. 2001;55:161-4.

69. Montes G, Hoyos AM, Jaramillo-Ayerbe F. Síndrome de Birt-Hogg-Dubé. Rev Asoc Colomb Dermatol. 2013;21:80-183.

70. Martínez-Pérez A, Santos-Alarcón S, Armañanzas-Villena E, Soriano-Camacho P. Síndrome de Birt-Hogg-Dubé y pólipos en el colon. Rev Gastroenterol Mex. 2016;81:53-4. 


\section{Capítulo 5}

\section{Enfermedad renal crónica}

La enfermedad renal crónica es un proceso de alteración de la función del riñón. Si bien en la insuficiencia renal aguda puede presentarse un edema asociado a la pérdida de proteínas, o prurito por el aumento de productos azoados, esta sintomatología es temporal. La piel está comprometida de manera importante cuando lo que se presenta es una enfermedad renal crónica.

La enfermedad renal crónica se refiere a la pérdida del funcionamiento de las nefronas de los riñones por más de tres meses, que desemboca en una insuficiencia renal terminal (1). Se puede constatar cuando la tasa de filtración glomerular es menor a $60 \mathrm{ml}$ por minuto por $1.73 \mathrm{~m}^{2}$. Este proceso fisiopatológico puede tener múltiples causas desencadenantes: la diabetes mellitus, la arteriopatía coronaria o la enfermedad hepática, la hipertensión arterial, las malformaciones congénitas, algunas glomerulonefritis, el lupus eritematoso sistémico y otros.

En general, los pacientes con alteraciones renales presentan algún grado de astenia y adinamia, alteraciones del sueño, disminución del apetito, cefaleas y, ocasionalmente, alteraciones del estado nutricional. Suelen tener anormalidades en la concentración de sodio y potasio en la sangre y, además, presentan hiperfosfatemia, hipocalcemia e hiperuricemia; pueden sufrir de anemia y presentar alteraciones de los lípidos: aumento de triglicéridos y de lipoproteínas con disminución del colesterol HDL y proteinuria. En la enfermedad renal crónica, el compromiso sistémico es múltiple y complejo, y la piel también se ve afectada (2). Dependiendo de la alteración del riñón, se divide en cinco estadios: en el I, la función se encuentra menos alterada y, en el V, está muy alterada. A los pacientes se les debe medir la creatinina sérica, la proteinuria y la albuminuria.

\section{Lesiones cutáneas en la enfermedad renal crónica}

Las lesiones cutáneas que se aprecian en la enfermedad renal crónica son: palidez, hiperpigmentación cutánea, xerosis, prurito y alteraciones de las uñas; en casi todos los pacientes, y en algunos pocos, se puede encontrar equimosis, edemas, calcificaciones cutáneas y calcifilaxia (3). Las dermatosis perforantes adquiridas se pueden presentar con mayor frecuencia en aquellos pacientes con diabetes mellitus de larga data e importante compromiso renal. Se describen más frecuentemente en pacientes con diálisis, pero no se ven con frecuencia en aquellos pacientes 
controlados con hemodiálisis, puede que en los que requieren diálisis sí, por estar en un proceso avanzado de su enfermedad. La dermatosis ampollosa de tipo porfiria cutánea tarda, ha sido descrita en pacientes con hemodiálisis y, quizá, obedezca a la alteración hepatobiliar de este estado avanzado del compromiso renal, y en los estadios terminales se puede ver la escarcha urémica.

Como ya se mencionó anteriormente, las alteraciones más frecuentes son los cambios del color de la piel, de pálido a ligeramente más oscuro, además de un tinte amarillento o terroso. Es una mezcla de palidez por la anemia, y una hiperpigmentación dada por la retención de $\beta$ carotenos y por un aumento de los productos azoados. La palidez puede mejorar con la diálisis, la hiperpigmentación es constante. El tono amarillento, en ocasiones, también puede ser por la alteración hepática que puede acompañar a la enfermedad renal crónica. La hiperpigmentación cutánea es difusa, más intensa en las áreas expuestas al sol, debido a un aumento de los niveles tisulares de $\beta \mathrm{MSH}$ (Melanocyte-Stimulating Hormones) y, como consecuencia del aumento de la síntesis de melanina, a veces se presentan reacciones fotoalérgicas o fototóxicas a los medicamentos utilizados, como en el caso de la furosemida (4).

La xerosis es un hallazgo clínico permanente y se puede presentar por disfunción de la capa córnea, con disminución de la capacidad de fijar agua y con una alteración proporcional a la cantidad de ácidos grasos libres y ceramidas que alteran los lípidos intracelulares y que ayudan a que se presente (5).

El prurito es uno de los síntomas que se encuentra con mayor frecuencia, del 15 al $49 \%$ de los pacientes lo presentan, puede ser leve, moderado o intenso, localizado en el $30 \%$ de los casos y en la mayoría (70 \% de los casos), generalizado (5). En otras series lo reportan con un porcentaje más bajo, del 25 al $50 \%$ de los pacientes presentan prurito generalizado. Se encuentra en la espalda, el abdomen, la cabeza y las extremidades y aparece en la mayoría de los pacientes de manera simétrica (6), por tiempo prolongado, mayor al año y es más intenso en los pacientes que se encuentran en diálisis, siendo mayor en la hemodiálisis que en la diálisis peritoneal.

El rascado continuo de ciertas zonas puede verse como escoriaciones, con hiperpigmentación lineal (figura 5.1) o dar un aspecto de líneas blanquecinas que evidencian la descamación debido a la xerosis intensa, que también puede ser evidente de manera generalizada y más notoria en las extremidades inferiores (figura $5.2)$ 

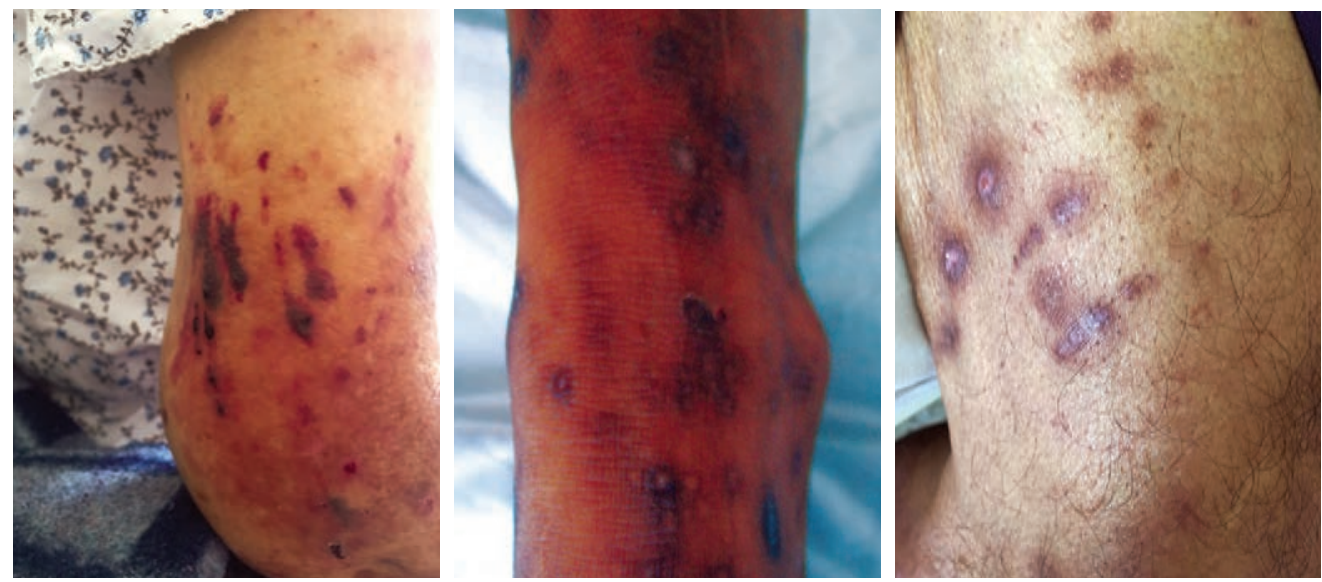

Figura 5.1. Hiperpigmentación cutánea y lineal. Los pacientes con enfermedad renal generalmente presentan hiperpigmentación y xerosis, aunque, ocasionalmente se observan unas zonas con hiperpigmentación lineal que pueden hacer parte de la acción que el roce y el rascado constante producen en la piel de los pacientes con sensación de prurito.
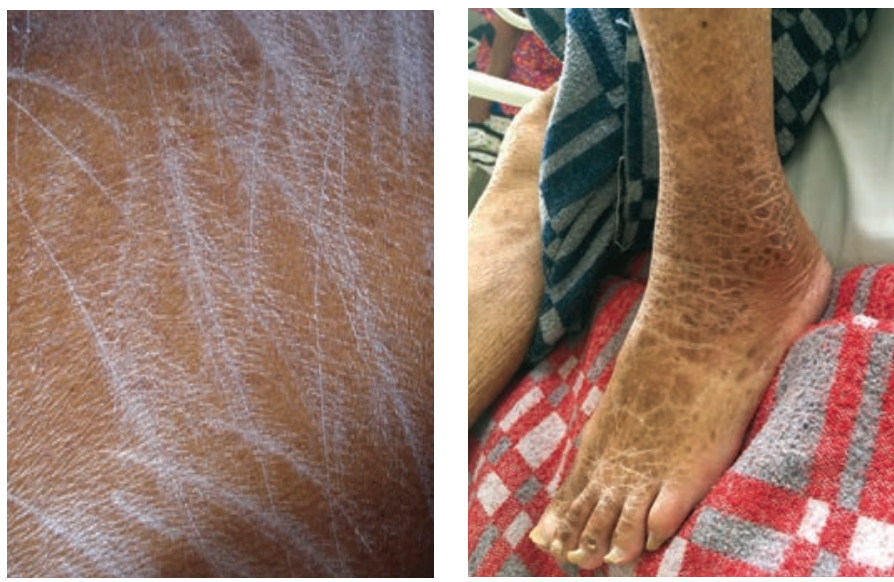

Figura 5.2 Líneas blanquecinas: xerosis y prurito, xerosis. La xerosis es un hallazgo clínico permanente en un paciente con enfermedad renal crónica. En algunas ocasiones, se puede apreciar que el rascado de estas zonas secas genera un aspecto de líneas blanquecinas que evidencian la descamación debido a la importante xerosis.

Cuando el rascado se presenta de manera continua, se va engrosando la piel y aparecen zonas de liquenificación que se ven inicialmente como lesiones lineales o se van circunscribiendo como lesiones papulares, con una piel engrosada que presenta un área central más pigmentada o decapitada por el rascado de tipo prurigo (figura 5.3). Estas lesiones pueden ser el inicio de una dermatosis perforante en la que se observa hiperqueratosis en el centro de las pápulas a causa de la eliminación 
epidérmica de las fibras elásticas o de colágeno alteradas, quizá, por la concentración elevada de productos azoados. En algunos casos se observan muy similares, las lesiones que vemos como pápulas decapitadas por el rascado y las de eliminación transepidérmica o enfermedades perforantes, solo podríamos diferenciarlos con una biopsia cutánea (figura 5.4).

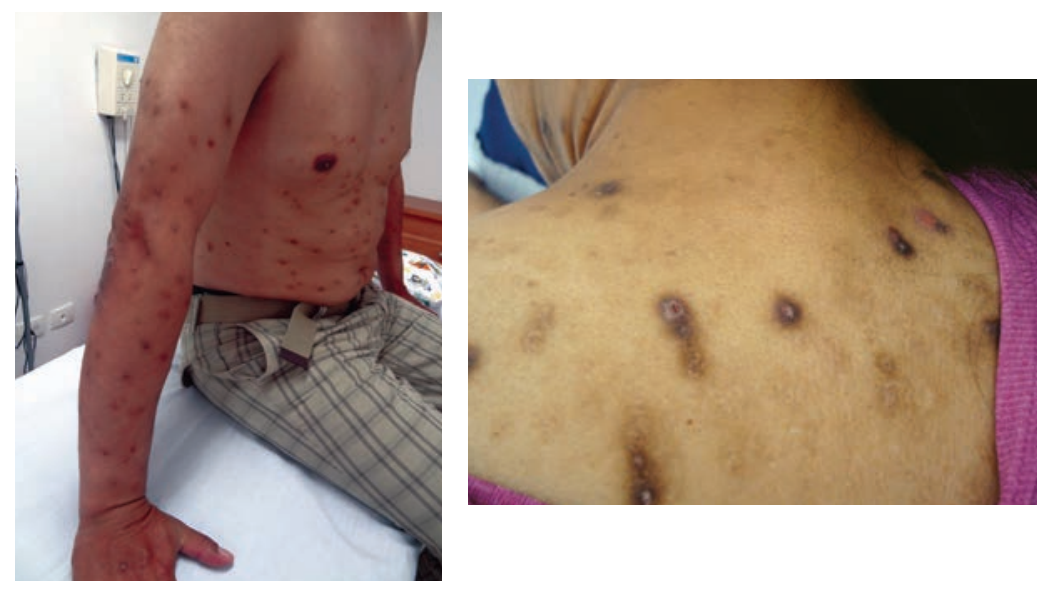

Figura 5.3. Lesiones de tipo prurigo. El rascado continuo de ciertas zonas va generando un engrosamiento y liquenificación de la piel, se va circunscribiendo a áreas papulares, redondeadas, semejantes a pápulas decapitadas por el rascado, a veces con escoriaciones de tipo prurigo.
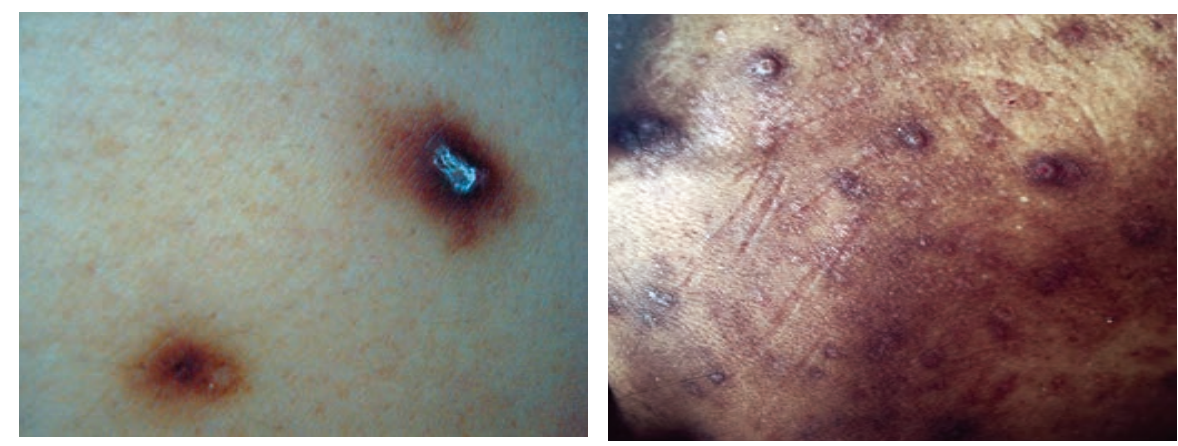

Figura 5.4. ¿Prurigo o dermatosis perforante? Las lesiones que parecían de prurigo, pueden confundirse con las dermatosis perforantes que estos pacientes pueden presentar. En ellas se observa una hiperqueratosis en el centro de las pápulas por la eliminación epidérmica de las fibras elásticas o de colágeno alteradas, quizá, por la concentración elevada de productos azoados. Para aclarar la situación, se necesita practicar una biopsia cutánea.

El prurito puede ser la consecuencia de múltiples alteraciones: concentraciones elevadas de productos azoados: creatinina y nitrógeno ureico, niveles aumentados de la hormona paratiroidea, por el aumento de calcio $y$, tal 
vez, la hiperfosfatemia sea la razón más importante; también se ha descrito por hipervitaminosis A, concentraciones elevadas de magnesio sérico, disfunciones neurológicas o alteraciones emocionales. Se debe recordar que la xerosis contribuye en gran parte a que se presente el prurito, y que se debe tenerla presente ya que se puede controlar más fácilmente.

Se puede presentar equimosis puesto que existe un aumento de la fragilidad vascular con una disfunción plaquetaria por la uremia.

En las uñas se encuentra una alteración en la que se visualizan dos tonos de color diferente, llamadas uñas 'mitad y mitad' (7). Lindsay reportó que las uñas 'mitad y mitad' fueron descritas por Bean en 1963, quien observó este patrón de uñas mitad oscuras y mitad claras (figura 5.5) en cuatro pacientes con productos azoados elevados. En la porción proximal, se ve una parte más blanquecina y opaca, y en la distal, una zona más oscura de color café-rojizo. Es frecuente encontrar algunas uñas de un color más blanquecino, en las cuales existe una ausencia de la lúnula (figura 5.6), que podría estar indicando una gran pérdida de proteínas.
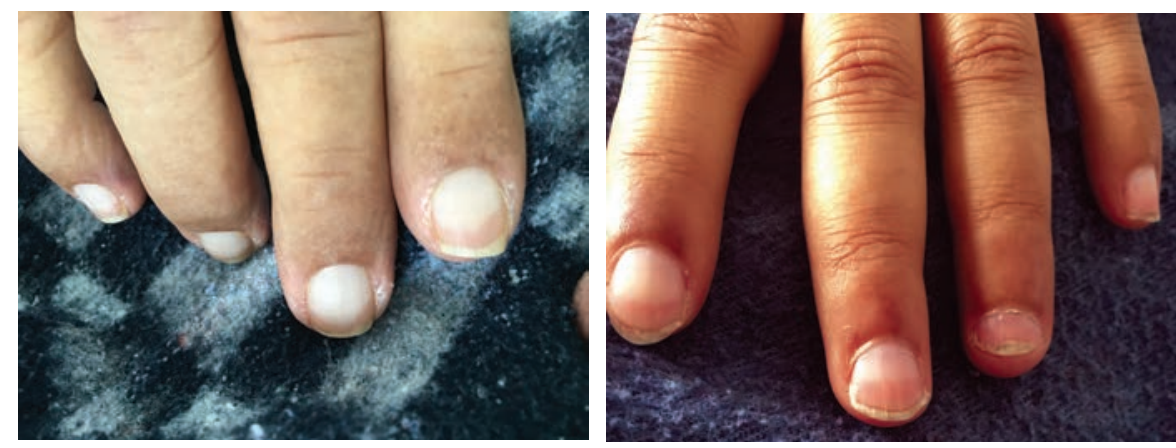

Figura 5.5. Uñas mitad y mitad. Se denominan uñas 'mitad y mitad' cuando se observa una parte más blanquecina y opaca en la porción proximal y una zona más oscura de color pardo-rojizo, en la porción distal de la uña. Es frecuente encontrar algunas uñas de un color generalizado más blanquecino.

Las calcificaciones cutáneas son frecuentes en los enfermos con hiperparatiroidismo o con alteraciones del metabolismo del calcio. Las calcificaciones también se pueden observar en los sitios de trauma como placas subcutáneas blanquecinas o masas de aspecto quístico; no obstante, también se presenta un fenómeno llamado 'calcifilaxia' debida a la oclusión vascular por los depósitos de calcio, lo que da origen a una necrosis con inflamación (lesiones de aspecto necrótico rodeadas de eritema o lesiones purpúricas, dolorosas) en las extremidades inferiores de los pacientes que presentan otras alteraciones como el aumento de los fosfatos o en alteraciones por hipercoagulabilidad como en algunas neoplasias malignas (8). 

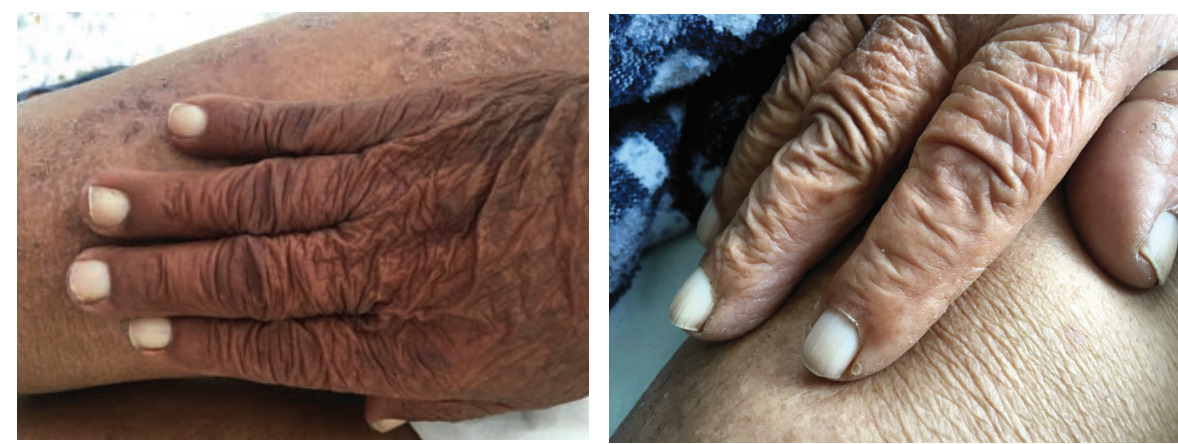

Figura 5.6. Ausencia de lúnula. Este fenómeno de ausencia de la lúnula -se refiere a la no visualización de esa zona arqueada blanquecina que se observa en la parte proximal de la uña- se puede ver más como si la uña tomara un color más blanquecino en la zona proximal de la misma, y podría estar indicando una gran pérdida de proteínas. La lúnula se debe valorar en el dedo pulgar, debido a que con frecuencia en las mujeres no se puede visualizar en los otros dedos.

Se ha descrito una dermopatía fibrótica nefrógena, que es una alteración fibrosante sistémica, poco usual, caracterizada por una piel indurada con engrosamiento y rigidez, de inicio agudo, en los pacientes diabéticos con insuficiencia renal (9). El factor $\beta$ de crecimiento transformador puede estar involucrado en la patogénesis, y existe una fuerte asociación entre su inicio con la exposición a los medios de contraste, como el gadolinio, empleados en los estudios de imagenología, en especial en los de resonancia magnética. Razón por la cual, en la actualidad, no se utilizan estos medios en los pacientes con enfermedad renal crónica.

Las dermatosis perforantes adquiridas se caracterizan por la aparición de unas pápulas elevadas que tienen una queratosis o tapón central, a través de los cuales se eliminan las fibras de colágeno o las fibras elásticas (10) y, a veces, se parecen a las lesiones de tipo prurigo con una zona de piel de $1 \mathrm{a} 2 \mathrm{~cm}$ más gruesa y elevada, circunscrita, con decapitación central secundaria al rascado, ante lo cual la histopatología aclarará el diagnóstico.

Las dermatosis perforantes adquiridas más conocidas son la foliculitis perforante, la elastosis serpiginosa perforante y las colagenosis reactivas perforantes y se ven asociadas a la diabetes mellitus y a la insuficiencia renal crónica. Estas fibras alteradas se eliminan a través de la piel como si fueran cuerpos extraños. En el caso de los pacientes diabéticos con insuficiencia renal crónica en los que aparece en el $5 \%$, esta dermatosis se conoce más como la enfermedad de Kyrle (11), pero podría presentarse cualquiera de las otras.

No está clara su fisiopatogénesis, aunque es probable que la alteración de estas fibras de colágeno o elásticas pueda ser producida por los niveles elevados de productos azoados, por el aumento de la fibronectina (12) o por encontrarse 
alterado el proceso de la 'glucolisación' en los pacientes diabéticos con insuficiencia renal crónica. Asimismo, se han reportado alteraciones de los niveles de calcio o secundarios al hiperparatiroidismo, al igual que sucede en la calcifilaxia observada en los pacientes con insuficiencia renal crónica (13).

En algunos pacientes diabéticos con insuficiencia renal crónica se presentan dermatosis ampollosas de tipo porfiria cutánea tarda de tipo I que no necesariamente tienen el carácter hereditario y familiar (de tipo II). Esta dermatosis se presenta con aparición de ampollas en los sitios expuestos a la luz e incluso más diseminadas; existe también una pseudoporfiria por medicamentos, que se puede desencadenar por el ácido nalidíxico, la furosemida o las tetraciclinas e incluso por otros medicamentos (14).

La escarcha urémica se ve cada vez menos y se presenta en los pacientes con insuficiencia renal terminal que ya no desean someterse a la diálisis; parecen gránulos blanquecinos, por el exceso de urocromos que se eliminan a través de la piel y, quizá, por el aumento de otros productos como el sodio y el fósforo en el sudor.

En las mucosas encontramos alteraciones asociadas a la insuficiencia renal crónica tales como xerostomía, queilitis angular, fragilidad gingival y estomatitis ulcerativa (15).

\section{Referencias}

1. Kenney MJ, Ganta CK. Autonomic nervous system and immune system interactions. Compr Physiol. 2014;4:1177-200.

2. Elenkov IJ, Wilder RL, Chrousos GP, Vizi ES. The sympathetic nerve--an integrative interface between two supersystems: The brain and the immune system. Pharmacol Rev. 2000;52:595638.

3. Bellinger DL, Millar BA, Perez S, Carter J, Wood C, Thyaga Rajan S, et al. Sympathetic modulation of immunity: Relevance to disease. Cell Immunol. 2008;252:27-56.

4. Kimyai-Asadi A, Usman A. The role of psychological stress in skin disease. J Cutan Med Surg. 2001;5:140-5.

5. Rosen SG, Sanfield JA, Morrow LA, Zweifler AJ. Relationship between plasma and platelet epinephrine concentrations in humans. Am J Physiol. 1987;252:E334-9.

6. Rector T, Olivari MT, Levine TB, Francis GS, Cohn JN. Predicting survival for a concentration. Am Heart J. 1987;114:148-52.

7. Goldstein DS, Stull R, Eisenhofer G, Sisson JC, Weder A, Averbuch SD, Keiser HR. Plasma 3,4-dihydroxyphenilanina (Dopa) and catecholamines in neuroblastoma or pheochromocytoma. Ann Inter Med. 1986;105:887-8.

8. Palma JA, Cook GA, Miglis MG, Loavenbruck A. Emerging subspecialties in neurology: Autonomic disorders. Neurology. 2015;84:e73-5. 
9. Sanders VM, Straub RH. Norepinephrine, the $\beta$-adrenergic receptor, and immunity. Brain Behav Immun. 2002;16:290-332.

10. Pupo RA, Wiss K, Solomon AR. Disorders affecting the skin and the heart. Dermatol Clin. 1989;7:517-29.

11. Miller IM. Co-morbidities in inflammatory dermatological diseases. Psoriasis, hidradenitis suppurativa, and cardiovascular risk factors. Dan Med J. 2015;62:B5143

12. Scheinfeld N. Diseases associated with hidranitis suppurativa: Part 2 of a series on hidradenitis. Dermatol Online J. 2013;19:18558.

13. Shlyankevich J, Chen AJ, Kim GE, Kimball AB. Hidradenitis suppurativa is a systemic disease with substantial comorbidity burden: A chart-verified case-control analysis. J Am Acad Dermatol. 2014;71:1144-50.

14. Morgan AJ, Schwartz RA. Diabetic dermopathy: A subtle sign with grave implications. J Am Acad Dermatol. 2008;58:447-51.

15. Katz AS, Goff DC, Feldman SR. Acantosis nigricans en pacientes obesos: formas de presentación e implicaciones para prevención de la enfermedad vascular aterosclerótica. Dermatol Online J. 2000;6:1

16. Hamrick MW, Ferrari SL. Leptin and the sympathetic connection of fat to bone. Osteoporos Int. 2008;19:905-12.

17. Watanabe A, Yoshimura A, Wakasugi T, Tatami R, Ueda K, Ueda R, et al. Serum lipids, lipoprotein lipids and coronary heart disease in patients with xanthelasma palpebrarum. Atherosclerosis. 1981;38:283-90.

18. Gaggl M, El-Hadi S, Aigner C, Sunder-Plassmann G. The renal history of Fabry’s disease. G Ital Nefrol. 2016;33:S66: 1724-5590

19. Uitto J, Li Q, Urban Z. The complexity of elastic fiber biogenesis in the skin - a perspective to the clinical heterogeneity of cutis laxa. Exp Dermatol. 2013;22:88-92.

20. De Paepe A, Malfait F. The Ehlers-Danlos syndrome, a disorder with many faces. Clinical Genetics. 2012;82:1-11.

21. Marconi B, Bobyr I, Campanati A, Molinelli E, Consales V, Brisigotti V, et al. Pseudoxanthoma elasticum and skin: Clinical manifestations, histopathology, pathomechanism, perspectives of treatment. Intractable Rare Dis Res. 2015;4:113-22.

22. Hayward C, Brock DJ. Fibrillin-1 mutations in Marfan syndrome and other type-1 fibrillinopathies. Hum Mutat. 1997;10:415-23.

23. González-López L, Gámez-Nava J, Sánchez L, Rosas E, Suárez-Almazor M, Cardona-Muñoz C, et al. Cardiac manifestations in dermatopolymyositis. Clin Exp Rheumatol. 1996;14:373-9

24. Vaillant L, Larmande P, Arbeille B, Desveaux B, Gruel Y, Lorette G. Livedo reticularis, cerebrovascular disorders and mitral disease: a new cause of Sneddon's syndrome?_Ann Dermatol Venereol. 1990;117:925-30.

25. Dutra LA, Braga-Neto P, Pedroso JL, Barsottini OG. Sneddon's syndrome: Case report and review of its relationship with antiphospholipid syndrome. Einstein (São Paulo). 2012;10:2302 .

26. Ekvall S, Wilbe M, Dahlgren J, Legius E, van Haeringen A, Westphal O, et al. Mutation in NRAS in familial Noonan syndrome - case report and review of the literature. BMC Med Genet. 2015;16:95. 
27. Li JS, Sexton DJ, Mick N, Nettles R, Fowler VG, Jr., Ryan T, et al. Proposed modifications to the Duke criteria for the diagnosis of infective endocarditis. Clin Infect Dis. 2000;30:633-8.

28. Barron KS. Kawasaki disease: Etiology, pathogenesis, and treatment. Clev Clin J Med. 2002;69(Suppl.2):SII69-78.

29. Hofman A, Breteler MB, van Duijn CM, Krestin GP, Pols HA, Stricker BH, Tiemeier H, Uitterlinden AG, Vingerling JR, Jacqueline CM, Witteman JC. The Rotterdam Study: Objectives and design update. Eur J Epidemiol. 2007;22:819-29.

30. Dowlatshahi EA, Kavousi M, Nijsten T, Ikram MA, Hofman A, Franco OH, Wakkee M. Psoriasis is not associated with atherosclerosis and incident cardiovascular events: the Rotterdam Study. J Invest Dermatol. 2013;133:2347-54.

31. Koehler EM, Schouten JN, Hansen BE, van Rooij FJ, Hofman A, Stricker BH, et al. Prevalence and risk factors of non-alcoholic fatty liver disease in the elderly: Results from the Rotterdam Study. J Hepatol. 2012;57:1305-11.

32. Vleeming W, van Amsterdam JG, Stricker BH, de Wildt DJ. ACE inhibitor-induced angioedema: Incidence, prevention and management. Drug Saf. 1998;18:171-88.

33. Samman PD, White WF. The "yellow nail syndrome". Br J Dermatol. 1964;76:153-7.

34. Nanda S, Dorville F. Yellow nail syndrome. CMAJ. Can Med Assoc J. 2009;181:614.

35. World Health Organization. Global tuberculosis report, 2015. 20a ed. Geneva: WHO; 2015.

36. Spelta K, Diniz LM. Cutaneous tuberculosis: A 26-year retrospective study in an endemic area of tuberculosis, Vitória, Espírito Santo, Brazil. Rev Inst Med Trop Sao Paulo. 2016;58:49.

37. Tchernev G, Tana C, Schiavone C, Cardoso JC, Ananiev J, Wollina U. Sarcoidosis vs. sarcoidlike reactions: The two sides of the same coin? Wien Med Wochenschr. 2014;164:247-59.

38. Tchernev G, Lotti T, Wollina U, Cardoso JC, Popova LV, Maximov GK, et al. Sarcoidosis in A. C. Milan (1899)?” Macedonian Journal of Medical Sciences. 2018;6:99-102. 


\section{Capítulo 6}

\section{Enfermedades cardiovasculares y broncopulmonares}

Quizá el corazón sea el principal ejecutor de todos los procesos que implican una mayor sensibilidad, tal como habrían pensado los antiguos románticos y que por tanto tiempo nos negamos a aceptar. Esto se hace más evidente en la medida que entendemos mejor las relaciones e interrelaciones que existen entre el sistema cardiovascular, el sistema nervioso autónomo (1) y el sistema inmunitario (2). Si alguna de estas tres ramas se altera repercute en las otras dos y las emociones podrían llegar a comandar las respuestas del organismo.

El sistema nervioso autónomo está dividido en dos ramas, el sistema nervioso simpático y el sistema nervioso parasimpático, indispensables en el mantenimiento de la homeostasis y en la salud del organismo y en las respuestas adaptativas al estrés (3). Muchos estudios han demostrado las relaciones cruciales del estrés en el desencadenamiento de las enfermedades (4).

Partimos del conocimiento de ciertas características que posee este órgano, el corazón, desconocidas por años. Estas tienen que ver con la actividad del sistema simpático suprarrenal. Jeffrey Halter, ya en 1987 hacia una revisión de aquellas células y tejidos capaces de guardar y liberar catecolaminas, tales como las plaquetas (5), y se refería a la influencia que el sistema autónomo tiene sobre el corazón. Rector, et al., describen el valor predictivo de los niveles de norepinefrina en la insuficiencia cardíaca congestiva (6). También describen cómo en aquellos pacientes que presentan tumores, como los feocromocitomas con liberación excesiva de catecolaminas, se encuentra una relación directa entre esta liberación y la disfunción miocárdica (7).

La liberación de catecolaminas repercute en el adecuado funcionamiento del corazón y, por tal razón, se debe tener en cuenta otra alteración, el síndrome disautónomo (8), que implica un trastorno de la función autónoma del sistema nervioso presente en algunas enfermedades cardiacas.

Se describen disfunciones del sistema nervioso autónomo, o adrenérgico, en varios síndromes familiares; algunos son raros como el trastorno de herencia autosómica dominante conocido como leucodistrofia, que se inicia en la edad adulta y cuyos individuos tienen trastornos del sistema nervioso central, con alteraciones cerebelosas y piramidales, y presentan niveles basales bajos de noradrenalina en una 
toma de sangre al azar. Otro ejemplo de la importancia de estos trastornos autónomos, es la neuropatía autónoma que está asociada a una disfunción suprarrenal medular y a una alteración distal de las neuronas simpáticas noradrenérgicas, que pueden producir insomnio e incluso muerte súbita.

En el momento que se produce la liberación de catecolaminas, posiblemente por estrés, una disminución de las concentraciones de glucosa, semejante a cuando existe una carga alta de insulina, hace que los niveles de glucemia bajen a $58 \mathrm{mg} / \mathrm{dl}$.

Este interesante tópico que parecería aislado de las alteraciones cutáneas, puede estar relacionado con algunas de las respuestas 'exageradas' que se presentan en algunos de los pacientes considerados 'atópicos', con presencia de asma, rinitis, dermatitis atópica, conjuntivitis alérgica, alteraciones gastrointestinales o migraña, en quienes se ha reportado 'hipoglucemia' y que parecería estar más asociado a situaciones estresantes $y$, posiblemente, a una alteración del sistema nervioso autónomo, con liberación aumentada de noradrenalina o con alteraciones en la hidroxilación de la dopamina.

En estos pacientes, los niveles aumentados de catecolaminas específicamente de noradrenalina- pueden desencadenar una disminución de la concentración de glucosa semejante a la de una carga alta de insulina. Asimismo, podrían ser los responsables de lo que se ha llamado 'colon irritable' o 'síndrome del intestino irritable', frecuente en estos pacientes atópicos que, además, presentan taquicardias episódicas con cierta frecuencia y alteraciones en la respuesta pupilar $u$ otras alteraciones referidas en estos síndromes disautónomos.

En resumen, las alteraciones o síntomas que se presentan en estos procesos de disautonomías son unos no dolorosos, como el síncope, el síndrome de taquicardia postural, el síndrome de fatiga crónica, el síndrome de vómitos cíclicos, y otros dolorosos, como la dispepsia funcional, el dolor abdominal funcional, la migraña abdominal, el síndrome de intestino irritable, la migraña, la cistitis intersticial, el síndrome de dolor regional complejo, el síndrome de Raynaud y la fibromialgia.

El síndrome de Raynaud se presenta debido a un vasoespasmo que puede ser parte de una respuesta autónoma alterada, y puede relacionarse con otras enfermedades mediadas inmunológicamente, como el lupus eritematoso sistémico, la artritis reumatoidea, la enfermedad mixta del tejido conjuntivo, el síndrome de Sjögren, la enfermedad celíaca, la miastemia gravis (raro) o el síndrome miasténico de tipo Lambert-Eaton. En estas dos últimas alteraciones, la predisposición es genética. Se describen neuropatías autónomas acompañando algunas infecciones, posiblemente porque los lipopolisacáridos de algunas bacterias que tienen como ligando a los receptores de tipo toll, inducen la estimulación simpática. 
Se debe estar alerta ante la presentación de alteraciones de los reflejos cardiovasculares, taquicardias posturales o ante trastornos de la termorregulación y de la sudoración que, en un momento dado, pueden hacer parte de estos trastornos autónomos. Para confirmar lo anterior, se debe solicitar en el momento de la sintomatología, la determinación de los niveles de catecolaminas, entre ellas la noradrenalina, para precisar la posible asociación existente (9).

Una vez analizadas las posibles relaciones del síndrome disautónomo y la piel, no se debe olvidar que los pacientes con síndromes poliglandulares $y$, específicamente, diabetes mellitus, presentan también neuropatías autónomas con compromiso de los sistemas cardiovascular, gastrointestinal, urogenital, pupilomotor y alteraciones de la sudoración.

Sin dejar de tener en cuenta estos síndromes disautónomos, a continuación, se consideran aquellas enfermedades de la piel que se asocian con las enfermedades cardiovasculares, principalmente las que implican un riesgo de oclusión de los vasos coronarios e infarto del miocardio, como sucede con las que acompañan al síndrome metabólico, la psoriasis entre ellas.

Algunas enfermedades que se presentan en el aparato cardiovascular o en el respiratorio se pueden hacer evidentes por cambios en la coloración de la piel, como sucede en los procesos que se acompañan de una alteración en la oxigenación de la sangre, que se hacen notorios por la coloración azul-violácea que aparece principalmente en sitios distales (acral), llamada cianosis.

En los niños puede aparecer esta cianosis en algunas cardiopatías congénitas, como la tetralogía de Fallot, la transposición de grandes vasos, la atresia tricuspídea o pulmonar, la malformación de Ebstein o presentar un tronco común aorta y arteria pulmonar, acompañados de comunicaciones entre las aurículas o los ventrículos, con aparición de hipertensión pulmonar, cambios en la curvatura de las uñas e hipertrofia de las falanges distales de las manos, llamados dedos en 'palillo de tambor' (figura 6.1). Para precisar cuál de ellas está presente y llegar al diagnóstico, se debe ordenar un ecocardiograma transtorácico.

Esta coloración azulosa aparece en relación con el cortocircuito cardiaco de derecha a izquierda, y también en el caso de las metahemoglobinemias. En los pacientes con vasoconstricción de pequeños vasos o con reducción del flujo periférico, como en la insuficiencia cardíaca y el choque, se pueden presentar cianosis distales. 


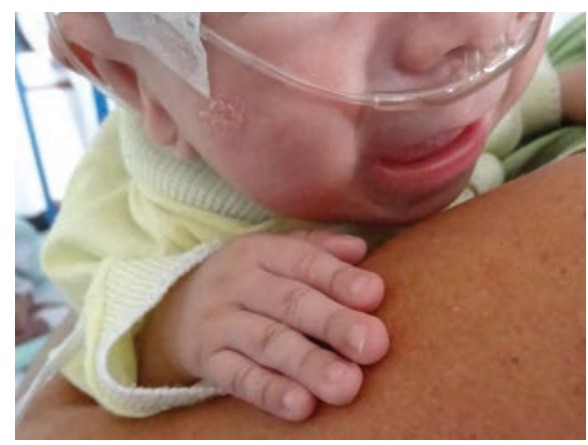

Figura 6.1. Dedos en palillo de tambor.. En los niños, esta cianosis puede aparecer en algunas cardiopatías congénitas, como a tetralogía de Fallot, la transposición de grandes vasos, la atresia tricuspídea o pulmonar, la malformación de Ebstein o el tronco común aorta y arteria pulmonar, acompañados de comunicaciones entre las aurículas o los ventrículos, con aparición de hipertensión pulmonar y cambios en la curvatura de las uñas e hipertrofia de las falanges distales de las manos, los llamados dedos en 'palillo de tambor'.

\section{Síndromes cardiocutáneos}

El corazón puede verse afectado por una variedad de trastornos multisistémicos, y cuando se habla del corazón se está hablando no solo del músculo, sino también de las válvulas, el pericardio, el sistema de conducción y las arterias coronarias (10). Existe un signo cutáneo que puede ser predictor de la enfermedad coronaria; se trata de los earlobe creases, un pliegue en diagonal que aparece con la edad en los lóbulos de las orejas, y va desde el trago hasta la mitad externa del lóbulo auricular (figura 6.2); si existe, se recomienda que estos pacientes sean evaluados para descartar una enfermedad arterial coronaria.

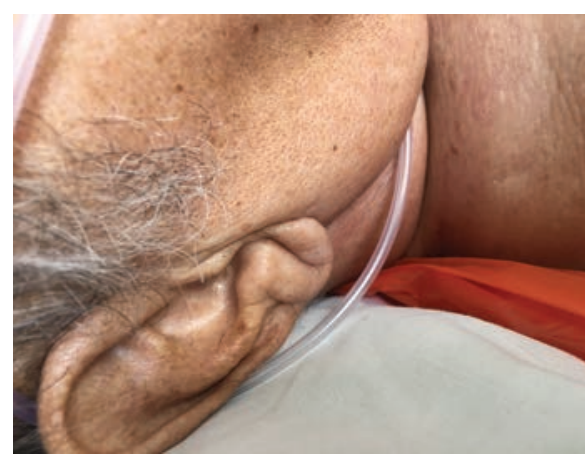

Figura 6.2. Pliegue diagonal en el lóbulo auricular. Existe un signo cutáneo que puede ser predictor de la enfermedad coronaria; se trata de los earlobe creases, un pliegue en diagonal que aparece con la edad en los lóbulos auriculares, y va desde el trago hasta la mitad externa del lóbulo auricular; si existe, se recomienda que estos pacientes sean evaluados para descartar una enfermedad arterial coronaria. Su valor aún está cuestionado. 
Algunas enfermedades dermatológicas se encuentran relacionadas con enfermedades cardiovasculares e infarto del miocardio. Se ha demostrado que las enfermedades inflamatorias de la piel, como la psoriasis (11) (figura 6.3) y la hidradenitis supurativa (12), se asocian con un mayor riesgo de enfermedad cardiovascular, generalmente, en el marco del síndrome metabólico.

Las placas escamosas infiltradas propias de la psoriasis no necesariamente tienen que ser muchas o de gran tamaño para ser consideradas. Por otro lado, no se puede olvidar que la psoriasis también se puede asociar con otras enfermedades autoinmunitariass. Elvalor predictivo de la psoriasis en cuanto a riesgo cardiovascular está dado por su relación con el síndrome metabólico, de la misma manera que en la diabetes mellitus, la obesidad o las alteraciones secundarias al aumento de andrógenos, como en el síndrome del ovario poliquístico.
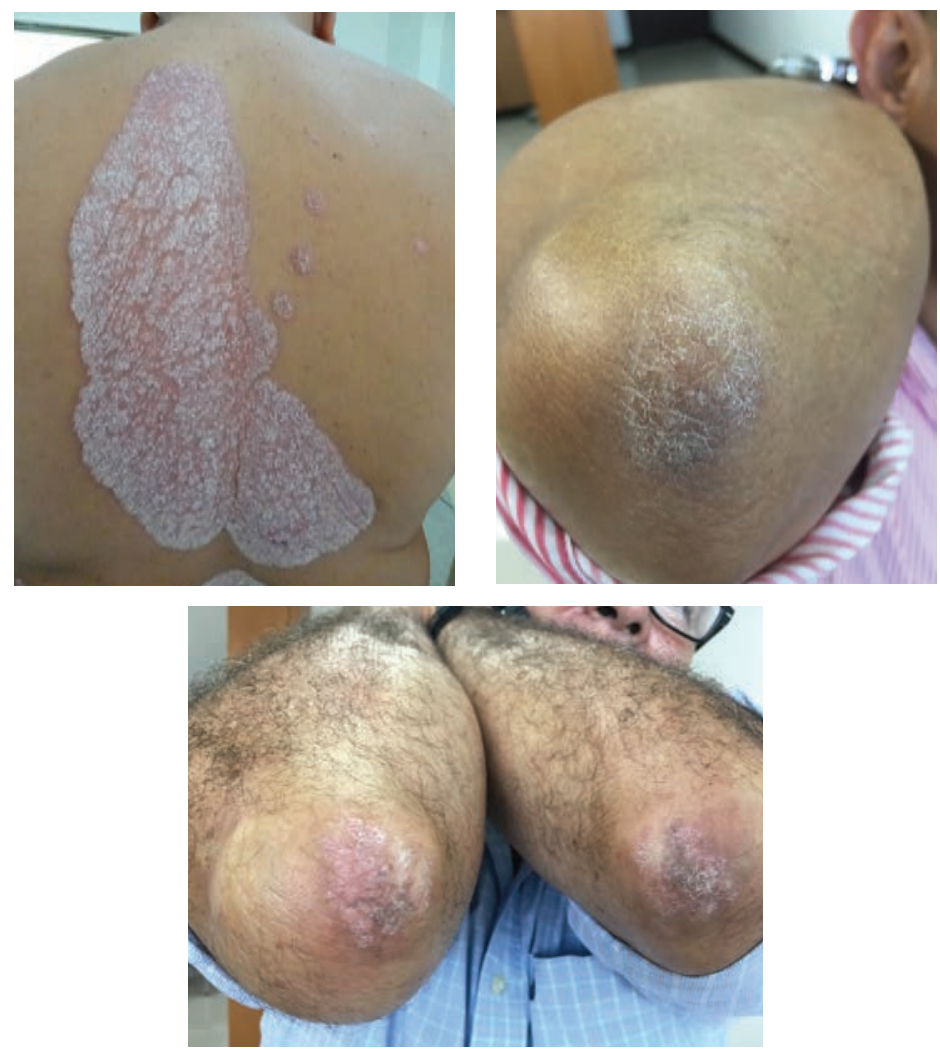

Figura 6.3. Psoriasis. Las placas escamosas infiltradas propias de la psoriasis se pueden asociar también a las enfermedades autoinmunitarias. Se observa un riesgo mayor de infarto agudo de miocardio en pacientes no necesariamente obesos, pero sí con dislipidemia, que presentan un engrosamiento e hiperqueratosis de los codos; las lesiones no necesariamente tienen que ser muchas ni de gran tamaño. 
La hidradenitis supurativa es una enfermedad sistémica inflamatoria, poco frecuente y enigmática, que aún no ha sido totalmente entendida. Se caracteriza por la presencia de dolor e inflamación en las regiones axilar o inguinal, o en la región anogenital, con presencia de tractos fibrosos supurativos. En la hidradenitis supurativa se puede encontrar que este compromiso inflamatorio glandular apocrino puede estar asociado a varias condiciones, como la obesidad, la dislipidemia, el síndrome de ovario poliquístico, el síndrome metabólico, la enfermedad cardiovascular, las alteraciones tiroideas y articulares (13) e incluso se han reportado casos con enfermedad de Crohn.

En segunda instancia, se consideran los pacientes con diabetes mellitus, que presentan una alteración en los miembros inferiores, principalmente en la cara anterior de las piernas, conocida como dermopatía diabética, signo de microangiopatía, que puede asociarse con la enfermedad arterial coronaria (14).

También, se debe tener en cuenta a los pacientes obesos que pueden presentar una acantosis nigricans, como resultado de la resistencia a la insulina, y que tienen una mayor probabilidad de sufrir de una enfermedad vascular arteriosclerótica (15). Por otro lado, estos pacientes presentan una disminución en la producción de leptina lo cual induce o facilita la dislipidemia (16).

La aparición de xantomas (figura 6.4) puede ser la primera señal de alarma en aquellos pacientes que tienen una dislipidemia, pues estas lesiones representan la acumulación de lípidos en los histiocitos, se localizan en la dermis y se manifiestan con lesiones planas máculo-papulosas de color amarillento en palmas, manos, cuello y tronco, que también aparecen más gruesos, papulosos o tendinosos. Los xantomas papulosos, llamados tuberosos, aparecen en los codos y en las rodillas, y pueden verse en tendones, como en el de Aquiles (17). Los tendinosos se presentan como pápulas firmes, lisas y amarillentas, ubicadas en tendones, ligamentos o fascias de las superficies extensoras; la piel se desliza fácilmente sobre ellos. Los tuberosos son más pequeños, las pápulas son poco coloreadas, suaves, amarillas o rojizas, indoloras, ubicadas en las superficies extensoras; pueden unirse y formar grandes masas globulares; indican alto riesgo de aterosclerosis.

Entre los llamados 'planos' encontramos los xantelasmas, que se caracterizan por ser pápulas de depósito, ubicados en los párpados; son placas amarillentas que se presentan en la cara, el cuello, los brazos, la parte alta del tronco o en las palmas, pero, a diferencia de los otros xantomas en los que siempre hay alteración lipídica, en estos pacientes no siempre es evidente la alteración de los lípidos. 


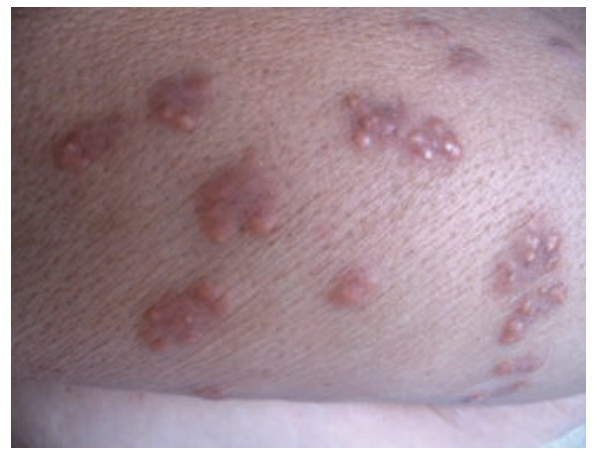

Figura 6.4. Xantomas . Estas lesiones representan la acumulación de lípidos en los histiocitos que se localizan en la dermis; se manifiestan con lesiones máculo-papulosas de color amarillento. Pueden ser planos, en las palmas, en las manos, en el cuello y en el tronco, o papulosos, también llamados tuberosos, en los codos y las rodillas; asimismo, pueden aparecer en tendones como el de Aquiles. Los tendinosos se presentan como pápulas firmes, lisas y amarillentas, ubicadas en tendones, ligamentos o fascias de las superficies extensoras; la piel se desliza fácilmente sobre ellos. Los tuberosos son más pequeños, las pápulas son poco coloreadas, suaves, amarillas o rojizas, indoloras, ubicadas en las superficies extensoras; pueden unirse y formar grandes masas globulares. Indican alto riesgo de aterosclerosis.

Se ha descrito una hipercolesterolemia de tipo xantoma en otra entidad con alteración del almacenamiento en lisosomas de origen hereditario ligado al cromosoma X, que es el angioqueratoma corporal difuso o enfermedad de Fabry (18).

Fue presentado por Johannes Fabry en 1898 para describir un síndrome familiar caracterizado por la presencia de lesiones angioqueratósicas, es decir, pequeñas lesiones vasculares cubiertas de una capa epidérmica hipertrófica. Estas pápulas angioqueratósicas pueden parecer verrugas con aspecto hemorrágico o, al menos, más ricas en vasos sanguíneos; se encuentran asociadas con frecuencia a una alteración renal cuya primera manifestación es la proteinuria. Esta alteración se genera por la deficiencia de la enzima ceramidotrihexosidasa de la galactosidasa A, que genera un aumento del depósito de glucolípidos, y se le conoce como la tesaurismosis. El compromiso vascular puede involucrar el cerebro, la retina, el riñón y el sistema cardiovascular; en este, se manifiesta con alteraciones de la conducción, aparición de angina e incluso infarto de miocardio.

En tercera instancia, se describen alteraciones del colágeno de tipo II, que puede afectar los cartílagos de los huesos, la tráquea y el pabellón auricular asociados a la insuficiencia aórtica o los aneurismas de la aorta. La más común es la policondritis del pabellón auricular (figura 6.5) que no sea de origen traumático; se inicia con una inflamación del tejido cartilaginoso del pabellón auricular, el cual permanece inflamado de una a dos semanas con episodios de remisión y poco a 
poco va dañando al cartílago. Esta inflamación se caracteriza por la infiltración de neutrófilos y, cuando se presente, se debe estar alerta para practicar un estudio cardiovascular completo.

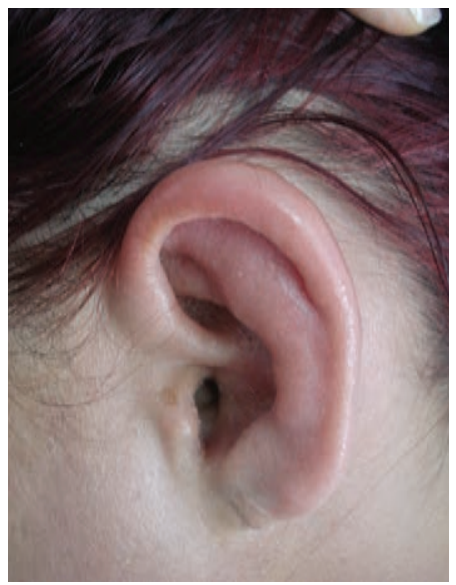

Figura 6.5. Policondritis del pabellón auricular. Se describen alteraciones del colágeno de tipo II, que puede afectar a los cartílagos de los huesos, la tráquea y el pabellón auricular, asociados a insuficiencia o aneurismas de la aorta. La inflamación se caracteriza por la infiltración de neutrófilos y, cuando se presenta, se debe estar alerta para realizar un estudio cardiovascular completo.

Existen algunos trastornos hereditarios, unos de carácter autosómico dominante y otros, autosómico recesivos, relacionados con alteraciones en la formación del tejido conjuntivo, tipo de colágeno, tejido elástico o ambos, y que presentan alteraciones en la piel y las articulaciones. Generalmente, presentan una exagerada hiperelasticidad asociada con lesiones cardiovasculares. Algunos tienen lesiones más evidentes en la piel y otros no, pero la hiperelasticidad es una de las constantes (19).

Entre ellos se debe tener en cuenta el síndrome de Ehlers-Danlos, en el que los pacientes presentan una piel laxa, que se estira fácilmente, y en los que se puede encontrar que algunas cicatrices están cubiertas de una piel muy delgada, a veces hiperpigmentada, que traduce una alteración de la reparación del tejido (20). Puede estar acompañado de un prolapso de la válvula mitral o de la tricuspídea, con dilatación de la aorta e insuficiencia de la válvula e incluso ruptura arterial.

Otros síndromes que se analizan a continuación también presentan una hipermovilidad articular asociada a anormalidades cardiacas, cambios valvulares o dilataciones arteriales y, ocasionalmente, presencia de fenómenos hemorrágicos. 
Se trata del pseudoxantoma elástico que es un síndrome en el que existe una calcificación anormal de las fibras elásticas (21). Las lesiones de piel se ven como pequeñas pápulas de depósito, de color amarillento, formando placas principalmente en el cuello (figura 6.6) y presentes en los pliegues, las axilas o las ingles. Puede estar acompañadas de manifestaciones cardiacas que incluyen la enfermedad isquémica con angina, los infartos de miocardio y, a veces, la insuficiencia cardiaca congestiva. Se pueden ver afectados otros vasos del cerebro o del abdomen con la correspondiente isquemia y manifestaciones a ese nivel.

El otro síndrome con hipermovilidad es el síndrome de Marfan, que se genera por una mutación en el gen que codifica para la filagrina 1, en el cromosoma 15 (15q21.1); se caracteriza por alteraciones musculoesqueléticas, oculares y cardiovasculares (22). Se trata de unos individuos longilíneos que pueden presentar diferentes alteraciones osteo-músculo-articulares, con un aumento de la movilidad articular más notoria en los dedos de las manos, que son largos y que, por la forma arqueada y puntiaguda distal que van tomando, se describen con el nombre de 'aracnodactilia' (figura 6.7). Los pacientes presentan estrías en la piel, subluxación del cristalino, alteraciones de las válvulas del corazón y dilataciones aneurismáticas de los vasos arteriales.

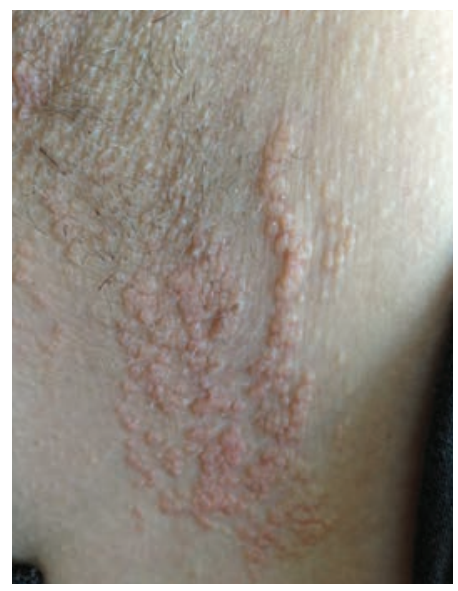

Figura 6.6. Pseudoxantoma elástico. Las lesiones de piel se ven como pequeñas pápulas de depósito, de color amarillento, formando placas, principalmente, en el cuello, y presentes enlos pliegues, las axilas o las ingles; se pueden acompañar de manifestaciones cardiacas que incluyen la enfermedad isquémica con angina e infartos de miocardio $y$, a veces, insuficiencia cardiaca congestiva. 

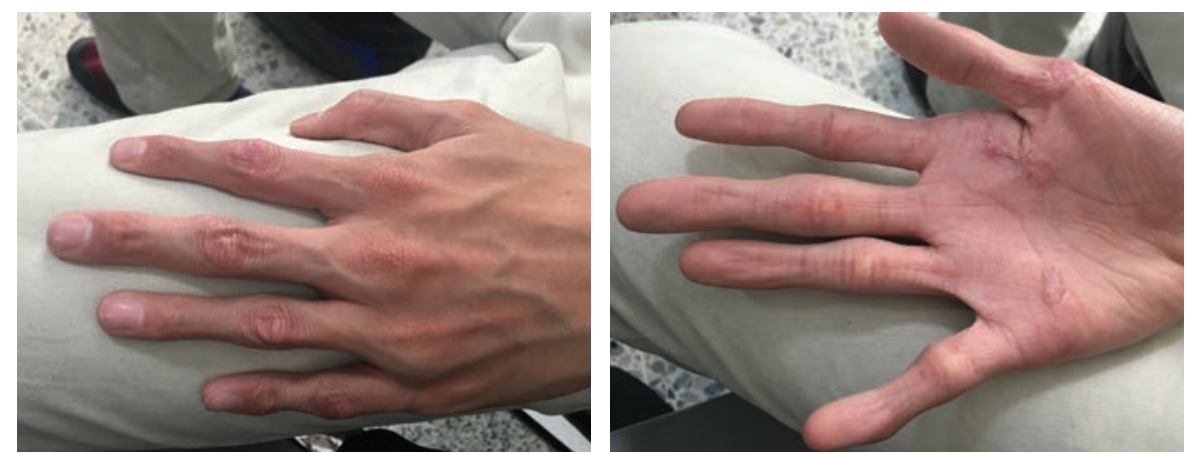

Figura 6.7. Aracnodactilia, síndrome de Marfan. Encontramos unos individuos longilíneos que pueden presentar diferentes alteraciones osteo-músculo-articulares, con aumento de la movilidad articular, más notoria en los dedos de las manos, que son largos y que, por la forma arqueada y puntiaguda distal que van tomando, se describen con el nombre de aracnodactilia.

Por último, se consideran las enfermedades autoinmunitarias del tejido conjuntivo que están incluidas entre las enfermedades asociadas a alteraciones cardiovasculares. En el lupus eritematoso sistémico puede presentarse una pericarditis y encontrarse una endocarditis con presencia de vegetaciones en las válvulas cardiacas, anormalidad conocida como la enfermedad de Libman-Sacks. En la esclerosis sistémica, o esclerodermia, se puede tener un mayor riesgo de afectación cardíaca, más en la esclerodermia difusa en los pacientes de raza blanca con HLADR6, o en la esclerosis localizada en los pacientes de raza negra. En la dermatomiositis es raro el compromiso cardiaco, pero, si aparece, es de mal pronóstico (23).

El síndrome de anticuerpos antifosfolípido puede manifestarse con un cambio de la coloración general de la piel que toma una coloración rojiza-azulosa en forma de ramificaciones que sigue los trayectos vasculares, llamada livedo reticularis. Esta se acompaña de fenómenos trombóticos y oclusivos dando lugar a manifestaciones como infarto de miocardio, accidentes cerebrovasculares o abortos a repetición, relacionados con el aumento de dichos anticuerpos.

Otras alteraciones trombóticas u oclusivas se pueden presentar por niveles elevados del factor VII, disminución de la proteína $\mathrm{S}$ o activación de la proteína C en los pacientes con síndrome de Sneddon, lo que sugiere una posible conexión entre la coagulopatía y la alteración vascular. Se han encontrado algunos pacientes con síndrome de Sneddon que, además, presentan alteración valvular mitral (24). Los émbolos de colesterol pueden ocluir los vasos y semejar fenómenos trombóticos, por lo que se deben tener en cuenta cuando se presenten fracturas, principalmente, de huesos largos (25). 
Existen otras enfermedades de índole genética, en las que se presentan alteraciones en estos dos sistemas, cardiovascular y piel, como sucede en el síndrome LEOPARD (Lentigines, Ocular hypertelorism, Pulmonary stenosis, Abnormalities of the genitalia, Retarded growth, Deafness), que presenta defectos congénitos de corazón acompañados de lentigos o efélides. Se mencionó anteriormente al referirnos a las alteraciones del sistema nervioso y piel. Este síndrome se conoce actualmente como síndrome de Noonan con efélides y hace parte de las llamadas 'rasopatías' que implican mutaciones en la vía NRAS como sucede en la neurofibromatosis (26).

Se deben tener en cuenta otras enfermedades en las que existe un compromiso de los dos sistemas -cardiovascular y piel- como es la progeria o síndrome de Werner, caracterizada por exhibir un envejecimiento prematuro, en cuyo caso se ven los cambios del envejecimiento en la piel asociados con la enfermedad arterial coronaria e infarto de miocardio.

La aparición de mixomas cardiacos puede asociarse a la presencia de mixomas en otros lugares, mixomas auriculares, mucocutáneos o neurofibromatosos en diferentes síndromes de origen genético, de tal manera que si se encuentra alguna lesión tumoral benigna de esta naturaleza en la piel, se debe estudiar al paciente por este posible compromiso.

Algunas alteraciones valvulares cardiacas se acompañan de ciertas lesiones cutáneas; se puede observar un enrojecimiento o rubor en las mejillas en las alteraciones de la válvula mitral (figura 6.8) y en alteraciones de falla cardiaca derecha por insuficiencia tricuspídea (figura 6.9) o en la estenosis pulmonar, que no se debe confundir con otros enrojecimientos con los que se debe hacer un diagnóstico diferencial.

Otro enrojecimiento que se debe tener en cuenta es el de aparición súbita, conocido como síndrome carcinoide. Se caracteriza por la aparición de un enrojecimiento que, inicialmente, aparece de madera episódica en el rostro y, a veces, se extiende al tórax, similar al anterior. Este puede ser el primer síntoma de la existencia de lesiones tumorales de las células argentafines asociadas al intestino o de un feocromocitoma, y se puede explicar por la liberación de sustancias vasoactivas, principalmente serotonina por parte de las células tumorales y, por esta razón, puede acompañarse de episodios de taquicardias y sudoración. Tampoco se debe olvidar el enrojecimiento facial asociado al asma, la mastocitosis o el que se produce en los pacientes diabéticos, conocido como rubor facial. Por otro lado, los individuos muy blancos tienen una mayor tendencia al rubor facial, fenómeno vasoactivo parecido en la rosácea, que incluso en algunos la puede anteceder. 

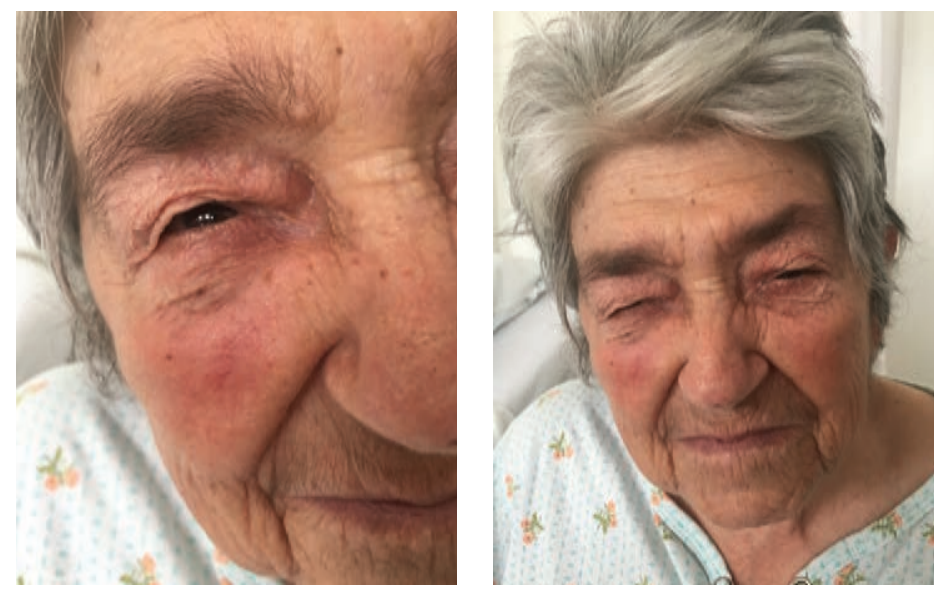

Figura 6.8. Enrojecimiento por insuficiencia mitral. Se produce un enrojecimiento, o rubor, en las mejillas, de forma redondeada en la zona más prominente de los pómulos
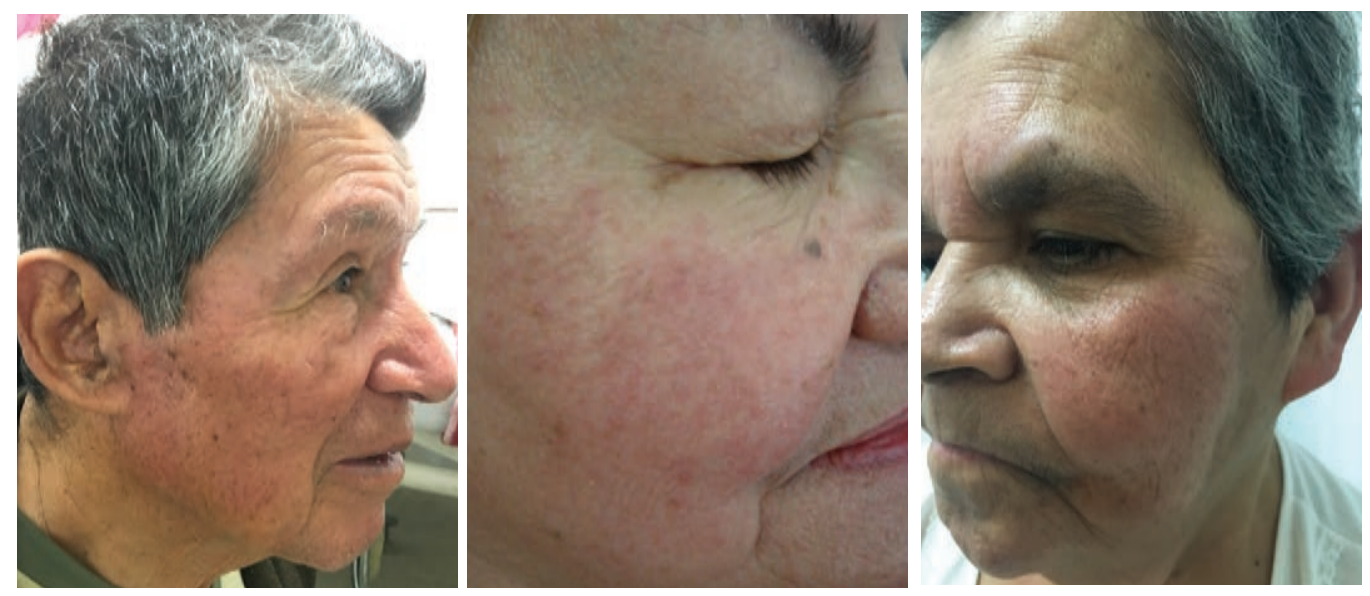

Figura 6.9. Enrojecimiento por insuficiencia tricuspídea. Cuando la insuficiencia es tricuspídea, también se produce un enrojecimiento de las mejillas, generalmente, bajo los pómulos.

Las válvulas cardiacas o los vasos arteriales también pueden verse afectadas por algunas enfermedades de origen infeccioso, como sucede con la fiebre reumática que se caracteriza por la aparición de fiebre, exantema máculo-papular, artralgias, artritis y corea de Sydenham, antecedida por un episodio de faringitis estreptocócica (Streptococus spp. del grupo A) que no fue tratado adecuadamente, y con posterior aparición de un soplo cardíaco, debido a alteraciones valvulares, principalmente de la válvula mitral. Esto se produce por un fenómeno de mimetismo molecular, en el 
cual la respuesta inmune desencadenada frente al microorganismo se dirige también a otros tejidos del cuerpo que le son similares.

Por otro lado, se encuentra la presencia de vegetaciones en las válvulas del corazón, posterior a una infección por Streptococus viridans del grupo D, o por otros grupos de estreptococos o de estafilococos, e incluso por otros microorganismos (27). Se conoce como endocarditis bacteriana; es una enfermedad infecciosa que se acompaña de un cuadro febril, con astenia y pérdida de peso, que afecta más frecuentemente a los individuos que tienen alteraciones valvulares previas, ya que los émbolos bacterianos se depositan en estas válvulas lesionadas y aparece característicamente un soplo cardíaco.

Estos émbolos también obstruyen los vasos pequeños de la piel y se observan lesiones parecidas a las de la vasculitis, con aparición de hemorragias subungulares en astilla (figura 6.10), lesiones máculo-papulares de aspecto de tipo vasculitis o hemorrágico que, si se localizan en las palmas o en las plantas, se llaman lesiones de Janeway y, si lo hacen en otra parte del cuerpo, reciben el nombre de nódulos de Osler. Se encuentran lesiones similares en el fondo de ojo, conocidas como manchas de Roth. En el 30 \% de los casos también aparecen petequias.
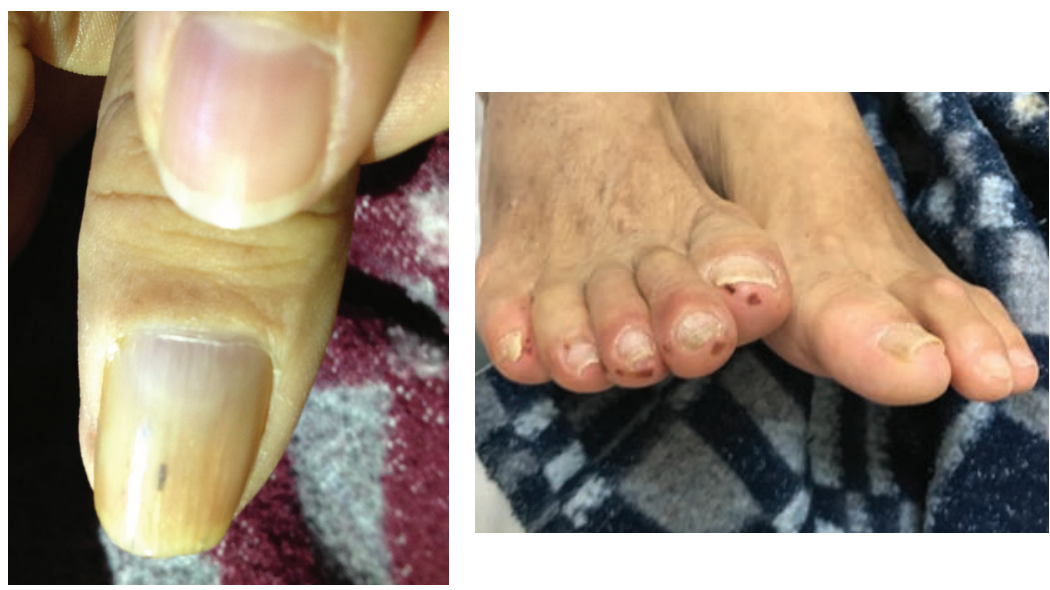

Figura 6.10. Endocarditis bacteriana. Las hemorragias en astilla son lesiones vasculares lineales que semejan una astilla; aparecen en las uñas, en piel de las palmas y de las plantas lesiones vasculares conocidas como 'lesiones de Janeway' o en las extremidades, más profundas y semejantes a las del eritema nudoso, conocidas como 'nódulos de Osler'. Los émbolos bacterianos se depositan en estas válvulas lesionadas y aparece característicamente un soplo cardíaco. 
La enfermedad de Kawasaki es una enfermedad de origen desconocido que aparece en la infancia; se ha clasificado como una vasculitis aguda de vasos medianos y se resuelve espontáneamente como puede suceder con una enfermedad viral (28). Las lesiones son generalizadas, exantematosas con lesiones de tipo máculo-papular, aunque pueden ser ampollosas o de tipo púrpura. Son características las lesiones en los pulpejos de los dedos, con denudación de la piel, acompañada de trombocitosis importante y afectación de las arterias coronarias y aparición de aneurismas; se presenta en 20 a $25 \%$ de los niños que lo padecen.

Para concluir, nos podemos referir a un estudio que se viene llevando a cabo en Europa por muchos años, llamado el estudio Rotterdam (29), que considera varias enfermedades frecuentes en la vejez con el objetivo de estudiar las relaciones que pueden existir entre ellas y la ocurrencia de mortalidad cardiovascular, enfermedad coronaria cardiaca y falla cardíaca. Entre las enfermedades frecuentes en la vejez, esta investigación considera, entre otras, la enfermedad de Parkinson, la de Alzheimer y otras demencias; la depresión y otros trastornos de ansiedad; la degeneración macular y el glaucoma; las enfermedades respiratorias y las hepáticas; la diabetes mellitus con una hemoglobina 'glicosilada' igual o mayor de $7 \mathrm{mmol} / \mathrm{L}$, la osteoporosis, las enfermedades dermatológicas y el cáncer.

En los reportes periódicos que hacen sus investigadores, han encontrado que entre los factores de riesgo cardiovascular, además de los genes que pueden determinar la mayor frecuencia de ciertas alteraciones, es importante tener en cuenta el índice de masa corporal. También nos recuerda que la adiposidad es una condición en la que existe un mayor riesgo de enfermedad coronaria; asimismo, consideran otros factores importantes como el incremento del colesterol, la hipertensión arterial, la alteración de los niveles de insulina y el aumento de la proteína $C$ reactiva presente en las enfermedades inflamatorias. La arteriosclerosis y el infarto de miocardio están asociados a la fibrilación auricular. Los pacientes con alteración tiroidea y los que tiene niveles altos de sulfato de dehidroepiandrosterona tienen un riesgo alto de fibrilación auricular. Las concentraciones altas de vitamina $\mathrm{D}$ pueden tener relación con una baja asociación con el síndrome metabólico, es decir, ser protectoras.

Entre las enfermedades dermatológicas que se tuvieron en cuenta en este estudio, las que se presentan con mayor prevalencia en las personas mayores son las relacionadas con la exposición crónica a la luz, como las queratosis actínicas, los carcinomas basocelulares y los escamocelulares, y, de ellos, el único que se incrementa de manera diferente a la población normal es el carcinoma escamocelular que aumenta en frecuencia y se relaciona con la inmunosupresión en pacientes que tienen o están siendo tratados por otras neoplasias. 
En estos pacientes mayores se encontró la presencia de otras dermatosis, como la de la insuficiencia venosa crónica, la xerosis y la presencia de enfermedades inflamatorias como el eccema, la dermatitis seborreica y la psoriasis. También consideraron la alopecia, sin especificar de qué tipo; seguramente, una mezcla de androgénica y difusa que son las que más se encuentran en el envejecimiento normal y, además, son dependientes de la herencia de cada individuo. No encontraron ninguna relación de estas enfermedades dermatológicas con las enfermedades cardiovasculares en el paciente mayor.

Entre estas alteraciones, la psoriasis ha sido considerada en otros estudios como un factor de riesgo cardiovascular. En el estudio Rotterdam no la encontraron asociada a la arteriosclerosis, ni a una mayor cantidad de eventos coronarios en comparación con la población general (30).

A pesar de que los estudios son contradictorios, el hecho es que hay una variedad de psoriasis que es más frecuente en los individuos alrededor de los 50 años, diabéticos, obesos o con enfermedad metabólica. Es en ellos en los que existe un mayor riesgo de enfermedades endocrinas, cardiovasculares o de infarto de miocardio; tienden, además, a tener signos de esteatosis e hígado graso no alcohólico (31), lo mismo que de presentar fibrosis hepática que se puede visualizar en la ultrasonografía. De cualquier manera, sigue siendo importante relacionar la aparición de las placas de psoriasis o de codos psoriasiformes después de los cincuenta años como un factor de riesgo cardiovascular y coronario, aun sin obesidad, generalmente acompañados de dislipidemia.

En este estudio, y en otros, similares se han utilizado varios biomarcadores en sangre, suero o plasma y en orina, como los niveles de glucemia, la hemoglobina 'glicosilada', la TSH, el $\mathrm{T}_{4}$ libre, las hormonas esteroideas, la vitamina $\mathrm{D}$, el calcio y el fósforo, para evaluar el riesgo de enfermedades endocrinas y metabólicas. Se ha encontrado que los niveles altos de las enzimas hepáticas se relacionan con la mortalidad, específicamente con riesgo cardiovascular, y que la elevación de la fosfatasa alcalina y de la aspartato-aminotransferasa, con mayor frecuencia de cáncer.

Finalmente, debemos tener en cuenta que los medicamentos utilizados para el control de ciertas alteraciones cardiovasculares también pueden causar alteraciones sistémicas con repercusiones en la piel, tal como sucede con la amiodarona, que además de inducir alteraciones tiroideas, puede presentarse fotosensibilización y pigmentaciones pardovioláceas en la piel, o con el amlodipino que además de cefaleas o edemas, en algunos pacientes se pueden producir unas reacciones liquenoides con una coloración violácea en zonas expuestas a la luz (figura 6.11); los diuréticos tiazídicos que pueden permitir reacciones fotoinducidas; las estatinas 
como la atorvastatina que desencadenan una xerosis importante, los inhibidores de la enzima convertidora de la angiotensina (IECA) que pueden desencadenar angioedema (32), lesiones semejantes a la pitiriasis rosada de Gibert o a la psoriasis o lesiones ampollosas; los $\beta$-bloqueadores que exacerban la psoriasis; y algunos otros que inducen síndromes semejantes al LES como son la hidralazina, la quinidina o la procainamida. Finalmente, la insuficiencia cardíaca congestiva (ICC) tendrá repercusiones en todo el organismo, incluyendo la piel, que se verá afectada por la retención de líquidos y el edema secundario al mismo

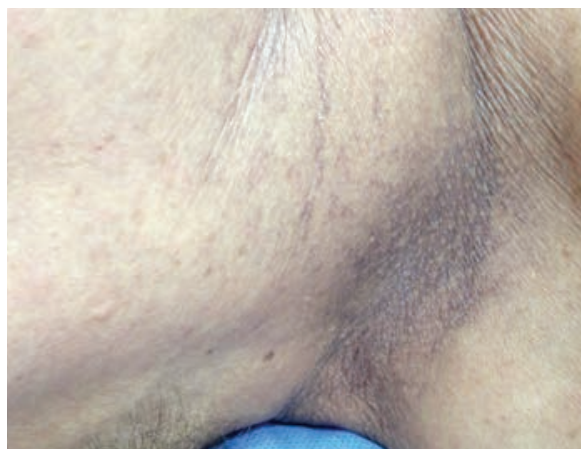

Figura 6.11. Pigmentación por amlodipino. Una pigmentación liquenoide se presenta en los pacientes que consumen este medicamento, con mayor frecuencia en las áreas expuestas a la luz.

\section{Alteraciones broncopulmonares}

Los cambios encontrados en la piel de los pacientes que padecen de afecciones cardiopulmonares no son específicos de una enfermedad en sí. Son más relevantes los cambios que se pueden observan secundarios a la dificultad y al aumento de la frecuencia respiratoria, al tiraje de los músculos intercostales o a la posición que adoptan los pacientes para que la entrada de aire sea mayor en los casos de disnea. También, se puede encontrar tórax aumentados de tamaño, 'en tonel', en los individuos con enfermedad pulmonar obstructiva crónica (EPOC), secundarios al tabaquismo o al contacto por años con el humo de leña.

Cuando se van a investigar las alteraciones cardiovasculares y broncopulmonares, de manera general, se puede encontrar que los dedos y las uñas nos brindan información del estado de estos órganos, ya sea que la cianosis sea evidente en las yemas de los dedos y en las palmas, o que lo sea el aumento de tamaño de las falanges distales o de la curvatura de las uñas, o que sea una coloración amarillenta de las uñas. 
El síndrome de las uñas amarillas es una rara alteración reportada con mayor frecuencia en los adultos, Se encuentran alteraciones del color de las uñas, linfedema en los tobillos y compromiso sinopulmonar (33). Las veinte uñas se observan de un color amarillento, con engrosamiento y cambios en la curvatura de las mismas y disminución de su crecimiento; puede haber pérdida de la lúnula y presentar alteraciones periungularess.

Se ha reportado asociado a enfermedades respiratorias, como la sinusitis, el derrame pleural o las bronquiectasias, que se caracterizan por la presencia de tos crónica con expectoración. También, pueden asociarse con neoplasias y enfermedades del tejido conjuntivo, como la artritis reumatoidea. Se cree que, en su patogénesis, puede existir una alteración del sistema linfático o un incremento de la permeabilidad de las proteínas que explique el linfedema, notorio en los tobillos. También, se ha sugerido un compromiso inmunológico, un estado de inmunocompromiso con deficiencia de inmunoglobulinas (34).

Por otro lado, se debe tener en cuenta que, si se observa una coloración amarillenta de las uñas, puede ser un signo de posible alteración broncopulmonar (figura 6.12), diferente a la pigmentación habitual que presentan las uñas de los dedos índice y medio de la mano dominante en los fumadores, que es más amarilla y oscura y solamente en esos dedos.

La oxigenación alterada de la sangre, que se visualiza con una pigmentación más azulosa que rojiza de la sangre a nivel distal, es un signo de hipertensión pulmonar, principalmente en las yemas de los dedos de las manos y de los pies o en la nariz y los pabellones auriculares, conocida como cianosis. Se puede presentar en los niños asociada a enfermedades congénitas del corazón, ya mencionada anteriormente, o que esté presente en una enfermedad hereditaria de origen autosómico recesivo que afecta las vías aéreas altas y bajas con compromiso rinosinusal y de los pulmones; además, afecta el sistema digestivo. Es la fibrosis quística, que es una enfermedad letal en la primera década de la vida, debido a la destrucción progresiva de estos tejidos.

En la hipertensión pulmonar, se encuentra un aumento de la curvatura de las uñas que se denomina 'uñas en vidrio de reloj' (figura 6.13). Si la hipertensión pulmonar es más grave o de mayor duración, se observa que los dedos en su porción distal cambian de forma, se hacen más 'abombados' por la falta de oxigenación y dan un aspecto de "dedos en palillo de tambor" (figura 6.14), también conocido como 'hipocratismo digital' u 'osteoartropatía hipertrófica'. 

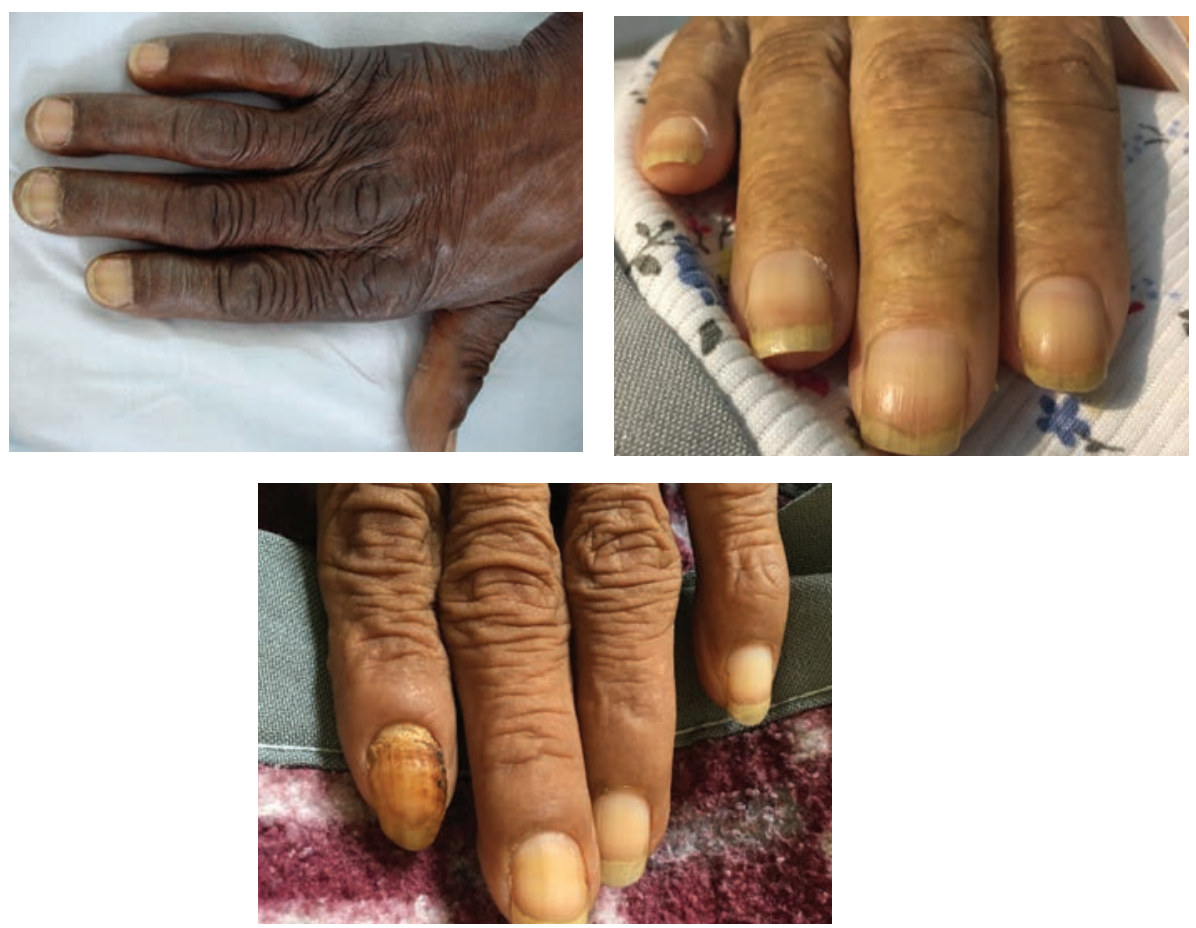

Figura 6.12. Uñas amarillas por compromiso broncopulmonar. Sin que se trate del 'síndrome de las uñas amarillas', que es una rara alteración reportada con mayor frecuencia en los adultos, en la cual se encuentran alteraciones del color de las veinte uñas, con engrosamiento y cambios en la curvatura de las mismas. Se observa que los pacientes con enfermedad pulmonar obstructiva presentan con mayor frecuencia uñas amarillentas, excluida la pigmentación propia de los dedos de los que consumen cigarrillos.

Esto es debido a la proliferación periarticular y ósea que se presenta en la porción distal de las falanges de los dedos de las manos y de los pies que es la que hace que cambien de forma. Aparecen, principalmente, en las personas adultas, acompañando a la hipertensión pulmonar en diferentes enfermedades pulmonares crónicas, como el EPOC, las bronquiectasias, la fibrosis pulmonar y las neoplasias malignas de tipo carcinoma broncogénico, pulmonar o pleural. Puede acompañar a la endocarditis bacteriana y también se presenta en otros procesos, como en la cirrosis biliar o en las enfermedades hipofisiarias y tiroideas. 

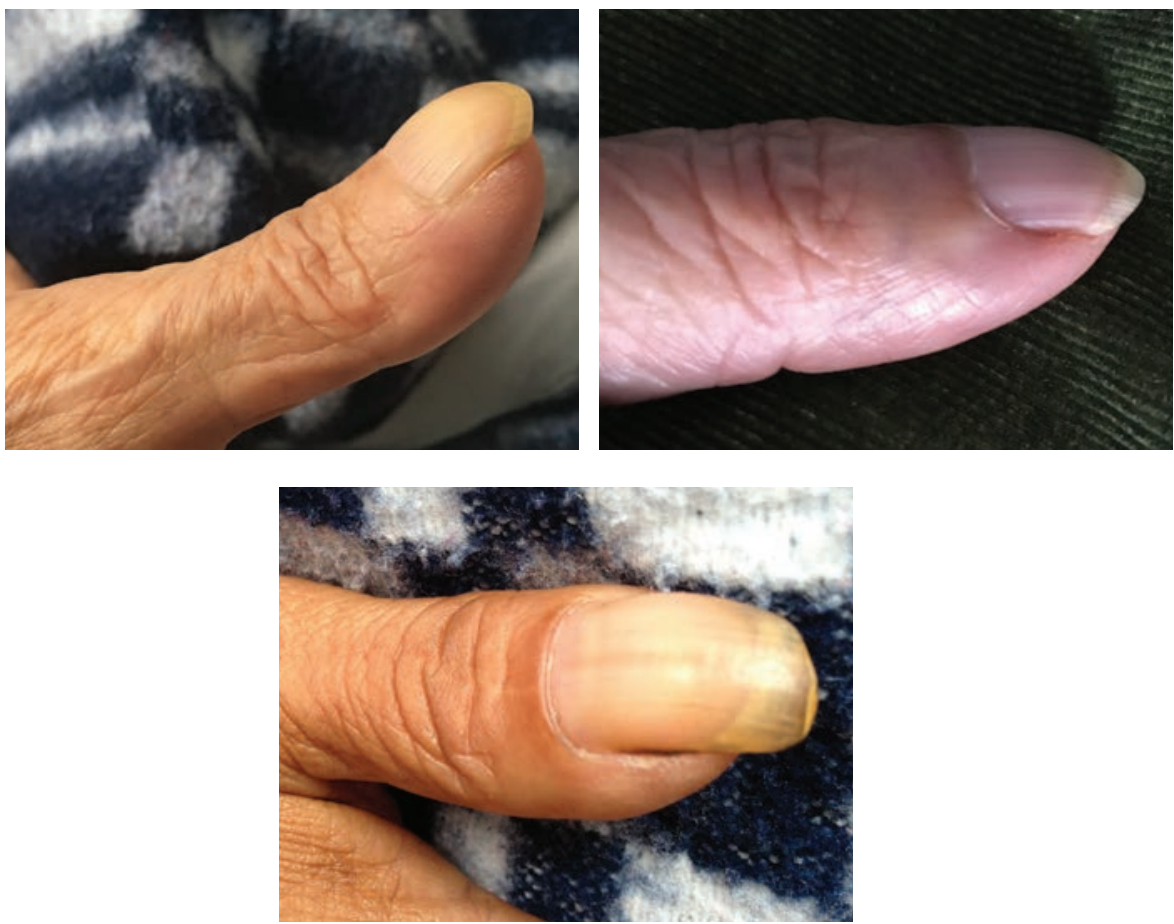

Figura 6.13. Uñas en vidrio de reloj. En la hipertensión pulmonar, se encuentra un aumento de la curvatura de las uñas, que se denomina uñas en vidrio de reloj, debido a que las micas o vidrios de los relojes antiguos eran curvados de manera convexa.

Las infecciones broncopulmonares por diferentes gérmenes que afectan el tracto respiratorio, se hacen presentes con algunas manifestaciones mucocutáneas que las acompañan. En algunos casos, los lesiones que aparecen son fenómenos vasculares reactivos y no es el mismo proceso infeccioso el que causa las lesiones en la piel, como sucede en las infecciones por Mycoplasma pneumoniae. Estas pueden desencadenar un eritema polimorfo o multiforme con máculo-pápulas de diversos tamaños, no mayores de $2 \mathrm{~cm}$, lesiones en diana de dos tonalidades, presentes en el tronco o en las extremidades, en las manos y en los pies o en los codos y en las rodillas, sin compromiso mucoso. 

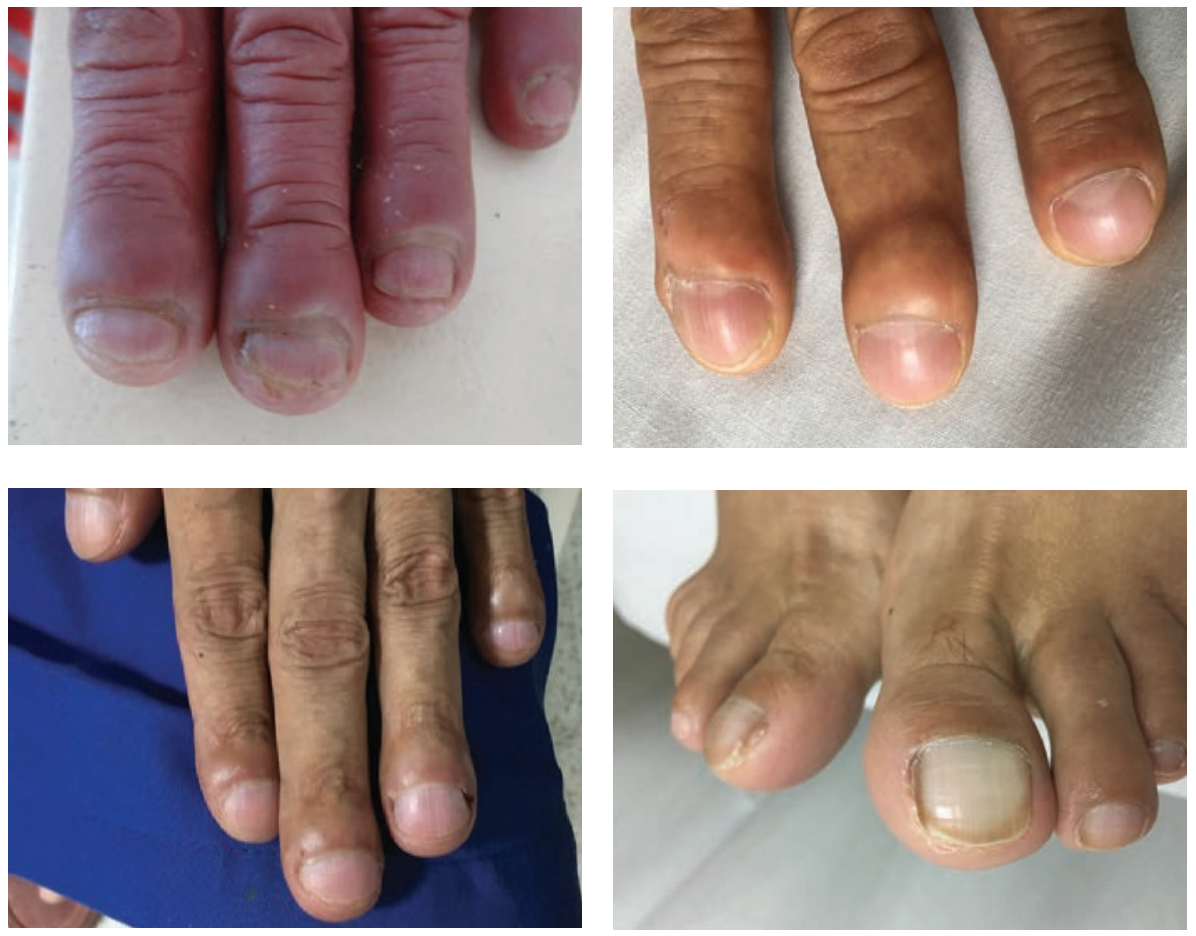

Figura 6.14. Dedos en palillo de tambor.

Los pacientes con síndrome de inmunodeficiencia adquirida, SIDA, presentan lesiones en la piel, acompañadas ocasionalmente por infecciones que afectan al pulmón, como sucede con Pneumocystis jiroveci. En estos pacientes, se pueden observar alteraciones cutáneas propias de la inmunodeficiencia, como la aparición de una dermatitis seborreica importante, ciertas infecciones de la piel de difícil manejo o reacciones serias a losmedicamentos. Lo anterior puede ayudar al clínico a enfocar la sospecha y a confirmar el diagnóstico de la infección por el virus de la inmunodeficiencia humana.

Cuando estos pacientes con sida adquieren por inhalación algunas infecciones fúngicas profundas, se puede encontrar presente el compromiso pulmonar y la aparición de ciertas lesiones en la piel. Bien sea por Cryptococcus neoformans o C. gattii o por Histoplasma capsulatum, las lesiones que se presentan en la piel son de diversa índole, variaciones de vesículas, pápulo-pustulosas, algunas de ellas con aspecto hemorrágico, lesiones ulcerativas en la mucosa oral o lesiones que pueden parecer moluscos virales o de aspecto tumoral ulcerado. Las de la histoplasmosis suelen ser de menor tamaño y las de criptococosis, de mayor tamaño 
y de aspecto tumoral ulcerado. Se deben solicitar los correspondientes exámenes de laboratorio para confirmar la infección (figura 6.15). No es fácil aseverar que existen unas lesiones específicas para estas micosis; se requieren los exámenes complementarios para poder llegar al diagnóstico preciso.
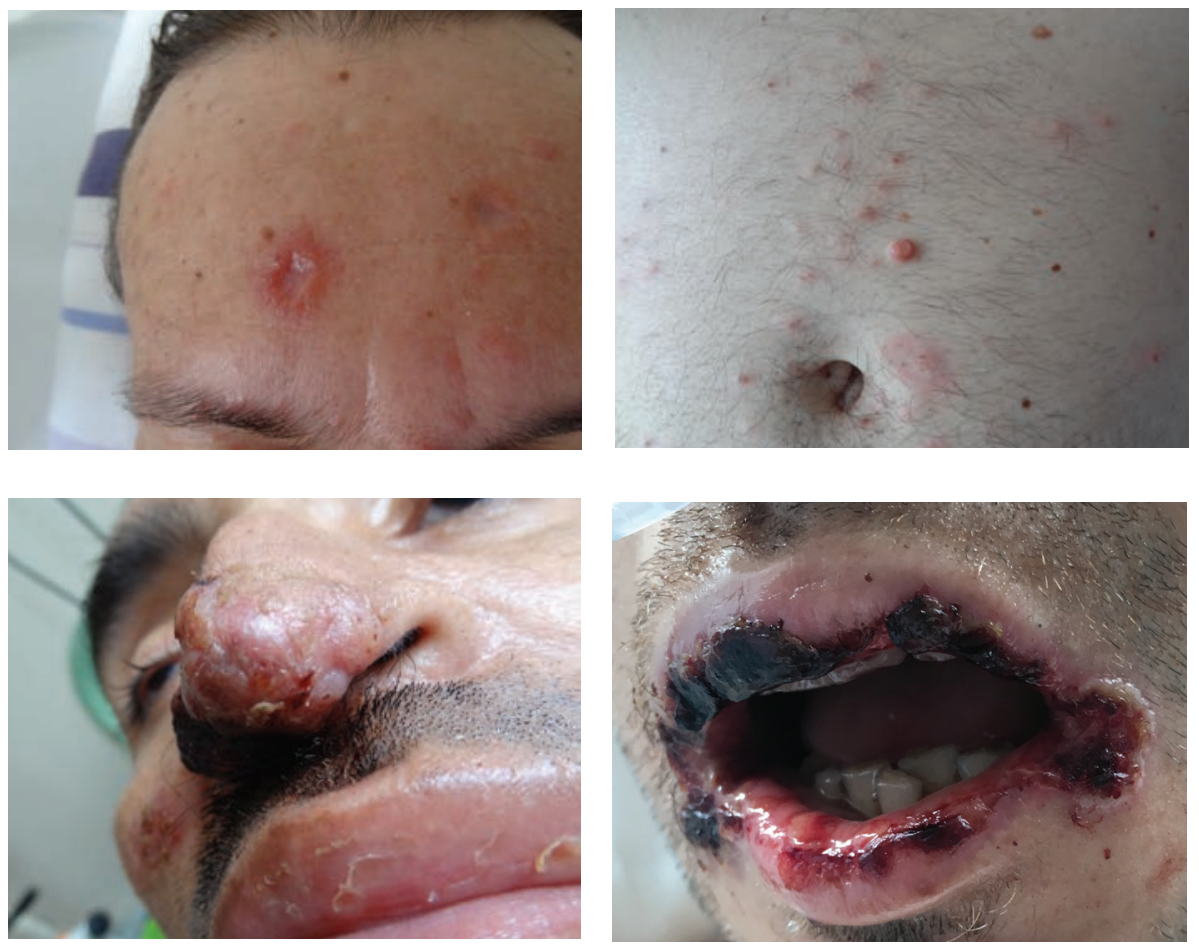

Figura 6.15. Histoplasmosis, criptococosis, sida. Las lesiones de histoplasmosis son muy variadas, y el compromiso ulcerativo oral puede ser la manifestación inicial. Las lesiones de piel pueden ser vesiculares, pápulo-pustulosas o hemorrágicas y, en ocasiones, recuerdan las lesiones de moluscos virales, de tamaño pequeño. Las lesiones por criptococosis suelen ser de mayor tamaño, de aspecto tumoral y en menor cantidad.

Las infecciones por Mycobacterium tuberculosis pueden comprometer tanto la piel como el pulmón; en el caso de comprometer la piel, las lesiones son aisladas, ulcerativas y granulomatosas, y el diagnóstico es histopatológico. Cuando la tuberculosis es pulmonar, el paciente puede presentar manifestaciones en la piel que ayudan a pensar en el diagnóstico (35). Los reportes de tuberculosis, según la Organización Mundial de la Salud, para el año 2014, en el mundo, fueron de 9,6 millones de casos con 1,4 millones de muertes (35). Los pacientes con sida e infectados por M. tuberculosis son numerosos, de tal manera que en estos pacientes con compromiso pulmonar se deberá solicitar la baciloscopia en esputo y si, además, 
de manera particular presentan lesiones en la piel, como las que se describen enseguida, la sospecha debe ser mayor.

Las lesiones cutáneas que acompañan a la tuberculosis pulmonar o de otro órgano pueden presentarse de diferentes maneras; la más conocida es el escrofuloderma, en los pacientes con tuberculosis pulmonar activa, con compromiso de los ganglios linfáticos que forman nódulos eritemato-parduzcos que forman fístulas a la piel y drenan material seropurulento. Se observan con frecuencia en la región cervical, submandibular, supraclavicular o axilar (figura 6.16). Las llamadas tuberculides pápulo-necróticas son fenómenos reactivos, con lesiones papulosas superficiales que se ulceran, centro necrótico, diseminadas en todo el tegumento cutáneo o, por otro lado, cuando se observan lesiones de tipo eritema nudoso ulcerado en los miembros inferiores, se debe sospechar tuberculosis. Este eritema nudoso ulcerado se conoce como eritema indurado de Bazin (36).
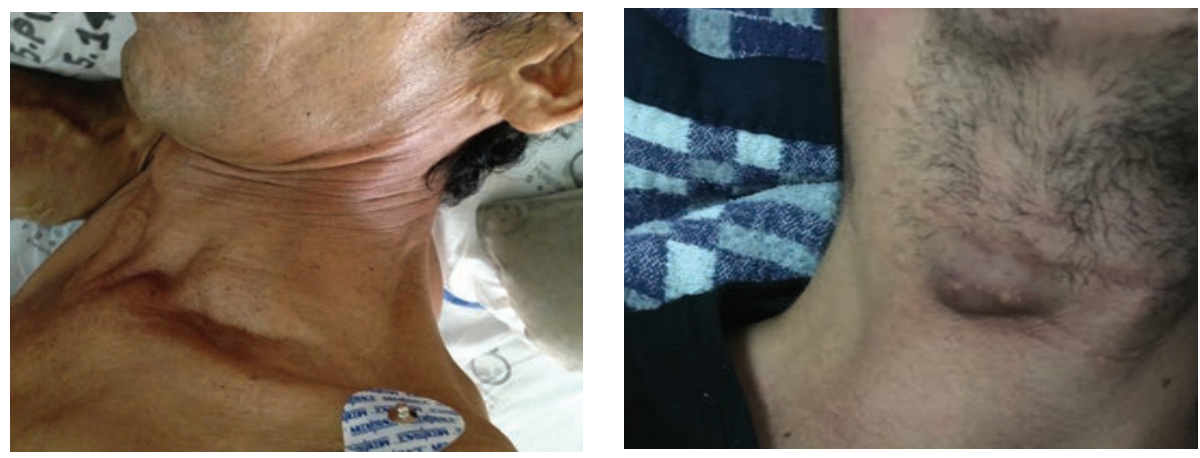

Figura 6.16 Tuberculosis: escrofuloderma. La presentan los pacientes con tuberculosis pulmonar activa y compromiso de los ganglios linfáticos, los cuales forman nódulos eritemato-parduzcos que originan fístulas a la piel y drenan material seropurulento, especialmente, en la región cervical, la submandibular, la supraclavicular y la axilar.

La sarcoidosis es otra enfermedad inflamatoria multisistémica crónica, granulomatosa, de origen desconocido, que puede comprometer la piel y los pulmones (37). Las lesiones más características son pápulas y nódulos de color amarillento, de muy pequeñas $(0,5 \mathrm{~cm}$ de diámetro) a mayores, que se agrupan de forma anular y recuerdan otras enfermedades granulomatosas, como el granuloma anular. Con frecuencia aparecen típicamente en cicatrices antiguas (figura 6.17a).

Pueden presentarse otras lesiones de aspecto lupoide, con placas eritematoamarillentas, infiltradas, en la punta de la nariz (figura 6.17b) o, a veces, lesiones granulomatosas más superficiales que forman conglomerados peribucales o peripalpebrales (figura $6.17 \mathrm{c}$ ). 

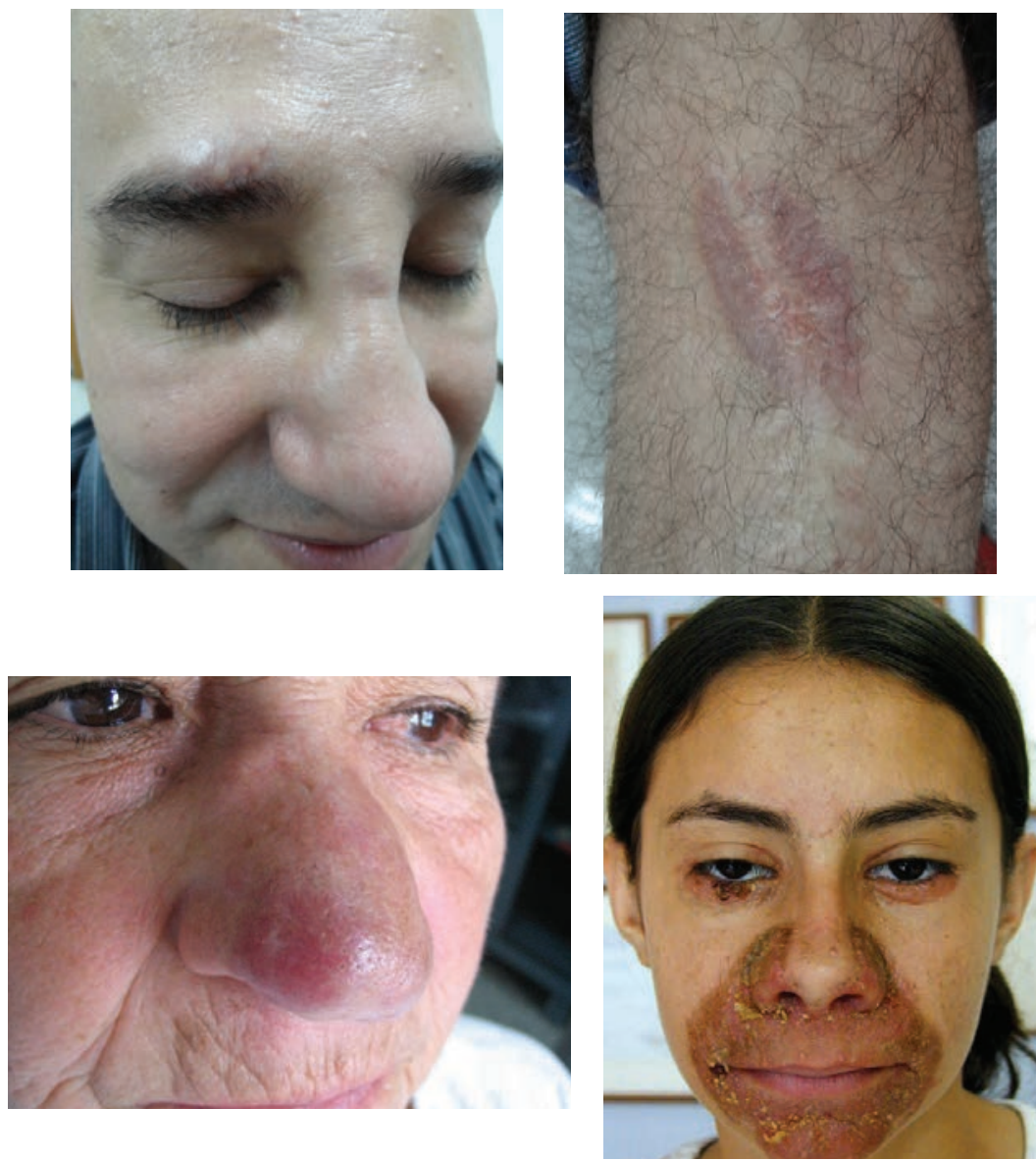

Figura 6.17. Sarcoidosis en a. cicatrices: las lesiones más características de la sarcoidosis son pápulas y nódulos de color amarillento, de muy pequeñas $(0,5 \mathrm{~cm}$ de diámetro) a mayores, que se agrupan de forma anular y recuerdan otras enfermedades granulomatosas, como el granuloma anular. Las lesiones de sarcoidosis, con frecuencia, aparecen típicamente en las cicatrices antiguas. b. nariz. c. peribucales y peripalpebrales: son lesiones de aspecto lupoide, con placas eritemato-amarillentas, infiltradas, en la punta de la nariz o, en ocasiones, lesiones granulomatosas más superficiales que forman conglomerados peribucales o peripalpebrales. Foto cortesia Dr. Sergio Arroyabe.

Algunas veces, las lesiones pápulo-pustulosas son discretas y diseminadas, aunque puede encontrarse compromiso de la mucosa oral, con adenopatías; en ocasiones, el compromiso sistémico es lo más importante, sea digestivo o pulmonar, y puede semejar una tuberculosis miliar acompañada de fiebre y sudoración nocturna. Se describe que, con frecuencia, si el compromiso pulmonar es importante con 
adenopatías en el mediastino, puede aparecer un eritema nudoso acompañando este proceso.

La sarcoidosis es una enfermedad autónoma, con una clara predisposición genética, entidad aún no entendida del todo, con un amplio espectro de manifestaciones de diversa índole y que no puede ser entendida de una sola manera.

El hallazgo histopatológico 'característico', con granulomas de células epitelioides sin caseificación o granuloma sarcoideo, no necesariamente es una sarcoidosis. Esta entidad podría ser entendida, al menos, de tres maneras diferentes. Primera, como un patrón de reacción infeccioso o parainfeccioso, generalmente frente a micobacterias; segundo, como una respuesta a la inhalación o la introducción a la piel de antígenos de compuestos inorgánicos inmunogénicos y, tercero, como una manifestación neoplásica (38).

\section{Referencias}

1. Kenney MJ, Ganta CK. Autonomic nervous system and immune system interactions. Compr Physiol. 2014;4:1177-200.

2. Elenkov IJ, Wilder RL, Chrousos GP, Vizi ES. The sympathetic nerve--an integrative interface between two supersystems: The brain and the immune system. Pharmacol Rev. 2000;52:595-638.

3. Bellinger DL, Millar BA, Perez S, Carter J, Wood C, Thyaga Rajan S, et al. Sympathetic modulation of immunity: Relevance to disease. Cell Immunol. 2008;252:27-56.

4. Kimyai-Asadi A, Usman A. The role of psychological stress in skin disease. J Cutan Med Surg. 2001;5:140-5.

5. Rosen SG, Sanfield JA, Morrow LA, Zweifler AJ. Relationship between plasma and platelet epinephrine concentrations in humans. Am J Physiol. 1987;252:E334-9.

6. Rector T, Olivari MT, Levine TB, Francis GS, Cohn JN. Predicting survival for a concentration. Am Heart J. 1987;114:148-52.

7. Goldstein DS, Stull R, Eisenhofer G, Sisson JC, Weder A, Averbuch SD, Keiser HR. Plasma 3,4-dihydroxyphenilanina (Dopa) and catecholamines in neuroblastoma or pheochromocytoma. Ann Inter Med. 1986;105:887-8.

8. Palma JA, Cook GA, Miglis MG, Loavenbruck A. Emerging subspecialties in neurology: Autonomic disorders. Neurology. 2015;84:e73-5.

9. Sanders VM, Straub RH. Norepinephrine, the $\beta$-adrenergic receptor, and immunity. Brain Behav Immun. 2002;16:290-332.

10. Pupo RA, Wiss K, Solomon AR. Disorders affecting the skin and the heart. Dermatol Clin. 1989;7:517-29.

11. Miller IM. Co-morbidities in inflammatory dermatological diseases. Psoriasis, hidradenitis suppurativa, and cardiovascular risk factors. Dan Med J. 2015;62:B5143 
12. Scheinfeld N. Diseases associated with hidranitis suppurativa: Part 2 of a series on hidradenitis. Dermatol Online J. 2013;19:18558.

13. Shlyankevich J, Chen AJ, Kim GE, Kimball AB. Hidradenitis suppurativa is a systemic disease with substantial comorbidity burden: A chart-verified case-control analysis. J Am Acad Dermatol. 2014;71:1144-50.

14. Morgan AJ, Schwartz RA. Diabetic dermopathy: A subtle sign with grave implications. J Am Acad Dermatol. 2008;58:447-51.

15. Katz AS, Goff DC, Feldman SR. Acantosis nigricans en pacientes obesos: formas de presentación e implicaciones para prevención de la enfermedad vascular aterosclerótica. Dermatol Online J. 2000;6:1

16. Hamrick MW, Ferrari SL. Leptin and the sympathetic connection of fat to bone. Osteoporos Int. 2008;19:905-12.

17. Watanabe A, Yoshimura A, Wakasugi T, Tatami R, Ueda K, Ueda R, et al. Serum lipids, lipoprotein lipids and coronary heart disease in patients with xanthelasma palpebrarum. Atherosclerosis. 1981;38:283-90.

18. Gaggl M, El-Hadi S, Aigner C, Sunder-Plassmann G. The renal history of Fabry's disease. G Ital Nefrol. 2016;33:S66: 1724-5590

19. Uitto J, Li Q, Urban Z. The complexity of elastic fiber biogenesis in the skin - a perspective to the clinical heterogeneity of cutis laxa. Exp Dermatol. 2013;22:88-92.

20. De Paepe A, Malfait F. The Ehlers-Danlos syndrome, a disorder with many faces. Clinical Genetics. 2012;82:1-11.

21. Marconi B, Bobyr I, Campanati A, Molinelli E, Consales V, Brisigotti V, et al. Pseudoxanthoma elasticum and skin: Clinical manifestations, histopathology, pathomechanism, perspectives of treatment. Intractable Rare Dis Res. 2015;4:113-22.

22. Hayward C, Brock DJ. Fibrillin-1 mutations in Marfan syndrome and other type-1 fibrillinopathies. Hum Mutat. 1997;10:415-23.

23. González-López L, Gámez-Nava J, Sánchez L, Rosas E, Suárez-Almazor M, Cardona-Muñoz C, et al. Cardiac manifestations in dermatopolymyositis. Clin Exp Rheumatol. 1996;14:373-9

24. Vaillant L, Larmande P, Arbeille B, Desveaux B, Gruel Y, Lorette G. Livedo reticularis, cerebrovascular disorders and mitral disease: a new cause of Sneddon's syndrome?.Ann Dermatol Venereol. 1990;117:925-30.

25. Dutra LA, Braga-Neto P, Pedroso JL, Barsottini OG. Sneddon's syndrome: Case report and review of its relationship with antiphospholipid syndrome. Einstein (São Paulo). 2012;10:230-2.

26. Ekvall S, Wilbe M, Dahlgren J, Legius E, van Haeringen A, Westphal O, et al. Mutation in NRAS in familial Noonan syndrome - case report and review of the literature. BMC Med Genet. 2015;16:95.

27. Li JS, Sexton DJ, Mick N, Nettles R, Fowler VG, Jr., Ryan T, et al. Proposed modifications to the Duke criteria for the diagnosis of infective endocarditis. Clin Infect Dis. 2000;30:633-8.

28. Barron KS. Kawasaki disease: Etiology, pathogenesis, and treatment. Clev Clin J Med. 2002;69(Suppl.2):SII69-78.

29. Hofman A, Breteler MB, van Duijn CM, Krestin GP, Pols HA, Stricker BH, Tiemeier H, Uitterlinden AG, Vingerling JR, Jacqueline CM, Witteman JC. The Rotterdam Study: Objectives and design update. Eur J Epidemiol. 2007;22:819-29. 
30. Dowlatshahi EA, Kavousi M, Nijsten T, Ikram MA, Hofman A, Franco OH, Wakkee M. Psoriasis is not associated with atherosclerosis and incident cardiovascular events: the Rotterdam Study. J Invest Dermatol. 2013;133:2347-54.

31. Koehler EM, Schouten JN, Hansen BE, van Rooij FJ, Hofman A, Stricker BH, et al. Prevalence and risk factors of non-alcoholic fatty liver disease in the elderly: Results from the Rotterdam Study. J Hepatol. 2012;57:1305-11.

32. Vleeming W, van Amsterdam JG, Stricker BH, de Wildt DJ. ACE inhibitor-induced angioedema: Incidence, prevention and management. Drug Saf. 1998;18:171-88.

33. Samman PD, White WF. The "yellow nail syndrome". Br J Dermatol. 1964;76:153-7.

34. Nanda S, Dorville F. Yellow nail syndrome. CMAJ. Can Med Assoc J. 2009;181:614.

35. World Health Organization. Global tuberculosis report, 2015. 20a ed. Geneva: WHO; 2015.

36. Spelta K, Diniz LM. Cutaneous tuberculosis: A 26-year retrospective study in an endemic area of tuberculosis, Vitória, Espírito Santo, Brazil. Rev Inst Med Trop Sao Paulo. 2016;58:49.

37. Tchernev G, Tana C, Schiavone C, Cardoso JC, Ananiev J, Wollina U. Sarcoidosis vs. sarcoid-like reactions: The two sides of the same coin? Wien Med Wochenschr. 2014;164:247-59.

38. Tchernev G, Lotti T, Wollina U, Cardoso JC, Popova LV, Maximov GK, et al. Sarcoidosis in A. C. Milan (1899)?" Macedonian Journal of Medical Sciences. 2018;6:99-102. 


\section{Capítulo 7}

\section{Alteraciones hematológicas y vasculares}

Las alteraciones que se producen en los diferentes elementos del sistema sanguíneo o hematológico dan origen a alteraciones visibles en la piel. Si existe una disminución de la cantidad de glóbulos rojos y, específicamente de la hemoglobina, estamos frente a una anemia, ya sea por deficiencias nutricionales, enfermedades crónicas, pérdida de sangre, destrucción excesiva de los glóbulos rojos o por alteraciones hereditarias; esto hace que la piel y las mucosas se vean pálidas. Las anemias más frecuentes pueden ser de diferente naturaleza: por falta de hierro, anemia ferropénica, alteraciones de la vitamina $\mathrm{B}_{12} \mathrm{o}$ ácido fólico; anemia perniciosa $\mathrm{o}$ megaloblástica, si existe una hemólisis; anemia hemolítica o anemia por alteraciones estructurales (forma de los glóbulos rojos), como sucede en la anemia de células falciformes que pueden llevar a una oclusión vascular.

En estas anemias, además de visualizarse el cambio de la coloración de la piel, se pueden alterar tanto el crecimiento del pelo como el de las uñas, como sucede en la anemia ferropénica, en cuyo caso existe un aumento de la caída del pelo, y las uñas de los dedos de las manos y de los pies pueden llegar a observarse cóncavas, una alteración conocida como coiloniquia.

La anemia perniciosa se ha visto asociada a vitiligo y la anemia de células falciformes a la presencia de úlceras de aspecto arterial en los miembros inferiores, debido a que los eritrocitos alterados obstruyen los vasos y posibilitan una necrosis del tejido que irriga ese vaso y da origen a una úlcera que es indistinguible de las de origen arterial.

No se debe olvidar que un paciente con anemia puede tener, por otro lado, una infección crónica, una insuficiencia hepática o renal, una neoplasia, una enfermedad endocrinológica o una enfermedad autoinmunitaria así que, si se presenta, es obligatorio estudiar al paciente.

Los fenómenos hemorrágicos que se ven en la piel con lesiones de tipo petequia, púrpura o equimosis pueden resultar de diferentes alteraciones o de anormalidades del número de las plaquetas o por deficiencias en los factores de la coagulación, como sucede en la hemofilias de tipo A; con deficiencia del factor VIII, 
hemofilia de tipo B; con deficiencia del factor IX, la enfermedad de von Willebrand, por deficiencias endógenas de factores anticoagulantes antitrombina III, proteína C, proteína $\mathrm{S} \mathrm{u}$ otras alteraciones de la fibrinólisis. Estos fenómenos deben ser analizados con los exámenes de laboratorio pertinentes para clasificarlos y saber si verdaderamente existe una alteración de la coagulación, es decir, una coagulopatía, o si se trata de otro fenómeno responsable de las lesiones púrpuras o violáceas, de apariencia similar, como sucede en los fenómenos vasculares reactivos, en las púrpuras o en las vasculitis.

Si se encuentra una lesión de aspecto hemorrágico, esta puede ser eritematosa, eritemato-violácea o púrpura y, muchas veces, no está claro si se trata de una alteración inflamatoria, hemorrágica o de una verdadera vasculitis, es importante observar si al oprimir la piel, se blanquea o no. Si se blanquea parcialmente, se está ante una inflamación con hemorragia, como puede suceder en las vasculitis; si se blanquea totalmente, solo hay inflamación, como sucede en los exantemas máculo-papulares, y si no se blanquea, es más importante la hemorragia y mínima la inflamación, como sucede con la aparición de las petequias en la trombocitopenia.

Es lo que se hacía antiguamente cuando se observaba a través de una lámina de vidrio y se decía si desaparecía o no a la vitropresión y aún es útil el concepto para saber si hay o no extravasación de la sangre. Cuando existe, se pueden ver lesiones puntiformes llamadas petequias; si la extravasación es superficial, se observa un color púrpura (más rojizo que azul) (figura 7.1 a) y si las lesiones son más profundas o el vaso es de mayor tamaño, el color será violáceo (más azul que rojo) (figura 7.1.b) y se conocen como equimosis.

Si las lesiones se acompañan de otro tipo de sangrado en otros órganos, como epistaxis, hemorragia gingival, hematuria, metrorragia $u$ otro, se debe estudiar al paciente desde el punto de vista hematológico, aclarando si se trata de una trombocitopenia o de otra alteración de la coagulación, o si se encuentra acompañando a una enfermedad sistémica como en el caso del lupus eritematosos sistémico (figura 7.2), en el cual se encuentran anticuerpos contra las plaquetas que explican la trombocitopenia. Sí solo existen alteraciones del número de las plaquetas sin otra patología podría tratarse de una púrpura trombocitopénica idiopática, ahora llamada púrpura trombocitopénica autoinmunitaria. 

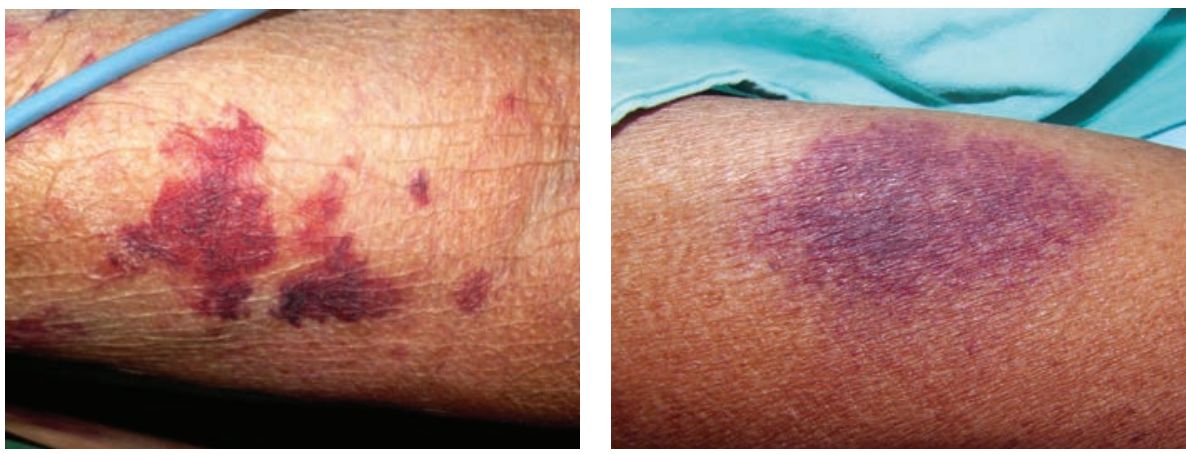

Figura 7.1. a. Lesión púrpura y b. lesión violácea. Cuando la extravasación de sangre proviene de los vasos más superficiales, se observa un color púrpura (más rojizo que azul) y si las lesiones son más profundas o el vaso es de mayor tamaño, el color será violáceo (más azul que rojo).

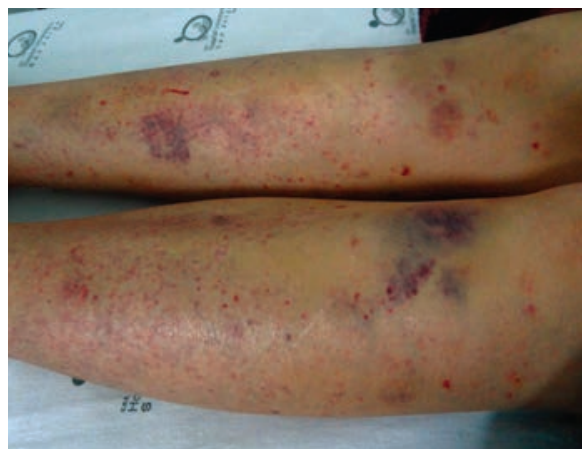

Figura 7.2. Lupus eritematoso sistémico, alteraciones de la coagulación. En algunos pacientes con lupus eritematoso sistémico, la manifestación inicial no es necesariamente articular, puede ser más una alteración hematológica, así que cuando se presente una trombocitopenia con sangrado fácil y fenómenos hemorrágicos, se debe estudiar al paciente desde el punto de vista hematológico, para dilucidar si se trata de una trombocitopenia o de otra alteración de la coagulación, o si se encuentra acompañando a una enfermedad sistémica, como en el caso del lupus eritematoso sistémico.

Se debe tener claridad que cuando se presentan dilataciones venosas en las piernas, se pueden presentar cambios en la coloración de la piel que podrían confundirse con una vasculitis. Las enfermedades vasculares venosas se caracterizan por dilataciones venosas, eccema por estasis con vesículas y prurito en las zonas de los vasos dilatados, y pigmentaciones ocre y púrpura secundarias a la hipertensión venosa por retorno circulatorio alterado en la insuficiencia venosa (figura 7.3). Este fenómeno que puede aparecer en circunstancias en las que el individuo permanece de pie o sentado por un tiempo prolongado -ocho o diez 
horas en un bus o en un avión- puede hacer que las lesiones sean puntiformes; este fenómeno se conoce como púrpura pigmentaria progresiva, debido a la extravasación de los eritrocitos por el aumento de presión. Es más frecuente en los dos tercios inferiores de las piernas afectadas y no son una verdadera vasculitis.

A continuación, se clasifican las vasculitis y las púrpuras para dar una idea de cómo enfocar este problema complejo.

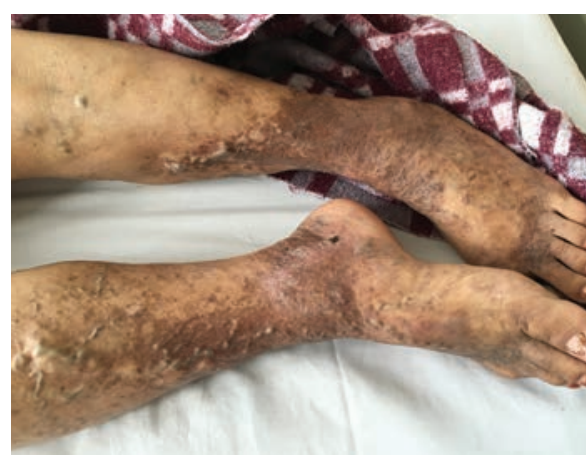

Figura 7.3. Síndrome varicoso: pigmentación ocre y púrpura. Las enfermedades vasculares venosas se caracterizan por la presencia de dilataciones venosas, eccema por estasis con vesículas y prurito en las zonas de los vasos dilatados, y pigmentaciones inicialmente purpúricas que se tornan de color amarillento parduzco u ocre secundarias a la extravasación de los eritrocitos por el aumento de presión, hipertensión venosa por el retorno circulatorio alterado en la insuficiencia venosa.

\section{Lesiones cutáneas por alteraciones vasculares}

Los plexos vasculares, superficial y profundo, que irrigan la piel, se encuentran en la dermis y debido a esta localización superficial, se pueden visualizar los diferentes eventos que en ellos se presentan, como la extravasación de sangre en una petequia o el cambio de la arquitectura de los vasos sanguíneos, como sucede con las telangiectasias en las que se pueden observar los vasos capilares aumentados de tamaño. Se pueden encontrar mejillas con mayor enrojecimiento o rubor en una insuficiencia mitral o tricuspídea. Si lo que observamos son vasos de mayor tamaño y engrosados en el tronco, se puede estar ante un evento conocido como 'circulación colateral' como en el caso de una hipertensión portal en un paciente con cirrosis, o en el caso de una neoplasia intratorácica que, de manera retrógrada, aumenta el flujo venoso en el caso de un conglomerado linfático tumoral. Si las telangiectasias se encuentran en la región periungular, el paciente puede sufrir de una diabetes o una de esclerosis sistémica. Si lo que visualizamos es una alteración eritematosa inflamatoria generalizada, posiblemente el paciente tenga un exantema que requiere del sistema inmunitario cutáneo para su resolución. 
Las variaciones de tamaño o de grosor de los vasos se traducen en diferentes lesiones visibles en la piel. Un vaso se ve tortuoso en el síndrome varicoso y la extremidad se enrojece con las características clínicas de la inflamación en una celulitis, con cambios de coloración de rosado a rojizo (eritema), calor, dolor y sintomatología acompañante o, en otras ocasiones, se pueden ver cambios menos eritematosos, pero más sintomáticos y dolorosos, como en la tromboflebitis, con engrosamiento de la extremidad. Por otra parte, se puede observar la extravasación de líquidos en los diferentes edemas cardiogénicos o renales, o depósitos de diferentes sustancias como sucede en el hipotiroidismo con el mixedema que, ocasionalmente y con mayor frecuencia, se acompaña de la presencia de equimosis.

Ante un diagnóstico dudoso, las lesiones clínicas y sus variaciones en el color nos ayudan a entender el tipo de compromiso. Si existen infiltrados granulomatosos, las lesiones toman un color amarillento, del color de la 'jalea de manzana' como enseñaban los antiguos semiólogos. La aparición de lesiones pustulosas no solo acompaña las infecciones, puede aparecer por acumulación de neutrófilos, como sucede en las dermatosis neutrofílicas, en el pioderma gangrenoso y en el síndrome de Sneddon-Wilkinson. La biopsia nos ayuda a enfocar cada caso en particular, ya que el infiltrado inflamatorio -de neutrófilos, eosinófilos o linfocitos- o los granulomas que acompañan el caso, aporta datos que pueden aclarar el proceso subyacente.

Las clasificaciones son múltiples; algunos de estos procesos se encuentran clasificados de manera diferente. En este capítulo nos vamos a referir a dos tipos de eventos; en primer lugar, a las lesiones que demuestran con su aparición que existe una situación interna alterada que lo desencadena, es decir, estas lesiones reflejan la existencia de una enfermedad sistémica de base y las vamos a llamar 'fenómenos vasculares reactivos'. Ellos son la urticaria por vasculitis, el eritema polimorfo o multiforme, los eritemas figurados, el síndrome de Sweet y el eritema nudoso (1). En segundo lugar, nos referiremos a las púrpuras con extravasación de eritrocitos y a las verdaderas vasculitis, que hacen parte de un fenómeno inflamatorio por depósito de complejos inmunes, con lesión del endotelio vascular y vasculitis leucocitoclásica.

\section{Fenómenos vasculares reactivos}

Las siguientes lesiones clínicas no son enfermedades en sí y pueden ser desencadenadas por diferentes enfermedades -infecciosas, autoinmunitarias o tumorales- de tal modo que, cuando se presentan, es obligatorio el estudio del paciente para aclarar a qué proceso patológico se encuentran asociados. 
Urticaria vasculítica. Se caracteriza por la aparición de pápulas edematosas que persisten por más de 24 a 48 horas y, a veces, tienen el borde más eritematoso que les da el aspecto de ser circulares o anulares; pueden verse hemorrágicas (figura 7.4), acompañando a varias enfermedades sistémicas (2). En ella existe un consumo del complemento y, por esta razón, se encuentran bajos niveles sanguíneos del mismo, medidos por C3, C4 o CH50. Esta forma de hipocomplementemia está asociada con mayor frecuencia a la enfermedad del suero, al lupus eritematoso sistémico, al síndrome de Sjögren, a la enfermedad por superposición, a la enfermedad tiroidea autoimmunitaria o a una neoplasia maligna interna.
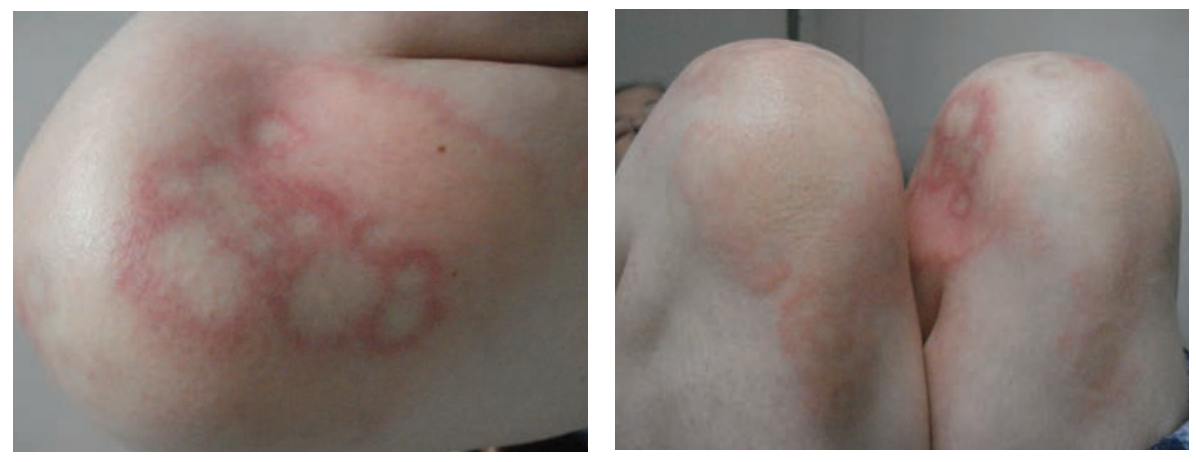

Figura 7.4. Urticaria vasculítica. La urticaria por vasculitis se caracteriza por la aparición de pápulas edematosas que persisten por más de 24 a 48 horas y, a veces, tienen el borde más eritematoso que les da el aspecto de ser circulares o anulares; pueden verse hemorrágicas, acompañando varias enfermedades sistémicas.

\section{Eritema multiforme, síndrome de Stevens-Johnson, necrólisis epidérmica} tóxica. El eritema polimorfo o multiforme se caracteriza por presentar lesiones de tipo diana o iris con aros concéntricos de dos o más tonalidades, uno dentro del otro, una zona central eritematosa más oscura o, en ocasiones, ampollosa, rodeada de otra más clara. Se presenta en sitios distales: manos, pies, codos o rodillas (figura 7.5) y puede comprometer las mucosas de manera muy discreta.

Si las lesiones comprometen las mucosas y la gravedad de las lesiones aumenta, se denomina síndrome de Stevens-Johnson. En este, las lesiones son más eritematosas o eritemato-violáceas y la aparición de ampollas es más frecuente; pueden empezar como máculas púrpura, lesiones en diana atípicas, acompañadas de lesiones en mucosas que se pueden ver como erosiones hemorrágicas que comprometen, al menos, dos sitios. 

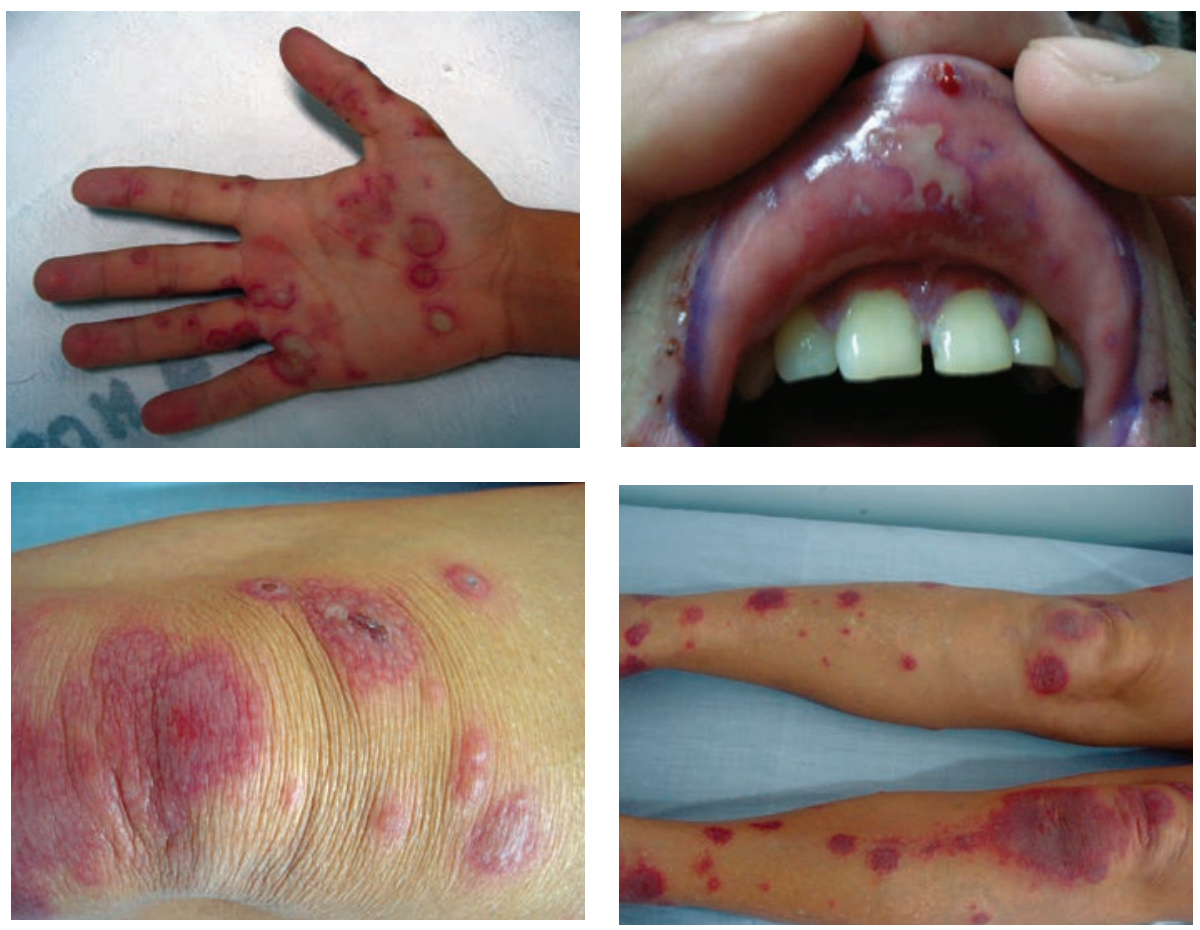

Figura 7.5. Eritema multiforme. El eritema polimorfo o multiforme se caracteriza por presentar lesiones de tipo diana o iris con aros concéntricos de dos o más tonalidades, uno dentro del otro, una zona central eritematosa más oscura o, en ocasiones, ampollosa, rodeada de otra más clara que se presenta en sitios distales: manos, pies, codos y rodillas.

En la histopatología se observa una degeneración vacuolar de la capa basal, con ampollas subepidérmicas y queratinocitos necróticos (3). Su recuperación es lenta. Si el compromiso del tegumento cutáneo es mayor del $30 \%$ de la superficie corporal, el resultado de esa gran coalescencia de ampollas es una denudación y se dice que estamos ante una necrólisis epidérmica tóxica (figura 7.6).

En el caso del eritema multiforme, las causas desencadenantes más importantes son las infecciones; virales (virus herpes), bacterianas (Mycoplasma pneumoniae) o por otros microorganismos como Mycobacterium leprae, Histoplasma capsulatum, Yersinia spp. o también puede estar acompañando a otras enfermedades como la sarcoidosis, el lupus eritematoso sistémico, la poliarteritis nudosa, la granulomatosis de Wegener o aparecer en el embarazo o acompañando algunas neoplasias. 

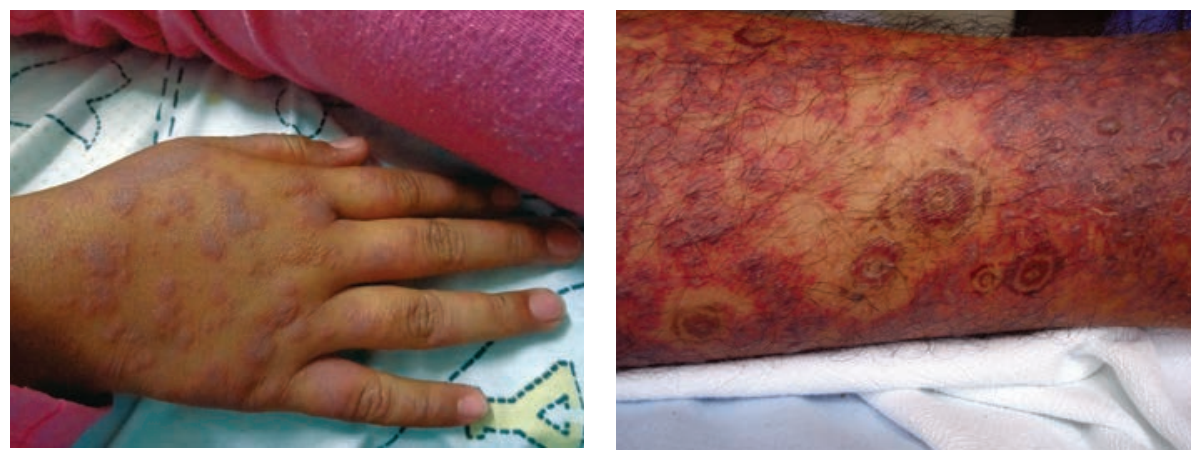

Figura 7.6. Síndrome de Stevens-Johnson y necrólisis epidérmica tóxica. Si las lesiones del eritema multiforme comprometen las mucosas y la gravedad aumenta, estamos ante un síndrome de Stevens-Johnson. En este, las lesiones son más eritematosas o eritematovioláceas y la aparición de ampollas es más frecuente; pueden empezar como máculas púrpura, acompañadas de lesiones en mucosas, que comprometen, al menos, dos sitios. Si el compromiso del tegumento cutáneo es mayor del $30 \%$ de la superficie corporal, el resultado de esa coalescencia de ampollas es una denudación y se dice que estamos ante una necrólisis epidérmica tóxica.

Cuando se presenta un síndrome de Stevens-Johnson o una necrólisis epidérmica tóxica con extenso compromiso cutáneo, lo más probable es que se haya desencadenado por medicamentos. Es importante tener claridad en estas variaciones para mejorar el pronóstico con un manejo correcto de cada circunstancia.

Eritemas figurados. Son fenómenos vasculares reactivos que se denominan así por tener lesiones eritematosas que adoptan patrones clínicos con diferentes figuras. Las más frecuentes son circulares o anulares; algunas son centrípetas, otras centrífugas; algunas presentan semiarcos o se inician circulares y pueden cambiar a serpiginosas o policíclicas (4). Las lesiones pueden ser inicialmente maculares o papulares eritematosas, edematosas e inflamatorias con crecimiento centrífugo y aclaramiento central, con descamación discreta en la periferia en la mayoría de los casos. Algunas tienen denudación periférica de la lesión, que implica una especie de necrosis leve con pérdida de la capa superficial de la piel, aparecen en el tronco y en las extremidades. Como es un patrón de reacción vascular, es probable que sea más frecuente en individuos propensos a las reacciones autoinflamatorias y puede asociarse con diferentes procesos infecciosos, inflamatorios o neoplásicos.

Los más conocidas son: el eritema anular centrífugo (figura 7.7), con lesiones anulares de curso crónico y recidivante asociadas a múltiples infecciones virales, bacterianas o fúngicas, como la candidiasis o infecciones por dermatofitos; o por ingestión de hongos (quesos); infección por Rickettsias o por parásitos como Ascaris lumbricoides; en enfermedades autoinmunitarias como en el lupus eritematoso subagudo o en el síndrome de Sjögren; por hipersensibilidad a medicamentos; en el 
hipertiroidismo, en enfermedades hepáticas, disproteinemias, discrasias sanguíneas, alteraciones inmunológicas o asociado a tumores (5).
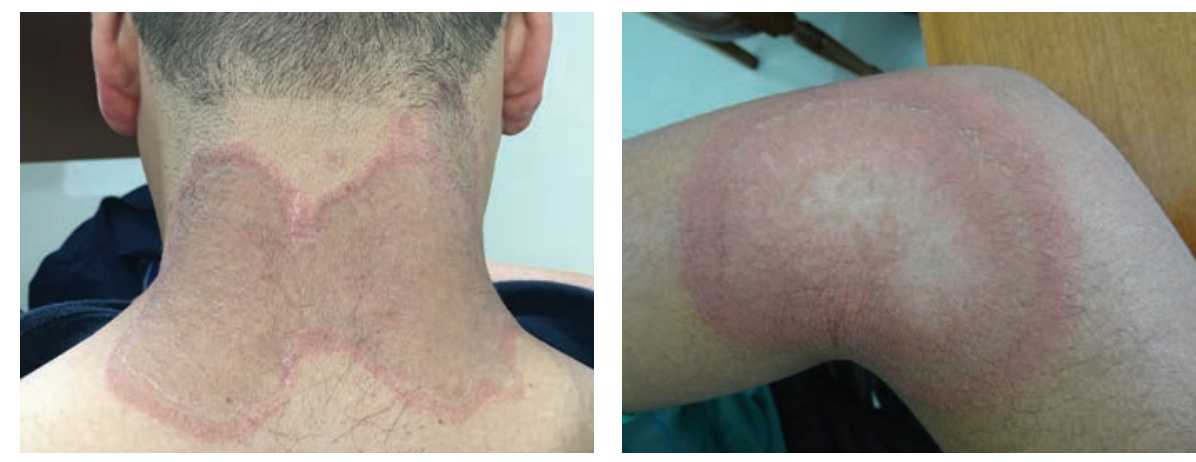

Figura 7.7. Eritema anular. Las lesiones son inicialmente maculares o papulares eritematosas, edematosas e inflamatorias con crecimiento centrífugo y aclaramiento central; algunas son anulares con descamación discreta en la periferia, conocidas como eritema anular centrífugo; aparecen en el tronco y en las extremidades y pueden ser recidivantes asociadas a múltiples infecciones, o por la ingestión de hongos (quesos), o asociado a enfermedades autoinmunitarias.

El eritema marginatum reumaticum, conocido con este nombre porque hace parte de la fiebre reumática, secundaria a una infección faríngea estreptocócica no bien manejada y, en la actualidad, es muy raro verlo gracias al buen manejo que se hace de las infecciones faríngeas por Streptococcus spp.

El eritema crónico migrans se encuentra relacionado con una infección por una espiroqueta del complejo Borrelia burgdorferi sensu lato transmitida por la picadura de una garrapata. Es la manifestación inicial y característica de la enfermedad de Lyme en la que se observa un círculo eritematoso y edematoso en cuyo centro se evidencia el lugar de la picadura de la garrapata (6). Este círculo aparece por el crecimiento centrífugo y va aumentando de tamaño a medida que pasan los días después de la picadura (figura 7.8. a). Se acompaña de un compromiso multisistémico que puede incluir manifestaciones en el sistema nervioso central, músculo-esqueléticas, cardiovasculares y un exantema (figura 7.8 b) que aparece desde unos pocos días hasta un mes. No es frecuente en nuestra latitud, si se ve. los pacientes generalmente la han adquirido en otros lugares.

El eritema gyratum repens se presenta con lesiones en el tronco principalmente y, como su nombre lo dice, las lesiones eritematosas e inflamatorias tienen múltiples formas de apariencia giratoria como si fueran vetas de madera. Este tipo de eritema figurado aparece como un fenómeno paraneoplásico asociado a neoplasias malignas y con mayor frecuencia al carcinoma de pulmón (7). 

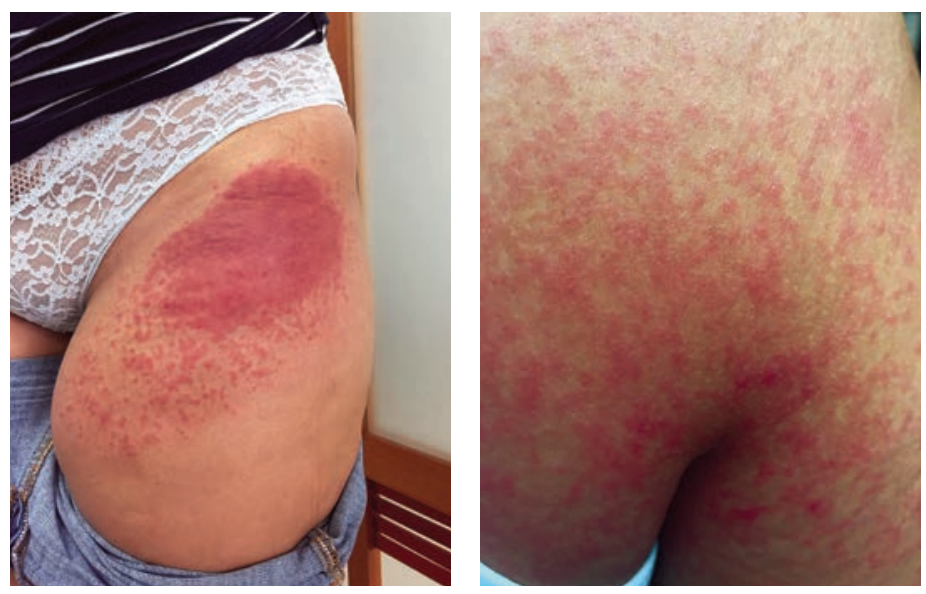

Figura 7.8. Enfermedad de Lyme: eritema crónico migrans y exantema. El eritema crónico migrans se encuentra relacionado con una infección por una espiroqueta del complejo Borrelia burgdorferi transmitida por la picadura de una garrapata. Es la manifestación inicial y característica de la enfermedad de Lyme, en la que se observa un círculo eritematoso y edematoso en cuyo centro se evidencia el lugar de la picadura de la garrapata. Este círculo aparece por el crecimiento centrífugo y va aumentando de tamaño a medida que pasan los días después de la picadura (figura 7.8. a); se acompaña de un compromiso multisistémico que incluye manifestaciones en el sistema nervioso central, músculo-esqueléticas, cardiovasculares y de la aparición de un exantema (figura 7.8. b) que aparece desde unos pocos días hasta un mes después.

El eritema necrolítico migratorio se caracteriza por presentar lesiones eritematosas máculo-papulares con lesiones vesiculosas o ampollosas en la periferia. La piel se va denudando dejando erosiones y costras, es más frecuente en las regiones alrededor de los orificios, en el abdomen o en las regiones interglúteas, acompañado de manifestaciones consuntivas. También se presenta acompañando tumores pancreáticos neuroendocrinos, como el glucagonoma (8). Ninguno de estos dos últimos eritemas figurados se presenta con frecuencia.

Síndrome de Sweet. Es un fenómeno vascular reactivo conocido también como dermatosis neutrofílica aguda febril, descrita por Sweet en 1964 (9). Se caracteriza por la presencia de fiebre y leucocitosis con neutrofilia, que acompaña la aparición de unas lesiones eritematosas y edematosas, de un color eritematoso fuerte, de aspecto "ajamonado" (figura 7.9). Pueden ser dolorosas y son más infiltradas que una lesión urticante, pero no se ven tan profundas como sucede en una lesión de un eritema nudoso.

Los pacientes habitualmente tienen de 30 a 50 años de edad, y pueden presentar otra sintomatología, como infecciones del tracto respiratorio alto por Streptococcus spp.; intestinales, por Salmonela spp. o Yersinia spp., o asociadas a 
infecciones por Mycobacterium spp. u otras. Además de las infecciones, puede acompañar ciertas neoplasias, generalmente de origen hematológico (10), o a otros tumores sólidos. Puede aparecer durante el embarazo o secundarios a la administración de medicamentos como factores estimuladores de colonias de granulocitos.

En la histopatología, se aprecia un fenómeno de vasculitis leucocitoclásica, con infiltrados de neutrófilos alrededor de las vénulas poscapilares, sin depósitos de fibrina ni trombos y con un llamativo edema de la dermis papilar (11). Con mucha frecuencia acompaña a la leucemia mieloide aguda y puede presentarse en otras alteraciones hematológicas o autoinmunitarias. Se presenta con mayor frecuencia en los adultos y en las mujeres; pueden aparecer en el rostro, el cuello y los miembros superiores con más frecuencia, aunque también pueden hacerlo en el tronco o en las extremidades inferiores.
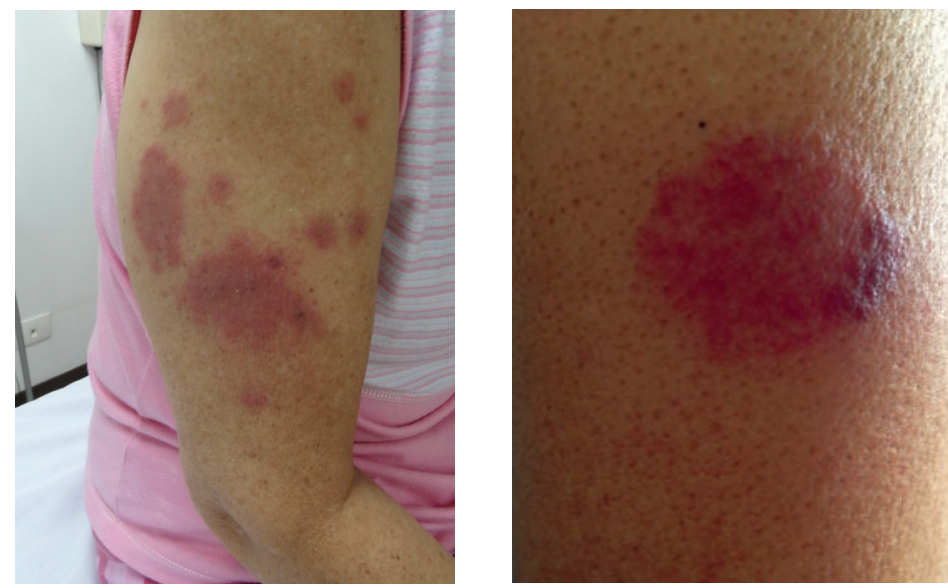

Figura 7.9. Síndrome de Sweet . El síndrome de Sweet es un fenómeno vascular reactivo, conocido también como dermatosis neutrofílica aguda febril. Se presenta con unas lesiones eritematosas y edematosas, de un color más fuerte y ligeramente engrosadas (ajamonadas), que pueden ser dolorosas.

Eritema nudoso. Clínicamente, se caracteriza por la aparición súbita de nódulos eritematosos, calientes y simétricos, bien delimitados; se palpan más grandes de lo que se ven, porque se localizan profundamente y la superficie puede estar ligeramente más brillante por la tensión de la inflamación (12) (figura 7.10).

Las lesiones suelen ser dolorosas y se localizan con mayor frecuencia en la cara anterior de los miembros inferiores, principalmente hasta las rodillas. Se presentan con mayor frecuencia entre los 20 y los 40 años y con una mayor incidencia en las mujeres. Suelen asociarse con la presencia de un síndrome varicoso. Cuando 
forman placas no bien delimitadas y de diferentes tamaños, se ha considerado que se trata de una hipodermitis nodular subaguda migrans, que puede ser una variedad del mismo proceso $(13,14)$.

La aparición de las lesiones se ha asociado a numerosas infecciones, entre las que cabe destacar las infecciones por Streptococcus beta hemolítico; por Mycobacterium spp., como en la tuberculosis y la lepra; en infecciones virales, como en la mononucleosis infecciosa, o desencadenadas por infecciones por Chlamydia, en leptospirosis u otras debidas a infecciones por Yersinia enterocolítica, Salmonella spp., Helicobacter pylori, enfermedad por arañazo de gato, o en infecciones fúngicas como la en la coccidiodomicosis o en la histoplasmosis.

También se ha descrito asociado a otras enfermedades sistémicas como la sarcoidosis, la enfermedad inflamatoria intestinal, la enfermedad de Behçet y, en general, a las enfermedades del tejido conjuntivo o a enfermedades autoinmunitarias como el lupus eritematoso sistémico y, finalmente, a algunas neoplasias hematológicas. Pueden aparecer inducido por medicamentos como los anticonceptivos orales, las penicilinas, las sulfonamidas o los analgésicos. Algunos pacientes lo han presentado después de la vacunación contra el virus de la hepatitis B.

La asociación con el síndrome varicoso o durante el embarazo se debe a que en estos individuos, al estar alterado el retorno circulatorio en los miembros inferiores, existe un mayor tiempo para que los depósitos de complejos inmunes se depositen en los vasos sanguíneos y alrededor de ellos.
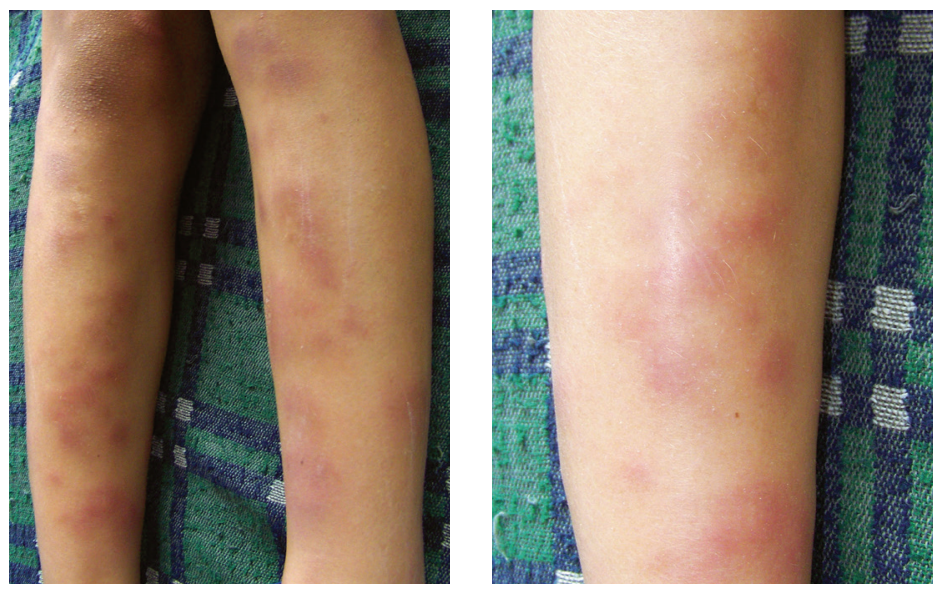

Figura 7.10. Eritema nudoso. Clínicamente, se caracteriza por la aparición súbita de nódulos eritematosos, calientes y simétricos, bien delimitados. Se palpan más grandes de lo que se ven, porque se localizan profundamente y la superficie puede estar ligeramente más brillante por la tensión de la inflamación. Suelen ser dolorosos y se localizan con mayor frecuencia en la cara anterior de los miembros inferiores, principalmente hasta las rodillas. 
Por otro lado, se debe tener en cuenta que algunos de estos pacientes que inicialmente clasifican dentro del eritema nudoso, podrían tener una poliarteritis nudosa, que es una vasculitis nodular y que se puede ver muy parecida. La biopsia aclara si se trata de una poliarteritis o de un eritema nudoso en cuyo caso se encuentra una paniculitis lobular con necrosis de caseificación rodeada de un infiltrado granulomatoso de macrófagos y células gigantes. Conceptualmente se parece a la hipodermitis nodular subaguda migrans, cuyas lesiones no son pequeñas y nodulares, sino de mayor tamaño y van cambiando de posición.

Es posible que en ocasiones se confundan estos cuadros del síndrome de Sweet, el eritema nudoso y la hipodermitis nodular subaguda.

\section{Púrpuras y vasculitis}

Se utiliza la palabra 'púrpura' para referirnos a la aparición de una coloración más rojiza que azulosa en la piel, generalmente, debida a la extravasación de eritrocitos, que compromete los vasos más superficiales. Cuando se utiliza el término 'violáceo', se hace para describir una coloración más azulosa que rojiza, en cuyo caso la extravasación proviene de los vasos más profundos, y puede deberse a alteraciones de la pared del vaso que permiten la salida de eritrocitos por trauma o por alteraciones de la coagulación.

Se habla de una vasculitis reconocida en la biopsia de piel (15), si los vasos dérmicos comprometidos presentan edema, extravasación de eritrocitos, acompañados de daño del endotelio vascular, con depósitos de fibrina, migración de polimorfonucleares y leucocitoclásica e incremento del número de células inflamatorias en la pared del vaso y en su alrededor. El daño puede ser reconocido por los neutrófilos alrededor de los vasos con polvo nuclear y leucocitoclasia, necrosis endotelial y del músculo liso, depósitos de fibrina y trombos o degeneración del tejido conjuntivo; se ha llamado vasculitis leucocitoclásica cutánea, generalmente, relacionada con depósitos de complejos inmunes. Es una vasculitis que se puede observar con diversas lesiones, desde una alteración eritematosa puntiforme con una zona más oscura, púrpura o violácea, en el centro o con una ampolla central y un halo más eritematoso alrededor no mayor de $0,5 \mathrm{a} 1 \mathrm{~cm}$ de diámetro, hasta una úlcera con necrosis y pérdida del tejido.

En el acercamiento a la comprensión de las vasculitis, no solo el aspecto de las lesiones es la clave para el diagnóstico, se necesita una historia clínica completa para comprender la naturaleza de la enfermedad y es obligatoria la biopsia de piel. En ella, se debe tener en cuenta para las diferentes clasificaciones, el tamaño y la naturaleza del vaso comprometido -en las vasculitis cutáneas, el vaso generalmente 
es pequeño-, el lugar donde se encuentran los infiltrados inflamatorios y el tipo de células que están presentes, si es linfocitaria, leucocitoclásica o granulomatosa. Datos que, sumados entre sí, junto con el hecho de que estén comprometidos otros órganos, son indispensables para aclarar la entidad responsable del cuadro clínico.

\section{Púrpuras}

Cuando se habla de púrpuras, se habla de un fenómeno en el cual se encuentra extravasación de la sangre. Las causas pueden ser múltiples, entre otras, por alteraciones intravasculares, es decir, por falta de algún componente sanguíneo necesario para la coagulación, o extravasculares, por alguna alteración de la pared del vaso o de los tejidos de sostén, como sucede en un paciente mayor sin enfermedad sistémica con lesiones en las zonas expuestas al sol, en cuyo caso se debe pensar en una púrpura senil de Bateman o púrpura actínica (figura 7.11) por daño de las fibras elásticas del vaso por la acción de la exposición crónica al sol. Si se encuentran lesiones que exceden las zonas expuestas a la luz y, además, el paciente está en tratamiento con esteroides sistémicos debido a otra enfermedad, se puede pensar en una púrpura secundaria al uso de esteroides (figura 7.12).

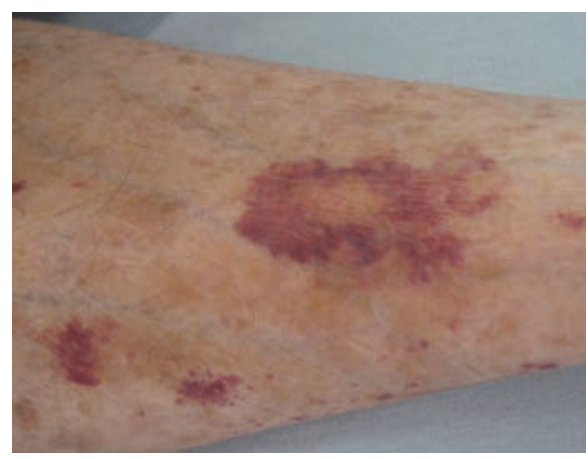

Figura 7.11. Púrpura actínica. Se refiere a la extravasación de eritrocitos que se produce por la alteración de la pared del vaso, como sucede en un paciente mayor con lesiones en las zonas expuestas a la luz, en cuyo caso se debe pensar en una púrpura actínica o senil, descrita por Bateman, debida a la alteración de las fibras elásticas de los vasos por el deterioro que produce la exposición solar de manera prolongada.

De manera menos frecuente, los vasos son más laxos y pueden estar alterados en las enfermedades genéticas del colágeno, como en el síndrome de Ehlers-Danlos, en el síndrome de Marfan, o en el pseudoxantoma elástico. 

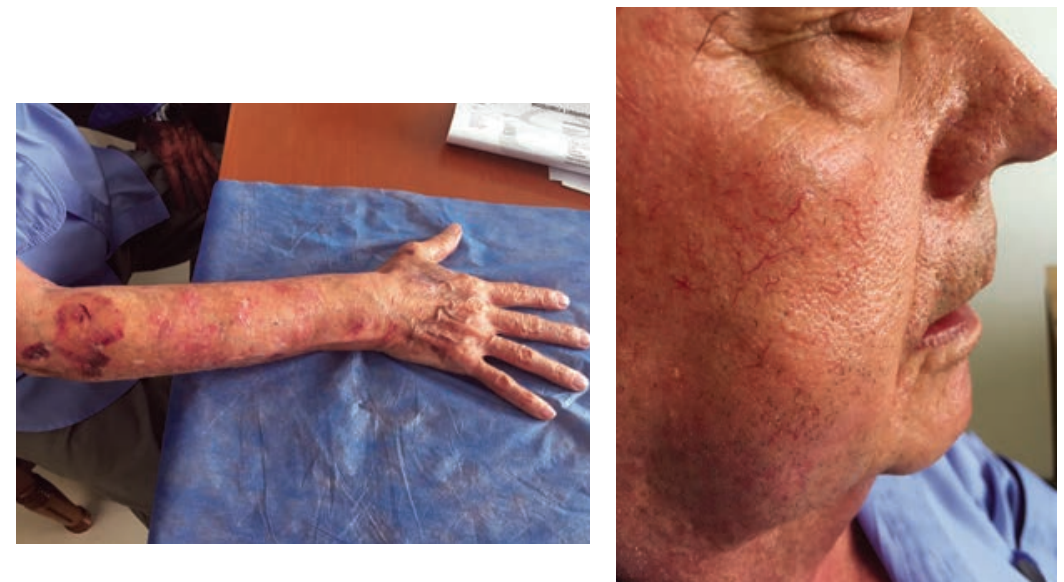

Figura 7.12. Púrpura secundaria al uso de esteroides. Si las lesiones exceden las zonas expuestas a la luz y el paciente está en tratamiento con esteroides sistémicos debido a otra enfermedad, se puede pensar en una púrpura secundaria al uso de esteroides.

Si las lesiones se presentan en los sitios de declive, posiblemente por un proceso prolongado de aumento de la presión en los vasos sanguíneos con extravasación de eritrocitos y en la histopatología no se observa leucocitoclasia sino linfocitos solamente, se puede decir que se trata de una púrpura pigmentaria progresiva y linfocitaria. Esta vasculitis corresponde a un proceso reparativo (11), como sucede en el síndrome varicoso con lesiones ocre y púrpura, descritas por el aumento de la presión venosa, o en entidades como la púrpura anular telangiectoide de Majochi. Por esta razón, es imprescindible la toma de una biopsia de piel para aclarar la situación que puede ser muy similar clínicamente.

Por otro lado, se pueden encontrar lesiones púrpura aisladas o generalizadas en otras enfermedades sistémicas, como en el hipotiroidismo, en la amiloidosis, en el síndrome de Cushing, en el escorbuto por deficiencia de vitamina $\mathrm{Cy}$ en la deficiencia de vitamina K. En la cirrosis hepática, se pueden encontrar estas alteraciones de los elementos de la coagulación y, si el paciente tiene una hipertensión portal, puede presentarse, además, una hemorragia digestiva masiva debido a la presencia de várices esofágicas. Si se encuentra una trombocitopenia, se puede sospechar una púrpura trombocitopénica autoinmunitaria o una púrpura asociada a otras enfermedades autoinmunitarias.

Las vasculitis cutáneas asociadas a las enfermedades del tejido conjuntivo, como el síndrome de Sjögren, la dermatomiositis, la enfermedad mixta del tejido conjuntivo, la artritis reumatoidea o el lupus eritematoso sistémico, se pueden manifestar con urticaria, o más frecuentemente una urticaria por vasculitis; por otro lado, también pueden estar asociadas a procesos malignos o inducidas por 
medicamentos. En la artritis reumatoidea, se pueden presentar unas lesiones ulcerativas de tipo pioderma gangrenoso que es una dermatosis neutrofílica y aparece como un fenómeno reactivo.

En las extremidades inferiores y, especialmente, en los dedos de los pies, se debe diferenciar una vasculitis de una embolia, de una enfermedad de Buerger o tromboangeiítis obliterante, de la presencia de una crioglobulinemia o de un síndrome de anticuerpos antifosfolípido. Si se observan lesiones violáceas o necróticas distales, se puede estar ante una oclusión vascular (figura 7.13), ante una coagulación intravascular diseminada o ante una sepsis.
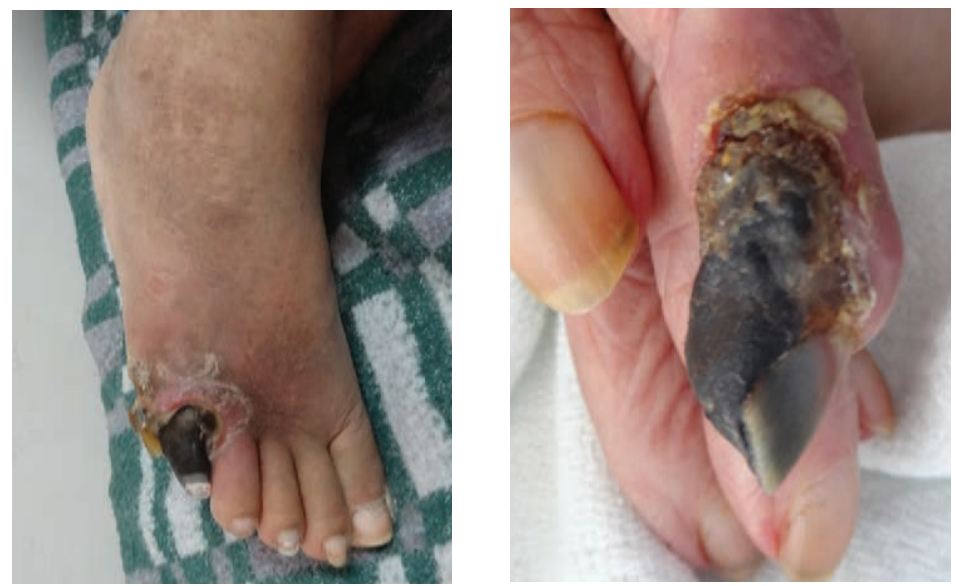

Figura 7.13. Oclusión vascular, lesiones necróticas distales. Cuando se producen lesiones necróticas en las extremidades inferiores y, especialmente, en los dedos de los pies se debe aclarar si se trata de una oclusión vascular, una vasculitis, una embolia, una enfermedad de Buerger o tromboangeítis obliterante, si existe una crioglobulinemia o si se trata de un síndrome de anticuerpos antifosfolípido.

En algunos casos, con mayor frecuencia en personas mayores, se puede producir una oclusión parcial o total de los vasos por trombos o émbolos, dentro de un fenómeno de hipercoagulabilidad y entre los diagnósticos por considerar, se debe pensar en procesos infecciosos o neoplásicos (figura 7.14).

Se pueden ver algunos fenómenos que pueden parecer vasculitis sin serlo, como se vio en el caso de una endocarditis bacteriana o en enfermedades como la dermatomiositis, la esclerodermia, la amiloidosis secundaria a la ingestión de ciertos fármacos, senil, por traumatismos, facticia o por tóxicos. Estas manifestaciones entre hemorrágicas u oclusivas vasculares, se pueden considerar como seudovasculitis (16). 


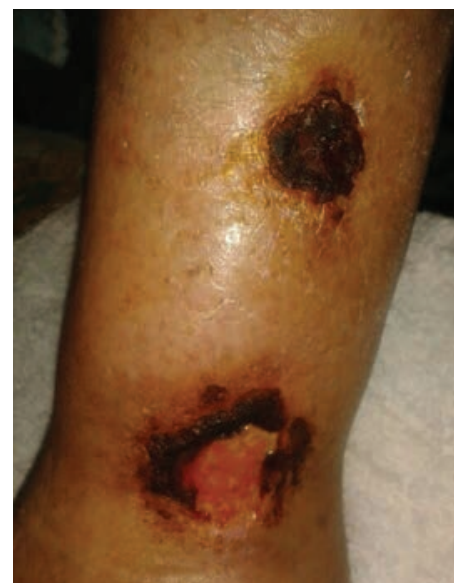

Figura 7.14. Úlceras arteriales por hipercoagulabilidad. Se observan dos lesiones ulcerativas, necróticas, en la cara externa de una de las piernas en una paciente sin enfermedad arterial de base y que inició este proceso asociado con unos fenómenos de hipercoagulabilidad en el marco del desarrollo de un cáncer gástrico.

Ante un diagnóstico clínico de púrpura o de vasculitis, es indispensable ordenar un hemograma, en el que se pueden observar todos los datos pertinentes al conocimiento de las tres líneas de células más importantes: la eritroide, para ver si existe anemia o poliglobulia, para determinar el número de células blancas y los porcentajes de cada tipo de células, que sirven para saber si hay una infección concomitante o no, y de qué naturaleza puede ser la afección por el tipo de células predominante $\mathrm{y}$, finalmente, el número de plaquetas determina si hay trombocitopenia o no.

Se debe solicitar la determinación del tiempo de protrombina y de la tromboplastina tisular para completar el estudio hematológico mínimo ante un evento que parece ser hemorrágico. Con los resultados de estos exámenes de laboratorio se puede saber si las plaquetas están en número suficiente y si existe o no un trastorno de alguna de las vías de la coagulación. La determinación de la velocidad de sedimentación globular y la de la proteína $\mathrm{C}$ reactiva son indispensables. Desde hace varios años, se sabe que el aumento de la velocidad de sedimentación globular o de la proteína $\mathrm{C}$ reactiva, pueden servir para diagnosticar una enfermedad del tejido conjuntivo.

\section{Vasculitis cutáneas}

La vasculitis cutánea, según Carlson y Chen (21), tiene una incidencia anual de 15,4 a 29,7 casos por millón de habitantes, afecta todas las edades y existe un 
ligero predominio de las mujeres. Es más frecuente en adultos que en niños en los que en la mayoría de los casos (90\%) se presenta como una púrpura palpable en la púrpura de Henoch-Schöenlein.

Las vasculitis cutáneas pueden ser primarias o ser la manifestación de reacciones a medicamentos, infecciones, enfermedades autoinmunológicas o asociadas a neoplasias (linfomas y leucemias). Medicamentos como las penicilinas, las sulfonamidas, el alopurinol, las tiacidas, las quinolonas, el propiltiouracilo y las hidantoínas pueden producir una vasculitis cutánea. También se ha descrito que las pueden causar agentes inmunomoduladores antagonistas del factor de necrosis tumoral, infecciones virales como la de la hepatitis B y C, el citomegalovirus, el HTLV1, y el parvovirus B19, bacterianas como la de Streptococcus spp., Neisseria spp. o Rickettsia spp. Se puede acompañar de síntomas generales como malestar general, fiebre y pérdida de peso, o localizadas como mialgias, mononeuritis múltiple, sangrado gastrointestinal y poliartritis.

La clasificación antigua, basada en las reacciones de hipersensibilidad tal y como las clasificaron Gell y Cooms (22) y que aún se utiliza para fines didácticos, no representa los múltiples epifenómenos que se producen de manera simultánea y que, quizá, en el futuro pueda cambiar en la medida que se conozca mejor la inmunidad innata, la inflamación, la genética y sus variabilidades.

Se cree que la reacción que se produce con mayor frecuencia en las vasculitis es una reacción de hipersensibilidad de tipo III, en la que hay depósitos de complejos inmunes que se pueden visualizar con la inmunoflorescencia directa. En ella aparecen polimorfonucleares en las primeras 2 a 8 horas y, después, linfocitos hacia las 18 a 24 horas, como sucede en la púrpura de Henoch-Schöenlein, urticaria por vasculitis, vasculitis por crioglobulinas y poliarteritis nudosa.

En la región del cuerpo donde se visualiza este depósito de complejos inmunes, existe, por lo general, alguna disminución del flujo sanguíneo que permite hacer visible lo que está sucediendo en el vaso. Por esta razón, es frecuente encontrarlas en los miembros inferiores y, con mayor razón, si existe un síndrome varicoso por la disminución del retorno venoso que posibilita su visualización, o en sitios de declive si el paciente se encuentra en decúbito permanente.

\section{Vasculitis leucocitoclásica}

La clasificación histopatológica es imprescindible ya que nos ayuda a comprender la naturaleza del fenómeno. Carlston (17) y otros colaboradores han dedicado tiempo a revisar y clasificar su naturaleza y su revisión es esclarecedora. 
Se habla de vasculitis, si estamos ante unas lesiones de aparición simétrica, de coloración eritemato-violáceo, maculares o ligeramente papulosas, de tamaño pequeño o con una diferencia de coloración y un centro hemorrágico o más violáceo o incluso ampolloso, en cuyo caso se debe saber si compromete o no los vasos pequeños, por lo que se necesita obtener una biopsia de piel (17). En ella el patólogo analiza si existe o no una vasculitis leucocitoclásica, para hacer el diagnóstico de una verdadera vasculitis cutánea de pequeños vasos y nos informa qué tipo de infiltrado celular está presente: si son polimorfonucleares, si es rico en eosinófilos, si hay linfocitos o si hay granulomas.

Una vez se aclare si se trata de una verdadera vasculitis o de una seudovasculitis, se debe correlacionar con el número y el lugar en donde se presentan las lesiones e investigar si se acompaña de otra alteración sistémica; por ejemplo, si tiene infecciones en ese momento o si está presente alguna enfermedad inflamatoria o de otro tipo, como puede ser un hipotiroidismo, una insuficiencia renal o hepática, o si sufre de algún trastorno genético o neoplásico, o si recibe medicamentos que puedan ser la causa de la alteración.

\section{Clasificaciones de la vasculitis}

La vasculitis es una condición que afecta el endotelio de los vasos y sus causas pueden ser de diferente naturaleza. Las clasificaciones clínicas son muchas y variadas (18), las más utilizadas a lo largo de las últimas décadas han sido la del American College of Rheumatology de 1982, revisada en 1990, y la otra, más utilizada hoy en día, es la que se hizo en 1994 (19) en la reunión de Chapell Hill, que luego fue revisada en el 2012.

En las vasculitis se considera inicialmente el tamaño del vaso comprometido y se habla de vasculitis de grandes vasos para referirse a la arteritis de Takayasu, y la arteritis temporal de células gigantes; a las vasculitis de medianos vasos, a la poliarteritis nudosa y, quizá, a la enfermedad de Kawasaki, la vasculitis mixta; a la de medianos o pequeños vasos, a la poliangeítis microscópica, al síndrome de ChurgStrauss, ahora conocido como granulomatosis eosinofílica con poliangeítis y a la granulomatosis de Wegener, ahora llamada granulomatosis con poliangeítis (20).

La arteritis temporal de células gigantes y la arteritis de Takayasu no presentan con frecuencia alteraciones de la piel; por esta razón, no nos detendremos en ellas.

En las vasculitis en las que se encuentran anticuerpos ANCA positivos, podría tratarse de una reacción mixta de tipo II y de tipo III tal como sucede en la poliangeítis microscópica y en la granulomatosis con poliangeítis, antiguamente llamada granulomatosis de Wegener. 
En la patogénesis de su aparición juegan un papel las moléculas de adhesión: integrinas, selectinas, la superfamilia de inmunoglobulinas y los diferentes antígenos polivalentes que desencadenan el proceso inflamatorio en el endotelio de las vénulas poscapilares. En algunos casos, se encuentra la presencia de anticuerpos anticélulas endoteliales (AECA) que se expresan de 2 a $86 \%$. Según el tipo de mecanismo desencadenante, se pueden encontrar anticuerpos que fijan complemento, linfocitos T CD8 positivos, reacciones de citotoxicidad celular que dependen de anticuerpos o anticuerpos citoplasmáticos antineutrofílicos, que se pueden encontrar con la inmunofluorescencia indirecta y que pueden predecir el riesgo de recaída.

Las vasculitis asociadas a ANCA incluyen vasculitis leucocitoclásicas cutáneas primarias como la granulomatosis con poliangeítis, la granulomatosis eosinofílica con poliangeítis, la poliangeítis microscópica y algunas vasculitis secundarias relacionadas con medicamentos, enfermedad intestinal inflamatoria y algunas enfermedades del tejido conjuntivo. Estos anticuerpos positivos se pueden dividir en dos patrones, perinucleares p-ANCA, y citoplásmaticos c-ANCA. Los p-ANCA pueden ser anticuerpos antimieloperoxidasa o frente a otros como a la lactoferrina o a la catepsina y encontrarse positivos en la poliangeítis microscópica y la granulomatosis eosinofílica con poliangeítis. Los c-ANCA son generalmente la proteinasa 3 y están fuertemente asociados a la granulomatosis con poliangeítis. Están descritos otros antieotaxina 3 contra los eosinófilos en granulomatosis eosinofílica con poliangeítis.

Las lesiones cutáneas se correlacionan con los hallazgos histopatológicos de vasculitis, según el tamaño del vaso comprometido. En las vasculitis de pequeños vasos, se debe precisar si las alteraciones aparecen en los capilares o en las vénulas poscapilares; en las de vasos medianos, si son arteriales o venosas y si tienen depósitos de IgA, IgM o IgG.

Las lesiones cutáneas cuando comprometen los vasos pequeños pueden ir desde máculas (figura 7.15. a) a pápulas (figura 7.15. b) que algunos describen como lesiones de tipo urticaria o púrpura palpable hasta vesículas o ampollas en algunas ocasiones.

Cuando el compromiso es de los vasos medianos se ven desde lesiones de tipo livedo reticularis, nódulos subcutáneos o úlceras hasta infartos digitales o lesiones pápulo-necróticas (figura 7.15. c); en ambos casos se localizan, generalmente, en los sitios de declive: parte baja de los miembros inferiores, glúteos y espalda. 

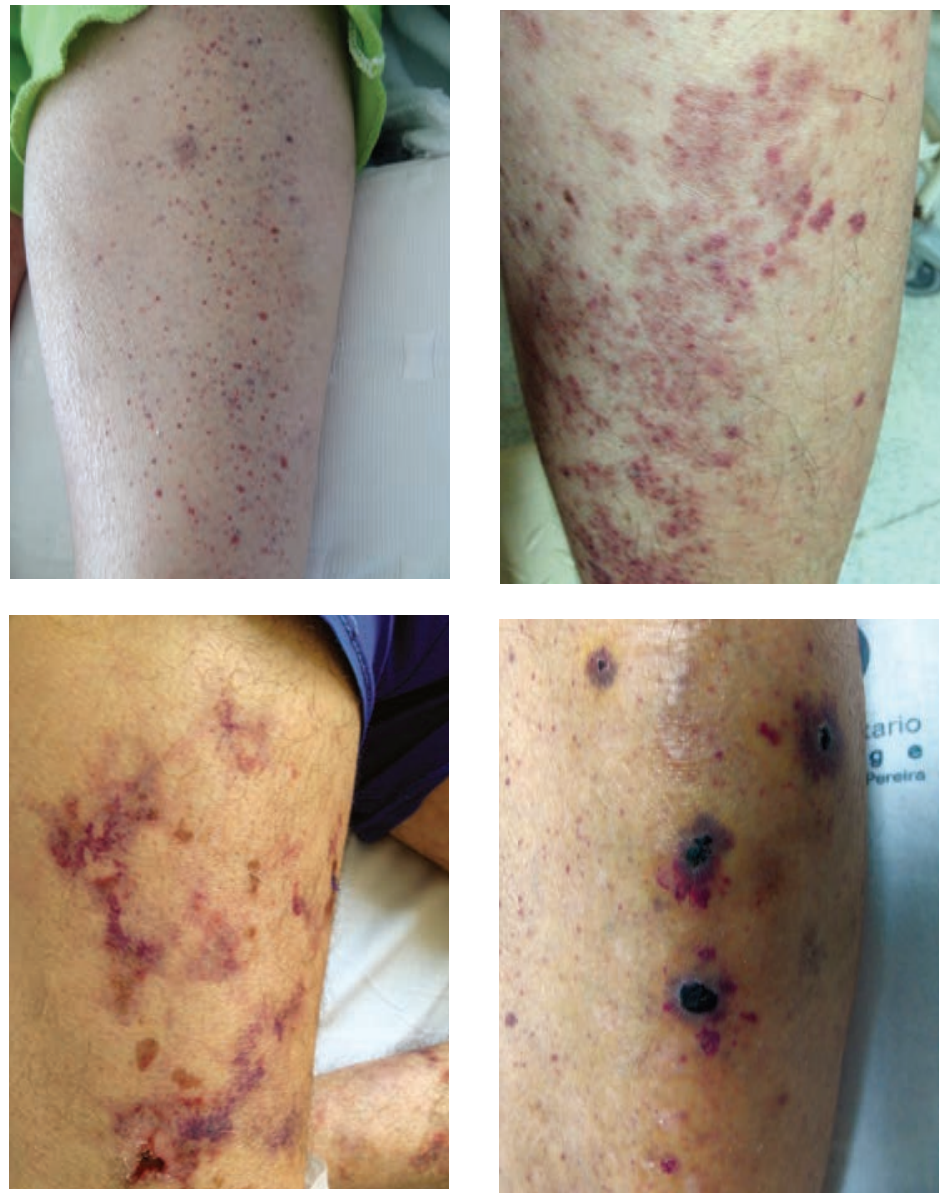

Figura 7.15. Vasculitis leucocitoclásica: macular, papular, livedoide y necrótica. Se habla de una vasculitis reconocida en la biopsia de piel. si los vasos dérmicos comprometidos presentan edema, extravasación de eritrocitos en su alrededor, acompañados de daño del endotelio vascular, con depósitos de fibrina, migración de polimorfonucleares y leucocitoclásia. Puede tener diferentes manifestaciones, desde una alteración eritematosa puntiforme con una zona más oscura púrpura o violácea en el centro, o con una ampolla central y un halo más eritematoso alrededor no mayor de $0,5 \mathrm{a} 1 \mathrm{~cm}$ de diámetro, hasta una úlcera con necrosis y pérdida del tejido.

Algo que puede ayudar en la clasificación clínica de estas lesiones cutáneas con un patrón histopatológico de vasculitis leucocitoclásica (11), es la coloración de las lesiones que puede ser más rojiza y hemorrágica en la púrpura de HenochSchönlein, o en la poliangeítis microscópica; más edematosa con un color 'ajamonado' en el síndrome de Sweet y en la vasculitis urticante, teniendo en cuenta que esta última puede dejar una pigmentación residual, o más amarillenta de tipo color jalea de manzana por el componente granulomatoso en la granulomatosis con poliangeítis, síndrome de Wells o granulomatosis eosinofílica con poliangeítis. 
A pesar de que las lesiones pueden ser similares y parecería que hacen parte de estos cuadros, tanto el síndrome de Wells o eosinofílico como el síndrome de Sweet son inflamaciones alrededor de las vénulas poscapilares y no suele haber necrosis fibrinoide ni presencia de trombos, a pesar de si se encuentran infiltrados de neutrófilos e infiltración variada de eosinófilos.

El síndrome de Wells se presenta con pápulas edematosas o lesiones ampollosas en las reacciones a medicamentos y las picaduras de insectos, en algunos casos del síndrome hipereosinofílico y puede aparecer en el penfigoide ampolloso, el pénfigo vulgar y en algunas dermatitis herpetiformes. El síndrome de Sweet, como fenómeno reactivo vascular, se presenta acompañando diferentes procesos, desde infecciones hasta neoplasias, generalmente linfoproliferativas, con lesiones eritematosas edematosas, dolorosas e infiltradas como intermedias entre unas lesiones de urticaria y unas de eritema nudoso; es llamativo el importante edema de la dermis papilar.

\section{Vasculitis cutáneas de pequeños vasos y sus lesiones cutáneas}

Las vasculitis de piel que se conocen son mixtas, de medianos y de pequeños vasos y las que se ven con mayor frecuencia son las vasculitis cutáneas de pequeños vasos, entre las cuales la urticaria por vasculitis, la vasculitis por crioglobulinemia y la vasculitis por hipersensibilidad o púrpura de Henoch-Schönlein, pueden ser las más frecuentes.

La urticaria por vasculitis con hipocomplementemia se manifiesta con lesiones que se inician como las de una urticaria con eritema y edema por extravasación de líquido, pero, a diferencia de ellas, persiste por más tiempo, 24 a 48 horas, y se tornan hemorrágicas. Se puede ver, entonces, como una púrpura palpable en las enfermedades del tejido conjuntivo, en la enfermedad del suero, asociada a infecciones, posterior a la ingestión de ciertos medicamentos, en las gammapatías monoclonales o en los procesos malignos hematológicos.

Vasculitis por crioglobulinemia. Las lesiones cutáneas pueden aparecer como pápulas eritematosas o de tipo púrpura palpable con extravasación y equimosis por la oclusión del vaso o lesiones semejantes a las del síndrome de Raynaud con un color azuloso o blanquecino por la oclusión vascular. Las crioglobulinas son anticuerpos circulantes que precipitan a bajas temperaturas. Son de varios tipos: de tipo I, monoclonal IgM asociada a las enfermedades linfoproliferativas del linaje de células B; de tipo II, monoclonal IgM contra policlonal IgG, y de tipo III, policlonal IgM contra policlonal IgG. Las de tipo II y III se pueden presentar en las vasculitis sistémicas y son desencadenadas por complejos inmunes; pueden estar asociadas a las enfermedades del tejido conjuntivo, o a las infecciones del virus de la hepatitis C. 
La púrpura de Henoch-Schönlein es una enfermedad descrita en niños, usualmente, los pacientes tienen menos de 20 años al comienzo de la enfermedad. Se presenta con lesiones de tipo púrpura palpable (figura 7.16), artritis, dolor abdominal agudo y, a veces, glomerulonefritis. Se caracteriza por la presencia de complejos de IgA que se depositan y son visibles con la inmunofluorescencia en los órganos comprometidos. Aparecen, generalmente, una a dos semanas después de infecciones del tracto respiratorio superior, infecciones por Streptococcus spp. u otros.
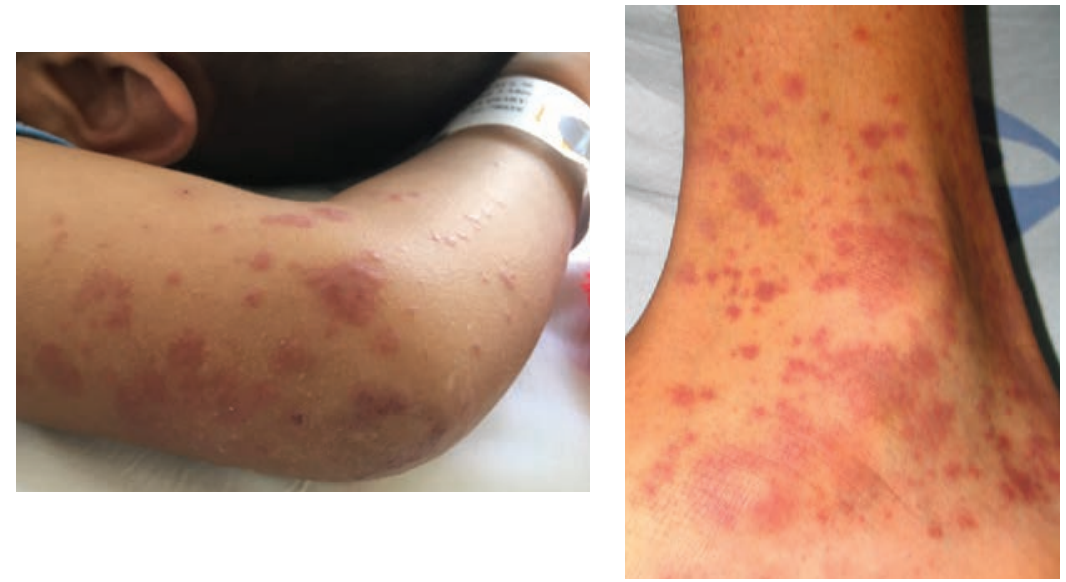

Figura 7.16. Púrpura palpable de Henoch-Schönlein. Como respuesta a un proceso infeccioso, los depósitos de IgA alrededor de los vasos sanguíneos, producen una vasculitis que se expresa con la aparición de unas lesiones papulosas, elevadas, de color púrpura, en las cuales se ve una zona central más rojiza u oscura, casi como si se pudiera ver el vaso comprometido.

Vasculitis cutáneas de medianos y pequeños vasos. Estas vasculitis, con su patrón de vasculitis leucocitoclásica, comprometen los vasos de pequeños y mediano calibre, tienen anticuerpos ANCA positivos y son la poliangeítis microscópica, la granulomatosis de Wegener y síndrome de Churg-Strauss con sus variaciones. Las lesiones cutáneas pueden ser de diferente naturaleza con aparición de máculas, pápulas urticantes o purpúricas, o aun lesiones vesiculosas o pustulosas, o pueden ser lesiones ulceradas.

La poliarteritis nudosa microscópica fue definida como poliangeítis microscópica en la reunión de Chapell Hill de 2012 (23), para designar a una entidad en la que se encontraba una vasculitis leucocitoclásica de pequeños o medianos vasos, sin formación granulomatosa y que podía comprometer varios órganos, con mayor frecuencia asociada a glomerulonefritis y que pocas veces presentaba lesiones en la piel (figura 7.17). La positividad de los anticuerpos ANCA es variable y, si aparecen, son de tipo p-ANCA positivos. 

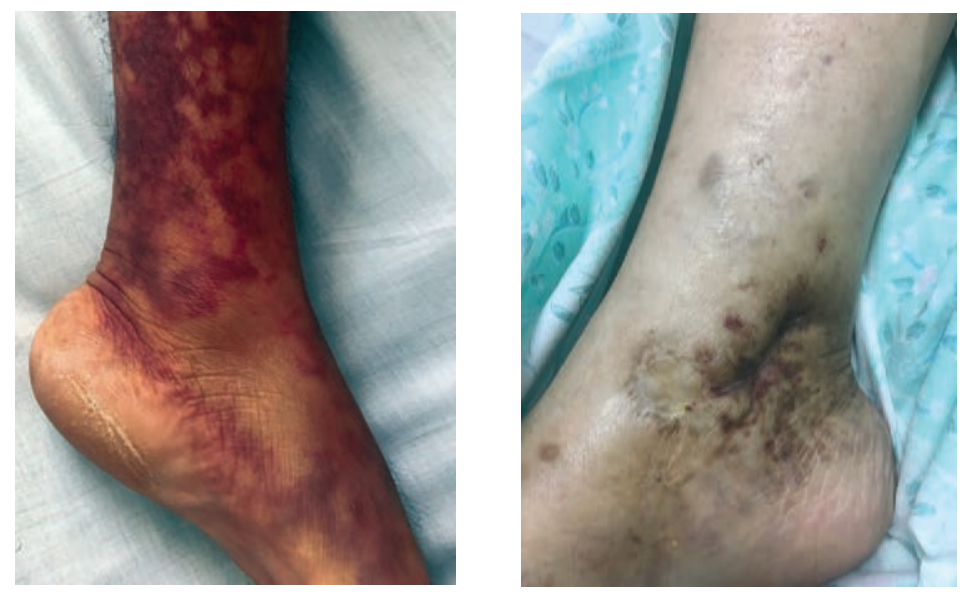

Figura 7.17. Poliarteritis nudosa. Se trata de una vasculitis de vasos medianos, necrosante y sistémica, con lesiones desde tipo púrpura palpable, nódulos subcutáneos y livedo reticularis, o ulcerativas, hasta infartos digitales o lesiones pápulo-necróticas. Se localizan, generalmente, en los sitios de declive: la parte baja de los miembros inferiores, los glúteos y la espalda.

La granulomatosis con poliangeítis, conocida antiguamente como granulomatosis de Wegener (24), es una enfermedad multisistémica que se caracteriza por presentar una vasculitis granulomatosa de pequeños y medianos vasos. Fue publicada por Wegener en 1939, en la que aparecen inicialmente síntomas respiratorios altos, con rinorrea, epistaxis o sinusitis, seguidos de una inflamación granulomatosa que puede destruir los tejidos de la línea media, con presencia de úlceras oronasales, y afectación del tabique nasal y deformación de la nariz. La tráquea, los bronquios y el parénquima pulmonar pueden estar comprometidos. Se presenta acompañada de síntomas constitucionales y con manifestaciones articulares, vasculitis en la piel (figura 7.18) y mononeuritis o polineuritis. El compromiso renal está presente en el $70 \%$ de los pacientes con una glomerulonefritis necrosante. En ella se encuentramos anticuerpos positivos c-ANCA, contra la proteinasa 3 de los neutrófilos.

La granulomatosis eosinofílica con poliangeítis, o vasculitis de ChurgStrauss (25), conocida anteriormente como angeítis alérgica granulomatosa, según la descripción de Churg y Strauss en 1951 (26), es una vasculitis de los pequeños vasos que se presenta con mayor frecuencia en el hombre. Se caracteriza por presentar un cuadro de asma bronquial, eosinofilia mayor de 1.500 por $\mathrm{mm}^{3}$, historia de rinosinusitis, compromiso pulmonar, vasculitis sistémica que incluye dos o más órganos extrapulmonares, neuropatía periférica y alteraciones en la piel de tipo vasculitis que pueden ir desde elementos maculares rojo-violáceos, máculopapulares o papulares, vésico-pustulosos o ulcerativos y necróticos (figura 7.19). 

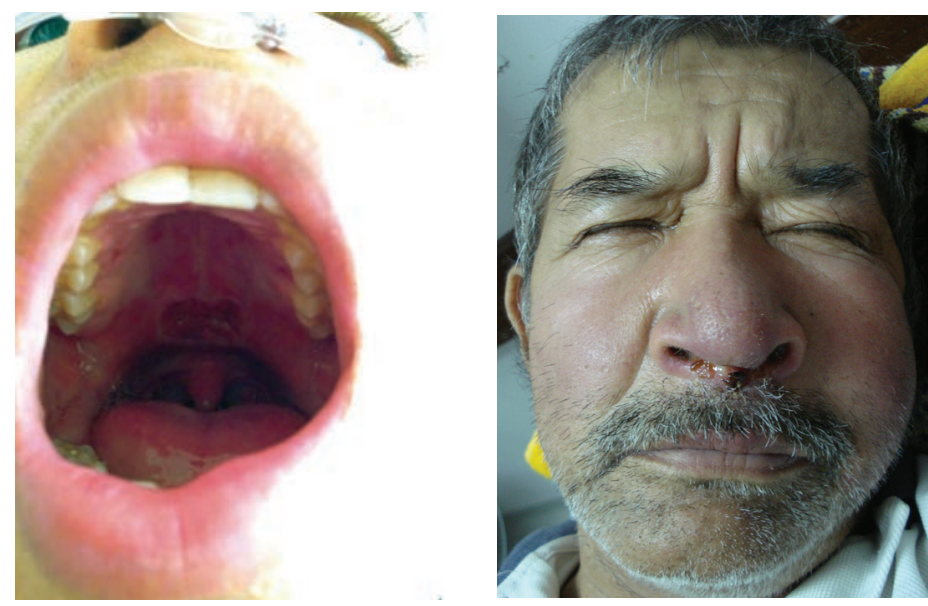

Figura 7.18. Granulomatosis con poliangeítis. Las lesiones pueden afectar la mucosa oronasal, con presencia de úlceras y afectación del tabique nasal y deformación de la nariz. La tráquea, los bronquios y el parénquima pulmonar pueden estar comprometidos. Se presenta acompañada de síntomas constitucionales y con manifestaciones articulares, vasculitis en la piel, mononeuritis o polineuritis.

Además, hay presencia de anticuerpos antineutrófilos (ANCA) positivos y de otros elementos que juegan papel en la fisiopatogénesis, como son las inmunoglobulas G4 y el subconjunto de linfocitos T CCL17, como sucede en los individuos atópicos. Los pacientes pueden llegar a presentar compromiso cardiaco, gastrointestinal, renal y del sistema nervioso central.

Según los criterios de la ACR de 1990, deben presentar asma, eosinofilia, neuropatía, infiltrados pulmonares difusos, sinusitis paranasal y eosinofilia extravascular; según los criterios de Laham, asma, eosinofilia mayor de $1.500 / \mathrm{mm}^{3}$, vasculitis sistémica que incluya dos o más órganos extrapulmonares.

En la histopatología, se observa una vasculitis granulomatosa o necrosante de pequeños vasos con acentuado infiltrado de eosinófilos y granulomas extravasculares, con lesiones en la piel del tipo de la dermatitis intersticial granulomatosa que también se encuentran en las enfermedades del tejido conjuntivo como el lupus eritematoso sistémico o la artritis reumatoidea, y que se puede ver tanto en la granulomatosis eosinofílica con poliangeítis, antiguamente conocida como el síndrome de Churg-Strauss, como también en la poliangeítis granulomatosa, nombre actual de la conocida granulomatosis de Wegener. Como se puede deducir, son más las variaciones individuales y es posible que en el futuro se consideren una sola entidad.

Lo que sí queda claro es que ante una vasculitis es obligatoria la solicitud de un hemograma con velocidad de sedimentación globular, proteína $\mathrm{C}$ reactiva, ANA, 
C3 y C4, ANCA y crioglobulinas e, indiscutiblemente, obtener una biopsia de piel que ayude a clarificar y clasificar el cuadro clínico.
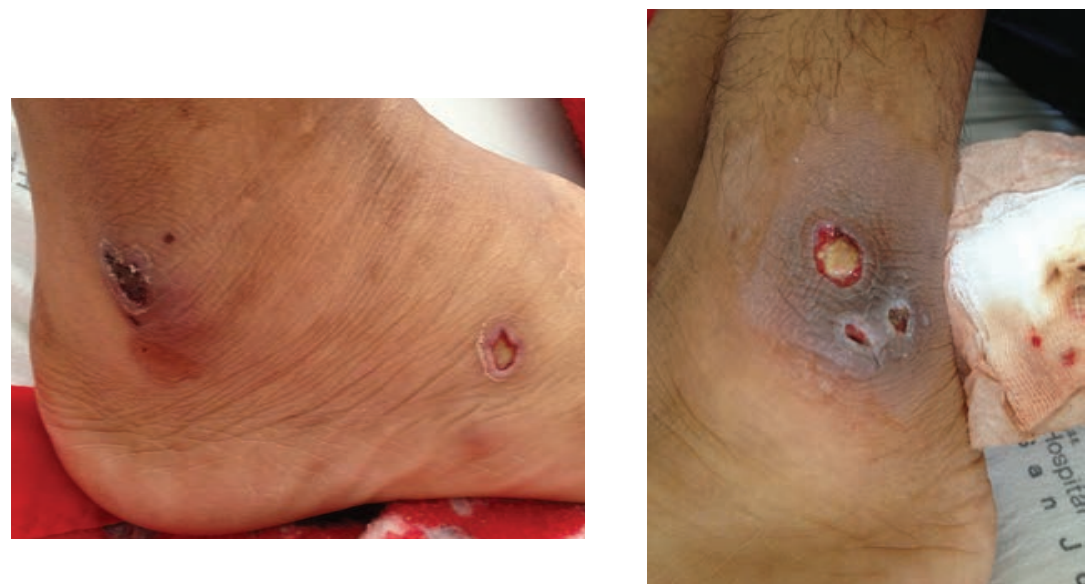

Figura 7.19. Granulomatosis eosinofílica con poliangeítis. Se trata de un cuadro de asma bronquial, con eosinofilia mayor de 1500 por $\mathrm{mm}^{3}$, historia de rinosinusitis, compromiso pulmonar y vasculitis sistémica que incluya dos o más órganos extrapulmonares, neuropatía periférica y alteraciones en la piel de tipo vasculitis que pueden ir desde elementos maculares rojo violáceos, máculo-papulares, vésico-pustulosos o ulcerativos y necróticos, con presencia de anticuerpos antineutrófilos (ANCA) positivos y de otros elementos que juegan un papel en la fisiopatogénesis como son las inmunoglobulinas G4 y el subconjunto de linfocitos T CCL17, como sucede en los individuos atópicos.

La presencia de eosinofilia en la granulomatosis eosinofílica con poliangeitis, la presencia de crioglobulinas en el caso de las vasculitis por crioglobulinas, las alteraciones en el examen parcial de orina en la vasculitis de Henoch-Schönlein que hacen evidente el compromiso renal, son las pruebas que se utilizan para el diagnóstico, pero no son específicas de cada enfermedad.

Por último, se menciona que, hasta el momento, las clasificaciones se han basado en los hallazgos etiológicos, pronósticos y de tratamiento, pero se quiere hacer énfasis en que las clasificaciones clínico-patológicas nos permitirán entender mejor el fenómeno.

\section{Referencias}

1. Brodell RT, Mehrabi D. Underlying causes of erythema nodosum-lesions may provide clue to systemic disease. Postgrad Med. 2000;108:147-9.

2. Guha B, Youngberg G, Krishnaswamy G. Urticaria and urticarial vasculitis. Comp Ther. 2003;29:146-56. 
3. Akkurt ZM, Uçmak D, Türkcü G, Yüksel H, Yildiz K, Arıca M. Expression of interleukin-17 in lesions of erythema multiforme may indicate a role for T helper 17 cells. Cent Eur J Immunol. 2014;39:370-6.

4. Holt P, Davies M. Erythema gyratum repens-an immunologically mediated dermatosis? Br J Dermatol. 1977;96:343-7.

5. Kim DH, Lee JH, Lee JY, Park YM. Erythema annulare centrifugum: Analysis of associated diseases and clinical outcomes according to histopathologic classification. Ann Dermatol. 2016;28:257-9.

6. Müllegger R, Glatz M. Skin manifestations of Lyme borreliosis: Diagnosis and management. Am J Clin Dermatol. 2008;9:355-68.

7. De La Torre-Lugo E, Sánchez J. Erythema gyratum repens. J Am Acad Dermatol. 2011;64:89-90.

8. Adam D, Cohen P, Ghazarian D. Necrolytic migratory erythema: Case report and clinical review. J Cutan Med Surg. 2003;7:333-8.

9. Cohen PR. Sweet's syndrome-a comprehensive review of an acute febrile neutrophilic dermatosis. Orphanet J Rare Dis. 2007;2:34.

10. Cohen PR, Kurzrock R. Sweet's syndrome: A neutrophilic dermatosis classically associated with acute onset and fever. Clin Dermatol. 2000;18:265-82.

11. Ratzinger G, Zelger BG, Carlson JA, Burgdorf W, Zeger B. Vasculitic wheel - an algotithmic approach to cutaneous vasculitides. JDDG J der Dtsch Dermatologischen Gesellschaft. 2015;13:1092-117.

12. Fine RM, Meltzer HD. Chronic erythema nodosum. Arch Dermatol. 1969;100:33.

13. Vilanova X, Piñol-Aguade J. Hypodermyte nodulaire subsigue migratice. Ann Dermatol Syphiligr. 1956;83:369-404.

14. De Almeida-Prestes C, Winkelmann RK, Su WPD. Septal granulomatous panniculitis: Comparison of the pathology of erythema nodosum migrans (migratory panniculitis) and chronic erythema nodosum. J Am Acad Dermatol. 1990;22:477-83.

15. Carlson JA, Chen KR. Cutaneous vasculitis update: Small vessel neutrophilic vasculitis syndromes. Am J Dermatopathol. 2006;28:486-506.

16. Carlson JA, Chen KR. Cutaneous pseudovasculitis. Am J Dermatopathol. 2007;29;44-55.

17. Carlson JA. The histological assessment of cutaneous vasculitis. Histopathology. 2010;56:3-23.

18. Jennette JC, Falk RJ, Andrassy K, et al. Falta citar tres autores. Nomenclature of systemic vasculitides. Arthritis Rheum. 1994;37:187-92.

19. David F. Fiorentino DF. Cutaneous vasculitis. Classification, 1994, Chapell Hill. J Am Acad Dermatol. 2003;48:311-44

20. Grayson PC, Cuthbertson D, Carette S, Hoffman GS, Khalidi NA, et al. New features of disease after diagnosis in six forms of systemic vasculitis. J Rheumatol. 2013;40:1905-12.

21. Carlson JA, Ng BT, Chen KR. Cutaneous vasculitis update: Diagnostic criteria, classification, epidemiology, etiology, pathogenesis, evaluation and prognosis. Am J Dermatopathol. 2005;27:504-28.

22. Coombs RRA, Gell PGH. 1963. In: Clinical aspects of immunology P. 137. Ed Oxford. In Coombs RR. Immunopathology. Br Med J. 1968;1:597-602.

23. Jennette JC, Falk RJ, Bacon PA, Basu N, Cid MC, Ferrario F, et al. Nomenclature of vasculitides. Arthritis Rheum. 2012;65:1-11.

24. Woywodt A, Haubitz M, Haller H, Matteson EL. Wegener's granulomatosis. Lancet. 
2006;367:1362-6.

25. Sinico RA, Bottero P. Churg-Strauss angiitis. Best Pract Res Clin Rheumatol. 2009;23:355-66.

26. Churg J, Strauss L. Allergic granulomatosis, allergic angiitis, and periarteritis nodosa. Am J Pathol. 1951;27:277-301. 


\section{Capítulo 8 \\ Enfermedades del tejido conjuntivo}

El nombre de 'tejido conjuntivo' designa a aquellos tejidos que le van a dar sostén a los órganos, en general, los huesos, el cartílago, las fascias, las articulaciones, la estructura principal de la dermis, las bolsas serosas y los vasos sanguíneos. Sus células se derivan del mesodermo y producen diferentes proteínas fibrilares: colágeno, elastina, reticulina y la sustancia fundamental (1). El llamado 'colágeno' es el elemento fibroso más abundante del tejido conjuntivo; es, por lo tanto, el principal componente estructural del organismo.

Las enfermedades del tejido conjuntivo pueden dividirse en dos grandes grupos: uno conformado por los trastornos hereditarios relativamente poco frecuentes con cambios en la estructura del mismo que podrían llamarse verdaderas enfermedades del colágeno, como son el síndrome de Marfan, el síndrome de EhlersDanlos y la osteogénesis imperfecta, y otro grupo conformado por las enfermedades adquiridas en las que las reacciones inmunológicas e inflamatorias se presentan en este territorio del tejido conjuntivo y a las que Klemperer denominó 'enfermedades colágenas difusas' (2). Se describen otras enfermedades con depósito exagerado de colágeno como son la esclerosis sistémica, la fibrosis pulmonar y la cirrosis.

Las enfermedades del tejido conjuntivo que se revisan incluyen el lupus eritematoso sistémico, la esclerosis sistémica y la dermatomiositis. La enfermedad de Sjögren puede también tener manifestaciones en la piel, de tipo vasculitis, además de las alteraciones de glándulas lacrimales y salivales. Asimismo, existe otro proceso reportado como enfermedad mixta del tejido conjuntivo o enfermedad por superposición, en la que coexisten variaciones de las tres enfermedades: el lupus eritematoso sistémico, la esclerosis sistémica y la dermatomiositis. El síndrome de anticuerpos antifosfolípido se manifiesta con lesiones eritemato-violáceas que siguen los trayectos vasculares que se visualizan a través de la piel, conocidos como livedo reticularis y se presenta de manera independiente o acompañando a alguna de las anteriores enfermedades (3). En 1859, Garrot introdujo el término de 'artritis reumatoidea' para referirse a una enfermedad crónica que compromete principalmente las articulaciones y que se puede acompañar de lesiones en piel de tipo vasculitis (4). 
En general, estas son enfermedades inflamatorias y sistémicas en las que se presentan lesiones en la piel o en los tejidos blandos. Hacen parte de las enfermedades autoinmunitarias, debido a que el organismo produce una serie de anticuerpos dirigidos contra algún antígeno propio y específico en cada una de ellas; estos surgen, posiblemente, porque existe una alteración en la eliminación de las células alteradas o apoptósicas.

En estas enfermedades son de gran importancia los factores genéticos y los ambientales que determinan la variedad de respuestas inmunológicas que se presentan, las cuales varían mucho de un individuo a otro, siendo más serias en la medida en que aparezcan más temprano. Se clasifican tanto por los hallazgos clínicos como por los de laboratorio; estos son complementarios e indispensables para darle una denominación específica a la enfermedad y para prever futuros pronósticos del comportamiento de la misma. Por esta razón, estos exámenes de laboratorio, en lo posible, deben realizarse desde el inicio de la sospecha clínica.

Se hace necesario aclarar qué tipo de autoanticuerpos están aumentados para saber qué tipo de proceso autoinmunitario se presenta. El primer paso es solicitar una medición de los anticuerpos antinucleares (ANA) de manera general y, luego, si son positivos, el título de los mismos y el patrón de presentación también serán una guía ya que difieren según la enfermedad que se intenta clasificar.

Se debe especificar cuál es el que se encuentra comprometido. Según se sospeche la enfermedad clínica, se solicita anti-ADN de doble cadena ante el lupus eritematoso sistémico, anticuerpos contra antígenos nucleares extractables (Extractable Nuclear Antigens, ENA), los cuales son numerosos, y los cuatro más conocidos son SSa o Ro, SSb o La, presentes en el síndrome de Sjögren o Ro en el lupus eritematoso cutáneo subagudo y en el lupus neonatal, Sm que determina posible vasculitis, y suele ser positivo en el lupus eritematoso sistémico y, por último, el RNP, que es positivo en la enfermedad mixta del tejido conjuntivo. Otros, como el Ma, el Jo-1 y el PM-1, pueden estar asociados a otras alteraciones. Se solicita también el factor reumatoideo y los anticuerpos anticitrulina, en caso de sospecharse artritis reumatoidea, y los anticuerpos citoplasmáticos antineutrófilo (ANCA), en las vasculitis de medianos y pequeños vasos, y el Scl-70, en la esclerosis sistémica.

Como se puede ver, algunos anticuerpos son específicos de ciertas enfermedades: los anti-ADN ds y los Sm del lupus eritematoso sistémico; los antiScl-70 para la esclerosis sistémica; los anticentrómero para el síndrome CREST; el anti-Jo1 para el compromiso respiratorio en la polimiositis y los anti PM-1 para la polimiositis. Otros son característicos de ciertas entidades, como sucede con los anticuerpos antihistonas en el lupus inducido por medicamentos (procainamida, hidralazina, quinidina). En los pacientes con un cuadro clínico de lupus eritematoso 
sistémico, se deben solicitar los niveles de complemento sérico, que con frecuencia se consumen durante las fases de actividad del lupus eritematoso sistémico y, por tal razón, se encuentran bajos. También, es posible que se presente un cuadro semejante al lupus eritematoso sistémico en pacientes con deficiencia de $\mathrm{C}_{2} \mathrm{y}$, además, algunos pueden tener anticuerpos antifosfolípido positivos. Este grupo de pacientes con enfermedades autoinmunitarias pueden tener enfermedades poliglandulares o autoinmunológicas asociadas, como sucede con las enfermedades de la glándula tiroides cuya etiología es autoinmune, en cuyo caso se encuentran anticuerpos antiperoxidasa $\mathrm{o}$ antitiroglobulina positivos.

\section{Lupus eritematoso}

El lupus eritematoso es una enfermedad inflamatoria, crónica, autoinmunitaria y multifactorial. En su patogénesis juegan papel factores genéticos, ambientales y hormonales. La primera descripción clara del lupus eritematoso fue hecha por Biett y reportada por su alumno Cazenave (5), con el nombre de eritema centrifugum y fue él quien utilizó la palabra 'lupus' en 1851 para referirse a las lesiones del lupus eritematoso discoide, debido a que las lesiones que observó tenían el 'aspecto de algo mordido por un lobo'.

El lupus tiene una gran variabilidad de presentaciones clínicas y la gravedad puede variar desde una expresión muy leve de la enfermedad con lesiones cutáneas únicas hasta llegar a tener un compromiso importante con afectación de múltiples órganos. Las lesiones pueden aparecer de forma aguda o irse instaurando lentamente, de forma subaguda o crónica. Su aparición y variedad dependen de varios factores, entre los cuales los genéticos son los más importantes. Del 70 al $85 \%$ de todos los pacientes tienen lesiones cutáneas y, además, es la segunda manifestación más frecuente en el lupus eritematoso sistémico, del 55 al $70 \%$ de los pacientes presentan afectación dermatológica después de los síntomas articulares (6).

El componente hormonal es de gran importancia debido a que la gran mayoría de los pacientes con lupus eritematoso sistémico son mujeres. Los estudios genéticos de las familias que tienen más de un miembro afectado por la enfermedad, han demostrado que, posiblemente, son muchos los genes que están relacionados con ella. Entre los genes del complejo mayor de histocompatibilidad asociados se encuentran en particular los HLA A1, B8 y DR3. 


\section{Clasificación de las lesiones cutáneas}

Hay tres variedades clínicas, según su presentación: lupus agudo o lupus eritematoso sistémico, lupus subagudo, anular policíclico o psoriasiforme y lupus crónico que, generalmente, es discoide.

Para la clasificación del lupus eritematoso agudo se han utilizado por muchos años los criterios del American College of Rheumatology (ACR). Estos conceptos han sido examinados varias veces; los más conocidos se elaboraron en 1982 y se revisaron en 1997 (7). En ellos se consideraban inicialmente las lesiones de lupus discoide, el eritema en alas de mariposa, la fotosensibilidad y las úlceras orales entre las lesiones que comprometen la piel y las mucosas.

En la última revisión del lupus en el 2012 (8), se seleccionaron 17 criterios para el diagnóstico del mismo: 11 criterios clínicos que incluyen las lesiones de tipo cutáneo y 6 criterios inmunológicos. Entre las lesiones presentes en la piel, se consideró el exantema malar que hace parte de la fotosensibilidad, la alopecia difusa cobró relevancia como criterio independiente, el lupus ampolloso se incluyó dentro del lupus agudo, y la necrólisis eritematosa tóxica de tipo lupus eritematoso sistémico que puede ser una variante del mismo.

El lupus agudo, o lupus eritematoso sistémico, es una enfermedad autoinmunitaria crónica cuyo espectro de manifestaciones es amplio. Ha sido considerada una enfermedad inflamatoria multisistémica, caracterizada por la producción de autoanticuerpos. Su incidencia puede ser de 12 a 50 casos por 100.000 habitantes y con una proporción de 8 a 9 mujeres por cada hombre (9). En los Estados Unidos, se considera que existen 2,2 casos de lupus eritematoso sistémico por cada 100.000 habitantes, y una relación de 9 a 1, con predominio de la mujer sobre el hombre (10).

En su aparición intervienen factores genéticos, ambientales y raciales. Es la variedad que se correlaciona con las manifestaciones sistémicas; el $72 \%$ de los pacientes que las presentan cumplen los criterios para lupus sistémico, suelen tener síntomas generales, como fatiga, fiebre y pérdida de peso, presentan dolores articulares o tipo fibromialgia.

Las lesiones de la piel se caracterizan por la aparición de una forma de fotosensibilidad en la cual aparece un eritema en la región malar, que se describe como 'eritema en alas de mariposa' (figura 8.1a) debido a que compromete las prominencias malares, pasando por el dorso de la nariz respetando el surco nasogeniano; el eritema se puede extender a los párpados y a la frente. Es de comienzo repentino $\mathrm{y}$, en ocasiones, se acompaña de leve descamación y edema. Suele durar días y, a menudo, 
acompaña las exacerbaciones de la enfermedad. Presentan, además, úlceras orales y alopecia difusa.

Ocasionalmente, se inicia como un exantema generalizado (figura 8.1b) y se puede confundir con una reacción a medicamentos. Pueden aparecer lesiones máculo-papulares, urticantes en todo el tegumento cutáneo o en las zonas más expuestas a la luz y, de manera menos frecuente, aparecen lesiones ampollosas. Algunos pacientes presentan livedo reticularis como manifestación del aumento de los anticuerpos antifosfolípido, en cuyo caso, el anticoagulante lúpico también será positivo. Es la forma más frecuente de presentación en la población pediátrica (11).
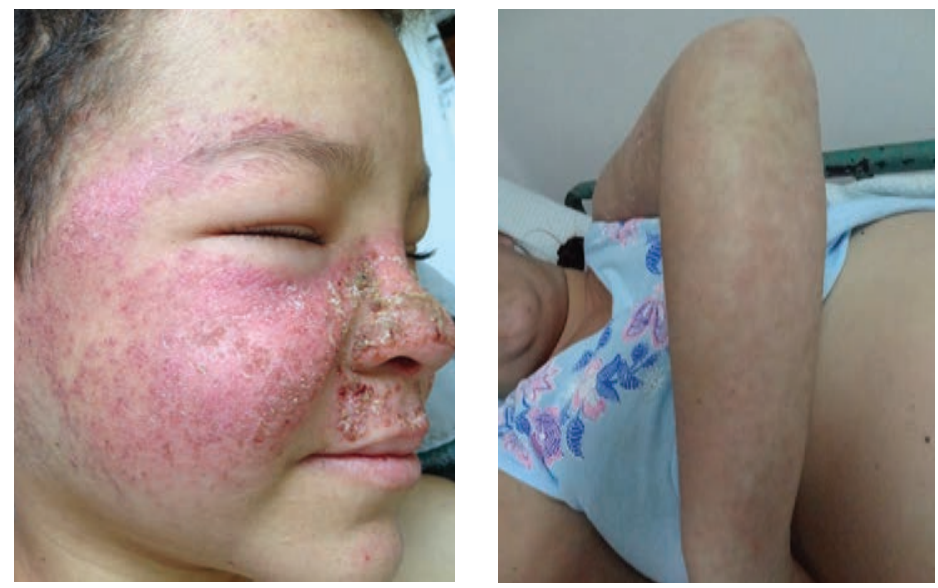

Figura 8.1. Lupus eritematoso sistémico Las lesiones se caracterizan por la aparición de un eritema en región malar conocido como a. Eritema en alas de mariposa, debido a que compromete las prominencias malares, pasando por el dorso de la nariz y respetando el surco nasogeniano; el eritema se puede extender a los párpados y a la frente; es de comienzo repentino y, en ocasiones, se acompaña de leve descamación y edema. Suele durar días y, a menudo, acompaña las exacerbaciones de la enfermedad. b. Exantema generalizado: Cuando un paciente con lupus eritematoso sistémico, esta en una fase aguda de la enfermedad, ocasionalmente, se acompaña de lesiones máculo-papulares tipo exantema o urticantes en todo el tegumento cutáneo o en las zonas más expuestas a la luz y, de manera menos frecuente, aparecen lesiones ampollosas.

El lupus subagudo, o lupus eritematoso cutáneo subagudo, se caracteriza por una erupción fotosensible extensa, que no deja cicatriz y que está localizada en las zonas expuestas a la luz como son el rostro, las caras de extensión de las extremidades superiores y las caras posteriores de las extremidades inferiores.

Las variantes más comunes de la forma subaguda que pueden extenderse a todo el cuerpo, son una forma psoriasiforme (figura 8.2), referida en dos tercios de los pacientes, con aparición de placas eritematosas con descamación o escamas más 
gruesas y que son indistinguibles de las lesiones de psoriasis (es probable que las dos entidades se presenten de manera concomitante) y que se pueden diseminar a todo el tegumento cutáneo, y una forma anular policíclica, en la tercera parte de ellos que aparece con placas eritematosas con leve descamación, anulares y de crecimiento centrífugo, de centro más claro. Se estima que el $50 \%$, aproximadamente, de los pacientes con lupus subagudo cumple los criterios para lupus y presentan anticuerpos anti-Ro positivos.
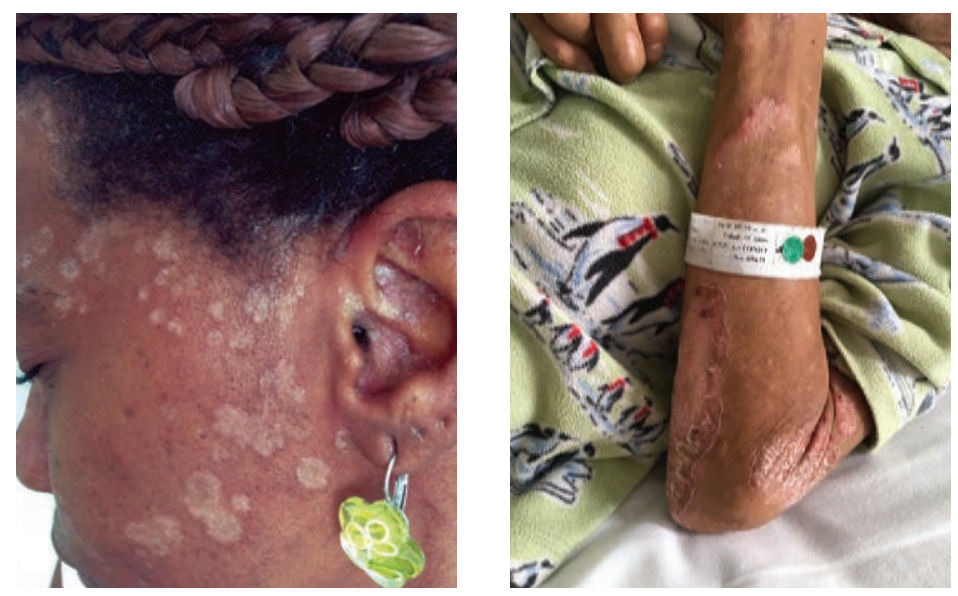

Figura 8.2. Lupus subagudo, variedad psoriasiforme. Existen dos variedades de lupus subagudo, el psoriasiforme, caracterizado por la aparición de placas eritematosas con descamación y escamas que se pueden diseminar a todo el tegumento cutáneo y que son indistinguibles de las lesiones de psoriasis, y una forma anular policíclica, que aparece en la tercera parte de los que hacen la variedad subaguda que aparece con placas eritematosas con leve descamación, anulares y de crecimiento centrífugo, de centro más claro.

Quizá se puedan encontrar otras formas de esta variedad subaguda que aparecen como erupciones en las áreas expuestas a la luz, y que pueden recibir varios nombres: urticaria solar o erupción polimorfa lumínica crónica; esta última se observa de manera más frecuente en nuestra población y se considera una entidad independiente más benigna que las anteriores, que no deja cicatrices y que no muestra correlación con compromisos renal, vascular o cerebral, o que puede considerarse también otra forma de lupus crónico.

La erupción polimorfa lumínica crónica se presenta en las áreas expuestas al sol, especialmente en el rostro, la parte superior del tórax, tanto anterior como posterior, el dorso de los antebrazos, el cuello y, en ocasiones, en el cuero cabelludo. Las lesiones son placas eccematosas o placas infiltradas eritematosas que también recuerdan a las descritas en la urticaria solar, parecidas a las del lupus tumidus, y que pueden hacer parte de este espectro y no presentan cambios inmunológicos. 
El lupus crónico es la forma más benigna de presentación del lupus, ya que está prácticamente confinada a la piel; los que la padecen tienen un bajo riesgo de sufrir de lupus eritematoso sistémico. Solo en 5 a $10 \%$ de ellos se reporta compromiso sistémico (12).

Existen varios subtipos de lupus cutáneo crónico. La forma más común es la conocida como lupus eritematoso discoide crónico; se caracteriza por lesiones o placas eritematosas circunscritas, con apariencia de discos en las zonas expuestas a la luz, como el rostro, el cuero cabelludo, los pabellones auriculares externos y las zonas expuestas del cuello o en todos los lugares al mismo tiempo. Las placas eritematosas presentan una escama central gruesa y adherente acompañada de tapones hiperqueratósicos que ocluyen los folículos pilosos y que, al ser retirada, permiten visualizar en su superficie una especie de espículas córneas, conocidas como lesiones de tipo 'clavo de tapicero'; la placa puede persistir por meses, dejando una zona central atrófica, hipopigmentada, rodeada de una zona hiperpigmentada, es decir, dejan una cicatriz y al comprometer el folículo piloso se establece una alopecia permanente (13) (figura 8.3).

El lupus eritematoso discoide crónico puede presentarse localizado, circunscrito a la cabeza y el cuello, o puede generalizarse por debajo del cuello a otras zonas expuestas al sol, como la zona de la $\mathrm{V}$ del escote, o a las caras de extensión de las extremidades. Si estas placas eritemato-descamativas adheridas con tapones foliculares presentan una zona escamosa más gruesa y elevada, se habla de un lupus discoide hipertrófico o verrugoso, y si las placas son profundas o con nódulos duros subcutáneos rojos que se ubican generalmente en las mejillas, los brazos y los glúteos y que se resuelven dejando zonas deprimidas $y$, a veces, hiperpigmentadas, puede tratarse de una paniculitis lúpica. Se reportan lesiones en las mucosas, lesiones de aspecto liquenoide y otras que recuerdan al eritema pernio que aparece desencadenado por el frío. 

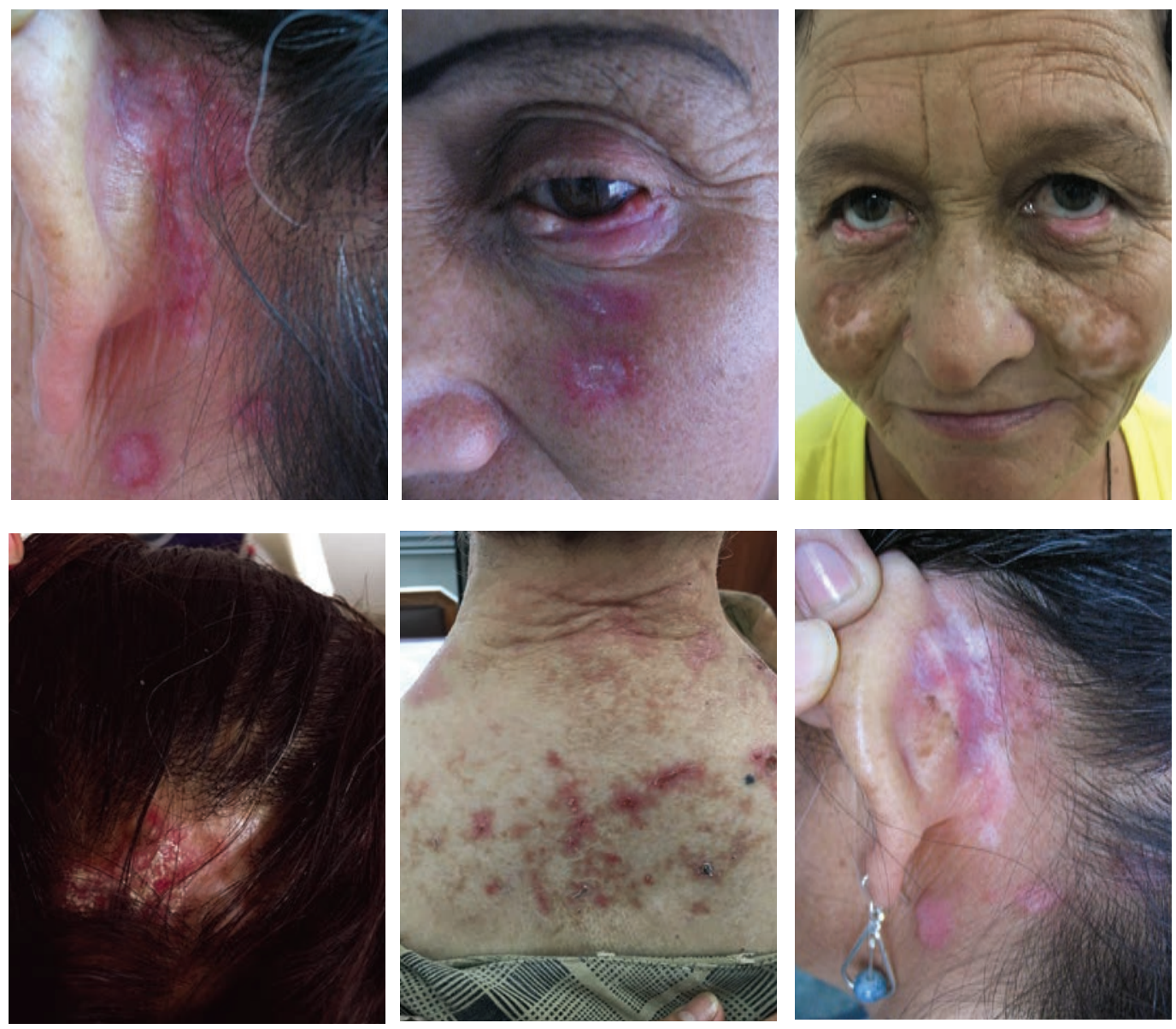

Figura 8.3. Lupus eritematoso discoide crónico. Se caracteriza por la aparición de lesiones o placas eritematosas circunscritas, redondeadas en las zonas expuestas a la luz, como el rostro, el cuero cabelludo, los pabellones auriculares externos y las zonas expuestas del cuello o en todos los lugares al mismo tiempo. Las placas eritematosas presentan una escama central gruesa y adherente acompañada de tapones hiperqueratósicos que ocluyen los folículos pilosos y que permiten, al ser retirados, la visualización en su superficie de una especie de espículas córneas, conocidas como lesiones tipo 'clavo de tapicero'; la placa puede persistir por meses, dejando una zona central atrófica, hipopigmentada, rodeada de una zona hiperpigmentada, es decir, dejan una cicatriz y, al comprometer el folículo piloso, se establece una alopecia permanente.

También se presentan en las zonas expuestas a la luz, unas placas eritematovioláceas, elevadas, turgentes, que parecen estar más infiltradas que el lupus discoide habitual; se puede tratar de una variedad de lupus subagudo y parecerse a las de la erupción polimorfa lumínica crónica que, en otras series, ha sido reportada como lupus tumidus (figura 8.4). 

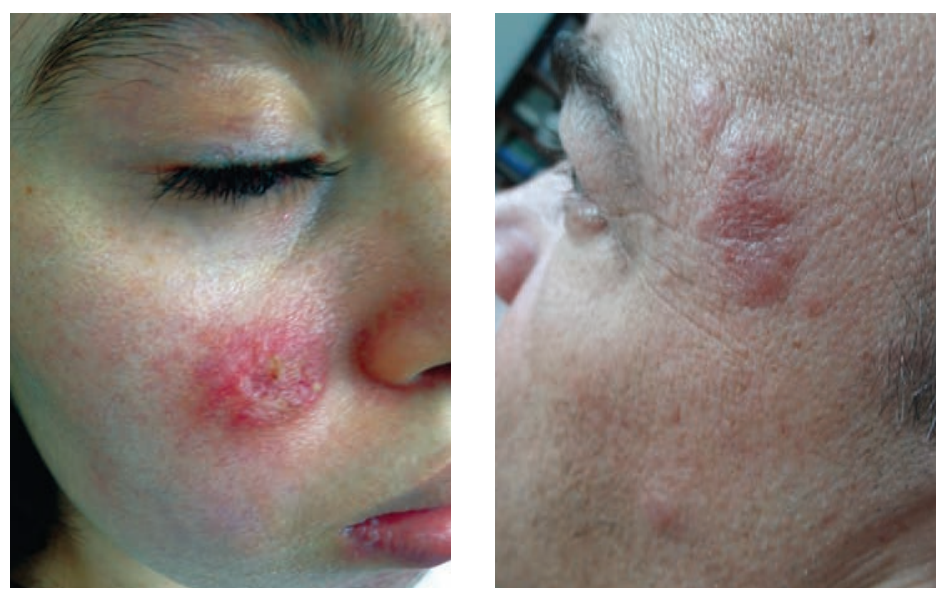

Figura 8.4. Lupus tumidus. También se presentan en las zonas expuestas a la luz, unas placas eritemato-violáceas, elevadas, turgentes, que parecen más infiltradas que el lupus discoide habitual; puede tratarse de una variedad de lupus subagudo y parecerse a las de la erupción polimorfa lumínica que, en otras series, ha sido reportada como lupus tumidus.

Todas estas variedades se tratan con derivados de la cloroquina y no suelen convertirse en lupus sistémico. En algunas ocasiones, se puede necesitar hacer un diagnóstico diferencial con otras lesiones de tipo pseudolinfoma o infiltración linfocítica de Jessner, que también pueden ser variaciones del mismo proceso o con verdaderos linfomas cutáneos de las células $\mathrm{T}$ o lesiones de lepra, ya que se pueden ver muy parecidas; no obstante, se debe recordar que en esta última se encuentran alteraciones de la sensibilidad.

Se ha hablado de una forma diseminada o generalizada del lupus crónico, en cuyo caso los pacientes presentan, además de las lesiones cutáneas en el rostro, unas lesiones más extensas acompañadas de lesiones de vasculitis en las yemas de los dedos o lesiones mucosas que podrían acercarse más a una forma sistémica y cuya distinción clínica es importante y hace obligatoria la correlación con la existencia de anormalidades en los exámenes de laboratorio para su clasificación y manejo.

Las clasificaciones son muchas; la más utilizada para la clasificación general del lupus eritematoso sistémico es la de la ACR, pero para comprender las variaciones de las manifestaciones cutáneas, es más preciso remitirnos a la propuesta por Gilliam, et al. (14), que dividieron las lesiones cutáneas en específicas e inespecíficas, clasificación que adoptamos con algunas modificaciones.

Es conveniente recalcar que en esta clasificación las lesiones inespecíficas sobrepasan el concepto de las lesiones que se presentan en el lupus eritematoso 
sistémico y hacen evidente que puede haber una superposición de enfermedades autoinmunitarias que se ha descrito con el nombre de 'síndrome de superposición' o 'enfermedad mixta del tejido conectivo'.

La esclerodactilia, los nódulos reumatoideos, la calcinosis cutis y la urticaria pueden hacer parte del lupus eritematoso sistémico, de la esclerosis sistémica, de la dermatomiositis, de la artritis reumatoidea y de la enfermedad de Sjögren. Las lesiones de tipo vascular, como la tromboflebitis y el livedo reticularis sugieren que el paciente presenta simultáneamente un síndrome de anticuerpos antifosfolípido. El fenómeno de Raynaud, la vasculitis leucocitoclásica (figura 8.5) y las úlceras en las piernas demuestran un compromiso vascular. En el lupus se han descritos varios tipos de lesiones ampollosas: el lupus ampolloso, el eritema polimorfo asociado a lupus o síndrome de Rowell y una asociación de pénfigo seborreico con lupus eritematoso sistémico que, en el futuro, habrá que dilucidar si son variaciones del mismo proceso.

La alopecia difusa (figura 8.6) se presenta con frecuencia en el lupus eritematoso sistémico; los otros hallazgos descritos pueden ser complicaciones por la alta sensibilidad a la luz, como es la mucinosis papular.
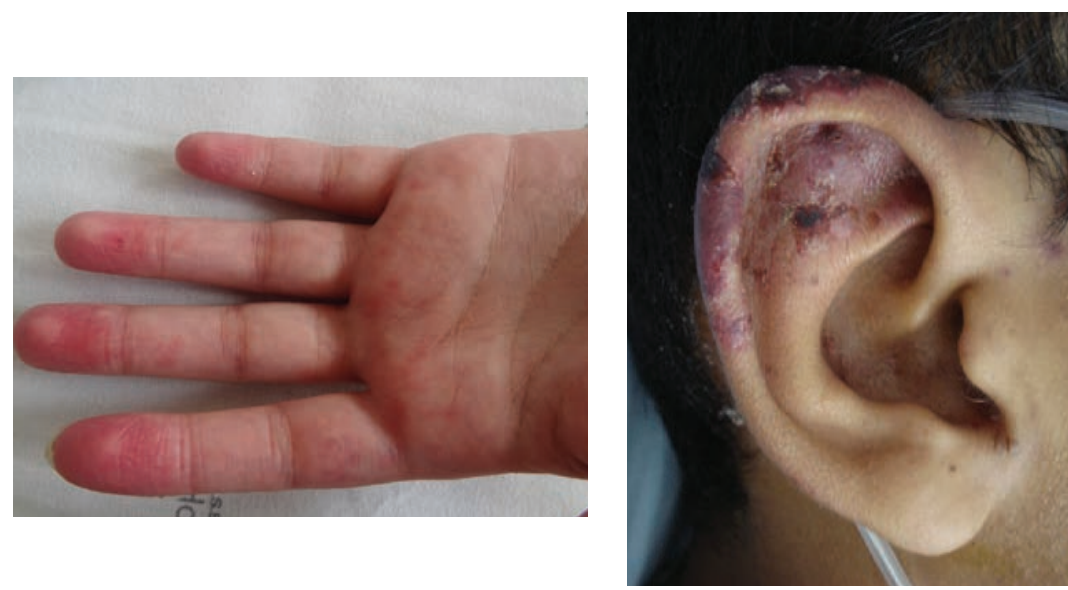

Figura 8.5. Lupus eritematoso sistémico, vasculitis distal. 

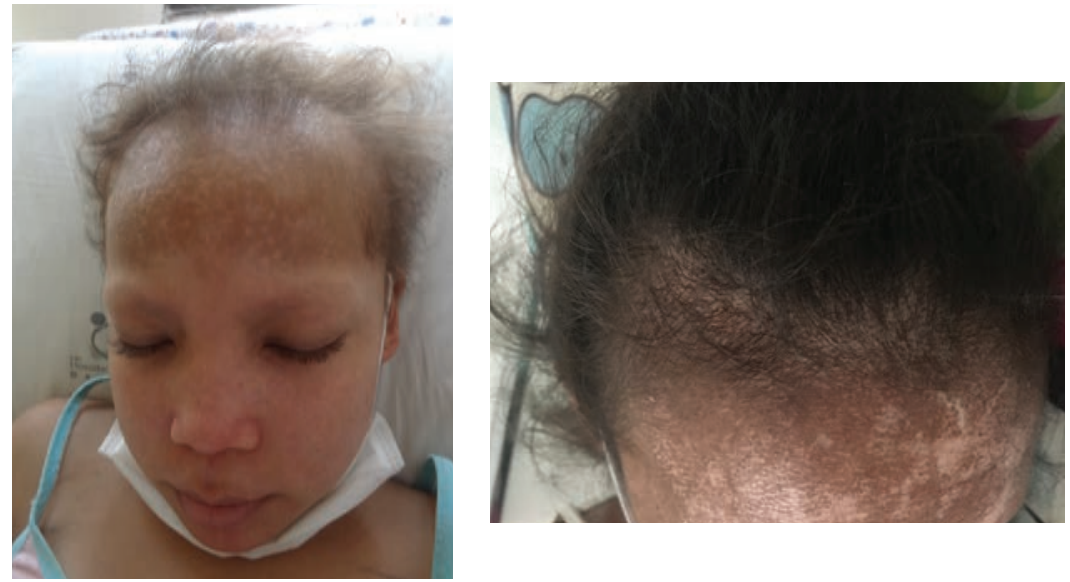

Figura 8.6. Lupus eritematoso sistémico, alopecia difusa. Los pacientes con lupus eritematoso sistémico suelen presentar úlceras orales y alopecia difusa. La alopecia se presenta de manera frecuente. Esta disminución difusa de la población pilosa, se constituye en uno de los criterios clínicos del lupus eritematoso sistémico y es más frecuente en las personas más jóvenes.

También se presenta un fenómeno de superposición entre enfermedades, como sucede con el lupus y el liquen rojo, que aún no se ha esclarecido; lo que sí se sabe es que, posiblemente, comparten una alteración de la capacidad de eliminar las células apoptóticas o muertas, y que esta falla podría desencadenar el proceso autoinmune (15). Además, como se vio en los capítulos anteriores, las enfermedades autoinmunitarias, como la artritis reumatoidea, el síndrome de Sjögren, la esclerosis sistémica y el lupus eritematoso sistémico, pueden acompañarse de alteraciones de las glándulas endocrinas, en lo que se ha llamado 'síndromes poliglandulares', en cuyo caso se pueden presentar lesiones de tipo acantosis nigricans benigna semejante a la encontrada en los pacientes con diabetes mellitus, o alteraciones que acompañan las enfermedades tiroideas, como el vitiligo o la alopecia areata.

Otras vasculitis cutáneas que acompañan al lupus eritematoso sistémico y aparecen en el 10 al $50 \%$ de los pacientes; se presentan frecuentemente en las yemas de los dedos de las manos y de los pies con la aparición de zonas eritematosas puntiformes, que pueden ser ligeramente dolorosas, o aparecer telangiectasias y eritema periungular, acompañados o no del fenómeno de Raynaud. Así como se presentan lesiones puntiformes, pueden aparecer lesiones de tipo púrpura palpable, o tipo urticaria por vasculitis con lesiones papulosas edematosas que persisten por más de 24 a 48 horas y que pueden dejar pigmentación por extravasación de los eritrocitos, pápulas o placas maculares eritematosas o del tipo eritema nudoso. 
No se debe olvidar que el lupus también puede ser inducido por medicamentos como la hidralazina o la procainamida y que puede aparecer en los casos de bajos niveles del complemento, principalmente de C2. Algunos pacientes presentan por tiempos indefinidos trombocitopenia, con aparición de lesiones púrpura, clasificadas como una púrpura trombocitopénica idiopática, o síndrome de Evans, y meses o años después hace su aparición el lupus eritematoso sistémico (figura 8.7).
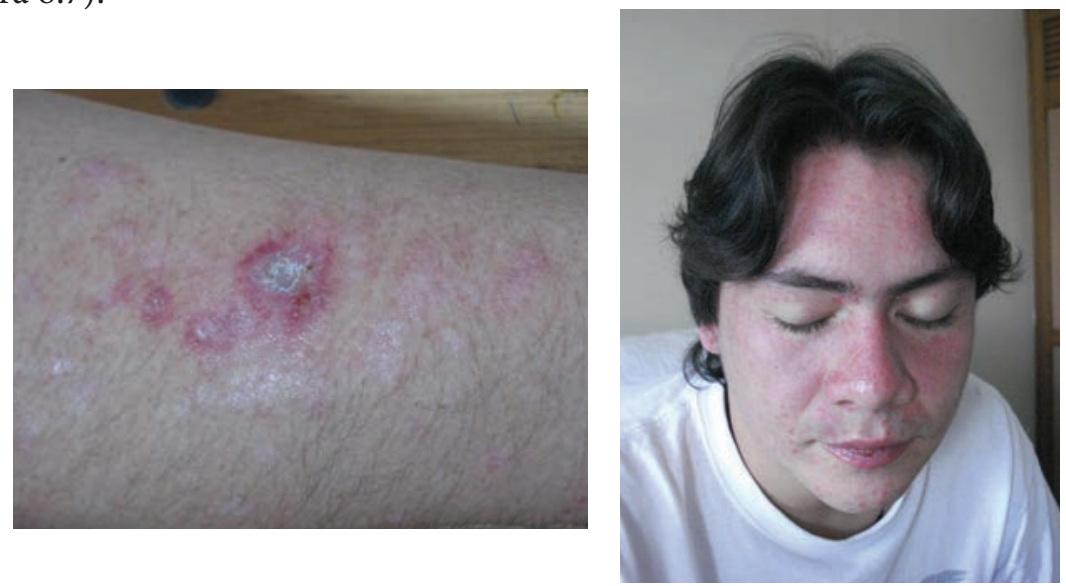

Figura 8.7 Síndrome de Evans, lupus eritematoso sistémico. Algunos pacientes presentan por meses o años una disminución del número de plaquetas (trombocitopenia), con aparición de lesiones púrpura, clasificadas como una púrpura trombocitopénica idiopática, o síndrome de Evans, y años después aparece el lupus eritematoso sistémico.

Acompañando estos hallazgos cutáneos, se pueden encontrar manifestaciones en otros tejidos, entre ellas lesiones articulares (sinovitis), hematológicas, inmunológicas, renales o inflamación de las membranas serosas que cubren los órganos, como son el pericardio y la pleura, así como alteraciones neuropsiquiátricas. En todas ellas existe como común denominador del proceso inflamatorio la generación de autoanticuerpos y la formación de complejos inmunes que se depositan junto con el complemento en los diferentes tejidos, así que serán positivos para ANA, específicamente positivos para anti-DNA ds, al igual que pueden ser positivos para el anti-Sm y tener bajos niveles de complemento.

Es importante recalcar que el tipo de enfermedad que se presenta en Colombia, según nuestros datos, son semejantes a los que existen a nivel mundial. El estudio multicéntrico binacional, Colombia-México, publicado por Molina, et al., en 1995 (16), en el que estudiaron 1.316 pacientes con lupus eritematoso sistémico - 1.209 mujeres y 107 hombres- encontró una relación de frecuencia en la presentación por sexo de 11,2 a 1, a favor de las mujeres, con un promedio de edad al establecerse el diagnóstico de 27 años (rango: 5 a 78 años). 
En ese estudio, las principales características clínicas y de laboratorio, fueron: artritis, $88 \%$; componente cutáneo, $67 \%$; alopecia, $47 \%$; fenómeno de Raynaud, 45 \%; nefritis, $45 \%$; anti-ADN, $41 \%$; leucopenia, $39 \%$; pleuritis, $36 \%$; trombocitopenia, $20 \%$; pericarditis, $13 \%$; anemia hemolítica, $12 \%$; convulsiones, $12 \%$, y sicosis, $8 \%$. De los 1.209 casos, 104 pacientes murieron durante el periodo de seguimiento. Las causas de muerte más frecuentes fueron actividad lúpica (52 \%) e infecciones (25\%). Este estudio nos permite decir que los hallazgos son similares a otros encontrados en la literatura anglosajona. El $67 \%$ de los pacientes con lupus eritematoso sistémico presenta lesiones cutáneas, así solo el 17 \% de ellos las tengan como manifestación inicial.

Ellupus neonatal es una forma de presentación rara producida por anticuerpos anti-Ro que afectan al neonato y que son transmitidos por vía transplacentaria por la madre. Tienen una incidencia de 1 en 12.000 a 20.000 nacidos vivos. El neonato presenta lesiones cutáneas transitorias de lupus eritematoso subagudo, con placas anulares concéntricas algo confluentes y que se resuelven espontáneamente en unos meses. También se acompañan de bloqueo cardíaco, trombocitopenia y hepatoesplenomegalia.

Entre las lesiones ampollosas que se pueden presentar en el lupus eritematoso, se ha descrito el síndrome de Senear-Usher, o pénfigo eritematoso, que con inmunofluorescencia hace evidente el lupus eritematoso sistémico que acompaña al pénfigo foliáceo. Se describen también lesiones ampollosas flácidas con costras eritematosas en las áreas expuestas al sol, que respetan las mucosas y que recibe el nombre de 'lupus eritematoso ampolloso'. Puede, también, aparecer una variedad de necrólisis eritematosa tóxica, llamada variedad lupus eritematoso sistémico.

Por otro lado, como se vio anteriormente, está descrita la concomitancia de lupus eritematoso y eritema multiforme conocida como síndrome de Rowell (17), con ANA positivos, de patrón moteado y anticuerpos anti-Ro y anti-La presentes. Aún no está completamente dilucidado, pero puede ser una variedad de lupus eritematoso cutáneo subagudo. Están descritos otros casos con autoanticuerpos contra el colágeno de tipo VII, en mujeres negras y jóvenes, con ampollas tensas y aparición de máculas eritematosas en las áreas expuestas de la piel, con compromiso mucoso variable y que, a menudo, no responden a los corticoides (18).

Se debe recordar que pueden tener anticuerpos anti-Ro positivos los pacientes con síndrome de Sjögren primario, lupus eritematoso cutáneo subagudo o lupus neonatal, o aparecer en las deficiencias hereditarias de complemento y en algunas manifestaciones de síndrome de superposición de lupus eritematoso cutáneo subagudo con síndrome de Sjögren y ANA negativos. 
La última revisión de los criterios del American College of Rheumatology fue necesaria en 2012, a partir de la variabilidad de las lesiones cutáneas y de los criterios que se presentaban, y se presenta a continuación (cuadro 8.1).

\section{Esclerosis sistémica o esclerodermia}

La esclerosis sistémica es una enfermedad autoinmunitaria, inflamatoria, crónica y sistémica del tejido conjuntivo, más frecuente en las mujeres que en los hombres (3:1), que suele aparecer en la mitad de la vida, de los 35 a los 45 años, con una incidencia anual de 2,7 por millón de habitantes (19). Se caracteriza por una alteración de la piel y de algunas vísceras con compromiso vascular, activación del sistema inmunológico, de las células endoteliales y de los fibroblastos, que llevan a un aumento de la síntesis y el depósito de colágeno y de otras proteínas de la matriz extracelular, como la fibronectina, la tenescina, la fibrilina 1 o de los glucosaminoglucanos de la piel y de otros órganos. Se presenta de manera limitada o difusa.

Las anormalidades debidas a esta proliferación afectan la estructura de los pequeños vasos permitiendo que se tornen rígidos y puedan llegar a obliterarse; esta alteración vascular y del tejido colágeno se acompaña de una fibrosis que afecta múltiples órganos. En la piel, lo más característico es la aparición de un engrosamiento y endurecimiento de la misma por acumulación de este depósito de matriz extracelular, y pérdida de la elasticidad conocida como esclerosis, acompañada del fenómeno de Raynaud -la afección vascular más frecuente- que puede estar acompañado de un engrosamiento de la íntima de los vasos $(20,21)$. Este fenómeno es causado por episodios de vasoespasmo de las arteriolas periféricas, a veces, con oclusión de las mismas, desencadenado por la exposición al frío. Se hace visible en los dedos de los pies y de las manos; se inicia con palidez y cianosis seguidas de eritema y edema al finalizar el episodio (figura 8.8).

Este fenómeno es la primera manifestación de la enfermedad y estos cambios visibles de palidez y cianosis de los dedos de las manos y de los pies, pueden llegar incluso a la necrosis de los mismos, especialmente en las partes distales de las yemas de los dedos. No necesariamente se comprometen todos los dedos de las manos o de los pies; al retornar la circulación, se observa un enrojecimiento y un leve edema de la región afectada, inicialmente transitoria y, a medida que se repite, se va estableciendo como permanente. 

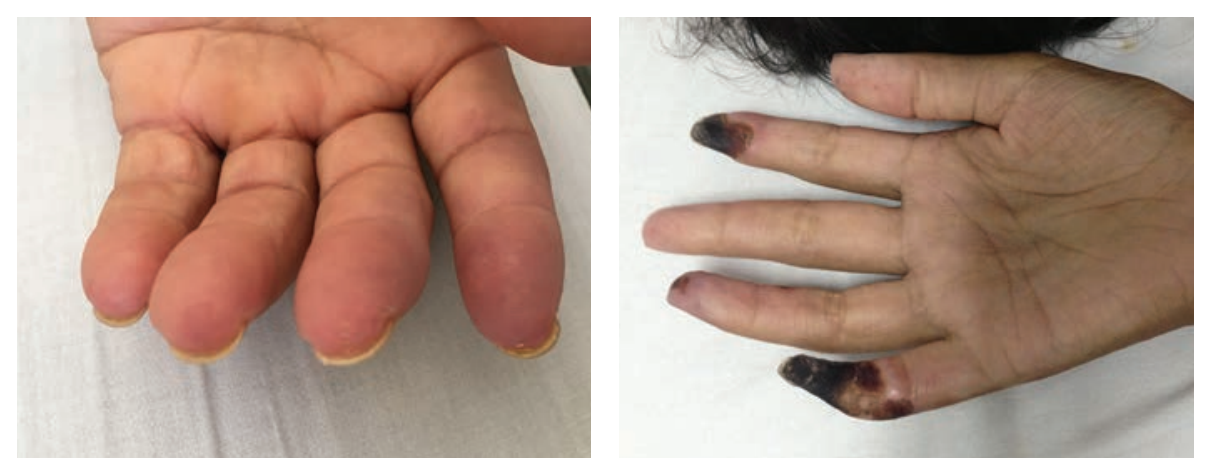

Figura 8.8. Fenómeno de Raynaud. Es una afección vascular que puede estar acompañado a un engrosamiento de la íntima de los vasos. Este fenómeno es causado por episodios de vasoespasmo de las arteriolas periféricas, a veces, con oclusión de las mismos, desencadenado por la exposición al frío. Se hace visible en los dedos de los pies y de las manos; se inicia con palidez y cianosis seguidas de eritema y edema al finalizar el episodio. Este fenómeno es la primera manifestación de la enfermedad y estos cambios visibles de palidez y cianosis en los dedos de las manos y de los pies, pueden llegar incluso a la necrosis de los mismos, especialmente en las partes distales de las yemas de los dedos.

El aspecto escleroso de la piel (figura 8.9) se debe a la neoformación de colágeno, que adopta un aspecto homogéneo y eosinofílico, y a la fibrosis que lo acompaña. Se puede encontrar, además, ectasias vasculares o telangiectasias generalizadas y, en otras, calcificaciones por depósitos de calcio que pueden llevar a ulceraciones.

En algunos pacientes se pueden comprometer otros órganos, como el corazón, los pulmones o los riñones, aunque el más afectado es el tubo digestivo, con un compromiso del esófago por disminución de la motilidad, que hace que exista una dificultad para el paso de los alimentos, inicialmente de los sólidos y posteriormente de los líquidos, o puede verse también un retardo en el vaciamiento gástrico, debido a esta alteración del movimiento del mismo. Según el lugar del sistema gastrointestinal que esté comprometido, se puede presentar reflujo gastroesofágico, distensión abdominal o vómitos, o si afecta el intestino delgado, puede causar malabsorción y diarreas, cuadros pseudoobstructivos, y si la afectación es del colon, estreñimiento u otras alteraciones como incontinencia fecal y prolapso rectal.

Se pueden presentar, asimismo, sangrados en cualquier parte del intestino, con aparición de hematemesis o melenas que suelen llevar a la aparición de una anemia ferropénica o incluso otros síntomas secundarios a la malabsorción acompañados de la pérdida de peso. Lo que determina un mal pronóstico en la esclerosis sistémica es el compromiso renal o pulmonar con hipertensión pulmonar, que suele ser tardío. 


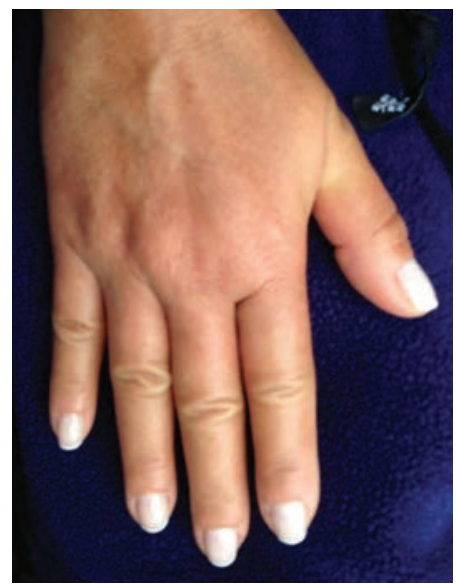

Figura 8.9 Esclerosis sistémica. La piel está esclerosa de manera notoria en las manos.

En estos pacientes se encuentran anticuerpos antinucleares positivos en el 90 al $95 \%$ de los pacientes, con un patrón nucleolar; dos de ellos son específicos para la esclerosis sistémica: los anticuerpos anticentrómero (ACA) asociados a la esclerodactilia en el síndrome CREST, y los anti-Scl-70 (o antitopoisomerasa I) que son los más específicos y se encuentran en el $25 \%$ de los pacientes con esclerosis difusa.

En cuanto a los estudios genéticos en la esclerosis sistémica, se ha encontrado un incremento en la expresión de antígenos de histocompatibilidad HLA-A1, -B8, -DR3 en pacientes blancos con esclerosis difusa y de HLA-DR6 en pacientes negros con esclerosis localizada. Existen muchos subgrupos de genes comprometidos, por ejemplo, se encontraron autoanticuerpos en los individuos expuestos a cloruro de vinilo que desarrollaron CREST asociados al HLA-DR5 o alelos del C4 (22).

Pueden cursar con otra enfermedad autoinmunitaria, como sucede con la coexistencia de la esclerosis sistémica asociada a la afectación de los conductos biliares, inflamación y destrucción de los mismos, conocido como síndrome de Reynolds. Del 9 al $29 \%$ de estos pacientes pueden tener ANA positivos con un patrón anticentrómero. Suele empezar de forma insidiosa con fatiga, prurito y sin ictericia; la supervivencia sin tratamiento de estos pacientes con afección biliar es de 10 años.

La esclerosis sistémica, o esclerodermia, compromete de manera generalizada todo el cuerpo. Se puede presentar también de manera localizada, con lesiones circunscritas a ciertas zonas de la piel, lo que se ha llamado 'esclerosis en placas' que, a la vez, puede estar localizada en la piel o puede ser difusa según los órganos que comprometa. Pueden presentarse alteraciones pigmentarias con 
zonas hipopigmentadas que alternan con hiperpigmentación y si estas se presentan ocupando gran parte del cuerpo, suelen asociarse a la esclerodermia difusa que es rápidamente progresiva.

\section{Esclerosis localizada}

Se habla de esclerosis localizada para referirse a una esclerosis que no es sistémica, sino que se encuentra en ciertas zonas y que también se le denomina 'morfea'. Se describen tres variaciones: morfea en placas, lineal o generalizada, y existen unos cuadros intermedios entre lo que se ha llamado liquen esclero-atrófico y morfea.

La morfea en placas (figura 8.10) es la forma más común de este tipo. Se puede presentar en gotas con lesiones de 2 a $5 \mathrm{~mm}$ o con una o múltiples placas de diversos tamaños; en la fase inicial, o activa, cada lesión se encuentra edematosa y ligeramente eritematosa y, poco a poco, se va tornando esclerosa, blanquecina y brillante con disminución del plegamiento y de la elasticidad, lo que la hace indurada a la palpación; algunas veces presenta un halo ligeramente más rojizo en la periferia de las lesiones que son de diversos tamaños, desde pocos centímetros hasta muy grandes comprometiendo zonas extensas del cuerpo; al final, va perdiendo el endurecimiento y se vuelve hiperpigmentada. Se presentan con mayor frecuencia en el tronco, aunque también pueden aparecer en las extremidades.

Aparecen como un fenómeno reactivo a múltiples causas desencadenantes, infecciones por Borrelia spp. o también por estreptococo $\beta$ hemolítico o por el virus del Epstein-Barr, secundaria a traumatismos, quizá más a fracturas y, en algunos casos, se encuentra el antecedente de un aborto.

La esclerodermia lineal se conoce también como morfea en 'golpe de sable'; se presenta en la infancia. El nombre se debe a que se localiza en la región superior y lateral de cualquiera de los dos lados de la frente, como si le hubiese sido propinado un 'sablazo' al individuo y le hubiera dejado una cicatriz. Inicialmente, las lesiones pueden ser hipopigmentadas y parecer un vitiligo, incluso con eritema inicial; luego aparece la despigmentación de la piel y, posteriormente, se establece la esclerosis y la atrofia de los tejidos afectados. A veces pueden llegar a presentar una hemiatrofia facial (síndrome de Parry-Romberg).

Con respecto a la morfea generalizada, en la literatura se puede encontrar que se la considera cuando las placas se van diseminando y confluyen unas al lado de las otras tomando una mayor parte del tegumento cutáneo. 

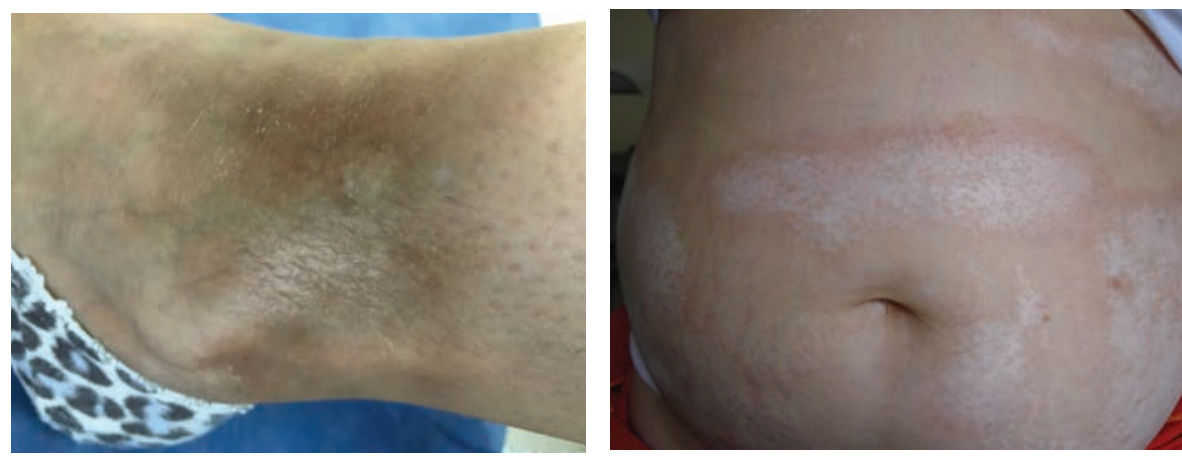

Figura 8.10. Esclerodermia localizada: morfea en placas. Es una esclerosis localizada con lesiones circunscritas a ciertas zonas de la piel que se ha llamado 'esclerosis en placas'.

\section{Esclerosis sistémica}

La esclerosis sistémica puede ser difusa o limitada a la piel y, en algunas ocasiones, no aparece la alteración cutánea y se habla de esclerosis sin esclerodermia.

La esclerosis sistémica se presenta limitada a la piel o con compromiso del tubo digestivo. Cuando solo compromete la piel, puede aparecer una piel indurada, engrosada y esclerosada, con zonas de calcinosis, fenómeno de Raynaud y telangiectasias y, por esta razón, se ha acuñado una sigla que recuerda que solo se limita a la piel y se conoce como síndrome CRST (calcinosis, Raynaud, esclerosis y telangiectasias) y si, además, compromete el tubo digestivo, y específicamente la motilidad del esófago, se dice que tiene un CREST, es decir, se agrega una E intermedia para hablar del compromiso esofágico.

Se ve, entonces, que la esclerosis puede estar limitada a la piel, razón por la cual se le llamó 'esclerodermia'; se inicia con el compromiso de las partes distales de las extremidades, asociada al fenómeno de Raynaud; tiene un curso crónico y lento, y puede generar esclerodactilia y cursar con úlceras en los dedos.

Es 15 a 20 veces más frecuente que la variedad difusa, la cual es sistémica y progresiva y compromete toda la piel; se inicia en las regiones centrales del cuerpo, con cambios hipopigmentarios en las extremidades en las que se observan parches de tipo 'sal y pimienta' (figura 8.11), debido a que se observan zonas hipopigmentadas alternando con una hiperpigmentación en una piel esclerosa. Tiene un curso rápido si es de la variedad difusa, de uno a cuatro años, y puede estar ausente el fenómeno de Raynaud, con presencia de telangiectasias, calcinosis tardía, haciéndose notoria 
la disminución de la apertura bucal en el rostro con un aumento de rágades a nivel peribucal y el aspecto de 'cara de pájaro'. La morbilidad y la mortalidad están dadas por el compromiso de otros órganos: el digestivo, el renal, el cardiaco o el pulmonar.

A nivel periungular, se pueden observar las alteraciones de los capilares que se encuentran en la matriz ungular las cuales se pueden observar con un estereoscopio o un dermatoscopio, pero, idealmente, debe practicarse una capilaroscopia. Se pueden encontrar en pacientes con artritis reumatoidea, esclerosis sistémica, dermatomiositis y esclerodermia (23).

El fenómeno de Raynaud puede, también, acompañar otras enfermedades del colágeno, el lupus eritematoso sistémico y, posiblemente, más la enfermedad mixta del tejido conjuntivo y se encuentran lesiones similares en la arteriosclerosis grave, la tromboangeítis obliterante o en el síndrome de Buerger por tabaquismo, secundario a la ingestión de derivados de la ergotamina o en trabajadores con exposición al cloruro de vinilo utilizado en la fabricación de PVC, que se pueden confundir con un fenómeno de Raynaud.
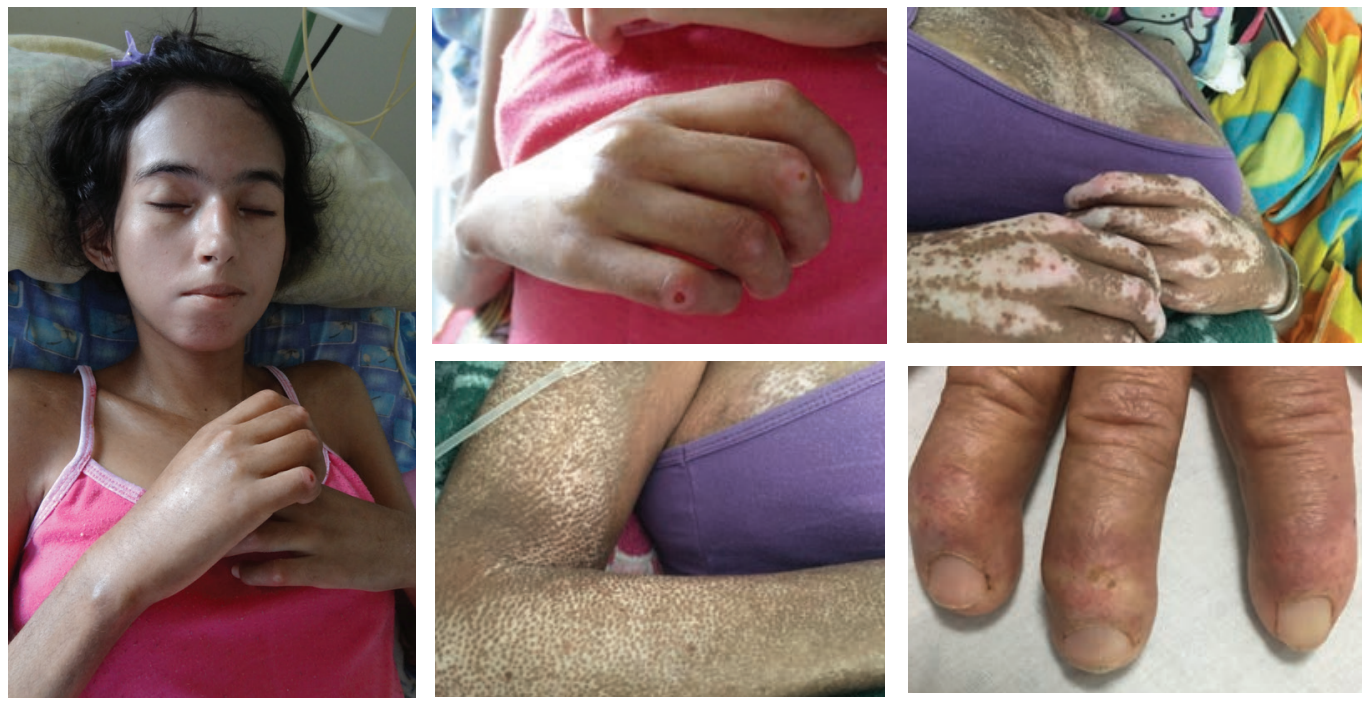

Figura 8.11. Esclerodermia difusa. La esclerosis sistémica difusa puede comprometer de manera generalizada todo el cuerpo y ser de rápida evolución, con aparición de lesiones de tipo 'sal y pimienta', con zonas más pigmentadas que alternan con zonas hipopigmentadas.

La esclerosis sistémica tiene un curso rápido si es de la variedad difusa, de uno a cuatro años y puede estar ausente el fenómeno de Raynaud, con presencia de telangiectasias, calcinosis tardía, haciéndose notoria la disminución de la apertura bucal en el rostro con un aumento de rágades a nivel peribucal y el aspecto de 'cara de pájaro. 


\section{Dermatomiositis}

La dermatomiositis es una enfermedad inflamatoria sistémica de origen autoinmunitario, con una mayor frecuencia en individuos HLA-B8 o -B14; se caracteriza por la presencia de alteraciones inflamatorias en la piel y en el músculo estriado.

Su expresión clínica es de una gran variabilidad; algunos pacientes presentan solamente lesiones de piel, y se ha llamado dermatomiositis sine miositis o amiopática; otros tienen concomitantemente lesiones en la piel y en el músculo, la más de las veces, y otros sólo tienen alteración muscular y en otras casuísticas se las considera como polimiositis.

Nosotros consideramos las tres alternativas de alteraciones en este cuadro llamado dermatomiositis. La incidencia de dermatomiositis-polimiositis es de 1 a 10 casos por millón de habitantes, afectando más a las mujeres que a los hombres en una relación 2 a 1 (24).

Existen dos variedades: la llamada juvenil, con una mayor incidencia de los 5 a los 15 años, y la del adulto, entre los 30 y los 50 años. Son dos entidades un poco diferentes: la juvenil hace parte de estas enfermedades del tejido conjuntivo, mientras que en la del adulto, dada la frecuente asociación con diferentes tumores, la hace una entidad distinta, siendo, en muchos casos, un síndrome paraneoplásico en 20 a $25 \%$ de los pacientes, asociado a diferentes neoplasias de ovario, pulmón, sistema gastrointestinal, mama o linfomas (25).

El cuadro se caracteriza en ambos casos por una miopatía inflamatoria con dolor y debilidad muscular proximal y simétrica de la cintura escapular y pélvica, que se manifiesta con dificultad para peinarse o cepillarse los dientes, para sujetarse o aprehenderse de la barra del bus, para levantarse del piso o de una silla, o para bajar y subir escaleras. Se presenta con elevación de las enzimas musculares séricas, cambios electromiográficos característicos y cambios inflamatorios en la biopsia de músculo, que es el mejor método para confirmar la miopatía inflamatoria, acompañados de lesiones cutáneas patognomónicas.

Estos criterios fueron propuestos por Bohan y Peter en 1975 (26). En la dermatomiositis juvenil, se refieren lesiones semejantes a las de los nudillos de las manos en los codos y en las rodillas; las complicaciones más frecuentes en los niños son las calcificaciones, las vasculitis y la paniculitis. En algunos grupos de investigación se cree que, si en la dermatomiositis del adulto se presenta un cuadro de vasculitis, se puede incrementar el riesgo de una neoplasia subyacente (27). El grupo de trabajo en dermatomiositis juvenil del Reino Unido e Irlanda recomienda incluir 
la resonancia magnética para miositis como un nuevo método diagnóstico (28). De igual manera, se están proponiendo nuevos criterios diagnósticos y abordajes serológicos más precisos para una mayor comprensión del proceso (29).

\section{Lesiones cutáneas}

En la dermatomiositis, las lesiones de la piel que se consideran signos patognomónicos de la enfermedad son el compromiso de la piel del dorso de los dedos de la mano, en las uniones interfalángicas -llamado pápulas de Gottrony el compromiso de la piel alrededor de los párpados, que se encuentra con una coloración violácea o eritemato-violácea, ligeramente edematosa, llamado 'eritema en heliotropo' por semejarse a la flor de ese color.

Esta coloración eritemato-violácea puede extenderse a otras zonas expuestas a la luz, como la región malar y frontal, la nuca, las regiones laterales de cuello, la $\mathrm{V}$ del escote, el tercio superior de la espalda, los hombros y la cara dorsal de las extremidades superiores; se ha llamado signo del chal o de la estola; de forme similar, se puede encontrar una coloración eritemato-violácea en las regiones laterales de los muslos, llamado signo de la funda de la pistola (holster). Las lesiones de la piel pueden parecerse a los cambios generados por la exposición crónica a la luz solar, es decir, una poiquilodermia, y se pueden confundir con una fotosensibilidad o una quemadura solar.

Las llamadas 'pápulas de Gottron' son un signo que describió Gottron al observar en la piel unas lesiones máculo-papulares eritematosas brillantes (30), con puntos atróficos en puntillado, localizadas en el dorso de las regiones metacarpofalángicas e interfalángicas de los dedos de las manos (nudillos) (figura 8.12). También se puede presentar un eritema con telangiectasias e hiperqueratosis cuticular en las regiones periungulares. Estas dilataciones o tortuosidades de los capilares en los pliegues ungulares son un indicador de la microangiopatía funcional. Las lesiones por fotosensibilidad pueden parecer inicialmente una quemadura solar, pero la asociación con las lesiones cutáneas descritas y algún indicio de compromiso muscular debe alertarnos.

Esta alteración de los capilares puede parecerse a la alteración periungular de la esclerosis sistémica, y puede presentarse una calcinosis, al igual que en el síndrome CRST, con mayor frecuencia en la variedad juvenil; también se reporta una alopecia difusa al igual que en el lupus eritematoso sistémico y, en ocasiones, se presenta asociado el fenómeno de Raynaud, como si de alguna manera fueran síndromes de superposición. 

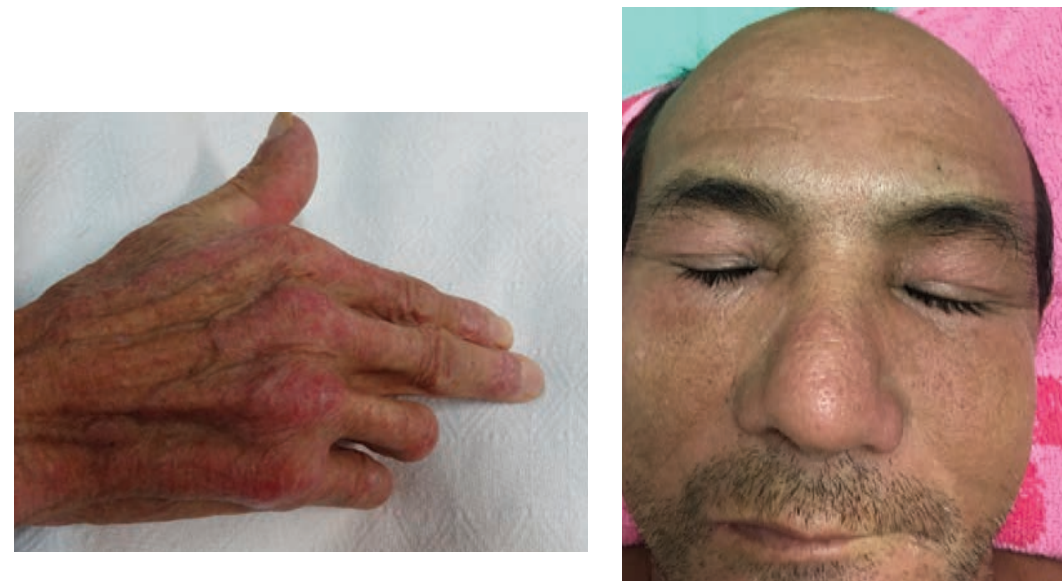

Figura 8.12. Dermatomiositis, pápulas de Gottron y eritema en heliotropo. En la piel del dorso de los dedos de la mano, aparecen unas lesiones llamado 'pápulas de Gottron', con lesiones máculo-papulares eritematosas brillantes con puntos atróficos en puntillado, localizadas en el dorso de las regiones metacarpofalángicas e interfalángicas de los dedos de las manos (nudillos). Además, se puede presentar un eritema en heliotropo de color violáceo en los párpados.

Se han reportado otras alteraciones como de enfermedad pulmonar de tipo neumonitis intersticial o por aspiración asociada a las alteraciones de motilidad del esófago que pueden presentarse y que también parecen lesiones por superposición pues son similares a las que se producen en los pacientes de esclerosis sistémica con la variedad CREST, por el compromiso de la deglución y del vaciamiento gástrico. De igual manera, se pueden encontrar algunas alteraciones secundarias a la vasculitis en la mucosa oral y presentar compromiso articular. Las asociadas al compromiso cardiaco son raras y de mal pronóstico.

Existen diferentes estadísticas que reportan disímiles porcentajes en cuanto a la frecuencia de asociación entre el cáncer y la dermatomiositis. Se dice que del 10 al $50 \%$ de los pacientes con dermatomiositis tienen o tendrán una neoplasia (25). En estos casos, la aparición de las lesiones suele ser más abrupta y evoluciona más rápidamente.

Se detectan autoanticuerpos en el $90 \%$ de los casos, algunos tendrán ANA positivos, los específicos de miositis, dirigidos a las enzimas que participan en la síntesis de proteínas; se detectan del 35 al $40 \%$ de los casos y, recientemente, se han correlacionado ciertos de ellos con diferentes fenotipos de dermatomiositis. Entre los anticuerpos específicos para la miositis, los más importantes son los anticuerpos antisintetasa, anti-amino-acetil-t-ARN sintetasa (anti-tARN sintetasa), de los que se han descrito cinco tipos (incluyendo Jo-1) y presentan enfermedad pulmonar 
intersticial, artritis, fenómeno de Raynaud y manos de mecánico. Los pacientes con anticuerpos anti-Mi-2 se asocian a dermatomiositis, tanto juvenil como del adulto, con los hallazgos clásicos en la piel y un pronóstico favorable. Los recientemente descritos, TIF1-y y NXP-2, pueden marcar a los adultos con alto riesgo de presentar neoplasias (31). El anti-MDA-5 (CADM-140) puede estar asociado a la enfermedad amiopática (32). El anti-PM/Scl y el anti-Ku parecen ser específicos para los pacientes que hacen una superposición entre la esclerosis y la dermatomiositis, llamada escleromiositis. Los anti-Jo1 se suelen encontrar cuando existe compromiso respiratorio en los pacientes con polimiositis importante en la dermatomiositis (33).

\section{Enfermedad mixta del tejido conjuntivo o síndromes de superposición o enfermedad indiferenciada}

Se menciona esta variedad clínica porque en muchas ocasiones se pueden encontrar pacientes con manifestaciones clínicas o de laboratorio de alguna de las tres enfermedades descritas previamente de manera simultánea. Quizá, por alguna razón que puede ser más genética, esto sucede.

Es una enfermedad sistémica de origen autoinmunitario con características clínicas de diferentes enfermedades del tejido conjuntivo, llamado también síndrome de Sharp, que lo describió en 1972 para referirse a la existencia de pacientes, generalmente del sexo femenino, con presencia de fenómeno de Raynaud, edema y acroesclerosis, sinovitis, miositis, con anticuerpos positivos a titulaciones altas anti-proteínas ribonucleares con un patrón moteado a la inmunofluorescencia (34). Otras casuísticas han asociado la afectación renal.

Si bien se ha descrito el fenómeno de Raynaud en pacientes con esclerosis sistémica, lupus eritematoso sistémico y dermatomiositis, sin hablar de enfermedad mixta del tejido conjuntivo, este concepto quizá permita entender que pueda llamarse así a la enfermedad que tienen los pacientes que presentan una mezcla de diferentes manifestaciones de lupus eritematoso sistémico, esclerosis sistémica, dermatomiositis, e incluso hallazgos de artritis reumatoidea o de un síndrome de Sjögren.

\section{Síndrome de Sjögren}

La enfermedad de Sjögren también puede presentar manifestaciones en la piel de tipo vasculitis, además de las alteraciones de las glándulas lacrimales y salivales. 
El síndrome de Sjögren es una enfermedad sistémica autoinmunológica, caracterizada por la presencia de xeroftalmía y xerostomía debido a una infiltración linfoide que lesiona las glándulas exocrinas (35).

Puede ser primario en el $50 \%$ de los casos, o asociarse a otras enfermedades autoinmunitariass en cuyo caso se llama secundario. El síndrome de Sjögren primario tiene una prevalencia aproximada de 0,5 a $1 \%$ en la población general y es más frecuente en las mujeres que en los hombres (9:1); sus picos de presentación son la tercera y la quinta década de la vida.

El síndrome de Sjögren secundario se asocia a artritis reumatoidea, lupus eritematoso sistémico, esclerosis sistémica, dermatomiositis y cirrosis biliar primaria. Los criterios para su diagnóstico incluyen la clínica de síntomas oculares (ojo seco y sensación de cuerpo extraño), síntomas orales (boca seca e inflamación glandular) y la confirmación por examen oftalmológico y evidencia gammagráfica o por biopsia del compromiso de la glándula salival, acompañado de positividad de anticuerpos antinucleares (ANA positivos) y de las variedades específicas de ENA de tipo SS-A/ SS-B. Algunos pacientes presentan también sequedad de la piel.

Se consideran algunos criterios para excluir este diagnóstico: antecedentes de radioterapia para linfoma de cabeza y cuello, sarcoidosis, infección por virus de la hepatitis $\mathrm{C}$ y virus de la inmunodeficiencia humana, reacción de injerto frente a huésped y la ingestión de medicamentos anticolinérgicos.

A pesar de que se considera un fenómeno excluyente el hecho de tener infección por hepatitis C, existe la posibilidad de que la asociación entre hepatitis $\mathrm{C}$ y síndrome de Sjögren tenga más relevancia de la que parece en cuanto a que este virus puede ser, al menos en algunas personas, el desencadenante del síndrome de Sjögren (36), ya que se sabe que muchos factores, incluidos los virus, pueden desencadenar estas enfermedades autoinmunitarias en personas predispuestas genéticamente.

Se pueden presentar otras lesiones en la piel, relacionadas con una vasculitis leucocitoclásica, y el paciente puede presentar una púrpura palpable con lesiones papulosas elevadas con coloración púrpura con extravasación de sangre en el centro o dejando la marca de la lesión elevada cuando va desapareciendo; es más frecuente en los miembros inferiores. Estos pacientes, al parecer, tienen una mayor probabilidad de presentar lesiones pulmonares o del sistema nervioso central que los que no la presentan; como se mencionó anteriormente, algunos presentan cuadros intermedios entre el lupus eritematoso sistémico y el síndrome de Sjögren, y los anticuerpos de diferente naturaleza nos ayudan en la clasificación. 
También puede presentarse una urticaria, que puede ser simple o de vasculitis; entiéndase como simple la aparición de elementos eritematosos, papulares y edematosos que se presentan diariamente con una duración máxima de veinticuatro horas a lo largo de todo el tegumento cutáneo. Si cada elemento dura más de 24 horas y empieza a tener un aspecto hemorrágico, se trata de una urticaria por vasculitis, que debe ser estudiada en todos los casos. A diferencia de la simple que, en caso de prolongarse por más de seis a ocho semanas, se establece que tiene una urticaria crónica y el paciente debe ser estudiado por la posibilidad de presentar diferentes tipos de procesos, desde infecciosos con enfermedades de tipo viral, bacterianas o parasitarias, hasta enfermedades autoinmunitariass como en las enfermedades tiroideas o en el síndrome de Sjögren (37).

Si el paciente con síndrome de Sjögren presenta infiltrados pulmonares de tipo nodular, crecimiento parotídeo persistente y adenomegalias, debe sospecharse un linfoma de células B (35).

\section{Artritis reumatoidea}

La artritis reumatoidea es una enfermedad inflamatoria de las articulaciones caracterizada por una sinovitis progresiva, erosiva y destructiva (38). En el $70 \%$ de los casos se detecta elevación del factor reumatoideo circulante. Algunos pacientes presentan manifestaciones extraarticulares, como son los nódulos reumatoideos, la epiescleritis, la fibrosis pulmonar, el hiperesplenismo (si, además, hay artritis y leucopenia, constituye el síndrome de Felty), y vasculitis leucocitoclásica en la piel (39). Estos pacientes que presentan un mayor grado de vasculitis parecen tener asociado el antígeno de histocompatibilidad HLA-DR4.

\section{Lesiones cutáneas}

Las lesiones cutáneas más frecuentes en la artritis reumatoidea corresponden a la vasculitis de pequeños vasos y pueden ser de diversa índole, desde lesiones muy pequeñas de $0,2 \mathrm{~cm}$ de diámetro, hasta lesiones más graves, que al ocluir el vaso evidencian una vasculitis necrosante (40). Estas se presentan como lesiones máculo-papulares hemorrágicas, purpúricas, dolorosas, que afectan los pulpejos de los dedos o que aparecen en las extremidades inferiores. También se pueden encontrar telangiectasias en las regiones periungulares o lesiones de tipo eritema elevatum diutinum, o lesiones de vasculitis leucocitoclásica granulomatosa rica en células plasmáticas y tejido fibrótico, presentes como placas infiltradas eritematosas en las rodillas y en los codos.

En esta y en otras enfermedades articulares se pueden presentar úlceras distales de características similares a las arteriales y, en otros casos, unas úlceras de 
crecimiento rápido que ya se describieron, asociadas en el $74 \%$ de los casos a las enfermedades inflamatorias intestinales, más frecuentemente a la colitis ulcerativa que a la enfermedad de Crohn. Se les llaman pioderma gangrenoso (figura 8.13), cuyas lesiones comienzan como una pústula estéril que progresa rápidamente a una úlcera dolorosa de tamaño y profundidad variables de bordes eritemo-violáceos, con fondo granulomatoso y exudado hemorrágico o necrótico, que pueden ser únicas o múltiples, y suelen acompañarse de síntomas generales (fiebre, mialgias, artralgias).

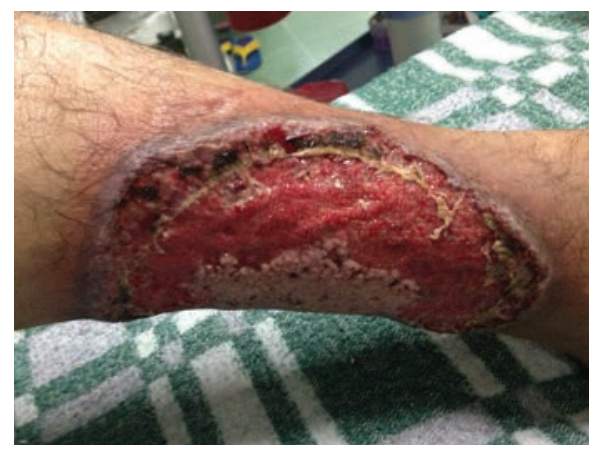

Figura 8.13. Pioderma gangrenoso en la artritis reumatoidea. Las lesiones de pioderma gangrenoso comienzan como una pústula estéril que progresa rápidamente a una úlcera dolorosa, de tamaño y profundidad variables, de bordes eritema-violáceos, con fondo granulomatoso y exudado hemorrágico o necrótico, que pueden ser únicas o múltiples, y suelen acompañarse de síntomas generales (fiebre, mialgias, artralgias).

Ocurren comúnmente en los miembros inferiores (región pretibial), aunque pueden presentarse en otros sitios; también tienen una tendencia a ubicarse en las zonas de trauma. Pueden verse en otras enfermedades reumatológicas, como la osteoartritis, la artritis psoriásica, las artritis seronegativas, la espondilitis y el lupus eritematoso sistémico y también en enfermedades mieloproliferativas. Los nódulos reumatoideos se presentan en el $20 \%$ de los casos con lesiones elevadas induradas que deforman el tejido blando aledaño a la articulación y se presentan en las manos y en los codos (figura 8.14).

Las vasculitis cutáneas asociadas a las enfermedades del tejido conjuntivo suelen ser granulomatosas, comprometiendo los vasos de mediano calibre; en algunas ocasiones, se caracterizan por una inflamación angiocéntrica $y$, en otros casos, la inflamación acompaña la vasculitis necrosante. 

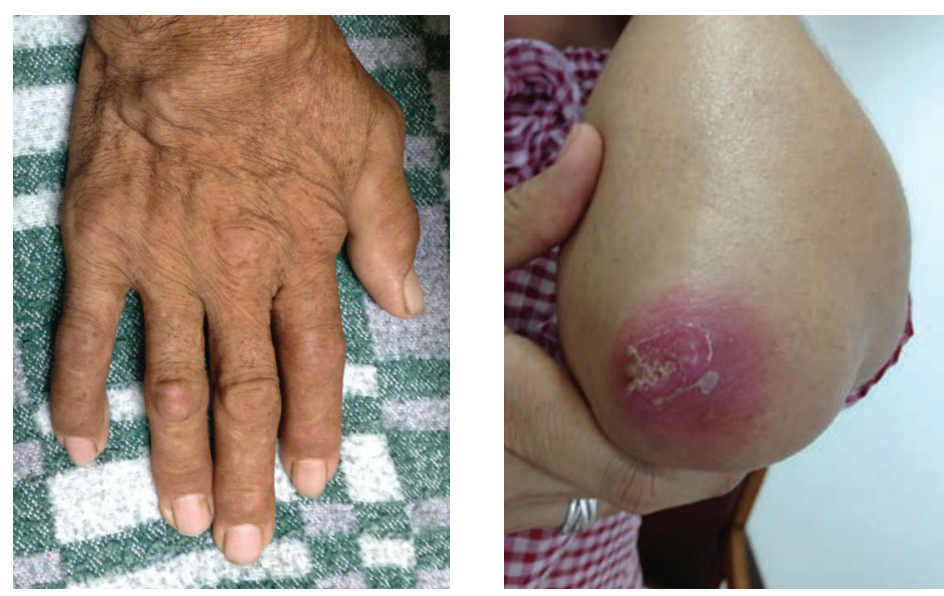

Figura 8.14. Artritis reumatoidea, nódulos reumatoideos en manos y en codos. Los nódulos reumatoideos se presentan en el $20 \%$ de los casos, con lesiones elevadas e induradas que deforman el tejido blando aledaño a la articulación y se presentan en las manos y en los codos.

\section{Síndrome de anticuerpos antifosfolípido}

El síndrome de anticuerpos antifosfolípido es una trombofilia autoinmunitaria adquirida, en la cual aparecen autoanticuerpos dirigidos contra los fosfolípidos aniónicos o las proteínas que se unen a los fosfolípidos (41). Estos anticuerpos están dirigidos principalmente contra la beta 2-glucoproteína I, presente en las células endoteliales, los monocitos, las plaquetas y los trofoblastos. Fue descrito como entidad separada por Harris y Hugues en 1980 (42) para asociar las trombosis múltiples, los abortos a repetición, la trombocitopenia y el livedo reticularis. Los anticuerpos antifosfolípido pueden aparecer como una enfermedad primaria o acompañando a una enfermedad del tejido conjuntivo, como sucede en el lupus eritematoso sistémico, la enfermedad mixta del tejido conjuntivo, el síndrome de Sjögren y otras colagenopatías; también acompaña algunas infecciones agudas y crónicas.

Los fenómenos trombóticos venosos y arteriales recurrentes, la aparición de abortos espontáneos a repetición secundarios a la trombosis de los vasos placentarios y la trombocitopenia son las expresiones más importantes de este síndrome. Entre los fenómenos trombóticos, la trombosis venosa profunda de las extremidades inferiores es la manifestación más común y afecta hasta el $50 \%$ de los pacientes. Se pueden presentar trombosis arteriales; el sitio más comprometido es el sistema nervioso central con accidentes cerebrovasculares, ataques isquémicos transitorios o infarto agudo de miocardio. Debe sospecharse cuando el paciente presente concomitantemente un livedo reticularis en la piel (figura 8.16). Puede presentarse también una hipertensión pulmonar. 


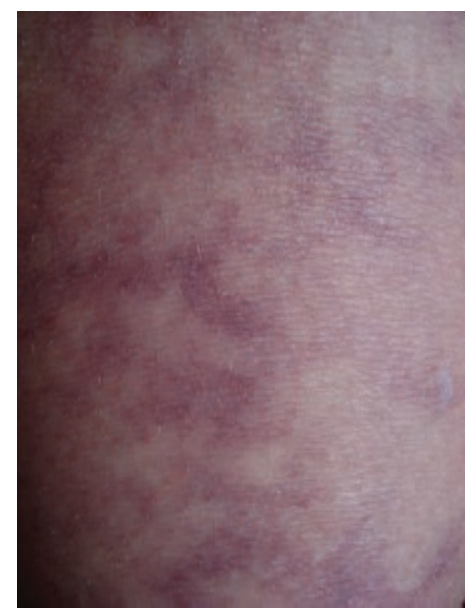

Figura 8.15. Livedo reticularis. Se manifiesta con lesiones eritemato-violáceas que siguen los trayectos vasculares y se visualizan a través de la piel; se conoce como livedo reticularis debido a la distribución y al color.

La prevalencia de anticuerpos antifosfolípido es muy variable, dependiendo de la población en estudio. La presencia de anticoagulante lúpico positivo puede estar presente en 1 a $5 \%$ de la población sana y en $0,3 \%$ de las mujeres embarazadas. Cuando se encuentre en una paciente con lupus eritematoso sistémico la presencia de abortos recurrentes, la frecuencia de positividad de anticuerpos antifosfolípido aumenta al $30 \%$. La incidencia de trombosis en los pacientes con lupus eritematoso sistémico y síndrome de anticuerpos antifosfolípido es del $30 \%$.

Además del lupus eritematoso sistémico, existen otras enfermedades asociadas a la presencia de los anticuerpos antifosfolípido, como son la artritis reumatoide, y la exposición a fármacos como la clorpromacina, las fenotiacinas, la procainamida y algunos antibióticos. Se han encontrado en infecciones virales -incluido el sida-, bacterianas o fúngicas y en neoplasias.

En el síndrome de anticuerpos antifosfolípido encontramos presentes anticuerpos anticardiolipinas y el anticoagulante lúpico positivo; por esta razón, los pacientes pueden tener una serología de tipo VDRL falsa positiva. Otros anticuerpos antifosfolipído son el antifosfatídico, el antifosfatidilcolina, el antifosfatidilserina y el antifosfatidilinisitol. Dado que la patogénesis primaria de este síndrome es la trombosis, el tratamiento es la anticoagulación.

La manifestación cutánea más importante del síndrome de anticuerpos antifosfolípido es el livedo reticularis; se describen fenómenos oclusivos debido a las trombosis distales con dedos azules. 
Como se ha visto, es muy frecuente la presencia de vasculitis leucocitoclásica en todas estas enfermedades autoinmunitarias revisadas, pero para tener un enfoque más preciso, debe ser claro que en el mayor porcentaje de los casos se asocian a lupus eritematoso sistémico (10 al 56 \%), le sigue el síndrome de síndrome de Sjögren (5 al 25\%) o lo que se ha llamado superposición lupus eritematoso sistémico-síndrome de Sjögren (33 \%); luego, la enfermedad mixta del tejido conjuntivo (10 al $33 \%$ ) y, finalmente, la artritis reumatoidea (1 al $20 \%$ ) (40).

Cuadro 8.1 Lupus eritematoso sistémico, Criterios del American College of Rheumatology modificados en 2012

\section{Once criterios clínicos}

1. Lupus cutáneo agudo
Erupción malar del lupus
Lupus ampolloso
Necrólisis eritematosa tóxica, variante de lupus eritematosos sistémico
Erupción maculopapular
Erupción por fotosensibilidad (sin diabetes mellitus)
Lupus subagudo cutáneo (psoriasiformes y anulares policíclicas)

2. Lupus cutáneo crónico

Lupus eritematoso discoide clásico: localizado o generalizado

Lupus hipertrófico (verrugoso)

Paniculitis lúpica

Lupus mucoso

Lupus eritematoso tumidus

Lupus pernio

Lupus discoide-liquen plano, superposición

3. Úlceras orales (paladar, boca, lengua o nariz)

4. Alopecia difusa no cicatricial

5. Artritis: sinovitis que involucre dos o más articulaciones caracterizadas por hinchazón, efusión o dolor en dos o más articulaciones y, al menos, 30 minutos de rigidez matutina.

6. Serositis, pleural y de pericardio

7. Compromiso renal: relación proteína-creatinina ( $\geq 500 \mathrm{mg}$ de proteína en 24 horas) o presencia de cilindros eritrocitarios

8. Compromiso neurológico: delirio (estado agudo de confusión), convulsiones, psicosis, mononeuritis, mielitis, neuropatía periférica o craneal

9. Anemia hemolítica

10. Leucopenia (menos de $4.000 / \mathrm{mm}^{3}$ ) o linfopenia (menos de $1.000 / \mathrm{mm}^{3}$ )

11. Trombocitopenia $\left(\right.$ menos de $\left.100.000 / \mathrm{mm}^{3}\right)$. 


\section{Seis criterios inmunológicos}

1. ANA positivos

2. Anticuerpos anti-ds DNA mayores del rango de referencia del laboratorio (o mayor 2 veces el rango de referencia en caso de prueba ELISA)

3. Anti-Sm: presencia de anticuerpos contra el antígeno Sm nuclear

4. Anticuerpos antifosfolípido positivos determinados con resultado positivo para anticoagulante lúpico o presencia de VDRL falso positivo, títulos medios o altos de anticuerpo anticardiolipina ( $\operatorname{IgA}$, $\operatorname{IgG}$ o $\operatorname{IgM}$ ), resultados positivos para anti $\beta 2$-glucoproteína I (IgA, IgG o IgM)

5. Complemento bajo: $\mathrm{C} 3, \mathrm{C} 4$ o $\mathrm{CH} 50$

6. Coombs directo positivo en ausencia de anemia hemolítica

\section{Referencias}

1. Rodnam GP, editor. Compendio de las enfermedades reumáticas. Primera edición. Barcelona: Sociedad Española de Reumatología, Arthritis Foundation; 1977.

2. Klemperer P. The concept of collagen diseases. Am J Pathol. 1950;26:505-19.

3. Wilson W, Gharavi A, Koike T, Lockshin MD, Branch DW, Piette JC, et al. International consensus statement on preliminary classification criteria for definite antiphospholipid syndrome. Arthritis Rheum. 1999;42:1309-11.

4. Garrod AB. The nature and treatment of gout and rheumatic gout. London: Walton and Maberly; 1859.

5. Smith CD, Cyr M. The history of lupus erythematosus. From Hippocrates to Osler. Rheum Dis Clin North Am. 1988;14:1-14.

6. Cervera R, Khamashta MA, Font J, Sebastiani GD, Gil A, Lavilla P, et al. Systemic lupus erythematosus: Clinical and immunologic patterns of disease expression in a cohort of 1,000 patients. Medicine (Baltimore). 1993;72:113-24.

7. Hochberg MC. Updating the American College of Rheumatology revised criteria for the classification of systemic lupus erythematosus. Arthritis and Rheumatism. 1997;40:1725.

8. Petri M, Orbai AM, Alarcón GS, Gordon C, Merrill JT, Fortin PR, et al. Derivation and validation of systemic lupus international collaborating clinics classification criteria for systemic lupus erythematosus. Arthritis Rheum. 2012;64:2677-86.

9. Kuhn A, Sticherling M, Bonsmann G. Clinical manifestations of cutaneous lupus erythematosus. JDDG. 2007;5:1124-37.

10. Helmick CG, Felson DT, Lawrence RC, Gabriel S, Hirsch R, Kwoh CK, et al. Estimates of the prevalence of arthritis and other rheumatic conditions in the United States: Part I. Arthritis and Rheumatism. 2008;58:15-25

11. Lee LA, Weston WL. Lupus erythematosus in childhood. Dermatol Clin. 1986;4:151-60.

12. Callen JP, Jorrizo JL, Bolognia J, Piette W, Zone J. Signos cutáneos de las enfermedades sistémicas. Cuarta edición. Barcelona: Elsevier; 2011. 
13. Albrecht J, Berlin JA, Braverman IM. Dermatology position paper on the revision of the ACR 1982 criteria for systemic lupus erythematosus. Lupus. 2004;13:839-49.

14. Gilliam JN, Sontheimer RD. Distinctive cutaneous subsets in the spectrum of lupus erythematosus. J Am Acad Dermatol. 1981;4:471-5.

15. Kuhn A, Herrmann M, Kleber S, Beckmann Welle M, Fehsel K, Martin Villalba A, et al. Accumulation of apoptotic cells in the epidermis of patients with cutaneous lupus erythematosus after ultraviolet irradiation. Arthritis Rheum. 2006;54:939-50.

16. Molina J, Molina J, Drenkard C, Cardiel M, Uribe O, Felipe O, et al. Systemic lupus erythematosus in 1,316 Latin American patients. A multicenter, binational study. Lupus. 1995;4(Supp.40):12430.

17. Duarte AF, Motta A, Pereira M, Baudrier T, Azevedo F. Rowell syndrome-case report and review of the literature. Dermatol Online J. 2008;14:15.

18. Roh EK, Vleugels RA, Hoang MP. Case records of the Massachusetts General Hospital. Case 392013. A 57-year-old woman with painful bullous skin lesions. N Engl J Med. 2013;369:2438-49.

19. Guevara-Pulido FO, Díaz-Cortés ME. Escleroderma. Acta Médica Colombiana. 2006;31:83-91.

20. Raynaud M. Local asphyxia and symmetrical gangrene of the extremities. London: New Sydenham Society; 1862.

21. Zapata K, García L. Fenómeno de Raynaud. Rev Asoc Colomb Dermatol. 2011;19:280-92.

22. Grarabrand DH, Dumas C. Epidemiology of organic solvents and connective tissue disease. Arthritis Research. 2000;2:5-15.

23. Fawcett RS, Linford S, Stulberg DL. Nail anormalities: Clues to systemic disease. Am Fam Physician. 2004;69:1417-24.

24. Restrepo JP, Medina LF, Molina M del P. Manifestaciones cutáneas de la dermatomiositis. Rev Asoc Colomb Dermatol. 2010;18:18-24.

25. Callen J, Wortmann R. Dermatomyositis. Clin Dermatol. 2006;24:363-73.

26. Bohan A, Peter F. Polymyositis and dermatomyositis. N Engl J Med. 1975;292:344-7.

27. Basset-Seguin N, Roujeau JC, Gherardi R, Guillaume JC, Revuz J, Torraine R. Prognostic factors and predictive signs of malignancy in adult dermatomyositis. A study of 32 cases. Arch Dermatol. 1990;126:633-7.

28. The Juvenile Dermatomyositis National Registry and Repository (UK and Ireland) clinical characteristics of children recruited within first 5 yr. Dermatomyositis Research Group. Rheumatology. 2006;45:1255-60.

29. Troyanov Y, Targoff IN, Payette MP, Raynauld JP, Chartier S, Goulet JR, et al. Redefining dermatomyositis. A description of new diagnostic criteria that differentiate pure dermatomyositis from overlap myositis with dermatomyositis features. Medicine (Baltimore). 2014;93:318-32.

30. Ricceri F, Prignano F. Gottron papules: A pathognomonic sign of dermatomyositis. CMAJ. 2013;185:148.

31. Fiorentino DF, Chung LS, Christopher-Stine L, Zaba L, Li S, Mammen AL, et al. Most patients with cancer-associated dermatomyositis have antibodies to nuclear matrix protein NXP-2 or transcriptional intermediary factor 1y. Arthritis and Rheumatism. 2013;65:2954-62.

32. Fiorentino D, Chung L, Zwerner J, Rosen A, Casciola-Rosen L. The mucocutaneous and systemic phenotype of patients with antibodies to MDA 5 (CADM-140): A retrospective study. J Am Acad Dermatol. 2011;65:25-34. 
33. Tanimoto K, Nakano K, Kano S MoriS, Ueki H, Nishitani H, et al. Classification criteria for polymiositis and dermatomyositis. J Rheumathol. 1995;22:668-74.

34. Sharp GE, Irving W, Tan E, Gould G, Holman H. Mixed connective tissue disease. An apparently distinct rheumatic disease síndrome associated with a specific antibody to an extractable nuclear antigen (ENA). Am J Med. 1972;52:148-59.

35. Díaz-Paul SC, Velásquez-Franco CJ, Pinto-Peñaranda LF, Márquez JD. Síndrome de Sjögren: revisión clínica con énfasis en las manifestaciones dermatológicas. Rev Colomb Reumatol. 2008;15:35-48.

36. Aceti A, Taliani G, Sorice M, Amendolea MA. HCV and Sjögren's syndrome. Lancet. 1992;339:1425-6.

37. Zuberbier T, Aberer W, Asero R, Bindslev-Jensen C, Brzoza Z, Canonica GW, et al. The EAACI/ GA(2) LEN/EDF/WAO Guideline for the definition, classification, diagnosis, and management of urticaria: The 2013 revision and update. Allergy. 2014;69:868-87.

38. Sayah A, English JC, 3rd. Rheumatoid arthritis: A review of the cutaneous manifestations. J Am Acad Dermatol. 2005;53:191-209.

39. Turesson C, Jacobson L, Bergström U. Extraarticular rheumatoid arthritis: Prevalence and mortality. Rheumatology. 1999;38:668-74.

40. Jorizzo JL, Daniels JC. Dermatologic conditions reported in patients with rheumatoid arthritis. J Am Acad Dermatol. 1983;8:439-57.

41. Harper B, Wills R, Pierangeli SS. Pathophysiological mechanisms in antiphospholipid syndrome. Int J Clin Rheumthol. 2011;6:157-71.

42. Harris EN, Hughes GRV. Antiphospholipid antibodies. In: McCarty DJ, editor. Arthritis and allied conditions. Philadelphia: Lea and Febiger; 1989. p. 1068-79. 


\section{Capítulo 9}

\section{Dermatosis paraneoplásicas}

Una vez que la humanidad ha controlado las enfermedades infecciosas y tiene más herramientas para el manejo de las enfermedades inflamatorias y autoinmunitarias, vemos cómo cada vez son más numerosos los individuos que presentan neoplasias malignas o cáncer. Existen reportes de la existencia de lesiones tumorales desde los tiempos remotos. Varias historias de la medicina se refieren a que este proceso está presente desde el antiguo Egipto y en India o se refieren a ella en los textos de Mesopotamia.

Se utilizó la palabra karkinos (cangrejo) para nombrar al cáncer (1). Los trabajos más recientes de la historia del cáncer tienen en cuenta conceptos que se originaron con Hipócrates en el siglo IV a. C. y los de John Hunter del siglo XVIII (2). El concepto, tal y como lo conocemos ahora, fue enunciado por Rudolph Virchow, quien habló del crecimiento descontrolado de las células y lo denominó 'neoplasia'.

En el estudio del Instituto Nacional de Cancerología se pone de relieve que su diagnóstico temprano es de suma importancia (3), si se tiene en cuenta que el cáncer presenta una mortalidad por neoplasias malignas de 157.017 en hombres y 162.310 en mujeres en Colombia para el periodo 2003-2012. Corresponde al 16,6 $\%$ de todas las muertes y es la tercera causa de muerte en hombres y la segunda en mujeres, con una tendencia estable a lo largo de los últimos años.

El Instituto Nacional de Cancerología publica periódicamente un libro sobre la incidencia, la mortalidad y la prevalencia del cáncer en Colombia. El último que cubre el periodo de 2007 a 2011 (4), reporta que, en Colombia, en general, el orden de frecuencia de los principales cánceres es el de mama, en primer lugar, seguido de los de próstata, cuello uterino, glándula tiroides, colon, recto y ano, estómago, ovarios y anexos, linfoma no Hodgkin, cuerpo del útero, tráquea, bronquios y pulmón.

Asimismo, se reporta que los tumores con mayor prevalencia para el departamento de Risaralda, en orden descendente, son: en primer lugar, el de mama, seguidos del de próstata, cuello uterino, colon, recto y ano, estómago, glándula tiroides, ovarios y otros anexos, cuerpo del útero, tráquea, bronquios y pulmón, y linfoma no Hodgkin. Como se puede apreciar, la situación del departamento 
de Risaralda es muy similar a la nacional, al menos, en los primeros tres tipos de cáncer más frecuentes. El de mama y el de próstata son los más prevalentes y los de estómago, tráquea, bronquios y pulmón están entre los primeros diez tumores más frecuentes.

En una de las últimas estadísticas de Pereira, se describe una serie de casos de cáncer en una institución oncológica de la ciudad en un periodo de 10 años (2001-2011) (5). En ese periodo, los cánceres que más generaron consultas fueron, en orden de frecuencia, los de mama, cuello uterino, próstata, estómago, bronquios y pulmón, colon, glándula tiroides, linfoma no Hodgkin difuso, recto y piel; también se reportan otros, como el de ovario y las leucemias linfoides. Cuando se evalúa la tendencia de los principales cánceres en la región, llama la atención el aumento significativo en los últimos tres años evaluados del cáncer de mama, el de próstata, el de cuello uterino y el de estómago.

Las primeras tres causas son las mismas que a nivel nacional, aunque el de estómago y el de bronquios y pulmón ocupan un lugar anterior a otras frecuencias y se menciona este hecho dado que los pacientes con cánceres de próstata, estómago, bronquios y pulmón pueden presentar dermatosis paraneoplásicas del tipo de exagerado crecimiento epidérmico con lesiones de tipo queratodermia punctata, queratodermia palmo-plantar, acrodermatitis de Bazex y acantosis nigricans.

Los tumores malignos constituyen un problema de gran relevancia en el perfil epidemiológico colombiano y, específicamente en el departamento de Risaralda; por esta razón esta revisión de alteraciones relacionadas con el desarrollo y crecimiento de los tumores malignos es de gran importancia.

Se sabe que los tumores malignos pueden producir sintomatología en su lugar de origen, pero, usualmente, cuando lo hacen el tumor ya es de gran tamaño y puede ser que haya dado metástasis. La meta que debemos tener como clínicos es la de ubicar el tumor lo más pequeño posible, ya que, si el diagnóstico se hace de manera temprana, se puede extirpar.

En la piel, se pueden encontrar lesiones tumorales propias de su estructura, como el carcinoma basocelular, el escamocelular o el epidermoide, el linfoma cutáneo de células $\mathrm{T}$ y el melanoma, pero, también, se pueden hallar metástasis de otros tumores con invasión de las células cancerosas a la dermis y al tejido celular subcutáneo y aparición de nódulos solitarios (figura 9.1) o metástasis en conglomerados rosados, eritematosos, violáceos o negruzcos, según sea la naturaleza del tumor primario (figura 9.2) (6). Además, se pueden presentar también como una infiltración directa de las células cancerígenas a la piel, como puede suceder en el 
cáncer de mama, o por la diseminación a través de los conductos que comunican la cavidad abdominal con el exterior a través del ombligo, como es el caso del nódulo de la hermana María José (Sister Mary Joseph nodule) (7), que semeja un granuloma telangiectásico y que está asociado frecuentemente a un carcinoma gástrico o a otros tumores intraabdominales (figura 9.3).

Se observa, también, que un tumor de la cavidad abdominal puede obstruir el drenaje linfático intraabdominal y producir linfedema, sobre todo si el tamaño de la lesión es exagerado y más si se encuentra hacia la parte baja de la cavidad abdominal. Este linfedema es notorio en el abdomen y en las extremidades inferiores, a veces en una de ellas más que en la otra, dependiendo de lo que comprima el tumor.

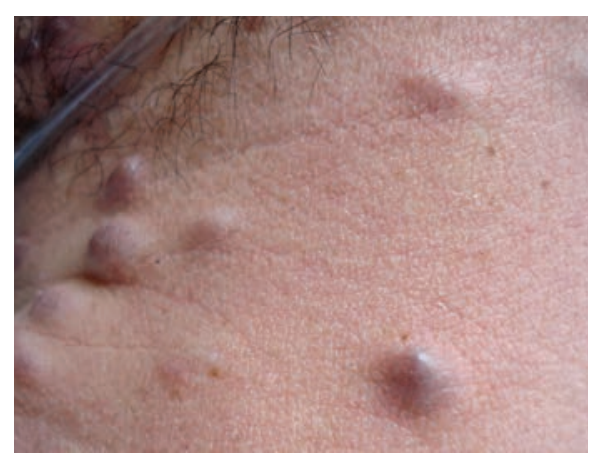

Figura 9.1. Nódulos solitarios

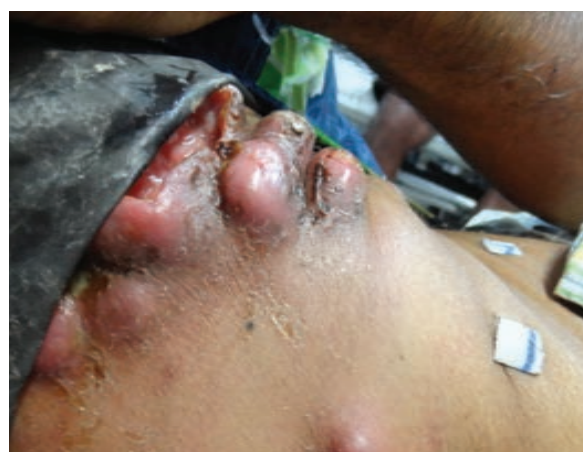

Figura 9.2. Metástasis en conglomerados 


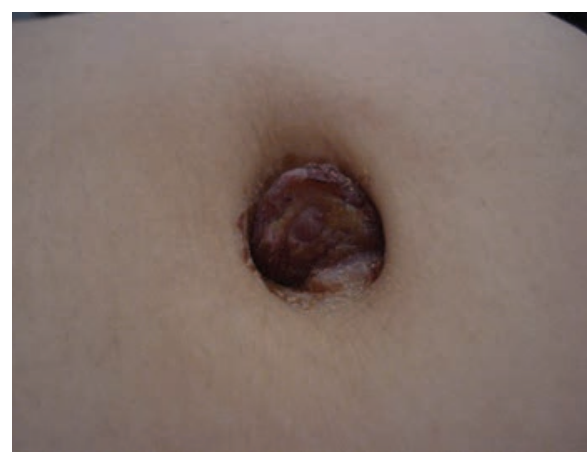

Figura 9.3. Nódulo de la hermana María José. En la piel, se pueden observar metástasis de otros tumores con invasión de las células cancerosas a la dermis y al tejido celular subcutáneo, con aparición de nódulos solitarios aislados o en conglomerados, algunos más profundos de diferente coloración -rosados, eritematosos, violáceos o negruzcos, según sea la naturaleza del tumor primario- y pueden ser sólidos o ulcerados.

Las lesiones metastásicas pueden provenir de diferentes regiones, por contigüidad en el caso de los de cánceres de mama, o a distancia, como los carcinomas gástrico o pulmonar, y a veces renal, que con frecuencia dan metástasis a cuero cabelludo y se manifiestan como tumoraciones exofíticas de naturaleza infiltrativa que se ulceran. Se han descrito metástasis a la punta de la nariz por los carcinomas de pulmón y en algunos casos de cáncer de mama; se ha visto que las metástasis semejan lesiones de tipo herpes zóster al tomar ciertos trayectos que más que neurológicos son linfangíticos (8) (figura 9.4).
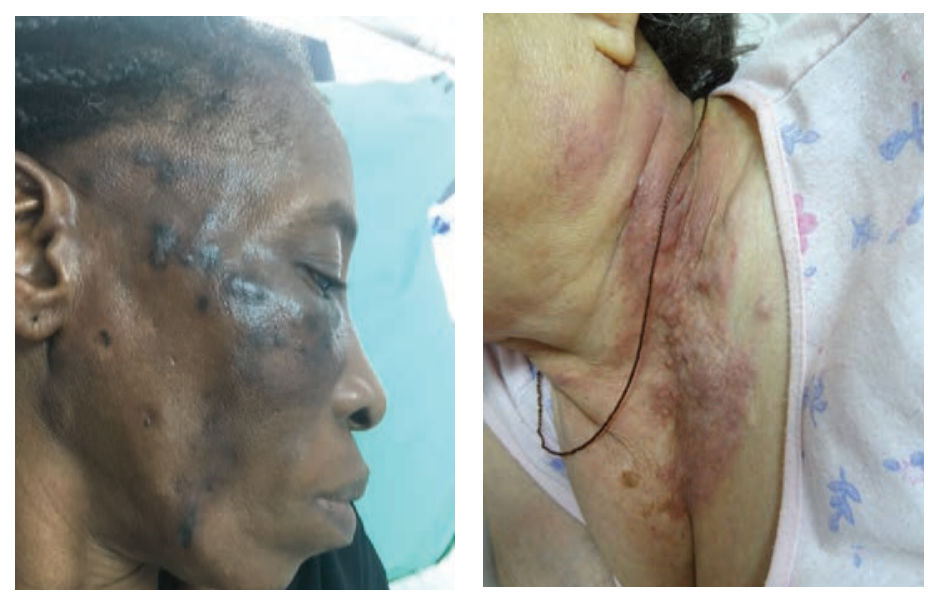

Figura 9.4. Carcinoma de mama, metástasis zosteriforme. También, se puede presentar como infiltración directa de las células cancerígenas a la piel como puede suceder en el cáncer de mama, o por diseminación linfática y semejar un herpes zóster. 
Nuestro objetivo es reconocer, no estas lesiones avanzadas, sino aquellas lesiones que aparecen de manera paralela al crecimiento del tumor y que nos pueden ayudan a hacer un diagnóstico más temprano, es decir, vamos a describir los llamados síndromes paraneoplásicos y, de manera más precisa, los cutáneos o dermatosis paraneoplásicas.

\section{Síndromes paraneoplásicos}

Se consideran como síndromes paraneoplásicas a las manifestaciones que aparecen acompañando el crecimiento de un tumor. Se presentan a distancia, de manera paralela al crecimiento del mismo, como lo postuló Helen Curth en 1943 (9). Es decir, son aquellas expresiones clínicas que hacen sospechar que el tumor interno se está desarrollando, de tal manera que su reconocimiento permite llegar a un diagnóstico temprano por medio de estas lesiones que se deben a que el tumor está emitiendo 'señales que transforman algunos tejidos del organismo', entre ellos la piel.

Estas señales pueden afectar el sistema nervioso y dar sintomatología neurológica; el sistema inmunitario, aumentando ciertas citocinas y dando origen a manifestaciones inflamatorias; el sistema endocrino, segregando sustancias semejantes a las hormonas con sus manifestaciones a causa de ello o con un aumento del calcio sérico. Es así que estos cambios se observan en la piel que es la suma de los tres sistemas: el neurológico, el inmunitario y el endocrino. En algunos casos, se produce un aumento de las células leucocitarias o de los mediadores de la inflamación y pueden aparecer leucocitosis, eosinofilia, granulocitosis, trombocitopenia o aplasia de eritrocitos (10), o inducir vasculitis (11) o fenómenos reactivos vasculares asociados al crecimiento tumoral. Entre ellos se reporta la urticaria por vasculitis, el eritema polimorfo, el síndrome de Sweet y el eritema nudoso. No se deben a la invasión del tumor en sí, ni a metástasis, sino que aparecen siguiendo el crecimiento del tumor.

Cuando comprometen la piel, se les llama 'dermatosis paraneoplásicas'. Se reportan en 7 a $15 \%$ de los tumores (12) y, a pesar de su baja frecuencia, es fundamental que el médico las conozca y pueda sospechar el inicio de la neoplasia e identificar precozmente las recidivas locales o las metástasis del tumor, ya que si se extirpa el tumor, estas dermatosis desaparecen, y si hay recurrencia del mismo, las lesiones reaparecen. Asimismo, se conoce que el $1 \%$ de los tumores presenta una lesión cutánea como primera manifestación.

Los tumores que producen el mayor número de manifestaciones dermatológicas son tres de los que se presentan con mayor frecuencia: el carcinoma 
gástrico, el bronquial y el pulmonar. Por consiguiente, con mayor razón se debe estar alerta ante estas manifestaciones dermatológicas.

\section{Dermatosis paraneoplásicas}

Los mecanismos de formación de estas dermatosis paraneoplásicas son la liberación de mediadores hormonales segregados por el tumor o la secreción directa de las sustancias del tumor.

Esta liberación de mediadores hormonales segregados por el tumor polipéptidos, citocinas, anticuerpos o sustancias que actúan como factores de crecimiento- influyen en el aumento de la producción del factor de crecimiento epidérmico y en la aparición de hiperqueratosis, acantosis o hiperplasia de toda la piel. Por otro lado, el aumento del factor de crecimiento epidérmico derivado de los fibroblastos, el factor de crecimiento tumoral a (TGFa) (13) y otros factores insulinoides de crecimiento como el IGF-1 (14) promueven el crecimiento de los tejidos. Otros tumores segregan o inducen factores semejantes a la hormona adrenonocorticoestimulante (ACTH) (15) o a la melanoestimulante (MSH), y producen un incremento del crecimiento de los queratinocitos, o un síndrome de Cushing ectópico y, a veces, puede aparecer hiperpigmentación focal (figura 9.5) o generalizada, como sucede en los carcinomas pulmonares de células pequeñas o en los carcinomas medulares de la glándula tiroides.

Como se puede ver, los síndromes paraneoplásicos están ligados a la secreción por parte del tumor de los factores estimulantes de crecimiento celular; por lo tanto, hay una relación entrelamasadel tumoryla cantidaddesustanciassegregadas, loqueexplica que cuando se presentan las manifestaciones cutáneas, el tumor ya es de importancia.

El primer reporte de un síndrome paraneoplásico fue hecho por Trousseau en 1825 (16), quien describió un aumento de la incidencia de trombosis venosa en pacientes con cáncer y, en 1890, Pollitzer y Janiuske describieron la acantosis nigricans como un signo cutáneo de una neoplasia interna (17). Poco a poco se fueron describiendo otras asociaciones (18), que no solo se manifestaban en la piel, sino que pueden presentar otro tipo de alteraciones neurológicas, hormonales o vasculares como la aparición de un rubor o enrojecimiento súbito asociado a síndromes carcinoides. 

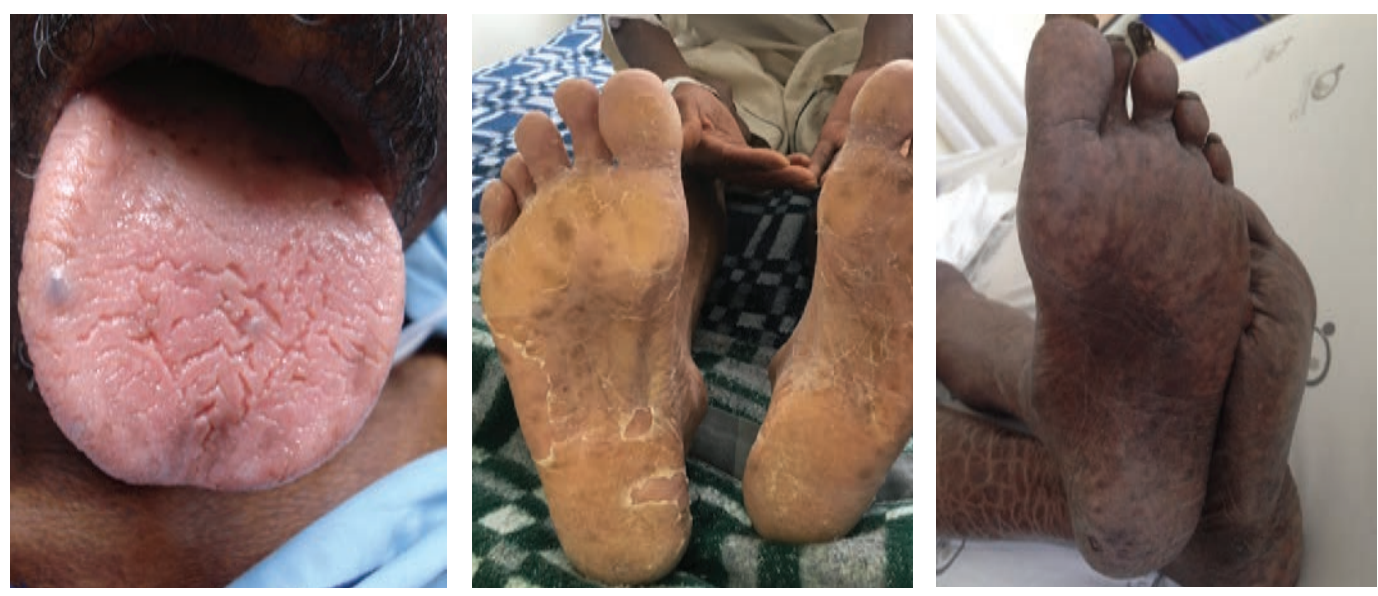

Figura 9.5 Hiperpigmentación, melanosis palmo-plantar. Algunos tumores secretan o inducen factores semejantes a la hormona melanoestimulante (MSH), produciendo un aumento de pigmentación, más notorio en palmas o plantas, que también puede observarse en mucosa oral o generalizada.

A continuación, se mencionan las principales expresiones paraneoplásicas que modifican la piel y los cánceres que más se relacionan con ellas.

\section{Dermatosis asociadas a la secreción directa de sustancias del tumor}

Las dermatosis paraneoplásicas se pueden asociar a la secreción directa de sustancias del tumor o a sustancias semejantes a la hormona adrenocorticotropina (ACTH) que pueden inducir un síndrome de Cushing paraneoplásico, también llamado síndrome de secreción ectópica de corticotropina (19). La secreción directa de las sustancias de tumores neuroendocrinos provenientes de la línea de células APUD (Amine Precursor Uptake and Decarboxylasa), pueden producir el síndrome carcinoide y son las responsables de la manifestación clínica, como sucede en los tumores provenientes de la línea de células neuroendocrinas conocidas como células de la vía precursora de la decarboxilasa de aminas ubicadas en el tracto digestivo, el pulmón, los bronquios y el ovario, que secretan gastrina, histamina, somatostatina, serotonina, sustancia $P$, péptido gastrointestinal, motilina, secretina, péptido $P$, enteroglucagón, péptido YY, 5-hidroxitriptamina o neurotensina, según de la zona de donde provenga el tumor. Producen el síndrome carcinoide con la aparición de síntomas vasomotores: rubor o enrojecimiento de aparición súbita, sudoración o con manifestaciones como dolor abdominal con diarrea o ataques severos de disnea.

Musich afirma que el término karzinoide fue introducido en 1907 por Oberndorffer para describir una clase morfológica distinta del tumor intestinal con 
un comportamiento menos agresivo que los típicos adenocarcinomas intestinales. En 1890, Ranson lo describió por primera vez; reportó la presencia de un tumor en el íleon con metástasis hepáticas en una mujer de 50 años que sufría de "dolor posprandial con diarrea, distensión abdominal, caquexia y ataques severos de disnea" (20).

Se trata de un grupo heterogéneo de neoplasias que comparten aspectos biológicos característicos y se los puede considerar como una entidad común. Se originan en las células neuroendocrinas, tienen características secretoras y, con frecuencia, se presentan con síndromes de hipersecreción. Estas células se hallan distribuidas difusamente en el organismo: páncreas endocrino, glándulas paratiroides, glándulas suprarrenales, hipófisis, células tiroideas productoras de calcitonina y células argentafines derivadas del tubo digestivo primitivo (causantes de tumores carcinoides). Debido a su afinidad de tinción se las ha denominado 'cromafines' o 'argentafines'. Se distinguen por su capacidad para producir sustancias peptídicas, que se almacenan en las vesículas de neurosecreción. Se reconocen más de 100 péptidos bioactivos diferentes. Los mensajeros hormonales más frecuentes son: la gastrina, la histamina, la somatostatina, la serotonina, la sustancia $\mathrm{P}$, el péptido gastrointestinal, la motilina, la secretina, el péptido $\mathrm{P}$, el enteroglucagón, el péptido YY y la neurotensina.

Los tumores que se derivan de estas células producen diferentes sustancias: gastrina, GRP, calcitonina, polipéptido pancreático, ACTH, CRH, GHRH, somatostatina y glucagón. La cromogranina $\mathrm{A}(\mathrm{CgA})$ es el producto común de secreción y su determinación se utiliza para el seguimiento de la enfermedad neoplásica neuroendocrina. Se destaca que las células neuroendocrinas, tanto las normales como las hiperplásicas, presentan frecuentemente en la superficie celular receptores para la somatostatina, brindando la posibilidad de practicar una centellografía diagnóstica y administrar el tratamiento necesario.

La secreción de sustancias semejantes a la hormona adrenocorticotropina $(\mathrm{ACTH})$, inducen un síndrome de Cushing paraneoplásico, también llamado 'síndrome de secreción ectópica de corticotropina', ya que su secreción no proviene del hipotálamo, ni se presenta por la secreción de corticoides de la glándula suprarrenal, sino que el aumento de la hormona se deriva del crecimiento de las células tumorales.

Del total de pacientes que presentan un síndrome de Cushing, del 5 al 10 \% están asociados a una neoplasia, y del 50 al 60\% de ellos, a tumores pulmonares neuroendocrinos (10). En estos pacientes, cuando presentan un síndrome de Cushing, no hay alteración de la redistribución de la grasa, lo que ayuda en el diagnóstico diferencial. Algunos tipos de cáncer pueden acompañarse de melanosis, 
una hiperpigmentación en parches o difusa relacionada con el crecimiento tumoral y cuyo responsable es el incremento de la hormona melanoestimulante (MSH). Sucede especialmente en el cáncer pulmonar de células pequeñas.

En los tumores de páncreas, dependiendo del tipo de células afectadas, puede aparecer una paniculitis cuando existe una enfermedad pancreática inflamatoria o tumoral, como en el adenocarcinoma, por la liberación de enzimas pancreáticas, como la lipasa y la tripsina, o se puede presentar un eritema necrolítico migratorio relacionado con la liberación de glucagón por parte de las células $\beta$ tumorales del páncreas en el glucagonoma (21).

En el mieloma secretor de inmunoglobulinas de cadena liviana que se depositan en lengua, corazón, tracto digestivo, nervios y piel, puede aparecer una amiloidosis, en la que se encuentra una macroglosia o lesiones periorbitarias de color púrpura como uno de los signos más característicos (figura 9.6). También se puede encontrar simultáneamente un pioderma gangrenoso o un síndrome de Sweet.

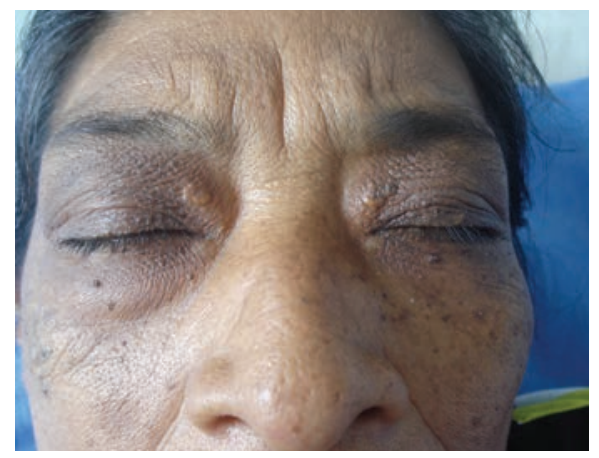

Figura 9.6. Amiloidosis, lesiones pardo-purpúria palpebrales. En el caso de un mieloma secretor de inmunoglobulinas de cadena liviana que se depositan en lengua, corazón, tracto digestivo, nervios y piel, puede aparecer una amiloidosis, en la que se puede encontrar una macroglosia o lesiones periorbitarias de color púrpura, como uno de los signos más característicos.

El crecimento de tumores está relacionado con el aumento de los factores estimulantes del crecimiento epidérmico lo cual genera una hiperqueratosis o una hiperplasia cutánea, como se puede apreciar en las siguientes dermatosis paraneoplásicas. A continuación, se describen las lesiones más frecuentes, divididas según el tipo de elemento que se encuentra aumentado, que es el responsable directo de la manifestación cutánea. 


\section{Dermatosis con alteraciones de la queratinización, o hipertrofia epidérmica}

La acantosis nigricans es una condición en la que se observa una hiperpigmentación junto con un engrosamiento epidérmico, más notorio en los pliegues. La piel engrosada e hiperpigmentada tiene un aspecto aterciopelado dado por la hipertrofia del tejido que se torna elevado y se percibe con una consistencia más suave, localizado principalmente en la nuca, las axilas y las ingles; a veces se hace visible en las areolas, el ombligo, las regiones perianal y glútea e, incluso, en los nudillos, en el dorso de las manos, en los codos y en las rodillas (figura 9.7).

Es diferente de la acantosis nigricans benigna que se asocia con la resistencia a la insulina (14), con obesidad, o a ciertas enfermedades de carácter hereditario o a ciertos fármacos (22). En la acantosis nigricans maligna se encuentra un compromiso mucoso y palmo-plantar, por lo tanto, estas características se deben tener en cuenta para distinguir una acantosis nigricans maligna de una benigna. El inicio después de los 40 años de edad, el compromiso extenso y serio, las lesiones en mucosas (figura 9.7) y las lesiones palmo-plantares hacen pensar en una neoplasia.

En el $84 \%$ de los casos, la acantosis nigricans se asocia a un adenocarcinoma de la cavidad abdominal (23). Del 69 al $75 \%$ de los casos se asocian a un adenocarcinoma gástrico. En la estadística de Curth se encontró que el $69 \%$ de los casos correspondía a un carcinoma gástrico, el resto a carcinomas de útero, hígado, intestino, colón, recto u ovarios (24).

Las palmas engrosadas con aspecto de 'tripa', se refiere al aumento de los surcos o dermatoglifos; se presenta en el $90 \%$ de los casos de carcinoma gástrico o pulmonar con acantosis nigricans en el $75 \%$ de los casos. Estos pacientes pueden tener palmas engrosadas con aspecto de 'tripa' y aumento de los surcos (figura 9.8), que puede ser la expresión palmo-plantar de la misma acantosis nigricans (25).

Lo mismo sucede con la aparición de pequeñas lesiones elevadas que engruesan e hipertrofian el tejido mucoso lingual, gingival y labial, como parte del síndrome de acantosis nigricans de tipo maligno, llamada papilomatosis oral múltiple diferente de las lesiones de tipo verrugoso de la enfermedad de Heck (inducidas por los virus papova) (26). La papilomatosis oral es una acantosis nigricans en las mucosas y se presenta en el $30 \%$ de los casos.

La hiperqueratosis palmo-plantar o queratodermia palmo-plantar (figura 9.9) corresponde a un engrosamiento superficial de la piel, ya que solo la capa córnea está aumentada de grosor. El paciente parece tener unas finas láminas hiperqueratósicas que se van acumulando y semejan una gran callosidad difusa, mas no compacta, como resultado de una alteración de la queratinización. 

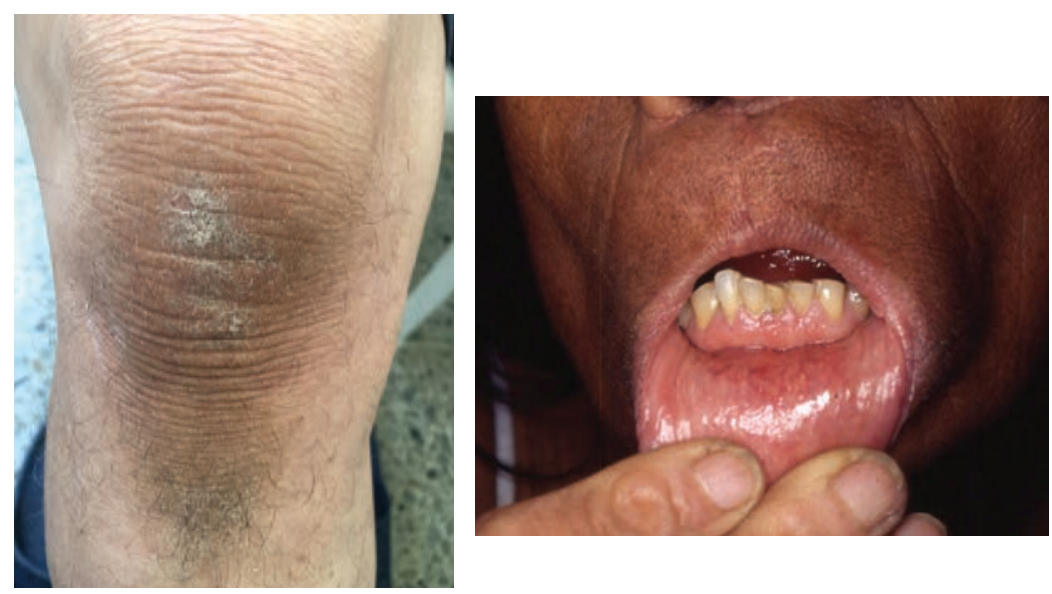

Figura 9.7 Acantosis nigricans, acantosis en superficies extensoras y papilomatosis en mucosas. En la acantosis nigricans asociada a tumores malignos, la piel engrosada e hiperpigmentada puede ser más notoria en los codos y en las rodillas, a veces, se puede hacer visible en las areolas, el ombligo, las regiones perianal y glútea, e, incluso, en los nudillos y en el dorso de las manos. El inicio después de los 40 años de edad, el compromiso extenso y serio, y las lesiones en las mucosas y palmo-plantares que hacen pensar en una neoplasia.

La queratodermia palmo-plantar se asocia al adenocarcinoma bronquial en el $70 \%$ de los casos. Puede asociarse también a otros tumores de esófago, gástricos, o pulmonares. El prototipo es el síndrome de Howel-Evans, un transtorno hereditario de carácter autosómico dominante con carcinoma de esófago de células escamosas, en el que se presenta engrosamiento palmo-plantar.

Cuando la queratodermia se presenta en la superficie palmar, puede verse generalizada o circunscrita a las prominencias óseas de las manos, en cuyo caso se ha hablado de 'palmas callosas' o 'manos de mecánico" (27) (figura 9.9).

En otros pacientes, la hiperqueratosis se presenta en zonas puntuales con aspecto queratósico y, a la vez, deprimido, que se ha llamado queratosis o queratodermia punctata; podría tratarse del signo más frecuente asociado a neoplasias, especialmente a adenocarcinoma, bronquial (28) o al de próstata (figura 9.10) 

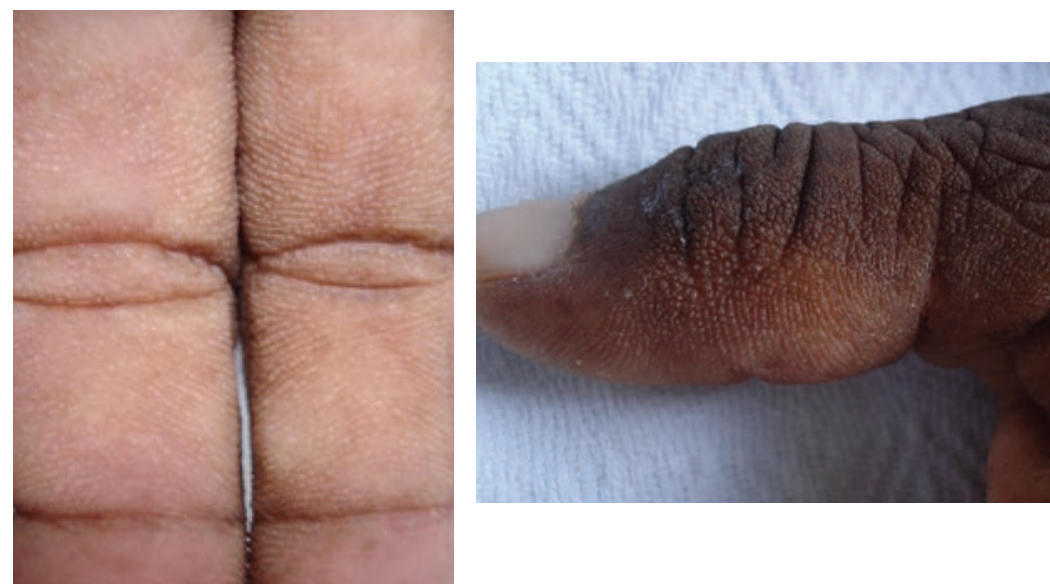

Figura 9.8. Manos con aspecto de tripa. Estos pacientes pueden tener palmas engrosadas con aspecto de 'tripa' y aumento de los surcos o dermatoglifos, que puede ser la expresión palmo-plantar de la misma acantosis nigricans. De la misma manera, la mucosa puede estar engrosada con la aparición de pequeñas pápulas hipertróficas.
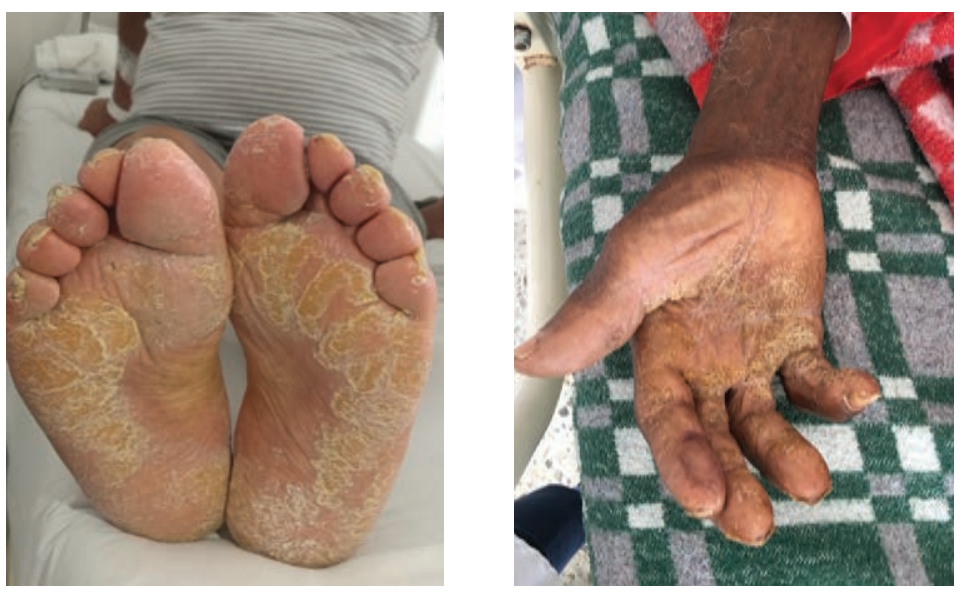

Figura 9.9. Queratodermia plantar y manos de mecánico. La queratodermia palmo-plantar, corresponde a un engrosamiento de la piel con una capa córnea aumentada de grosor. El paciente parecetener unas finas láminas hiperqueratósicas que se acumulan y semejan una gran callosidad difusa, mas no compacta, como resultado de un estímulo exagerado de crecimiento. La queratodermia que se presenta en las manos -a diferencia de la plantar que suele ser generalizada-suele verse circunscrita a las prominencias óseas de las manos, en cuyo se habla de 'palmas callosas' o 'manos de mecánico'. 

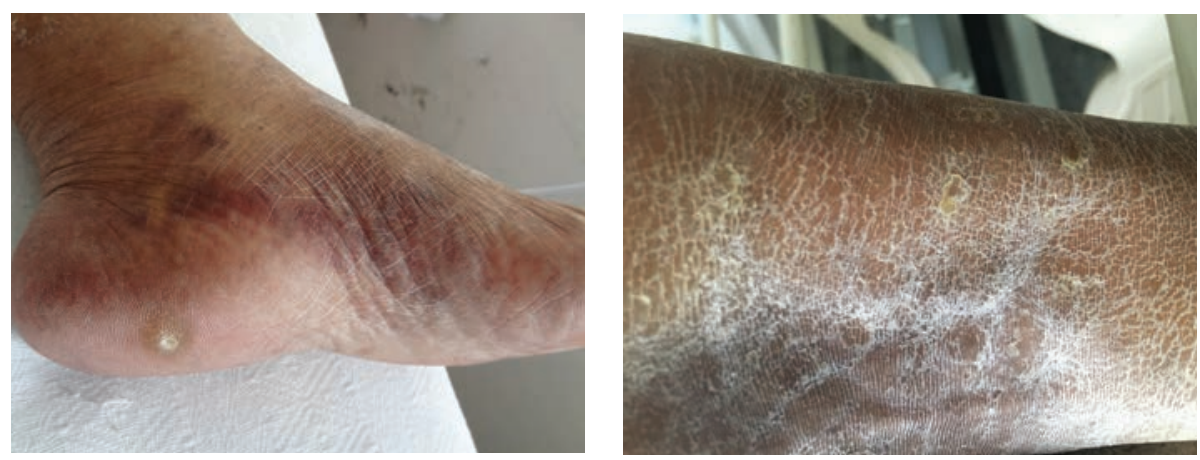

Figura 9.10. Queratodermia punctata. En otros pacientes, la hiperqueratosis se presenta en zonas puntuales con aspecto deprimido que se ha llamado queratosis o queratodermia punctata; podría tratarse del signo más frecuente asociado a neoplasias.

No se debe olvidar que las queratodermias y las queratodermias punctatas pueden hacer parte de otros trastornos de la queratinización y ser de naturaleza familiar, en cuyo caso aparecen desde temprana edad y no guardan relación con lo descrito. También se presentan engrosamientos de la capa córnea pero más superficiales en otros pacientes, como obesos, o con alteraciones hormonales, hipotiroideos, diabéticos o con psoriasis, en cuyo caso las placas eritemato-escamosas se deben distinguir de las de la queratodermia.

Otras alteraciones de la queratinización pueden ser variantes de un proceso similar que altera la formación normal de la piel, como la acroqueratosis paraneoplásica o sindrome de Bazex (29), que se manifiesta con lesiones eritematosas de aspecto hiperqueratósico, con descamación o escamas, que aparece de manera simétrica en las regiones distales del cuerpo, afectando las manos y los pies y, a veces, las uñas con engrosamientos, en ocasiones puede verse lesiones descamativas en la punta de la nariz y en el borde de los pabellones auriculares (figura 9.11).

La acroqueratosis paraneoplásica se puede presentar en el $100 \%$ de los carcinomas epidermoides de la cavidad oral, del tracto respiratorio superior de la parte superior del esófago.

El síndrome de Bazex es más frecuente en la raza blanca; en los hombres aparece alrededor de los 60 años de edad asociado a HLA A2, B8 y acompaña los carcinomas que afectan las vías aéreas superiores y el sistema digestivo superior. Aproximadamente, el $50 \%$ de las neoplasias se encuentran en la cavidad oral, la faringe y la laringe (30) y la mayoría corresponde a adenocarcinomas (31). Existen descripciones de asociaciones con adenocarcinomas de estómago, colon, sistema biliar y carcinoma hepatocelular. 

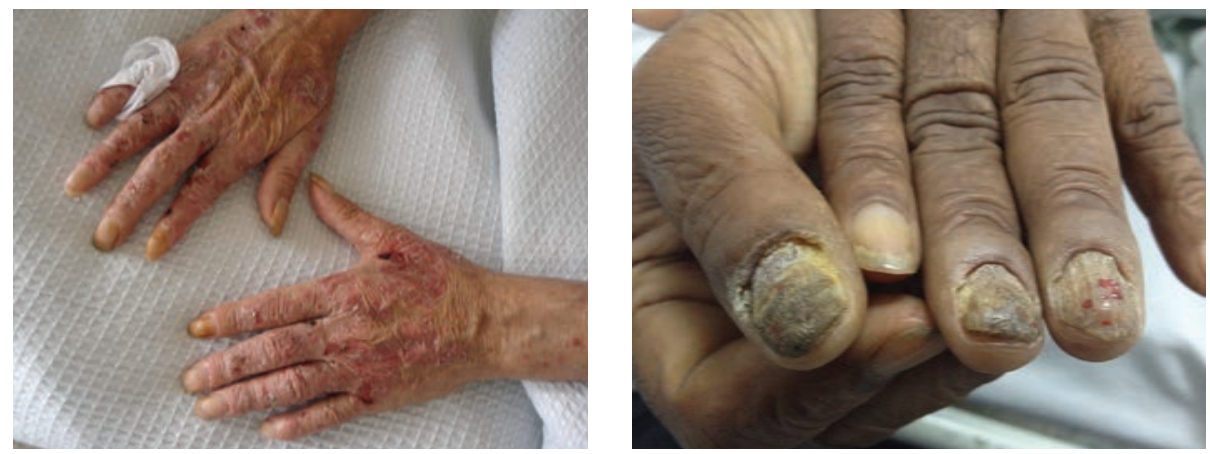

Figura 9.11. Síndrome de Bazex. Son lesiones eritematosas de aspecto hiperqueratósico, con descamación o escamas, que aparecen de manera simétrica en las regiones distales del cuerpo, afecta las manos o los pies y, a veces, las uñas, la punta de la nariz, el borde de los pabellones auriculares, los codos o las rodillas.

Si la alteración de la queratinización compromete la piel de manera generalizada, aparece como una ictiosis en la que se observa una sequedad extrema, como si la piel estuviese craquelada, se formaran figuras poligonales que recuerdan las escamas de pescado, llamada ictiosis adquirida. Se puede encontrar de manera generalizada o en parches, como ocurre en la llamada pitiriasis rotunda que aparece como si hubiera placas circulares de ictiosis en diferentes partes del cuerpo asociadas al crecimiento tumoral; se ha descrito en varios tumores, entre ellos el carcinoma de colon.

La ictiosis adquirida (figura 9.12) puede asociarse con el linfoma de Hodgkin en el $70 \%$ de los casos. No es fácil considerar este estado ictiosíforne en algunos pacientes emaciados y desnutridos, pues estos cambios xerodérmicos se pueden asociar con el déficit nutricional.
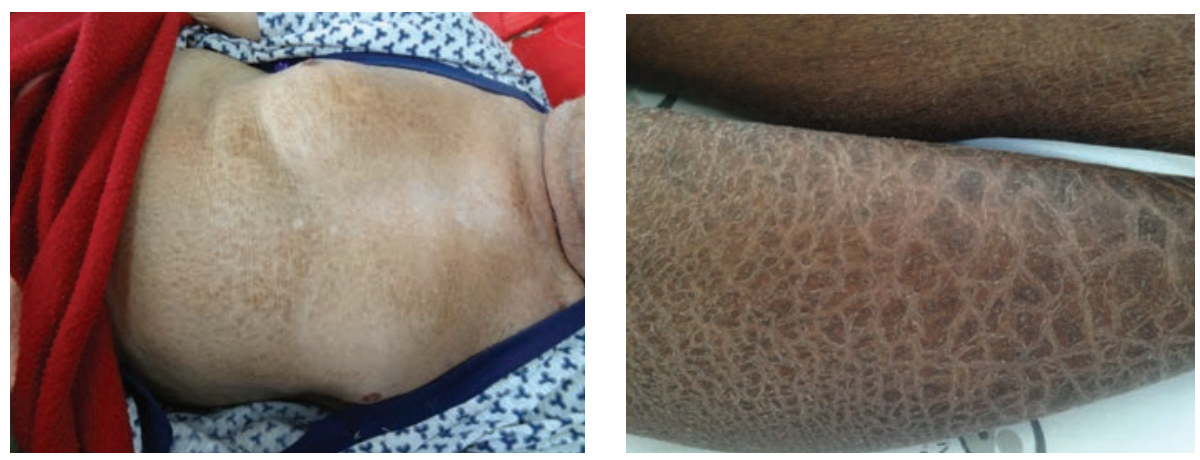

Figura 9.12. Ictiosis adquirida. Si la alteración de la queratinización compromete la piel de manera generalizada, aparece como una ictiosis en la que se observa una sequedad extrema, como si la piel estuviera craquelada,, se formaran figuras poligonales que recuerdan las escamas de pescado, llamada ictiosis adquirida. La ictiosis adquirida puede asociarse con el linfoma de Hodgkin en el $70 \%$ de los casos. 


\section{Dermatosis secundarias a hiperplasia cutánea}

Las alteraciones que se mencionaron anteriormente están relacionadas con alteraciones de la queratinización, o hipertrofia epidérmica, ahora nos referiremos a los cambios relacionados con la hiperplasia cutánea, es decir, ya no solo se encuentra una hiperqueratosis de la epidermis, sino que en estos síndromes la hiperplasia de la piel y sus anexos es mayor y forma verdaderas excrecencias o tumoraciones cuya característica es el rápido crecimiento, es decir, crecen en poco tiempo o aumentan de tamaño.

Pueden aparecer fibroepiteliomas, queratosis seborreicas (32), crecimiento exagerado del vello o aparición de lesiones tumorales benignas derivadas del folículo piloso o de la glándula sebácea con mayor frecuencia, ya sean benignas $\mathrm{u}$, ocasionalmente, malignas, como sucede en el carcinoma basocelular asociado a otras neoplasias.

El signo de Leser-Trélat son verrugas seborreicas eruptivas que se han reportado con adenocarcinoma gástrico, de vejiga o de útero. El síndrome de LeserTrélat fue descrito para referirse a queratosis seborreicas de aparición súbita o de manera eruptiva, de predominio en el tronco y en las extremidades, asociado a las neoplasias malignas internas (figura 9.13) (33).

Estas lesiones de tipo queratosis seborreicas pueden aparecer en la piel, lo hacen poco a poco, ya que se conoce que con el proceso del envejecimiento y la pérdida del control del crecimiento de las células al igual que con el proceso del encanecimiento que sucede de manera lenta, se va instaurando paulatinamente. Lo relevante en este caso es la aparición rápida, esto es lo que la asocia con el aspecto maligno.

En el síndrome de Leser-Trélat, la mayoría de los pacientes o, por lo menos, el $50 \%$ tiene adenocarcinomas, $32 \%$ de origen gastrointestinal, estómago, colon o recto $\mathrm{y}$, con menor frecuencia, de esófago, duodeno, páncreas, vejiga, útero o hepatocelular (34).

La papilomatosis cutánea florida con formación de fibroepiteliomas en el cuello y en los pliegues, es significativa si su aparición es rápida y con numerosas lesiones, como sucede con las queratosis seborreicas; es, entonces, cuando se debe sospechar la existencia de un tumor.

La hipertricosis lanuginosa adquirida se asocia en el $100 \%$ de los casos con un carcinoma de pulmón o de colon y recto. Se ha descrito un síndrome de aparición repentina y exagerado crecimiento de vello de tipo lanugo, delgado y descolorido, 
en el rostro y en el cuerpo, llamado hipertricosis lanuginosa adquirida asociado al carcinoma de mama, colorrectal o de pulmón.
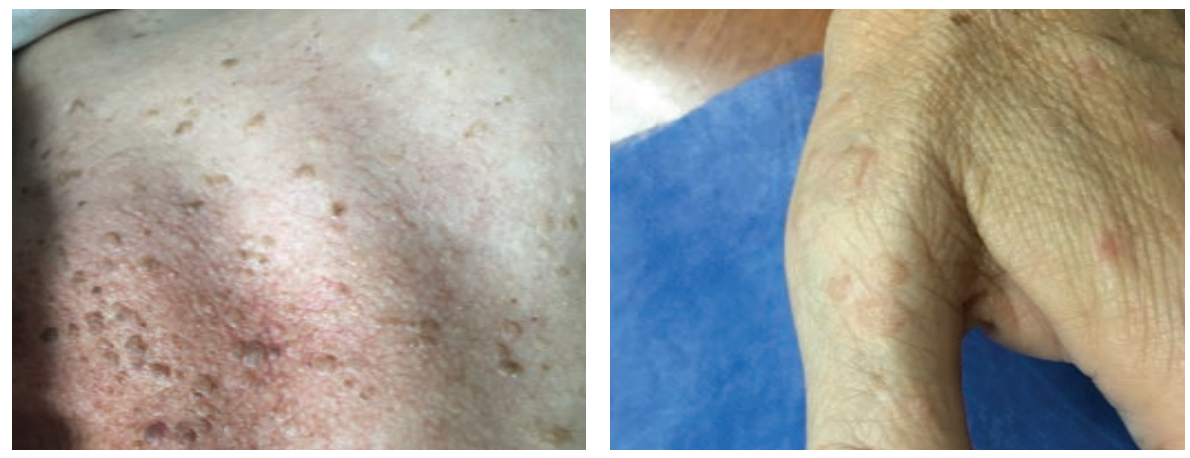

Figura 9.13. Signo de Leser Trélat. Fue descrito para referirse a la aparición de queratosis seborreicas de forma súbita o de manera eruptiva, con predominio en el tronco y en las extremidades, asociado con neoplasias malignas internas. Lo relevante en este caso es la aparición rápida, esto es lo que la asocia al proceso maligno.

La osteoartropatía hipertrófica con periostitis de los huesos largos, a veces con dedos en palillo de tambor se asocia en el $90 \%$ de los casos con carcinoma microcítico de pulmón, carcinoma broncogénico primario, mesotelioma y metástasis pulmonares.

En la osteoartropatía hipertrófica, o paquidermoperiostosis, también puede encontrarse un engrosamiento de la piel del cuero cabelludo y de la frente, de las manos y de los pies, concomitante con un engrosamiento de las estructuras óseas de las extremidades en las que, además, se observa periostitis de los huesos largos y, a veces, dedos en palillo de tambor. Se asocia con el carcinoma de pulmón (microcítico) en el $90 \%$ de los casos, o a un mesotelioma con metástasis a pulmón, o a un carcinoma broncogénico. (figura 9. 14)

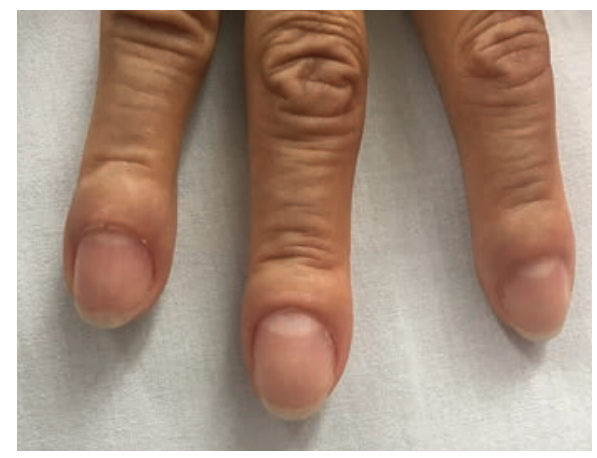

Figura 9.14. Dedos en palillo de tambor: osteoartropatía hipertrófica 


\section{Dermatosis secundarias a otras alteraciones inmunológicas y vasculares}

Estas dermatosis acompañan a otros tumores como sucede con la aparición de enfermedades autoinmunitarias, como la dermatomiositis, la esclerosis sistémica, el lupus eritematoso sistémico, o de enfermedades ampollosas, como el pénfigo vulgar conocido como paraneoplásico o el penfigoide ampolloso que acompañan a las neoplasias (35). El pénfigo paraneoplásico se asocia con linfomas, leucemias, macroglobulinemia o enfermedad de Castleman.

La dermatomiositis del adulto -con miositis, eritema en heliotropo y pápulas de Gottron-puede ser un síndrome paraneoplásico en 15 a $34 \%$ de los casos. Como ya se revisó en el capítulo anterior, es una entidad que puede comprometer simultáneamente o por separado la piel y el músculo (36).

La miopatía inflamatoria se presenta con debilidad muscular que compromete la cintura escapular y la pélvica. Las características lesiones de piel son una coloración eritemato-violácea en los párpados, descrita como eritema en heliotropo por su semejanza con la flor de ese color violáceo (figura 9.15a), acompañada de lesiones en las zonas expuestas a la luz. Se pueden extender al rostro, el cuello, la ' $V$ ' del escote, el tercio superior de la espalda, los hombros y las extremidades superiores; a primera vista, parecer como si fuera una quemadura solar (figura 9.15 b y c).

Asimismo, pueden aparecer unas lesiones máculo-papulares eritematosas, brillantes, con puntos atróficos en puntillado, localizadas en la piel de las regiones interfalángicas de los dedos de la mano (en los nudillos), llamado signo o pápulas de Gottron. Además, los pacientes pueden presentar alteraciones periungulares, con telangiectasias e hiperqueratosis.

En estos pacientes se encuentra una elevación de las enzimas musculares, creatinfosfocinasa (CPK), creatina, aldolasa, DHL. La electromiografía es anormal en los casos en los que hay miopatía y el diagnóstico de mayor precisión se hace con la biopsia de músculo en la que los cambios inflamatorios y la alteración del tejido muscular confirman el diagnóstico.

Los tumores más frecuentes asociados con la dermatomiositis son los adenocarcinomas; según cada población, puede haber diferencias en cuanto a frecuencia, de neoplasias del tracto gastrointestinal -colon y recto-, o de bronquio o pulmón (37), nasofaríngeo, páncreas, mama u ovario. 

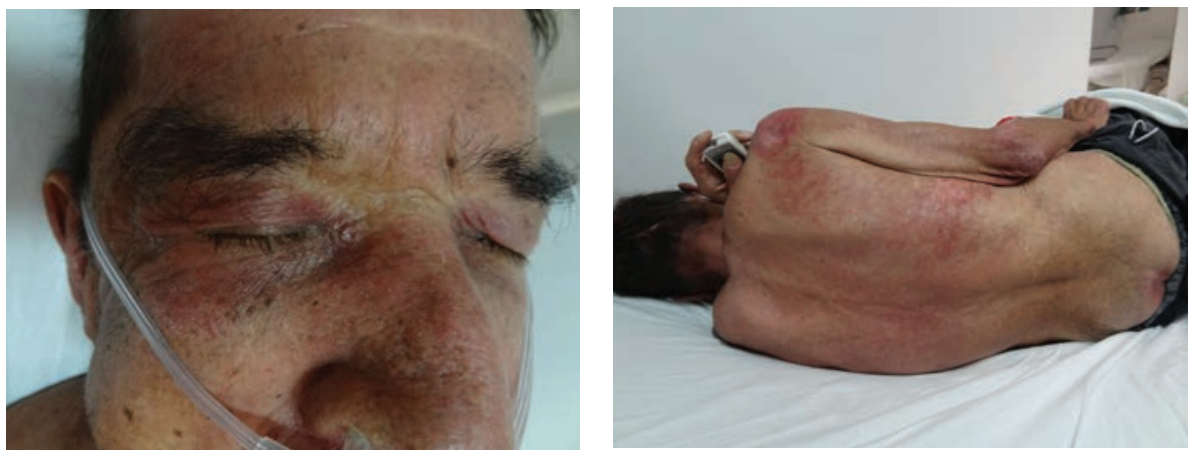

Figura 9.15. Dermatomiositis: a. eritema en heliotropo en los párpados. Las lesiones alrededor de los párpados tienen una coloración violácea, o eritemato-violácea ligeramente edematosa, llamada eritema en heliotropo por semejarse a la flor del heliotropo. b. signo del chal. Las lesiones de piel aparecen en las zonas expuestas a la luz y se pueden extender al rostro, las mejillas, la frente, las sienes, el cuello, la ' $\mathrm{V}$ ' del escote, el tercio superior de la espalda, los hombros y las extremidades superiores; a veces, casi como si fueran una quemadura solar.

En el síndrome CREST o en la esclerosis sistémica, se ha visto un aumento de la asociación con la anemia perniciosa, con la tiroiditis de Hashimoto, como enfermedad autoinmunitaria, y también se ha encontrado asociada a neoplasias, como el seminoma de ovario.

Las erupciones ampollosas que se describen en asociación con tumores malignos son los pénfigos, de naturaleza autoinmunitaria, en cuyo caso se encuentran anticuerpos dirigidos contra las plakinas en los queratinocitos (desmogleínas 1 y 3 , desmoplakina, periplakina, envoplakina u otros) y, por esta razón, se presenta la acantólisis o separación de las células que forman la ampolla.

El pénfigo paraneoplásico fue descrito por Anhalt, et al. (38), en 1990. Las lesiones se presentan en las mucosas y en la piel. Todas las mucosas suelen estar comprometidas: la oral, la faríngea, la conjuntival, la anogenital y la gastrointestinal, con lesiones ampollosas (figura 9.16). En la piel aparece una mezcla de lesiones hetereogéneas, ampollosas, con placas de color eritematoso y violáceo que pueden simular el eritema multiforme, el penfigoide ampolloso, el pénfigo vulgar, el liquen plano o variedades de expresión ampollosa y liquenoide (39).

El pénfigo se ha asociado a trastornos linfoproliferativos de las células B casi exclusivamente. Los linfomas no Hodgkin son los más frecuentes, seguidos por la leucemia linfocítica crónica, la macroglobulinemia de Waldenström y la enfermedad de Castleman. Se han descrito asociados a tumores como los timomas y aun a otros como los sarcomas. Se han descrito otras enfermedades ampollosas asociadas a neoplasias como el penfigoide ampolloso en el 5,8 \% de los casos. 

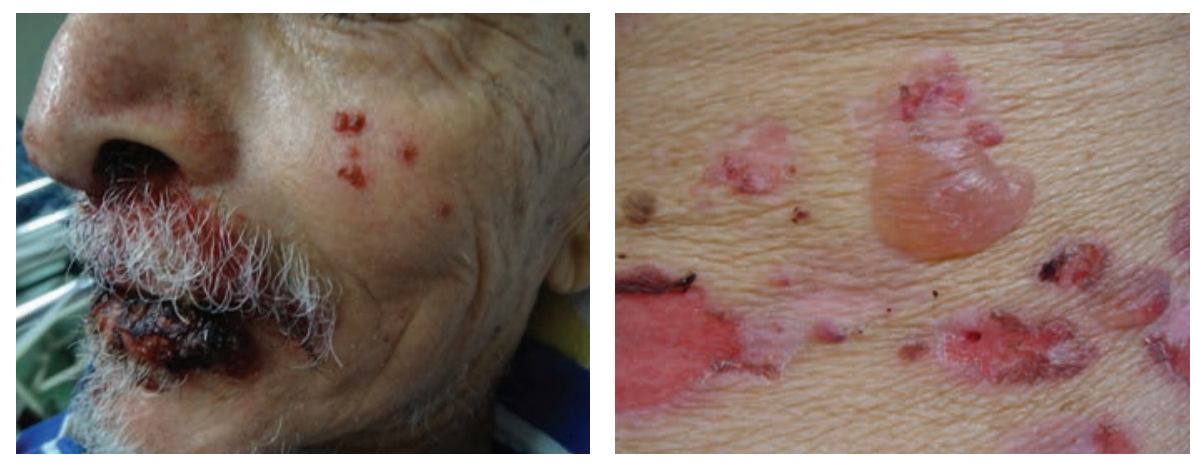

Figura 9.16. Pénfigo paraneoplásico. El pénfigo paraneoplásico fue descrito por Anhalt, et al., en 1990 Las lesiones se presentan en las mucosas y en la piel. Todas las mucosas suelen estar comprometidas: la oral, la faríngea, la conjuntival, la anogenital y la gastrointestinal, con lesiones ampollosas. En la piel aparece una mezcla de lesiones hetereogéneas, ampollosas, con placas de color eritematoso y violáceo que pueden simular el eritema multiforme, el penfigoide ampolloso, el pénfigo vulgar, el liquen plano o variedades de expresión ampollosa y liquenoide.

Se presentan, también, entre estas alteraciones inmunológicas y vasculares que acompañan a otros tumores, algunos fenómenos vasculares reactivos asociados a cánceres como la vasculitis leucocitoclásica (39), el eritema multiforme, los eritemas figurados, el eritema nudoso, el pioderma gangrenoso y el síndrome de Sweet.

Las lesiones de vasculitis pueden verse como una urticaria con lesiones edematosas urticantes, que persisten por más de 24 a 48 horas y pueden dejar fenómenos hemorrágicos o tener una zona central más púrpura, como en iris, o lesiones urticantes más eritematosas en la perifería.

El eritema multiforme que se ha descrito con lesiones de tipo diana, con dos coloraciones concéntricas, eritematosas, y centro más violáceo o ampolloso puede acompañar otros tumores o hacer parte de lo que se ha llamado 'pénfigo paraneoplásico’.

Se reconocen dos eritemas figurados asociados con las neoplasias, el eritema gyratum repens y el eritema necrolítico migratorio.

El eritema gyratum repens aparece con unas placas o lesiones eritematoedematosas en banda, que forman diferentes figuras en la piel del individuo que las presenta, como si las bandas giraran para cambiar de forma; aparecen anulares, onduladas o concéntricas y luego serpiginosas. De ese cambio de forma se deriva su nombre. Pueden parecer vetas de madera.

Esta entidad ha sido descrita asociada siempre a una neoplasia, ya que pueden verse otros eritemas figurados, como el eritema anular centrífugo, con 
aparición de lesiones anulares de borde ligeramente más grueso y, ocasionalmente, con ligera descamación que, como ya se vio anteriormente, se asocia a múltiples procesos infecciosos más que a neoplasias y que ha sido reportado en la literatura científica (40). El eritema gyratum repens se ha descrito asociado a carcinomas de pulmón, esófago y mama en el 82 \% de los casos, y con menor frecuencia a neoplasias malignas gastrointestinales o a linfomas (41).

El otro ertitema figurado es el eritema necrolítico migratorio que fue descrito por primera vez por Becker, et al., en 1942, en una mujer que presentaba pérdida de peso, anemia y tromboembolia. Se le diagnosticó un tumor de páncreas y aumento del glucagón sérico; además, presentaba una dermatitis necrótica vésicoeritematosa y estomatitis. Wilkinson propuso el nombre actual de 'glucagonoma' en 1973 y está asociado en el 100 \% de los casos con la liberación de glucagón por las células tumorales pancreáticas.

El síndrome de Sweet es una dermatosis neutrofílica, febril y aguda, caracterizada por la aparición de lesiones eritemato-edematosas infiltradas, como una especie de estado intermedio entre una placa de urticaria y una de eritema nudoso, que suelen ser dolorosas y se acompañan de fiebre (42) (figura 9.17). Se presenta relacionado con una neoplasia, generalmente, hematológica o hace parte de un proceso inflamatorio reactivo en enfermedades infecciosas o inflamatorias, como la enfermedad intestinal inflamatoria, la artritis reumatoidea o la sarcoidosis.

Como síndrome paraneoplásico, se asocia en el 54 \% de los casos a tumores, generalmente, de origen hematológico, en el $20 \%$ de ellos con una leucemia mieloide aguda y otros como síndromes mielodisplásicos, mieloma múltiple o linfomas, más que a neoplasias de un órgano sólido.

Se describen otras dermatosis neutrofílicas asociadas a tumores como es el caso del pioderma gangrenoso (figura 9.18) que se puede presentar en el $7 \%$ de las leucemias mieloides agudas, el mieloma múltiple o la paraproteinemia IgA. Se han descrito también eritemas nudosos asociados a neoplasias.

El crecimiento tumoral se puede manifestar con la aparición de vasculitis, oclusión vascular o hipercoagulabilidad. Se debe recordar la tromboflebitis superficial, migratoria y recurrente, o síndrome de Trousseau, que aparece en el 50 $\%$ de los adenocarcinomas de páncreas (figura 9.19). 

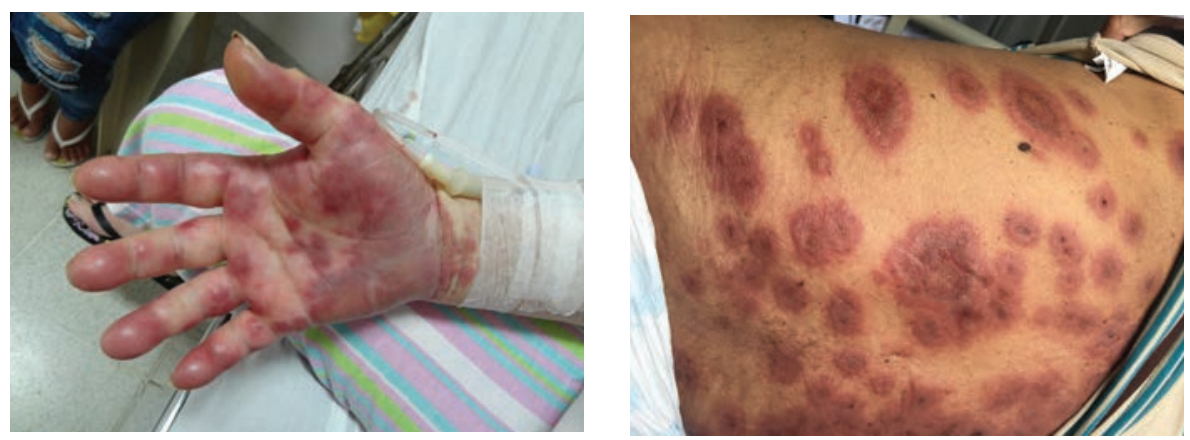

Figura 9.17. Síndrome de Sweet. El síndrome de Sweet es una dermatosis neutrofílica, febril y aguda, caracterizado por la aparición de lesiones eritemato-edematosas infiltradas, como una especie de estado intermedio entre una placa de urticaria y una de eritema nodoso, que suelen ser dolorosas y se acompañan de fiebre. Como síndrome paraneoplásico, se asocia en el $54 \%$ de los casos a tumores, generalmente, de origen hematológico, en el $20 \%$ de ellos con una leucemia mieloide aguda y otros como los síndromes mielodisplásicos, el mieloma múltiple y los linfomas, más que a neoplasias de un órgano sólido.

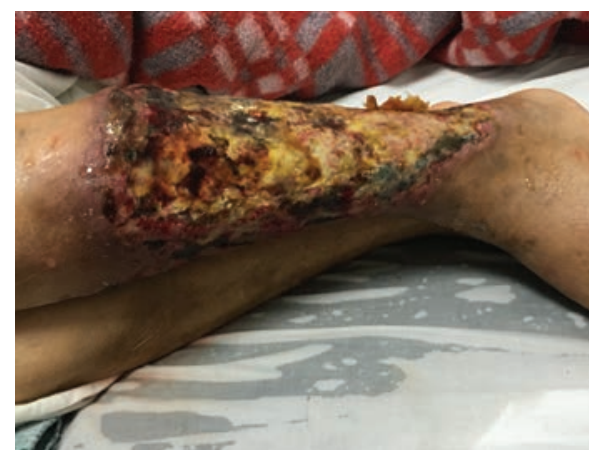

Figura 9.18. Pioderma gangrenoso. Se describen dermatosis neutrofílicas asociadas a tumores como es el caso del pioderma gangrenoso que se puede presentar en el $7 \%$ de las leucemias mieloides agudas, el mieloma múltiple o la paraproteinemia IgA. Se han descrito también eritemas nudosos asociados a neoplasias.

El aumento de las crioglobulinas también puede hacer parte de esta patogénesis oclusiva. Estos fenómenos vasculares oclusivos pueden de manera discreta semejar pápulas decapitadas por el rascado. (figura 9.20 a), se han reportados como isquemia digital, fenómeno de Raynaud (figura 9.20 b) y pioderma gangrenoso. Se encuentran, también, reportes de tromboembolismo venoso asociado a neoplasias (43).

En otros casos existe una producción aumentada de citocinas por parte de las células tumorales, que favorece la aparición de dermatosis o que produce daño al tejido con generación de autoanticuerpos y depósitos de complejos inmunes en los vasos. 

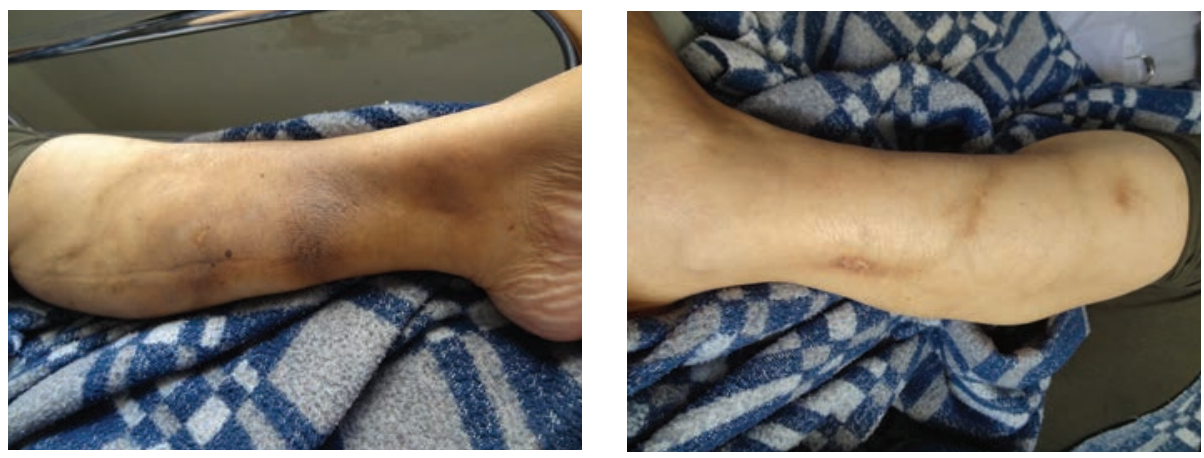

Figura 9.19. Tromboflebitis migratoria. Se debe recordar la tromboflebitis superficial, migratoria y recurrente, o síndrome de Trousseau que aparece en el $50 \%$ de los adenocarcinomas de páncreas.

Esto condiciona la respuesta inflamatoria, pudiendo manifestarse con una vasculitis leucocitoclásica, con infiltración de la pared vascular por neutrófilos, degeneración de los mismos y necrosis fibrinoide. Se describen acompañando tumores de origen hematológico, vasculitis en el $5 \%$ de las leucemias mieloides crónicas, leucemia de células peludas, mieloma múltiple y linfomas; también se han reportado acompañando el carcinoma renal (44).

Además, se ha reportado prurito acompañando varios tumores, pero, indiscutiblemente, cuando aparezca este síntoma se debe investigar, en primera instancia, la presencia de un linfoma de Hodgkin, ya que parece ser el más relacionado.

Algunos pacientes con linfomas Hodgkin y no Hodgkin, leucemias o mieloma múltiple pueden presentar lesiones cutáneas infiltradas y granulomatosas, a veces, incluso, ulcerativas que semejan otros procesos granulomatosos aun infecciosos de tipo leishmaniasis con histopatologia de granuloma inflamatorio.

\section{Otras dermatosis asociadas a neoplasias}

Otras neoplasias pueden cursar con alteraciones en los dedos de las manos y en las uñas. Se ha encontrado los dedos en palillo de tambor con aumento del tamaño de la falange distal acompañado de un incremento de la convexidad del lecho ungular secundario a la falta de oxigenación que se ha llamado 'uñas en vidrio de reloj. Se observan en el carcinoma broncogénico primario y en las metástasis pulmonares. 

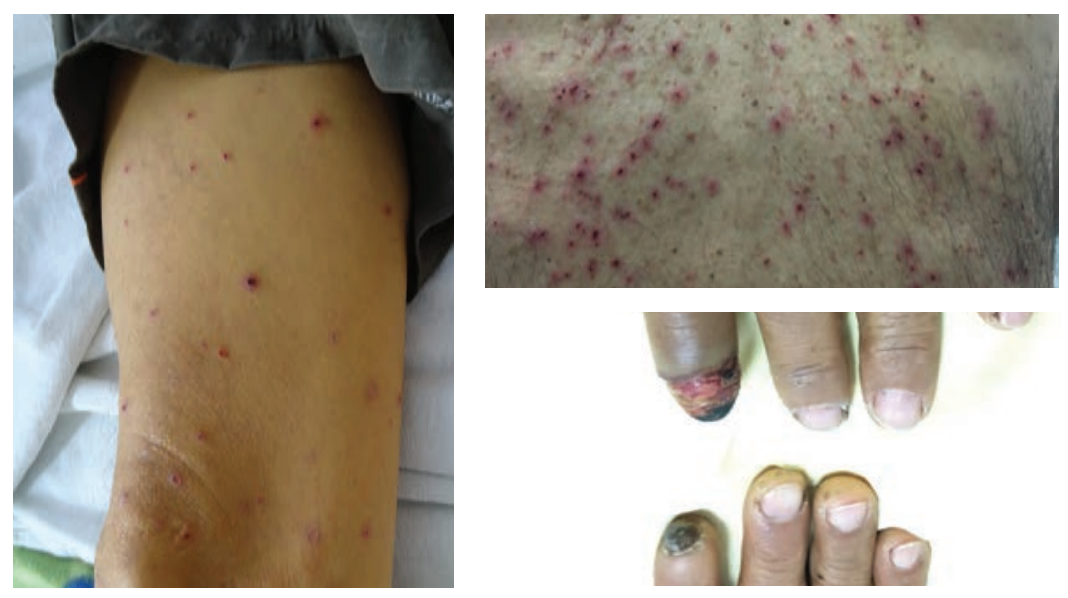

Figura 9.20. Hipercoagulabilidad, vasculitis: pápulas decapitadas por el rascado, isquemia digital, fenómeno de Raynaud. Estos fenómenos vasculares oclusivos se han reportado como isquemia digital,fenómeno de Raynaud y pioderma gangrenoso. El aumento de las crioglobulinas también puede hacer parte de esta patogénesis oclusiva.

Asimismo, se ha descrito el síndrome de las uñas amarillas en tumores como el carcinoma de mama, el de endometrio y los de vesícula, laringe, pulmón, melanoma metastásico, sarcoma metastásico, linfoma de Hodgkin y en tumores carcinoides. En algunos pacientes, además, pueden aparecer unas bandas longitudinales de color negro a marrón, muy fuerte, denominadas melanoniquia; de la misma manera, pueden aparecen pigmentaciones melánicas en las palmas y en las plantas o incluso en las mucosas, en los tumores que producen MSH.

El cáncer de mama puede dar un cuadro llamado enfermedad de Paget, que se refiere a la salida del adenocarcinoma mamario a través del pezón. En el caso de neoplasias de origen hepático o que han hecho metástasis al hígado, puede haber un aumento de angiomas eruptivos. Se han descrito eritrodermias generalizadas en los pacientes con cáncer de colon.

La hipercalcemia puede ser un signo de neoplasia; se ha relacionado con el carcinoma de células escamosas de esófago, el mieloma múltiple, el cáncer de mama, el linfoma y las metástasis osteolíticas. Raramente, la calcificación paraneoplásica se puede presentar con depósitos de calcio en la dermis y en el tejido subcutáneo. La patogénesis es variable, posiblemente por el aumento de la producción tumoral de hormona paratiroidea $(\mathrm{PTH})$, vitamina $\mathrm{D}$, citocinas, RANKL-KB u osteoprotegerina. 
El escleromixedema es una forma generalizada de la mucinosis papular, que se presenta como pápulas liquenoides discretas o como placas induradas confluyentes en la cara, los brazos y las manos. Entre las neoplasias asociadas se encuentra la macroglobulinemia de Waldenström, las leucemias, el linfoma de Hodgkin, los linfomas y las gammapatias monoclonales de cadena ligera IgG $\mathrm{k}$.

Otras lesiones se presentan asociadas a la presencia de neoplasias internas, cuya característica es la de ser múltiples lesiones de tipo "pápulas faciales" (45) y pueden ser 'carnosas', verrugosas, cerosas, rojo-amarillentas, rojo-amarronadas, amarillentas o amarillas y, en cada caso, se relacionan con un síndrome diferente (cuadro 9.1).

En el caso de las 'carnosas', se puede hablar del síndrome de Birt-HoggDubé asociado a neoplasia renal; del síndrome basocelular nevoide, asociado al meduloblastoma, el craneofaringioma o el meningioma; o de la neurofibromatosis de tipo 1 relacionada con la aparición de gliomas y sarcomas.

Si las lesiones son de aspecto verrugoso, se puede pensar en el síndrome de Cowden asociado a las neoplasias de mama, glándula tiroides, endometrio o cerebelo.

En el caso de las de aspecto ceroso, se podría pensar en amiloidosis, mieloma múltiple o gammapatía monoclonal.

Si las lesiones son de color rojo amarillentas puede tratarse de una esclerosis tuberosa con lesiones tumorales de tipo hamartoma, astrocitoma, glioblastoma, rhabdomioma cardíacos, carcinoma renal o angiomiolipomas renales. En estos pacientes, también, sehan descrito carcinomas pulmonaresylinfangioleiomiomatosis.

Asimismo, se han descrito lesiones de esta coloración cerosa en la neoplasia endocrina múltiple de tipo I, relacionada con los tumores de la hipófisis, las glándulas paratiroides, el enteropancreático o síndrome carcinoide.

Si la coloración es rojo café o rojo-marrón se ha asociado con reticulohistiocitosis multicéntrica que presenta mayor predisposición a la aparición de neoplasias.

Se pueden encontrar lesiones de color amarillento en el síndrome de MuirTorre, acompañando un carcinoma colorrectal o genitourinario, en otros casos. Las lesiones amarillas se encuentran relacionadas, en el caso del xantogranuloma necrobiótico, con el mieloma múltiple u otros trastornos mieloproliferativos. Es posible que la presencia de queratoacantomas o carcinomas basocelulares y la presencia de múltiples adenomas sebáceos se asocien a otros tumores. 
Se pueden encontrar, además, unos síndromes con herencia autosómica dominante caracterizados por presentar lesiones tumorales de tipo hamartoma en el tracto gastrointestinal, de tipo pólipos intestinales con la aparición de lesiones tumorales en la piel, derivadas del folículo piloso o del anexo sebáceo, del tejido nervioso aledaño, de células pigmentarias o de vasos sanguíneos, o formando fibroepiteliomas de piel, generalmente, en el rostro y que se pueden relacionar con neoplasias en cuyo caso pueden cursar con hemorragia digestiva u obstrucción intestinal.

El síndrome de Birt-Hogg-Dubé es una genodermatosis causada por mutaciones del gen de la foliculina, de herencia autosómica dominante. Se caracteriza por presentar tumores benignos derivados de las glándulas sebáceas: fibrofoliculomas y quistes pulmonares asociados a tumores malignos renales. Se ha reportado poliposis intestinal y cáncer colorrectal (46).

El síndrome del carcinoma basocelular nevoide, o síndrome de Gorlin-Gotz (47), es un trastorno hereditario autosómico dominante que se presenta desde la primera infancia con múltiples lesiones de tipo nevo basocelular en el que existe una mayor propensión para desarrollar carcinomas basocelulares, con mayores posibilidades de presentar otras neoplasias del sistema nervioso o de los tejidos de sostén. Es frecuente encontrar queratoquistes odontogénicos en las mandíbulas, alteraciones esqueléticas de tipo costilla bífida, pequeñas zonas puntiformes hiperqueratósicas palmo-plantares (pits) y calcificaciones intracraneales; a veces se reportan neoplasias que pueden ser meduloblastomas, meningiomas, fibromas o fibrosarcomas de ovario, fibrosarcomas mandibulares, fibromas cardíacos u otros (48).

El síndrome de Cowden se caracteriza por presentar múltiples lesiones de tipo hamartoma que incluyen triquilemomas, tricoleiomiomas en rostro, papilomatosis oral o neuromas mucosos, queratosis palmar asociada a pólipos intestinales y que se puede, además, asociar a otras alteraciones tumorales en numerosos órganos, glándula tiroides, endometrio, ovarios, mama y cerebro.

La reticulohistiocitosis multicéntrica es una enfermedad sistémica granulomatosa que puede afectar las articulaciones y los huesos. En la piel se presenta con lesiones pápulo-nodulares amarillentas o de color marrón rojizo-amarillento en la cara y la mucosa oral, acompañadas de lesiones en las manos, con artritis de las articulaciones interfalángicas distales. Se observa una asociación paraneoplásica en el $25 \%$ de los casos, que incluye leucemias y tumores sólidos -de mama, cuello uterino, colon, pulmón, páncreas, estómago y piel- y pueden presentar regresión espontánea. 
En el síndrome de Muir-Torre aparecen neoplasias sebáceas benignas y se pueden asociar a tumores del colon o, con el tiempo, a otros cánceres de piel, como el carcinoma sebáceo, el carcinoma basocelular, el queratoacantoma o el carcinoma escamocelular.

Otros síndromes de herencia autosómica dominante pueden asociarse a diferentes tumores. El síndrome de Gardner corresponde a una poliposis adenomatosa familiar que se puede asociar al carcinoma de colon, con hipertrofia congénita del epitelio pigmentario y a lesiones tumorales benignas en rostro de tipo pilomatrixoma, tricoma múltiple, tumores desmoides, quistes epidérmicos, fibromas o lipomas.

El síndrome de Cronkhite-Canada fue descrito por Cronkhite, et al., en 1955. Reportaron la asociación de la poliposis gastrointestinal de tipo hamartoma con alteraciones en la piel, con la aparición de máculas hiperpigmentadas de diversos tamaños desde milímetros hasta varios centímetros, localizadas en el dorso de las manos, las palmas, los brazos, el cuello, el rostro y el cuero cabelludo. Las uñas pueden estar atróficas, de aspecto opaco y con onicólisis. Además, puede acompañarse de alopecia. Un número pequeño de pacientes puede tener cáncer de colon (8\%) o gástrico (5\%).

El síndrome de Peutz-Jeghers fue descrito por Peutz en 1921 en una familia holandesa y fue publicado por Jeghers 28 años después (49). Se presenta por una mutación en los genes $S T K 11 / L K B 1$, que codifican una cinasa de serina-treonina 11, localizada en la banda19p13.3 (50). Se caracteriza por la aparición de máculas hiperpigmentadas de color marrón o negruzco de menos de $5 \mathrm{~mm}$ en los labios y en la mucosa oral, asociados con la poliposis intestinal. Pueden coexistir con otros lentigos en otras mucosas - genital, perianal o periumbilical-y excepcionalmente en otros lugares como en el dorso de las manos, en las plantas y en las palmas, acompañados de poliposis gastrointestinal y localizados más en yeyuno e íleon que en colon, recto, estómago o duodeno. Son hamartomas con un bajo potencial de volverse malignos; no obstante, en un bajo porcentaje se pueden presentar carcinomas gastrointestinales (51), como el adenocarcinoma de colon (52), de intestino delgado o gástrico o de otro lugar.

Otras alteraciones pueden aparecer como resultado del compromiso inmunitario que sufre el paciente y no se deben interpretar como si fueran síndromes paraneoplásicos. Es el caso de los pacientes que presentan infecciones, como herpes zóster, debidas a la alteración del estado inmunológico y que no son específicas de ningún tumor, pero si aparecen se deben tener en cuenta. 
Cuadro 9.1. Pápulas faciales marcadoras de Malignidad

\begin{tabular}{|c|c|c|}
\hline Pápulas faciales & Desorden & Malignidad asociada \\
\hline \multirow[t]{6}{*}{ "Carnosas" } & Birt-Hogg-Dubé & S. renal \\
\hline & Basal cell nevus & S. meduloblastoma \\
\hline & & Craneofaringioma \\
\hline & & Meningioma \\
\hline & Neurofibromatosis & Gliomas, sarcomas \\
\hline & Tipo I & >riesgo de malignidad \\
\hline \multirow[t]{2}{*}{ Verrugosas } & Cowden & Seno, tiroides \\
\hline & & Endometrio, cerebelo \\
\hline \multirow[t]{2}{*}{ Serosas } & Amiloidosis & Mieloma multiple \\
\hline & & Gammapatia monoclonal \\
\hline \multirow[t]{7}{*}{ Rojo-amarillentas } & Esclerosis tuberosa & Hamartomas \\
\hline & & Astrocytoma \\
\hline & & Glioblastomas \\
\hline & & Rhabdomiomas cardiacos \\
\hline & & Carcinoma renal \\
\hline & & angiomiolipomas renales \\
\hline & & linfangioleiomiomatosis Pulmonar \\
\hline \multirow[t]{3}{*}{ Rojo-amarillenta } & Neoplasia endocrina & Pituitaria, paratiroides \\
\hline & Multiple tipo I & Enteropancreatico \\
\hline & Carcinoide & \\
\hline \multirow[t]{2}{*}{ Rojo-café } & Reticulohistiocitosis & Variados \\
\hline & Multicéntrica & \\
\hline \multirow[t]{3}{*}{ Amarillentas } & Muir-Torre S. & Colorectal, genitourinario \\
\hline & Queratoacantomas & Seno, pulmón \\
\hline & Adenomas sebáceos & Hematologicos, otros \\
\hline \multirow[t]{2}{*}{ Amarillas } & Xantogranuloma & Mieloma multiple \\
\hline & Necrobiotico & Desorden mieloproliferativo \\
\hline
\end{tabular}




\section{Referencias}

1. Rodnam GP, editor. Compendio de las enfermedades reumáticas. Primera edición. Barcelona: Sociedad Española de Reumatología, Arthritis Foundation; 1977.

2. Klemperer P. The concept of collagen diseases. Am J Pathol. 1950;26:505-19.

3. Wilson W, Gharavi A, Koike T, Lockshin MD, Branch DW, Piette JC, et al. International consensus statement on preliminary classification criteria for definite antiphospholipid syndrome. Arthritis Rheum. 1999;42:1309-11.

4. Garrod AB. The nature and treatment of gout and rheumatic gout. London: Walton and Maberly; 1859.

5. Smith CD, Cyr M. The history of lupus erythematosus. From Hippocrates to Osler. Rheum Dis Clin North Am. 1988;14:1-14.

6. Cervera R, Khamashta MA, Font J, Sebastiani GD, Gil A, Lavilla P, et al. Systemic lupus erythematosus: Clinical and immunologic patterns of disease expression in a cohort of 1,000 patients. Medicine (Baltimore). 1993;72:113-24.

7. Hochberg MC. Updating the American College of Rheumatology revised criteria for the classification of systemic lupus erythematosus. Arthritis and Rheumatism. 1997;40:1725.

8. Petri M, Orbai AM, Alarcón GS, Gordon C, Merrill JT, Fortin PR, et al. Derivation and validation of systemic lupus international collaborating clinics classification criteria for systemic lupus erythematosus. Arthritis Rheum. 2012;64:2677-86.

9. Kuhn A, Sticherling M, Bonsmann G. Clinical manifestations of cutaneous lupus erythematosus. JDDG. 2007;5:1124-37.

10. Helmick CG, Felson DT, Lawrence RC, Gabriel S, Hirsch R, Kwoh CK, et al. Estimates of the prevalence of arthritis and other rheumatic conditions in the United States: Part I. Arthritis and Rheumatism. 2008;58:15-25

11. Lee LA, Weston WL. Lupus erythematosus in childhood. Dermatol Clin. 1986;4:151-60.

12. Callen JP, Jorrizo JL, Bolognia J, Piette W, Zone J. Signos cutáneos de las enfermedades sistémicas. Cuarta edición. Barcelona: Elsevier; 2011.

13. Albrecht J, Berlin JA, Braverman IM. Dermatology position paper on the revision of the ACR 1982 criteria for systemic lupus erythematosus. Lupus. 2004;13:839-49.

14. Gilliam JN, Sontheimer RD. Distinctive cutaneous subsets in the spectrum of lupus erythematosus. J Am Acad Dermatol. 1981;4:471-5.

15. Kuhn A, Herrmann M, Kleber S, Beckmann Welle M, Fehsel K, Martin Villalba A, et al. Accumulation of apoptotic cells in the epidermis of patients with cutaneous lupus erythematosus after ultraviolet irradiation. Arthritis Rheum. 2006;54:939-50.

16. Molina J, Molina J, Drenkard C, Cardiel M, Uribe O, Felipe O, et al. Systemic lupus erythematosus in 1,316 Latin American patients. A multicenter, binational study. Lupus. 1995;4(Supp.40):12430 .

17. Duarte AF, Motta A, Pereira M, Baudrier T, Azevedo F. Rowell syndrome -case report and review of the literature. Dermatol Online J. 2008;14:15.

18. Roh EK, Vleugels RA, Hoang MP. Case records of the Massachusetts General Hospital. Case 392013. A 57-year-old woman with painful bullous skin lesions. N Engl J Med. 2013;369:2438-49.

19. Guevara-Pulido FO, Díaz-Cortés ME. Escleroderma. Acta Médica Colombiana. 2006;31:83-91. 
20. Raynaud M. Local asphyxia and symmetrical gangrene of the extremities. London: New Sydenham Society; 1862.

21. Zapata K, García L. Fenómeno de Raynaud. Rev Asoc Colomb Dermatol. 2011;19:280-92.

22. Grarabrand DH, Dumas C. Epidemiology of organic solvents and connective tissue disease. Arthritis Research. 2000;2:5-15.

23. Fawcett RS, Linford S, Stulberg DL. Nail anormalities: Clues to systemic disease. Am Fam Physician. 2004;69:1417-24.

24. Restrepo JP, Medina LF, Molina M del P. Manifestaciones cutáneas de la dermatomiositis. Rev Asoc Colomb Dermatol. 2010;18:18-24.

25. Callen J, Wortmann R. Dermatomyositis. Clin Dermatol. 2006;24:363-73.

26. Bohan A, Peter F. Polymyositis and dermatomyositis. N Engl J Med. 1975;292:344-7.

27. Basset-Seguin N, Roujeau JC, Gherardi R, Guillaume JC, Revuz J, Torraine R. Prognostic factors and predictive signs of malignancy in adult dermatomyositis. A study of 32 cases. Arch Dermatol. 1990;126:633-7.

28. The Juvenile Dermatomyositis National Registry and Repository (UK and Ireland) clinical characteristics of children recruited within first 5 yr. Dermatomyositis Research Group. Rheumatology. 2006;45:1255-60.

29. Troyanov Y, Targoff IN, Payette MP, Raynauld JP, Chartier S, Goulet JR, et al. Redefining dermatomyositis. A description of new diagnostic criteria that differentiate pure dermatomyositis from overlap myositis with dermatomyositis features. Medicine (Baltimore). 2014;93:318-32.

30. Ricceri F, Prignano F. Gottron papules: A pathognomonic sign of dermatomyositis. CMAJ. 2013;185:148.

31. Fiorentino DF, Chung LS, Christopher-Stine L, Zaba L, Li S, Mammen AL, et al. Most patients with cancer-associated dermatomyositis have antibodies to nuclear matrix protein NXP-2 or transcriptional intermediary factor 1y. Arthritis and Rheumatism. 2013;65:2954-62.

32. Fiorentino D, Chung L, Zwerner J, Rosen A, Casciola-Rosen L. The mucocutaneous and systemic phenotype of patients with antibodies to MDA 5 (CADM-140): A retrospective study. J Am Acad Dermatol. 2011;65:25-34.

33. Tanimoto K, Nakano K, Kano S MoriS, Ueki H, Nishitani H, et al. Classification criteria for polymiositis and dermatomyositis. J Rheumathol. 1995;22:668-74.

34. Sharp GE, Irving W, Tan E, Gould G, Holman H. Mixed connective tissue disease. An apparently distinct rheumatic disease síndrome associated with a specific antibody to an extractable nuclear antigen (ENA). Am J Med. 1972;52:148-59.

35. Díaz-Paul SC, Velásquez-Franco CJ, Pinto-Peñaranda LF, Márquez JD. Síndrome de Sjögren: revisión clínica con énfasis en las manifestaciones dermatológicas. Rev Colomb Reumatol. 2008;15:35-48.

36. Aceti A, Taliani G, Sorice M, Amendolea MA. HCV and Sjögren's syndrome. Lancet. 1992;339:1425-6.

37. Zuberbier T, Aberer W, Asero R, Bindslev-Jensen C, Brzoza Z, Canonica GW, et al. The EAACI/ GA(2) LEN/EDF/WAO Guideline for the definition, classification, diagnosis, and management of urticaria: The 2013 revision and update. Allergy. 2014;69:868-87.

38. Sayah A, English JC, 3rd. Rheumatoid arthritis: A review of the cutaneous manifestations. J Am Acad Dermatol. 2005;53:191-209. 
39. Turesson C, Jacobson L, Bergström U. Extraarticular rheumatoid arthritis: Prevalence and mortality. Rheumatology. 1999;38:668-74.

40. Jorizzo JL, Daniels JC. Dermatologic conditions reported in patients with rheumatoid arthritis. J Am Acad Dermatol. 1983;8:439-57.

41. Harper B, Wills R, Pierangeli SS. Pathophysiological mechanisms in antiphospholipid syndrome. Int J Clin Rheumthol. 2011;6:157-71.

42. Harris EN, Hughes GRV. Antiphospholipid antibodies. In: McCarty DJ, editor. Arthritis and allied conditions. Philadelphia: Lea and Febiger; 1989. p. 1068-79. 


\section{Conclusiones}

He escrito este libro para despertar el interés de los futuros médicos en todo lo que expresa el cuerpo por medio de la piel.

La capacidad de reconocer las diferentes enfermedades se inicia con una cuidadosa y pausada observación del individuo por considerar. El cálculo rápido de la posible edad y del peso que tiene -si demasiado delgado, puede pensarse en una enfermedad consuntiva; si demasiado grueso, con gran aumento del perímetro abdominal, podemos estar ante un paciente con una enfermedad metabólica.

Es importante considerar el color de la piel que, si bien es difícil hacerlo, dado el mestizaje de los colombianos y la variabilidad de los posibles colores, en un momento dado, esta característica puede orientarnos a un proceso patológico. Si demasiado pálida, puede tratarse de una anemia, que se puede confirmar observando la mucosa conjuntival del párpado inferior; si la piel está amarillenta, puede ser una anemia en un individuo de piel oscura, o una carotinemia si la coloración es predominante en las palmas y en las plantas, o una ictericia si el compromiso de las mucosas es más notorio. Si el color de la piel es terroso y el individuo está consuntivo y pálido, se podría pensar en que tiene una neoplasia, pero si la hiperpigmentación es más notoria, podría tratarse de una insuficiencia renal crónica o de un hipertiroidismo.

Si las mucosas o la piel tienen parches grisáceos o hiperpigmentados, podemos estar ante un paciente con enfermedad de Addison, y si el aspecto de la piel, además de hiperpigmentado es aterciopelado, podemos estar ante un paciente con hemocromatosis.

En los casos de compresiones medulares o asociados a neoplasias aparecen máculas hiperpigmentadas en las plantas y en las palmas que, por otro lado, bien podrían ser los efectos de una exagerada secreción de la hormona estimuladora de los melanocitos (MSH) en un paciente con una neoplasia.

La sequedad o no de la piel es otro dato importante que se debe considerar. Si se aprecia seca, o xerótica, podemos estar ante un paciente atópico, desnutrido, hipotiroideo o de edad avanzada, pero si el cambio es reciente, se puede pensar en una ictiosis paraneoplásica; por lo tanto, no se puede olvidar que el tiempo de aparición de cualquier síntoma es clave en la sospecha de la posible causa del problema. Además, si la piel ha perdido su brillo, nos debemos detener a mirar cuidadosamente a este sujeto que puede estar presentando algún tipo de enfermedad. 
Esta mirada inicial permite un interrogatorio dirigido para aclarar la presunción inicial de la causa de su sintomatología para que la elaboración de la historia clínica sea más completa y que, junto con los exámenes de laboratorio pertinentes, nos conduzca a diagnósticos más acertados.

Como dermatóloga, considero que ciertas lesiones requieren la ayuda de la interpretación de la biopsia para arribar al diagnóstico preciso, pero, en otros casos, esta solo nos brinda información que complementa la historia clínica, los exámenes suplementarios pertinentes y las imágenes necesarias para llegar al diagnóstico exacto, con el que se puede establecer el manejo más adecuado.

En la observación de la piel, no se debe olvidar que la mirada detenida de las manos y de los pies nos pueden ayudar en la búsqueda de una rápida información orientadora. La textura de la piel de los dedos, la coloración de las puntas de los mismos, de las palmas y de las plantas, el adelgazamiento o el engrosamiento de las falanges distales, la presencia o no de la lúnula de las uñas, los cambios del color o del tono de las uñas, los engrosamientos, las separaciones, las líneas o las depresiones son datos relevantes para reconocer el tiempo de la enfermedad o la naturaleza de la misma. Asimismo, en la observación de las palmas de las manos y de las plantas de los pies se debe considerar no solo la coloración sino también la presencia de queratodermia o del engrosamiento de la piel, y si compromete una parte o toda la palma o o la planta y si existen o no pigmentaciones lenticulares.

En la consideración de descamación o de queratodermia de las plantas, se puede tratar de algo tan sencillo, como una tiña pedis, con eritema y descamación interdigital y la presencia de 'collaretes' de descamación que hacen supone la previa existencia de vesículas en las plantas, es decir, un eccema dishidrótico o puede tratarse de queratodermias simples debidas a desnutrición, sobrepeso, diabetes o hipotiroidismo, o se puede tratar de lesiones de mayor grosor visibles en pacientes con psoriasis.

Si se observan escamas que se van adosando y toman una apariencia gruesa, se puede tratar de una dermatosis paraneoplásica, en cuyo caso se debe considerar si son queratodermias totales, parciales o puntiformes. En estas últimas, se puede pensar en la posibilidad de un carcinoma broncogénico o pulmonar más frecuentemente, pero si son pequeñas puede tratarse de un carcinoma de próstata. Si estamos frente a un paciente con acroqueratosis de manos y pies que, además, presenta queratodermia en la punta de la nariz y en el borde de los pabellones auriculares, podemos estar ante una neoplasia del tracto aéreo superior o del esófago.

Por otro lado, es importante considerar las pigmentaciones oscuras lenticulares, más frecuentes en las palmas o en las plantas, difíciles de clasificar y que pueden ser normales en los individuos de raza negra -aunque no en todos- $y$ que aparecen en las neoplasias o en las alteraciones compresivas o en las secciones medulares. 
Cada país y cada región tienen diferentes patologías predominantes, estas observaciones se han hecho en el Hospital Universitario San Jorge de Pereira donde la gran mayoría de los pacientes acuden a urgencias por EPOC, insuficiencia cardiaca congestiva, infarto agudo de miocardio, insuficiencia renal crónica, diabetes, innumerables infecciones -incluido el sida- y neoplasias terminales.

Por último, inspirada por Andrzej Szczeklik en su libro "Catarsis" (1) y teniendo en cuenta la larga lista de maravillosos individuos que a lo largo del tiempo han descrito nuestro cuerpo y que nos han enseñado la forma como cada grupo de los sistemas que lo componen trabaja de manera perfecta y sin pausa, tenemos que considerar que hemos tardado varios siglos en ver y aclarar sus diversas interrelaciones y que aún hoy asistimos a este desconocimiento que nos incita al conocimiento.

Por otra parte, no debemos olvidar la capacidad sanadora inherente a nuestras propias estructuras, como tampoco, la clara relación entre la mente y el cuerpo para desencadenar o detener una enfermedad, atendiendo también a los pequeños defectos que podemos traer en nuestros genes o a las diferentes mutaciones que se pueden haber presentado para la consideración de cada individuo enfermo.

Solo así, elaborando una historia clínica completa, podremos llegar a un diagnóstico preciso que nos permita llevar a nuestros pacientes a un manejo tan completo como sea posible. Como nos recuerda Szczeklik, es claro que el secreto de la curación reside en la enfermedad misma, esta es una confesión del cuerpo y si no la escuchamos, no podremos llevar a nuestros pacientes a la curación o, por lo menos, a obtener un soporte adecuado. Veamos y escuchemos los cambios que nuestro cuerpo emana ya que ellos nos permitirán llegar a diagnósticos y manejos más tempranos.

\section{Referencias}

1. Szczeklik A. Catarsis. Barcelona: Editores Acantilado; 2010. 
La piel es el órgano más grande del cuerpo humano, ocupa dos metros cuadrados; es, a la vez, el más externo y, por lo tanto, el más visible, de tal manera que su exploración física muestra no solo las lesiones que pueden estar afectándola directamente, sino que también permite apreciar el efecto de algunos cambios internos. Por tal razón, su análisis aporta datos para la comprensión de las alteraciones de los órganos internos.

Desde el inicio de una enfermedad sistémica se presentan signos y síntomas en la piel. Por ello, todo médico general debe estar familiarizado con estas manifestaciones cutáneas para que pueda, de manera rápida, llegar a un diagnóstico clínico temprano, que le permita luego confirmar esa posible alteración e iniciar el tratamiento más adecuado o remitir el paciente al especialista experto en la alteración por tratar.

Este documento tiene como objetivo fundamental demostrar que la piel no solo es una envoltura externa, sino que es un órgano autónomo en muchas funciones para enfrentarse a un medio externo adverso y que, además de su función protectora, posee una serie de capacidades intrínsecas como órgano inmunitario y endocrino, que le permiten una interacción activa con los órganos internos. Es un órgano neuroinmunocrino.

Cada uno de los capítulos revisa las manifestaciones cutáneas de las enfermedades más representativas de los sistemas del cuerpo humano: el neurológico, el endocrinológico y el hematológico, y las interacciones con el aparato cardiovascular, el respiratorio, el gastrointestinal y el renal, al igual que las alteraciones que se producen en las enfermedades del tejido conjuntivo. Por último, se muestra cómo los tumores malignos de los órganos internos tienen una repercusión importante en la piel y, por tal razón, se presentan las lesiones paraneoplásicas con el propósito de llegar a un diagnóstico oportuno de las lesiones malignas que las desencadenan.

Esta recopilación está basada en la experiencia clínica de la autora y en una revisión amplia de la literatura médica especializada, con la cual se pretendió revisar las creencias vigentes del conocimiento actual de cada tema y busca enfocar al médico que no es dermatólogo en el reconocimiento de situaciones que lo pueden alertar de una enfermedad sistémica. Su mirada afinada le permitirá reconocer las lesiones que se presentan en la piel como manifestación de los procesos patológicos internos con el propósito de llegar a un diagnóstico acertado de manera más temprana.

\section{Universidad Tecnológica de Pereira}

